\title{
Building at the Speed of Light: \\ Prefabrication, Transport, and Assembly
}

Victoria University of Wellington's Entry into the U.S.

Department of Energy Solar Decathlon 2011

By Eli Nuttall

A thesis submitted to the Victoria University of Wellington

in fulfilment of the requirements for the Degree of Master of Architecture.

School of Architecture and Design

Victoria University of Wellington, 2012 


\section{TABLE OF CONTENTS}

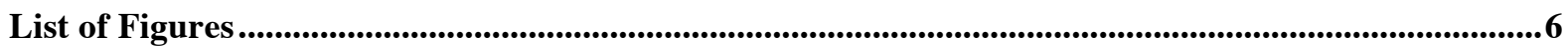

Acknowledgements...................................................................................................................................20

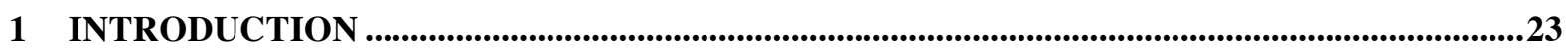

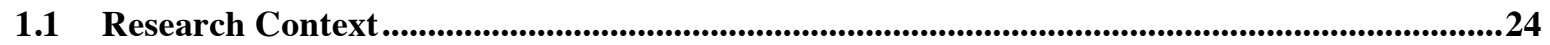

1.2 Aim and Scope .....................................................................................................................................25

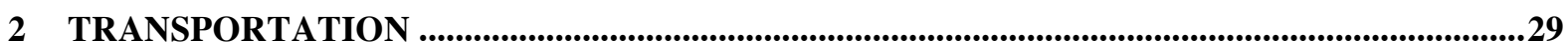

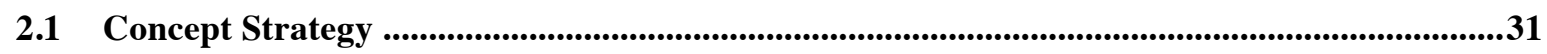

2.2 Constraints/Limitations ...............................................................................................................31

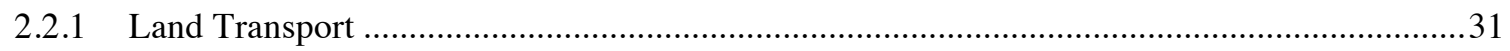

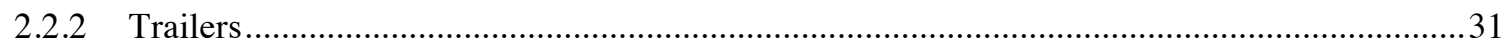

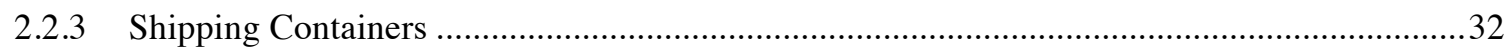

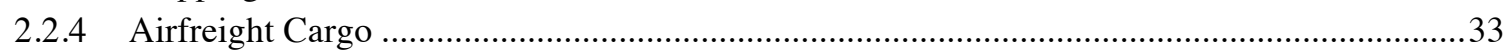

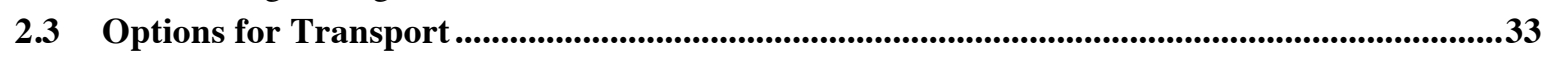

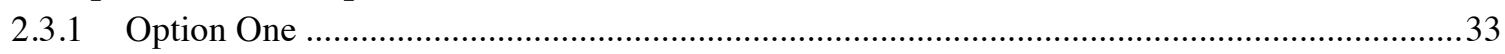

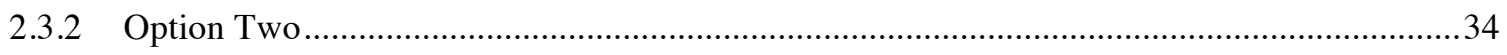

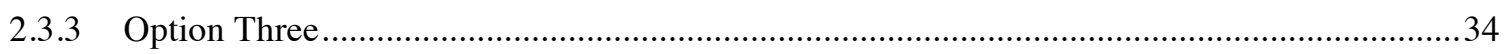

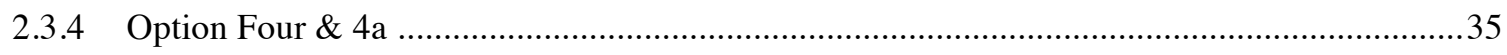

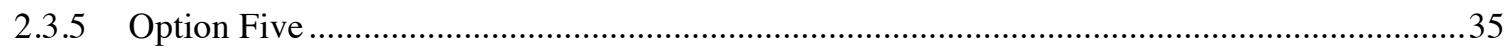

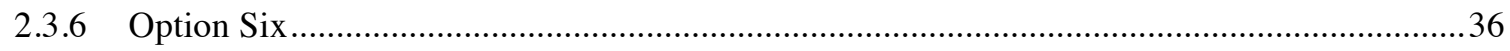

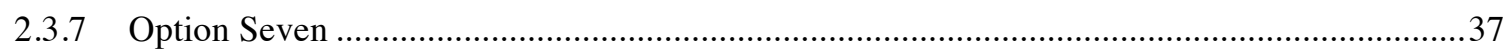

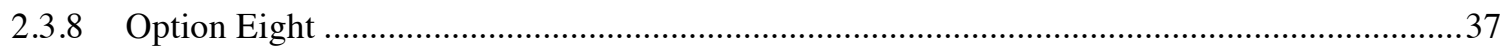

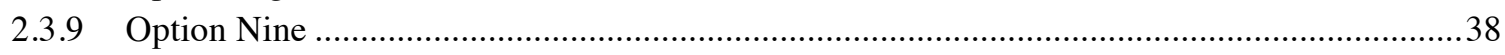

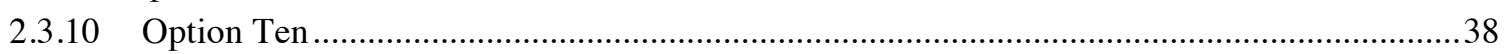

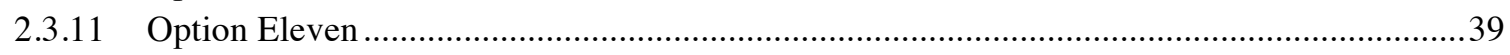

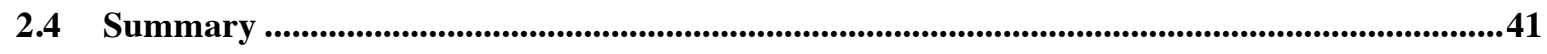

2.5 Implications.........................................................................................................................44

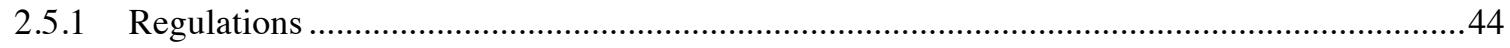

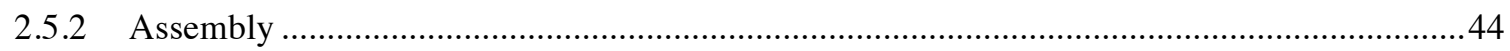

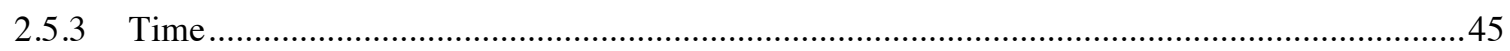

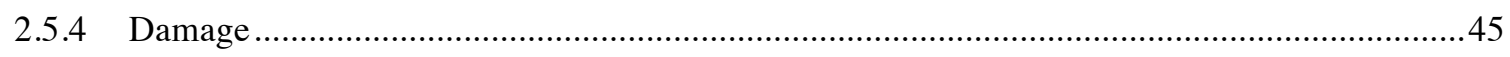

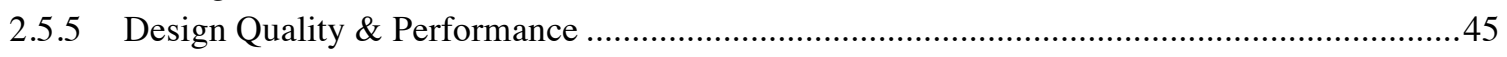

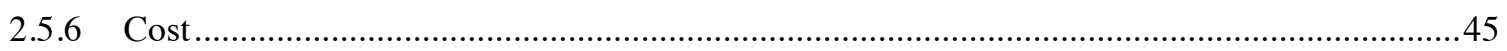

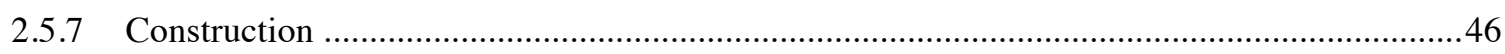

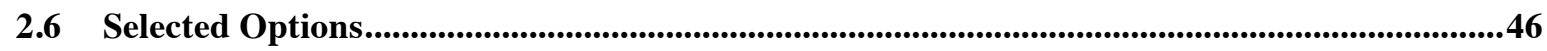

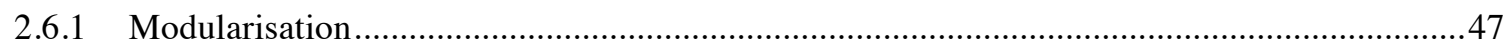

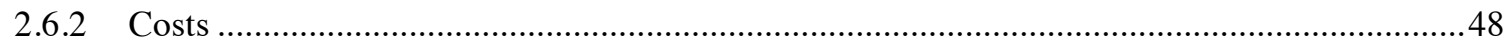

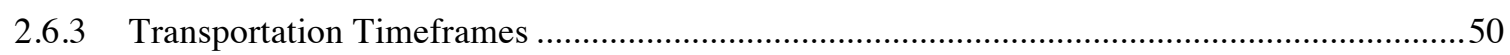

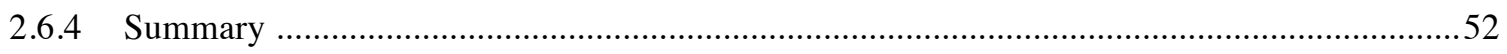

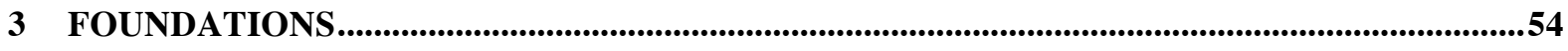

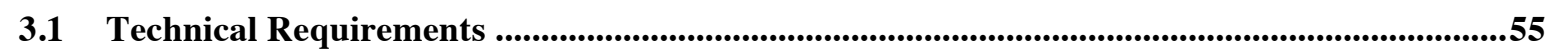

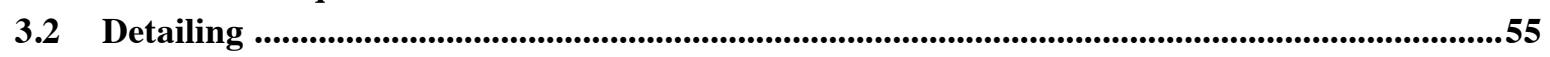

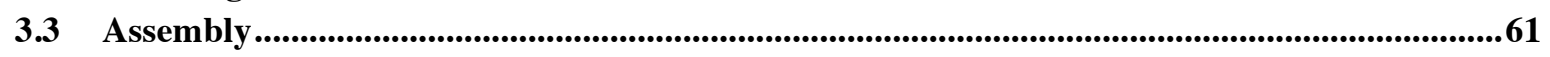

4 MODULE CONSTRUCTION ................................................................................................................65 


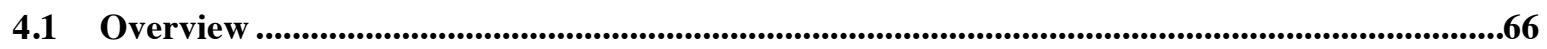

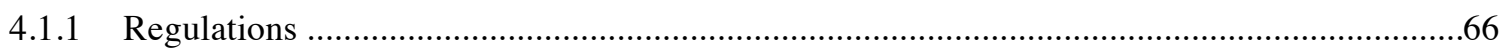

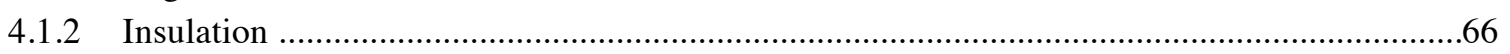

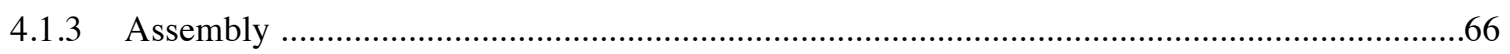

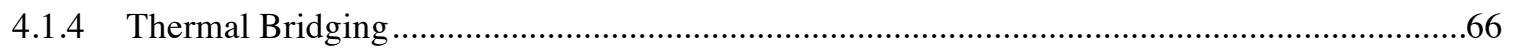

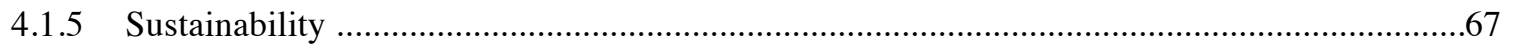

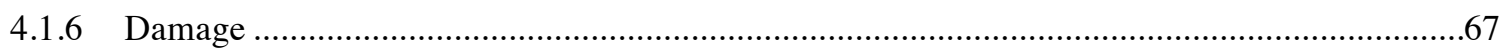

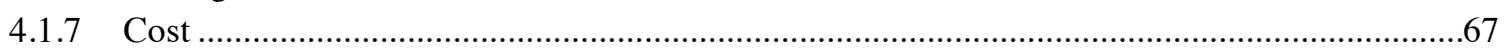

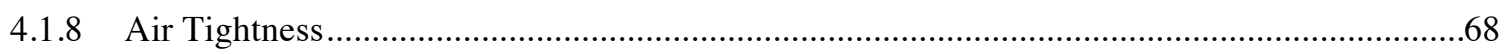

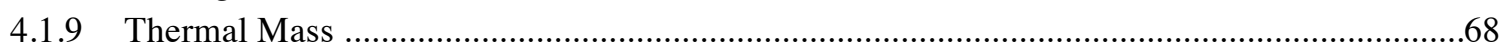

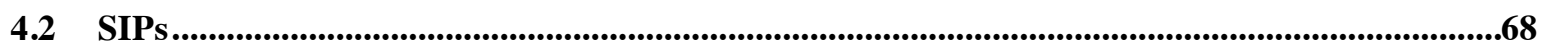

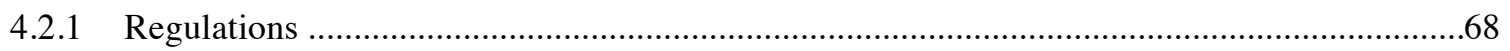

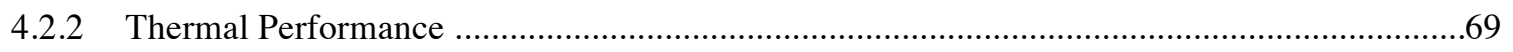

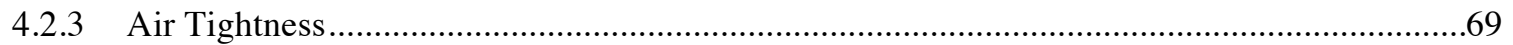

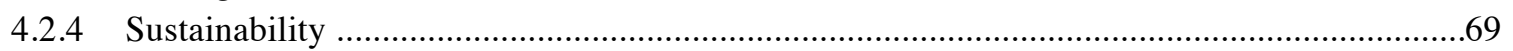

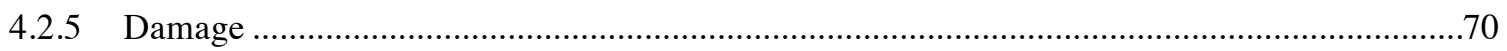

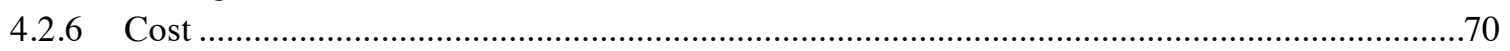

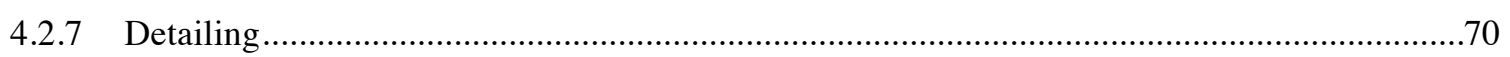

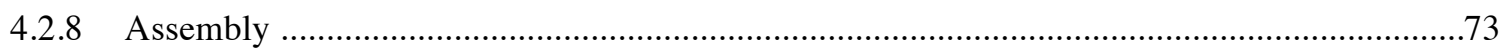

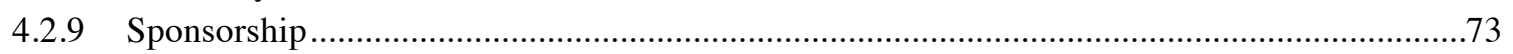

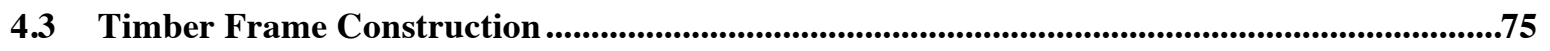

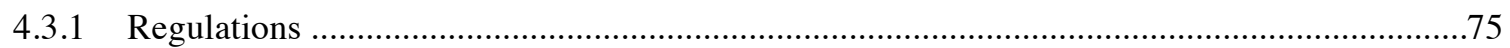

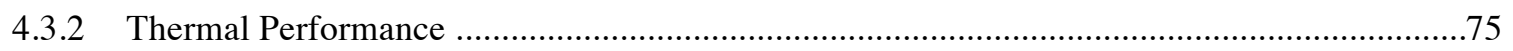

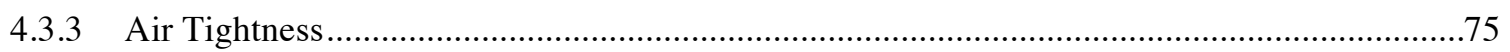

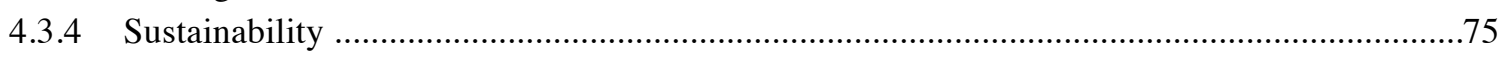

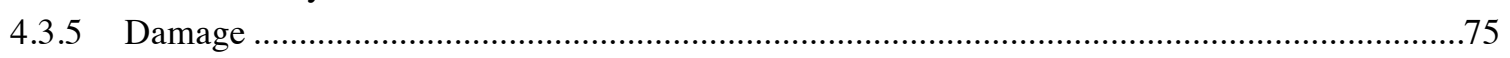

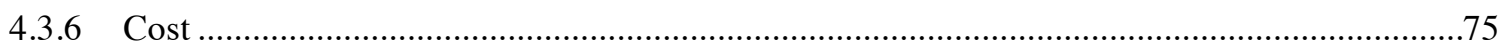

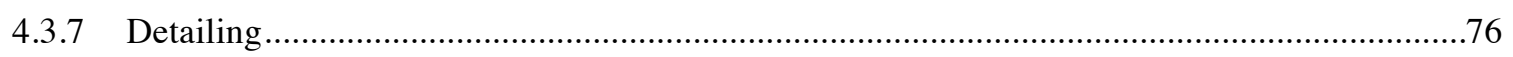

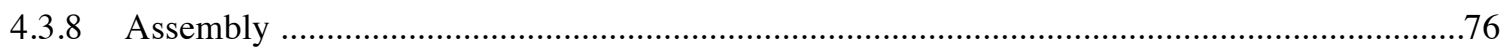

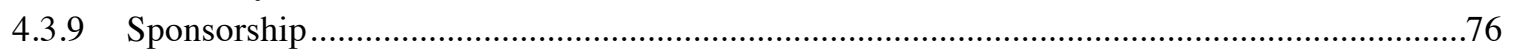

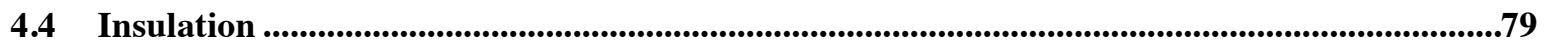

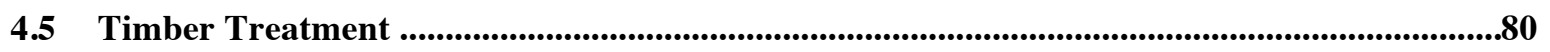

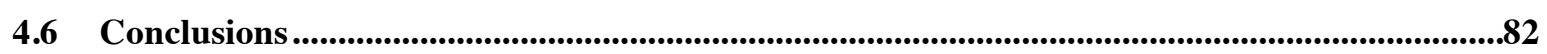

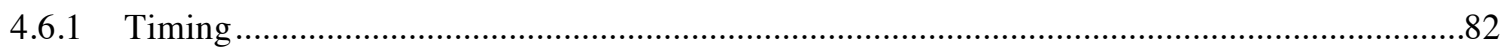

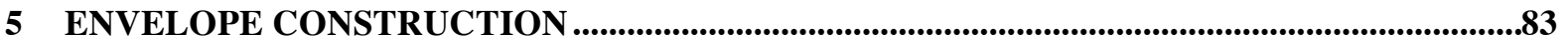

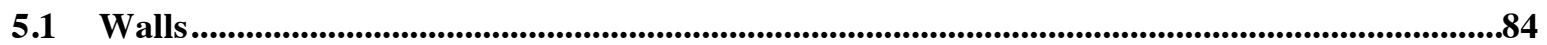

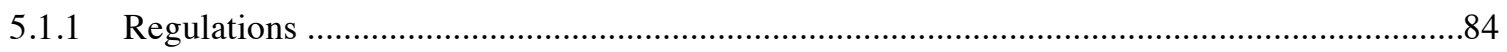

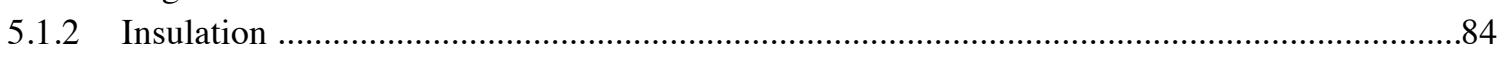

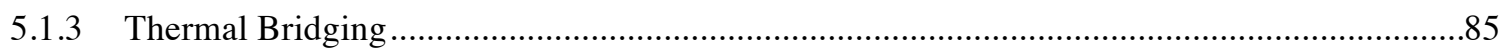

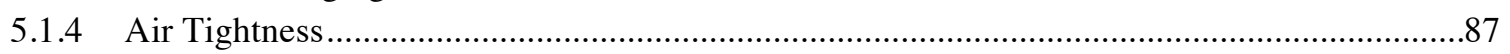

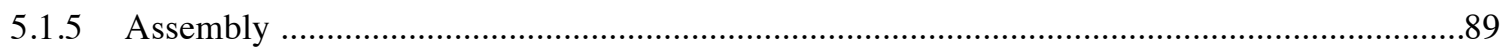

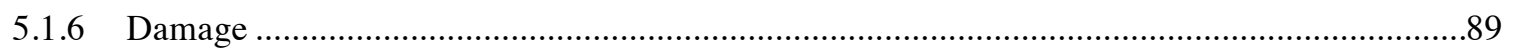

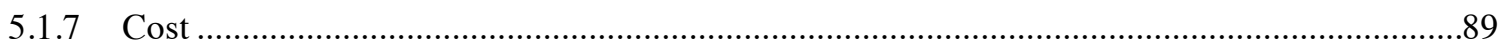

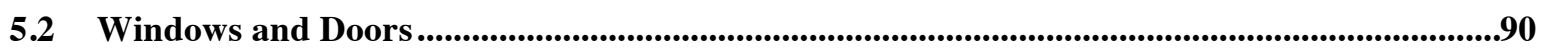

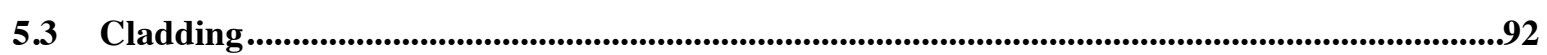

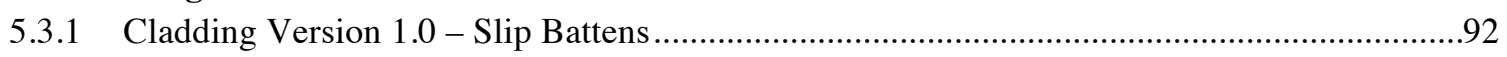

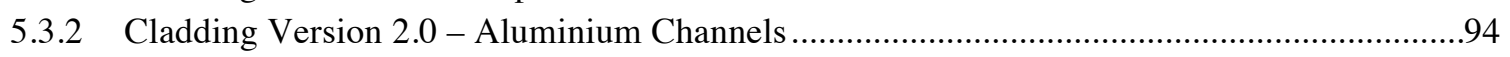

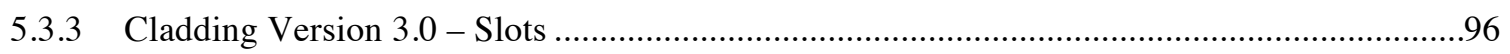

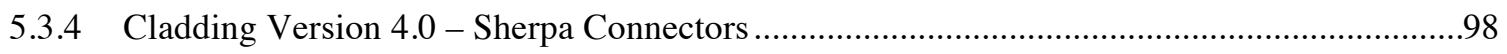

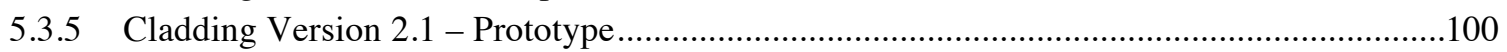

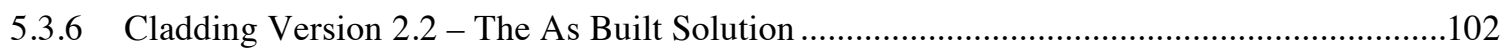

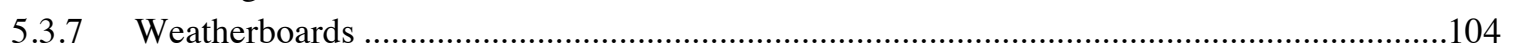

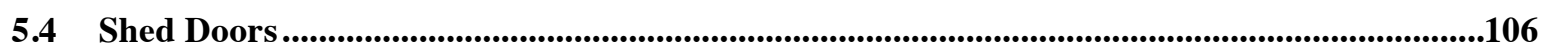




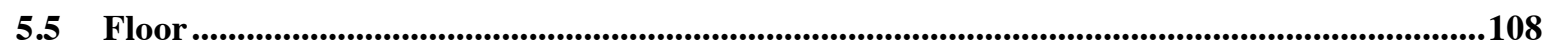

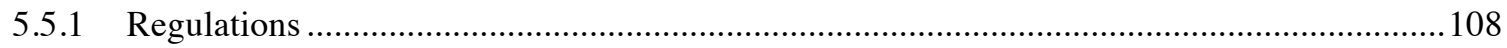

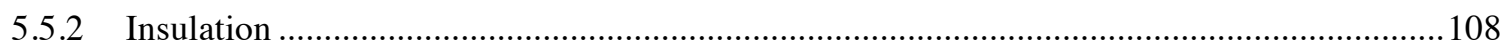

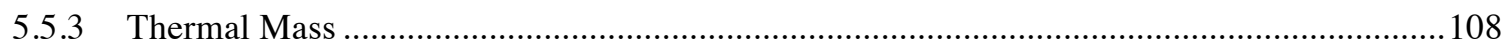

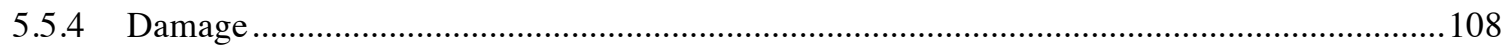

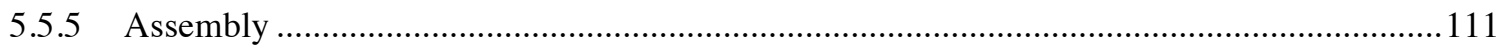

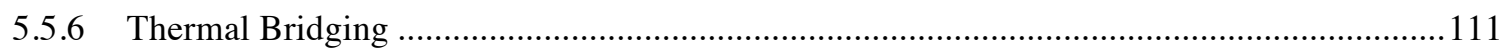

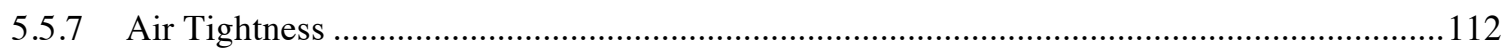

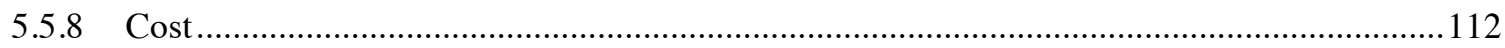

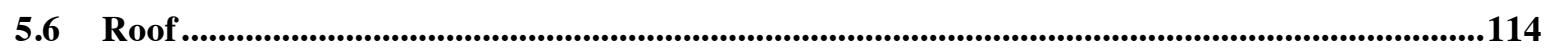

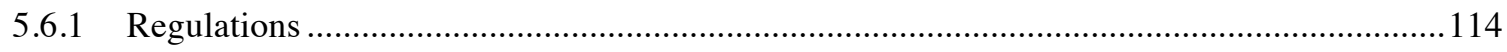

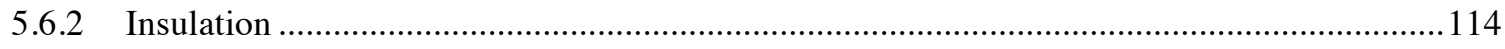

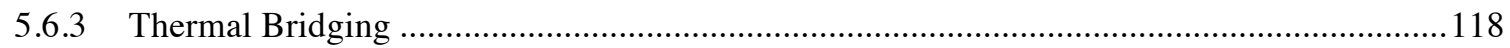

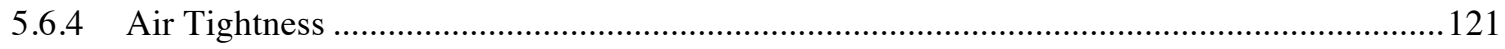

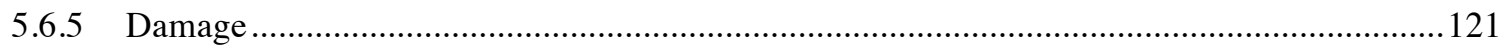

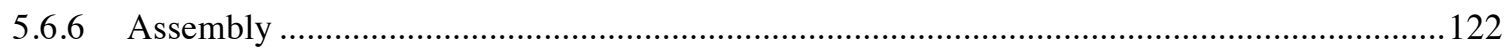

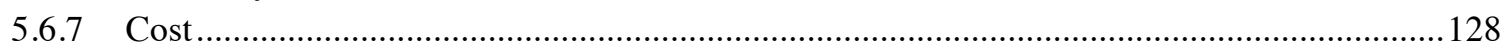

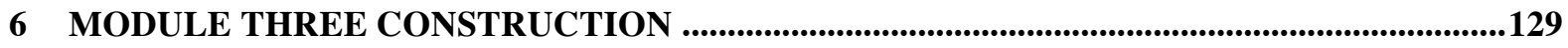

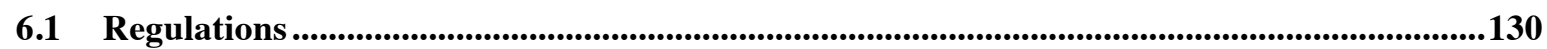

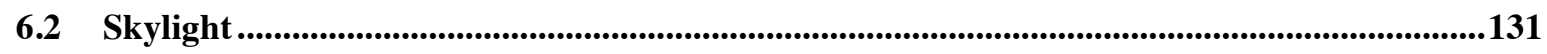

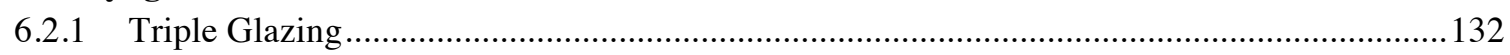

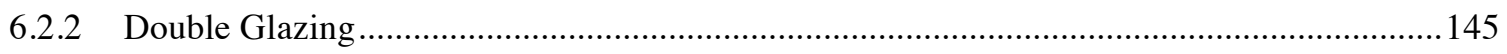

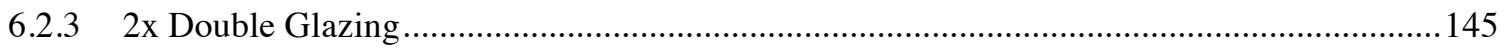

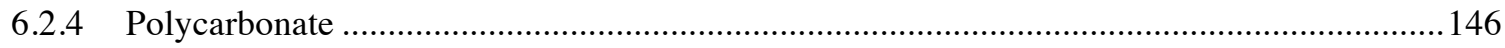

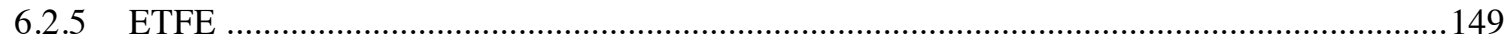

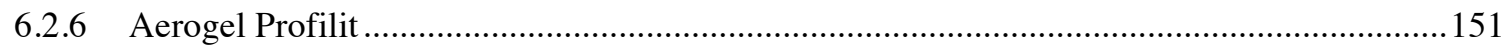

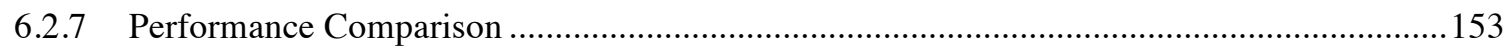

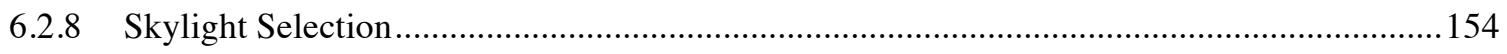

6.3 Module Three Roof ....................................................................................................................154

6.4 Module Three Floor .................................................................................................................155

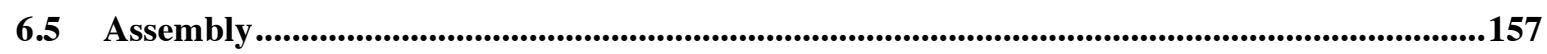

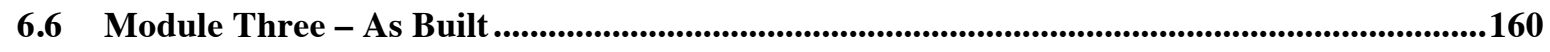

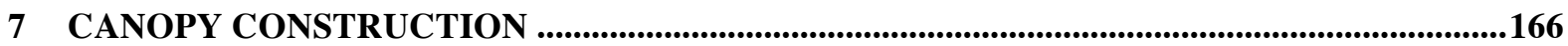

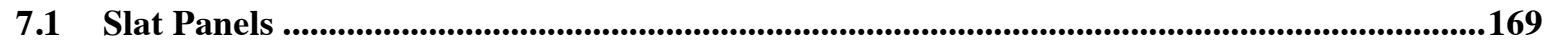

7.2 Glulam Structure ...........................................................................................................................177

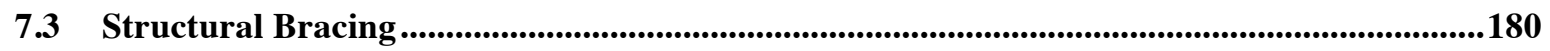

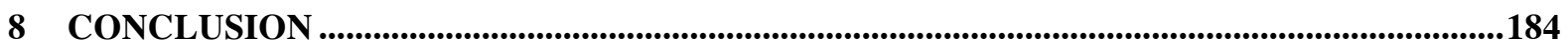

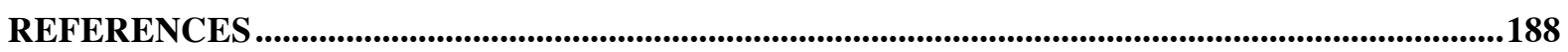

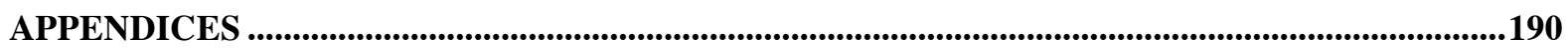

Solar Decathlon Contest Criteria ........................................................................................................190 


\section{LIST OF FIGURES}

Figure 1: The First Sketch

Figure 2: Rendered Image From Conceptual Design Submission - Exterior Perspective

Figure 3: Rendered Image From Conceptual Design Submission - Interior Perspective 1 .......................26

Figure 4: Rendered Image From Conceptual Design Submission - Interior Perspective 2 ......................26

Figure 5: Rendered Floor Plan From Conceptual Design Submission …...........................................27

Figure 6: World Map Showing Transportation Journey of the First Light House ....................................29

Figure 7: Rendered Image From Conceptual Design Submission - Exploded Building Elements ..............30

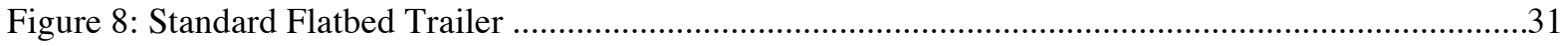

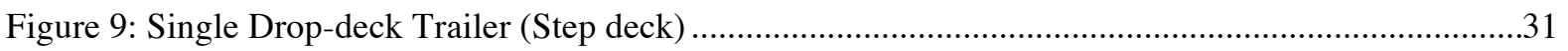

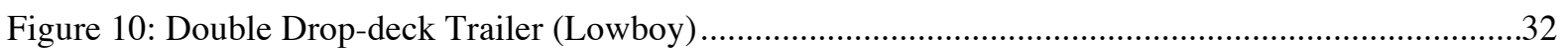

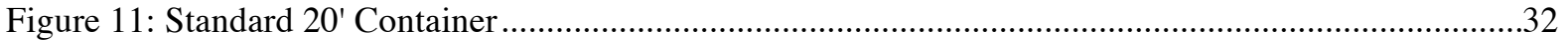

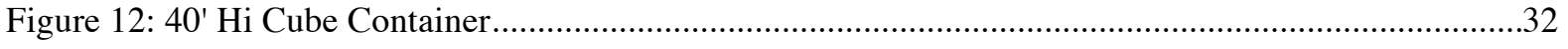

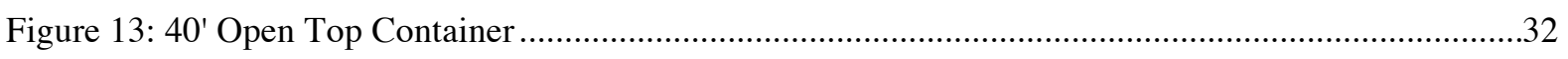

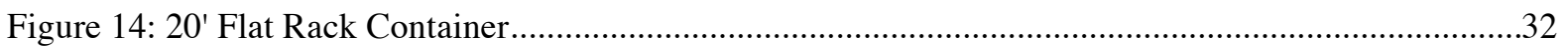

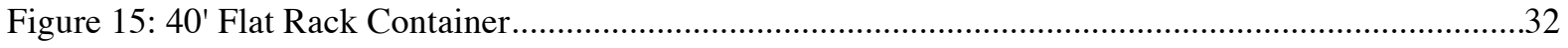

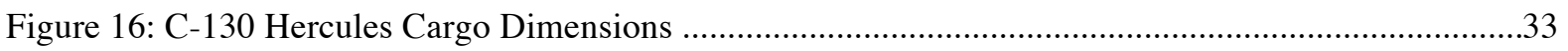

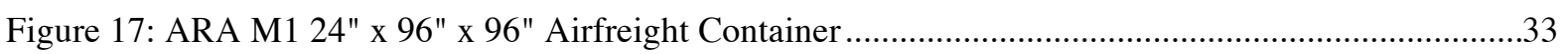

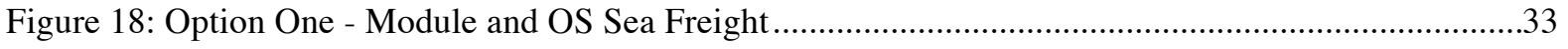

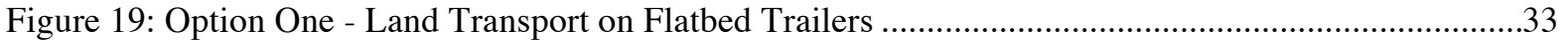

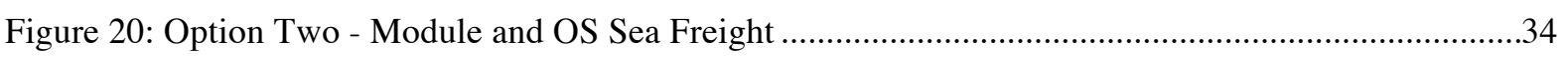

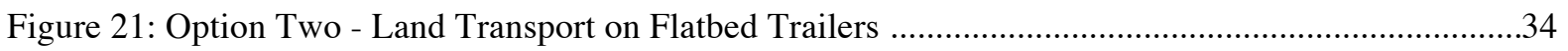

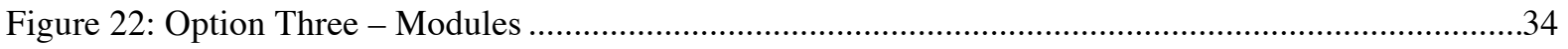

Figure 23: Option Three - Land Transport on Single Drop-deck Trailers ............................................34

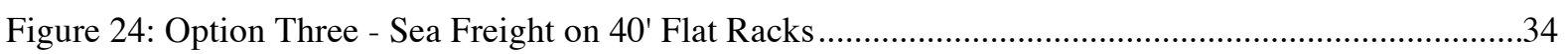

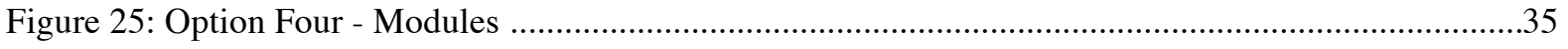

Figure 26: Option Four - Land Transport on Single Drop-deck Trailers .............................................35

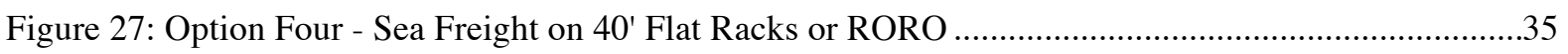


Figure 28: Option Five - Modules and OS Sea Freight

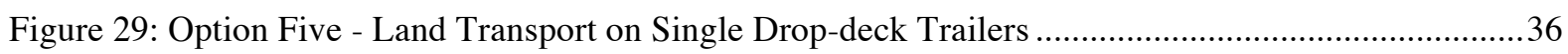

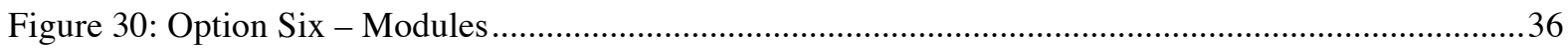

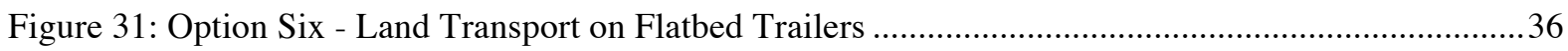

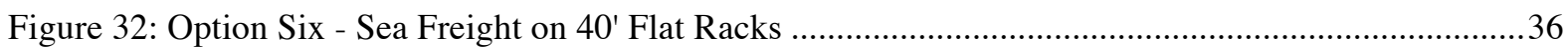

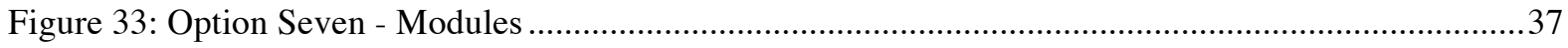

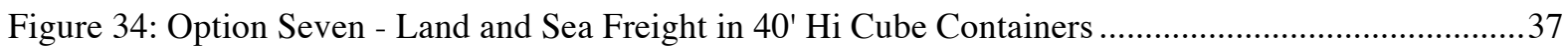

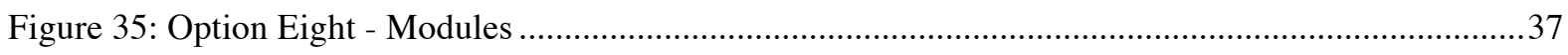

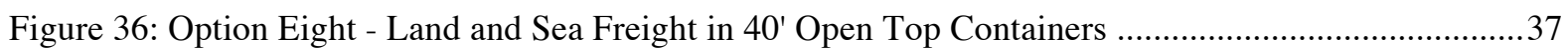

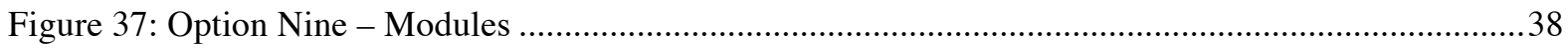

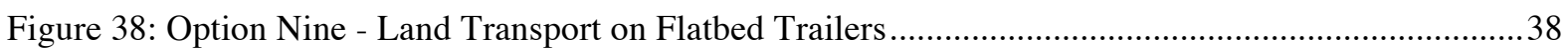

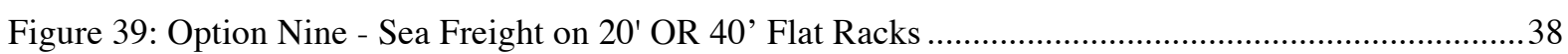

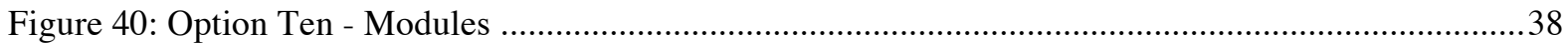

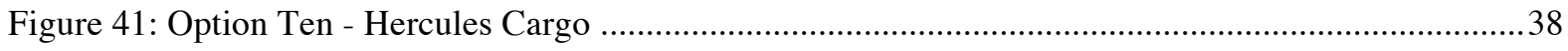

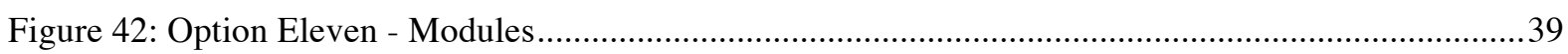

Figure 43: Option Eleven - Land and Air Transport in Standard Air Freight Container............................39

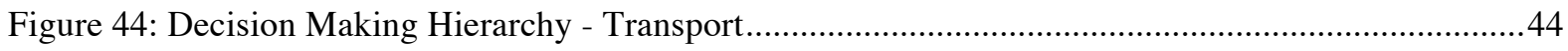

Figure 45: House Split Longitudinally for 40’ Flat Rack Transport.................................................47

Figure 46: House Split Longitudinally for OOG 40 'Flat Rack OR RORO Transport .............................47

Figure 47: House Split Transversely for Flat Rack Transport .....................................................47

Figure 48: House Split Transversely and Panelised for Flat Packing ...............................................47

Figure 49: House Split Longitudinally and Horizontally for Packing Into 40' Open Top Containers .........47

Figure 50: Project Timeline for Shipping Options 3, 4 \& 9 Using Flat Rack Containers .........................50

Figure 51: Project Timeline for Shipping Option 4a Using a Roll-on Roll-off Service ..........................51

Figure 52: Project Timeline for Shipping Option 7 - Flat Rack Containers and Option 8 Using Open Top Containers

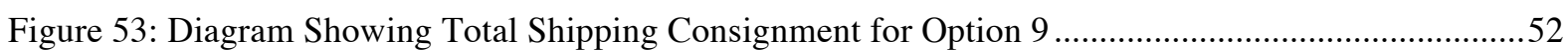

Figure 54: 3D Diagram Showing Flat Packed Components ..............................................................53

Figure 55: 3D Diagram Showing Maximum Module Dimensions ..................................................53

Figure 56: Foundation Components - Exploded Assembly ........................................................54

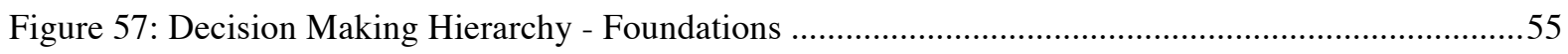


Figure 58: Solar Envelope Dimensions - SD 2011 Rules

Figure 59: Diagram Showing Foundation 'Tracks’ and Assembly Sequence .....

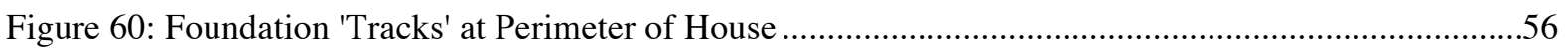

Figure 61: Perimeter Foundation Tracks - Elevation Showing Lowered Building Height ........................56

Figure 62: Foundation Detail - Adjustable Scaffold Screw Footing .....................................................56

Figure 63: Foundation Components - Exploded Assembly ........................................................57

Figure 64: Construction Photo Showing Foundation Section .............................................................57

Figure 65: Construction Photo Showing Bolted Foundation Splice .......................................................57

Figure 66: Construction Photo Showing Smooth Internal Edge of Foundation Splice..............................57

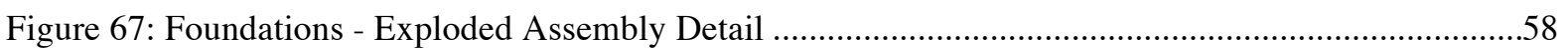

Figure 68: Construction Photo Showing Assembled Foundation .......................................................59

Figure 69: Frank Kitts Park (FKP) Assembly Photo Showing Adjustable Screw Footings and Spacer Sleeves

Figure 70: Construction Photo Showing Concealed Adjustable Foundation Components .59

Figure 71: Construction Photo Showing Welded Plate. 59

Figure 72: Diagram Showing Potential Foundation Rotation ..... 60

Figure 73: Construction Photo Showing Outrigger and Column Rotation .60

Figure 74: Construction Photo Showing Chem.-Set Threaded Rod Anchor .60

Figure 75: FKP Assembly Photo Showing Timber Wedges ............................................................60

Figure 76: Construction Photo - Laminated Plywood Base-plate .......................................................61

Figure 77: FKP Assembly Photo Showing Foundation Base-plates ...................................................61

Figure 78: Assembly Drawing - Foundation Base-plate Layout ....................................................61

Figure 79: FKP Assembly Photo - Foundations Laid at Approximate Locations...................................62

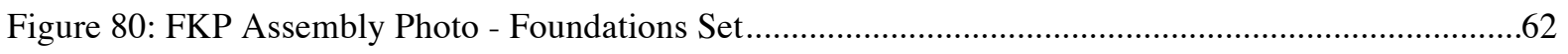

Figure 81: Assembly Drawing - Foundation Alignment Using Triangulation ....................................62

Figure 82: Assembly Drawing Showing Module Placement Using Crane (BL) ...................................62

Figure 83: SD Assembly Photo Showing Module Bracing and 'Lowboy' Trailer .....................................62

Figure 84: SD Assembly Photo Showing Stropping and Lifting of the Shed Module .............................63

Figure 85: SD Assembly Photo Showing Module Three Placed on Foundations ....................................63

Figure 86: SD Assembly Photo Showing Module Five Being Placed on Foundations ............................63

Figure 87: SD Assembly Photo Showing Hydraulic Power Ram Used to Move Modules ........................63 
Figure 88: Overview of Prefabricated Module Components (JM)

Figure 89: Decision Making Hierarchy - Module Construction

Figure 90: The weighted effect of construction cost on points scored in the Affordability contest

(SDRules2011)

Figure 91: Diagram Showing Main Components of a SIP (SIPA, 2007) ..........................................68

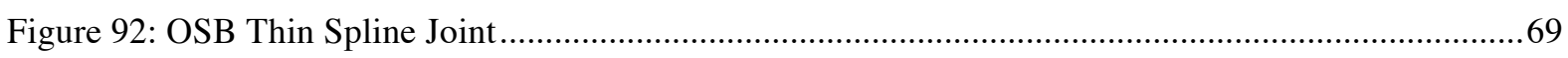

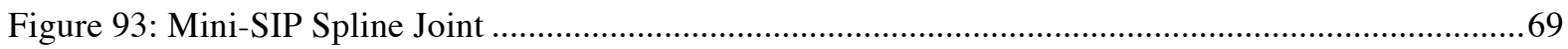

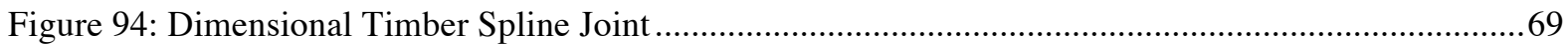

Figure 95: Section Showing 10 1/4" R-Control SIP Module (JM) .................................................. 71

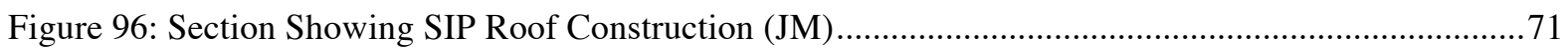

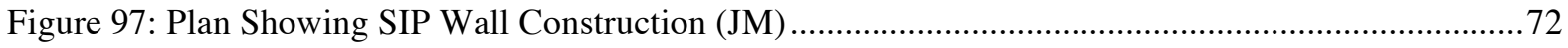

Figure 98: Section Showing SIP Floor Construction (JM) ..................................................... 72

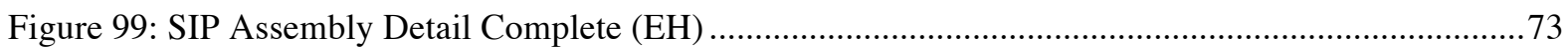

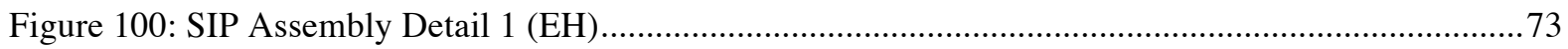

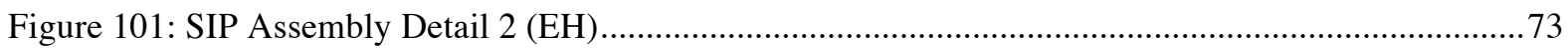

Figure 102: Sectional 3D Through Module Showing Timber Frame Construction (JM) ........................76

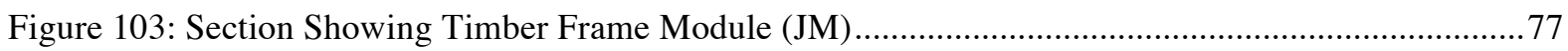

Figure 104: Section Showing Timber Frame Roof Construction (JM) ............................................. 77

Figure 105: Plan Showing Timber Frame Wall Construction (JM) ................................................. 78

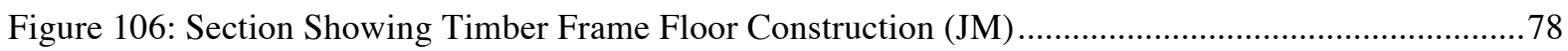

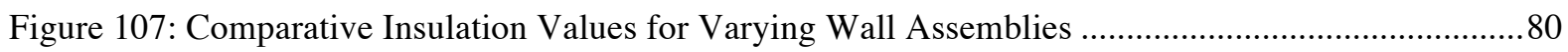

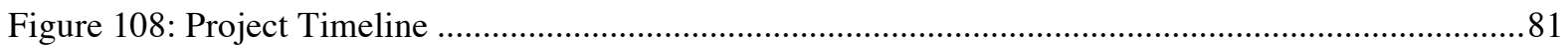

Figure 109: R-Controls Proposed Timeline for Constructing With SIPs ..........................................82

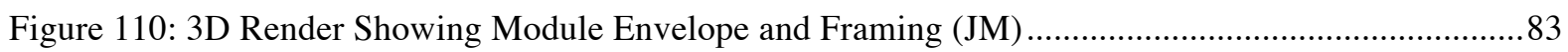

Figure 111: Decision Making Hierarchy - Wall Construction .................................................... 84

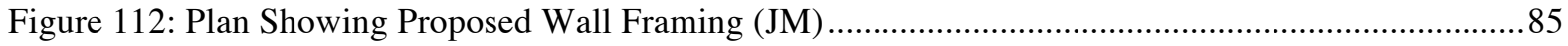

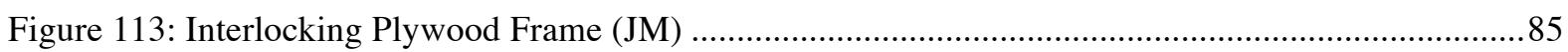

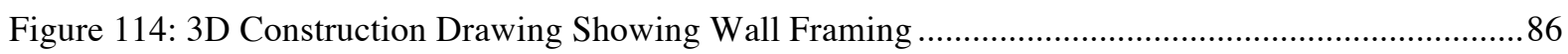

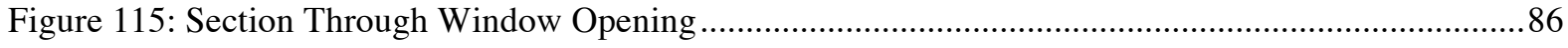

Figure 116: Construction Photo Showing the Manufacture of Wall Panels at Carters Pre-nail Plant..........86

Figure 117: Construction Photo Showing Delivery of Prefabricated Wall Panels ..................................86 
Figure 118: Construction Photo Showing Prefabricated Living Room Wall Panels

Figure 119: Construction Photo Showing Insulated Wall Panels

Figure 120: Construction Photo Showing Wall Panel Erected on Floor................................................87

Figure 121: Diagram Showing Intello Vapour Diffusion (Proclima) ...................................................8

Figure 123: Construction Photo Showing Intello Vapour Check .........................................................88

Figure 122: Plan Detail Showing Wall Construction and Intello Vapour Check (JM) ............................88

Figure 124: Engineers Sketch Showing S/S Steel Tension Cables ...................................................89

Figure 125: Thermal Bridging Simulation for Timber Frame vs. Thermally Broken Aluminium Frame ....90

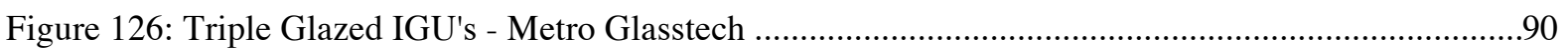

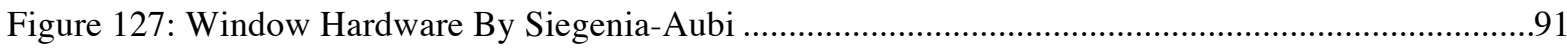

Figure 128: Construction Photo Showing Window Sill and Jamb Flashings .......................................91

Figure 129: Cladding Version 1.0 - Detail of Timber Support and Neoprene Dampener (BL) .................92

Figure 130: Cladding Version 1.0 - Detail of Neoprene Dampener (BL) .........................................92

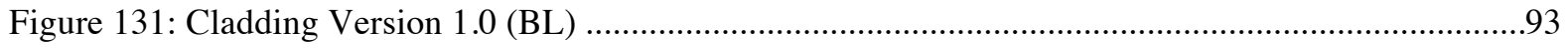

Figure 132: Cladding Version 2.0 - Plan Detail Showing Clipping Method (BL) ..................................94

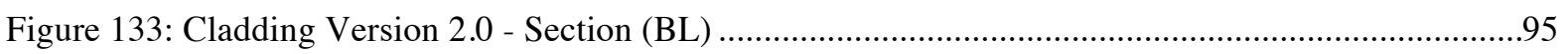

Figure 134: Cladding Version 3.0 - Section Detail Showing Lapping of Weatherboard Panels (BL) .........96

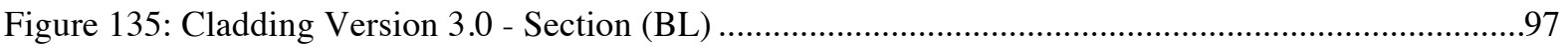

Figure 136: Cladding Version 4.0 - Sherpa WTS3 Spezial Connectors (Sherpa) ..................................98

Figure 137: Cladding Version 4.0 - Detail Showing Interlocking Sherpa Connectors (BL) .....................98

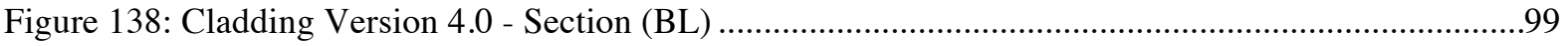

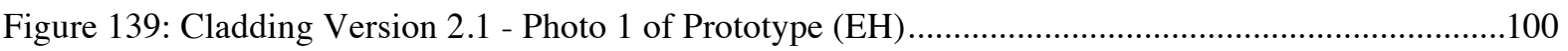

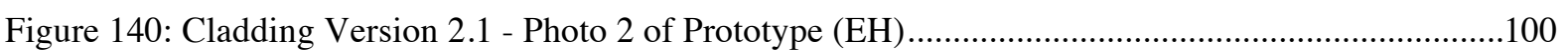

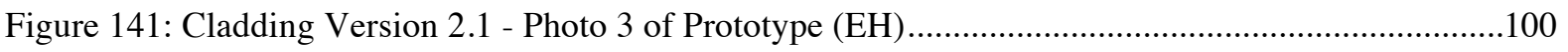

Figure 142: Cladding Version 2.1 - Section Detail for Prototype (BL) ..........................................101

Figure 143: Cladding Version 2.1 - Plan Detail for Prototype (BL) ...............................................101

Figure 144: Cladding Version 2.2 - Plan Detail Showing Angle Used for Tolerance (BL) .....................102

Figure 145: Cladding Version 2.2 - Plan Detail Showing Plastic Locking Buffer (BL) ........................102

Figure 146: Cladding Version 2.2 - Optimised Aluminium Angle Slots for Ease of Assembly (Before and

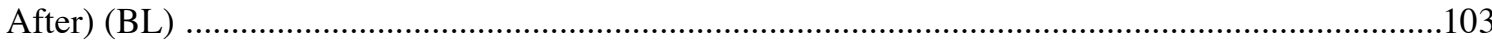

Figure 147: Construction Photo Showing Wall Cladding Channels .....................................................103 
Figure 148: Construction Photo Showing Cladding Angles

Figure 149: Cladding Version 2.2 - Cladding Panel Angle Types (BL)......

Figure 150:FKP Photo Showing the Ease of Carrying a Cladding Panel 105

Figure 151: FKP Photo Showing the Installing of a Cladding Panel. 105

Figure 152: 3D Model Showing Vertical Bi-Fold Shed Door 106

Figure 153: 3D Render Showing Bi-Fold Shed Door 106

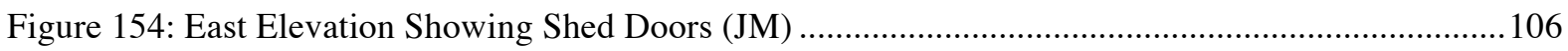

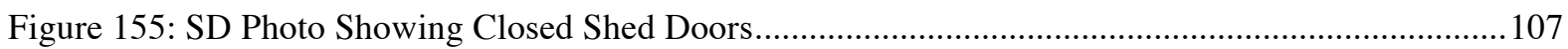

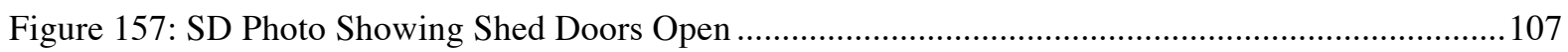

Figure 156: SD Photo Showing Shed Doors Open For Presentation................................................. 107

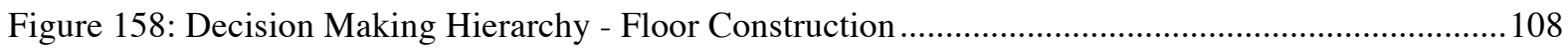

Figure 159: Fabrication Drawing - Thermal Mass....................................................................... 108

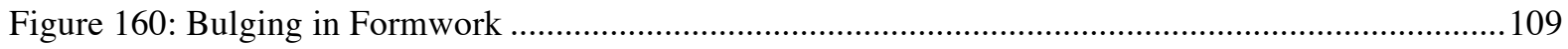

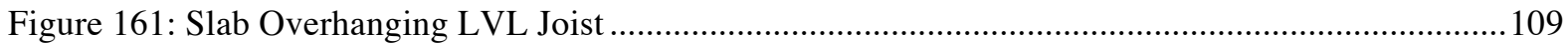

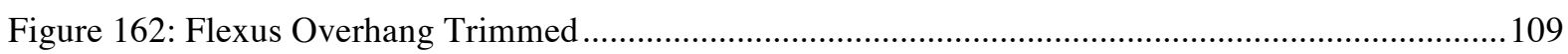

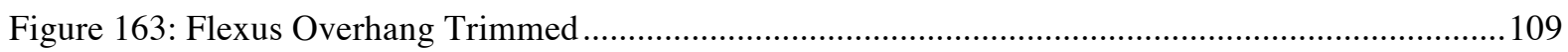

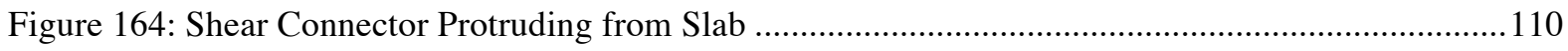

Figure 165: Aluminium Edge Clashing Removed ................................................................ 110

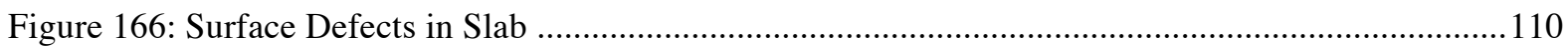

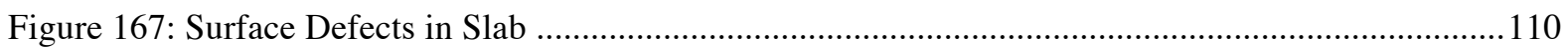

Figure 168: Construction Detail Showing Typical Inter-Module Floor Join.......................................111

Figure 169: Floor Construction Option One - Transverse Joists Without Concrete (JM) ........................112

Figure 170: Floor Construction Option Two - Longitudinal Hyjoists Without Concrete (JM) ................112

Figure 171: Floor Construction Option Three - Longitudinal LVL Joists With Flexus Slab (JM) ...........112

Figure 172: Decision Making Hierarchy - Roof Construction ......................................................114

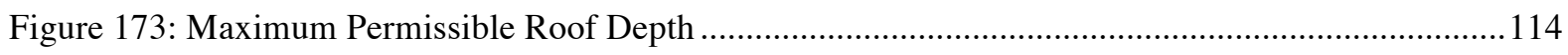

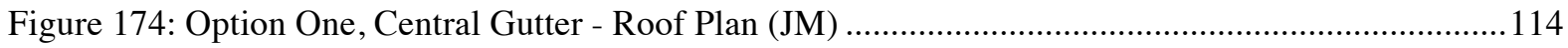

Figure 175: Option One, Central Gutter - Longitudinal Section (JM) ..........................................115

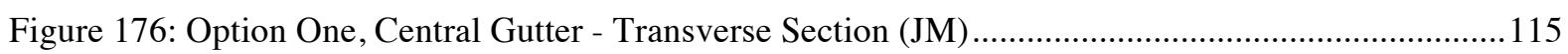

Figure 177: Option Two, Gable Roof \& Large Gutters - Roof Plan (JM)...........................................115

Figure 178: Option Two, Gable Roof \& Large Gutters - Transverse Section (JM) ..............................115 
Figure 179: Option Three, Transverse Gable \& Edge Gutters - Roof Plan (JM)

Figure 180: Option Three, Gable \& Edge Gutters - Longitudinal Section (JM).

Figure 181: Option Three, Gable \& Edge Gutters - Transverse Section (JM)......

Figure 182: Option Four, Long. Gable Roof - Longitudinal Section (JM) ....

Figure 183: Option Four, Long. Gable Roof - Transverse Section (JM)

Figure 184: Fabrication Drawing - Exploded Roof Panel

Figure 185: Fabrication Drawing - Complete Roof Panel

Figure 186: Fabrication Drawing Showing Individually CNC Cut Plywood Ribs

Figure 187: Fabrication Drawing Showing Framing Elements of Roof Panel

Figure 189: Construction Photo Showing Non-Load Bearing Box-Beam .120

Figure 190: Construction Photo Showing Insulated Box-Beam 120

Figure 188: Construction Photo Showing Prefabricated Roof Frames at Ferndale Furniture Ltd..... .120

Figure 191: Fabrication Drawing Showing Change in Rib Width for Different Roof Types

Figure 192: Fabrication Drawing - Example of Roof Type Key

Figure 193: Fabrication Drawing Showing Fillets and Chamfers to Roof Surface (JM)

Figure 194: Construction Elevation Showing Downpipe Locations.

Figure 195: 3D Sketch Showing Scupper and Downpipe Components......

Figure 196: Engineers Detail of Roof Locating Dowel

Figure 197: EPDM Parapet strip to Module Join Detail

Figure 198: Clip-on Parapet Flashing Detail

Figure 199: SD Photo Showing Clip-on Parapet Flashing - Exterior Finish

Figure 200: Clip-on Parapet Flashings - Assembly Drawing

Figure 201: Fall Arrest/Restraint Equipment (Capital Safety, 2012)

Figure 202: Calculating Fall Clearance Distance

Figure 203: A Fall Restraint System (OSH Academy: Occupational Safety \& Health Training, 2010) ....124

Figure 205: DBI Sala L4544 Roof Anchors - Installation .125

Figure 206: DBI Sala L4544 Roof Anchor .125

Figure 204: Roof Plan Showing Anchor Points 125

Figure 207: Fall Arrest Anchor - Structural Detail 126

Figure 208: Manual Rope-Grab Adjuster and Lifeline (Capital Safety, 2012) .126

Figure 209: Swing Down Hazard - Roof Plan .126 
Figure 210: Swing Down Hazard.

Figure 211: Fall Clearance Distance - First Light House

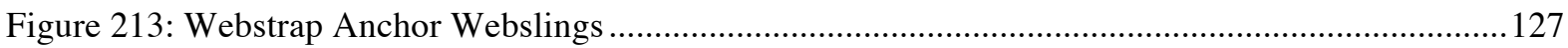

Figure 214: Websling Attached to Beam, Lanyard Over Rafters ...........................................................127

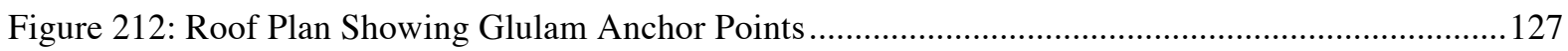

Figure 215: Exploded 3D Diagram Showing Module Three Components (Excl. Floor) ...........................129

Figure 216: Decision Making Hierarchy - Module Three ………................................................................130

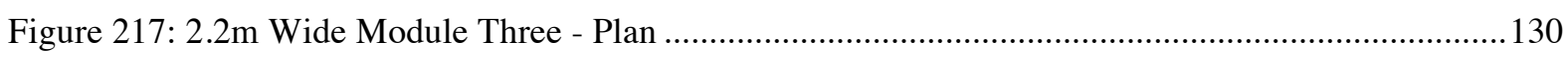

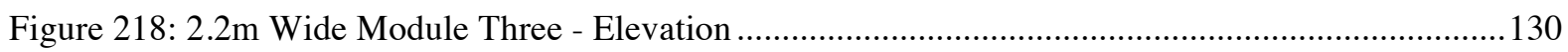

Figure 219: Variations in hourly internal air temperature with glazing area between $0 \%$ and $100 \%$ of original skylight size for the period from Sept 15 - Oct 15 (Jagersma, 2012) ...................................131

Figure 220: Section through Module Three showing reduced size of skylight and services bulkhead ......132

Figure 221: Roof Plan - Central Ridge Triple Glazed Skylight (RM) ....................................................132

Figure 222: Central Ridge and IGU Connection Details - Triple Glazed Skylight (RM) ..........................133

Figure 223: Ceiling Threshold Flush with Louvres, Protruding Gutter (RM) ..........................................133

Figure 224: Ceiling Threshold Below Louvres, Flush Gutter and Vertical Weatherboard Linings (RM).133

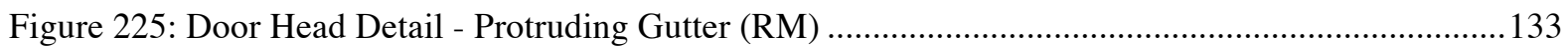

Figure 226: Door Head Detail - Flush Gutter (RM) ……………….....................................................134

Figure 227: Scupper and Internal Spouting Plan Detail (RM) ................................................................134

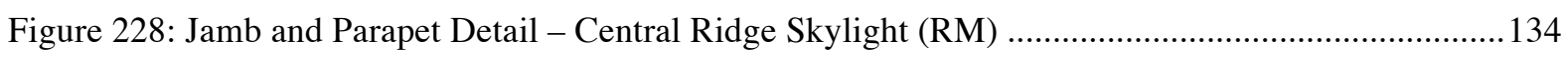

Figure 229: Triple Glazed Skylight - Internal Louvres.........................................................................134

Figure 230: Example of Automated Internal Louvres - Closed (Atelier Workshop Aotearoa, 2005)........135

Figure 231: Example of Automated Internal Louvres - Closed (Atelier Workshop Aotearoa, 2005) .......135

Figure 232: Example of Manual User Control - Chicken Point Cabin (Olson Kundig Architects, 2012) .135

Figure 233: Triple Glazed Skylight Option Two Roof Plan - Central Ridge and Concealed Gutters (RM)

Figure 234: Triple Glazed Skylight Option Two - APL Profile Edge Detail (RM) ...................................136

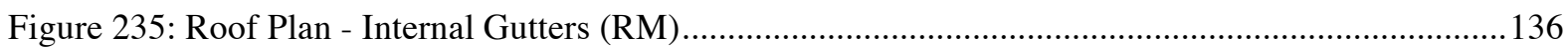

Figure 236: Metro Series Thermal Height Skylight Profiles by APL.....................................................136

Figure 237: Conceptual Design Section of M3 ..................................................................................137

Figure 238: Conceptual Design Render of M3 - The Central Space ……...............................................137

Figure 239: Custom Formed Internal Gutter - S/S Casing (RM) _...........................................................137 
Figure 240: Custom Formed Internal Gutter - Plywood Casing (RM)

Figure 241: Custom Formed Internal Gutter - Welded Steel Support (RM)

Figure 242: Skylight Head and Parapet Detail - Internal Gutter (RM) .............................................138

Figure 243: Option One Rear Section Detail - Concealed Downpipes (RM) ....................................138

Figure 244: Option Two Rear Section Detail - Exposed Spouting (RM) .........................................138

Figure 245: Option Three Rear Section Detail - Custom Formed Rain Head (RM).............................139

Figure 246: Triple Glazed Skylight Option Three Section - Thermal Roller Blinds (RM) .....................139

Figure 247: Triple Glazed Skylight Option Three Section - Roller Blind Concealment (RM) .................139

Figure 248: Triple Glazed Skylight Option Two Section - Spaceloft Upholstered Blind Concealment (RM)

Figure 249: Triple Glazed Skylight Option Two Section - Retractable Louvres (RM) ..... .140

Figure 250: Triple Glazed Skylight Option Two - 3D Model Showing Concealed Louvre or Roller Blind Track 140

Figure 251: Two Falls, Thermal Heart Skylight .141

Figure 252: Two Falls, Thermal Heart Skylight - Roof Plan (RM)

Figure 253: Thermal Heart Skylight Frame by APL - Customized for 42mm IGU

Figure 254: Thermal Heart Skylight - Glazing Bar Trimmed to Fit with Timber Beam (RM)

Figure 255: Thermal Heart Skylight - North Panel Draining Onto Solid Section of Roof (RM)

Figure 256: Thermal Heart Skylight - Exposed Front Gutter (RM)

Figure 257: Thermal Heart Skylight - Partial Section Showing Falls Above and Below Neighbouring

Module (RM)

Figure 258: Thermal Heart Skylight Jamb Detail - Skylight Below Parapet (RM)

Figure 259: Thermal Heart Skylight Jamb Detail - Skylight Below Parapet (RM)

Figure 260: One Fall, Thermal Heart Skylight - Roof Plan (RM)

Figure 261: One Fall at Both $3^{\circ}$ and $5^{\circ}(\mathrm{RM})$.

Figure 262: Skylight Jamb Detail Ascending Above Neighbouring Parapet at $5^{\circ}$ (RM).....

Figure 263: Skylight Jamb Detail Remaining Below Neighbouring Parapet at $3^{\circ}(\mathrm{RM})$

Figure 264: One Fall, Skylight Head Detail at $3^{\circ}(\mathrm{RM})$

Figure 265: One Fall, Skylight Gutter Detail at $3^{\circ}(\mathrm{RM})$

Figure 266: Thermosash Detail Proposal Using a Typical Mullion Frame

Figure 267: APL - Thermally Broken Double Glazed Skylight Details .145

Figure 268: Danpalon Panels (Everlight NZ Ltd, 2009) 146 
Figure 269: Danpalon Skylight - Drainage Plan (RM)

Figure 270: Danpalon Skylight - Gutter Detail (RM)

Figure 271: Danpalon Skylight - Apex Detail (RM)

Figure 272: Danpalon Skylight - Jamb Detail (RM).....

Figure 273: Danpalon Skylight - AB Bar Detail (Everlight NZ Ltd, 2009) 148

Figure 274: Example of Danpalon - Skylight 148

Figure 275: Example of Danpalon - Lincoln Rd, Auckland (Everlight NZ Ltd, 2009) 148

Figure 276: Example of Danpalon - Conservatory 148

Figure 277: ETFE - Pasadena Art Centre by Daly Genik Architects (Woyke, 2007) 149

Figure 278: ETFE Variable Texlon - Open (Vector Foiltec, 2010) 149

Figure 279: ETFE Variable Texlon - Closed (Vector Foiltec, 2010)

Figure 280: ETFE Variable Texlon - Duxford Visitors Centre (Vector Foiltec, 2010).

Figure 281: ETFE Skylight - Roof Plan (RM) 150

Figure 282: ETFE Skylight - Gutter Detail at Pillow Edge (RM) 150

Figure 283: ETFE Skylight - Gutter Detail at Pillow Join (RM).

Figure 284: ETFE \& Triple-Glazing - Gutter Detail and Bi-Fold Door Junction (RM) 151

Figure 285: ETFE \& Triple-Glazing - Jamb Detail at Module Join (RM) 151

Figure 286: Pilkington Profilit Channel Glass with Luminaire Aerogel 151

Figure 287: Profilit Aerogel Channel Glazing - Roof Plan (RM)

Figure 288: Profilit Aerogel Channel Glazing - Section (RM)

Figure 289: Profilit Channel Glazing - Gutter Detail (RM)

Figure 290: Profilit Channel Glazing - Gutter Detail 2 (RM)

Figure 291: Profilit Channel Glazing - Ridge Detail (RM)

Figure 292: Graph Showing Average Heating and Cooling Loads for the Various Skylight Constructions for September 1 - October 31 in Washington, DC (Jagersma, 2012).

Figure 293: Construction Drawing Showing Skylight Inter-Panel Jamb Detail..... 154

Figure 294: Thermosash Triple Glazed Skylight - Section Showing Transverse Orientation of Skylight

Panels (RM)

Figure 295: Construction Photo Showing Module Three Roof Suspended Between LVL Beams

Figure 296: Module Three Roof - Section Showing Timber Framing (JM)

Figure 297: Module Three Floor Panels - Separated During Construction

Figure 298: Module Three Floor Panels - LVL Joists Notched for Door Tracks 
Figure 299: Module Three Floor Panels - Framing Plan .156

Figure 300: 3D Sketch Showing Inter-Module Junction .157

Figure 301: Module Three - Insulated Box-Beams .157

Figure 302: Module Three - Crane-Lifted Into Place.

Figure 303: Module Three Main Elements - Assembled .158

Figure 304: Module Three Main Elements - Exploded 3D

Figure 305: Construction Details Showing Bi-Fold Head \& Skylight Junction and Bi-Fold Jamb and InterModule Join.

Figure 306: Construction Details Showing Bi-Fold Head \& Roof Junction and Bi-Fold Door Sill..... 162

Figure 307: Construction Detail Showing Skylight Apex Detail and Roller Blind

Figure 308: Construction Detail Showing Skylight Jamb and Inter-Module Join

Figure 309: Interior Photo of Module Three From Study, One Roller-Blind Closed (Credit: Paul Hillier)

Figure 310: Interior Photos Showing Skylight During Wet Weather (left) and at Dusk (right) (Credit:

Stefano Paltera/U.S. Department of Energy Solar Decathlon).....

Figure 311: Exterior Photo Showing the Aluminium Corrugate Cladding Gutter of Module Three 165

Figure 312: Construction Drawing Showing Assembled Canopy Timber Elements..... .166

Figure 313: Conceptual Design Submission - Rendered Exterior Perspective .167

Figure 314: Conceptual Design Submission - 1:50 Scale Model....

Figure 315: Conceptual Design - 3D Sketchup Model Showing Canopy

Figure 316: Conceptual Design Submission - 1:50 Scale Model Showing Solar Panel Arrangement .......167

Figure 317: Canopy Structural Iteration - 3D Model Showing Longitudinal Primary Beams .................168

Figure 318: Canopy Structural Iteration - 3D Model Showing Slats on Underside of Rafters ..................168

Figure 319: Canopy Structural Iteration - 3D Model Showing Flat Canopy ........................................168

Figure 320: SD Photo Showing the Completed Canopy ...............................................................169

Figure 321: Canopy Slat Angle Tests at 100mm Centres - Sketchup Model for Summer in Wellington, NZ

Figure 323: Construction Photo Showing Cedar Slat Fixing ..........................................................170

Figure 324: Construction Photo Showing Notched Cedar Battens ...................................................170

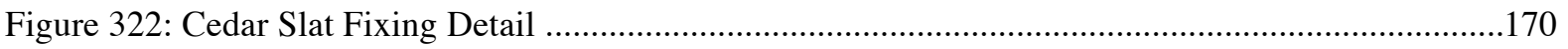

Figure 325: Cutting Schedule for Cedar Slat Battens ...........................................................

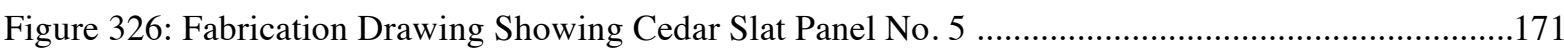


Figure 327: Construction Photo Showing Cedar Slat Panels

Figure 328: Construction Photo Showing the Installation of a Cedar Slat Panel

Figure 329: Assembly Drawing - Slat Panel Locations

Figure 330: FKP Assembly Photo Showing Cedar Slat Panel Fixing Bracket

Figure 331: SD Photo Showing Vertical Cedar Slats

Figure 332: FKP Photo Showing Vertical Slats at Entrance to House (Credit: Paul Hillier)

Figure 333: Fabrication Detail Showing Fixing of Vertical Cedar Slats

Figure 334: Fabrication Detail Showing Fixing of Cedar Batten

Figure 335: Cutting Schedule for Vertical Slat Battens.....

Figure 336: FKP Aerial Photo Showing Vertical Slats Above Skylight (Credit: Paul Hillier) 174

Figure 337: FKP Interior Photo Showing Vertical Slats Above Skylight (Credit: Paul Hillier)

Figure 338: FKP Assembly Photo Showing Vertical Slat Panels Directly Fixed to Glulam Beam

Figure 339: Fabrication Drawing Showing Slat Panels and Slat Cutting Schedule

Figure 340: Fabrication Drawing - South Elevation Showing Structural Glulam Members

Figure 341: Fabrication Drawing - East Elevation Showing Structural Glulam Members

Figure 342: FKP Assembly Photo Showing Glulam Canopy Structure

Figure 343: FKP Assembly Showing Tapered Primary Glulam Beams (Credit Ruth Armishaw - NZ Wood)

Figure 344: Fabrication Drawing - Column Base Fixing

Figure 345: Fabrication Drawing - Column Base Fixing

Figure 346: Construction Photo Showing Column Base Fixing

Figure 347: FKP Assembly Photo Showing Foundation Plate Protruding Through Planter Boxes 178

Figure 348: FKP Assembly Photo Showing Foundations Concealed by Landscaping 178

Figure 349: Fabrication Drawing Showing Primary Beam to Column Fixing 178

Figure 350: FKP Assembly Photo Showing S/S Glulam Plates

Figure 351: FKP Assembly Photo Showing Glulam Beams and Columns Fixed to Form Portal Frames .179

Figure 352: FKP Assembly Photo Showing Glulam Portals Lifted by Crane....

Figure 353: FKP Assembly Photo Showing Glulam Portals Place on Foundations (Credit: Ruth Armishaw $-\mathrm{NZ}$

Figure 354: Fabrication Drawing Showing Spax Screw Fixing Between Glulam Rafter and Beam 180

Figure 355: Sectional Drawing Showing Tilting Glulam Beam 180

Figure 356: Fabrication Drawing Showing Column Bracing Strut 
Figure 359: 3D Model Showing Canopy Bracing Bracket Between Primary Glulam Beams... .181

Figure 360: Engineers Sketch Showing Canopy Bracing Bracket..... .181

Figure 361: Engineers Sketch Showing Parapet Mounting Bracket..... 181

Figure 362: SD Assembly Photo Showing Canopy Bracing Bracket Protruding Through Slat Panel .......182

Figure 363: Engineers Sketch Showing Canopy Tension Bracing 182 


\section{ACKNOWLEDGEMENTS}

The First Light house was a collaborative project relying on the involvement of many talented, hardworking, and passionate individuals. Acknowledgement must of course be given to the industry sponsors whos ongoing support made the First Light project possible. I would like to also thank the following people for their personal contribution and investment in the project.

\section{To the First Light Team:}

Anna Farrow, Ben Jagersma, Nick Officer, Guy Marriage, John Munro, Brendan Laurence, Ethan Hunter, Amanda Crosby, Liam Fox, Lizzie Earl, Alex Handley, Andrew Mills, Andrew Munn, Bede Robertson, Belinda Dods, Bronwyn Phillipps, James Phillips, Daniel Starkey, Jae Warrander, Josh McGlone, Robert Southwell, Sen Dong, John Gilmour, Zak Meyers, Byron Mallett, Sophie Prebble, Donna Howell, Hayley Rogers, Ullrich Kohler

\section{To the First Light Fanshawe Team:}

Wendy Wilson, Shaun Haskett, Stephen Hotke, Shawn Douglas, Tyler McLean, Matt Stewart, Jason King, Joel Foster, Jeremy Gardner, Rob Geoghan-Morphet, Joel van Bynen, Spencer Marcolini, Josh Hoggard, Darcy Comerford, Kyle Kan, Spencer Vermue, Juduk Lee, Ben Gerber

To the following people for their time, advice, and guidance:

Tricia Walbridge, Joe Manelski, Dave O’Donovan, Steve Ryder, Alistair Cattenach, Ryan Clarke, Sally Ogle, Jesse Mathews, Robert Vale, Brenda Vale, Robert Burgess, Tobias Danielmeier, Kah Chan, Leon Gurevitch, Diane Brand, David Bibby

To my Mum \& Dad and last, but by no means least, to my ever-supporting partner and First Lights biggest fan:

Janelle Roulston 


\section{INTRODUCTION}

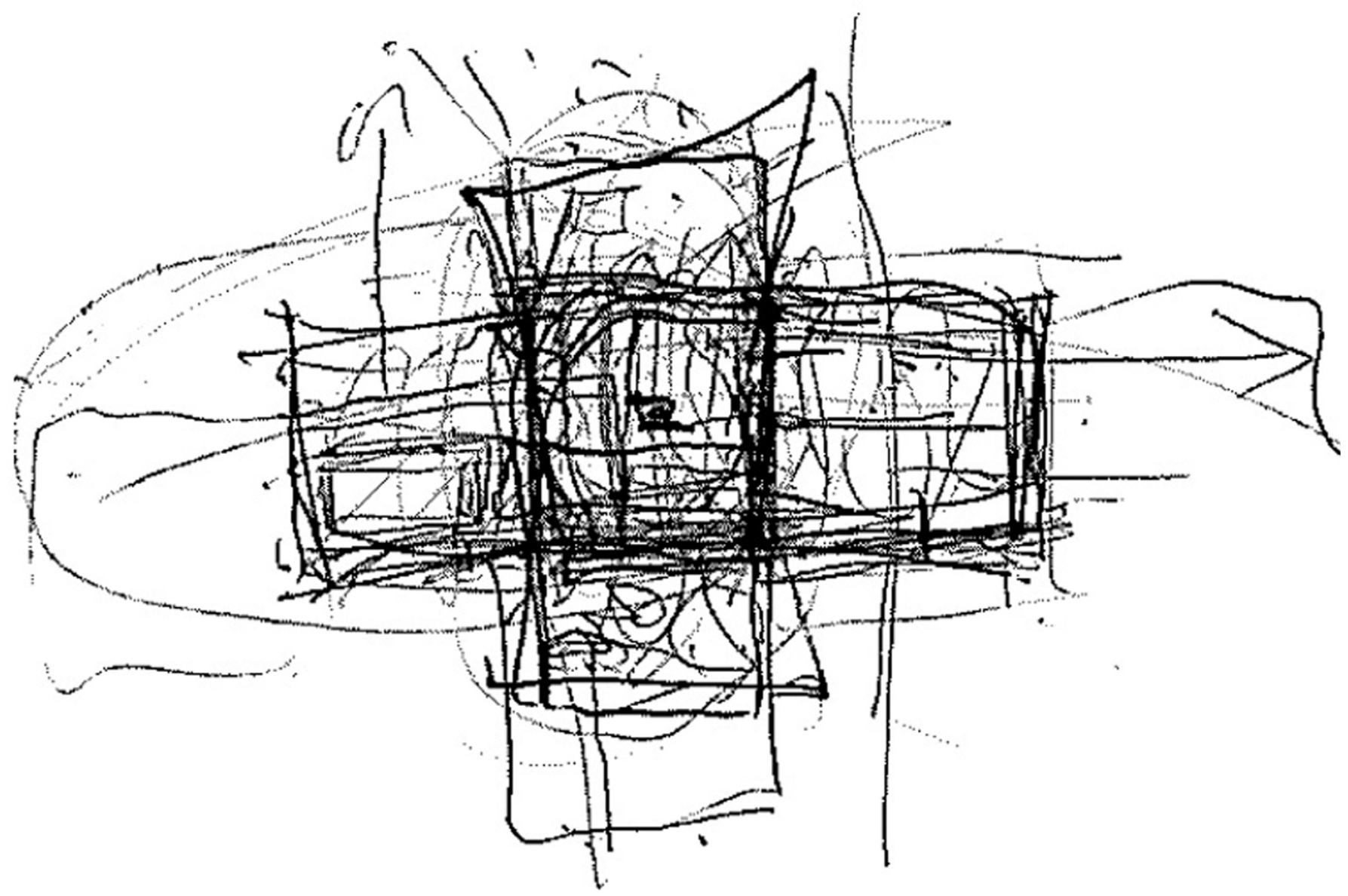

Figure 1: The First Sketch 


\section{INTRODUCTION}

This thesis will examine the logistical strategies and construction techniques used in the making of the First Light house. First Light was the 2011 team entered by Victoria University of Wellington to compete in the US Department of Energy (DOE) Solar Decathlon. The team is largely comprised of students and staff in Architecture and the Building Sciences, but also spans to include students from; Design, Landscape Architecture, Marketing and Communications, Tourism Management, and Commerce. The competition took place in September of 2011 and marked the culmination of a two year period of development within the University.

The U.S. Department of Energy Solar Decathlon challenges collegiate teams to design, build, and operate solar-powered houses that are cost-effective, energyefficient, and attractive.

(U.S. Department of Energy, 2012)

The Solar Decathlon has established a very focussed and complex brief that, due to its competitive nature, demands an extremely high level of logistical and technical innovation. It captures many of the core issues that architects and engineers are facing today. These issues are centred on energy efficiency, energy production, affordability, and the making of a more liveable and sustainable built environment.

\subsection{RESEARCH CONTEXT}

The Solar Decathlon is a bienniel event run by the U.S. Department of Energy and takes place in Washington, DC, USA. It challenges 20 University teams from around the world to design and build solar-powered houses, to transport their houses to the National Mall in Washington, DC, and compete in 10 contests across a ten day public exhibit. "The winner of the competition is the team that best blends affordability, consumer appeal, and design excellence with optimal energy production and maximum efficiency." (U.S. Department of Energy, 2012). The 10 contests are designed to reflect the many aspects that make up a successful home. They are each evenly weighted assessing energy efficiency, liveability, buildability, affordability, and the level of public and industry outreach that each team can generate. The 10 contents are as follows:
1. Architecture

2. Market Appeal

3. Engineering

4. Communications

5. Affordability

6. Comfort Zone

7. Hot Water

8. Appliances

9. Home Entertainment

10. Energy Balance

Detailed information on the judging criteria for each of the contests can be found in Appendix Solar Decathlon Contest Criteria. The overriding purpose of the competition is to:

Educate student participants and the public about the many cost-saving opportunities presented by clean-energy products

Demonstrate to the public the opportunities presented by cost-effective houses that combine energy efficient construction and appliances with renewable energy systems that are available today

Provide participating students with the unique training that prepares them to enter our nation's clean-energy workforce.

(U.S. Department of Energy, 2012)

First Light's performance at the competition resulted in $3^{\text {rd }}$ place overall and the following placings in each of the 10 contests:

- Architecture $2^{\text {nd }}$

- Market Appeal

$3^{\text {rd }}$

- Engineering

$1^{\text {st }}$

- Communications

$5^{\text {th }}$

- Affordability

$9^{\text {th }}$

- Comfort Zone

$12^{\text {th }}$

- Hot Water

$1^{\text {st }}$

- Appliances

$14^{\text {th }}$

- Home Entertainment

$8^{\text {th }}$

- Energy Balance

$1^{\text {st }}$

Two additional underlying and unjudged requirements of the Solar Decathlon involve the transport of the house to the competition site and its rapid assembly. First Light was among four international teams and faced the longest journey to get to the competition. The transporting of a house half way around the world came with many challenges, from dimensional limitations, customs requirements, and durability, to significant additional time and cost. Almost every key decision made throughout the design process in some way reflected these distinct 
challenges. The unique assembly requirements also had a major impact on the design, influencing the choice of construction techniques, materials and detailing. The house had to be assembled within seven days, with predominantly student labour, in a foreign country complying with foreign building codes. This thesis will address these issues in detail explaining their requirements, limitations, influences, and the resulting design outcomes.

\subsection{AIM AND SCOPE}

The aim of this work is to present the design process from conception to competition. The findings are ordered chronologically following the naturally iterative process of design that was undertaken. Detail is given as to the main decision making influences for each element or strategy. These influences were many and varied, ranging from logistics, construction, performance, and aesthetics, to the costs and availability of products and materials. In most cases several options are presented, all of which were explored through the creative and technical process of design.

Although the first concept for the house was designed in May of 2009, this thesis will focus on design developments from the March 2010 US DOE 'Conceptual Design Submission' onwards [Figure 2, Figure 3, Figure
4, \& Figure 5]. This submission set the conceptual framework from which the entire project expanded. The design was based on the lifestyle of living at the "kiwi bach", a New Zealand holiday home. This lifestyle entailed values of social interaction, simplicity of technology, and a connection with the outdoors and surrounding environment. It was the intent that an expression of these values would identify First Light as a uniquely New Zealand entry at the 2011 Solar Decathlon. The following abstract is from the Market Appeal design summary.

While the house was inspired by the Kiwi bach it would also be ideal as a permanent residence for a couple. Although it is a compact home, the owners are given the flexibility to entertain and accommodate family and friends.

The layout of the First Light house provides functional, flexible social spaces, which can be transformed to suit the owner and make the most of the natural environment. The house has been designed to create multi-functional rooms while keeping practical concerns, such as storage, in mind. A house perfect for a couple can be modified easily to accommodate friends and family spontaneously.

The dining area can be used to entertain large or small groups and a custom-built furniture unit in the living room can be transformed to accommodate overnight guests.

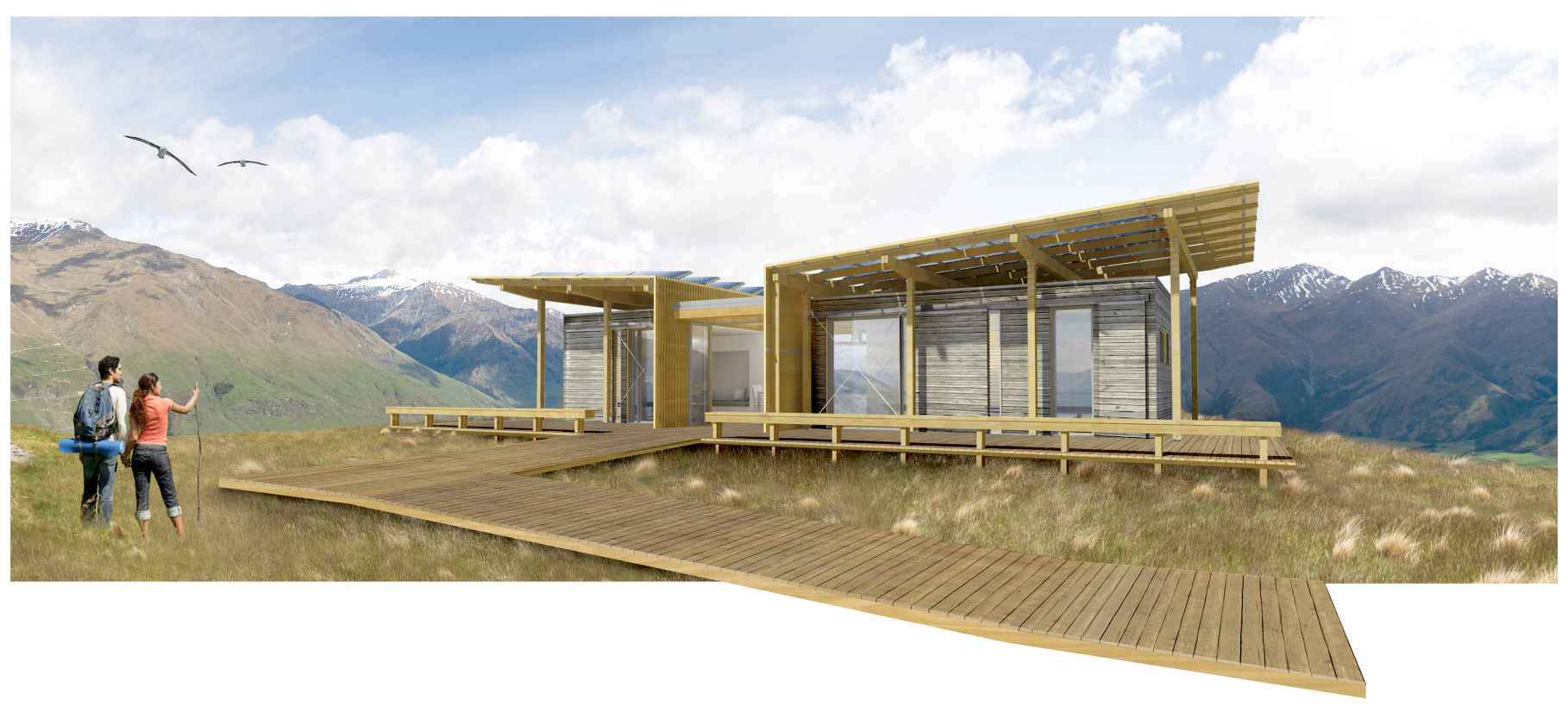

Figure 2: Rendered Image From Conceptual Design Submission - Exterior Perspective 


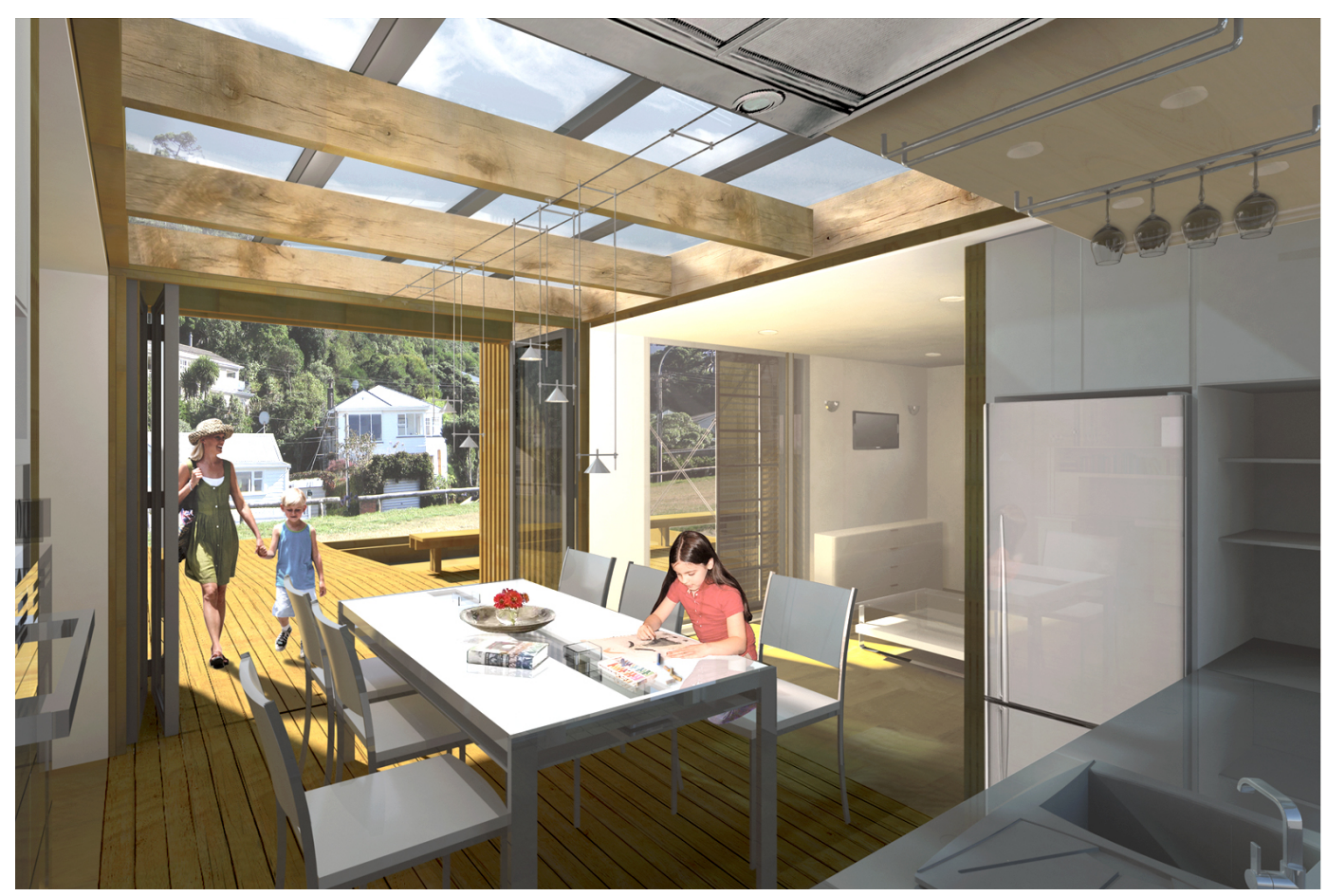

Figure 3: Rendered Image From Conceptual Design Submission - Interior Perspective 1

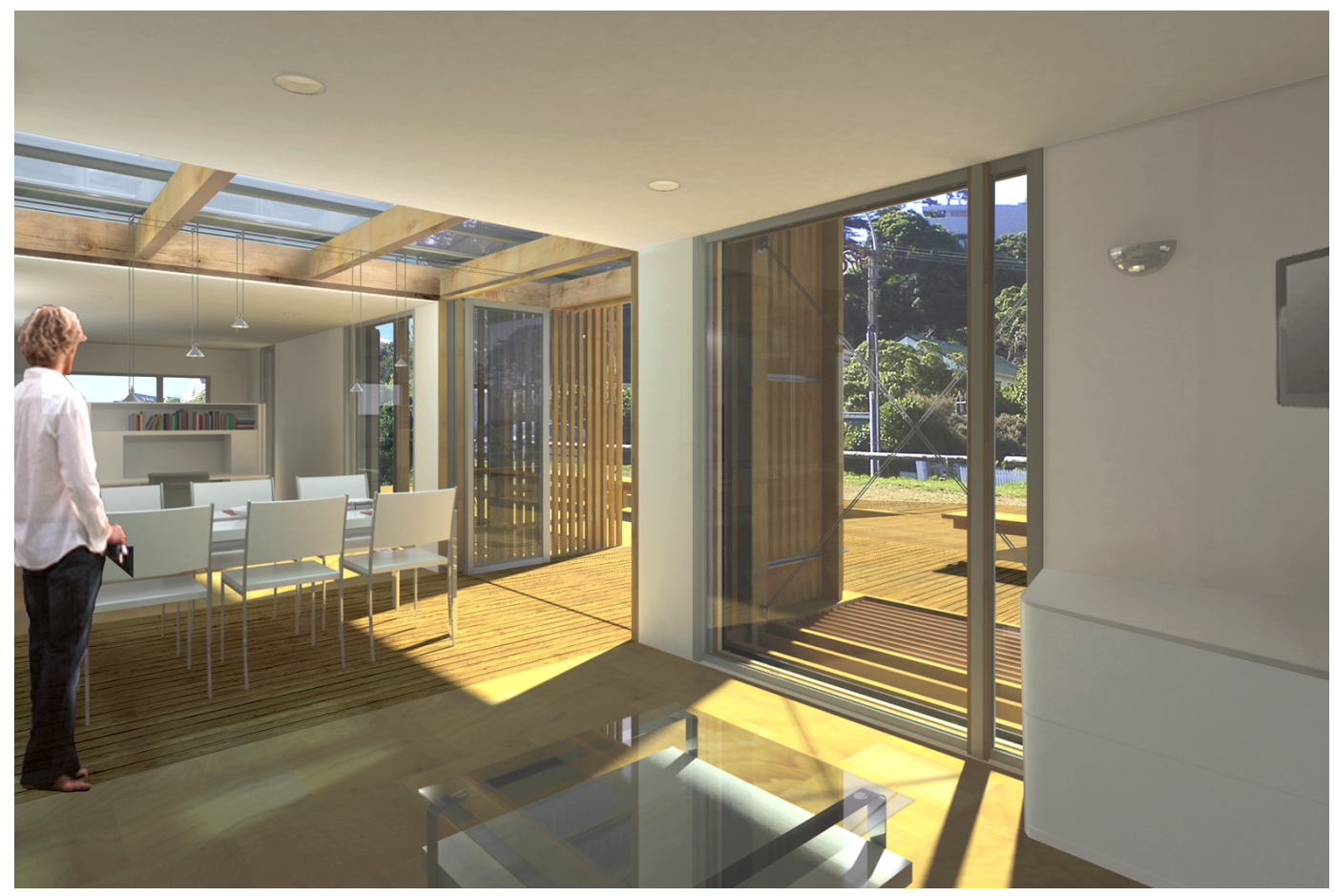

Figure 4: Rendered Image From Conceptual Design Submission - Interior Perspective 2 


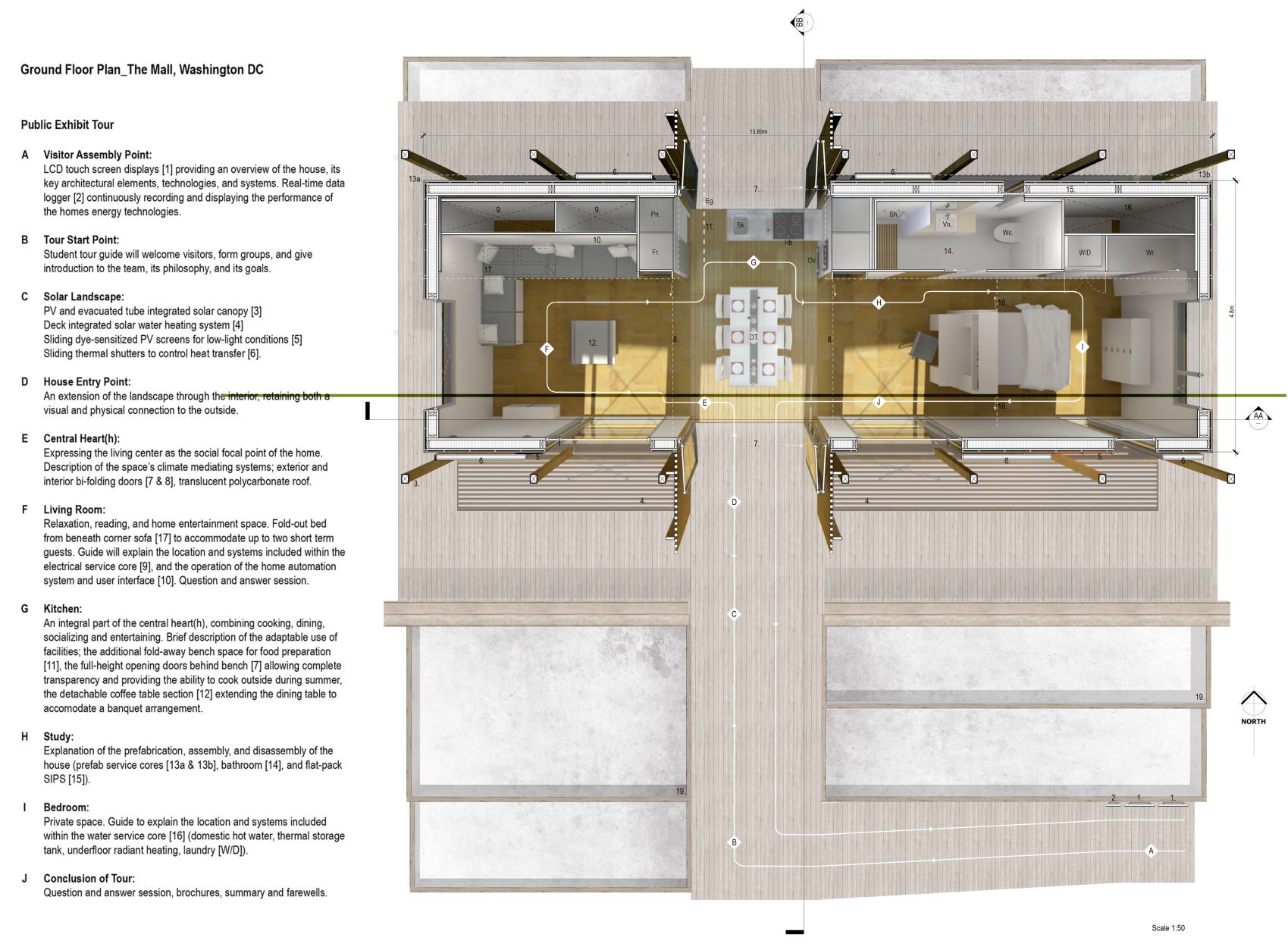

Figure 5: Rendered Floor Plan From Conceptual Design Submission

This thesis will distinctly focus on the scope of; logistics - transport and assembly aspects of the First Light house, and construction - the making of the First Light house.

The field of Interior Design is covered by Anna Farrow (2012) in, Inside the First Light House. Discussion on the building performance aspects of the house and competition can be found in, The Ten Day Bach: A Net Zero Energy Home by Ben Jagersma (2012). The project management, communications, marketing and sponsorship of First Light is presented by Nick Officer (2012) in, Everything But the Building: Project Organisation, the First Light House Solar Decahtlon 2011. Continual reference to these three documents will be made throughout this thesis. Particular reference is given to Ben Jagersmas Research due to the inseparable relationship between construction and performance.

The chapters have been arranged under the following headings:

1 Transportation

2 Foundations

\section{Module Construction \\ 4 Envelope Construction \\ 5 Module Three Construction \\ 6 Canopy Construction}

While these are presented in a general chronological order, many design iterations took place simultaneously with each element having an interconnected impact on the overall outcome. The intention behind the design decisions is presented alongside explanations as to their successes or failings at the competition. Recommendations are made throughout with regards to improving on and/or challenging these decisions.

This thesis is considered to be a documentation of the collective work that went into the making of the First Light project. Many collaborators including students, staff, academics, professionals, and industry partners were directly involved throughout the design process. Where specific work of others is presented here it will be acknowledged with the authors initials. The following students contributed directly to the many figures that accompany this text: 
John Munro (JM)

Envelope Construction

Rebecca McLaughlan (RM)

Module Three Construction

Brendan Laurence (BL)

Logistics \& Cladding

Ethan Hunter (EH)

Prototyping 


\section{TRANSPORTATION}

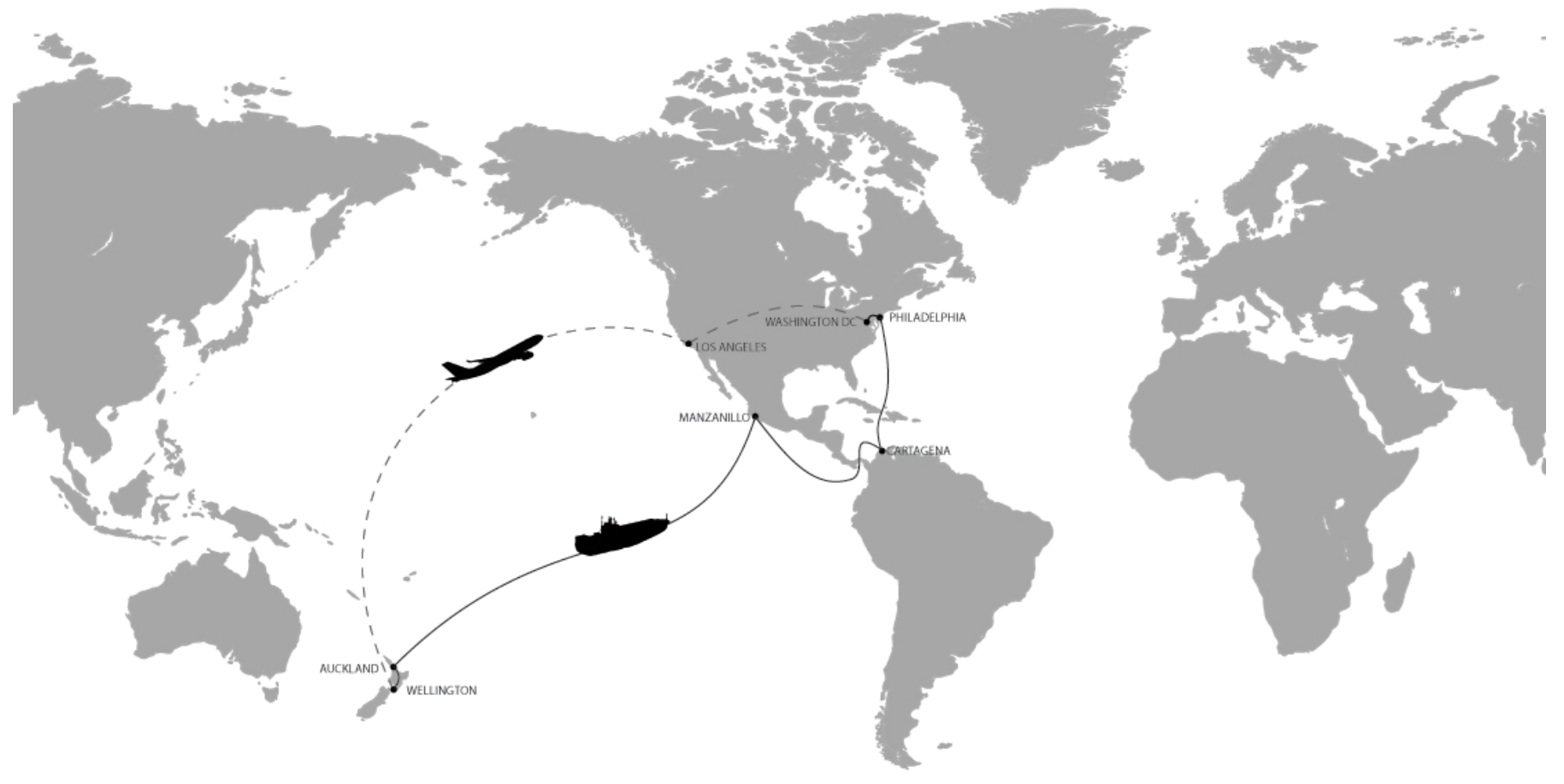

Figure 6: World Map Showing Transportation Journey of the First Light House 

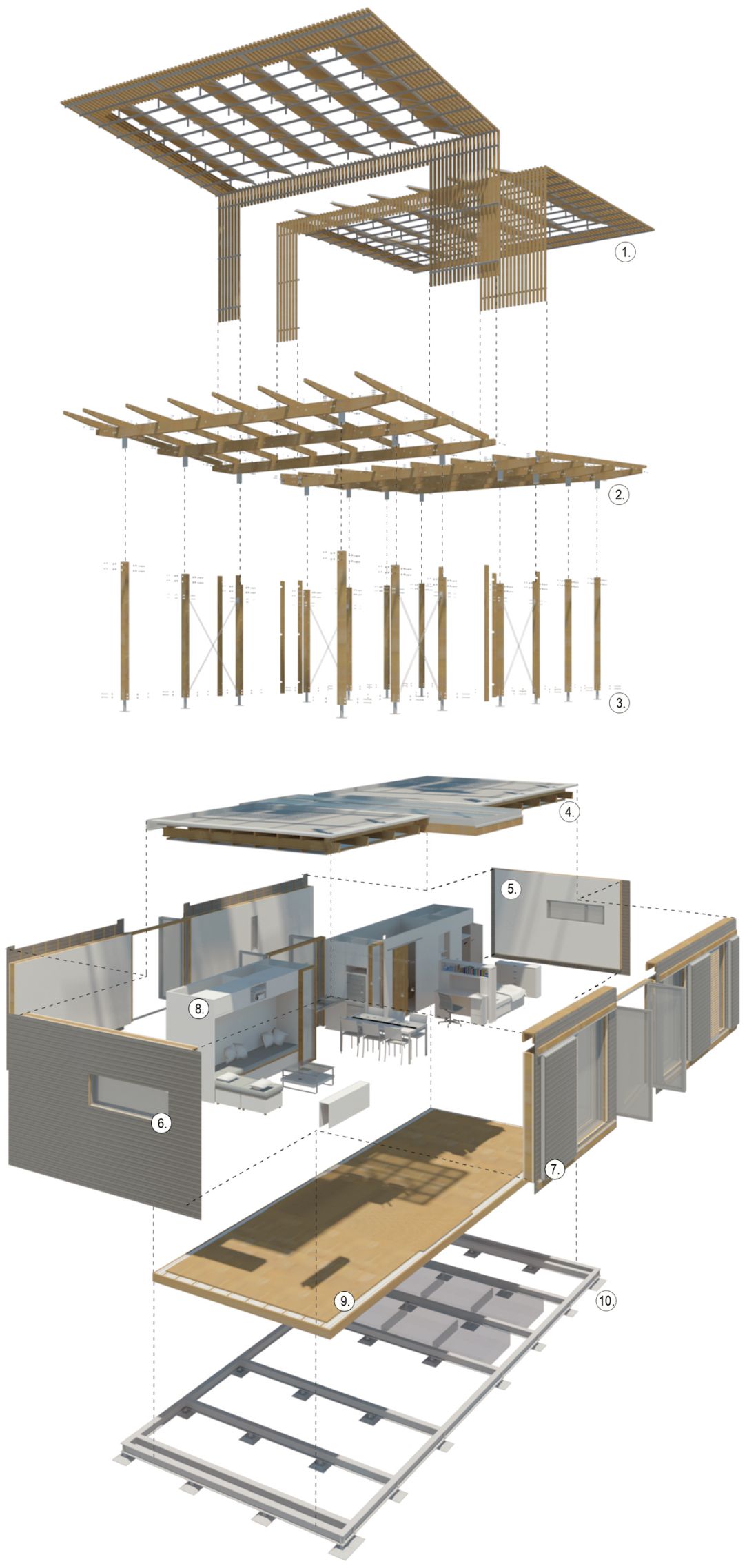

Exploded Schematic

Fabrication Elements

(1.) Solar Canopy

evacuated solar tubes, $4 \mathrm{~kW}$ thermal output

$8 \mathrm{~kW}$ monocrystaline photovoltaic array, $758 \times 1580 \mathrm{~mm}$

ventilated plywood photovoltaic surround

extruded aluminium photovoltaic mounting system with locking

connectors, adjustable rail height and angle

$50 \times 22 \mathrm{~mm}$ matai slats pre cut and bolt fixed

$50 \times 50 \times 3 \mathrm{~mm}$ steel T-sections fixed to pre cut rafter

$30 \times 30 \times 3 \mathrm{~mm}$ galvanized steel angle

$70 \times 12 \times 3 \mathrm{~mm}$ stainless steel U-channel sections for bracing

(2.) $150 \times 50 \mathrm{~mm}$ tapered heat treated timber purlin

$250 \times 120 \mathrm{~mm}$ structural steel flitch timber rafter

prefixed purlin steel support U-bracket, bolt connected

(3.) $120 \times 150 \mathrm{~mm}$ heat treated timber posts

inset steel connecting plate, bolt fixed

$10 \mathrm{~mm}$ adjustable structural tension bracing, bolt fixed

$70 \mathrm{~mm}$ circular hollow section post footing, bolt fixed

(4.) Roof/Ceiling System

2-ply bituminous sheeting, vapor barrier, $15 \mathrm{~mm}$ plywood timber ceiling purlins, $18 \mathrm{~mm}$ plywood, timber rafters

$200 \mathrm{~mm}$ compression resistant rigid foam thermal insulation

$12 \mathrm{~mm}$ plywood paint finished

galvanized steel box rainwater gutter and down pipes

triple glazed $16 \mathrm{~mm}$ semi translucent poly-carbonate with $15 \mathrm{~mm}$ cavity, extruded aluminium frame

$180 \times 70 \mathrm{~mm}$ heat treated timber supporting frame

5. Wall System

$150 \times 22 \mathrm{~mm}$ exterior horizontal cedar weatherboards clip fixed on $22 \mathrm{~mm}$ battens with ventilated cavity

vapor barrier for moisture control and weather tightness

$36 \mathrm{~mm}$ 3-layed structural plywood sandwich panel, vapor barrier

$150 \times 50 \mathrm{~mm}$ timber panel end blocking

$150 \mathrm{~mm}$ compression resistant rigid foam thermal insulation

$36 \mathrm{~mm}$ 3-layed structural plywood sandwich panel

$10 \mathrm{~mm}$ interior plywood finish, painted white

6. Window/Door

low-e argon filled triple glazing laminated for safety, in extruded aluminium frame with $15 \mathrm{~mm}$ cavity

(7.) Sliding Elements

$150 \times 22 \mathrm{~mm}$ exterior horizontal cedar weatherboards, vapor barrie $18 \mathrm{~mm}$ plywood

$100 \mathrm{~mm}$ compression resistant rigid foam thermal insulation

$18 \mathrm{~mm}$ plywood

vapor barrier

timber blocking

mechanically operated sliding aluminium rails

neoprene thermal air seals

$2 \times 330 \mathrm{~W}$ dye-sensitized photovoltaics, $6 \mathrm{~mm}$ glass laminated, inset in aluminium frame

(8.) Internal Service Core

$36 \mathrm{~mm}$ structural plywood painted white

wet areas finished with $12 \mathrm{~mm}$ water resistant gypsum board painted white

9. Floor Construction

$22 \mathrm{~mm}$ recycled timber tongue and groove flooring

highly conductive aluminium sheet, cross-linked polyethylene tubing $36 \mathrm{~mm}$ plywood, rebated with tubing cavities

$50 \times 150 \mathrm{~mm}$ pinus radiata joists

$200 \mathrm{~mm}$ compression resistant rigid foam thermal insulation

$18 \mathrm{~mm}$ plywood

(10.) Foundations

prefabricated $200 \times 140 \mathrm{~mm}$ steel I-section bolt fixed

composite bearer and joist layout

on adjustable seismic screw jack pedestals

structural steel tie-down

Figure 7: Rendered Image From Conceptual Design Submission - Exploded Building Elements 


\section{TRANSPORTATION}

\subsection{CONCEPT STRATEGY}

The concept design for the First Light house was very much approached from an 'end use' perspective. The contest criteria of the competition made for the brief and the 'kiwi bach' provided the concept. Transportation requirements were considered at a very high level only. The conceptual design submission was part of the team selection process for the 2011 competition. As such, the aim was to express the potential that the design had for excelling in the competition thereby winning a place as one of the 20 teams selected to compete.

In terms of the conceptual design submission, the approach to transport and assembly was to flat-pack the building envelope and to have two solid service cores, with all components fitting into standard shipping containers [Figure 7]. It wasn't until the team was accepted into the competition that thorough research into the logistical aspects of transport and assembly was undertaken.

\subsection{CONSTRAINTS/LIMITATIONS}

The first step towards establishing a transportation strategy was to gain an understanding of the general constraints and/or limitations of both land and sea freight. The following is a general summary of the dimensional limits for transport.

\subsubsection{Land Transport}

These dimensions have been collated from, Land Transport Rule Vehicle Dimensions and Mass Amendment 2010 (Ministry of Transport, 2010):

NZ Land Transport Limits (without permit):

Height (excluding ropes, chains, and $\quad=4.250 \mathrm{~m}$ straps)

Height (including ropes, chains, and $\quad=4.275 \mathrm{~m}$ straps)

Width (excluding mirrors)

$=2.500 \mathrm{~m}$

Width (including mirrors)

$=2.980 \mathrm{~m}$

Length (one semi-trailer)
The following dimensions have been collated from, Virginia Hauling Permit Manual (Commonwealth of Virginia Department of Motor Vehicles, 2009):

USA Land Transport Limits (without permit):

Height (including load) $=4.114 \mathrm{~m}$

Width (excluding mirrors) $=2.590 \mathrm{~m}$

Length (semitrailer)

$$
=14.63 \mathrm{~m}
$$

Oversize permits are required for any loads in excess of the above dimensions. These can range from a written permit alone to requiring specific signage, pilot vehicles, and limited hours of travel.

\subsubsection{Trailers}

The following diagrams have been compiled from the, Contract Flatbed Equipment Guide (North America's Transportation Service, 2009). Availability of trailers and vehicles was to be later verified by a freight forwarding company.

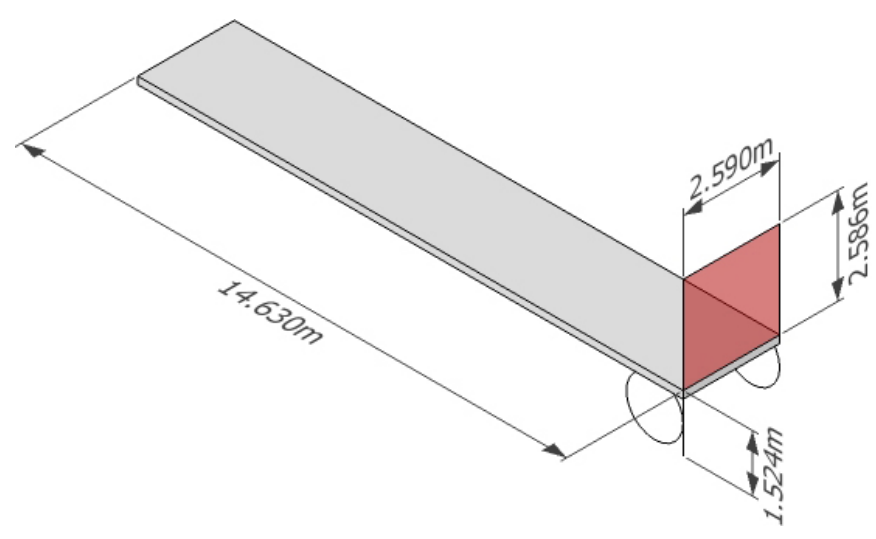

Figure 8: Standard Flatbed Trailer

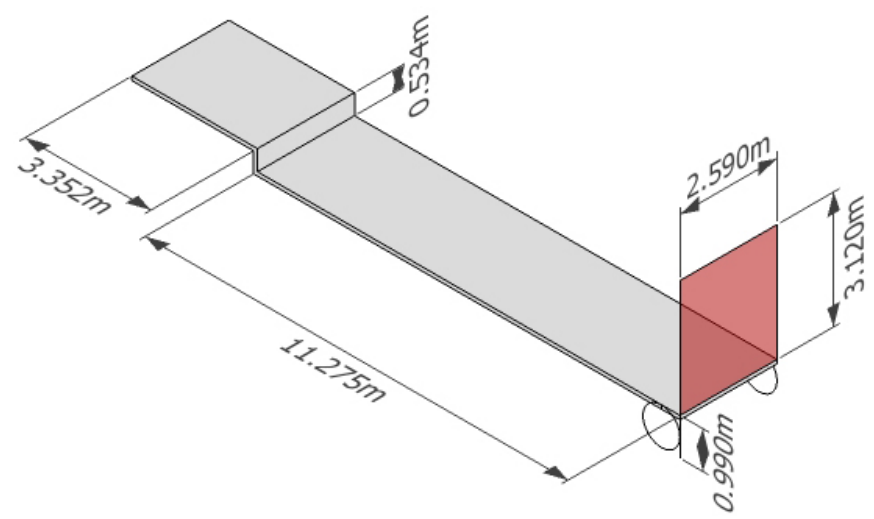

Figure 9: Single Drop-deck Trailer (Step deck) 


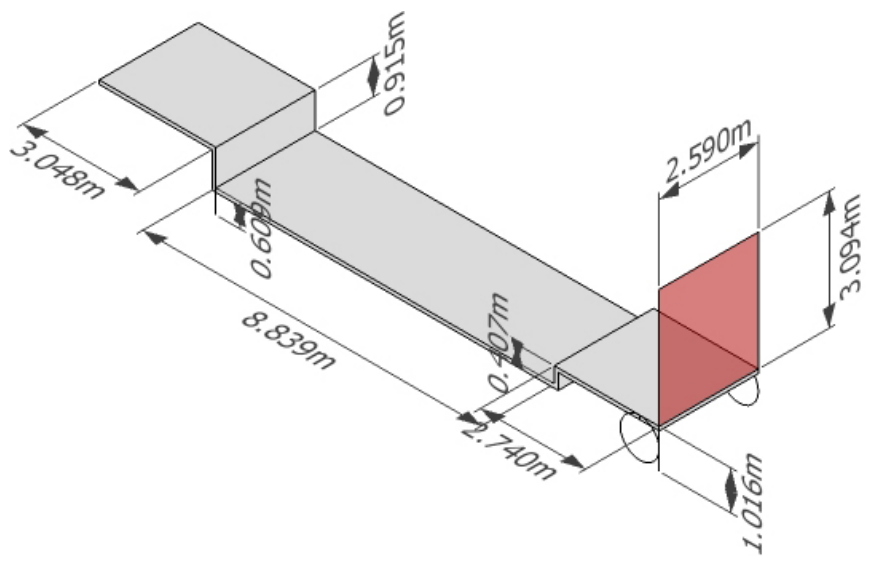

Figure 10: Double Drop-deck Trailer (Lowboy)

* All dimensions shown are internal measurements

\subsubsection{Shipping Containers}

The following internal dimensions are for Hamburg Sud standard shipping containers (Hamburg Sud).

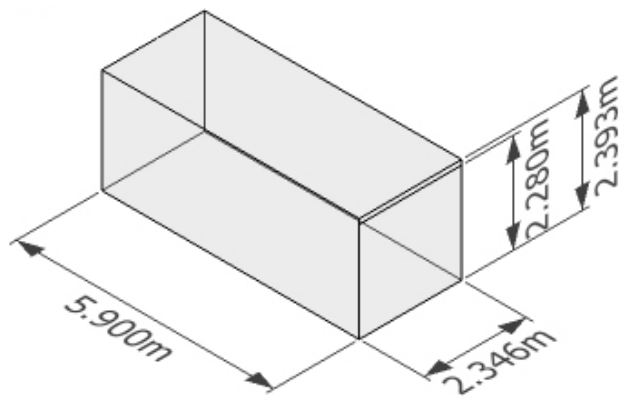

Figure 11: Standard 20' Container

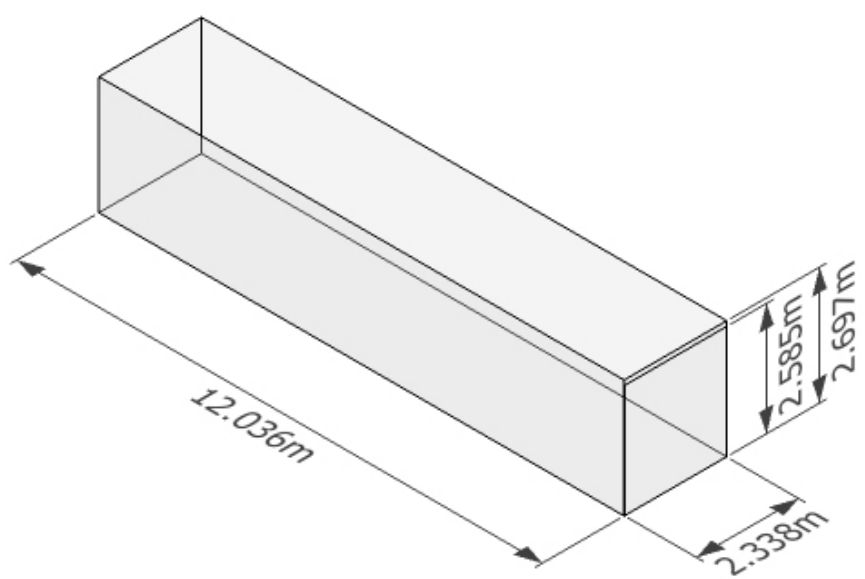

Figure 12: 40' Hi Cube Container

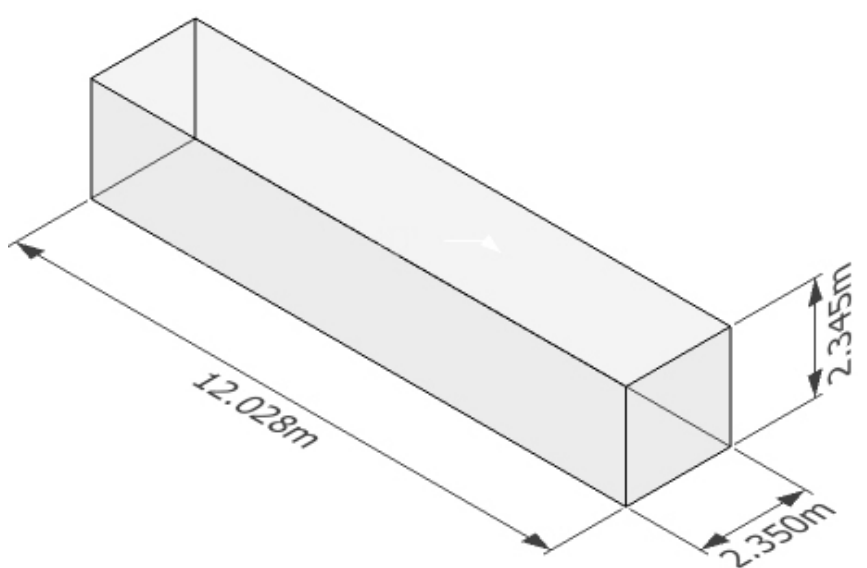

Figure 13: 40' Open Top Container

The following internal dimensions are for Maersk Flat Rack containers (Maersk Line).

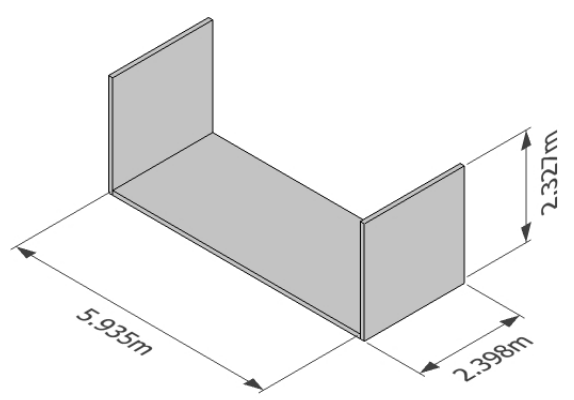

Figure 14: 20' Flat Rack Container

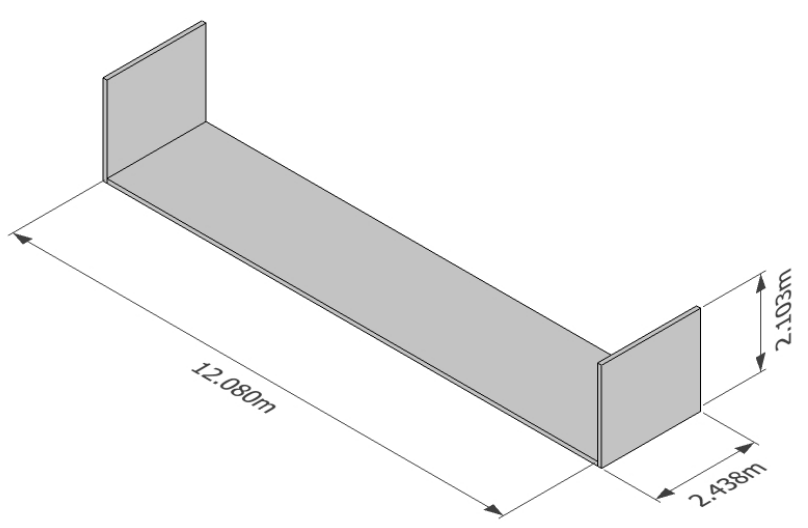

Figure 15: 40' Flat Rack Container 


\subsubsection{Airfreight Cargo}

The following internal cargo dimensions are for an Air Force C-130 Hercules (Federation of American Scientists, 2010).

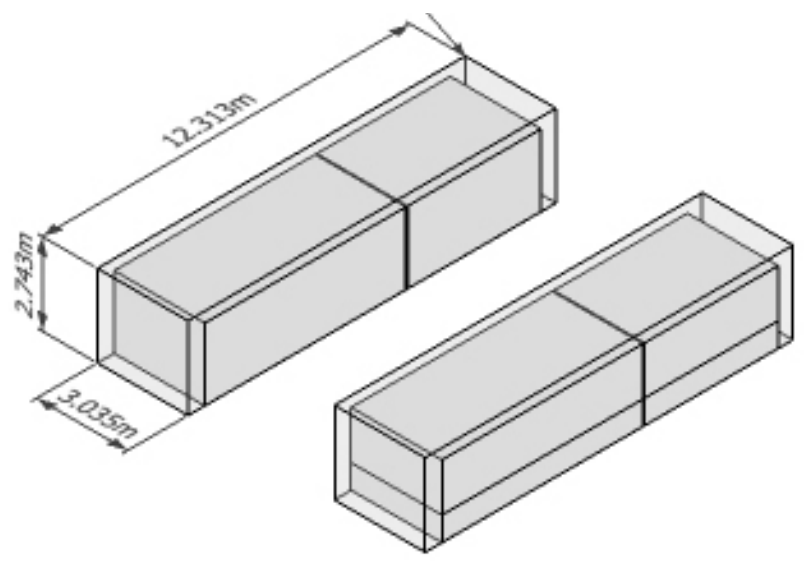

Figure 16: C-130 Hercules Cargo Dimensions

The following internal dimensions are for ARA M1 Airfreight containers (International Air Freight Shipping, 2012).

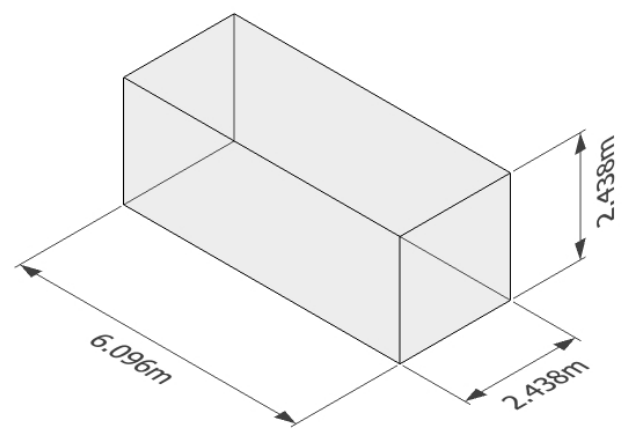

Figure 17: ARA MI 24" x 96" x 96" Airfreight Container

\subsection{OPTIONS FOR TRANSPORT}

Although the concept design and general layout for the house was already established, there still existed many different options for transport. The following is an overview of each of the transportation options that were explored during the developed design phase.

\subsubsection{Option One}

Entire house envelope structurally engineered to be transported as one complete unit [Figure 18 \& Figure 19]. Foundation, decking, and canopy to be flat-packed into standard shipping containers.

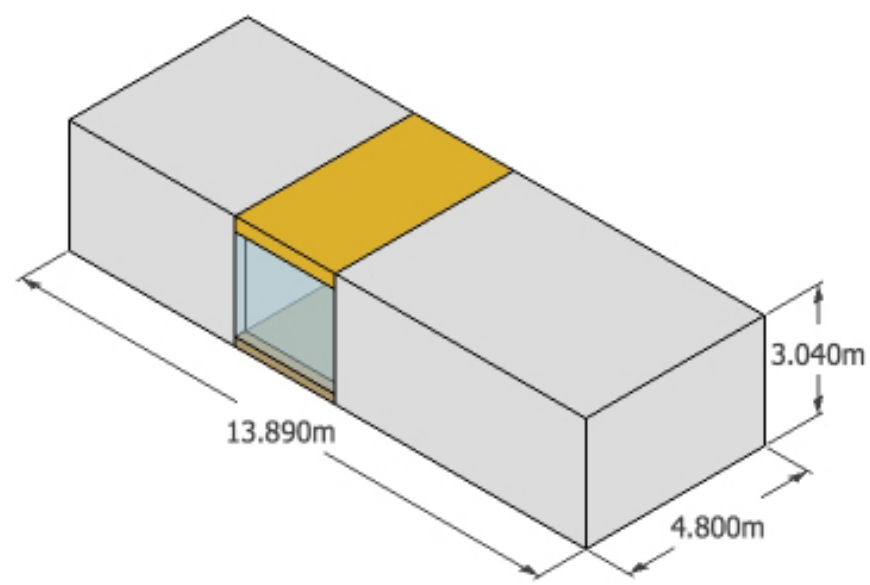

Figure 18: Option One - Module and OS Sea Freight

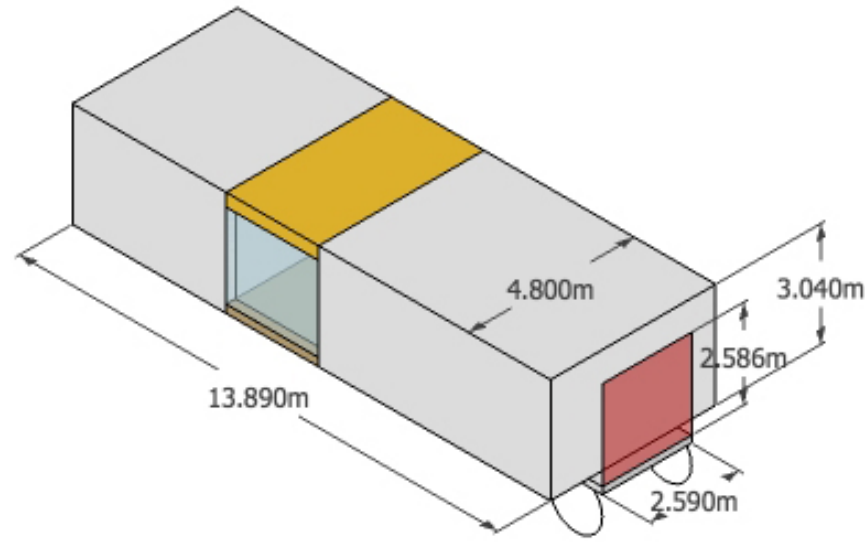

Figure 19: Option One - Land Transport on Flatbed Trailers 


\subsubsection{Option Two}

House split longitudinally into 2 structurally independent modules [Figure 20 \& Figure 21]. Foundation, decking, and canopy to be flat-packed into standard shipping containers.

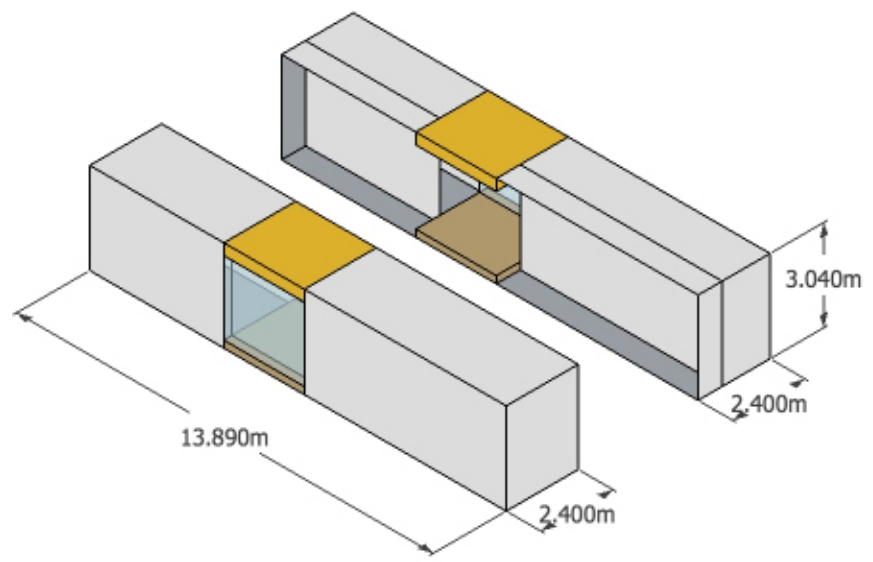

Figure 20: Option Two - Module and OS Sea Freight

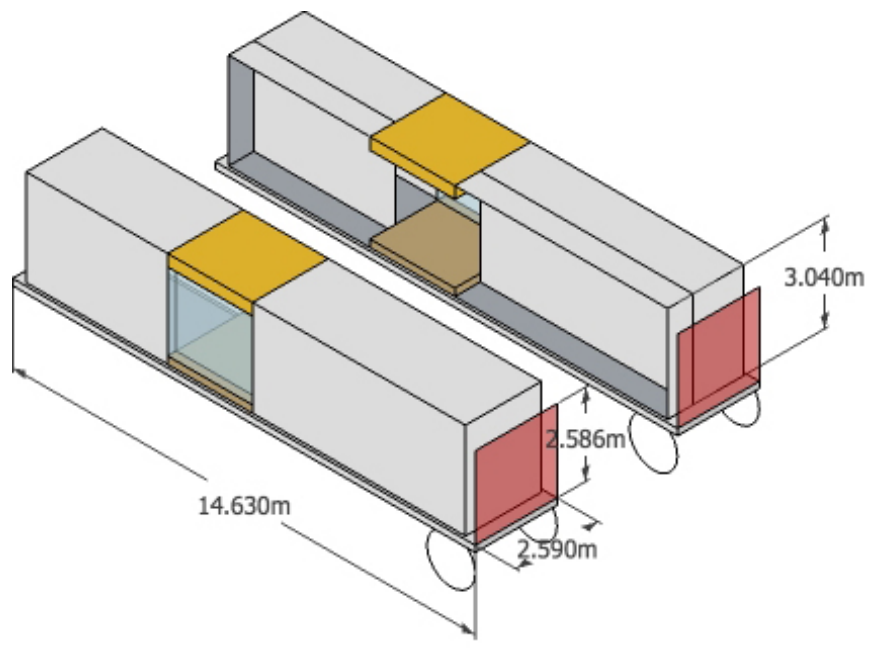

Figure 21: Option Two - Land Transport on Flatbed Trailers

\subsubsection{Option Three}

Central module flat-packed and house split longitudinally into 4 structurally independent modules [Figure 22, Figure 23 \& Figure 24]. Foundation, decking, and canopy to be flat-packed into standard shipping containers.

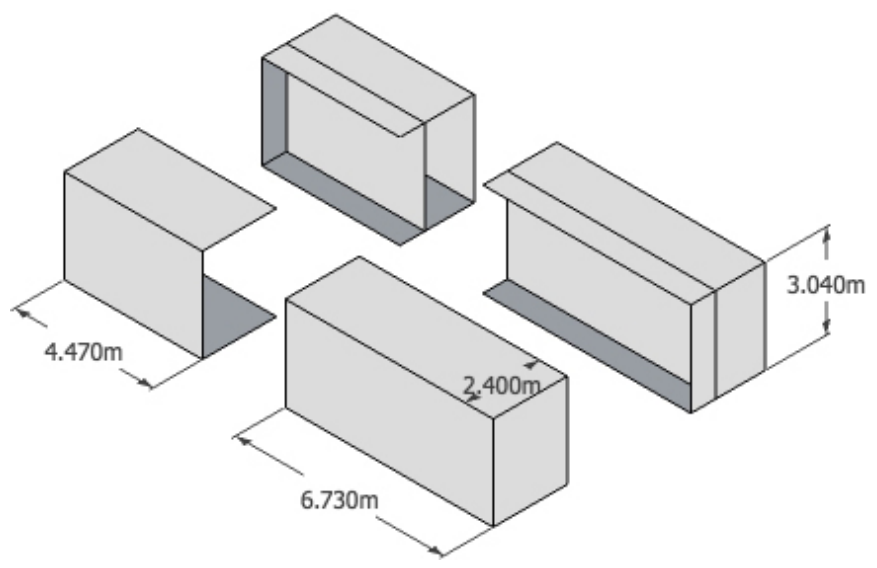

Figure 22: Option Three-Modules

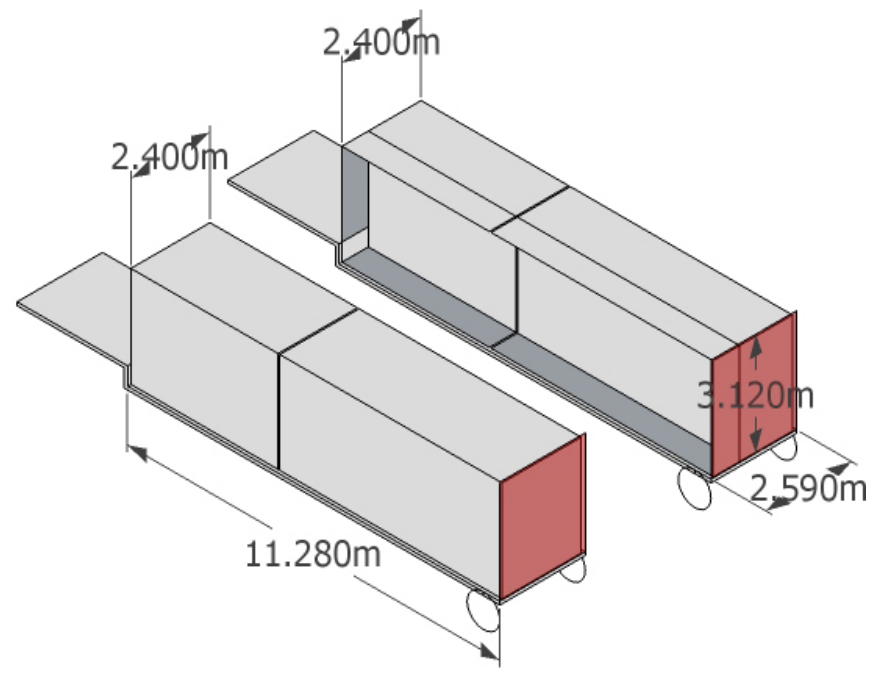

Figure 23: Option Three - Land Transport on Single Drop-deck Trailers

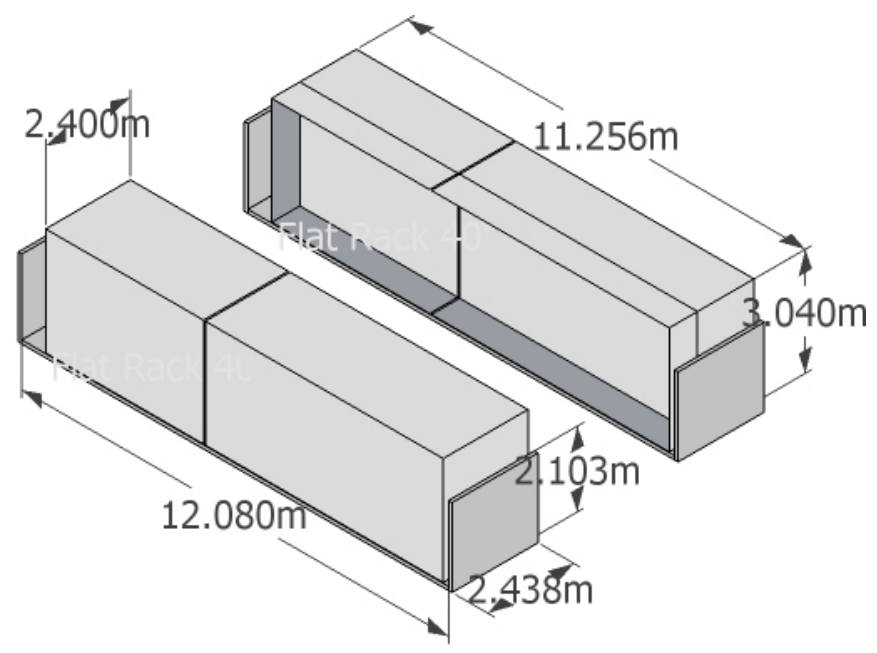

Figure 24: Option Three - Sea Freight on 40' Flat Racks 


\subsubsection{Option Four \& 4a}

Same arrangement as Option Three however, modules are cut asymmetrically to align with internal longitudinal wall [Figure 25, Figure $26 \&$ Figure 27]. These can be shipped either on Flat Rack containers or with a Roll-on Roll-off service. A Roll-on Roll-off (RORO) service is typically used for shipping non-standard, oversized cargo such as heavy machinery and yachts. Rather than using a shipping container, the cargo is loaded onto large mobile platforms. These platforms are then 'rolled on' to the boat. There are less dimensional restrictions for this form of freight and the cost is usually charged per cubic volume of cargo.

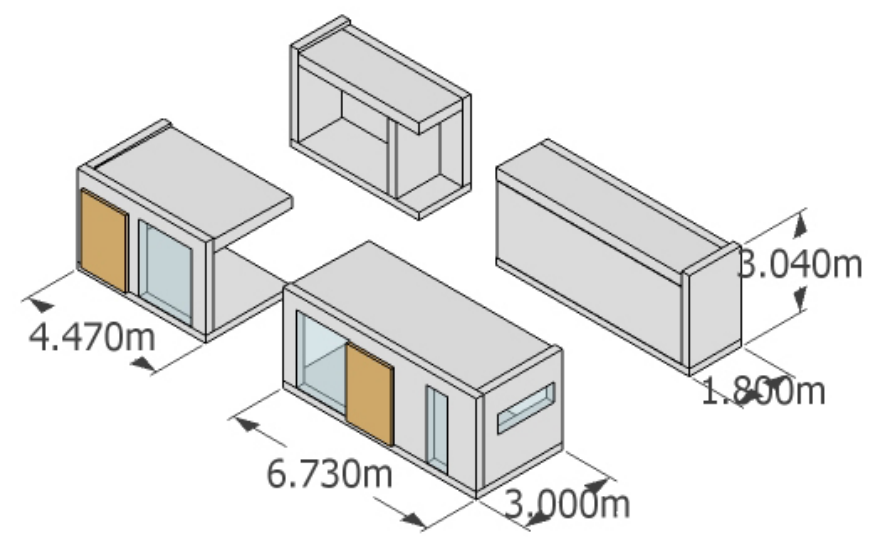

Figure 25: Option Four - Modules

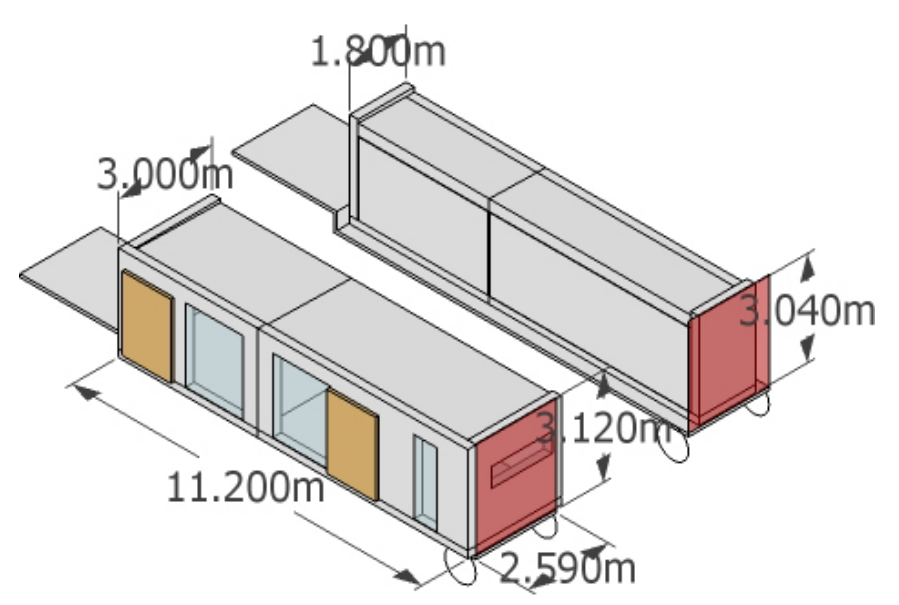

Figure 26: Option Four - Land Transport on Single Drop-deck Trailers

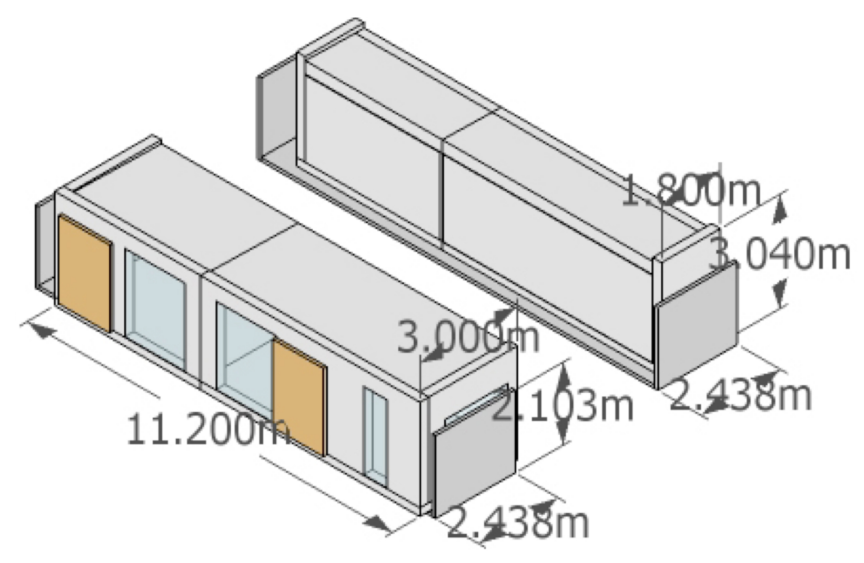

Figure 27: Option Four - Sea Freight on 40' Flat Racks or RORO

\subsubsection{Option Five}

Central module flat-packed and house divided into 2 structurally independent modules [Figure 28 \& Figure 29]. Foundation, decking, and canopy to be flat-packed into standard shipping containers.

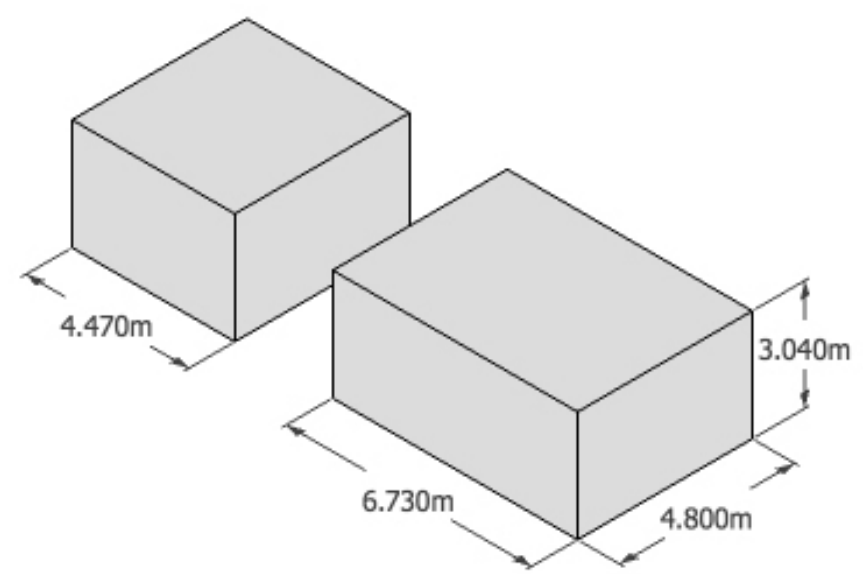

Figure 28: Option Five - Modules and OS Sea Freight 


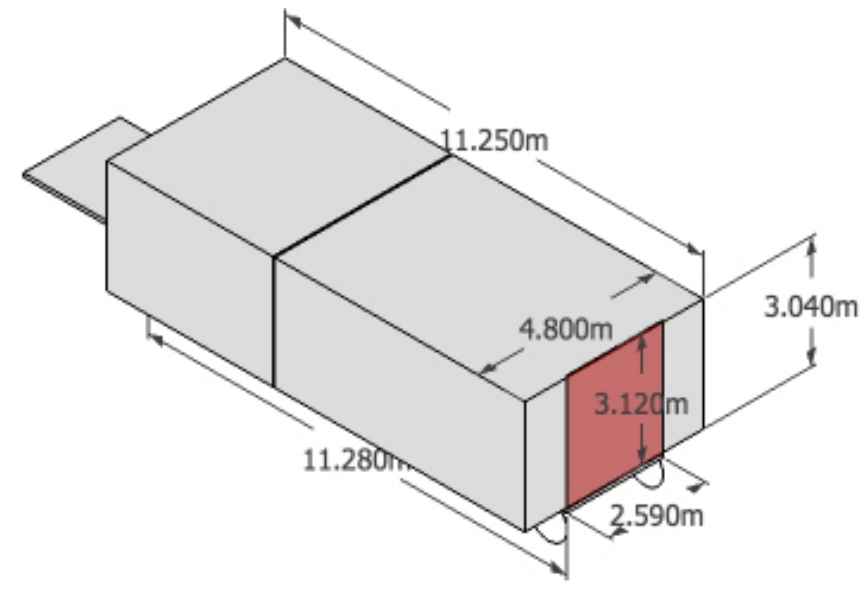

Figure 29: Option Five - Land Transport on Single Drop-deck Trailers

\subsubsection{Option Six}

Building dimension reduced to fit 40' Flat Rack shipping container. House split longitudinally into 2 structurally independent modules [Figure 30, Figure 31 \& Figure 32]. Foundation, decking, and canopy flat-packed into shipping containers.

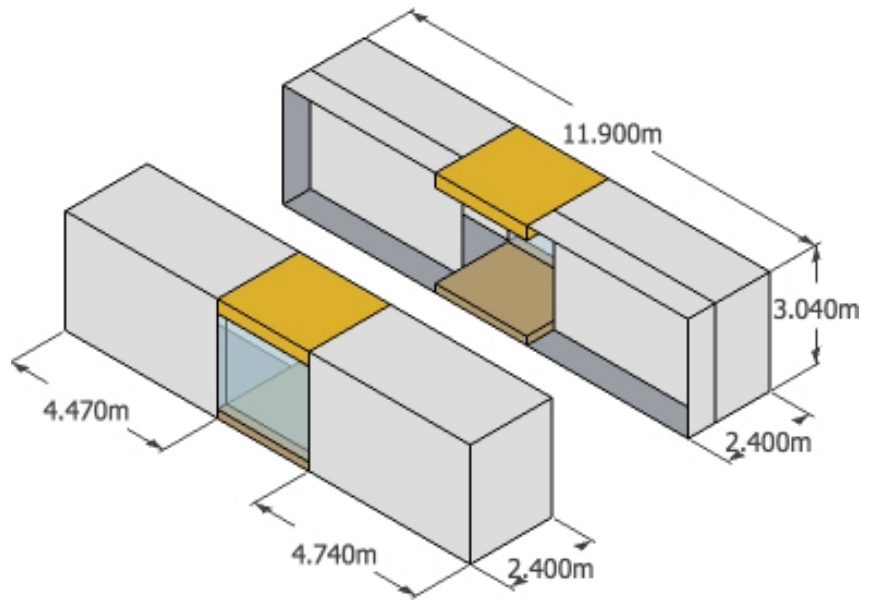

Figure 30: Option Six-Modules

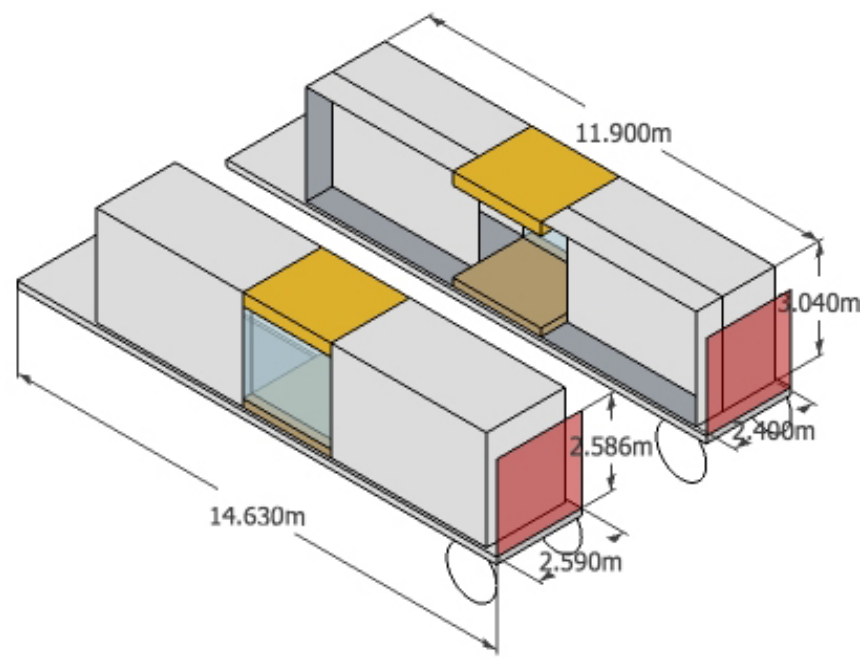

Figure 31: Option Six - Land Transport on Flatbed Trailers

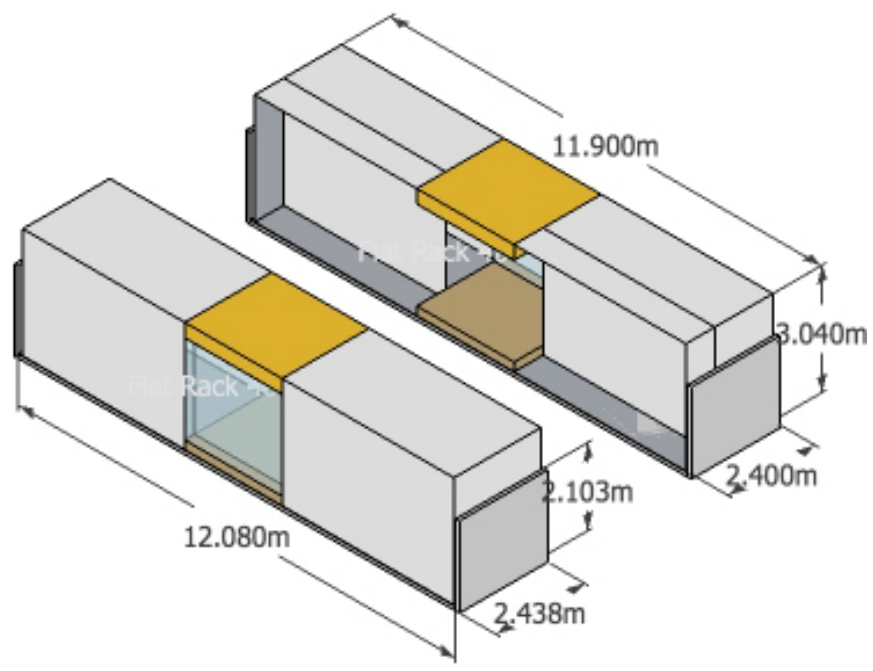

Figure 32: Option Six - Sea Freight on 40' Flat Racks 


\subsubsection{Option Seven}

Flat-packed building envelope with prefabricated service cores [Figure $33 \&$ Figure 34]. Foundation, decking, and canopy also flat-packed into shipping containers.

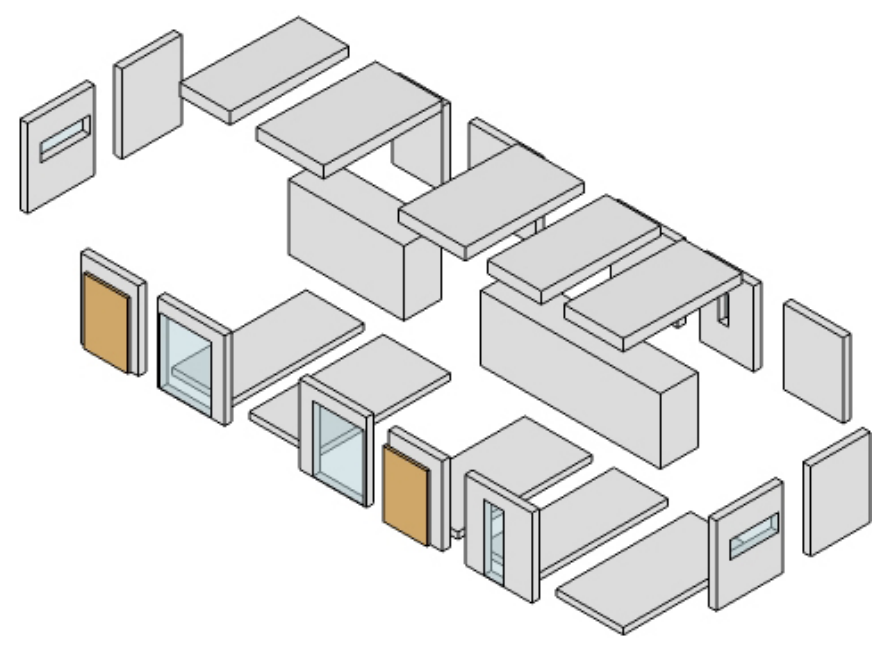

Figure 33: Option Seven - Modules

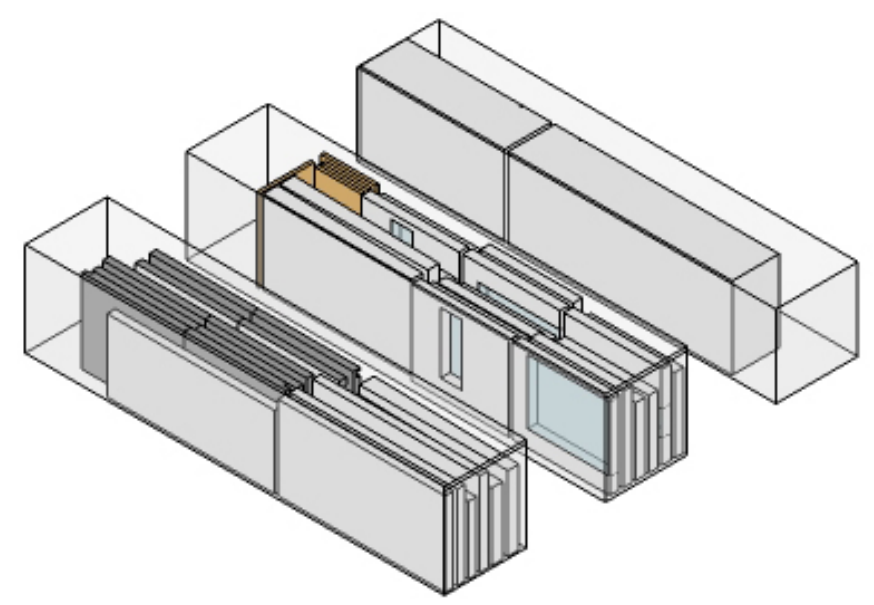

Figure 34: Option Seven - Land and Sea Freight in 40' Hi Cube Containers

\subsubsection{Option Eight}

Central module flat-packed, remaining house split longitudinally and horizontally for packing into open top containers [Figure $35 \&$ Figure 36].

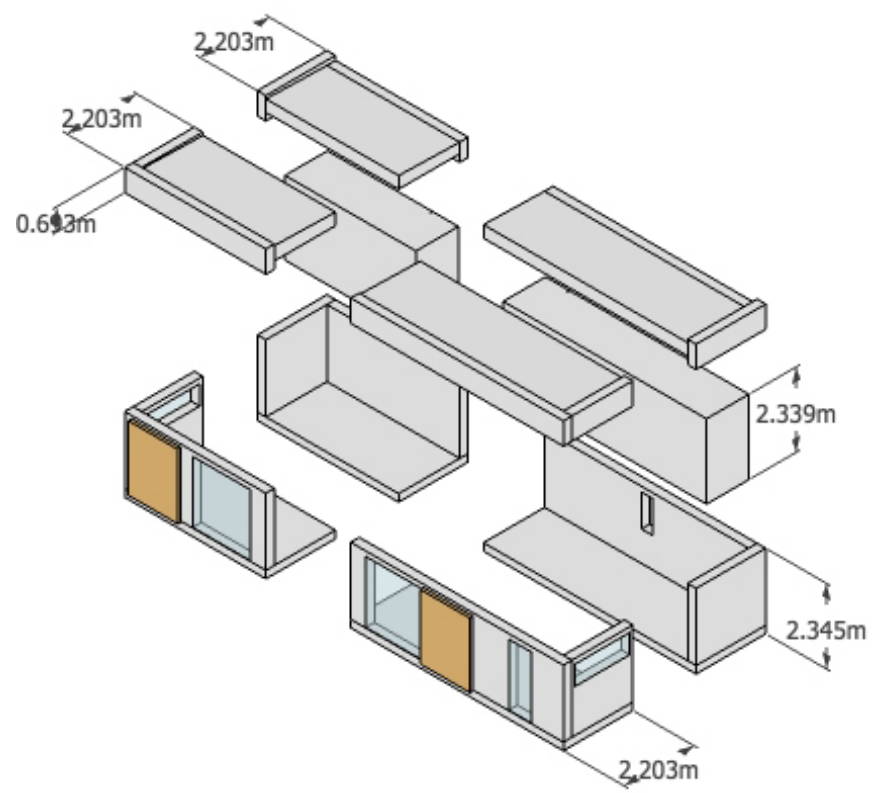

Figure 35: Option Eight - Modules

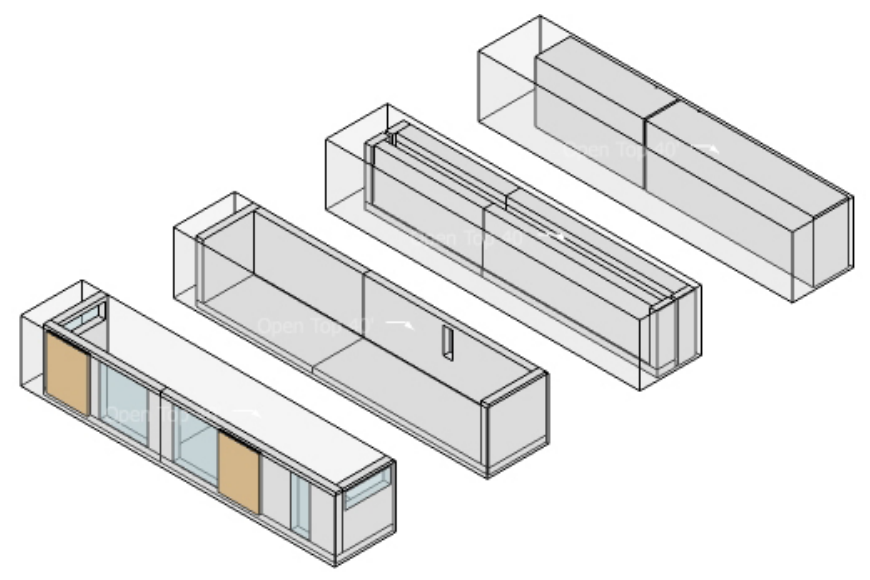

Figure 36: Option Eight - Land and Sea Freight in 40' Open Top Containers 


\subsubsection{Option Nine}

Central module flat-packed and remaining building split transversely to create 5 equal modules [Figure 37, Figure 38 \& Figure 39]. Foundation, decking, and canopy to be flat-packed into standard shipping containers.

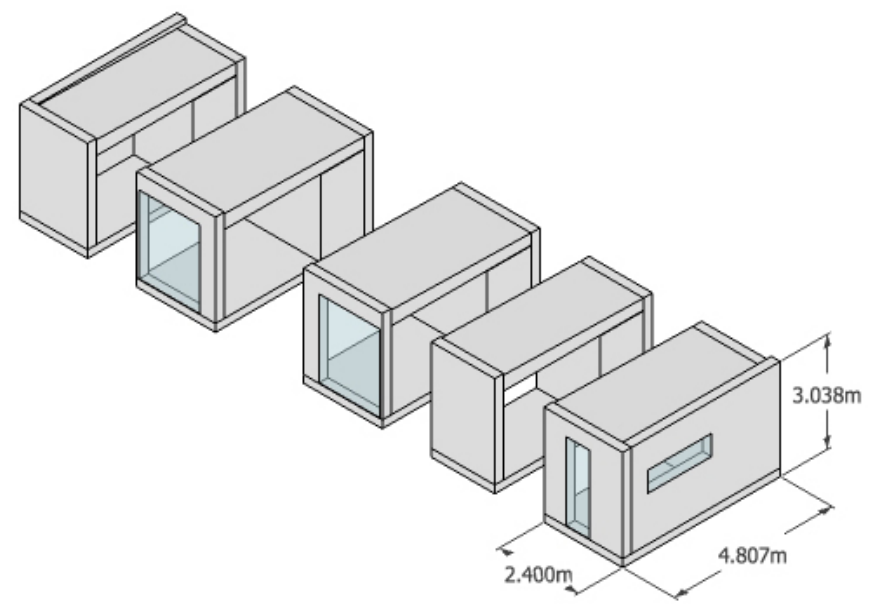

Figure 37: Option Nine-Modules

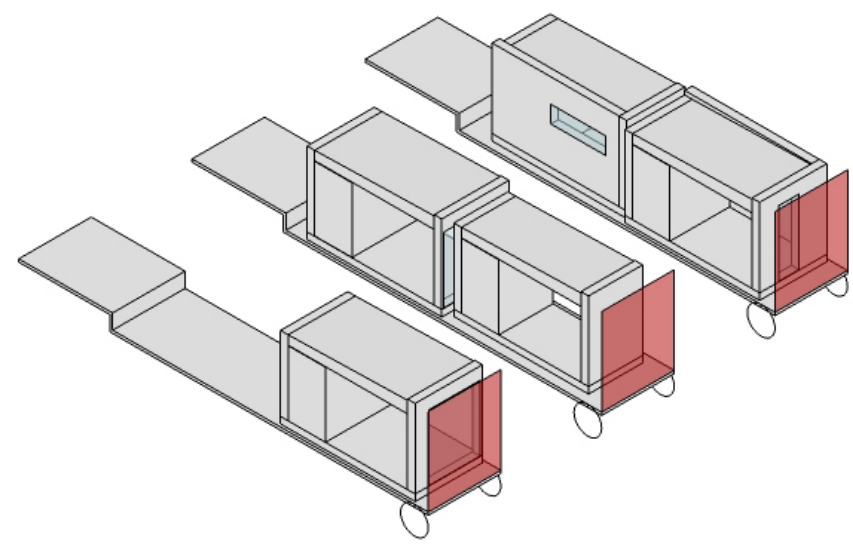

Figure 38: Option Nine - Land Transport on Flatbed Trailers

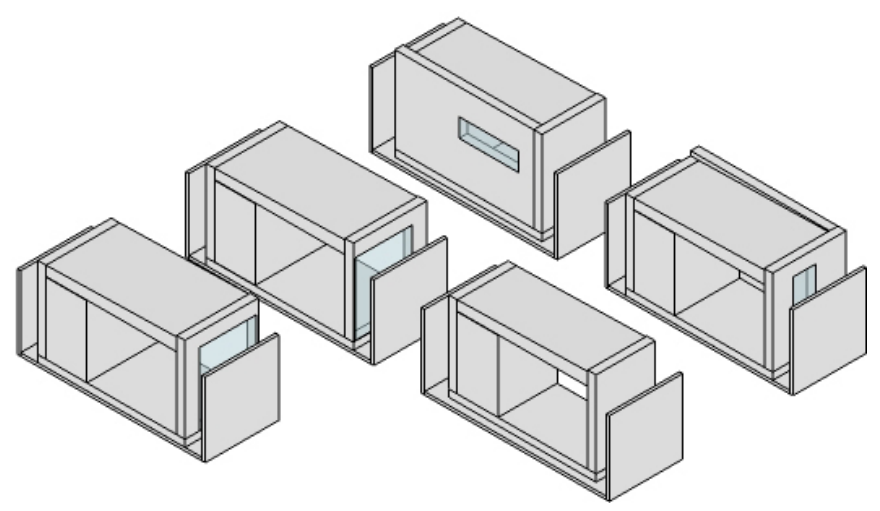

Figure 39: Option Nine - Sea Freight on 20' OR 40' Flat Racks

\subsubsection{Option Ten}

Air freight using Air Force C-130 Hercules. Central module flat-packed and house split longitudinally into 4 structurally independent modules [Figure 40 \& Figure 41]. Foundation, decking, and canopy to be flat-packed into standard shipping containers.

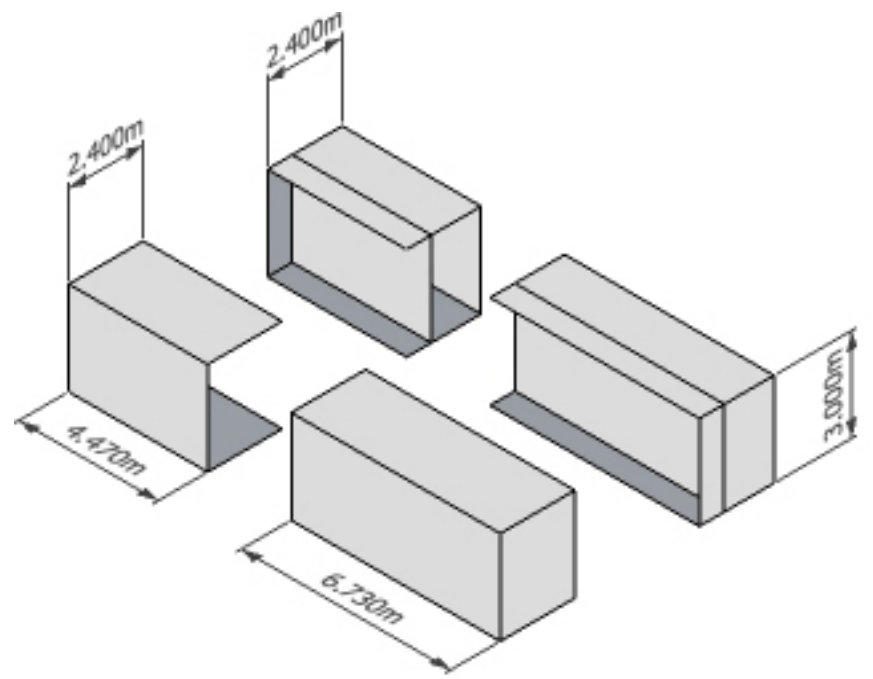

Figure 40: Option Ten - Modules

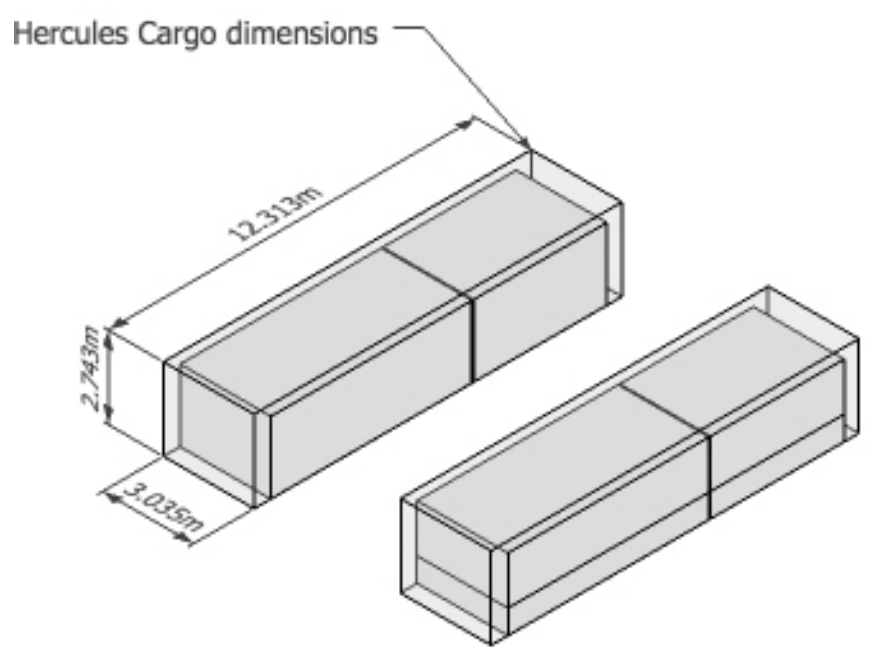

Figure 41: Option Ten - Hercules Cargo 


\subsubsection{Option Eleven}

Entire house flat-packed to fit into standard air freight containers.

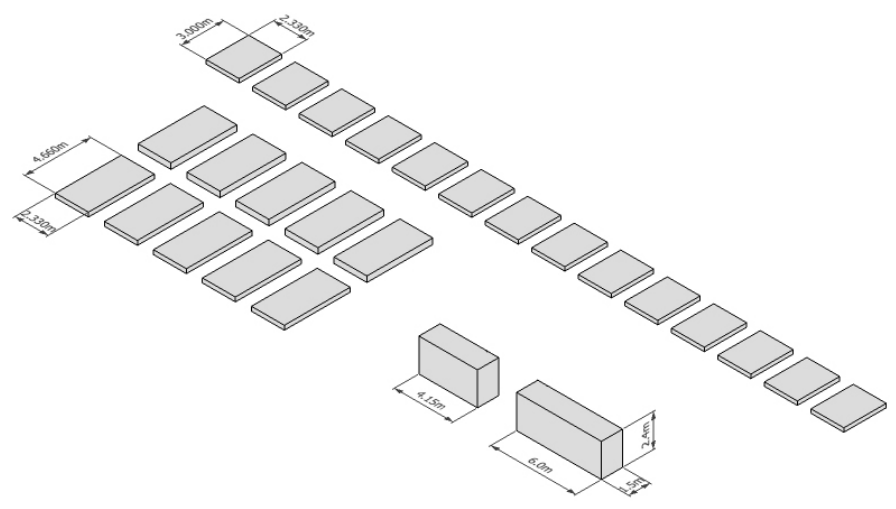

Figure 42: Option Eleven - Modules

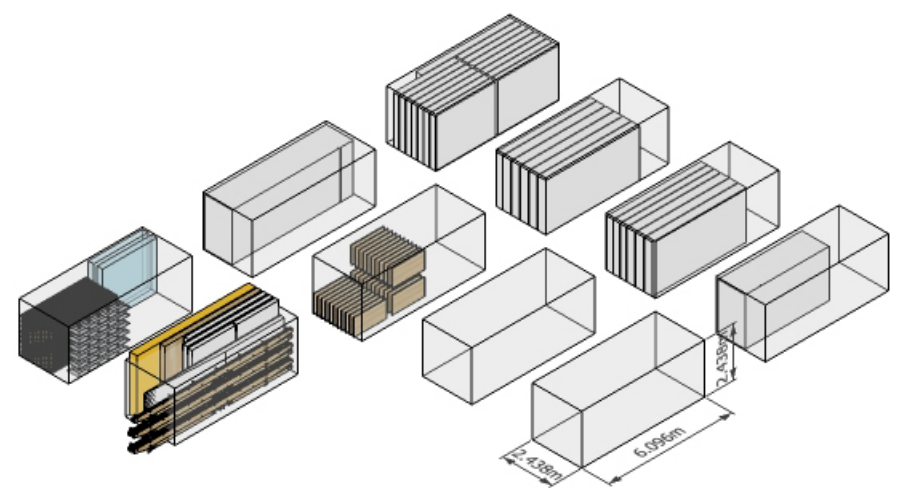

Figure 43: Option Eleven - Land and Air Transport in Standard Air Freight Container 
2.4 SUMMARY OF FINDINGS

\begin{tabular}{|c|c|c|c|c|c|c|c|c|c|c|c|c|c|c|c|c|}
\hline \multirow[b]{2}{*}{ Opt. } & \multirow[b]{2}{*}{ Description } & \multirow{2}{*}{$\begin{array}{c}\text { Modules } \\
\text { No. } \\
\text { Modules }\end{array}$} & \multicolumn{5}{|c|}{ Regulations } & \multicolumn{4}{|c|}{ Design Quality \& Performance } & \multicolumn{3}{|c|}{ Assembly } & \multirow{2}{*}{$\begin{array}{c}\text { Cost } \\
\text { Transport } \\
\text { Cost } \\
\text { Ranking }\end{array}$} & \multirow{2}{*}{$\begin{array}{c}\text { Time } \\
\text { Transpor } \\
\text { Time } \\
\text { Ranking }\end{array}$} \\
\hline & & & Sea Freight & Land Transport & $\begin{array}{c}\text { Land } \\
\text { Permit } \\
\text { Req. }\end{array}$ & $\begin{array}{c}\text { Air } \\
\text { Freight }\end{array}$ & \begin{tabular}{|c} 
Over- \\
Dimensions \\
(H/W/L)
\end{tabular} & \begin{tabular}{|c|} 
Overall House \\
Dimensional Limitations \\
$(\mathrm{H} / \mathrm{W} / \mathrm{L})$
\end{tabular} & $\begin{array}{c}\text { Impact } \\
\text { on FL } \\
\text { plan }\end{array}$ & Add. Structure & Impact on Aesthetics & $\begin{array}{c}\text { No. Of } \\
\text { Unique Joint } \\
\text { Details }\end{array}$ & \begin{tabular}{|c|} 
Heavy \\
Machinery
\end{tabular} & $\begin{array}{c}\text { Assembly } \\
\text { Time } \\
\text { Ranking }\end{array}$ & & \\
\hline 1 & One OS unit & 1 & $\begin{array}{l}\text { 1x Roll-on roll-off } \\
+2 \times 40 ' \text { Hi Cube } \\
+1 \times 20^{\prime} \text { Stds }\end{array}$ & $\begin{array}{l}\text { 1x } 40^{\prime} \text { Flatbed } \\
\text { trailer } \\
\text { + Hiab/swinglift for } \\
\text { containers }\end{array}$ & $\mathrm{Y}$ & N/A & $\begin{array}{l}\mathrm{H}=+0.46 \mathrm{~m} \\
\mathrm{~W}=+2.30 \mathrm{~m} \\
\text { (land) }\end{array}$ & $\begin{array}{l}\text { Further limitations to be } \\
\text { explored for H \& W } \\
\mathrm{L}=14.63 \mathrm{~m}\end{array}$ & $\mathrm{~N} / \mathrm{A}$ & $\begin{array}{l}\text { Significant reinforcing and } \\
\text { bracing required to support } \\
\text { overhang on trailer \& crane } \\
\text { lift }\end{array}$ & & 0 & $\begin{array}{l}\text { Very large } \\
\text { crane }\end{array}$ & 1 & 10 & 12 \\
\hline 2 & \begin{tabular}{|l}
$\begin{array}{l}\text { Longitudinal } \\
\text { split }\end{array}$ \\
\end{tabular} & 2 & $\begin{array}{l}\text { 2x Roll-on roll-off } \\
+2 \times 40 ' \text { Hi Cube } \\
+1 \times 20^{\prime} \text { Stds }\end{array}$ & $\begin{array}{l}2 \times 40 \text { ' Flatbed } \\
\text { trailers } \\
+ \text { Hiab/swinglift for } \\
\text { containers }\end{array}$ & $\mathrm{Y}$ & $\mathrm{N} / \mathrm{A}$ & \begin{tabular}{|l|}
$\mathrm{H}=+0.46 \mathrm{~m}$ \\
(land)
\end{tabular} & $\begin{array}{l}\mathrm{H}=2.58 \mathrm{~m} \\
\mathrm{~W}=5.00 \mathrm{~m} \\
\mathrm{~L}=14.63 \mathrm{~m}\end{array}$ & $\mathrm{~N} / \mathrm{A}$ & $\begin{array}{l}\text { Support \& bracing required } \\
\text { for roof at cut line }\end{array}$ & $\begin{array}{l}\text { Join in longitudinal } \\
\text { direction }\end{array}$ & 4 & \begin{tabular}{|l} 
Large crane \\
\end{tabular} & 3 & 8 & 10 \\
\hline 3 & \begin{tabular}{|l|} 
M3 flat-packed \\
\& longitudinal \\
split
\end{tabular} & $\begin{array}{c}4 \\
+\mathrm{M} 3\end{array}$ & $\begin{array}{l}\text { 2x 40' Flat Racks } \\
+2 \mathrm{x} 40^{\prime} \mathrm{Hi} \text { Cube } \\
+2 \mathrm{x} 20^{\prime} \mathrm{Stds}\end{array}$ & $\begin{array}{l}\text { 2x Dropdeck trailers } \\
+ \text { Hiab/swinglift for } \\
\text { containers }\end{array}$ & M3 only & $\mathrm{N} / \mathrm{A}$ & $\begin{array}{l}\mathrm{H}=+0.94 \mathrm{~m} \\
\text { (sea) }\end{array}$ & $\begin{array}{l}\mathrm{H}=3.12 \mathrm{~m} \\
\mathrm{~W}=4.86 \mathrm{~m} \\
\mathrm{~L}=11.28 \mathrm{~m}+3.0 \mathrm{~m} \mathrm{M} 3\end{array}$ & N/A & $\begin{array}{l}\text { Support \& bracing, temporary } \\
\text { or other, required at roof cut } \\
\text { line in both directions }\end{array}$ & $\begin{array}{l}\text { Join in longitudinal } \\
\text { direction \& } \\
\text { permanent structure }\end{array}$ & $\begin{array}{c}6 \\
+\mathrm{M} 3\end{array}$ & $\begin{array}{l}\text { Crane or } \\
\text { forklift }\end{array}$ & 8 & 5 & 6 \\
\hline 4 & \begin{tabular}{|l|} 
M3 flat-packed \\
\& asymmetrical \\
longitudinal \\
split
\end{tabular} & $\begin{array}{c}4 \\
+\mathrm{M} 3\end{array}$ & $\begin{array}{l}\text { 2x } 40^{\prime} \text { Flat Racks } \\
+2 \times 40^{\prime} \text { Hi Cube } \\
+2 \times 20^{\prime} \text { Stds }\end{array}$ & $\begin{array}{l}\text { 2x Dropdeck trailers } \\
+ \text { Hiab/swinglift for } \\
\text { containers }\end{array}$ & $\begin{array}{c}\mathrm{Y} \\
+\mathrm{M} 3\end{array}$ & $\mathrm{~N} / \mathrm{A}$ & $\begin{array}{l}\mathrm{H}=+0.94 \mathrm{~m} \\
\mathrm{~W}=0.56 \mathrm{~m} \\
\text { (sea) } \\
\mathrm{W}=+0.50 \mathrm{~m} \\
\text { (land) }\end{array}$ & $\begin{array}{l}\mathrm{H}=3.12 \mathrm{~m} \\
\mathrm{~L}=11.28 \mathrm{~m}+3.0 \mathrm{~m} \mathrm{M} 3\end{array}$ & $\mathrm{~N} / \mathrm{A}$ & $\begin{array}{l}\text { Support \& bracing required } \\
\text { for roof at cut line }\end{array}$ & $\begin{array}{l}\text { Disguised } \\
\text { longitudinal join }\end{array}$ & $\begin{array}{c}6 \\
+\mathrm{M} 3\end{array}$ & $\begin{array}{l}\text { Crane or } \\
\text { forklift }\end{array}$ & 6 & 7 & 8 \\
\hline $4 \mathrm{a}$ & $\begin{array}{l}\text { M3 flat-packed } \\
\& \text { asymmetrical } \\
\text { longitudinal } \\
\text { split RORO }\end{array}$ & $\begin{array}{c}4 \\
+\mathrm{M} 3\end{array}$ & $\begin{array}{l}\text { 4x Roll-on roll-off } \\
+2 \times 40 ' \text { Hi Cube } \\
+2 \times 20^{\prime} \text { Stds }\end{array}$ & $\begin{array}{l}\text { 2x Dropdeck trailers } \\
+ \text { Hiab/swinglift for } \\
\text { containers }\end{array}$ & $\begin{array}{c}\mathrm{Y} \\
+\mathrm{M} 3\end{array}$ & $\mathrm{~N} / \mathrm{A}$ & $\begin{array}{c}\mathrm{W}=+0.50 \mathrm{~m} \\
\quad \text { (land) }\end{array}$ & $\begin{array}{l}\mathrm{H}=3.12 \mathrm{~m} \\
\mathrm{~L}=11.28 \mathrm{~m}+3.0 \mathrm{~m} \mathrm{M} 3\end{array}$ & $\mathrm{~N} / \mathrm{A}$ & $\begin{array}{l}\text { Support \& bracing required } \\
\text { for roof at cut line }\end{array}$ & \begin{tabular}{|l|} 
Disguised \\
longitudinal join
\end{tabular} & $\begin{array}{c}6 \\
+\mathrm{M} 3\end{array}$ & $\begin{array}{l}\text { Crane or } \\
\text { forklift }\end{array}$ & 7 & 4 & 9 \\
\hline 5 & $\begin{array}{l}\text { M3 flat-packed } \\
\& 2 \text { large OS } \\
\text { units }\end{array}$ & $\begin{array}{c}2 \\
+\mathrm{M} 3\end{array}$ & $\begin{array}{l}\text { 2x Roll-on roll-off } \\
+2 \times 40^{\prime} \text { Hi Cube } \\
+2 \times 20^{\prime} \text { Stds }\end{array}$ & \begin{tabular}{|l|} 
1x 40 ' Dropdeck \\
trailer \\
+ Hiab/swinglift for \\
containers \\
\end{tabular} & $\begin{array}{c}\mathrm{Y} \\
+\mathrm{M} 3\end{array}$ & $\mathrm{~N} / \mathrm{A}$ & $\mathrm{W}=+2.30 \mathrm{~m}$ & $\begin{array}{l}\mathrm{H}=3.12 \mathrm{~m} \\
\text { Further limitations to be } \\
\text { explored for } \mathrm{W} \\
\mathrm{L}=11.28 \mathrm{~m}+3.0 \mathrm{~m} \mathrm{M} 3\end{array}$ & $\mathrm{~N} / \mathrm{A}$ & $\begin{array}{l}\text { Significant reinforcing and } \\
\text { bracing required to support } \\
\text { overhang on trailer \& crane } \\
\text { lift }\end{array}$ & & $\begin{array}{c}3 \\
+\mathrm{M} 3\end{array}$ & \begin{tabular}{|l} 
Large Crane \\
\end{tabular} & 4 & 9 & 11 \\
\hline 6 & \begin{tabular}{|l|} 
Longitudinal \\
split \& \\
foreshortened \\
floor plan \\
\end{tabular} & 2 & $\begin{array}{l}\text { 2x 40' Flat Racks } \\
+2 \times 40^{\prime} \text { Hi Cube } \\
+1 \times 20^{\prime} \text { Stds }\end{array}$ & $\begin{array}{l}2 \times 40 \text { ' Flatbed } \\
\text { trailers } \\
+ \text { Hiab/swinglift for } \\
\text { containers }\end{array}$ & $\mathrm{Y}$ & $\mathrm{N} / \mathrm{A}$ & $\begin{array}{l}\mathrm{H}=+0.46 \mathrm{~m} \\
\text { (land) } \\
\mathrm{H}=+0.94 \mathrm{~m} \\
\text { (sea) }\end{array}$ & $\begin{array}{l}\mathrm{H} \text { dependent on local } \\
\text { transport authorities } \\
\mathrm{W}=2.43 \mathrm{~m} \\
\mathrm{~L}=12.08 \mathrm{~m}\end{array}$ & $\begin{array}{l}\text { T Length } \\
\text { reduced } \\
\text { by } \\
\sim 2.12 \mathrm{~m}\end{array}$ & $\begin{array}{l}\text { Support \& bracing required } \\
\text { for roof at cut line }\end{array}$ & $\begin{array}{l}\text { Join in longitudinal } \\
\text { direction }\end{array}$ & 4 & \begin{tabular}{|l} 
Large crane \\
\end{tabular} & 2 & 3 & 5 \\
\hline 7 & $\begin{array}{l}\text { Flat-Pack \& } \\
\text { prefabricated } \\
\text { service cores }\end{array}$ & $\begin{array}{l}24 \text { panels } \\
+2 \text { cores } \\
+\mathrm{M} 3\end{array}$ & $\begin{array}{l}5 \times 40^{\prime} \mathrm{Hi} \text { Cubes } \\
+2 \times 20^{\prime} \text { Stds }\end{array}$ & $\begin{array}{l}\text { Hiab/swinglift for } \\
\text { containers }\end{array}$ & $\mathrm{N}$ & $\mathrm{N} / \mathrm{A}$ & $\mathrm{N} / \mathrm{A}$ & $\begin{array}{l}\text { Size of panels and service } \\
\text { cores restricted by } \\
\text { dimensions of containers }\end{array}$ & $\mathrm{N} / \mathrm{A}$ & $\begin{array}{l}\text { Joins between panels will } \\
\text { need to be structural }\end{array}$ & $\begin{array}{l}\text { Many joins both } \\
\text { internally and ext. }\end{array}$ & $\begin{array}{c}8 \\
+\mathrm{M} 3\end{array}$ & \begin{tabular}{|c} 
Small crane \\
or forklift
\end{tabular} & 11 & 1 & 3 \\
\hline 8 & $\begin{array}{l}\text { M3 flat-packed } \\
\& \text { house sliced } \\
\text { for open top } \\
\text { containers }\end{array}$ & $\begin{array}{c}8 \\
+\mathrm{M} 3\end{array}$ & $\begin{array}{l}\text { 4x 40' Open Tops } \\
+2 \times 40^{\prime} \text { Hi Cube } \\
+2 \times 20^{\prime} \text { Stds }\end{array}$ & $\begin{array}{l}\text { Hiab/swinglift for } \\
\text { containers }\end{array}$ & M3 only & N/A & N/A & $\mathrm{W}=4.40 \mathrm{~m}$ & $\begin{array}{l}\text { Width } \\
\text { reduced } \\
\text { by } \\
\sim 0.40 \mathrm{~m}\end{array}$ & $\begin{array}{l}\text { Support \& bracing required } \\
\text { for roof at cut line }\end{array}$ & $\begin{array}{l}\text { Horizontal join in } \\
\text { walls +longitudinal } \\
\text { joins }\end{array}$ & $\begin{array}{c}8 \\
+\mathrm{M} 3\end{array}$ & Crane & 10 & 2 & 4 \\
\hline 9 & $\begin{array}{l}\text { M3 flat-packed } \\
\text { \& house sliced } \\
\text { transversely }\end{array}$ & $\begin{array}{c}5 \\
+\mathrm{M} 3\end{array}$ & $\begin{array}{l}2 \times 40^{\prime} \text { Flat Racks } \\
+1 \times 20^{\prime} \text { Flat } \\
\text { Rack } \\
+2 \times \text { Hi Cube } \\
+2 \times 20^{\prime} \text { Stds }\end{array}$ & $\begin{array}{l}\text { 3x Dropdeck trailers } \\
\text { + Hiab/swinglift for } \\
\text { containers }\end{array}$ & M3 only & $\mathrm{N} / \mathrm{A}$ & $\begin{array}{l}\mathrm{H}=+0.94 \mathrm{~m} \\
\text { (sea) }\end{array}$ & $\begin{array}{l}\mathrm{H}=3.12 \mathrm{~m} \\
\mathrm{~W}=5.6 \mathrm{~m} \\
\mathrm{~L}=12.72 \mathrm{~m}+3.0 \mathrm{~m} \mathrm{M} 3\end{array}$ & Minimal & $\mathrm{N} / \mathrm{A}$ & Transverse joins & $\begin{array}{c}5 \\
+\mathrm{M} 3\end{array}$ & $\begin{array}{l}\text { Crane or } \\
\text { forklift }\end{array}$ & 5 & 6 & 7 \\
\hline 10 & Hercules & $\begin{array}{c}4 \\
+\mathrm{M} 3\end{array}$ & $\mathrm{~N} / \mathrm{A}$ & & & & & & & & & $\begin{array}{c}6 \\
+\mathrm{M} 3\end{array}$ & & 9 & 12 & 2 \\
\hline 11 & Std Air Freight & $\begin{array}{l}24 \text { panels } \\
+2 \text { cores } \\
+\mathrm{M} 3\end{array}$ & $\mathrm{~N} / \mathrm{A}$ & & & & & & & & & $\begin{array}{c}8 \\
+\mathrm{M} 3\end{array}$ & & 12 & 11 & 1 \\
\hline
\end{tabular}

Table 1: Summary of Transportation Methods 


\section{$2.5 \quad$ IMPLICATIONS}

Through exploring the many available transportation methods it became obvious that each would have a different and potentially dramatic impact on construction, project timing, and budget.

Given the logistical complexity involved it was necessary to reduce the number of options being explored. This was primarily due to the limited availability of time and resources needed to carry out a full analysis of each option. The initial assessment of possible transportation methods provided a sound background from which to narrow the scope of the research. However, with so many unknowns still facing the project, it was important to select options that would enable a great degree of flexibility. The strategy at the time very much became one of; what option contains the least risk now, the least likely risk in the future, and how much scope for adaptation does it allow should circumstances change.

As presented in the table above, there are many variables at play when considering an appropriate method for transport, each entailing a unique set of opportunities and risks. Figure 44 below illustrates a hierarchy of the main factors affecting the decision making process for transportation:

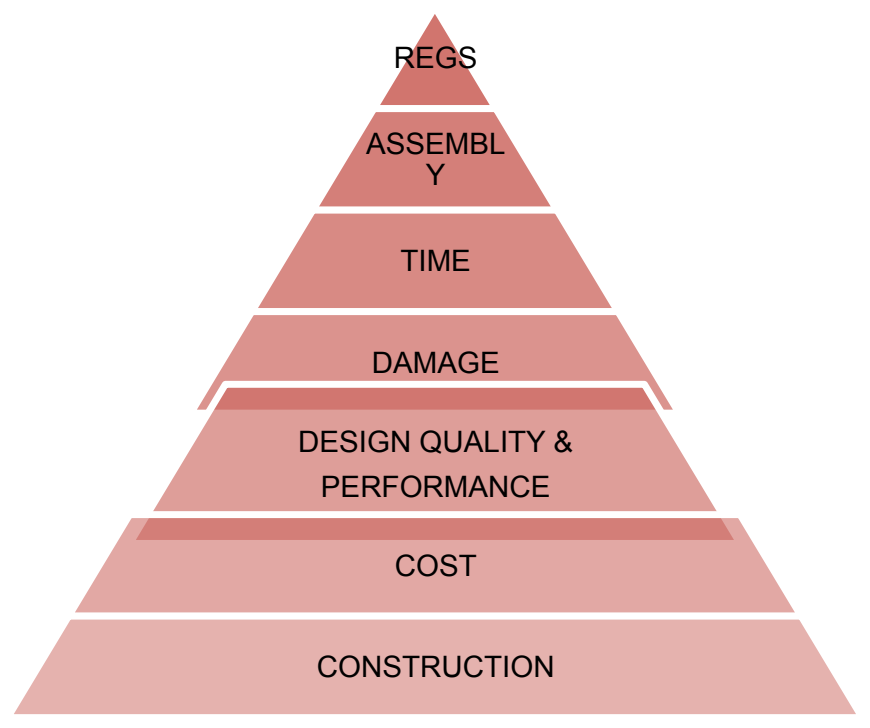

Figure 44: Decision Making Hierarchy - Transport

Each factor would have to be investigated relative to its impact on the other six in order to determine the best method of transport. Although all would be influential to the overall outcome of the project, each was given its place in an order of priority.

\subsubsection{Regulations}

At the top of the spectrum of risks is the potential for a complete project stoppage due to a failure to meet the regulatory requirements of local Transport Authority's, Customs Agency's, and Freight Forwarding Companies. The selection of a method for transport was primarily contingent on access to reliable and accurate information in these three areas. Without this knowledge the project could have faced major problems further down the track.

\subsubsection{Assembly}

The second priority relates to the ability to quickly and accurately reassemble the house in Washington DC, with a student team, and within 7 days. A simple formula was devised on how to achieve this based on knowledge gained from past competition entries: the fewer the components and the less complicated the connections the better the end result.

A balance between manual labour and the use of heavy machinery had to be found, weighing up the benefits of speed vs. cost vs. site access. There have been significant problems at past Solar Decathlon events caused by the backlog of trucks and cranes all trying to enter the site at the same time. Estimates had to be made relative to the potential for hold ups of using heavy machinery versus the time required to assemble smaller components by hand.

Lessons learned from past solar decathlon houses paved the way for many of the decisions that were made both with respect to transport and to construction. These past houses provided the best possible precedent for meeting the unique requirements of the competition, more so than investigating other examples of transportable buildings. Other New Zealand based projects that were investigated include;

- Port-a-Bach - Atelier Workshop

- Bachkit \& iPad - Andre Hodgeskin

- Habode - Rod Gibson

Although these examples were addressing unique briefs, quite different from the Solar Decathlon, they all had to develop clever solutions to the challenge of transportation. Cost too was a major implication for these projects with a focus on making a prefabricated house economically competitive. Detailed analysis of these precedents has been omitted to simplify the scope of this research. The remainder of this thesis will focus on the 
decisions made specifically with respect to the First Light project and the 2011 Solar Decathlon.

It had been well reported that teams who had undertaken a practice assembly were significantly advantaged compared to those teams which had not (Werner, 2010). Given that the competition takes place in a foreign country, with different construction processes, few industry contacts, and on an imperial system of measurement, it was critical for the house to be assembled almost completely independent of outside assistance. Running a practice assembly in Wellington would ensure that all necessary tools, components, and skills would be acquired before reaching the competition. It also meant that planning and organisation could be tested and optimised for the most efficient use of time and personnel. A successful and meaningful practice assembly requires a great deal of additional resources and would put further pressure on the program. It was therefore important to consider this early on in the project and allow sufficient time, not only for the assembly itself, but also for the analysis and optimisation of the process afterwards. Furthermore, a practice assembly would act as an exhibition creating publicity for the University and its industry supporters, generating added incentive for potential sponsors.

\subsubsection{Time}

Time quickly became the most valuable commodity of the entire project. Producing a house of competition winning quality and one that could be transported across the world required a significant investment of time and resources. The extent of unknowns facing the project demanded a large amount of contingency to be built into a program that was already compressed due to the late announcement of SD2011 teams, organisational teething problems, and the additional time it would take to ship the house.

\subsubsection{Damage}

The potential for damage was always a high risk given that common house building techniques do not typically address the issue of transportation. This presented the project with a great deal of uncertainty in terms of what would be required of the house during transport. These unknowns ranged from the forces that would be involved on the back of a truck, to four weeks in potentially violent seas, to the environmental conditions the house would be subjected to while travelling across the equator. Although these implications would most dramatically influence the choice of construction details and materials, they remained important in the initial determination of how to best divide and transport the house. Close coordination with logistics experts, freight forwarding companies, and the engineer would be critical for ensuring the safe delivery of the house to Washington DC.

\subsubsection{Design Quality \& Performance}

As the ultimate goal of the project was to excel in the 10 Decathlon contests, these too provided an important consideration for transport. The house must be assembled quickly but must also maintain a high standard of finish and visual quality. These aspects would be judged in the subjective contests of Architecture and Market Appeal, worth $10 \%$ each. The team's objective for marketing the house made a point of appreciating its inherent modular nature while also promoting a beautiful and functional place to live.

With such a limited floor area to work within $\left(57-90 \mathrm{~m}^{2}\right)$ it was important that the house retain a sense of spaciousness and of appropriate scale \& proportion. Transportation would clearly have an impact on the dimensions of the house and these considerations played an important role in the selection of a suitable transportation method.

The performance of the house with respect to Engineering, Thermal Comfort and Energy Balance were equally important, again accounting for $10 \%$ each of the overall competition. Construction materials and details would need to be vigorously developed and of a high standard in order to achieve the desired performance once reassembled. Reducing the amount of additional structure required for transport also assisted in reducing the overall cost of construction; an important consideration given that points are awarded at the competition for affordability $(10 \%)$.

\subsubsection{Cost}

The costs involved in transporting the house accounted for a significant portion of the project budget. Cost did not however feature as highly in the list of priorities as might have been expected. It was believed that the prestigious nature of the competition, coupled with the obvious exposure and publicity benefits available to sponsors, would attract significant backing from industry. It was 
also defined that expenditure on transport had no impact on the judging of the affordability contest.

\subsubsection{Construction}

Simplicity of construction would not only promote an effective reassembly once at the competition, but would also make for a faster, more economic manufacturing process in New Zealand. The experience level of the student team was also an important consideration in selecting how to approach construction and transport. Sophistication could be added at the manufacturing phase as a means to limit complexity during reassembly. This was in the knowledge that outside contractors would be responsible for the construction of the house, with students primarily involved with the reassembly only. Construction was therefore a lower priority at the time as it was believed that adequate skills and resources were available to resolve and build the house irrespective of how it would be transported.

\subsection{SELECTED OPTIONS}

Through considering the wide range of implications for each transportation method, from structural to aesthetic to ease of assembly; six primary options were identified for further investigation. The more ambitious options were dropped to avert unnecessary risk further down the track.

Options 3, 4, 4a, 7, 8 \& 9 were believed to be the most realistic methods available that would also provide for the greatest scope of flexibility. Table 2 below summarises the main reasons contributing to the selection of the preferred transport options. Although some of the options had a higher overall ranking, they entailed specific characteristics which rendered them inappropriate for use.
Freighting requirements were summarized for the purpose of better communicating them with potential shipping companies. The shipping consignments were investigated and quoted by transport and logistics company Mainfreight:

1. Flat Racks (Option 3) Figure 45

- 2x 40’ Flat Rack containers

- 2x 40’ Hi Cube container

- 2x 20' Standards containers

2. $\mathrm{O} / \mathrm{S}$ Flat Rack (Options 4) Figure 46

- $1 x$ O/S 40’ Flat Rack container

- 1x 40’ Flat Rack container

- 2x 40’ Hi Cube container

- 2x 20' Standard containers

3. O/S Roll-on Roll-off (Option 4a) Figure 46

- 4x Roll-on Roll-off modules

- 2x 40’ Hi Cube container

- 2x 20’ Standard containers

4. Flat Pack (Option 7) Figure 48

- $5 x$ 40’ Hi Cube containers

- 2x 20' Standard containers

5. Open Tops (Option 8) Figure 49

- 4x 40’ Open Top containers

- 2x 40’ Hi Cube containers

- 2x 20’ Standard containers

6. Flat Racks (Options 9) Figure 47

- 2x 40’ Flat Rack containers

- 1x 20’ Flat Rack containers

- 2x 40’ Hi Cube container

- 2x 20’ Standards containers

Through working with Mainfreight, the engineer, and continuing design development, a full understanding of the time, cost, and quality impacts of each transport option were obtained. The following sections provide a comparative analysis of these findings.

\begin{tabular}{|c|c|l|l|}
\hline Rank & Option & Description & Main Reason \\
\hline 1 & 6 & Longitudinal split, foreshortened plan & Not willing to compromise floor plan to this extent \\
2 & 1 & One O/S unit & Raises too many risks in terms of land transport \\
3 & 2 & Longitudinal Split & Land transport permitting issues (excessive height) \\
\hline 4 & 7 & Flat-packed, prefabricated service cores & Likely to be cheapest form of transport \\
4 eq & 9 & M3 flat-packed, transverse split & Simplicity of structure and ease of assembly \\
5 & 8 & M3 flat-packed, open tops & House modularised but fully protected during shipping \\
6 & 3 & M3 flat-packed, longitudinal split & Few modules = ease of assembly \\
7 & $4 a$ & M3 flat-packed, asymmetrical split roro & Few modules = ease of assembly \\
8 & 4 & M3 flat-packed, asymmetrical split & Few modules \& structurally well located cut line \\
\hline 9 & 5 & M3 flat-packed, 2 large O/S units & Raises too many risks in terms of land transport \\
10 & 10 & Hercules & Only possible with sponsorship which did not eventuate \\
11 & 11 & Standard air freight & Likely to be too expensive \\
\hline
\end{tabular}




\subsubsection{Modularisation}

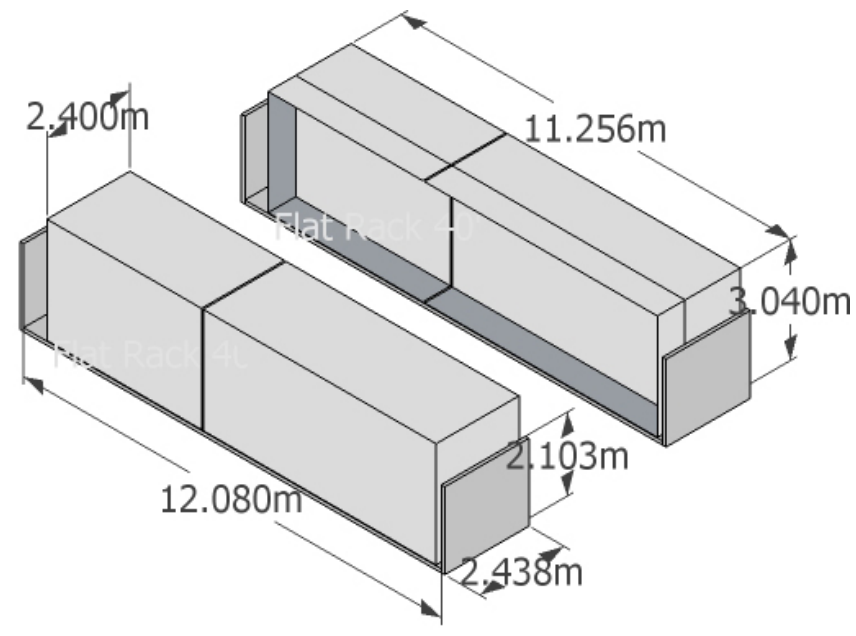

Figure 45: House Split Longitudinally for 40’ Flat Rack Transport

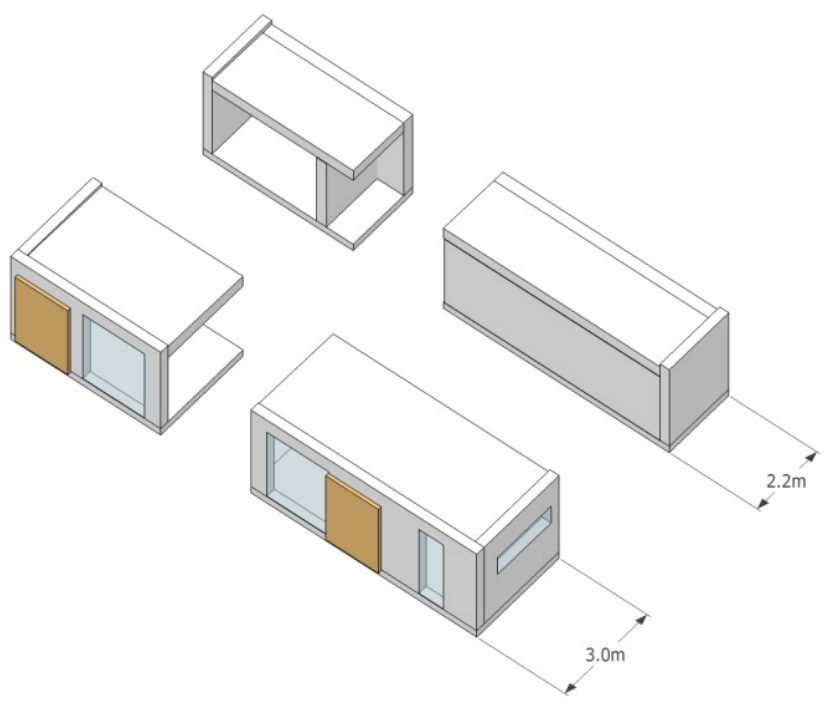

Figure 46: House Split Longitudinally for OOG 40 'Flat Rack OR RORO Transport

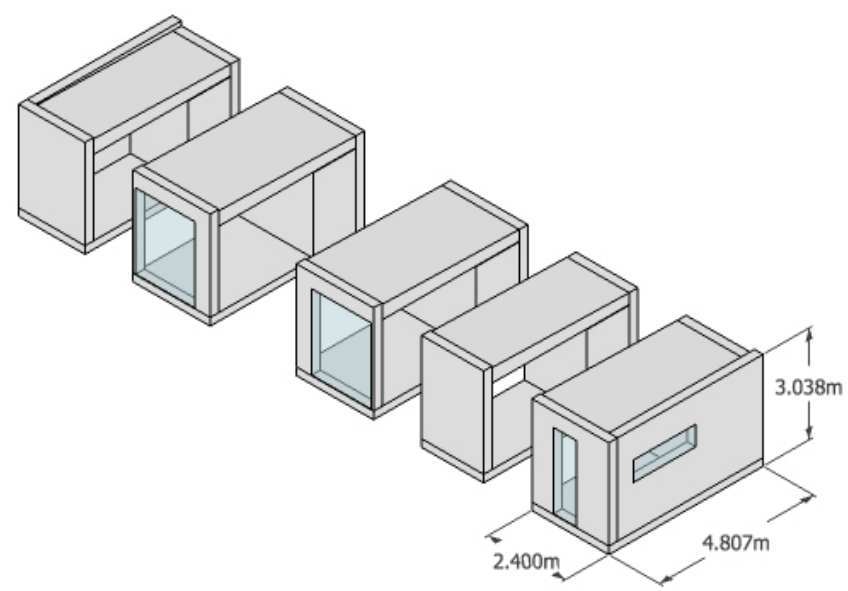

Figure 47: House Split Transversely for Flat Rack Transport

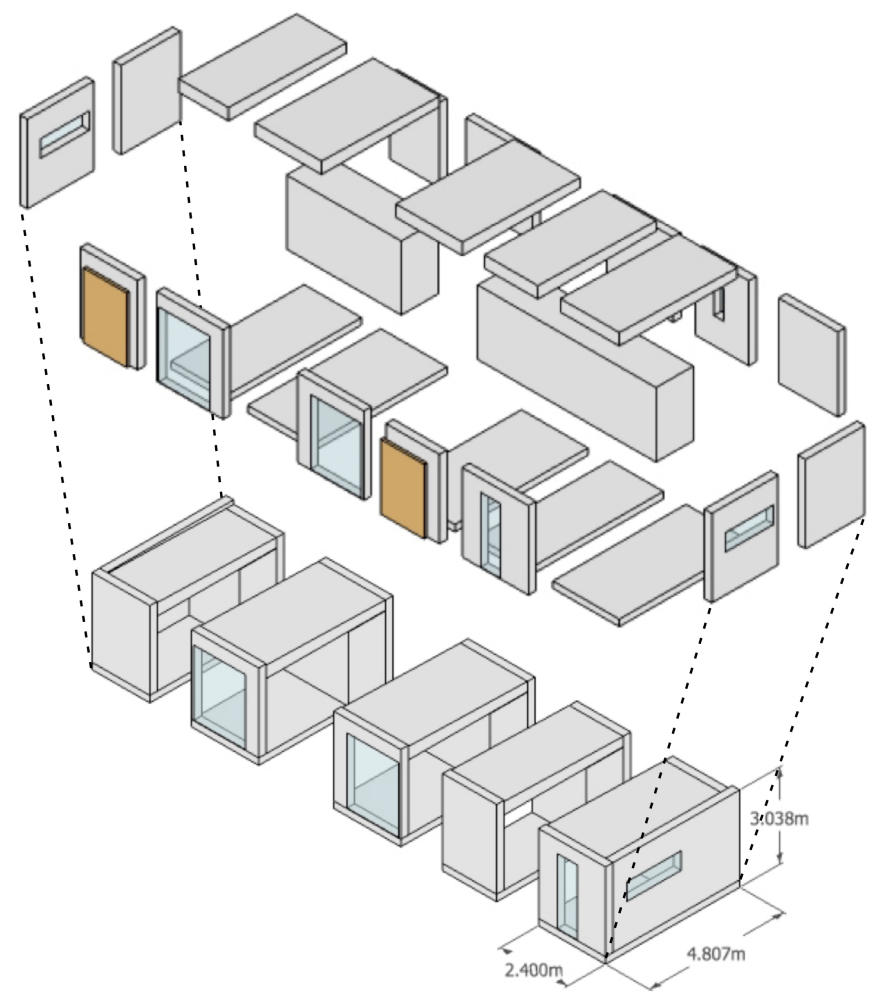

Figure 48: House Split Transversely and Panelised for Flat Packing

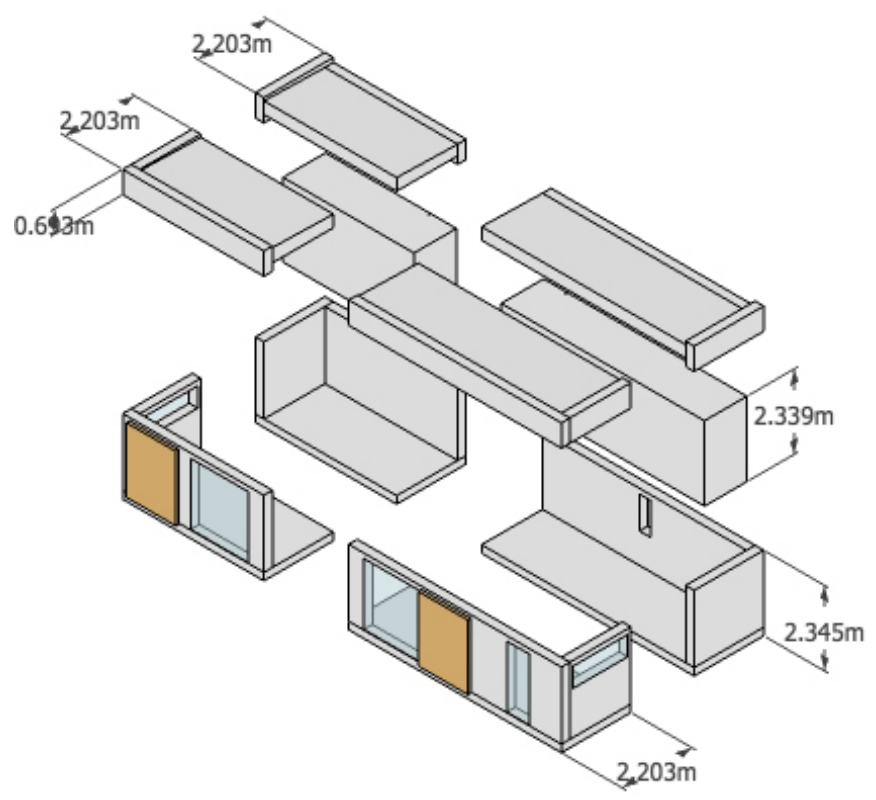

Figure 49: House Split Longitudinally and Horizontally for Packing Into 40' Open Top Containers 


\subsubsection{Costs}

Mainfreight were engaged to provide initial quotes for the preferred shipping options. The costs per container have been summarised and presented below:

\begin{tabular}{|l|c|c|}
\hline Container Type & $\begin{array}{c}\text { Initial Estimate \$NZ Return } \\
\text { (excl. USA Land Transport) }\end{array}$ & $\begin{array}{c}\text { Final Estimate \$NZ Return } \\
\text { (incl. USA Land Transport) }\end{array}$ \\
\hline 20' Standard Container & $\$ 16,634$ & $\$ 20,862$ \\
40' Hi Cube Container & $\$ 23,315$ & $\$ 31,217$ \\
20' Flat Rack Container & $\$ 29,026^{*}$ & $\$ 38,318$ \\
40' Flat Rack Container & $\$ 40,882$ & $\$ 53,848$ \\
40' Out of Gauge (OOG) Flat Rack Container & $\$ 78,026$ & $\$ 103,000^{* *}$ \\
Roll-on Roll-off & $\$ 60,224$ & $\$ 79,325^{* *}$ \\
\hline
\end{tabular}

Table 3: Estimated Shipping Costs per Container

* An initial estimate for the 20' Flat Rack container was not received, the price presented here is an approximation based on later quotes

** Final estimates for both the 40' OOG Flat Rack container and the Roll-on Roll-off service were not requested, the prices presented here are an approximation based on earlier quotes

Costs for the overall shipping consignment of each transportation option are as follows:

\begin{tabular}{|c|l|c|c|}
\hline Option & Description & $\begin{array}{c}\text { Initial Estimate NZ\$ Return } \\
\text { (excl. USA Land Transport) }\end{array}$ & $\begin{array}{c}\text { Final Estimate NZ\$ Return } \\
\text { (incl. USA Land Transport) }\end{array}$ \\
\hline 3 & M3 flat-packed, longitudinal split & $\$ 161,662$ & $\$ 211,854$ \\
4 & M3 flat-packed, asymmetrical split & $\$ 198,806$ & $\$ 261,006^{*}$ \\
$4 \mathrm{a}$ & M3 flat-packed, asymmetrical split roro & $\$ 200,346$ & $\$ 262,807^{*}$ \\
7 & Flat-packed, prefabricated service cores & $\$ 149,843$ & $\$ 197,810$ \\
8 & M3 flat-packed, open tops & $\$ 173,158^{* *}$ & $\$ 229,027^{* *}$ \\
9 & M3 flat-packed, transverse split & $\$ 190,688^{* * *}$ & $\$ 250,172$ \\
Actual & M3 flat-packed, transverse split & $\$ 180,735$ & $\$ 239,667$ \\
\hline
\end{tabular}

Table 4: Estimated Total Shipping Costs for Each Transportation Option

* Final estimates for both the 40' OOG Flat Rack container and the Roll-on Roll-off service were not requested, the prices presented here are an approximation based on earlier quotes

** Estimates for the 40' Open Top containers were never received, the costs presented here are assuming a similar price per container as the 40' High Cube containers

*** An initial estimate for the 20' Flat Rack container was not received, the costs presented here is an approximation based on later quotes 
It was important to consider the overall cost implication of each transportation option. In particular, Option 7 Flat-Packing, and Option 8 - Open Tops would require additional assembly time in preparation for the competition. The individual panels/components would need to be constructed into modules, the services would installed and connected, and all panel joins would need to be weatherproofed and finished. This preassembly would entail some basic additional costs. For comparative purposes the following assumptions were made, these do not include the costs for additional contractors or equipment.

\section{Option 7 - Additional Preassembly Costs (NZ\$):}

$\$ 197,810$ return shipping cost (final estimate)

$\$ 100 /$ day (food \& transport) for NZ team in DC x 21 days x 6 people pre-assembly

$=\$ 12,600$

$+\$ 100 /$ day (food \& transport) for NZ team in DC x 14 days $x 6$ people post-disassembly

$=8,400$

+5 weeks warehouse rental at $\sim \mathrm{NZ} \$ 1,000 \mathrm{p} / \mathrm{wk}$

$=\$ 6,000$

$=\$ 27,000$ additional costs

Total Comparable Cost $=\$ 224,810$

\section{Option 8 - Additional Preassembly Costs (NZ\$):}

$\$ 229,027$ return shipping cost (final estimate)

$\$ 100 /$ day (food \& transport) for NZ team in DC x 21 days x 6 people pre-assembly

$=\$ 12,600$

$+\$ 100 /$ day (food \& transport) for NZ team in DC x 14 days x 6 people post-disassembly

$=\$ 8,400$

+5 weeks warehouse rental at $\sim \mathrm{NZ} \$ 1,200 \mathrm{p} / \mathrm{wk}$

$=\$ 6,000$

$=\$ 27,000$ additional costs

\section{Total Comparable Cost $=\$ \mathbf{2 5 6 , 0 2 7}$}

The costs presented here are for the transport of a New Zealand built house to Washington DC, and back again.
Alternative approaches to transport were later explored in an attempt to reduce overall project costs [Chapter 4.2.9 Sponsorship]. 


\subsubsection{Transportation Timeframes}

Comparative timelines were developed for each of the transportation methods as a means of better understanding their overall impact on the project [Figure 50, Figure $51 \&$ Figure 52]. Following the quotes, Mainfreight was also able to advise on the shipping time required for each option. All of the containerised options would take approx. 35 days from port to port while the Roll-on Rolloff service would take 55 days. The additional three weeks for Option 4a would have put significant pressure on an already compressed timeline, reducing the estimated contingency to just two weeks [Figure 51].

Estimations of the time required for the Wellington test assembly, show case, and packaging phases were also included. Although the 'left over' time is noted here as contingency, it was well understood that this would quickly get taken up due to the many unknowns still facing the project. For this reason it was critical that as much contingency as possible was preserved in the early stages of planning. The additional preassembly time and associated risks of Option 7 and 8 reduced the contingency by three and a half weeks when compared to the Flat Rack options [Figure 52]. While the date for arrival back in New Zealand was not of such a concern, it would also be greatly affected by the method of transport.

\section{Options 3, 4 \& 9 : Flat Racks}

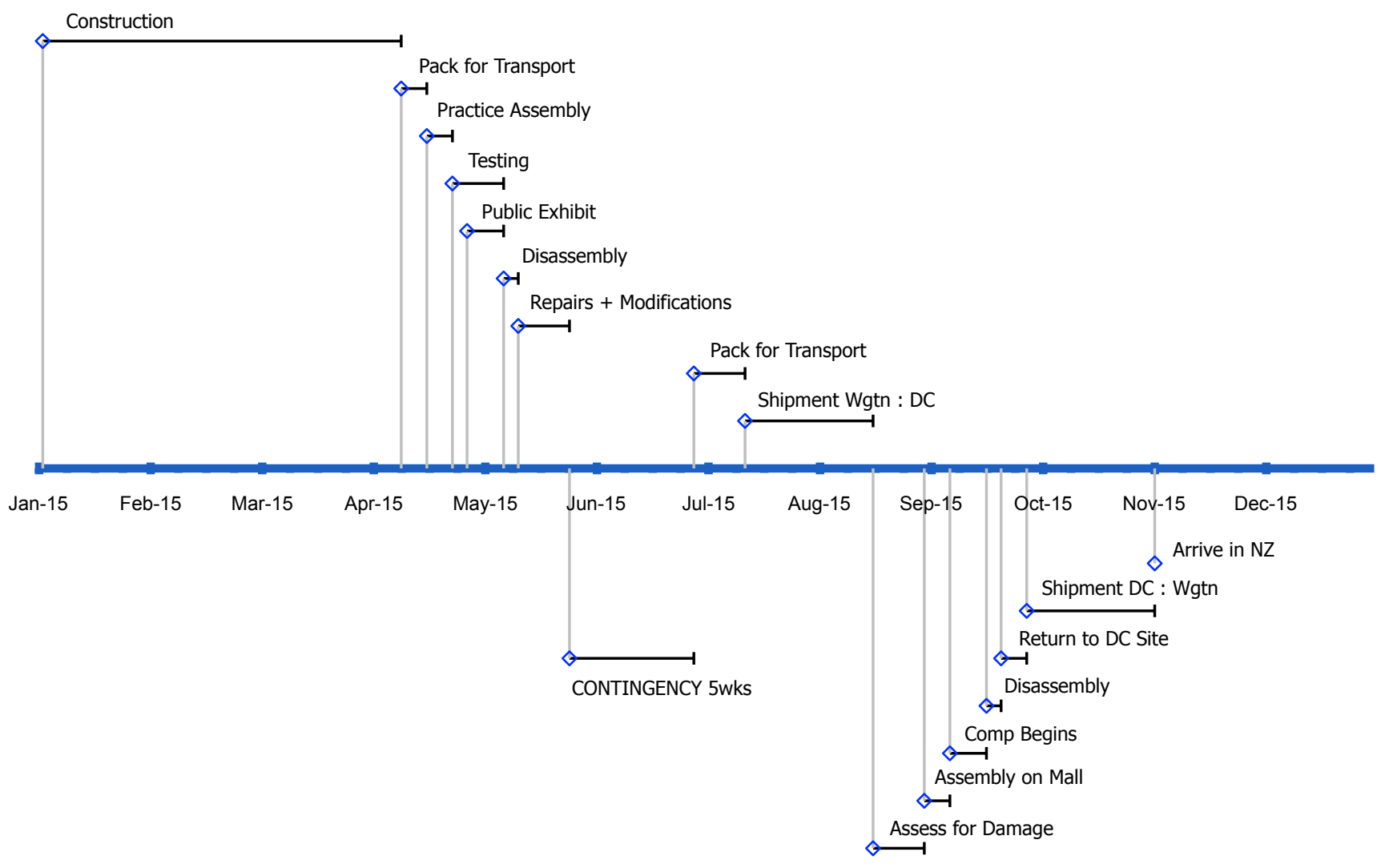

Figure 50: Project Timeline for Shipping Options 3, 4 \& 9 Using Flat Rack Containers 


\section{Option 4a, Roll-on Roll-Off Service}

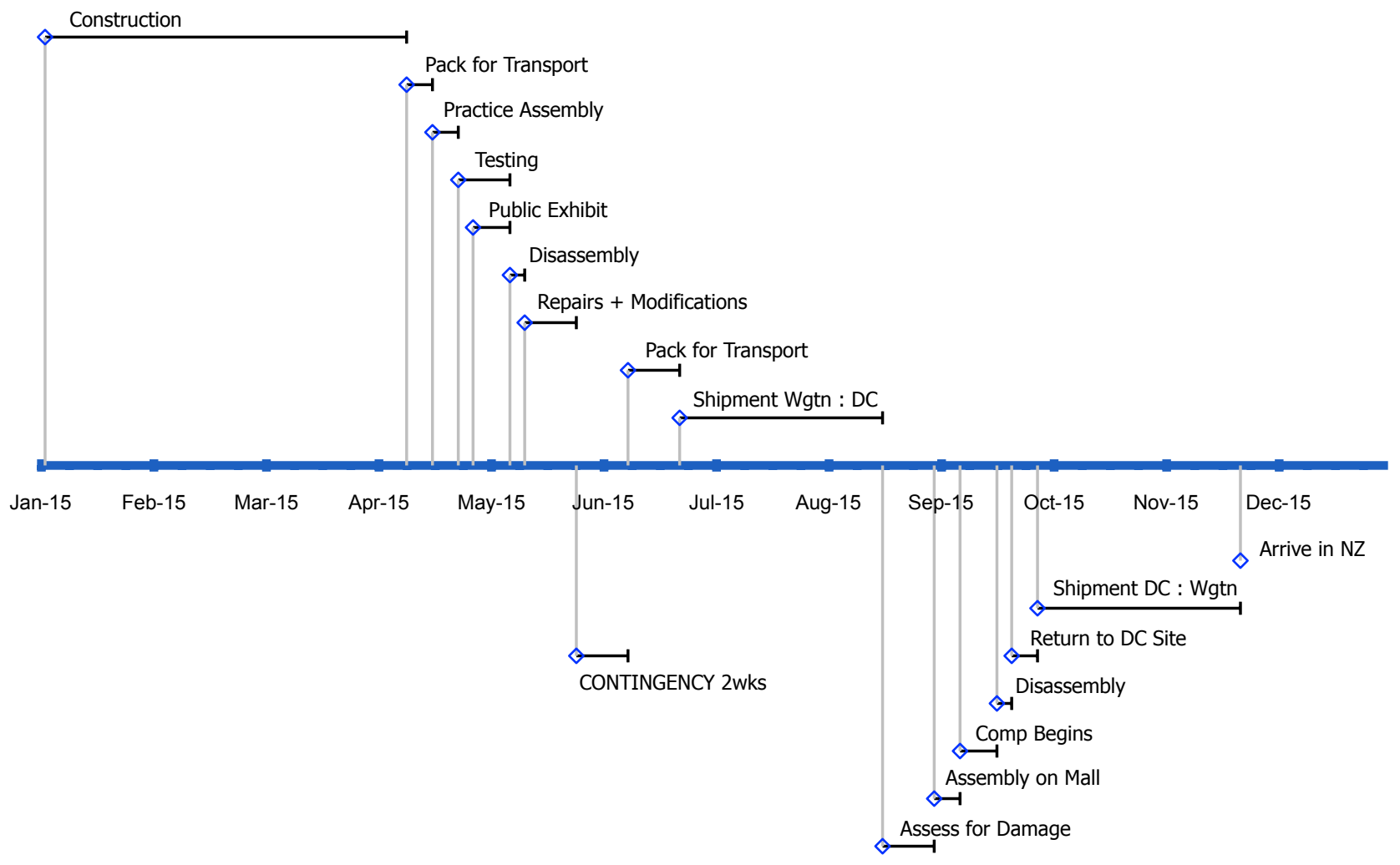

Figure 51: Project Timeline for Shipping Option 4a Using a Roll-on Roll-off Service

\section{Flat Pack and Open Tops}

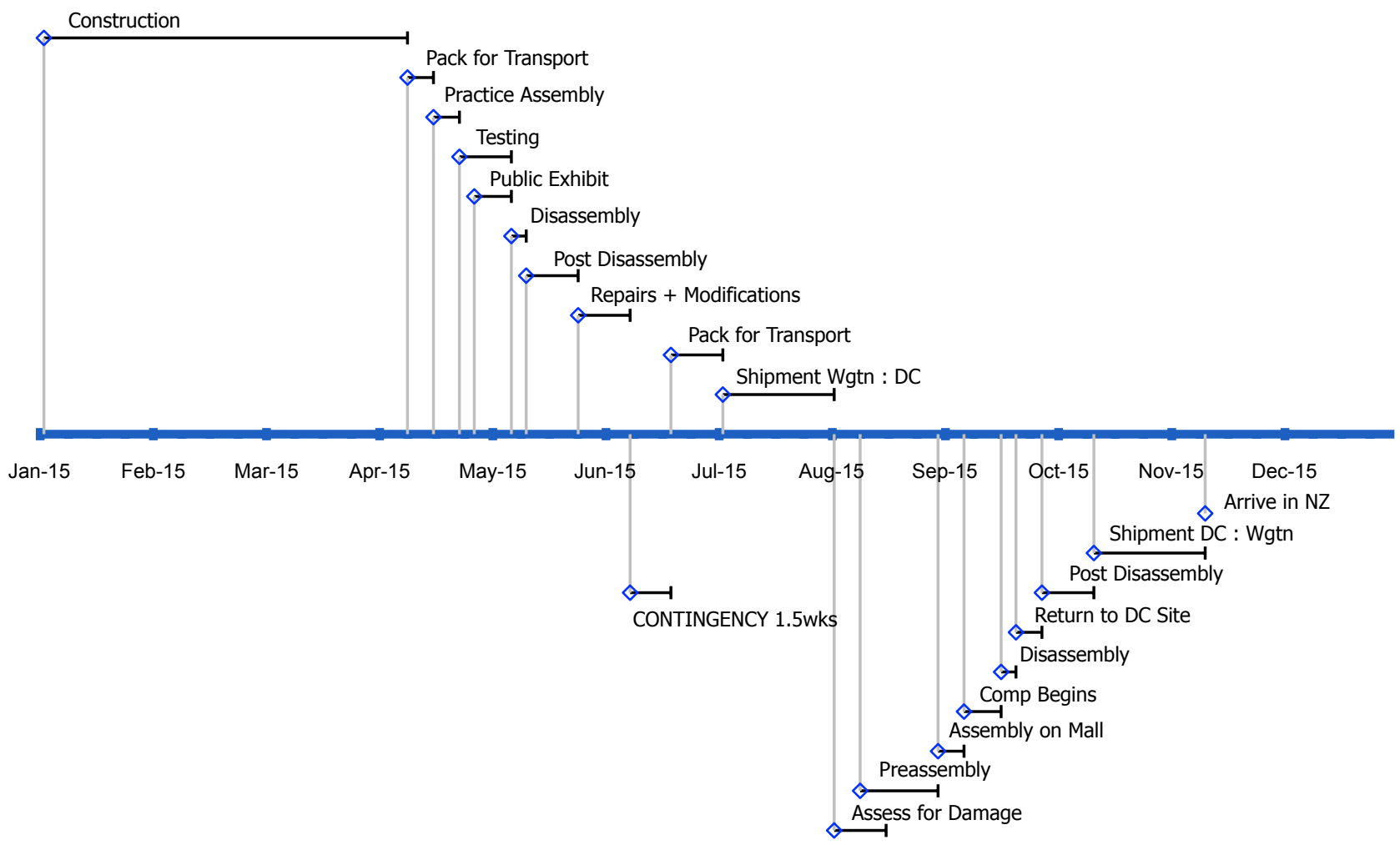

Figure 52: Project Timeline for Shipping Option 7 - Flat Rack Containers and Option 8 Using Open Top Containers 


\subsubsection{Summary}

The overall costs for transportation proved to consume a significant portion of the project budget. While some of the shipping options were relatively more expensive than others, they presented many other less quantifiable advantages. These ranged from the ease of assembly and additional contingency time to the overall peformance of the envelope. Each option would also have a different and potentially dramatic impact on the visual and spatial quality of the house. Ceiling heights and internal dimensions may become restricted by transport regulations and the types of connections details would reflect the method of transport.

Option 9 was elected as the preferred method for transport. It would involve the dividing of the house transversely into five equal modules for sea freight on Flat Rack containers (within permissable width), and the flat packing of the central module and exterior elements into standard shipping containers [Figure 53 \& Figure 54].The central module would need to be preassembled into a complete module offsite in Washington D.C. All six modules could then be transported on double drop deck trailers within the permissable dimensions ( $3 \mathrm{~m}$ wide central module requiring permit only). These trailers will allow the transport of one module per trailer due to the shortened length of the main deck. Option 9 would have a return transportation cost of $\mathbf{\$ 2 5 0 , 1 7 2}$ and take 35 days at sea contributing towards five weeks of contingency in the program.

An additional advantage of Option 9 is that it significantly reduces a range of risks surrounding construction detailing, weatherproofing, thermal performance, finishes, and assembly when compared to the other five options. While the return transportation costs of Option 9 are $\$ 25,362$ more than the flat packed Option 7, it will avoid the complicated additional preassembly phase. This would result in an additional four weeks contingency compared to Option 7. With both direct and indirect costs considered, Option 3 (the longitudinal split) proved to be the cheapest at $\$ 211,854$. Great difficulty was however anticipated with this method regarding the structural support of the house modules once separated. The symmetrical and transverse module divisions of Option 9 also later proved to have significant advantages during assembly.

With the confirmation of a viable and well outlined method of transportation, the following dimensional guidelines were established for the developed design phase [Figure 55].

Max height of module

$=3400 \mathrm{~mm}$

Max finish floor height

$=720 \mathrm{~mm}$

Desired max finished floor height

$=600 \mathrm{~mm}$

Max site differential

$=458 \mathrm{~mm}$

Max module width

$=2300 \mathrm{~mm}$

Max module length

$=5400 \mathrm{~mm}$

Min internal bedroom width

$=3120 \mathrm{~mm}$

(accessibility requirements)

Min internal bathroom width

$=1550 \mathrm{~mm}$
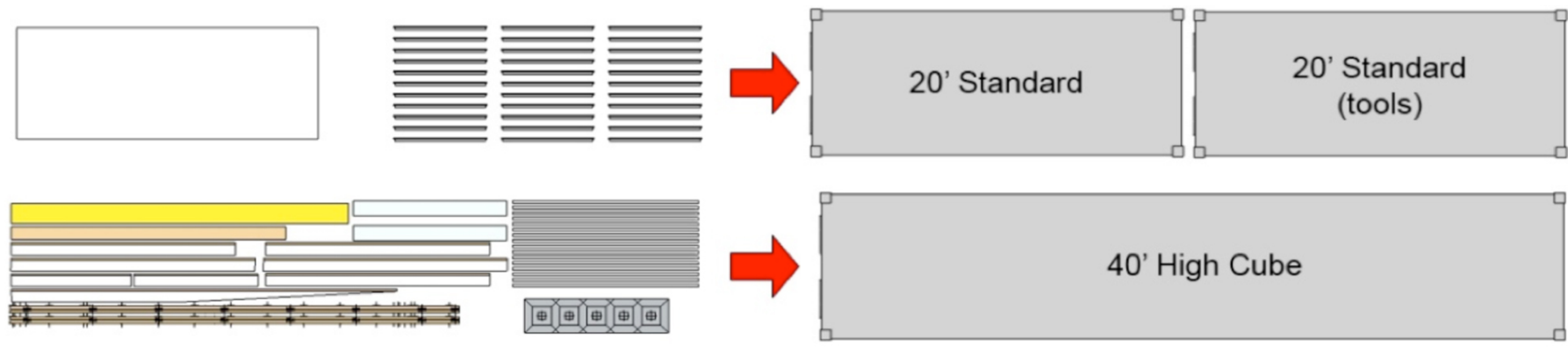

40' High Cube

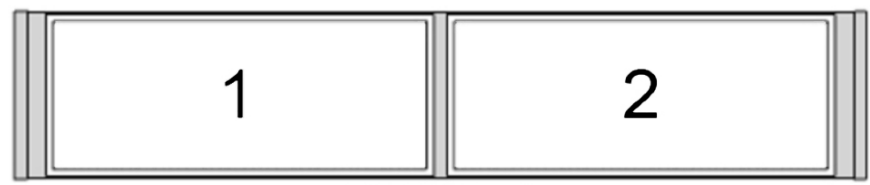

40' Flat Rack
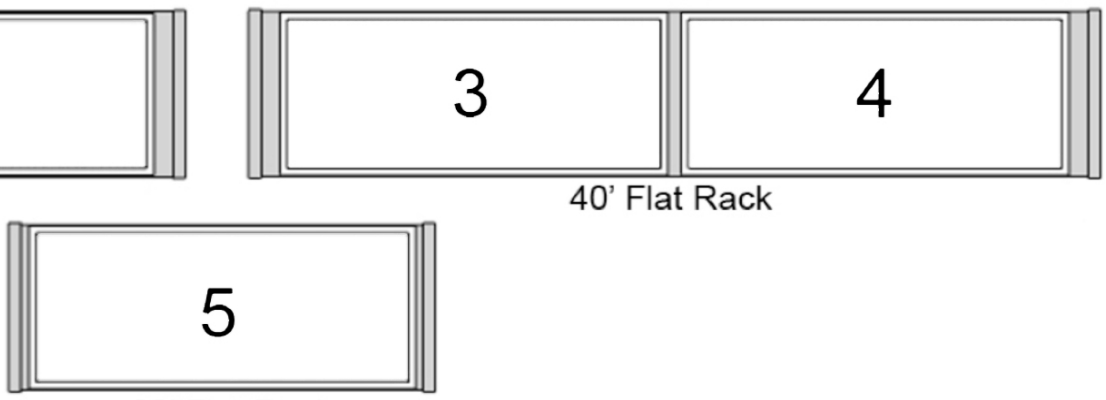

20' Flat Rack

Figure 53: Diagram Showing Total Shipping Consignment for Option 9 


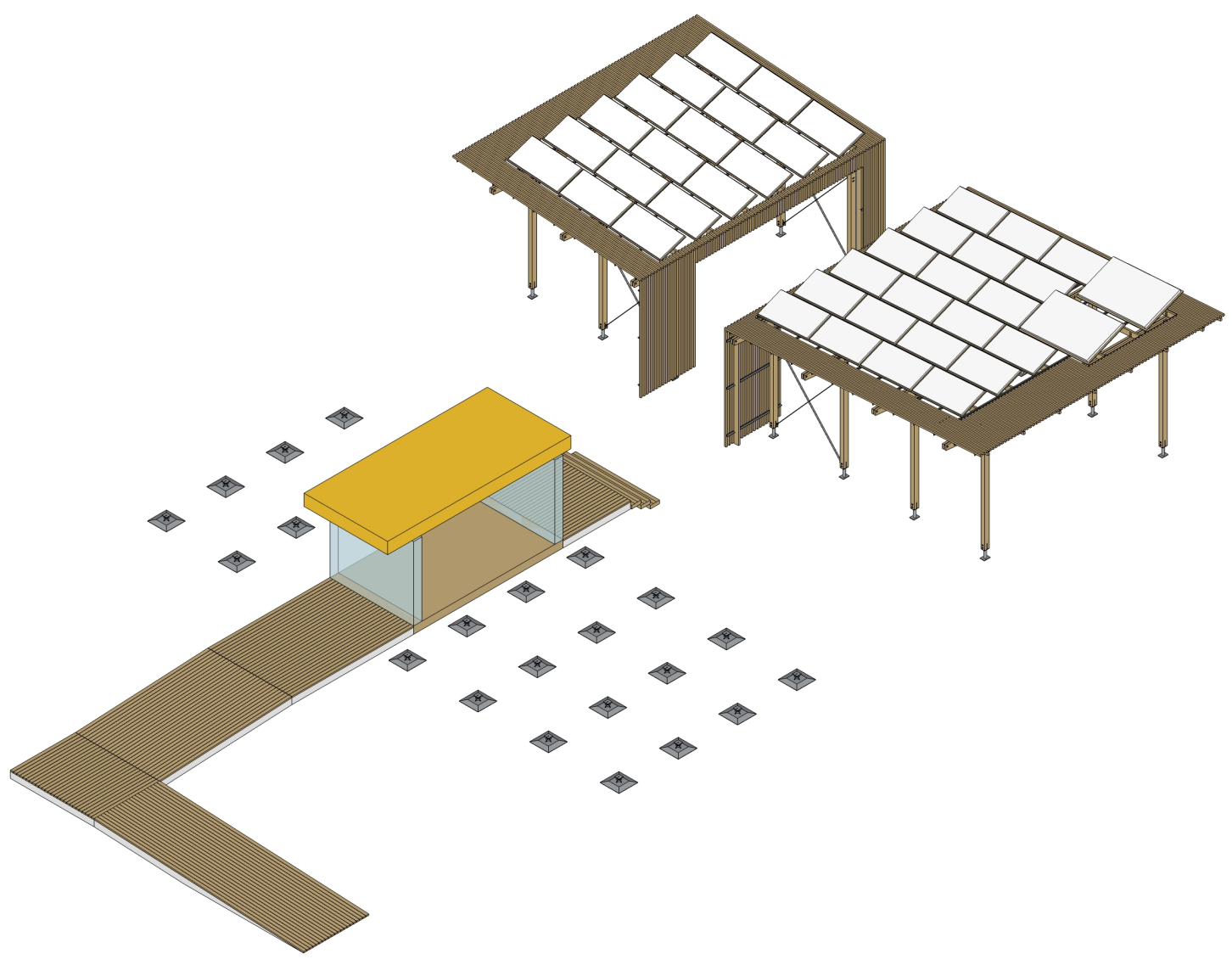

Figure 54: 3D Diagram Showing Flat Packed Components

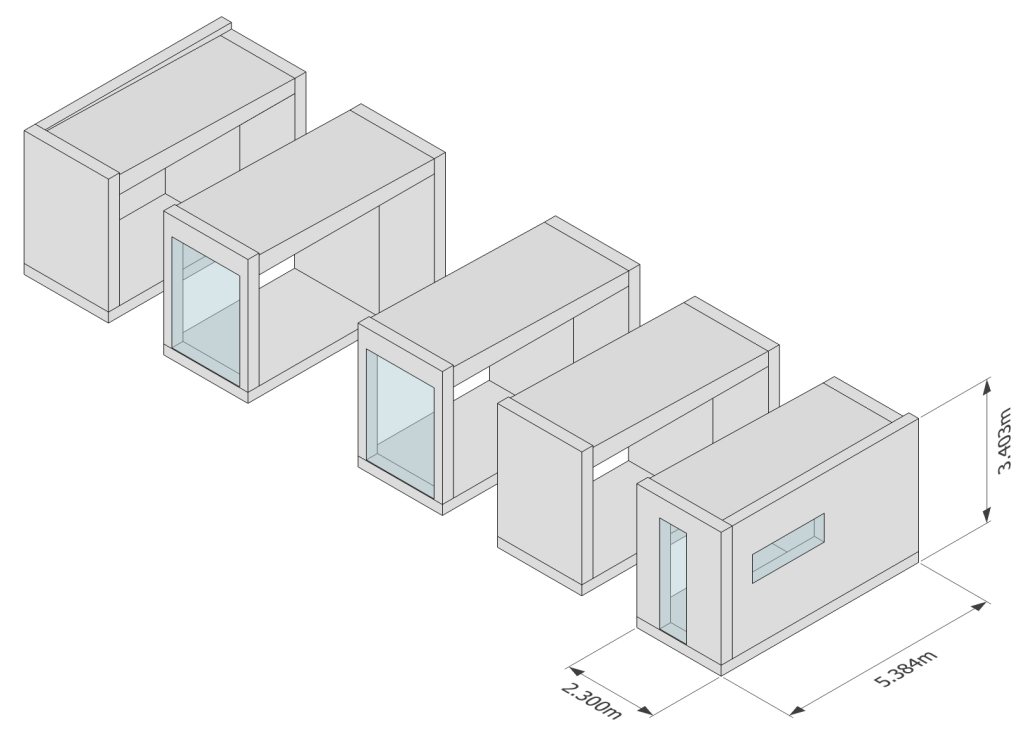

Figure 55: 3D Diagram Showing Maximum Module Dimensions 


\section{FOUNDATIONS}

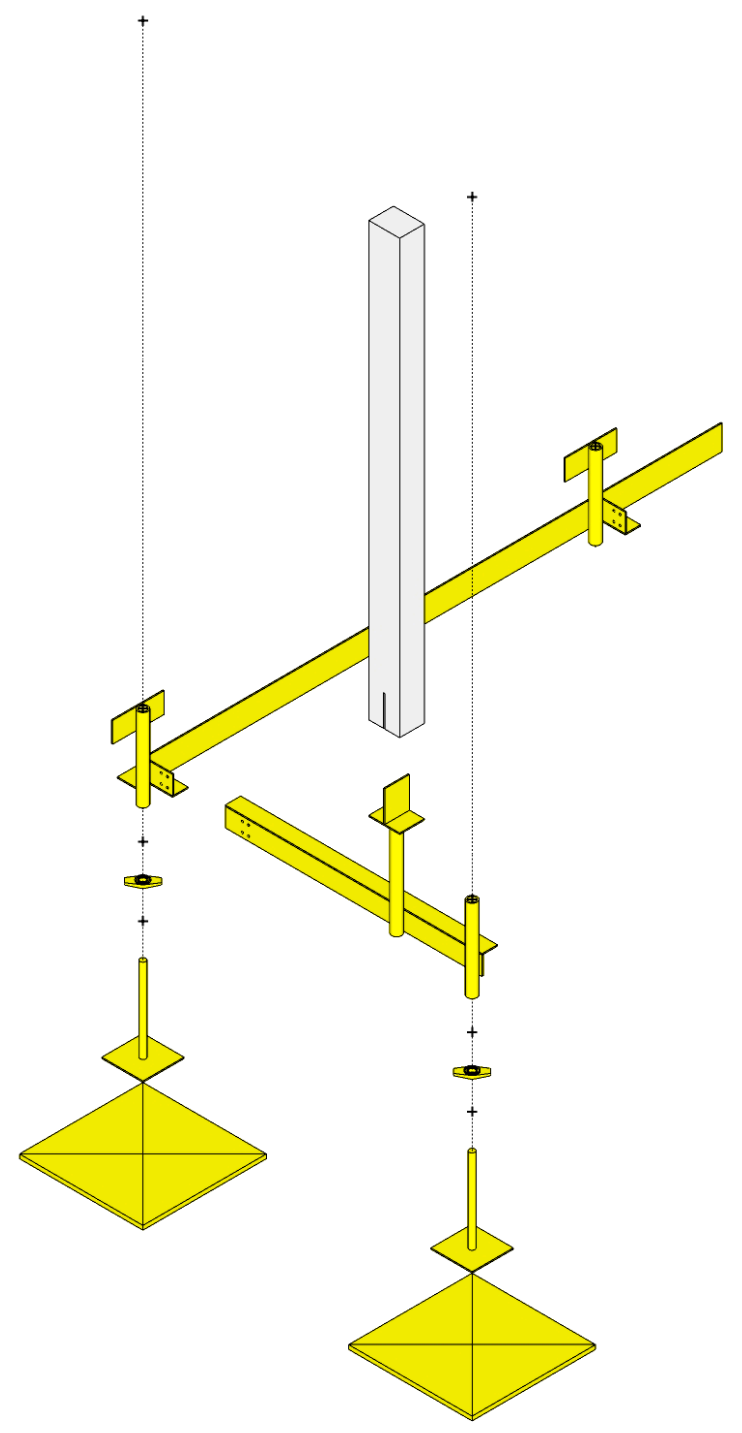

Figure 56: Foundation Components - Exploded Assembly 
Design criteria for the foundations were largely based on structural and assembly requirements, along with the engineers specification [Figure 57]. Aesthetics were important but only with the objective to conceal the foundations from sight. The foundations accounted for a critical structural component of the house and would be pivotal in terms of the assembly process, hence costs featured as a much lower priority.

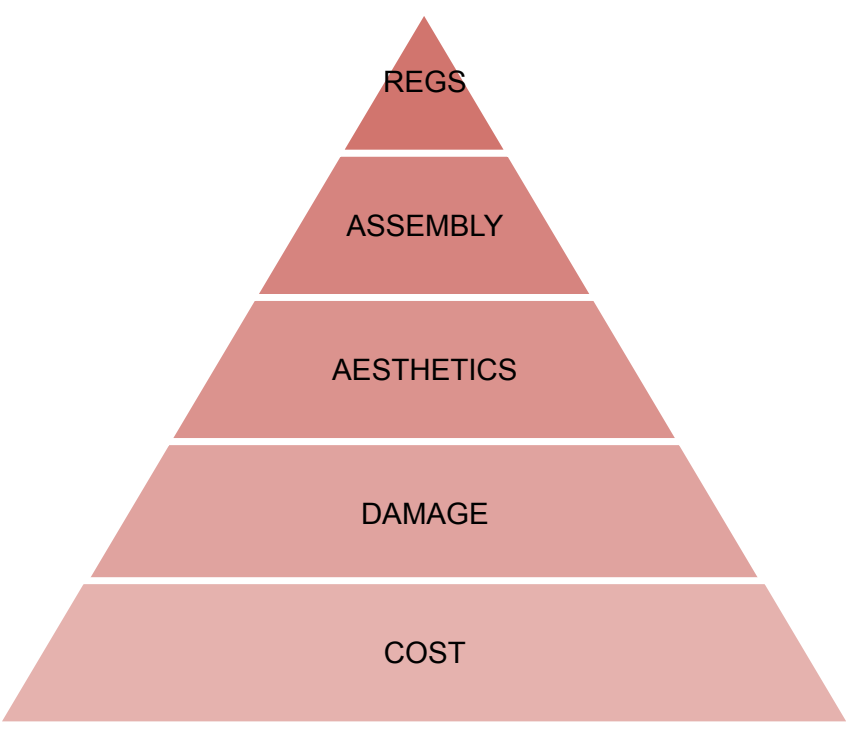

Figure 57: Decision Making Hierarchy - Foundations to $457 \mathrm{~mm}$ of penetration. Additionally, a degree of adjustability of $457 \mathrm{~mm}$ had to be built into the foundations to allow for potential elevation changes at West Potomac Park. The foundations would also have to provide support to the columns of the canopy.

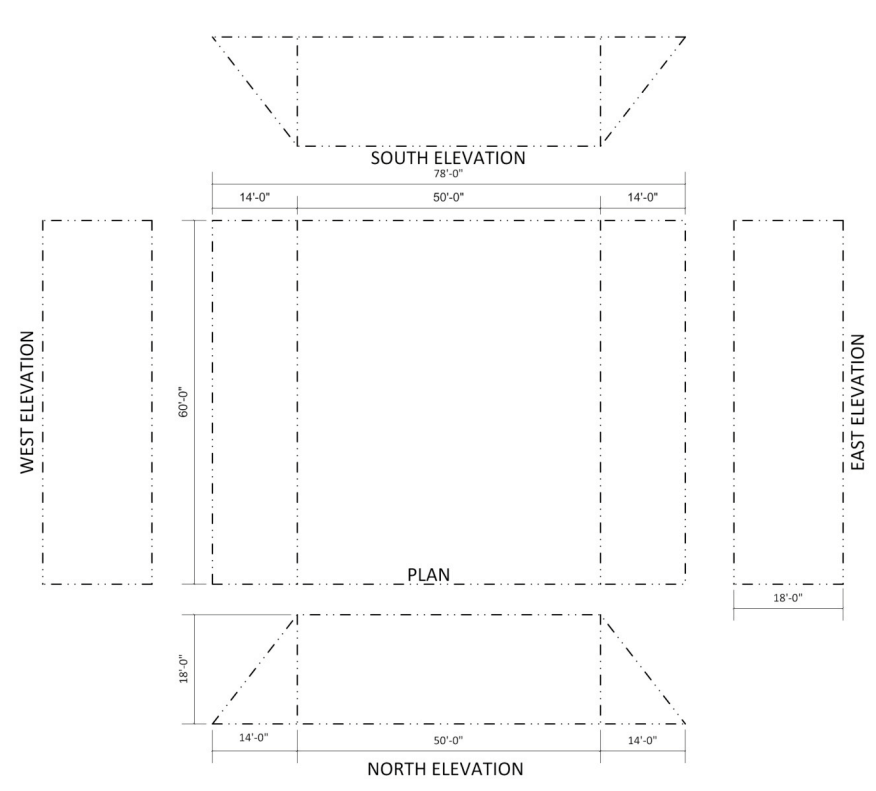

Figure 58: Solar Envelope Dimensions - SD 2011 Rules

\subsection{DETAILING}

The foundations were proposed to run in 'tracks' enabling access for a forklift in-between to place each module [Figure 59]. The benefit of using a forklift in this instance, is that the modules can be pushed along the tracks until a tight fit is achieved. Locating 'pegs' could be used to ensure the accurate realignment of the modules as they came together, like Lego. Some difficulty may be experienced in setting out the foundations as it is critical that they remain level, parallel and stable during module placement. There was a risk that in bad weather the repeated movement of the forklift would cause major damage to the ground between the foundations. Temporary ground protection could be used to mitigate this problem. 

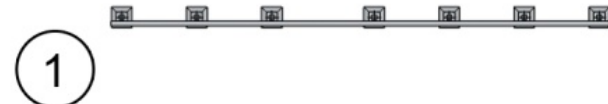

1
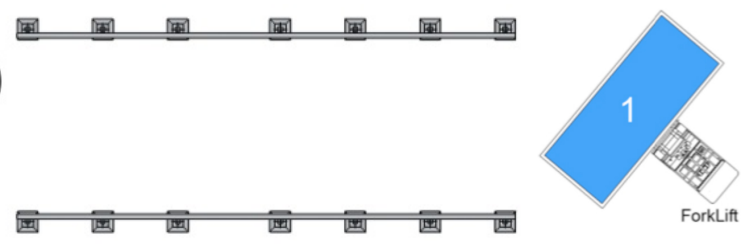

(2)

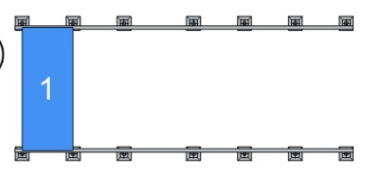

(3)

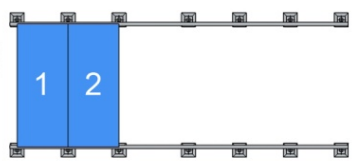

(4)

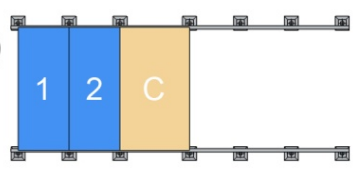

(5)

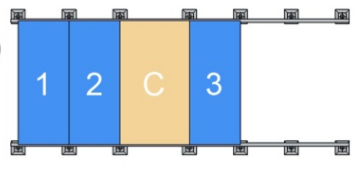

(6)

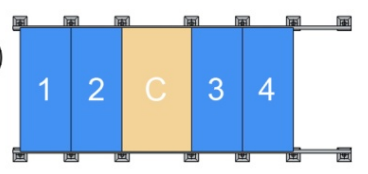

(7)

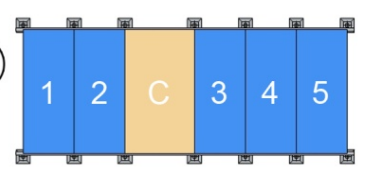

Figure 59: Diagram Showing Foundation 'Tracks' and Assembly Sequence

The locating of the foundations at the perimeter of the house created an additional and significant advantage to assembly; The adjusting mechanism could be made accessible without requiring access underneath the house [Figure 60]. This enabled minor adjustments to the foundations to be made quickly, easily, and even after the modules had been placed. It also meant that the height of the modules above ground could be significantly reduced. With the use of a steel equal angle, the modules were even further lowered to within only $160 \mathrm{~mm}$ above ground [Figure 61 \& Figure 62]. Standard adjustable scaffold screw footings were used to achieve the required adjustability and steel 'outriggers' provided support to the canopy columns.

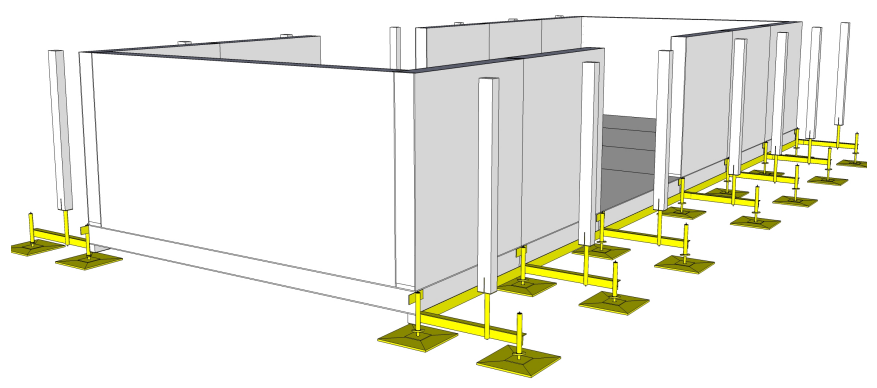

Figure 60: Foundation 'Tracks' at Perimeter of House

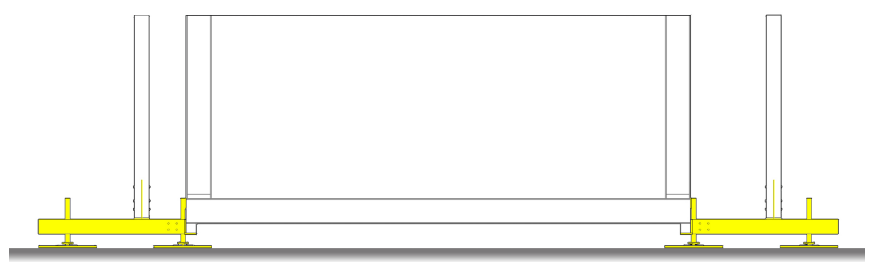

Figure 61: Perimeter Foundation Tracks - Elevation Showing Lowered Building Height

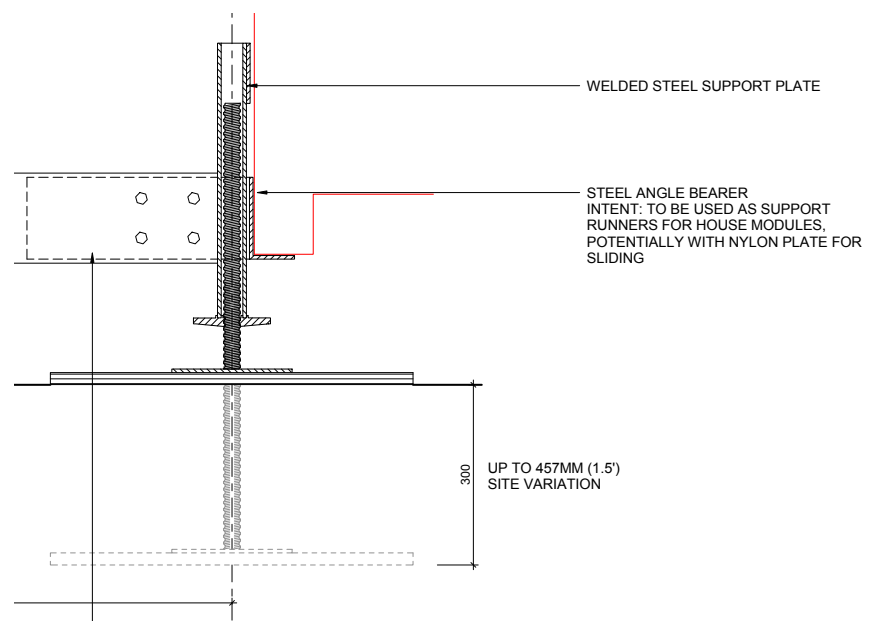

Figure 62: Foundation Detail-Adjustable Scaffold Screw Footing 


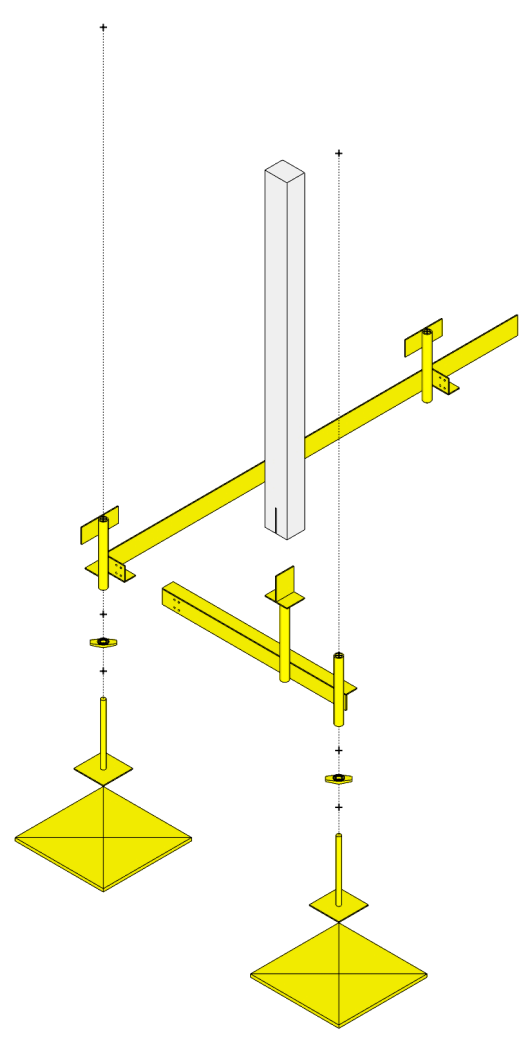

Figure 63: Foundation Components - Exploded Assembly

It was initially intended that the steel foundation components would be compartmentalised and bolted together during assembly [Figure 63]. This would make things easy to handle on site by hand, but more importantly would make for an economic packaging of the components into standard shipping containers. Unfortunately there would have been too much 'slop' in the bolted connection between the outrigger and the bearer. As a result this joint was to be permanently welded, neccesitating a different approach to packaging. To maintain a level of compartmentalisation, each foundation 'track' was divided into three sections [Figure 64]. The sections were then connected during assembly with a bolted splice, designed to preserve a smooth internal edge for sliding the modules along [Figure $65 \&$ Figure 66].

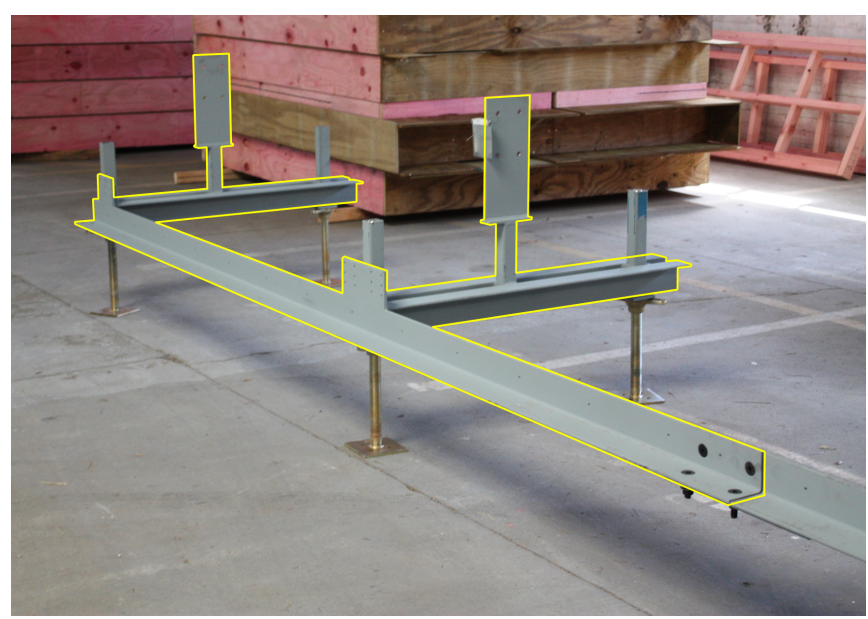

Figure 64: Construction Photo Showing Foundation Section

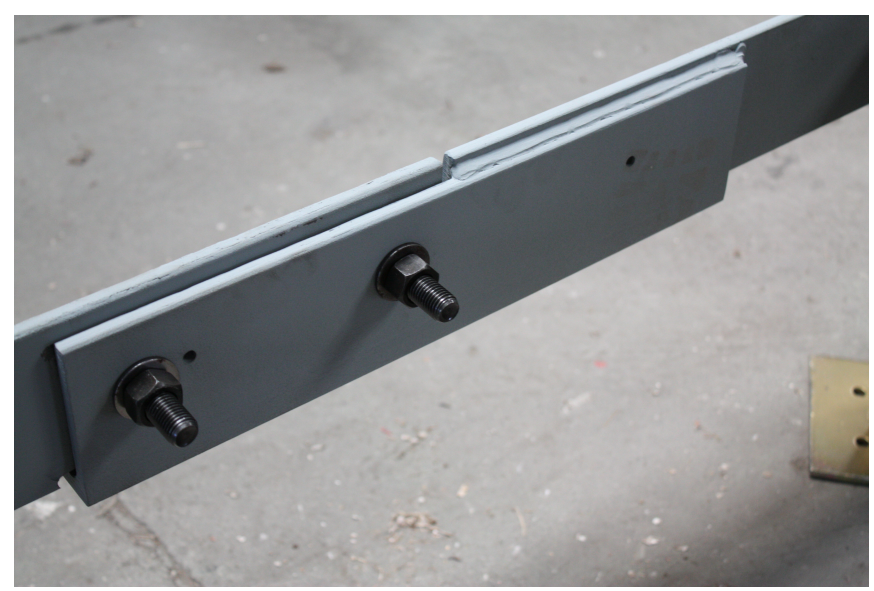

Figure 65: Construction Photo Showing Bolted Foundation Splice

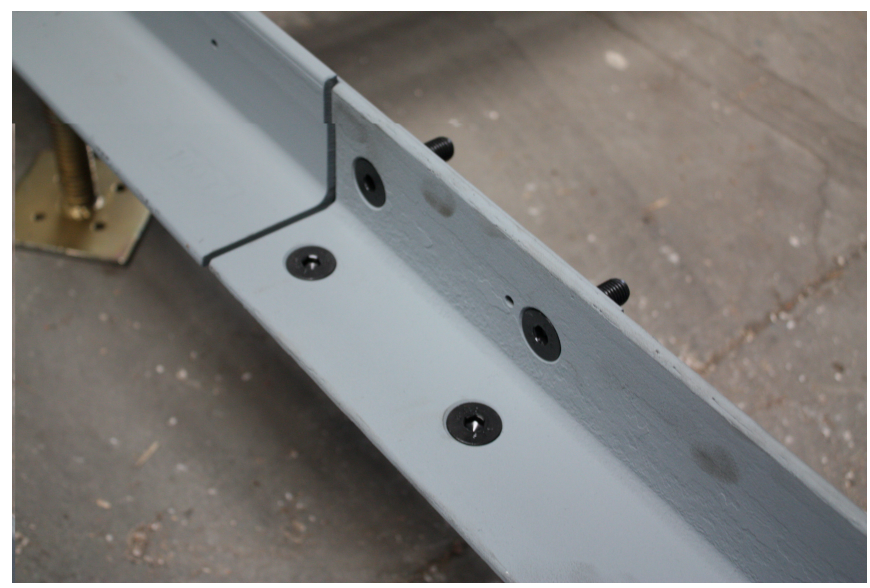

Figure 66: Construction Photo Showing Smooth Internal Edge of Foundation Splice 


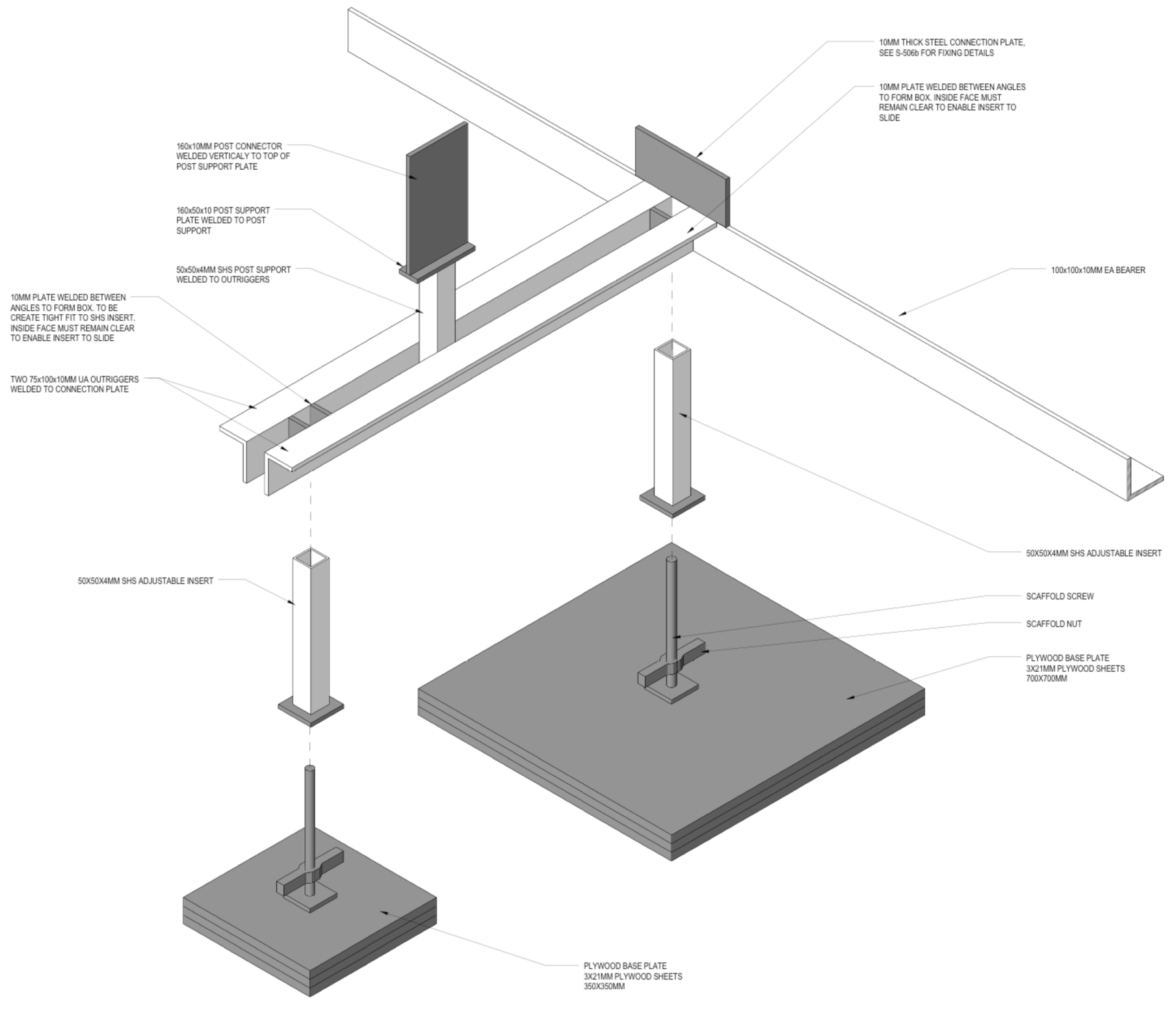

Figure 67: Foundations - Exploded Assembly Detail 
Other minor changes were seen in the engineer's final design to optimise the solution [Figure 67 \& Figure 68]. These included using a SHS sleeve as opposed to scaffold tubing for better strength and to form a tight fit with the outriggers. Additional sleeves were installed as necessary to achieve the correct height with the screw footing providing the final $150 \mathrm{~mm}$ of adjustability [Figure 69]. The screw footing and sleeve components closest to the house were concealed from sight within the cladding cavity [Figure 70].

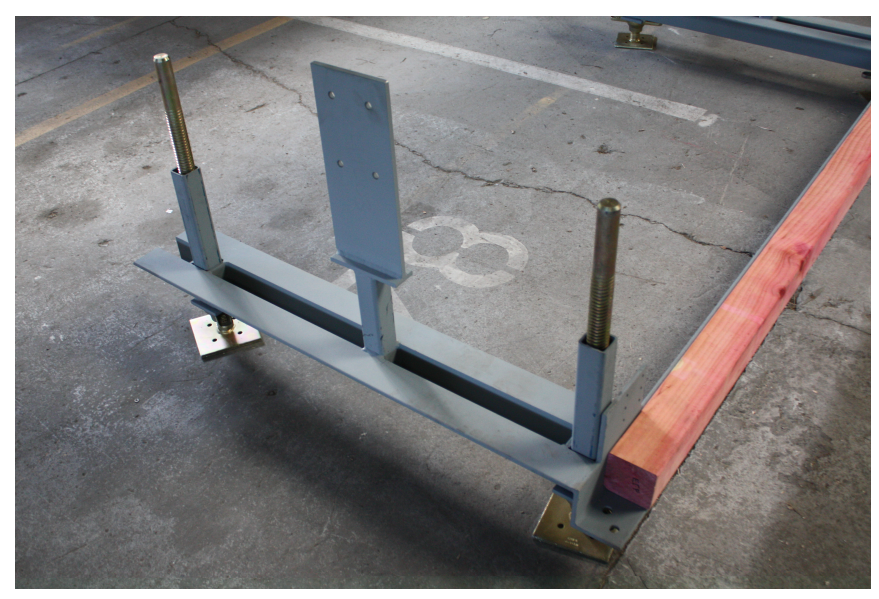

Figure 68: Construction Photo Showing Assembled Foundation

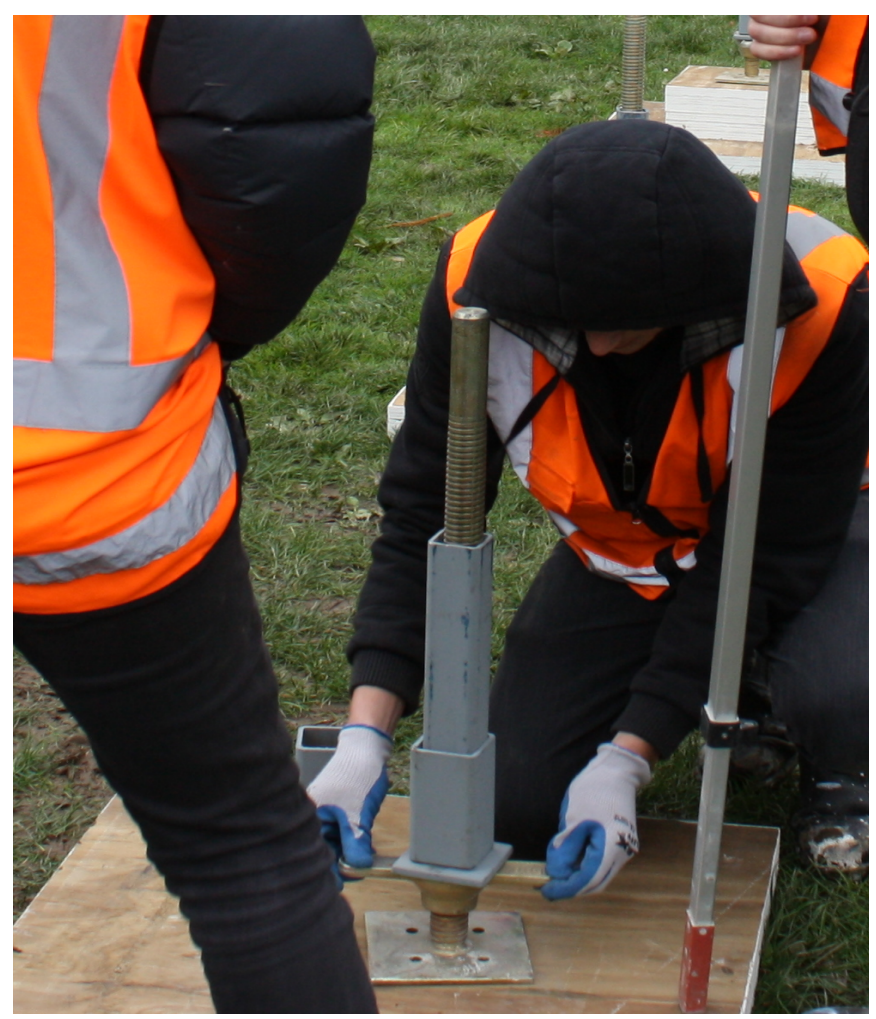

Figure 69: Frank Kitts Park (FKP) Assembly Photo Showing Adjustable Screw Footings and Spacer Sleeves

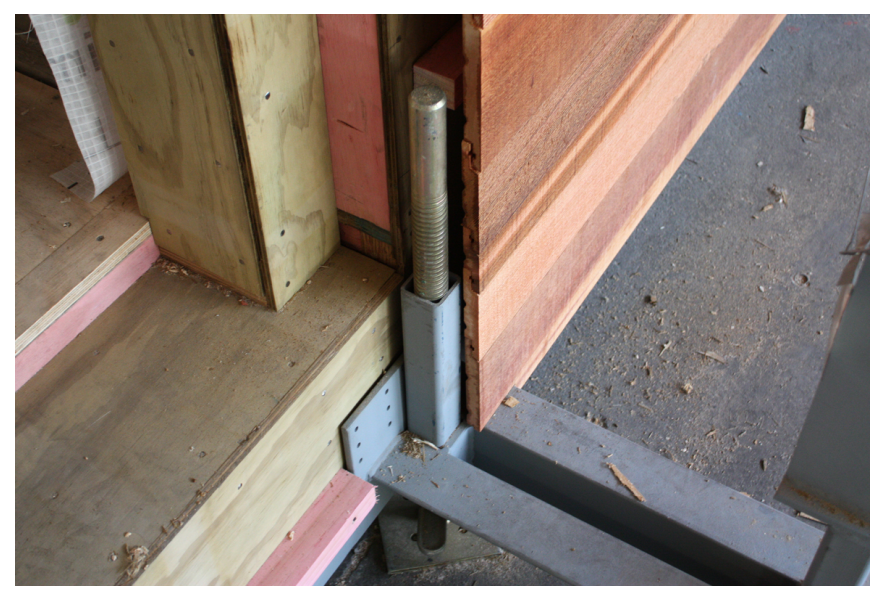

Figure 70: Construction Photo Showing Concealed Adjustable Foundation Components

A welded plate is incorporated on top of the angle bearer to help resist the rotational forces which are caused by the module sitting outside the line of the footing [Figure $71 \&$ Figure 72]. This method relies on the very close fit of the house module between the two steel angle foundation bearers. Tek screws are specified to ensure a strong connection between the module and the foundation. Some tolerance however had to be provided to allow the modules to be dropped in place. This tolerance, coupled with the large weight of the modules, forced the outriggers to still incur a notable degree of rotation. Figure 73 Illustrates the rotational effect on the outrigger and column. The end of the outrigger is essentially cantilevered, sitting approx. $30 \mathrm{~mm}$ above the foundation support sleeve. This results in a signifant misalignment of the column which is forced to lean in towards the house. Figure 73 is not the worst example of the problem with the most pronounced rotation occuring at module 5 . This is likely due to the additional end wall increasing the overall weight of the module.

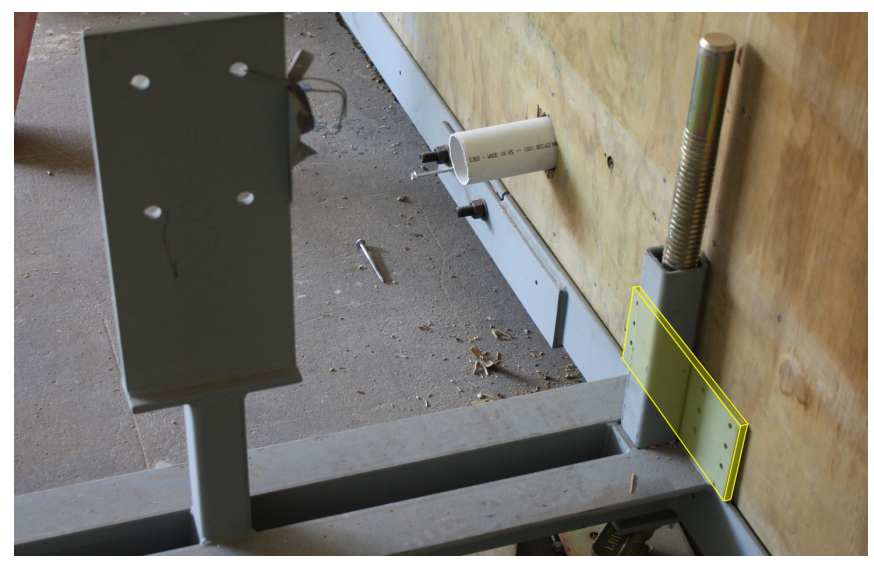

Figure 71: Construction Photo Showing Welded Plate 


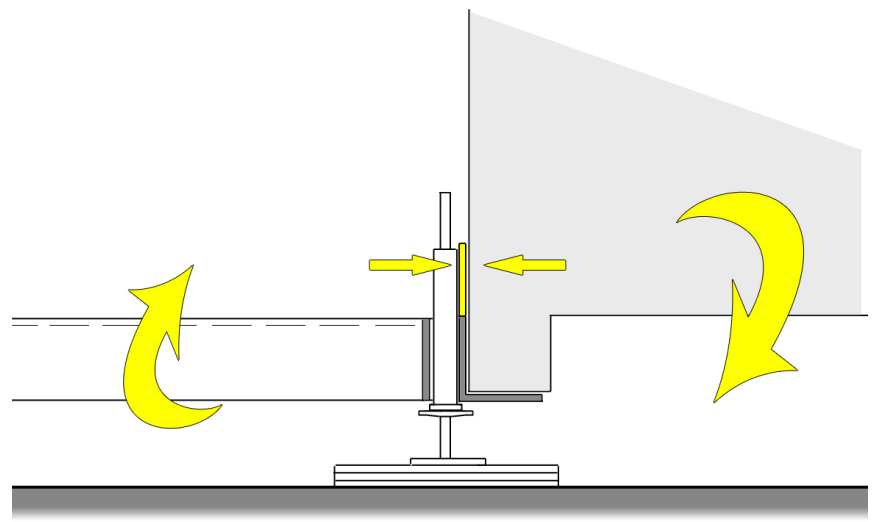

Figure 72: Diagram Showing Potential Foundation Rotation

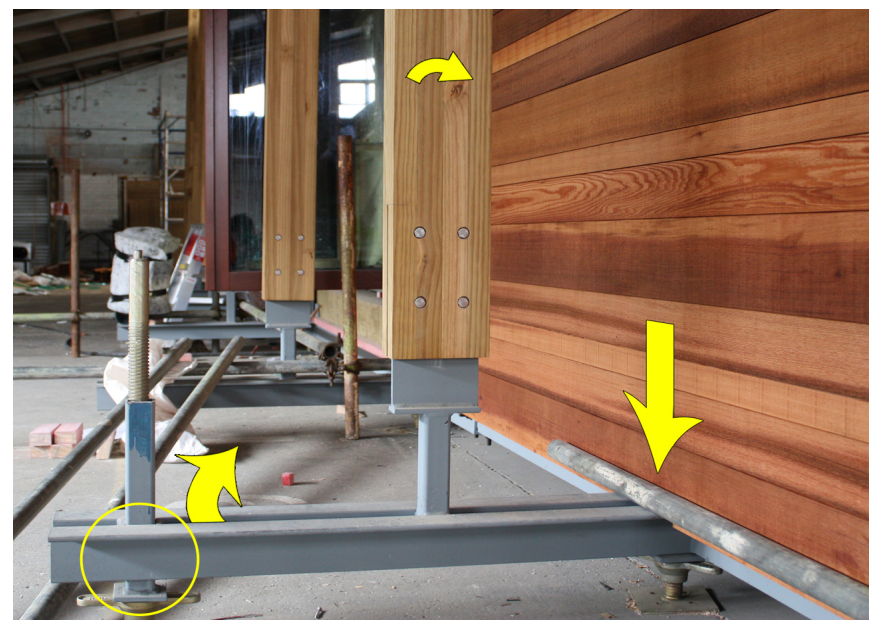

Figure 73: Construction Photo Showing Outrigger and Column Rotation

It was found that the outrigger could be lowered with the weight of one person jumping on the end of it. For this reason it was anticipated that the weight of the canopy, once assembled, would offset the rotation all together. This rotation did however need to be negated during construction to enable the accurate fabrication of the canopy. A threaded rod was chem-set into the concrete floor of the warehouse between the outrigger angles to act as an anchor [Figure 74]. A plate and wingnut were then used to force the outrigger down until it was level and rested firmly on the scaffold footing sleeve. The wingnuts were released upon the completion of the canopy. Although most of the outrigger rotation was counteracted by the weight of the canopy, it was still preferable to prevent the rotation during assembly, before the bulk of the canopy was in place. To achieve this, timber wedges were inserted between the module and the steel foundation plate [Figure 75]. This method worked well resulting in level outriggers and plumb columns.

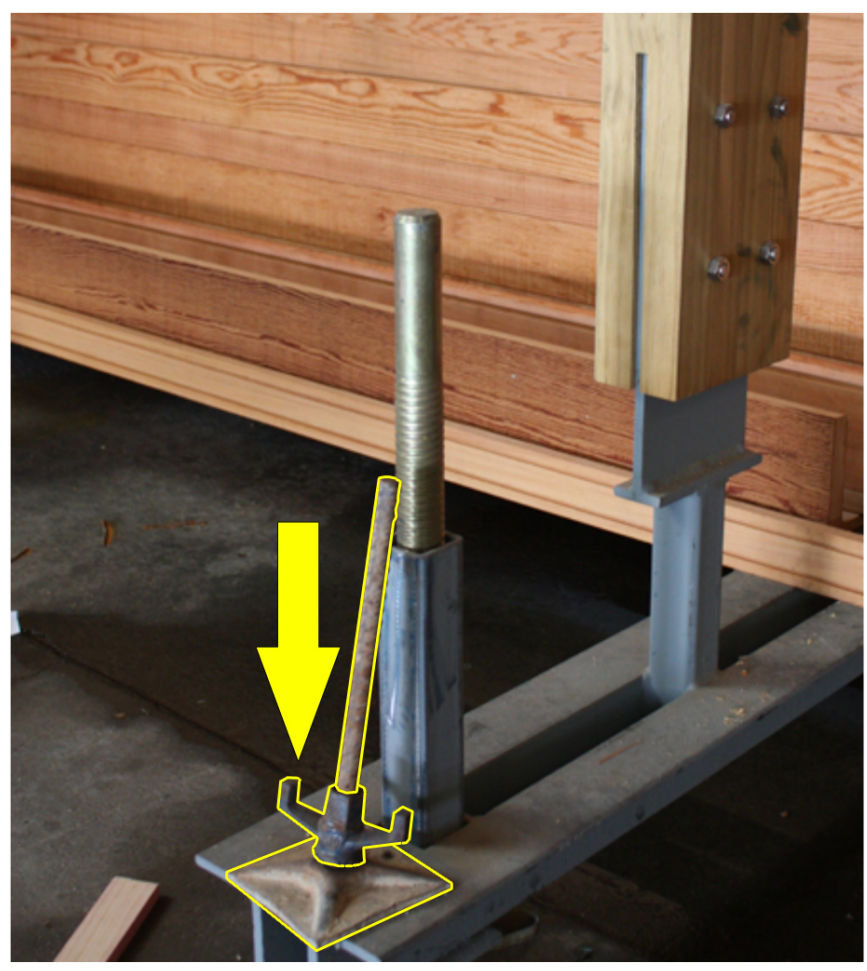

Figure 74: Construction Photo Showing Chem.-Set Threaded Rod Anchor

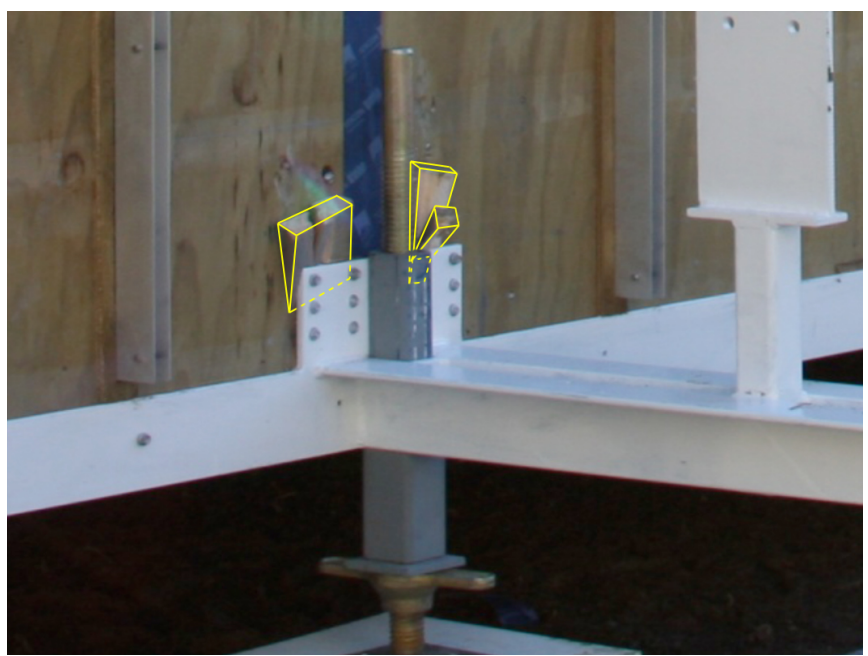

Figure 75: FKP Assembly Photo Showing Timber Wedges

Each scaffold foot is supported by a $3 x$ laminated $21 \mathrm{~mm}$ plywood baseplate [Figure 76 \& Figure 77]. These are designed to a dimension sufficient to meet the SD Building Code in terms of soil bearing pressure. During the competition these baseplates were dramatically deformed under the weight of the house, causing some of the footings to sink up to $30 \mathrm{~mm}$. No noticeable deformation occurred during the practice assembly at Frank Kitts Park (FKP). It is thought that the deformation was due to the very poor and uneven ground on West Potomac Park. Poor site conditions, combined with 
periods of rain, likely caused some areas beneath the baseplate to sink more than others. As a result, the baseplates were only fully supported in certain areas causing them to bend in areas of no support. As the baseplates are hidden from sight by landscaping elements, this problem was not realised until disassembly. The sinking of the footings likely contributed to the earlier problems with module alignment and the extreme forces exerted on the tension cable tie as described later in Chapter 5.5.5 Assembly.point

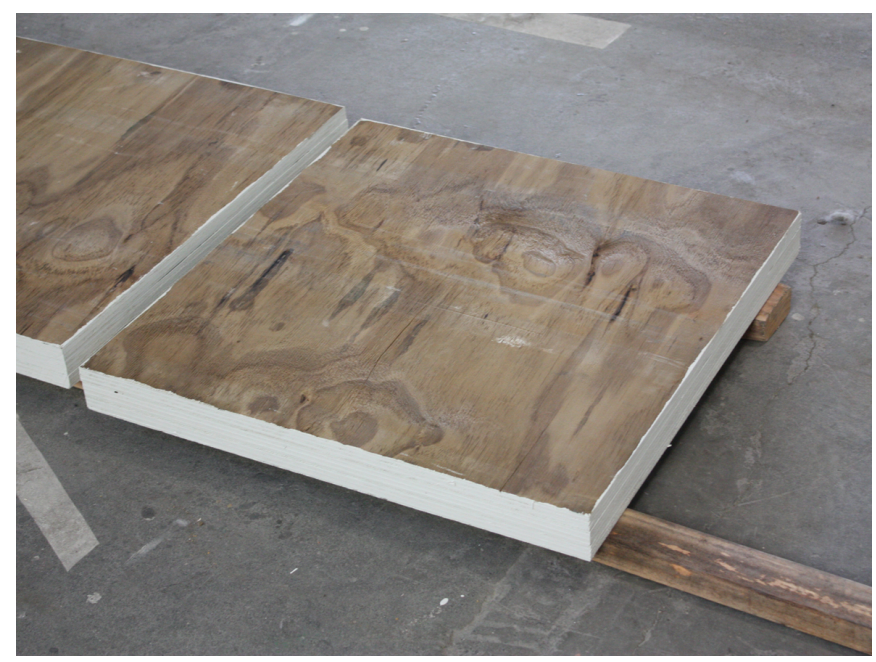

Figure 76: Construction Photo - Laminated Plywood Base-plate

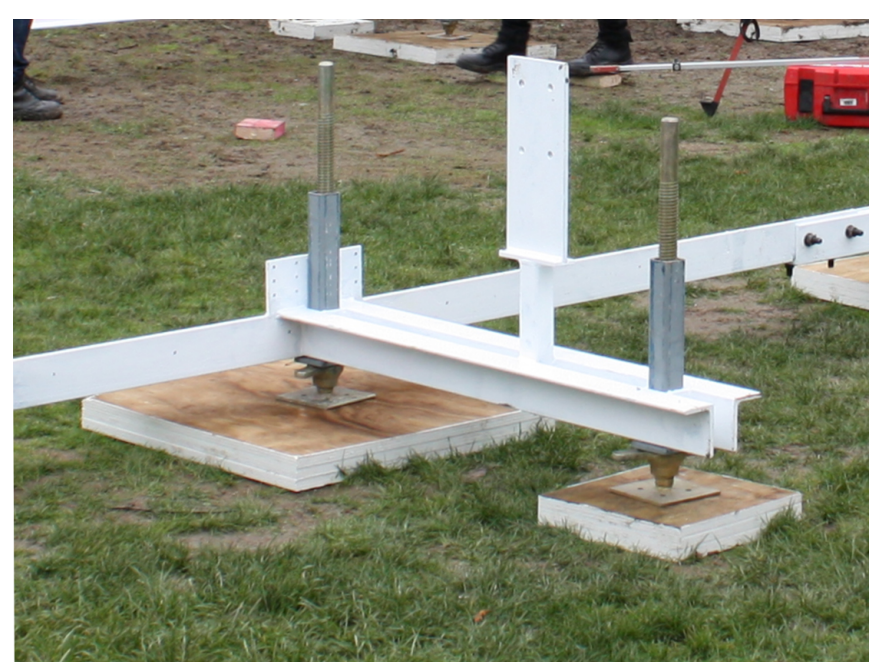

Figure 77: FKP Assembly Photo Showing Foundation Baseplates

\subsection{ASSEMBLY}

Detailed instruction documents were prepared for the assembly of the foundations. The first step was to lay the plywood baseplates out [Figure 78]. The accurate placement of the foundaitons relative to the site boundary was critical since the house is designed to the full extent of this boundary.

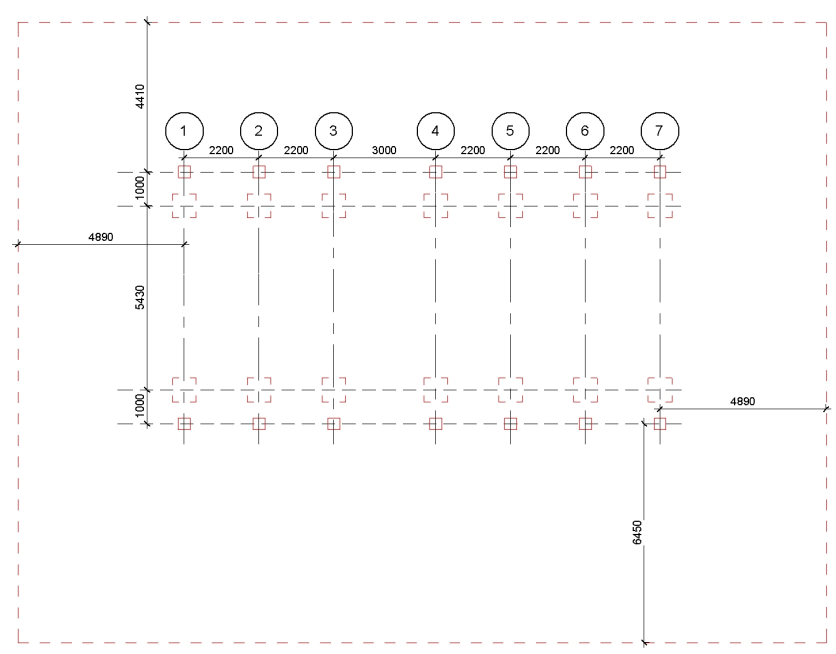

Figure 78: Assembly Drawing - Foundation Base-plate Layout

The larger foundation components were placed at their approximate locations with a hiab crane [Figure 79]. The scaffold screw footings and sleeves were inserted and the completed sections were then manually aligned on the baseplates and bolted together at the splices [Figure 80]. Through the use of laser levels, rulers, stringlines, and tapemeasures, an accurate location, height and parallel separation of the foundations was achieved [Figure 81]. Any excess scaffold footing thread protruding through the sleeve at the outrigger foot is then trimmed. This allows the decking to sit above the footing thread concealing it from view. 


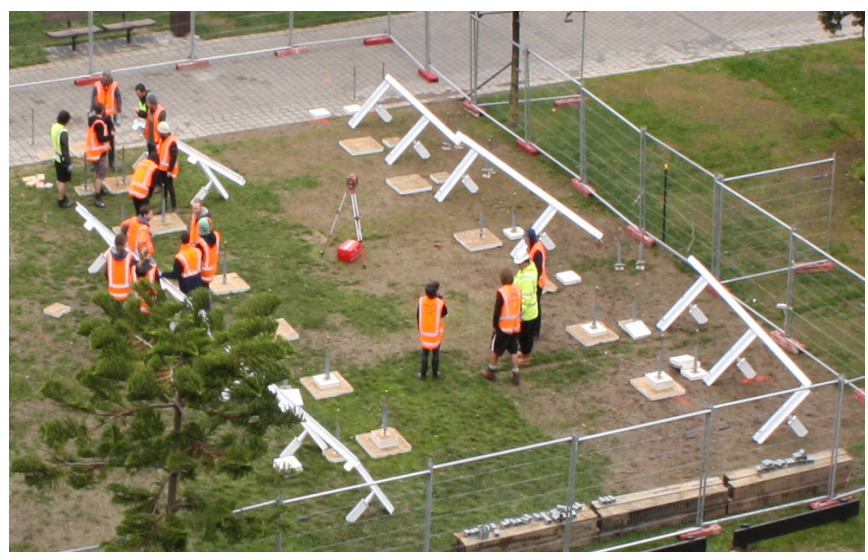

Figure 79: FKP Assembly Photo - Foundations Laid at Approximate Locations

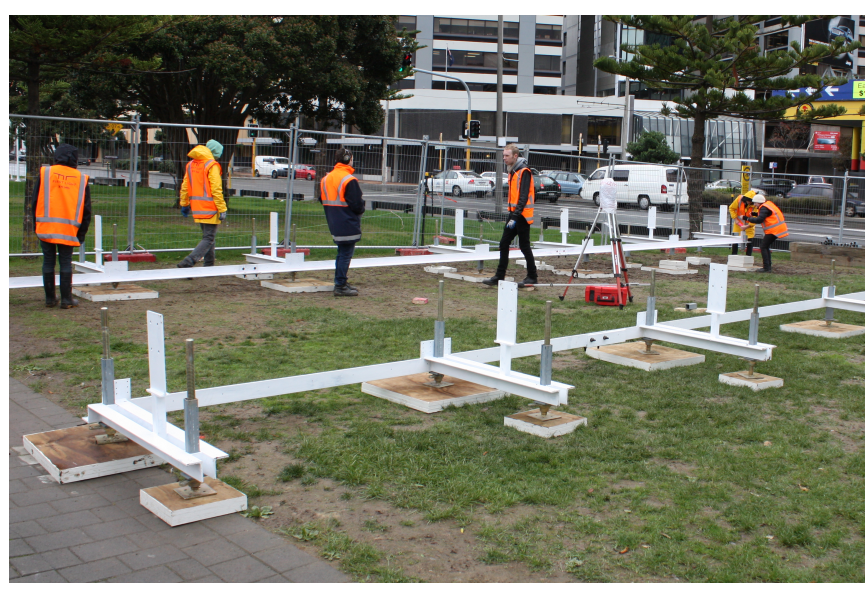

Figure 80: FKP Assembly Photo - Foundations Set

FOUNDATION ANGLE 2

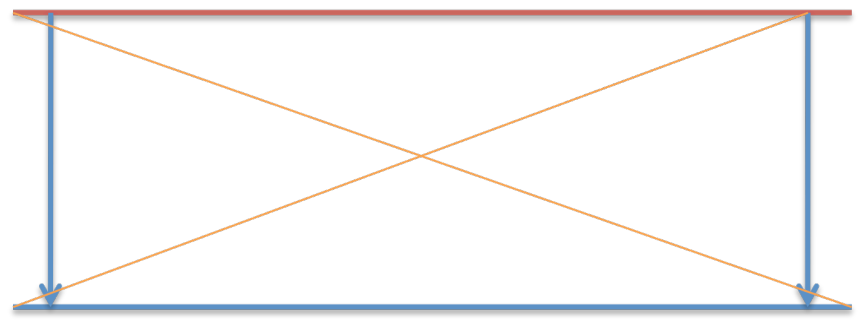

FOUNDATION ANGLE 1

Figure 81: Assembly Drawing - Foundation Alignment Using Triangulation

It was ultimately decided that a crane would provide the fastest and most accurate means of module placement [Figure 82]. Although each module has at least one permanent longitudinal wall to resist racking, additional timber framing is installed to improve strength [Figure 83]. The modules are delivered to site on alternating double drop-deck 'lowboy' trailers (to meet land transport height restrictions). They are then stropped and lifted off the trailer into place on the foundations [Figure 84]. A spreader bar is utilised to prevent the strops from damaging the roof panel. Each module is placed $200-$ $400 \mathrm{~mm}$ away from the adjacent module and then hydraulically jacked across until a tight fit is achieved [Figure 85 \& Figure 86]. 2x Portapower 10T Hydraulic Rams are fixed to each steel foundation bearer [Figure 87]. The module is then jacked along the foundation evenly with additional timber blocks used to lengthen the ram as needed. Some minor adjusting of the screw footings was required to achieve a parallel and tight fit between the modules on all four edges.

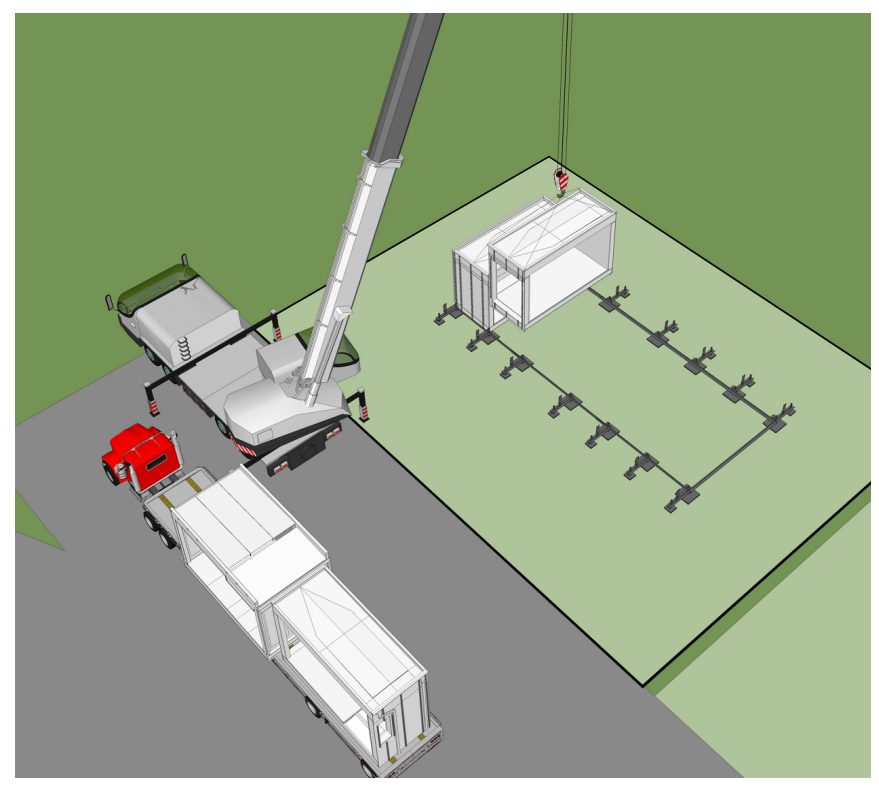

Figure 82: Assembly Drawing Showing Module Placement Using Crane (BL)

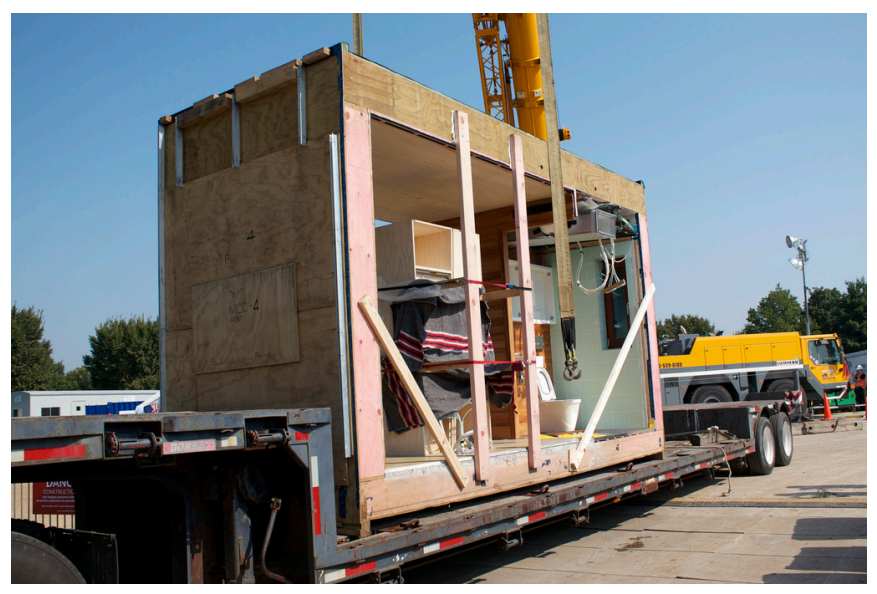

Figure 83: SD Assembly Photo Showing Module Bracing and 'Lowboy' Trailer 


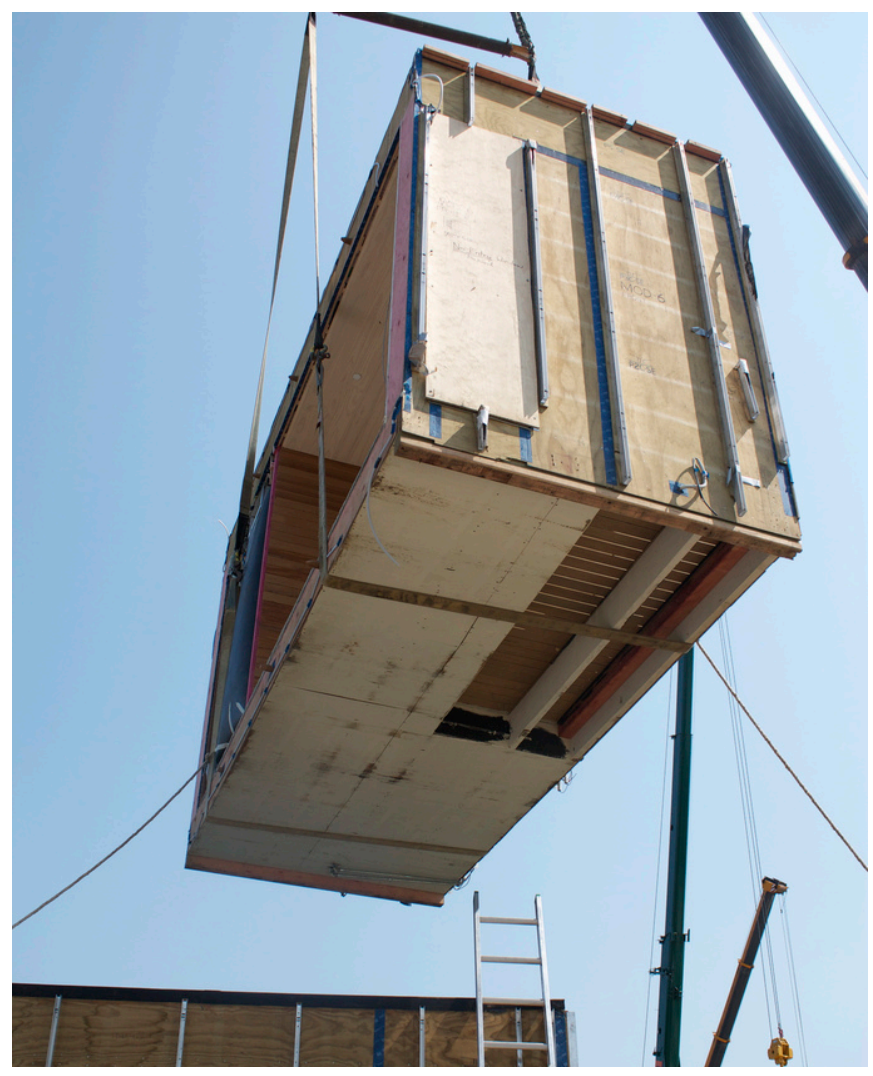

Figure 84: SD Assembly Photo Showing Stropping and Lifting of the Shed Module

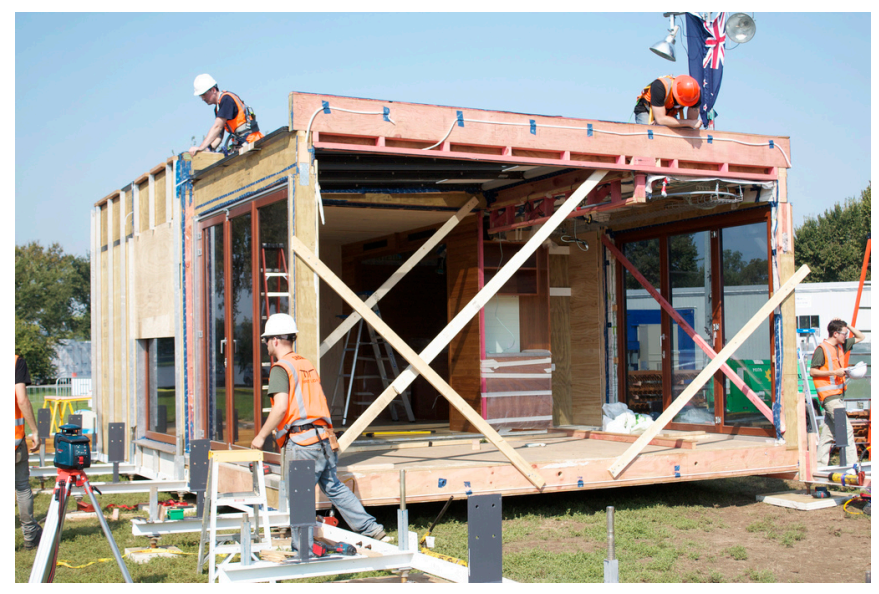

Figure 85: SD Assembly Photo Showing Module Three Placed on Foundations

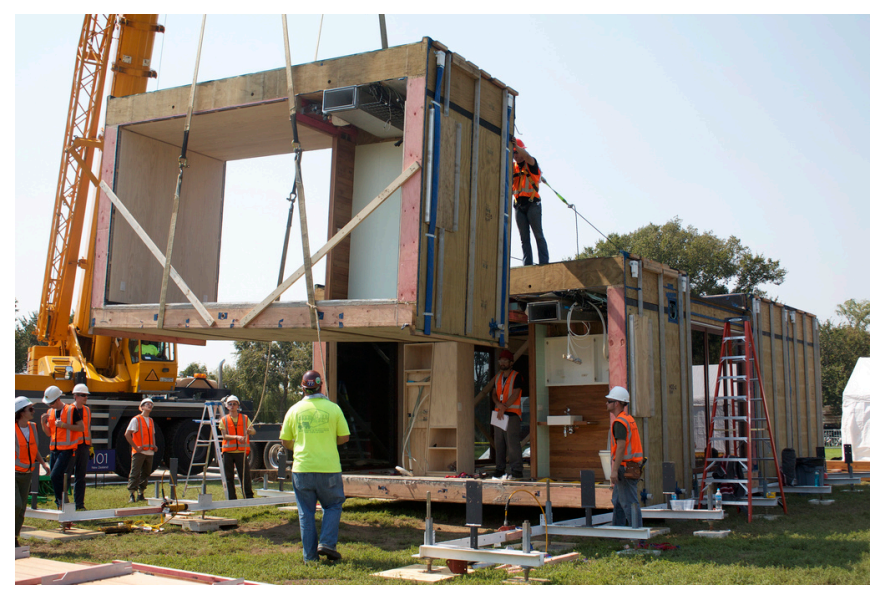

Figure 86: SD Assembly Photo Showing Module Five Being Placed on Foundations

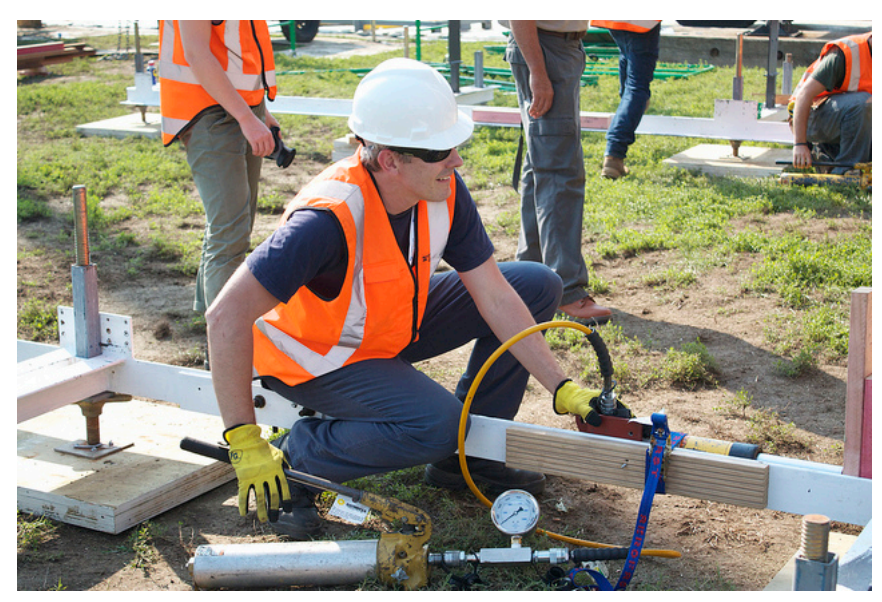

Figure 87: SD Assembly Photo Showing Hydraulic Power Ram Used to Move Modules 


\section{MODULE CONSTRUCTION}

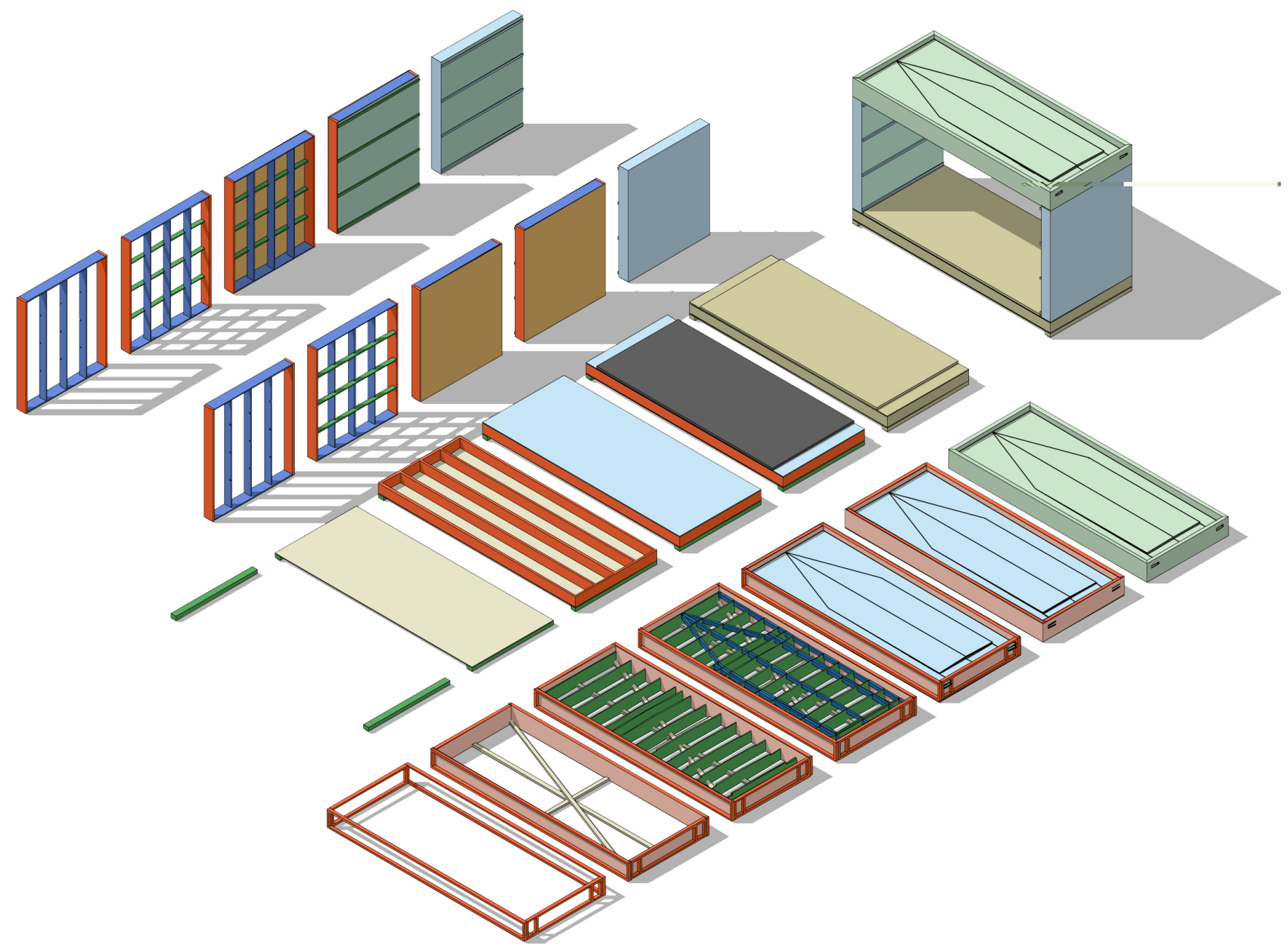

Figure 88: Overview of Prefabricated Module Components (JM) 


\section{MODULE \\ CONSTRUCTION}

\subsection{OVERVIEW}

With the method of transportation firmly locked in, detailed development of module construction could proceed. The development of construction details had to be an ongoing and cyclical process, juggling many different factors at once. A set of principles similar to those considered for transport drove the investigation into construction techniques. For the modules however an emphasis would be placed more heavily on performance. Figure 89 Below illustrates the hierarchy of criteria surrounding module construction with insulation and thermal bridging featuring as high priorities. Time remained one of the driving considerations throughout the remainder of the project impacting on each of the decision making criteria.

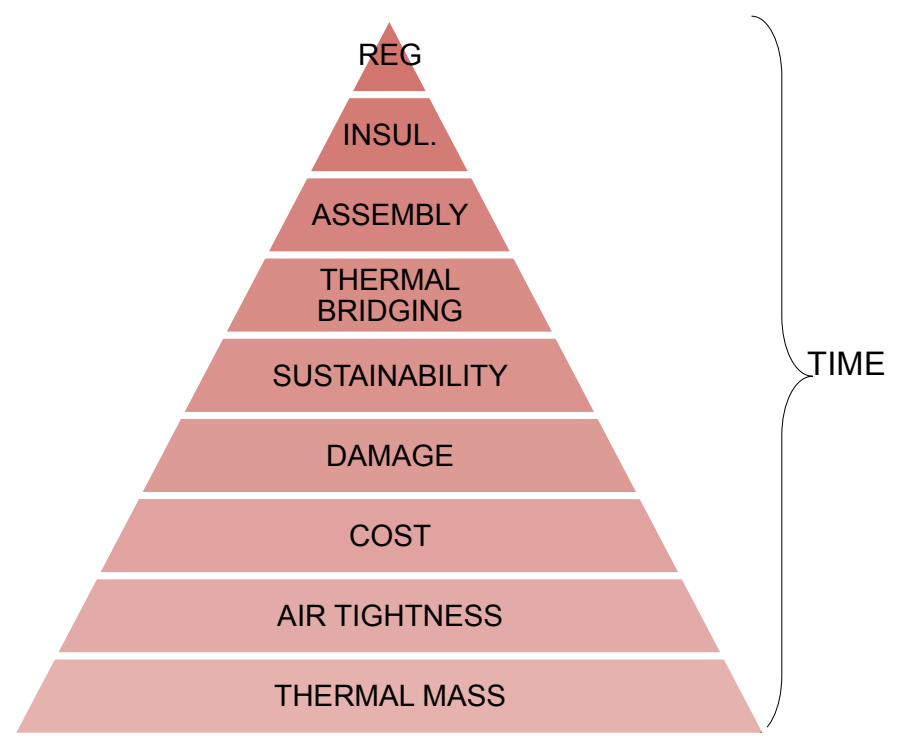

Figure 89: Decision Making Hierarchy - Module Construction

\subsubsection{Regulations}

The competition demanded a level of regulatory compliance over and above the typical construction of most houses in New Zealand. The house would have to meet the requirements of; the New Zealand Building Code, the International Building Code (USA), the Solar Decathlon Building Code, Customs Authorities both in NZ and the USA, the Solar Decathlon Rules, and must also obtain a temporary building permit for exhibition on Frank Kitts Park. These factors again had to be held as a high priority for failure to meet any one of them could impair or even prevent the team's participation in the Solar Decathlon.

Regulations also cover structural and weatherproofing requirements. Structurally the modules would need to meet seismic design for Wellington as well as withstand crane and fork lift during assembly and transportation. The basic structural principle of the foundation was to provide support along the two longitudinal edges of the house [Chapter 3 FOUNDATIONS]. The floor of the modules would therefore have to span approx. $5.4 \mathrm{~m}$ across its length.

\subsubsection{Insulation}

Through research and computer simulation it was identified that an insulation value of R6.5 throughout the building envelope would be optimum. This not only presented challenges for construction detailing but also influenced the finished floor area, finished ceiling height (based on limitations for land transport), and overall building appearance.

\subsubsection{Assembly}

The easy, fast, and successful reassembly of the house in Washington DC remained a top priority throughout the developed design phase. Construction had to not only be thought through in detail it also had to be thought through in reverse. The aim was to have the house transported in as close to its final state as possible. This would be achieved by limiting the number of removable components and simplifying the means by which they get put back together. The methods of assembly would also directly affect the overall appearance of the house. Attention had to be paid to the selection of materials and the degree of tolerance that would need to be built in to any connection details.

\subsubsection{Thermal Bridging}

The transfer of energy through a building is dependent on the conductivity of the materials which make up its envelope. By reducing the amount of continuous conductive materials that cross the envelope, i.e. structure, the thermal performance of the envelope can be greatly improved (Ward, 2006). This is an important and 
sometimes overlooked consideration and one that was explored comprehensively in the details of the First Light house.

\subsubsection{Sustainability}

The issue of sustainability and whether one approach is more 'sustainable' than the other is a complicated one and a question that would require extensive research to answer. First Light as a project and as a brand valued the objectives of sustainability even beyond the direct criteria of the competition. The competition approaches sustainability very much from an energy use perspective as opposed to a material selection one. For this reason, along with the lack of time to research objective information on the environmental impacts of construction materials, it was not possible to pursue the "sustainability" of considered options to their full conclusion. As was the case with many decisions throughout the project a selection would have to be made based on the best consideration of the information available. Sustainability would affect this decision but only in so far as the quality of the information that could be obtained.

The Solar Decathlon also raises many questions around its own intrinsic environmental impact. Is it truly sustainable to be sending a house and a team of students half way around the world to assemble a house for a 10 day showcase? The short answer is yes. The slightly more elaborate answer is that the awareness that the project raises along with advancing energy efficient technologies will make a positive environmental impact in the long term.

Interestingly, due to the criteria involved with the market appeal contest, great value was placed on the public perception of the "sustainableness" of the house. To this end, it was almost more important to sell the sustainable story as opposed to making the story sustainable. Of course this raises ethical questions around the whole design process. It was agreed that the team's best efforts would be made in selecting sustainably responsible materials and products and that an honest approach to the publicising of these decisions would be taken. It was also felt that the biggest contribution the project could make towards the issue of sustainability is in the research outcomes that it could generate. To this end an independent evaluation of the environmental impact of the house was sought. PE International came on board offering to undertake a Life Cycle Assessment (LCA) of the house.

\subsubsection{Damage}

The robustness of connection details and the durability of materials had to be carefully considered. This house would need to survive through three assemblies, trucking, and two ocean voyages. The house must not only be robust but must also enable a degree of flexibility and allow for fine tuning to be performed once reassembled.

The decision had concurrently been made to use a cladding system that could be removed for transport and 'clipped-on' during assembly. This meant that the modules did not have to be concerned with any cosmetic exterior damage that may be inflicted during transport and/or assembly.

\subsubsection{Cost}

Costs were predominantly considered in relation to the affordability contest, as opposed to the actual costs incurred in New Zealand. It was believed that construction materials would be easily procured through sponsorship due to the obvious marketing opportunities generated by the project. This was especially true for those products which are typically used in residential construction and that would be visible to the specifier. In comparison to the overall project, construction costs only accounted for a moderate amount of the total budget. In terms of a competition strategy it made sense to invest value in the house and cut costs elsewhere if need be.

The affordability contest challenges teams to build for $\$ 250,000$ or less; however the biggest impact on points would only occur should construction costs exceed US\$350,000 as shown in Figure 90.

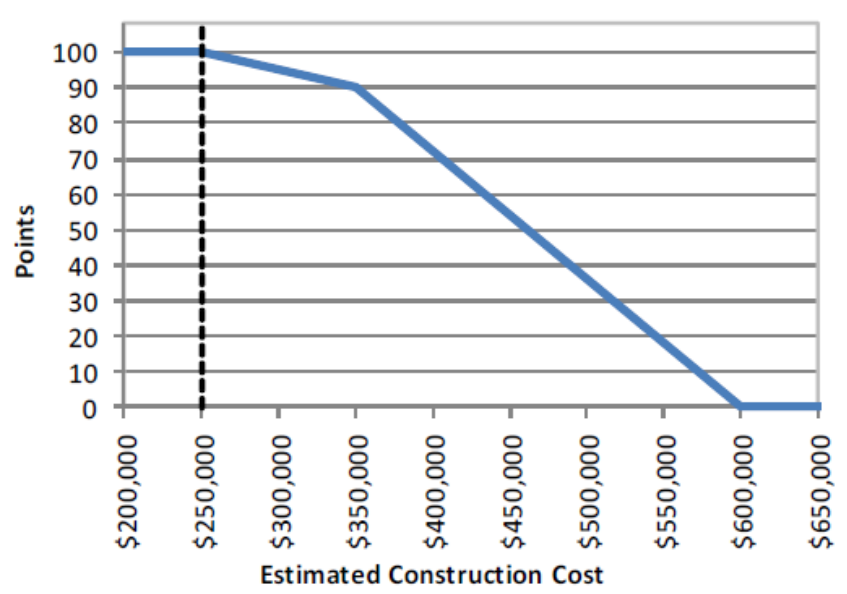

Figure 90: The weighted effect of construction cost on points scored in the Affordability contest (SDRules2011) 
The strategy was taken to aim for a construction cost of $\leq$ US $\$ 350,000$. When compared to the competition target of US $\$ 250,000$, it was believed that at the expense of 10 points (1\% overall), the project would earn many more points across the other 9 contests by investing the extra US $\$ 100,000$. The affordability contest would judge houses based on a US construction market, this put an emphasis on costing building materials and products as if purchased in the USA as opposed to local rates.

\subsubsection{Air Tightness}

There are four main factors which influence the thermal environment:

1. Air Temperature

2. Mean Radiant Temperature

3. Relative Humidity

4. Air Velocity

Thermal comfort is the combination of these four factors in relation to human activity and clothing level. When thermal comfort is reached occupants neither feel too hot nor too cold. This is known as the body heat balance, where body heat production (metabolic rate) $=$ heat loss or gain by evaporation, radiation, and convection (Race, 2006).

The Solar Decathlon contest, Thermal Comfort, excludes any radiant effects assessesing the indoor air temperature and relative humidity only. It is therefore critical that the infiltration of air through the envelope be controlled to prevent any changes in the internal air temperature and/or relative humidity. This control would consequently ensure the most efficient use of energy by the mechanical heating and cooling system.

\subsubsection{Thermal Mass}

Through extensive computer simulations it was ascertained that a component of thermal mass equivalent to $50 \mathrm{~mm}$ of concrete should be incorporated within the exposed floor area of each module. This would provide the minimum amount of thermal mass needed to stabilise diurnal swings in air temperature likely to be experienced during the ten days in Washington DC (Jagersma, 2012). It was predicted that some difficulty might be found with using thermal mass and therefore it did not feature as highly on the list of priorities. These difficulties included the risk of cracking with a material such as concrete, especially when undergoing the stresses of transport, the significant additional weight that it would add to the house, as well as the limited influence that it might have in the judging of the thermal comfort contest (Jagersma, 2012).

\subsection{SIPS}

Wide research led to the consideration of SIPs (Structurally Insulated Panels) for the construction of the house modules. SIPs are comprised of rigid foam insulation with either an OSB (Oriented Strand Board) or metal skin on either side [Figure 91]. SIPs would excel in almost all of the performance based criteria identified above.

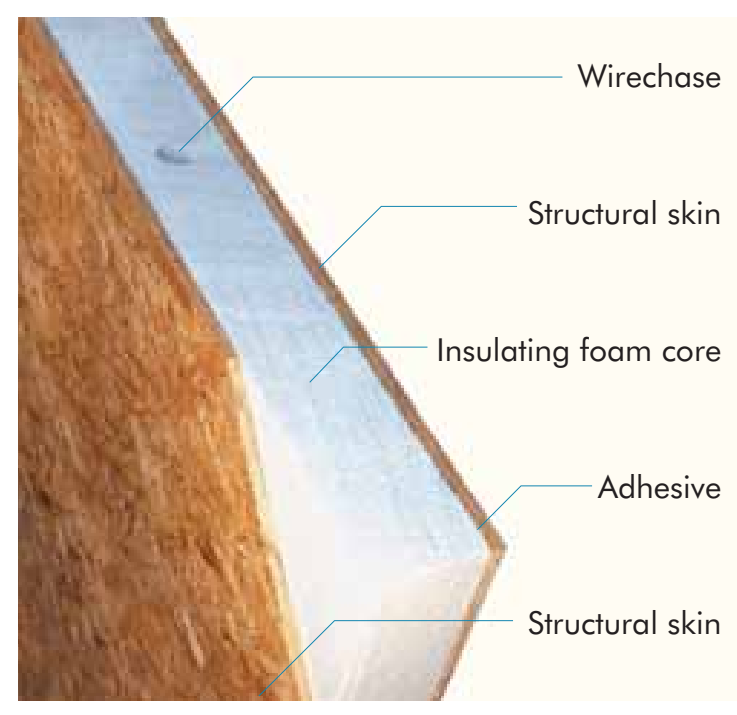

Figure 91: Diagram Showing Main Components of a SIP (SIPA, 2007)

\subsubsection{Regulations}

SIPs were a relatively new technology in New Zealand and there are only limited examples of its use. Timber SIPs were not even being manufactured in New Zealand at the time and as such certification of imported panels was not available tested to NZ Standards. This presented a lot of uncertainty in terms of how the local council would approve their use. SIPs are however very widely used in the USA and it was anticipated that minimal compliance issues from a US perspective would be encountered. 


\subsubsection{Thermal Performance}

The continuous nature of the rigid insulation of SIPs provides for very high R-values relative to the panels' thickness. The standard panel thicknesses produced by RControl and their relative R-values are presented in Table 5 below:

\begin{tabular}{ccc}
$\begin{array}{c}\text { Panel } \\
\text { Thickness* }\end{array}$ & $\begin{array}{c}\text { R-Value } \\
\left(\mathbf{2 3 . 9 ^ { \circ } \mathbf { C } ) *}\right.\end{array}$ & $\begin{array}{c}\text { R-Value } \\
\left(\mathbf{4 . 4}^{\circ} \mathbf{C}\right)^{*}\end{array}$ \\
\hline $115 \mathrm{~mm}$ & 2.6 & 2.8 \\
$165 \mathrm{~mm}$ & 4.0 & 4.3 \\
$210 \mathrm{~mm}$ & 5.2 & 5.6 \\
$260 \mathrm{~mm}$ & 6.5 & 7.0 \\
$311 \mathrm{~mm}$ & 7.9 & 8.5 \\
$*$ All values have been converted from Imperial
\end{tabular}

Table 5: R-Control Panel Thickness vs. R-value (R-Control, 2008)

Because the rigid insulation acts as part of the structure, it maximises the quantity of insulation while at the same time almost entirely eliminating thermal bridging. In typical SIP construction the edges between panels can even be connected with continuous rigid insulation. Figure 92, Figure 93 \& Figure 94 illustrate the standard panel-to-panel joints (Morley, 2000).

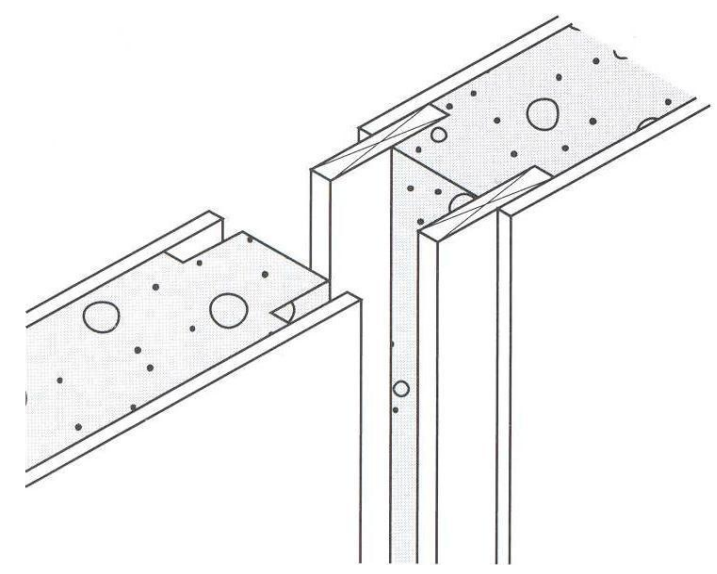

Figure 92: OSB Thin Spline Joint

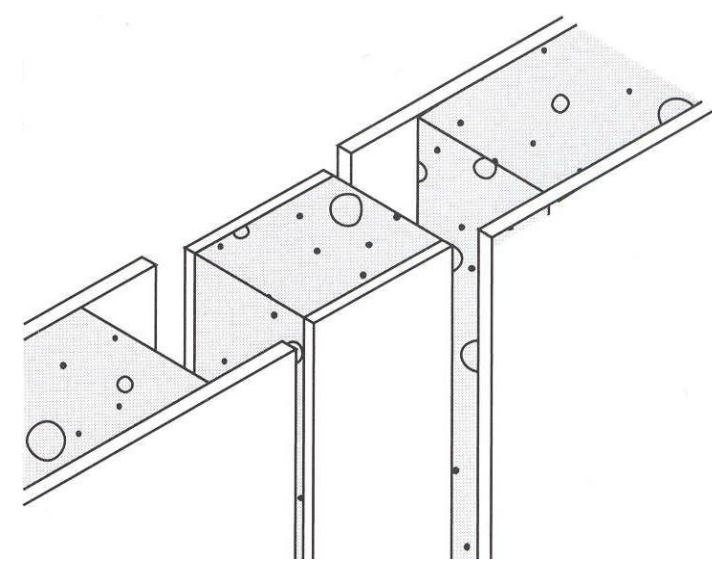

Figure 93: Mini-SIP Spline Joint

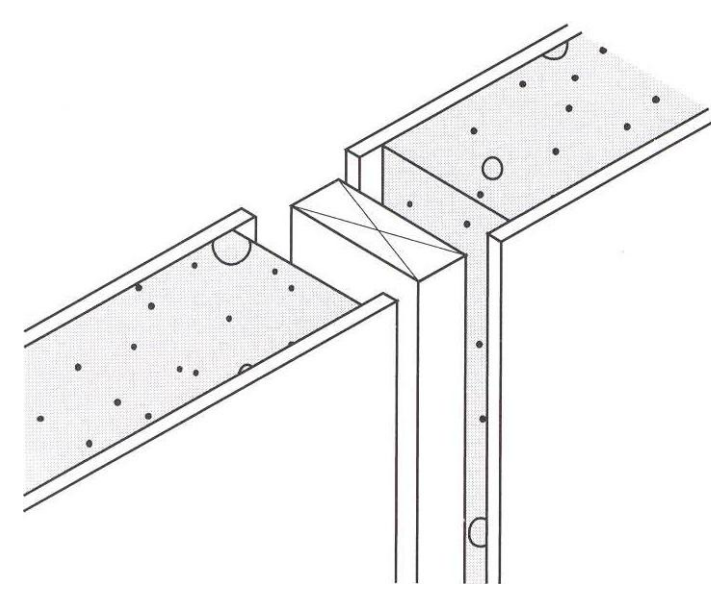

Figure 94: Dimensional Timber Spline Joint

\subsubsection{Air Tightness}

The foam and the OSB together form a rigid air barrier (RAB) creating a continuous line of air tightness around the envelope. Although this has obvious advantages for thermal performance, it also demands a high degree of ventilation control in order to manage humidity and maintain the indoor air quality.

\subsubsection{Sustainability}

Issues of sustainability were also explored. SIPs have low embodied energy at production and make use of low grade wood chips for the OSB (SIPA, 2007). The efficiency achieved during the manufacturing of SIPs dramatically reduces wastage. SIPs do however rely on the use of hazardous chemicals and glues both in the polystyrene core and the OSB sheathing (McInosh \& Harrington, 2007). The polystyrene is non-biodegradable and the OSB is essentially rendered the same by virtue of the glues that bond it together. Polystyrene may be 
recycled however this can only be taken so far with it likely ending up as disposable packaging material. Use of SIPs in this case would also incur a lot of "carbon miles" due to the importation of the panels.

\subsubsection{Damage}

The vulnerability to damage of SIPs is minimal due to the continuous layer of OSB on either side of the panel. There are however limitations on the types of internal linings that can be used in order to achieve the required fire rating. Due to the synthetic nature of the rigid insulation and the glues used in the OSB, SIPs are particularly resistant to the absorption of moisture and therefore any dimensional changes due to humidity. The OSB does however need to be fully protected from direct contact with water as it is prone to swelling under full immersion. This raised some questions as to its appropriateness for use as a substrate to the roof membrane and also as a waterproofing layer behind the cavity of the cladding. Further compliance research would need to be undertaken in this respect.

SIPs provide a very high level of accuracy during manufacture which would be of great value when reassembling the house modules. Each panel could be machine cut to the exact required dimensions and with predetermined openings for windows and services.

\subsubsection{Cost}

The biggest advantage in using SIPs is that they are relatively cheap to manufacture. It was realized early on that a very thick envelope construction would be required to achieve the desired insulation value. SIPs provided four main performance aspects in one complete, off-the-shelf system: Insulation, structure, bracing, and air tightness. They are factory produced and are comprised of only a few components: OSB, rigid foam insulation, and timber beams. The panels can also be factory cut to the desired dimension, openings included. These factors would have made for a very cheap envelope system and one that can be quickly assembled together to make the modules. Based on a previous competition evaluation, SIPs were estimated at a total of US\$181.16 per m2 (Material Cost of US\$109.79/m2 + Labour Cost of US\$71.36/m2). RControl would later provide a quote of US\$14,518 for the supply of materials for the entire envelope (approx. NZ\$19,360).

\subsubsection{Detailing}

The Rectilinear geometry of the house modules was well suited to the use of SIPs and the associated details were relatively simple. A 10 1/4" SIP panel would provide the correct insulation value and typical R-Control construction details could be used [Figure 95]. LVL (Laminated Veneer Lumber) members were included along the length of the SIPs at the module edge. This would provide strength and durability to the vulnerable edge during transport and also assist with spanning. The OSB layers would provide adequate bracing allowing each module to be structurally independent, with simple bolted connections between them.

Roof falls could be achieved using sloped rigid insulation with a waterproofed membrane (WPM) over the top [Figure 96]. Further investigation would be required to assess the building code compliance of this system. An H3.2 treated layer of plywood may be required beneath the membrane layer. Two falls to the centre of the roof across its width would create a very slim overall roof profile. This was important considering the restrictions imposed on height for land transport. It was also crucial that a clear ceiling height of $2.5 \mathrm{~m}$ or greater was maintained to achieve the desired feeling of spaciousness within the house.

The walls of each module consist of one complete SIP with LVL studs at the edge [Figure 97]. Vertical battens could be fixed at close centres to the outside of the SIP walls for attachment of the cladding. Concerns were raised as to the ability of the SIP to support the cladding with a risk of the OSB becoming delaminated under its weight. Further investigations would have to be carried out in this respect relying on sign off from either the manufacturer or the engineer. The outer OSB layer would need to have building paper or some other water resistant layer applied to it in order for it to act as the second line of weatherproofing behind the cladding. Since the OSB is not treated to an H3.2 level, the outer cladding layer would have needed to be a full weatherproof system, not just a rain screen.

LVL joists would be incorporated in the floor where needed to assist with spanning and reduce deflection [Figure 98]. Size, type, and quantity would be determined based on the floor load. This additional structure would be greatly increased should concrete be used as a thermal mass on the floors. 


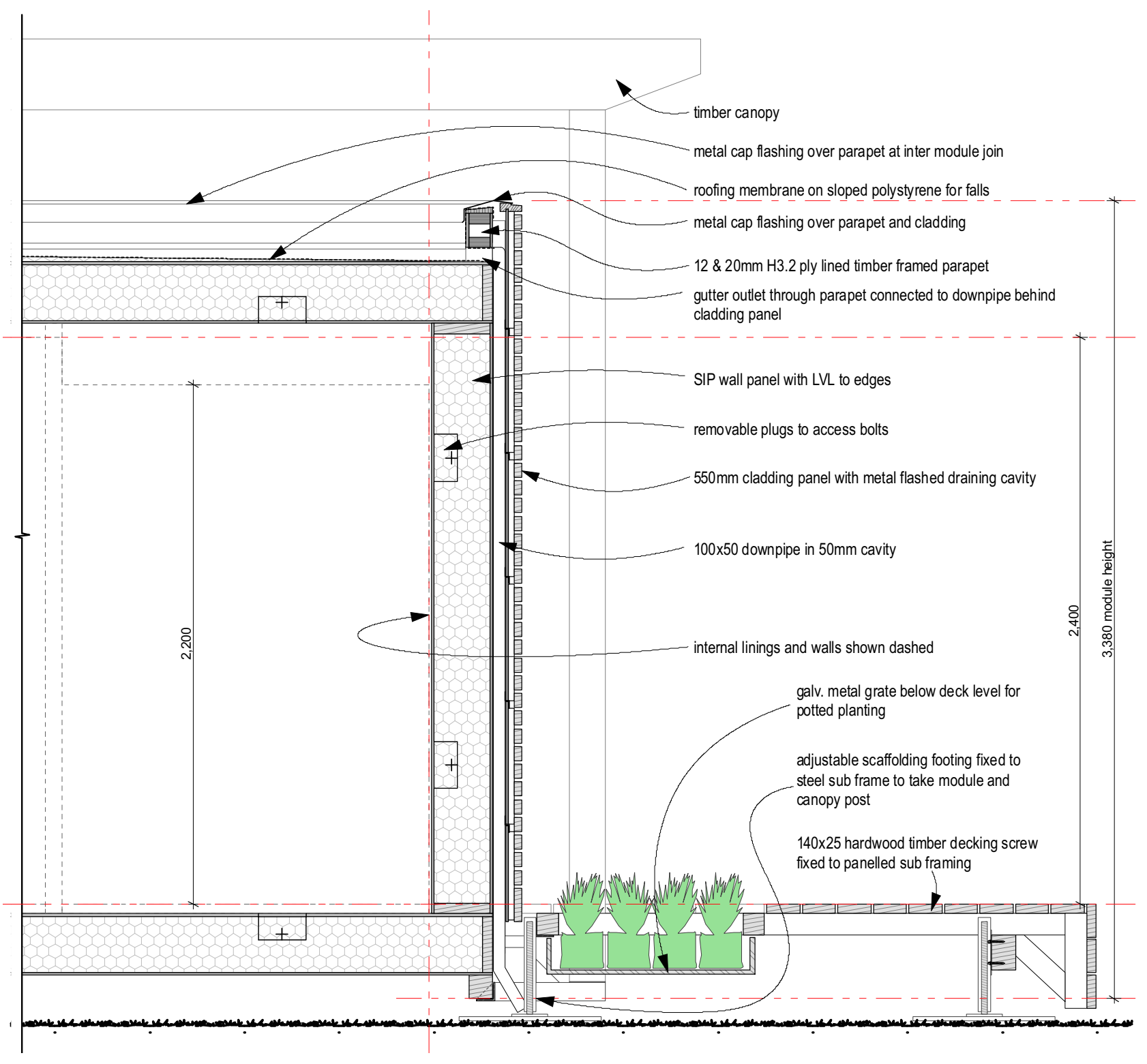

Figure 95: Section Showing 10 1/4" R-Control SIP Module (JM)

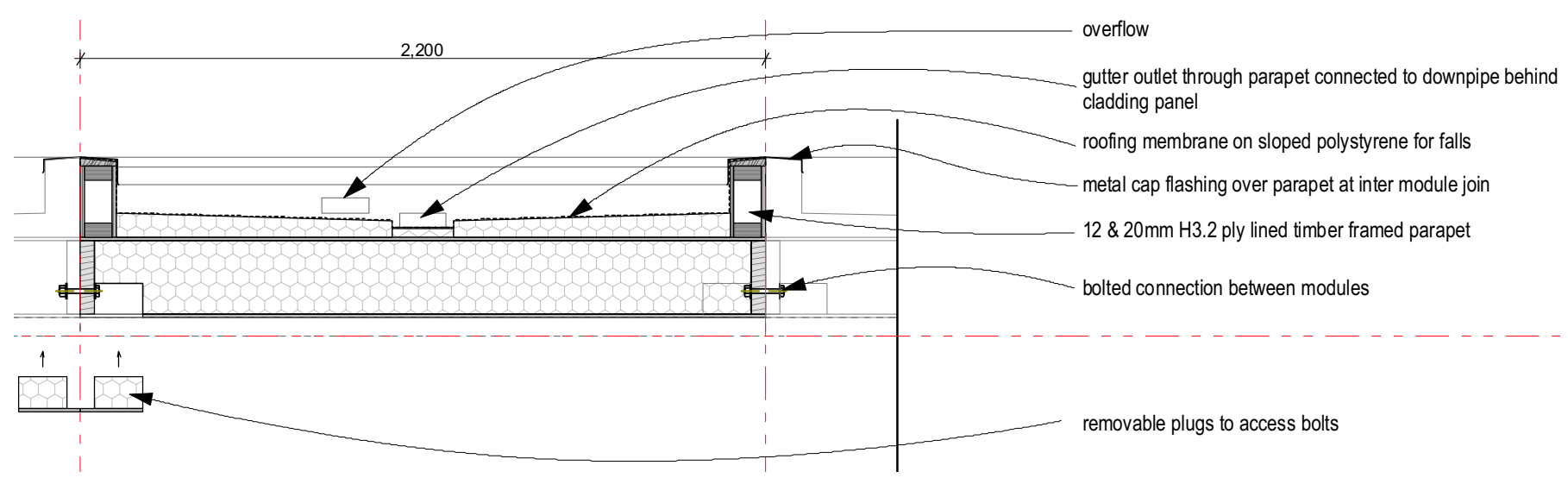

Figure 96: Section Showing SIP Roof Construction (JM) 


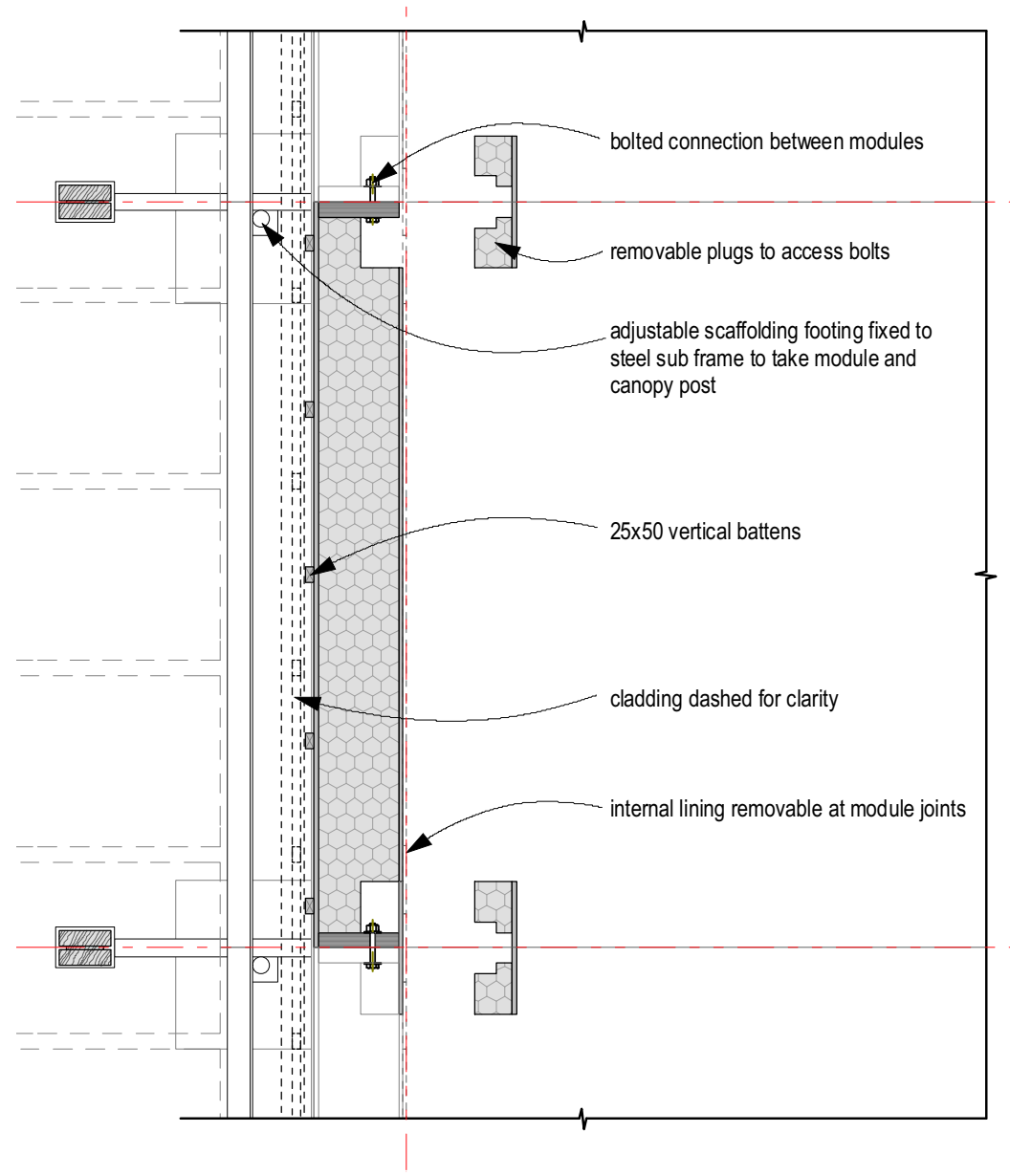

Figure 97: Plan Showing SIP Wall Construction (JM)

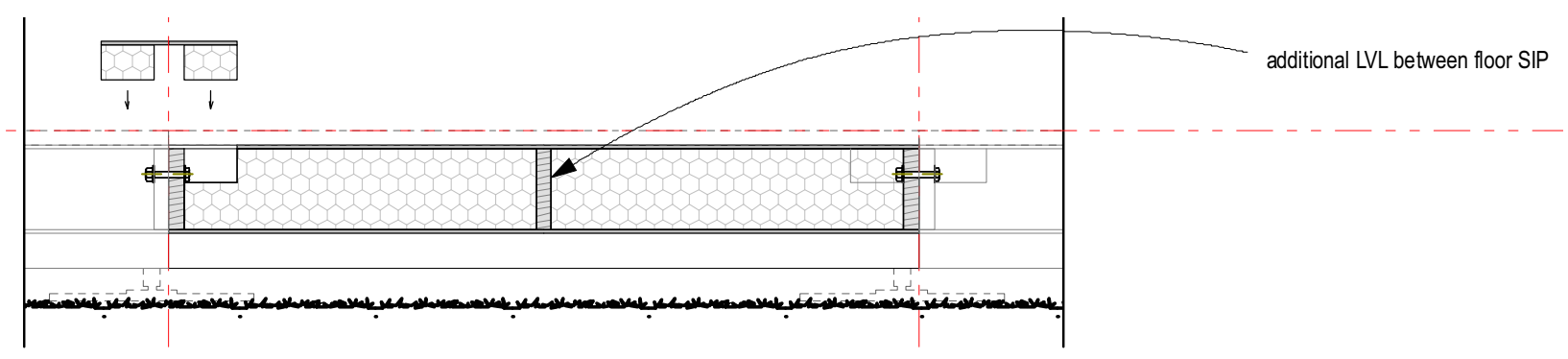

Figure 98: Section Showing SIP Floor Construction (JM) 


\subsubsection{Assembly}

Once the SIPs were constructed into modules the process of assembling them together would be very simple. Each module would be structurally self-supporting with the internal walls providing the necessary bracing. The modules would only require additional temporary protection to the windows and open sections during transport. The exterior of the SIPs may require additional waterproofing, however extra surface protection would not be required for physical damage. Each module could be fork lifted and/or crane lifted onto the steel foundation 'tracks'. Additional timber blocking might be required in the floors to prevent damage by the forks. Strops with a spreader bar to prevent damage would be used when crane lifting. Each module could then be pushed along the foundation to meet its neighbouring module and the two would be bolted together. Compressible rubber seals were envisioned as a means to create an airtight seal between the modules.

Removable plugs would be necessary to gain access to the inter-module bolts. These plugs could be fully insulated and sealed with tape once installed. A 1:1 scale model was made and proved to be a very useful tool for exploring connection details and how they could be made accessible [Figure 99, Figure $100 \&$ Figure 101].

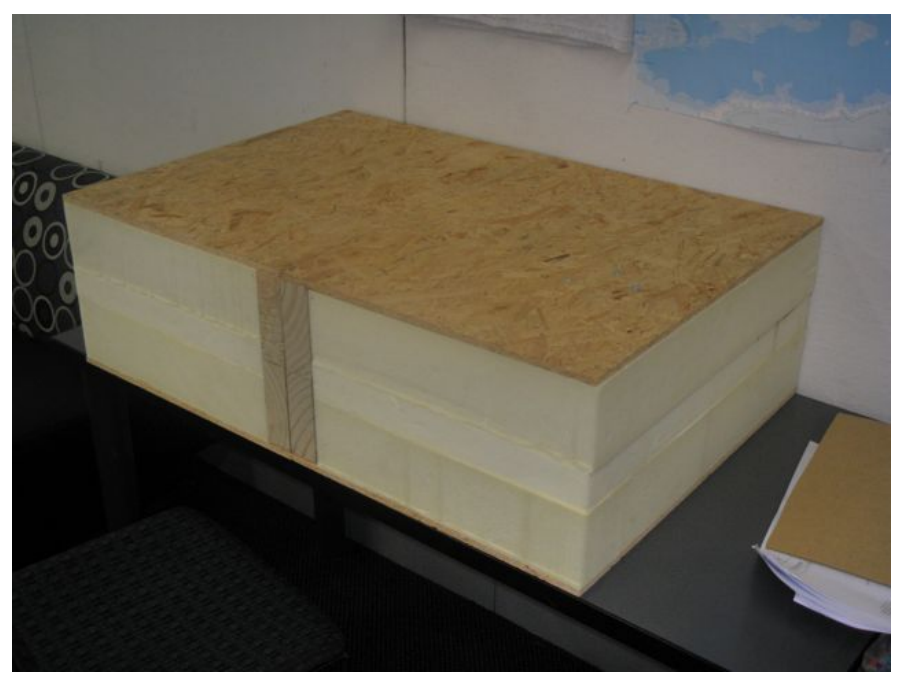

Figure 99: SIP Assembly Detail Complete (EH)

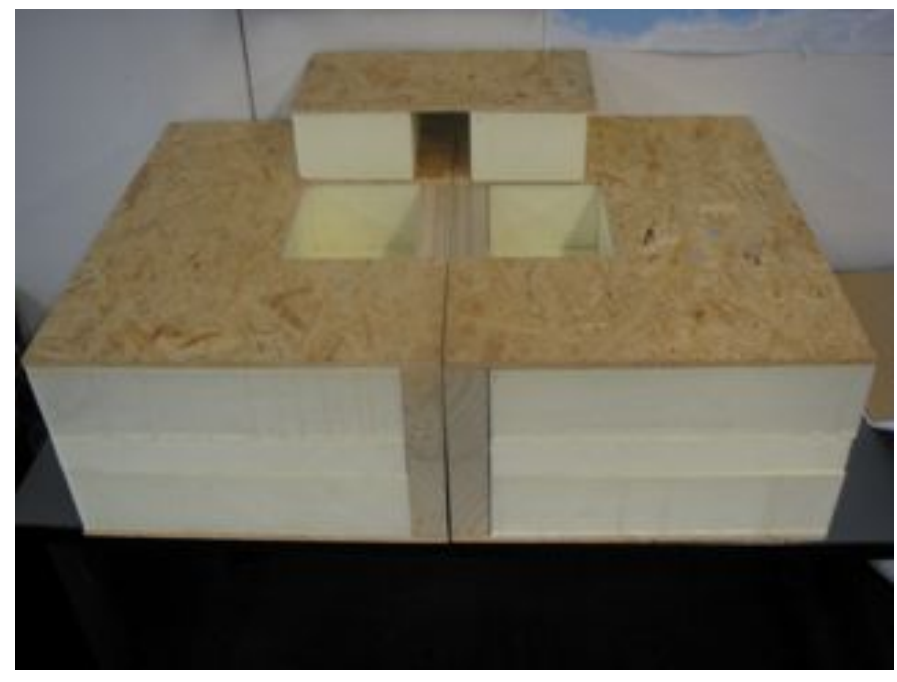

Figure 100: SIP Assembly Detail 1 (EH)

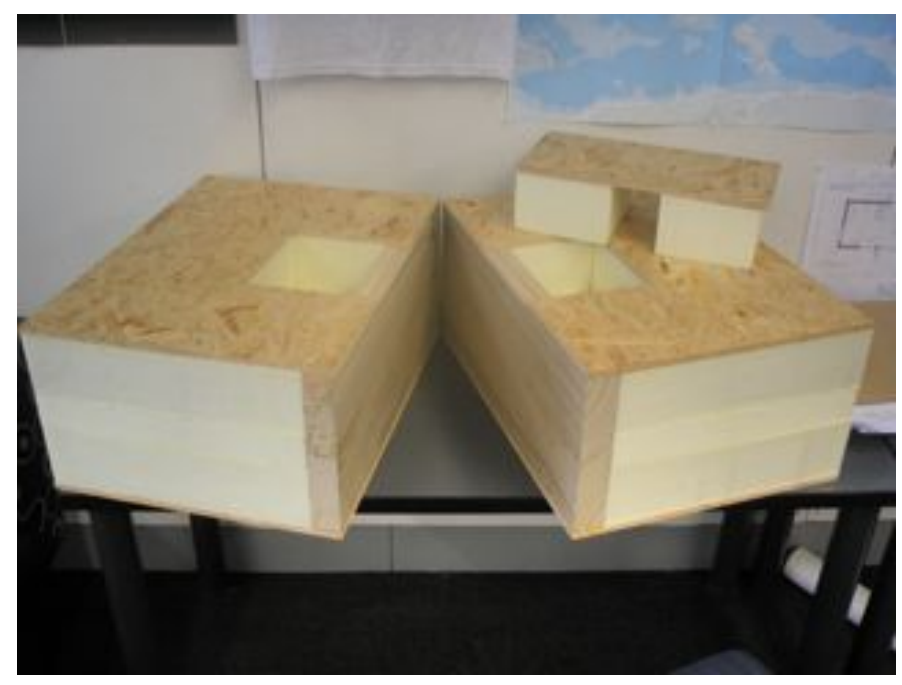

Figure 101: SIP Assembly Detail 2 (EH)

\subsubsection{Sponsorship}

The major concern in using SIPs was that they were not yet available in New Zealand at the time of construction. Through discussion with USA based company R-Control, it was deemed viable that panels could be shipped from the US for construction here in New Zealand. At the time R-Control was beginning an Australian based manufacturing plant and had an interest in gaining exposure in the New Zealand market. They were therefore very forthcoming with sponsorship, even offering enough product to build two First Light houses. As a result, this offer reincarnated the idea of possibly constructing the house in the USA. Given the expense involved in transporting the house from New Zealand and back again, it was considered that two houses might get built; one for 
exhibit and sale in New Zealand, and another competition house built locally in the US. Ultimately this option was turned down, primarily due to the added unknowns and increased risks of building two houses in two different countries. The following approximate costs were used to assess the financial feasability of building two houses vs. one.

Sponsored SIP value per house: $\$ 19,360$

R-Control PanelsConstruction budget for house: $\$ 450,000$

Return transportation cost for house: $\$ 250,000$

\section{Additional Costs for Building 2x Houses - One House in NZ and One House in the USA:}

Total construction budget for $2 \mathrm{x}$ houses $=\$ 900,000$

Less sponsored SIPs

- $\$ 38,720$

Total cost remaining

$=\$ 861,280$

Construction + transport cost $(1 \mathrm{x}$ house $)=\$ 700,000$

\section{Total additional cost to project}

$=\$ 161,280$

The building of a NZ house and a separate USA competition house would come with an additional cost of NZ $\$ 161,280$. It is important to note however that the construction of $2 x$ houses would of course generate an additional asset to the University. If the houses were to each sell for only half of their value, then comparatively the $2 x$ house option would save NZ\$63,720 overall, i.e:

\section{Overall Project Saving From Building 2x Houses (Including Sale of Houses at $50 \%$ Value):}

Construction + transport cost $(1 \mathrm{x}$ house $)=\$ 700,000$

Less income from $1 \mathrm{x}$ sale

- $\$ 225,000$

Total cost of $1 \mathrm{x}$ house option

$=\$ 475,000$

Total construction cost ( $2 \mathrm{x}$ houses $)$

$=\$ 861,280$

Less income from $2 \mathrm{x}$ sale

- $\$ 450,000$

Total cost of 2x house option

$=\$ 411,280$

Total additional saving from $2 \mathrm{x}$ houses $=\$ 63,720$

These figures do not include any other additional costs that may be incurred outside of construction and transport. They also do not include any other potential sponsorship arrangements.
Although the option of building $2 \mathrm{x}$ houses may prove to have some financial merit in the long run, it posed too many additional risks in the early phases of the project. This option would cause a loss of control over the construction process, increased difficulty for raising sponsorship, and a diminishing of the New Zealand story.

The decision was subsequently made to proceed with the building of one competition house here in NZ that would be transported to Washington DC.

This exercise did however present an option for building one house only in the USA should funding for the project fall through, i.e:

\section{Total Cost for Building One House in the USA Only:}

Total costruction budget

$=\$ 450,000$

Less sponsored SIPs

- $\$ 19,360$

Total construction cost

$=\$ 430,640$

When compared to the costs of constructing and transporting a house from New Zealand, this option would be NZ $\$ 269,360$ less. An option of selling a New Zealand built house in the US was equally investigated should costs increase beyond reach. This would avoid the return journey costs saving approx. $\$ 125,000$ from the $\$ 700,000$ total cost. This option would however require a different approach to code compliance in order to be a permanent USA building.

The desired option, of course, was to build the house in New Zealand, with NZ products, materials, and techniques, to transport the house to Washington, DC, win the competition, and return the house back to a permanent site in New Zealand. 


\subsection{TIMBER FRAME CONSTRUCTION}

Typical timber frame construction was investigated for the purpose of providing an objective comparison with SIPs. Steel frame construction was explored and ruled out early on due to deficiencies in thermal performance and high embodied energy at production. Steel would certainly have its advantages especially with respect to strength, durability, and precision - all factors which would be of great value during the assembly phase of the competition. It was however decided that timber would give the greatest advantage overall providing good thermal properties and the "green" NZ story that would help First Light stand out against the competition.

\subsubsection{Regulations}

Timber frame construction is a very common building technique in New Zealand. Although this project required a unique approach to how it would be built and then unbuilt, the basic principles of timber construction could still be applied. This would align the project with many examples of housing in New Zealand and with the national Building Code. It might however present some disparities with common building practices in the US, both in terms of detailing and with material selection. These issues, however, could be overcome with sufficient research and close consultation with the US DOE building inspector. Some complications might also arise with respect to the importation of woods and other materials into the USA. The types of chemicals used to treat timber later became a significant challenge for the project.

\subsubsection{Thermal Performance}

Timber frame construction provides a great thermal advantage due to the low conductivity of wood. When compared to steel, timber is a far superior structural material to use in terms of reducing thermal bridging. Where possible, structural members could be staggered to further reduce the effect of thermal bridging and maximise the insulation value of the envelope. With a structural system independent of the insulation, timber framing could accommodate a wide variety of insulation products [4.4 Insulation]

\subsubsection{Air Tightness}

Timber construction is not inherently air tight, however there are supplementary products and systems available to achieve this. These will later be described in Chapter 5.1.4 Air Tightness

\subsubsection{Sustainability}

Timber frame construction would make the most of a local and sustainable resource, largely Pinus Radiata, which could be argued to store $\mathrm{CO} 2$. Treatment chemicals would however be required to improve the timber's durability in some parts of the construction. Care must be taken in the selection of treatment methods so as to avoid the potentially environmentally detrimental effects of some chemicals. Treatment may also prevent the wood from later being burnt as a source of energy. Insulation products with varying degrees of environmental impact could be considered in conjunction with the use of timber frame construction.

\subsubsection{Damage}

Timber frame construction is relatively resistant to damage while also providing a high degree of flexibility for making changes. Damaged sections could be easily repaired or replaced and minor adjustments could be made during the fitting together of removable components. Timber would however be highly susceptible to water damage and dimensional changes due to humidity. Both could potentially cause major problems when it came to bringing the modules back together during reassembly.

\subsubsection{Cost}

The costs involved for timber construction can easily be estimated through the use of quantity surveying guidebooks. These estimates however would need to be on a detailed rates basis due to the unusual assembly of the frame. These rates provided an initial understanding of costs for timber frame construction. A comparative analysis was subsequesntly carried out by quantity surveyors RLB to compare SIPs, Standard Timber Framing, and LVL Framing as if used for the same envelope. The results were as follows: 
SIPs

$=\$ 34,750$

Standard Timber Framing

$=$

$\$ 64,763$

LVL Framing

$=$

$\$ 68,353$

\subsubsection{Detailing}

The construction details for both SIPs and Timber Frame needed to be suitably developed in order to make a wellinformed decision on the advantages of one over the other. In developing the timber frame option the objective of minimising the structure and thereby maximising insulation was the primary aim. Great consideration was also given to the stability of timber products under varying climates and moisture levels. To this end, laminated products were held in high regard both for their slender profile and their resistance to deformation when wet.

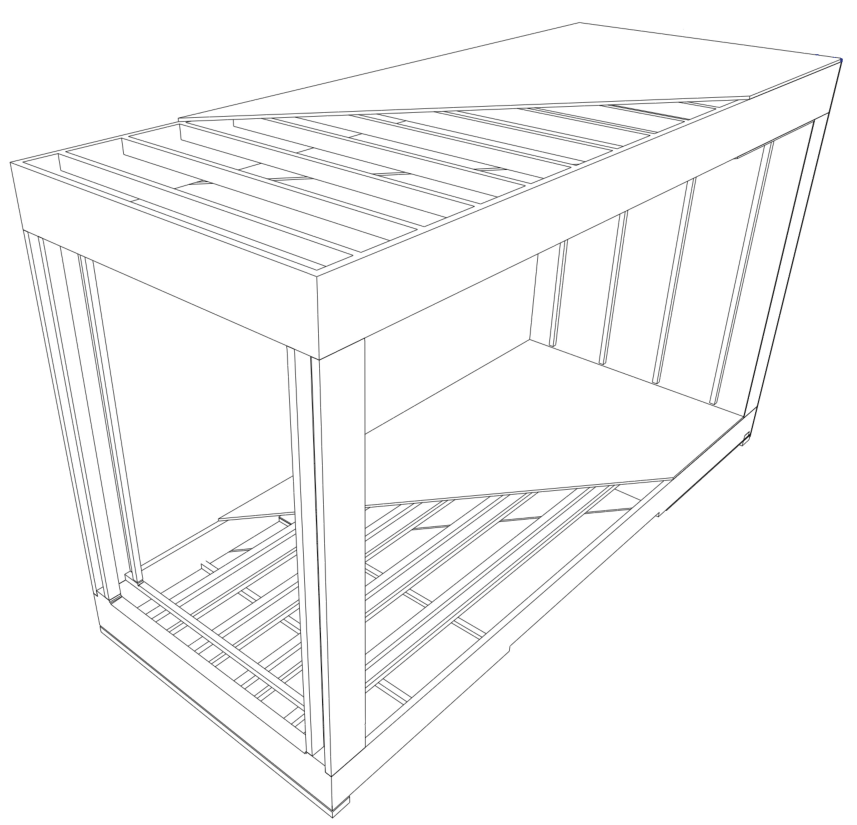

Figure 102: Sectional 3D Through Module Showing Timber Frame Construction (JM)

The makeup of the parapeted roof would essentially be the same assembly as the SIP system. In this case however timber framing provides the structure with a sloped polystyrene layer to achieve the falls [Figure 103 $\&$ Figure 104]. The timber frame could then be filled with any choice of insulation.

In the walls, a staggered stud arrangement was designed as a means to reduce thermal bridging [Figure 105]. To go one step further, the internal members could be oriented horizontally. This would allow a clear span in between the vertical stud wall on the outside and the inside framing. The uninterrupted void could then be filled with a range of rigid,

batted, or loose fill insulation. The wall could then be encased in plywood for structural bracing and to make an air tight sandwich panel. As with the SIP system timber LVL members could be incorporated at the module edge for robustness.

Hy-joists could be utilised in the floor to achieve the $5.6 \mathrm{~m}$ span [Figure 106]. The slender plywood web provides great strength on its edge while also limiting

the amount of thermal bridging across the depth of the joist. These could be appropriately sized to take the added weight of concrete if needed for thermal mass.

\subsubsection{Assembly}

Once the timber panels were constructed into the modules, an identical assembly process as to the SIP system would follow [Chapter 4.2.8 Assembly]

\subsubsection{Sponsorship}

Timber framed construction allowed sponsorship to be either sought for the complete package or broken down into suppliers of the individual parts. Given that there are numerous suppliers for each component i.e. plywood, LVL, Hy-joists, timber framing, insulation, WPM etc, it was envisioned that sponsorship would be easily gained to cover these items. 


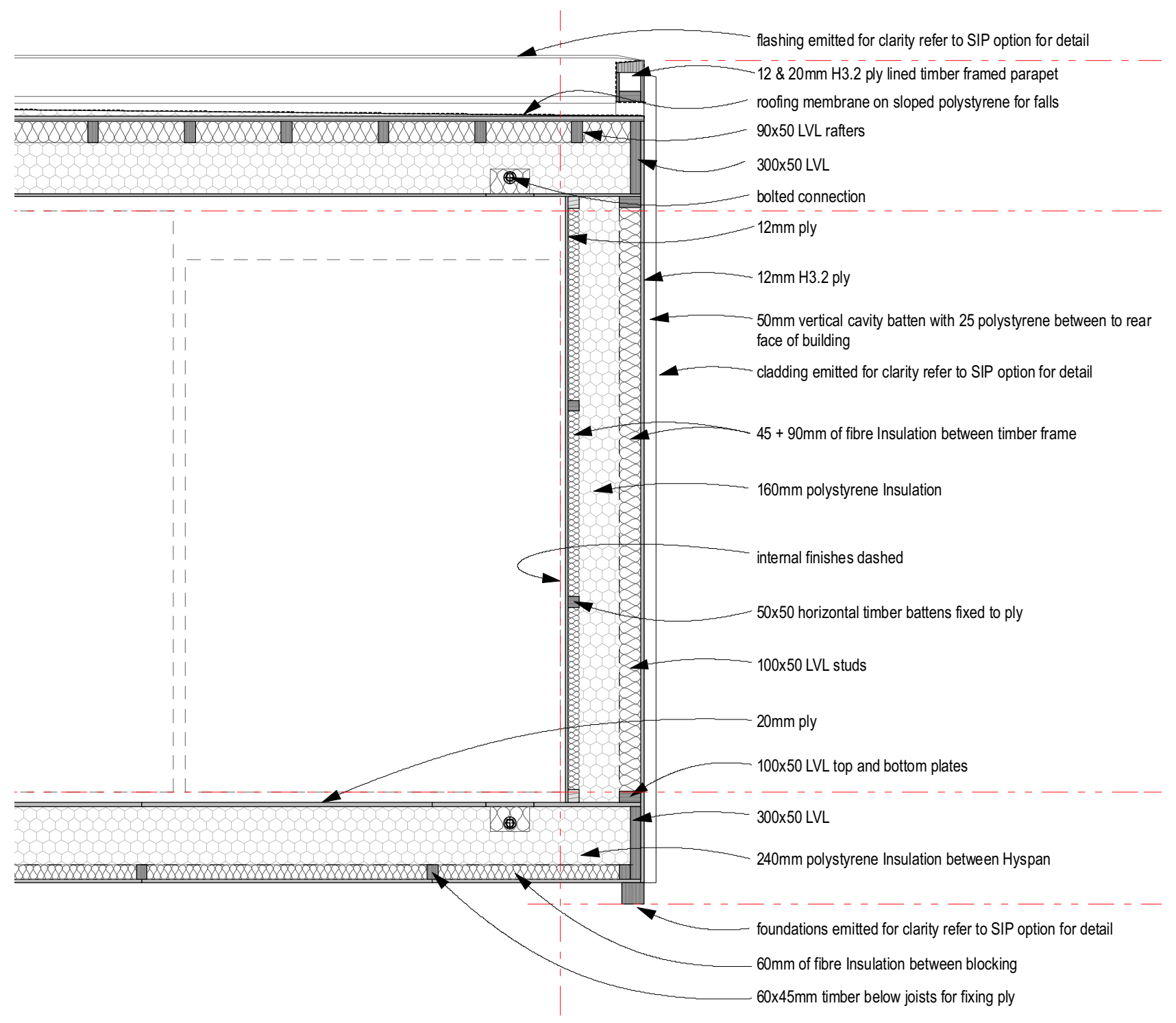

Figure 103: Section Showing Timber Frame Module (JM)

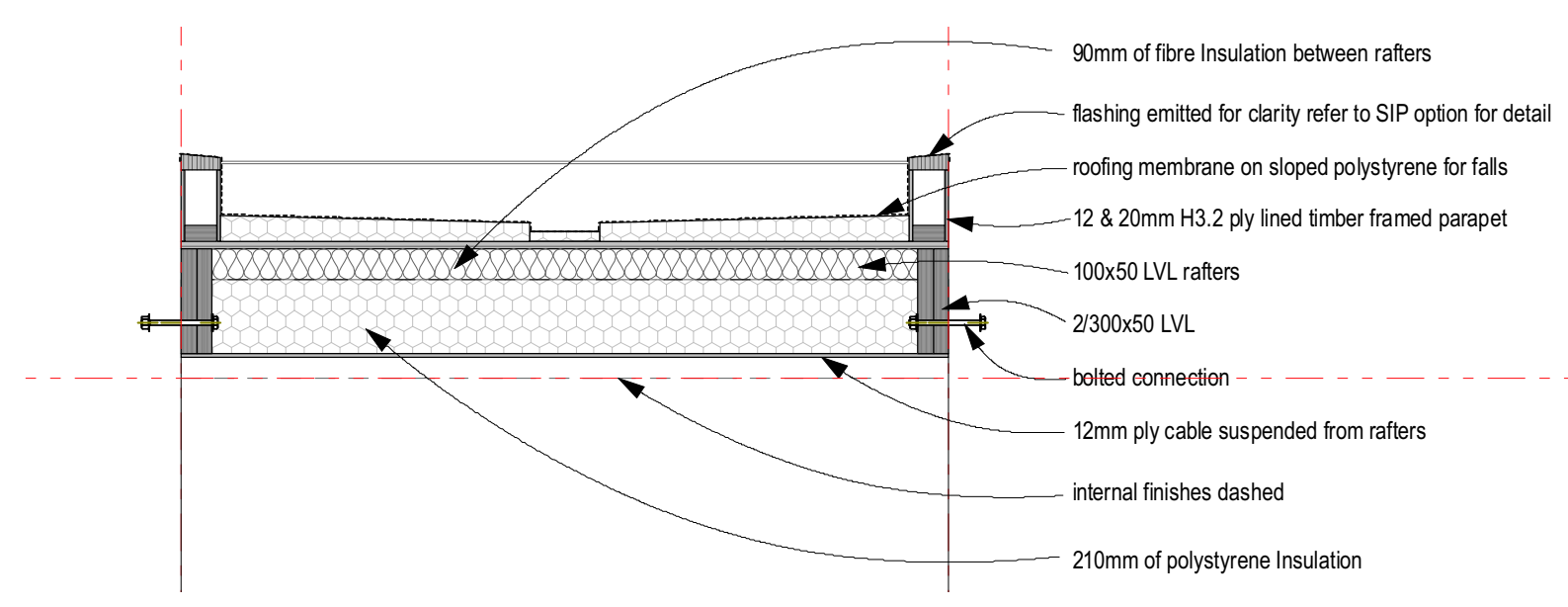

Figure 104: Section Showing Timber Frame Roof Construction (JM) 


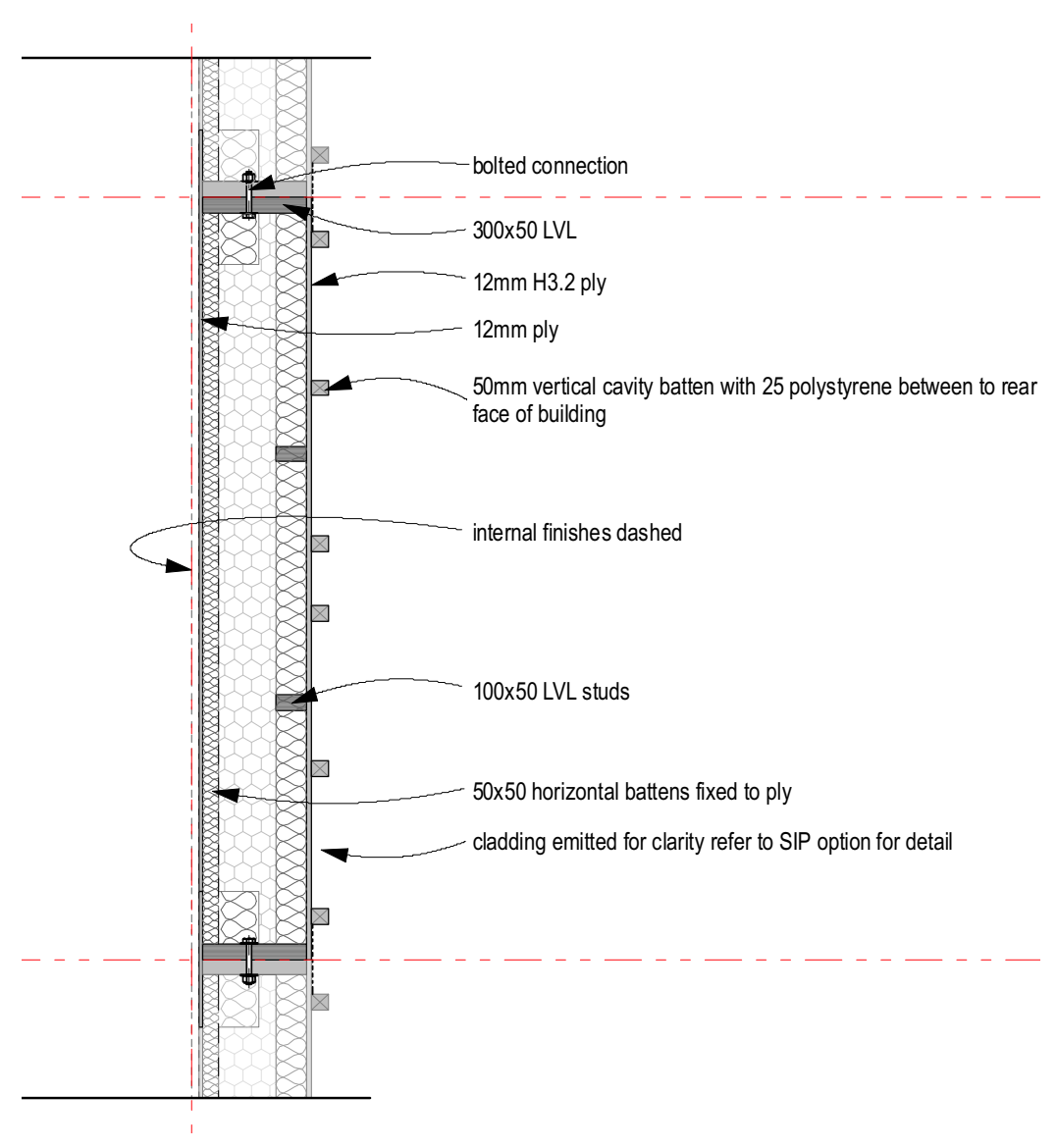

Figure 105: Plan Showing Timber Frame Wall Construction (JM)

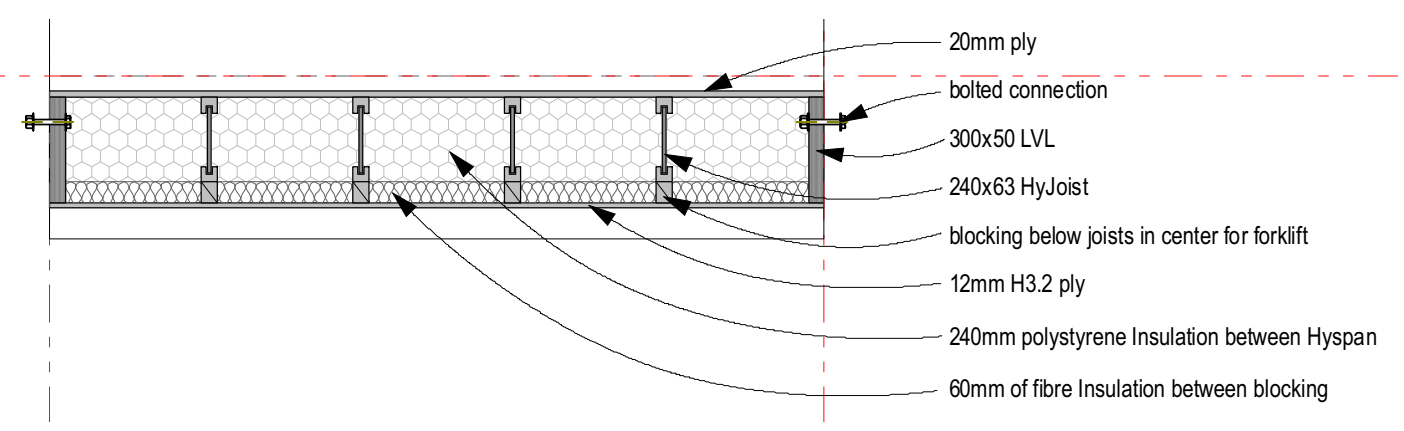

Figure 106: Section Showing Timber Frame Floor Construction (JM) 


\subsection{INSULATION}

A variety of common insulation products were tested to give an indication of their impact on the overall R-Value vs Wall Thickness. It was important to consider the makeup of the wall as opposed to simply comparing Rvalues of products thickness for thickness. Insulation products are supplied in differing thicknesses and would demand a a range of slightly different wall constructions in order to achieve the desired R7 composite insulation value. Table 6 below presents the findings of 14 alternative wall assemblies relative to the insulation value achieved by each. The wall was used as a benchmark since it contained an average degree of complexity and thus would give a good indication as to what insulation values could equally be achieved in the floors and roof. Note that a common value of neither thickness nor Rvalue could be used for comparative purposes due to the factors described above.

\begin{tabular}{|c|c|c|c|}
\hline No. & Insulation Type & Composite R-Value & Total Wall Thickness (mm) \\
\hline 1 & $(101-4 ")$ SIP & 6.92 & 397 \\
2 & PinkBatts 230mm & 6.63 & 366 \\
3 & PinkBatts 270mm & 7.81 & 406 \\
4 & Ecofleece 230mm & 5.69 & 366 \\
5 & Ecofleece 270mm & 6.59 & 406 \\
6 & Ecofleece 320mm & 7.51 & 456 \\
7 & Polystyrene 180mm & 7.18 & 361 \\
8 & PinkBatts 230mm Poly Cavity & 7.29 & 391 \\
9 & Ecofleece 230mm Poly Cavity & 6.85 & 391 \\
10 & Straw Bale 650mm & 6.86 & 736 \\
11 & Rockwool 270mm & 7.01 & 406 \\
12 & Cellulose 250mm & 6.93 & 406 \\
13 & & & 361 \\
14 & Ecofleece 225mm AIM & 6.53 & 361 \\
\hline
\end{tabular}

Table 6: Comparative Insulation Values for Varying Wall Assemblies

\begin{tabular}{|c|c|c|c|}
\hline \multicolumn{4}{|c|}{ BUILDING COMPONENT R VALUE } \\
\hline & Building Element & R Value & Thickness (mm) \\
\hline Interior & Internal Surface Resistance & 0.09 & \\
\hline Finish 1 & Interior Lining Ply $12 \mathrm{~mm}$ & 0.09 & 12 \\
\hline Finish 2 & Interior Cavity $25 \mathrm{~mm}$ & 0.13 & 25 \\
\hline Layer 1 & Inner Ply $12 \mathrm{~mm}$ & 0.09 & 12 \\
\hline Layer 2 & Wall layer 1 - Ecofleece $50 \mathrm{~mm}$ & 0.93 & 50 \\
\hline Layer 3 & Wall layer 2 - Ecofleece $90 \mathrm{~mm}$ & 2.12 & 90 \\
\hline Layer 4 & Wall layer 3 - Ecofleece $90 \mathrm{~mm}$ & 1.83 & 90 \\
\hline Layer 5 & Outer Ply $12 \mathrm{~mm}$ & 0.09 & 12 \\
\hline Layer 6 & Cavity $50 \mathrm{~mm}$ & 0.13 & 50 \\
\hline Layer 7 & Exterior cladding & 0.16 & 25 \\
\hline Exterior & External Surface Resistance & 0.03 & \\
\hline & Total R Value of building component & 5.69 & 366 \\
\hline
\end{tabular}

Table 7: Example of Wall Assembly Breakdown and Associated R-Values 


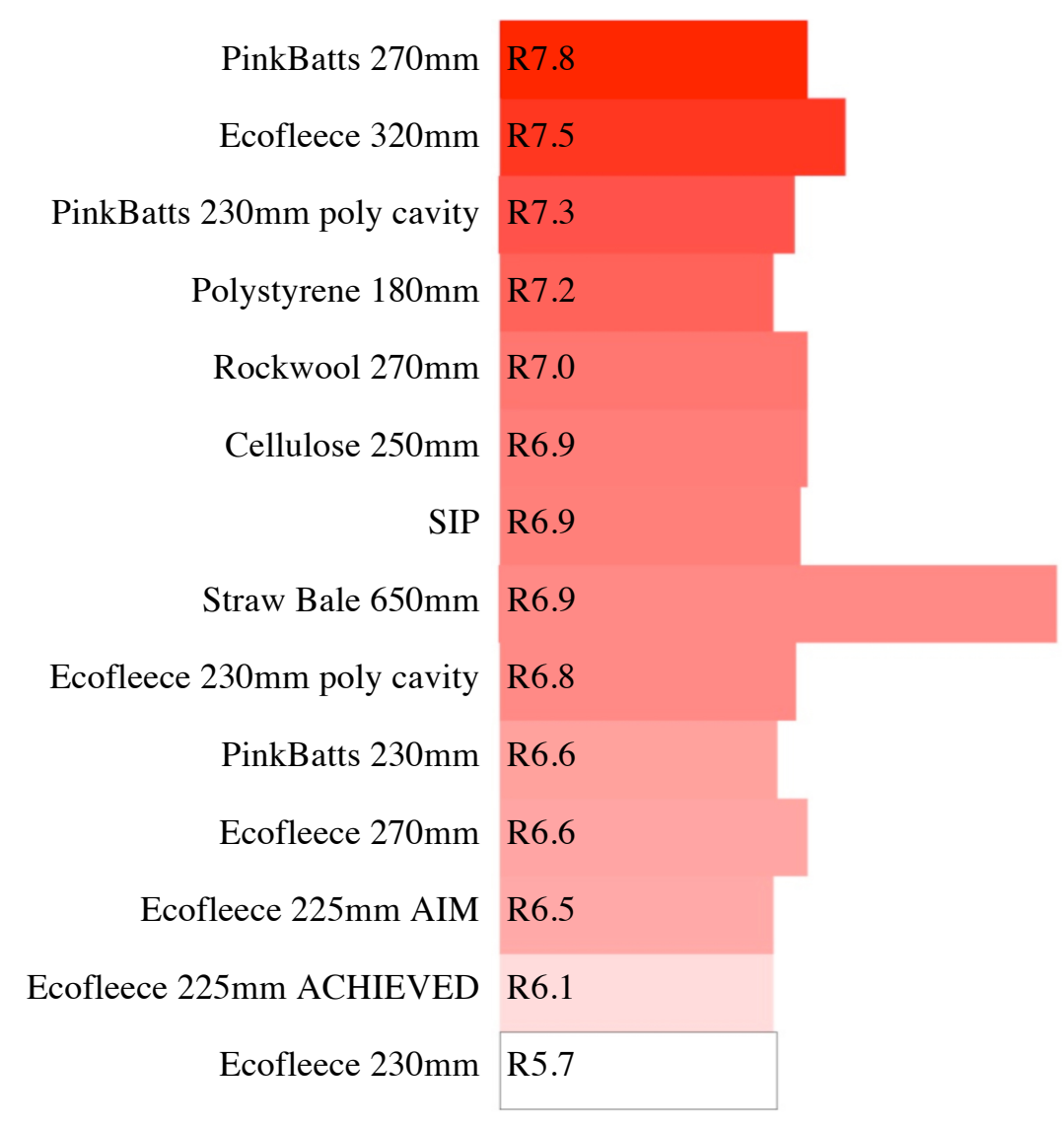

Figure 107: Comparative Insulation Values for Varying Wall Assemblies

Figure 107 above illustrates relative wall thicknesses compared to the composite R-value that they achieve. The Insulation types are ordered from most insulating to least.

\subsection{TIMBER TREATMENT}

A requirement of the competition is that houses must meet the IBC (International Building Code). According to the IBC, any timber used in residential construction must meet the requirements of the AWPA (American Wood Preservation Association). The AWPA does not recognise CCA (Copper Chromium Arsenic) or LOSP (Light Organic Solvent-based Preservative) as approved treatment methods (AWPA, 2009). CCA and LOSP are the two most commonly used treatment methods for achieving durability to hazard class $\mathrm{H} 3$ level in New Zealand. It was therefore specified that the alternative treatment methods $\mathrm{CuAz}$ (Copper Azole) and/or ACQ (Alkaline Copper Quaternary) were to be used in situations requiring $\mathrm{H} 3$ or higher. The AWPA approves the use of Boron treatment for timber that is not in direct contact with the elements.
Boron treated timber is widely available and used in New Zealand for achieving a hazard class H1.2 (Department of Building and Housing, 2011).

It was quickly realised that the requirement for ACQ or $\mathrm{CuAz}$ treatment was beyond the scope of many of the NZ timber treatment plants. This caused long and signifcant delays to the construction program, the effects of this are illustrated in Figure 108. The optimistic delivery of the main envelope components for December 2010 was dramatically pushed back by up to two and half months in some cases. The manufacturing of the wall, floor, and roof elements all relied on the supply of plywood and LVL.

During December 2010, the First Light team became aware of impending changes to NZS 3602, and a revised proposal from the DBH (Department of Building and Housing), based on the report "Consultation on proposals for a single hazard class for framing timber inside the building envelope - Through proposed changes to the Acceptable Solution for Building Code Clause B2 (Durability)" published by the DBH in Sept 2010. 
This document "proposes changes to the Acceptable Solution for Building Code Clause B2 (Durability) to:

- amend the existing reference to New Zealand Standards NZS 3602, Timber and Woodbased Products for Use in Building, and reference NZS 3640, Chemical Preservation of Round and Sawn Timber with modifications.

- adopt H1.2 as the single hazard class for timber framing inside the building envelope, except for the critical performance of cantilevered deck joists..."
The document proposes the use of Boron H1.2 as the suitable treatment process, and notes that in practice, the H1.2 Boron level of treatment is achieving similar results to other treatments at higher levels (Department of Building and Housing, 2010). The team cross-checked this with the AWPA Standards (2010) where SBX (Boron salts) was listed as an acceptable timber treatment system for the pine species intended for use. Therefore a change in specification to Boron H1.2 for internal timber framing was made. This enabled access to more readily available timber and allowed the much delayed manufacturing of the floor, wall, and roof elements to proceed.

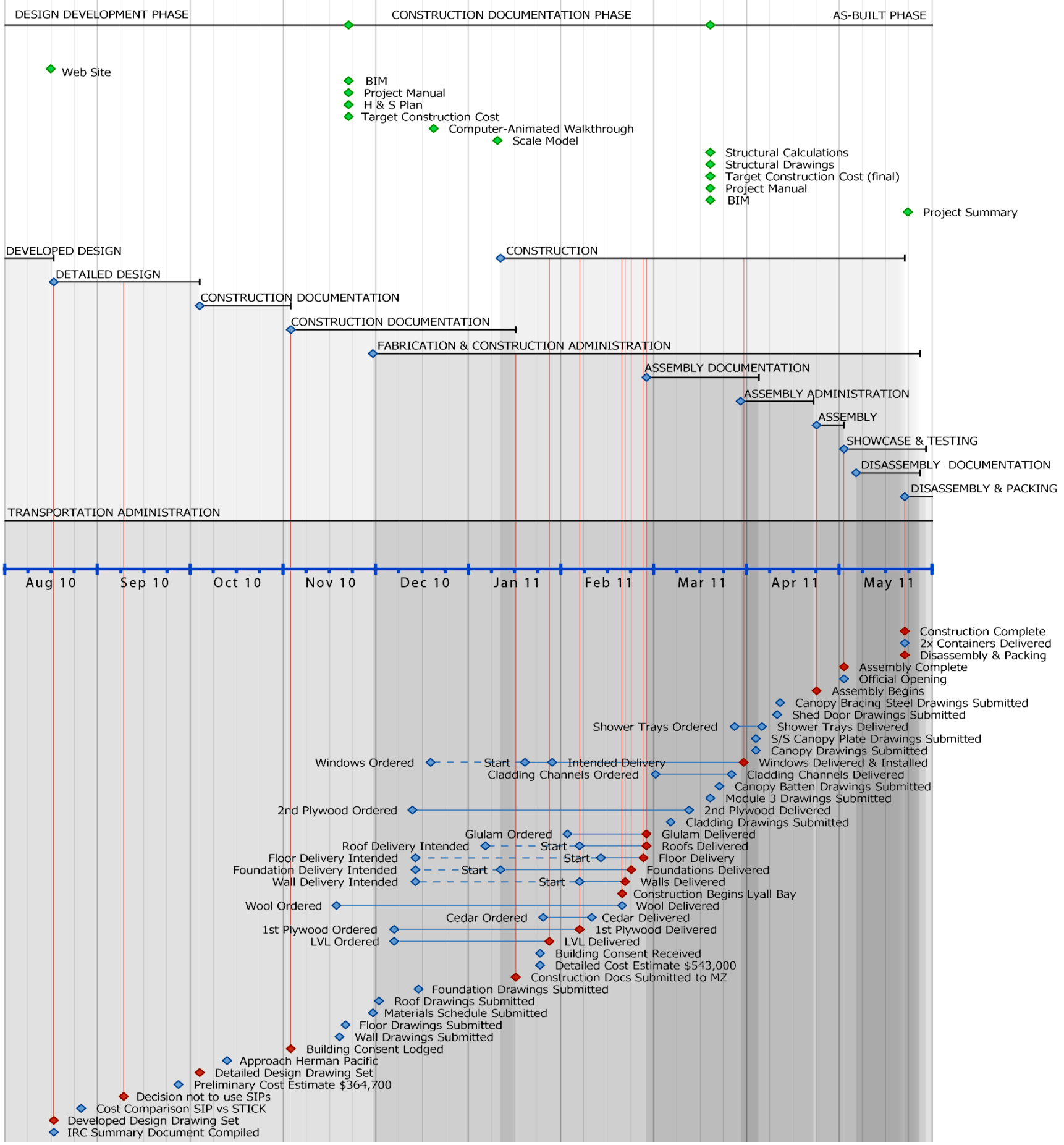

Figure 108: Project Timeline 


\subsection{CONCLUSIONS}

The advantages of using SIP vs Timber Frame were spread across the hierarchy of considerations for module construction. SIP would be more cost effective saving $\$ 34,000$, would likely achieve a higher R-value, better air tightness and less thermal bridging. Timber frame would present fewer issues with code compliance, slightly more flexibility during assembly, more resistance to damage and would arguably have better capacity for supporting thermal mass. Timber frame would also provide an opportunity to use local materials and to promote New Zealand companies and a New Zealand story.

\subsubsection{Timing}

At the expense of time, both options continued to be explored. R-Control was tasked to present a timeline for delivering the panels with an outline of what information they would need from the design team and when they would need it. Development of details for both SIP and timber frame continued and sponsors for the supply of associated products were sought. This exercise consumed a lot of office time and resources and it was quickly realised that a committed decision needed to be made if other upcoming deadlines were to be met. Upon receiving R-Control's proposal the decision to proceed with timber frame construction was made.

\section{Commitment Day 11 Sep 2010}

Days Needed

$\begin{array}{rcr}\text { Design Lockdown (FL) } & 3 & 14-\text { Sep-10 } \\ \text { Review and inputing project (RCA) } & 10 & 24-\text { Sep-10 } \\ \text { Review 3D (FL) Approval } & 4 & 28 \text {-Sep-10 } \\ \text { To Production (RCA)* } & 14 & 12-\text { Oct-10 } \\ \text { To Containerisation (RCA)* } & 14 & 26 \text {-Oct-10 } \\ \text { To US West Coast* } & 5 & 31 \text {-Oct-10 } \\ \text { TransPacific to Wellington* } & 45 & 15-\text { Dec-10 } \\ \text { Port Clearance } & 3 & 18 \text {-Dec-10 } \\ \text { To Assembly Site } & 2 & 20 \text {-Dec-10 } \\ \text { Contingency } & 12 & 1 \text {-Jan-11 } \\ & 0 & 1 \text {-Jan-11 } \\ & 0 & 1 \text {-Jan-11 }\end{array}$

Figure 109: R-Controls Proposed Timeline for Constructing With SIPs

At the time of the decision the project was still on track to make a January start date for construction. Working back from this date R-Control determined that the envelope design would need to be locked down within three days of receiving the proposal [Figure 109]. This would require module dimensions and all openings for windows, doors etc to be established. It would also be advantageous to have all electrical, plumbing, and mechanical openings and systems designed so they can be machine "chased" into the panels. It was felt that the design team was at least two weeks away from comfortably locking in all major design decisions. These decisions extended beyond the dimensional requirements of R-Control, including performance and other material selections. Council approval for the use of SIPs was also yet to be obtained.

To commit to SIPs and deliver on R-Control's requirements in time would have entailed increased risks and a great loss of flexibility and control over the design. Window openings and locations were still being developed, undergoing optimisation for performance in conjunction with changes to the floor plan. Services were also still being resolved and were yet to have their spatial requirements locked down. Given the extremely tight time frame it was discussed whether blank SIPs would be appropriate. This would allow panels to be ordered immediately and would essentially let all decisions (within the boundaries of the blank panel dimensions) remain flexible up until the date of their arrival. Blank panels would subsequently need to be cut and manipulated by local carpenters with very limited experience in their use. This would negate the advantages of SIPs in terms of machined accuracy, speed of production, reduced wastage, and the 'pre-fab' story. An argument can however be made for the benefits afforded by locking in decisions early on a project like this. With such a limited timeline, delaying decisions only puts further pressure on later decisions, many of which become far more influential to the final outcome.

Ultimately it was determined that timber frame construction would entail the least risk and promote the greatest flexibility while still achieving the required performance. 


\section{ENVELOPE CONSTRUCTION}
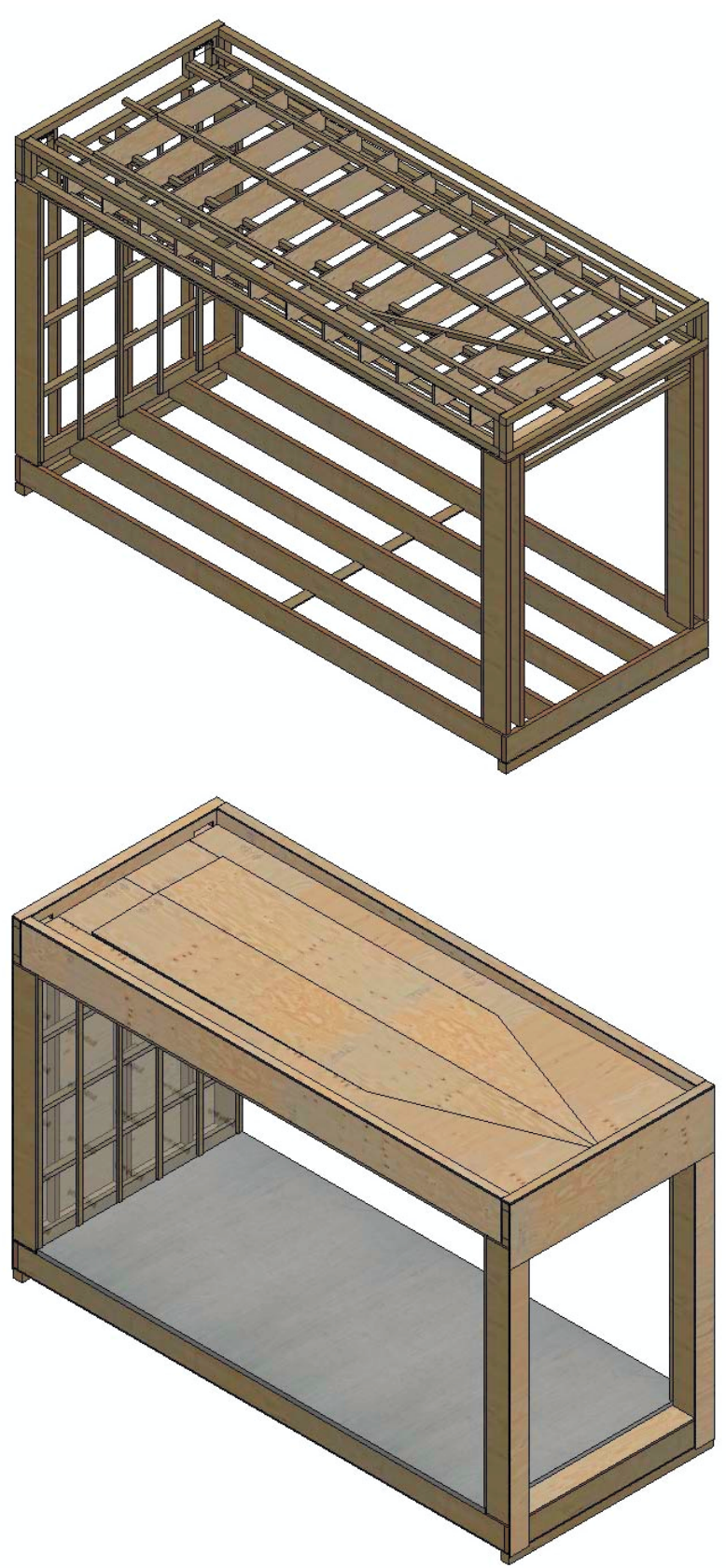

Figure 110: 3D Render Showing Module Envelope and Framing (JM) 


\section{ENVELOPE \\ CONSTRUCTION}

For the purpose of providing clarity, the following sections will explain the decision making process involved for each major element; Wall, Floor and Roof, relative to the construction methods previously described in Chapter 4.3 Timber Frame Construction. The commitment to using timber framing marked a major milestone in the developed design phase of the project. Many other decisions were formally locked in shortly after this decision was made; Benchmark performance criteria for the envelope were outlined, the basic layout of the shed and services equipment was confirmed, dimensional limits for transportation were clarified, and primary material selections were made.

The developed design drawing set dated $18^{\text {th }}$ August 2010 signalled a transition for the project into the detailed design phase. The following chapters provide an explanation of how details were developed and optimised, their documentation, and their execution during construction.

\subsection{WALLS}

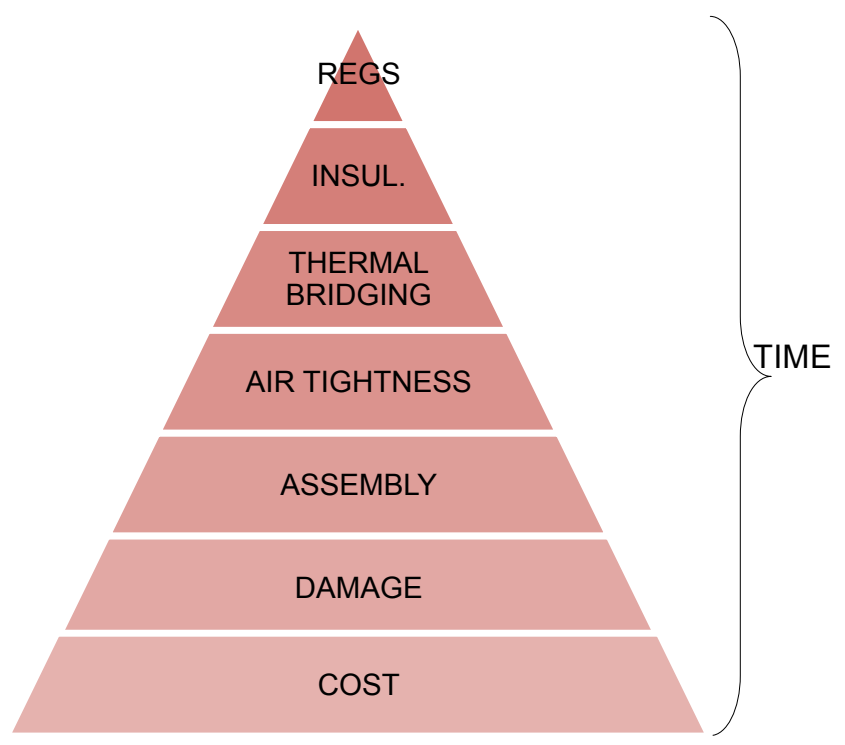

Figure 111: Decision Making Hierarchy - Wall Construction

\subsubsection{Regulations}

The wall construction would have to meet New Zealand code (particularly with respect to waterproofing), the IBC, and the structural requirements for a typical Wellington site in a very high wind zone with earthquakes.

\subsubsection{Insulation}

An investigation of available insulation products during developed design uncovered the implications of each product to both construction and performance. There were however a number of other factors that had to be considered before an appropriate insulation prouct could be selected. These ranged from costs and sponsorship to sustainability and market appeal.

EcoInsulation was one of the first insulation companies to be approached and were also one of the most forthcoming in terms of sponsorship. The values and ambitions of First Light aligned well with what EcoInsulation were trying to promote as a company. They are a relatively new company who were interested in developing new products and pushing their brand to the forefront of sustainable thinking. Early concerns were discussed in terms of reaching the desired R-value of R6.5 without an obtrusively thick panel. EcoInsulation accepted the challenge and set about creating a new batt product that would achieve a much greater R-value per thickness than was currently on the market for wool insulation. This product was hoped to compete against and in fact exceed the performance of other non-wool batt products. EcoInsulation committed themselves to achieving the following R-values for two products which could be used for the First Light house:

1. 1x 90mm Batt @R2.4

2. 3x 45mm Batts@R1.4

This would result in a composite insulation value of $\mathbf{R 6 . 5}$

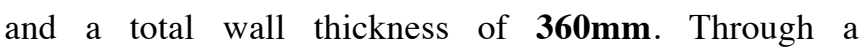
sponsorship arrangement with BRANZ these new products were tested and later verified to achieve R5.8 at $360 \mathrm{~mm}$. Although this would not achieve the desired R6.5 it did give an acceptable compromise overall. A standard 240x45mm LVL (Laminated Veneer Lumber) member could be used at the perimeter of the wall with the insulation layers divided as follows [Figure 112]:

1. $90 \mathrm{~mm}$ exterior stud wall

2. $105 \mathrm{~mm}$ clear void

3. $45 \mathrm{~mm}$ internal frame 


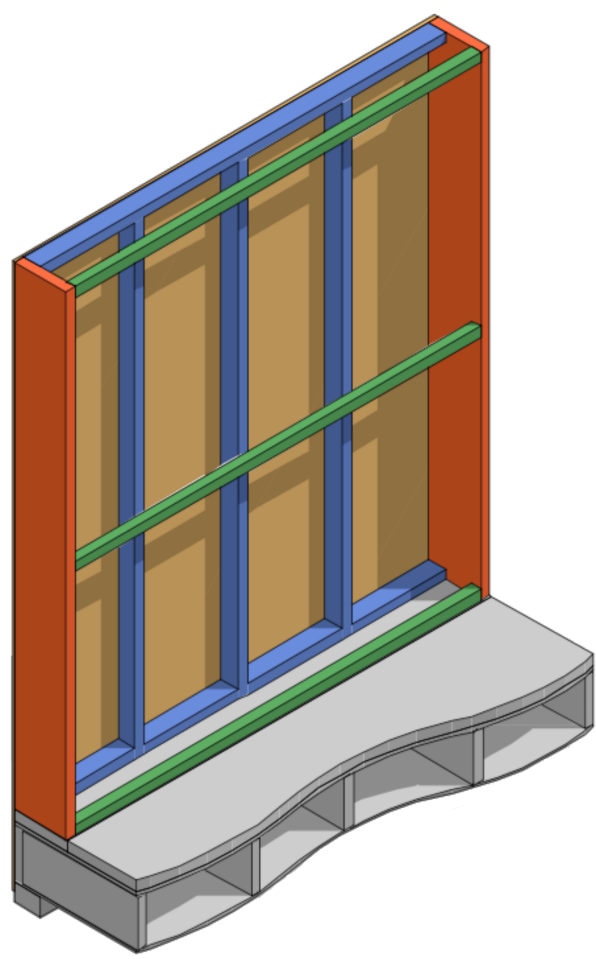

Figure 112: Plan Showing Proposed Wall Framing (JM)

The thickness of the wall could have been increased to further improve the R-value. A thicker wall however would the result in a loss of internal floor area and higher associated costs. It was felt that these factors would outweigh the benefits of the improved insulation in a wall thickness greater than $360 \mathrm{~mm}$.

It was also agreed that the best approach would be to stick with one form of insulation for the entire envelope. This would not only benefit construction but would also create ease when finding sponsorship with a clearer story to tell. As presented in Table 6 on page 79, there existed a number of alternative insulation products that have achieved a similar level of performance i.e. PinkBatts could have been used and would have achieved R6.6 at $360 \mathrm{~mm}$. EcoInsulation did however present other beneficial characteristics in addition to its insulation Rvalue:

- It performs well in humid environments without any loss of performance

- It is manufactured with recycled off-cuts from the carpet industry

- It is made locally with New Zealand wool from the backs of New Zealand sheep

- It is uncommon in the US and would promote the unique NZ identity of the First Light house

- There was some uncertainty as to how it would be priced in a US market
The options were put forward to the building performance team who took the above points into consideration when reassessing the thermal simulations. With all factors considered, the decision was made to proceed with the use of the new EcoInsulation "Ecofleece" product achieving an insulation value of $\mathbf{R 5 . 8}$ at $\mathbf{3 6 0} \mathrm{mm}$ in the walls.

The arrangement of framing layers within the wall panel was further developed to both improve its structural integrity while still promoting an efficient use of insulation.

\subsubsection{Thermal Bridging}

The move away from SIPs necessitated a close consideration of the impact on performance caused by timber frame construction. A separated and perpendicular framing arrangement had already been explored during developed design. This method proved to achieve a very economic use of framing while maximising the overall thermal performance of the wall.

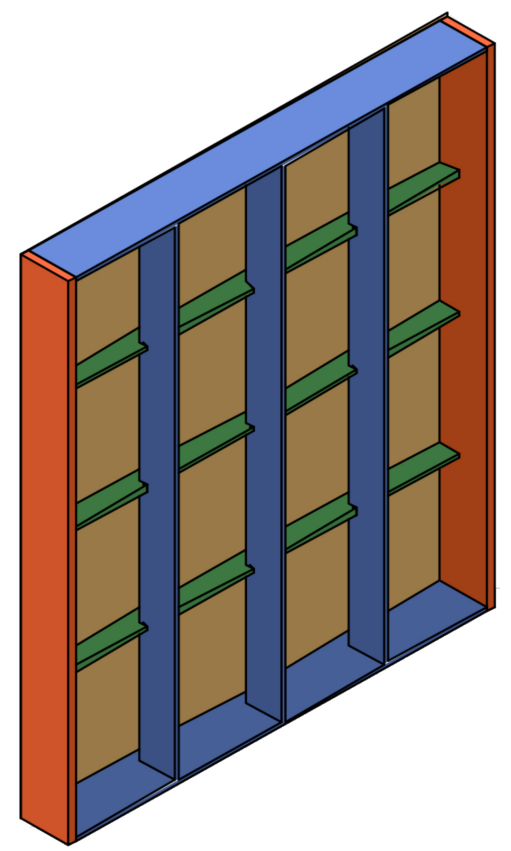

Figure 113: Interlocking Plywood Frame (JM)

A system of interlocked plywood webs was developed in an attempt to further mitigate the effects of thermal bridging [Figure 113]. This would greatly reduce the volume of framing in the wall thus increasing the amount of insulation and decreasing thermal bridging. There were however concerns over the structural capacity of the vertical webs to support the cladding system. Using 
plywood webs would also create difficulty when fixing sheathing, battens, linings etc into the $18 \mathrm{~mm}$ or $21 \mathrm{~mm}$ plywood edge. It was anticipated that this type of wall panel would be significantly more expensive than if standard framing was used and, perhaps more importantly, would incur additional cost as a "custom" item in the US quantity surveyors cost estimate.

Minor adjustments were made to further optimise the construction not only for thermal performance but also to improve structural integrity and reduce costs [Figure 114]. The studs are distributed across the wall panel to provide cladding support at $730 \mathrm{~mm}$ centres. 2x 90x45 timber studs and 1x 140x45 timber stud in the centre achieve the required rigidity for the panel. Internal $70 \times 45$ timber members at $645 \mathrm{~mm}$ centres span between the LVL perimeter studs and are blocked off the centre $140 \times 45$ timber stud. This outcome achieves a great degree of simplicity while meeting all of the required performance, structural, assembly and aesthetic requirements.

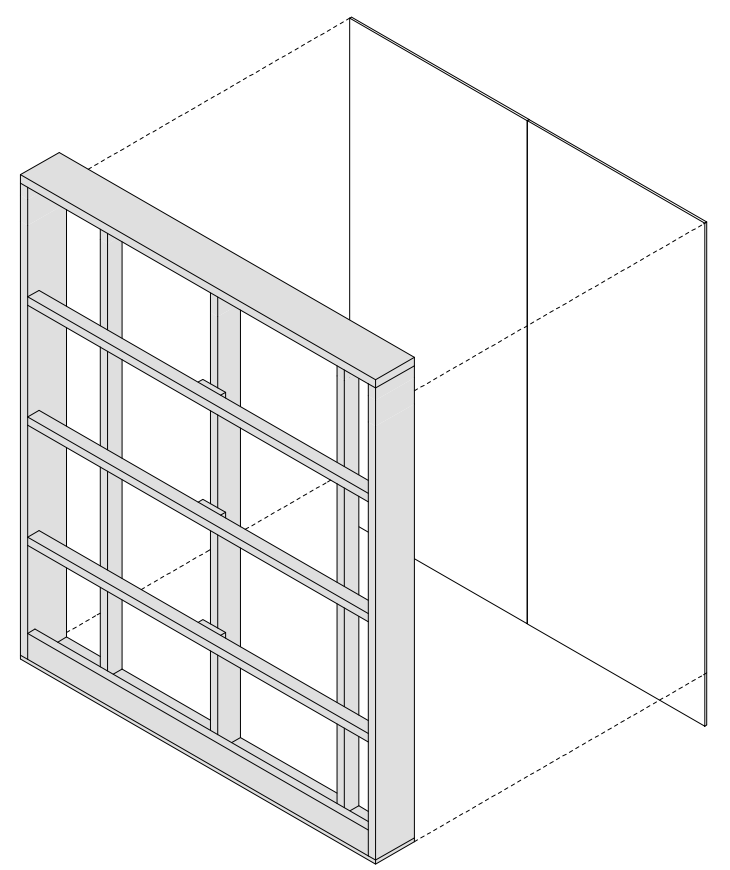

Figure 114: 3D Construction Drawing Showing Wall Framing

Window lintels were constructed with gusseted plywood frames rather than solid timber to further minimise any effects of thermal bridging [Figure 115]. Plywood was also used for the window jamb frame and bottom plates, again achieving an extremely efficient ratio of framing to insulation volume. The following photographs illustrate the as-built wall panels through their main steps of construction.

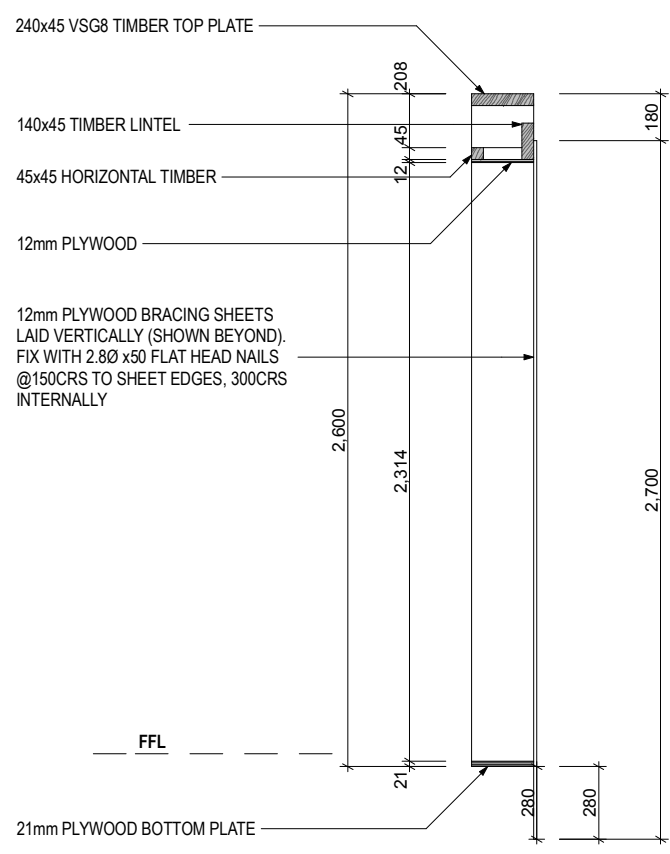

Figure 115: Section Through Window Opening

Figure 116: Construction Photo Showing the Manufacture of Wall Panels at Carters Pre-nail Plant

Figure 117: Construction Photo Showing Delivery of Prefabricated Wall Panels 


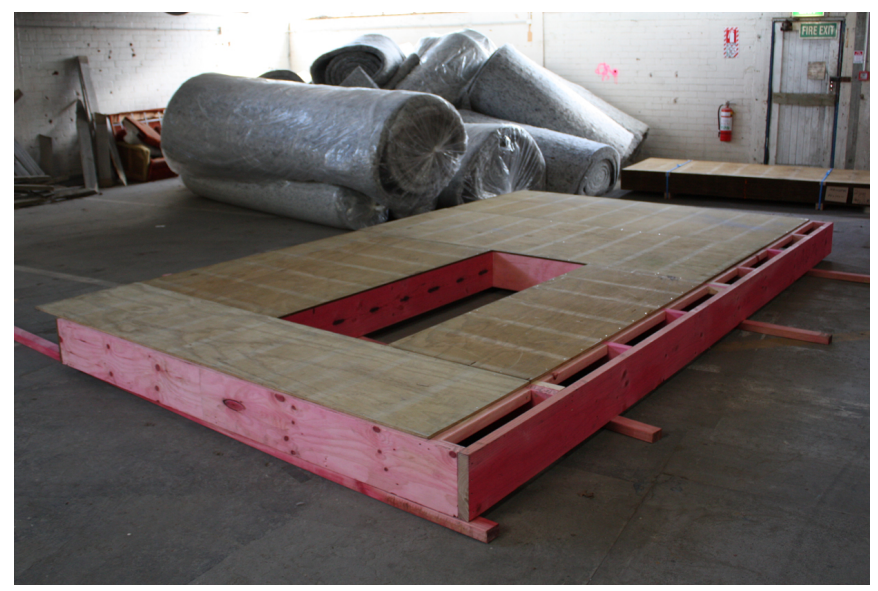

Figure 118: Construction Photo Showing Prefabricated Living Room Wall Panels

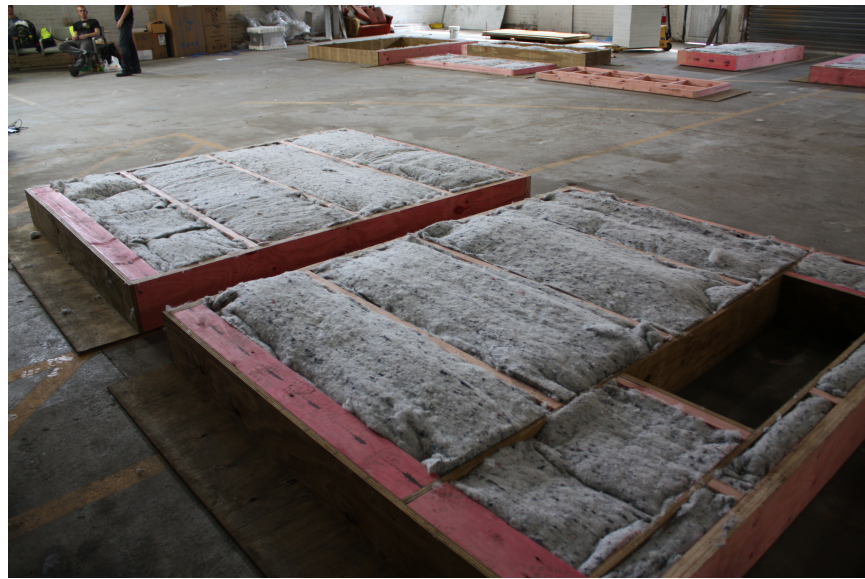

Figure 119: Construction Photo Showing Insulated Wall Panels

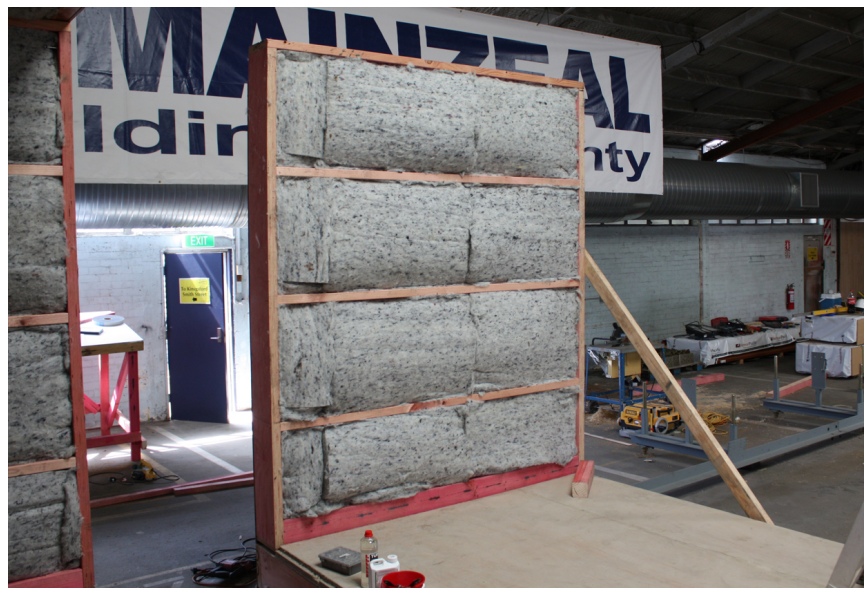

Figure 120: Construction Photo Showing Wall Panel Erected on Floor

\subsubsection{Air Tightness}

Through consultation with building performance specialists both in the private sector and at BRANZ, some fundamental deficiencies in the proposed wall construction were identified. A similar sandwich panel style construction to SIPs with a rigid air barrier (RAB) on either side of the wall was initially proposed. This type of arrangement in conjunction with batt insulation could lead to a damaging build up of moisture within the wall. This would potentially result in dramatically reduced thermal performance, mould, rot and ultimately the structural failure of the wall itself.

In typical New Zealand construction the wall is allowed to 'breathe' through the outside layer which is open to a drained and vented cavity behind cladding. There is also potential for the wall to ventilate to the inside through permeable gypsum linings.

Since it was of great advantage for the modules to be watertight during transport, it was elected to use plywood as the outer layer. This would also provide the required structural bracing and the protection against damage needed during both transport and assembly.

It is critical for the wall to have the capacity to ventilate or 'breathe' to promote the drying of any moisture that may build up within the construction itself. Having an RAB layer on the outside necessitated the use of an 'intelligent vapour membrane' on the inside. This would prevent the ingress of moisture into the wall while still promoting the transfer of moisture out of it. The use of 'intelligent' vapour membranes is a relatively new method of construction in New Zealand however products such as ProClima Intello are commonly used in much colder Northern Europe climates.

The typical practice in colder climates is to have an RAB on the inside of the wall and a more permeable outer layer. This is because the general direction of moisture diffusion is from the inside of the building to the outside. In a relatively neutral climate such as Wellington in New Zealand, moisture diffusion from the outside to the inside during summer is almost equal to the diffusion outwards in winter. Preliminary moisture diffusion analysis was performed using the software WUFI. This showed that no significant build up of moisture would occur in the wall assembly in Wellington, even without a vapour retarder on the inside (seasonal drying was sufficient to stabilise moisture levels within the wall). When simulated for colder climates however a noticeable build up of moisture was observed. Intello Vapour Check membrane is designed for use on the internal side of the envelope, providing a solution to this problem. It performs as an air 
barrier while at the same time offering high diffusion tightness in winter and maximum diffusion openness in summer (Proclima).

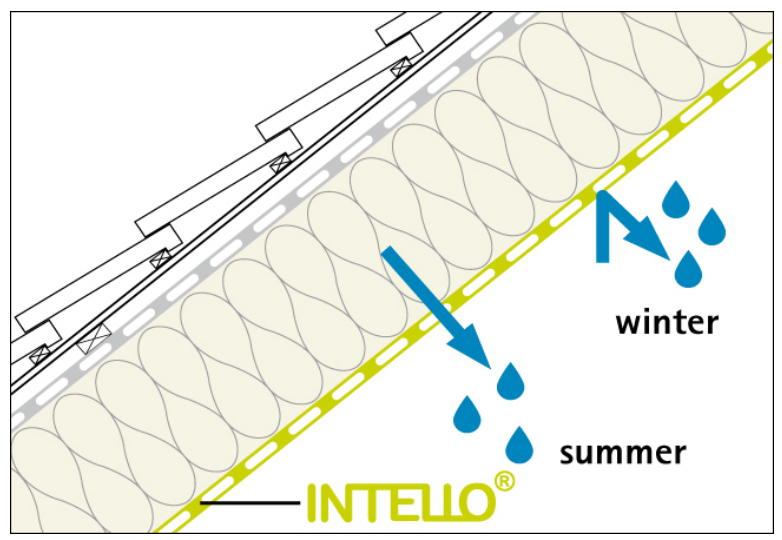

Figure 121: Diagram Showing Intello Vapour Diffusion (Proclima)

The use of Intello would consequently prevent the use of non-permeable internal linings such as plywood, which was currently specified by the interior design team. It was also determined that the proposed $25 \mathrm{~mm}$ cavity would not accommodate the amount of ventilation to allow moisture diffusion from behind the plywood.

Ultimately the decision was made to proceed with a RAB plywood layer on the outside and a ProClima Intello vapour check membrane on the inside [Figure 122 \& Figure 123]. Tescon Vana air tightness tape was used for all joins in the exterior plywood and as a sacrificial seal at the module join during assembly. The internal linings would need to be vapour permeable and for this reason vertically oriented pine tongue \& groove boards were used with a permeable white-wash finish.

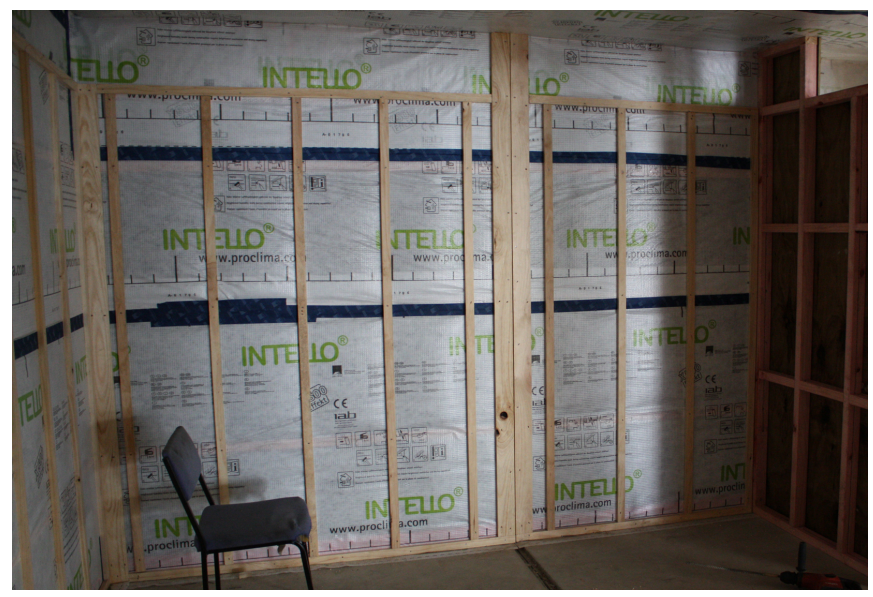

Figure 123: Construction Photo Showing Intello Vapour Check

The biggest challenge to the air tightness of the wall construction was in the services bulkhead where electrical cables, ducting, and plumbing necessitated multiple penetrations through the wall. A combination of Tescon Vana airtightness tape and proprietary ProClima expansion grommets were used to minimise air infiltration at these weak point

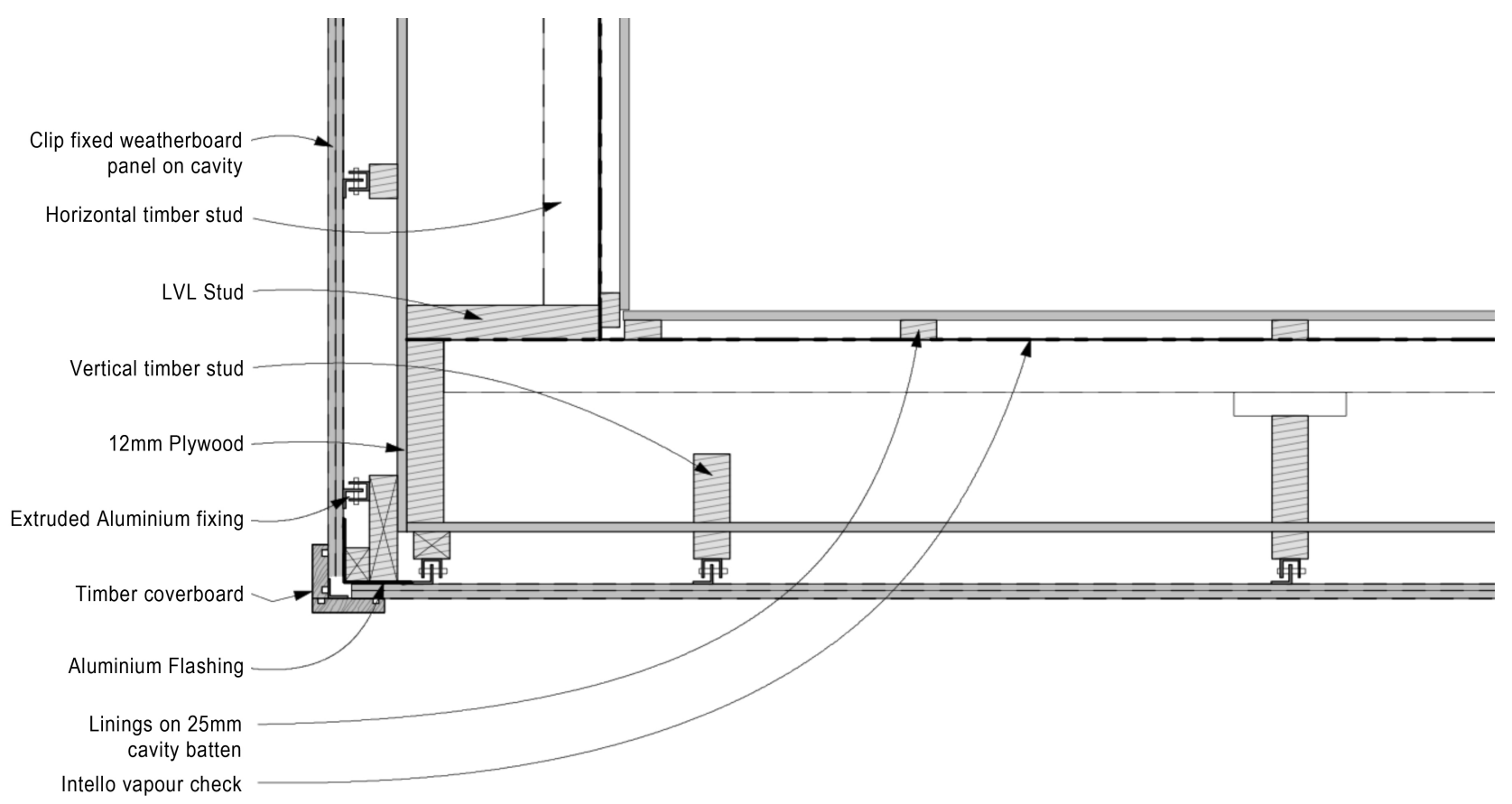

Figure 122: Plan Detail Showing Wall Construction and Intello Vapour Check (JM) 


\subsubsection{Assembly}

The assembly strategy for the wall panels was very simple - provide a flush edge that is true and that will create a tight fit with the adjacent module. The initially proposed bolted system proved to add unnecessary complexity to the process. The removable access panels would also make for a potentially messy internal finish. To avoid this problem the access panels could be located on the outside of the walls however this could not be the case for the roof and floor.

\section{DIAPHRAGM}
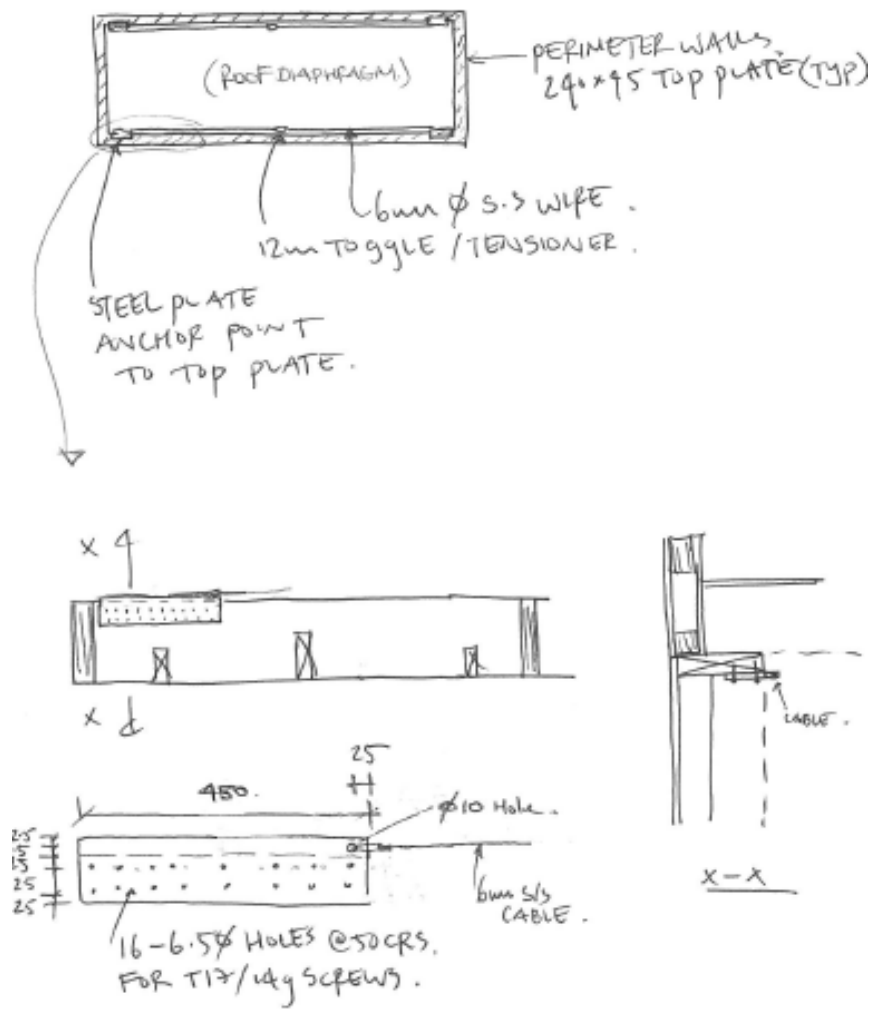

Figure 124: Engineers Sketch Showing S/S Steel Tension Cables

To simplify the assembly process $2 \mathrm{x}$ adjustable $\mathrm{s} / \mathrm{s}$ (stainless steel) cables were employed to hold the modules together. These cables are attached to the top plate of the walls in modules $1 \& 6$ [Figure 124]. The cables are then concealed behind a removable scotia. During assembly the cables are attached and tightened using a tensioner located above the entrance doors in module three. It was specified by the engineer that once tensioned the cables "should be capable of producing a low E note once struck". As discussed in Chapter 3 FOUNDATIONS, some of the foundation pads sunk at the competition site, causing the entire house to splay at the top. This put a significant amount of force into the s/s cables. The system held together, as designed. However when it came to removing the $\mathrm{s} / \mathrm{s}$ cables during dissassembly, the excessive force made it impossible to undo the tensioner. The locking pin had to be 'tapped' out and the cable left to spring loose. Health and safety concerns were raised as to the destructive consequences that releasing the cable could have. To reduce the amount of force on the cables and mitigate the splaying effect, several truckstrops were linked together around the top of the entire house and tightened. The windows and doors were covered and the house evacuated of students.

\subsubsection{Damage}

Fundamental materials for the wall construction were already confirmed during the developed design phase. Plywood sheathing would be used on the exterior for weatherproofing as well as bracing and protection to the modules during transport. LVL perimeter studs would provide the required structural strength but more importantly a robust edge to the wall. The laminations give the plywood and LVL dimensional stability particularly in varying humidities and temperatures - a critical factor for transport.

\subsubsection{Cost}

(Including cladding, shed doors and excluding internal finishes)

Initial RLB US estimate $=$ US $\$ 28,600$

Final DOE QS US estimate $=$ US $\$ 31,500$

Initial RLB NZ estimate $=\$ 20,500$ (excl. cladding and doors)

Final RLB NZ estimate $=\$ 62,850$

Actual NZ Cost $=$ Unknown 


\subsection{WINDOWS AND DOORS}

Windows and doors present one of the biggest performance challenges to designing a house to passive principles. They create clear weak points due to the low insulation value of the glass, the thermal bridging of the frame, opening components and their seals, and the direct solar gains which they allow. The First Light concept called for light, open spaces, extensive views to the outside, and an ability to naturally ventilate the house, all of which suggest a large amount of glazing. Again, through the use of computer simulations, an acceptable compromise between glazing for views, light and ventilation vs. the overall thermal performance of the envelope was reached. To make the most of solar gains in winter, the majority of glazing would be located on the South façade with minimal glazing to the North. The North windows were primarily used to provide light and ventilation in the bathroom and laundry. The South windows would require adequate shading to prevent overheating in summer while still promoting the desired heat gains in winter. Central to the design concept was the notion that full views and access should be maintained through the middle of the house. This was achieved with large 3-leaf glazed bifold doors to the north and south of the central module. To further promote this space as an expression of the outdoors, a large skylight was also incorporated. The optimisation of this skylight required significant investigation and will be later explained in Chapter 6 MODULE THREE CONSTRUCTION.

There are four primary types of window frame available in New Zealand; aluminium, thermally broken aluminium, timber, and PVC. PVC was ruled out due to environmental concerns coupled with the 'plastic' look of the frame itself. Through research it was discovered that standard aluminium frames create a significant thermal weak point due their conductivity. Two options remained; thermally broken alumnium and timber [Figure 126]. It was specified that triple glazing should be used to achieve the best possible insulation value of the glazed unit itself. These would be in the form of triple argon filled, low E IGU's (Insulated Glazing Units) [Figure 126].

\section{TIMBER FRAME}
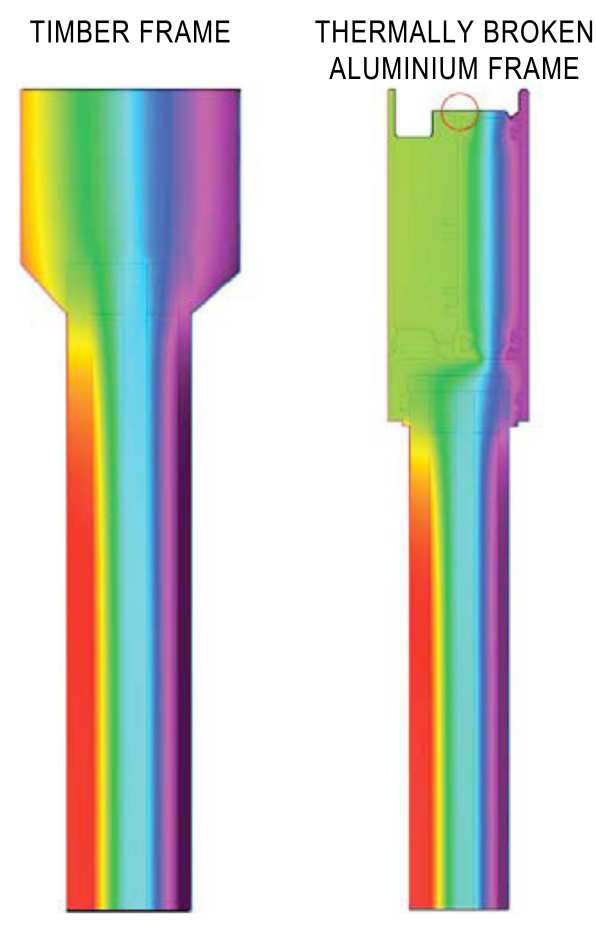

Figure 125: Thermal Bridging Simulation for Timber Frame vs. Thermally Broken Aluminium Frame

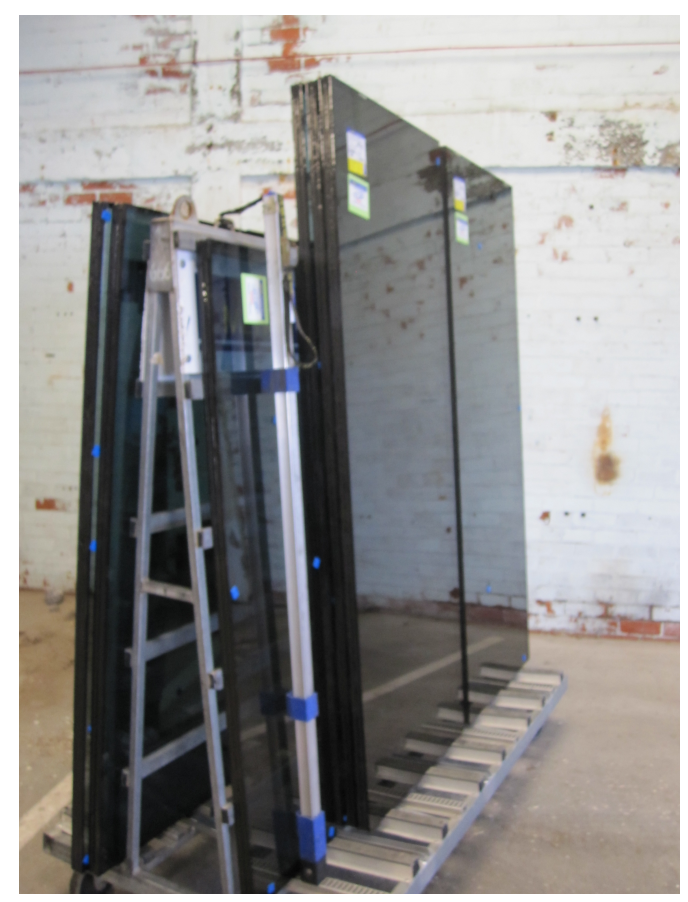

Figure 126: Triple Glazed IGU'S - Metro Glasstech

Triple glazing is not common in New Zealand and most available frames were not sized to accommodate the additional thickness of the IGU. Timber proved to allow the greatest flexibility in this respect. Timber would also give the desired aesthetic finish and as such the search was narrowed to two local window manufacturers: Nelson based company Eurovision and Ecowindows in Raglan. 
Comparative performance characteristics and costs involved for each were as follows:

\section{Eurovision}

Frame Type: Aluminium outside / timber inside

\begin{tabular}{|l|l|l|l|}
\hline IGU & U-Value & $\begin{array}{l}\text { COST (incl } \\
\text { GST 15\%) }\end{array}$ & Start Date \\
\hline $\begin{array}{l}\text { Dbl argon } \\
\text { fill lowE }\end{array}$ & 1.3 & $\$ 31,660.15$ & $\begin{array}{l}\text { End of } \\
\text { Sept }\end{array}$ \\
\hline $\begin{array}{l}\text { Trpl argon } \\
\text { fill lowE }\end{array}$ & 0.9 & $\$ 34,139.85$ & $\begin{array}{l}\text { End of } \\
\text { Sept }\end{array}$ \\
\hline
\end{tabular}

\section{EcoWindows}

Frame Type: All timber

\begin{tabular}{|l|l|l|l|}
\hline IGU & U-Value & $\begin{array}{l}\text { COST (incl } \\
\text { GST 15\%) }\end{array}$ & Start Date \\
\hline $\begin{array}{l}\text { Dbl argon } \\
\text { fill lowE }\end{array}$ & 1.5 & $\$ 22,457.20$ & Mid Nov \\
\hline $\begin{array}{l}\text { Trpl argon } \\
\text { fill lowE }\end{array}$ & 1.0 & $\$ 24,715.80$ & Mid Nov \\
\hline
\end{tabular}

Ecowindows were elected to manufacture the windows. Although their windows would achieve a slightly lower insulation value (by R0.11 or $10 \%$ ), they were $\$ 9,400$ $(27 \%)$ cheaper, and had a shorter manufacture time. Ecowindows were also more forthcoming with sponsorship.

An interesting fact to note here is the minimal increase in cost from double to triple glazing (approx. $\$ 2,370$ or $7.8 \%$ - $10.1 \%$ ). This would suggest that a great degree of cost exists in the frames themselves and perhaps also in the setting up of the double and/or triple glazing process. However these costs are again specific to this project and may not reflect the general pricing in the marketplace.

Given the unavailability of New Zealand made, high performance window hardware, Ecowindows utilises hardware from Germany based company Siegenia-Aubi [Figure 127]. Siegenia-Aubi had experience with past Solar Decathlons and thus also saw value in sponsoring the project. This hardware enabled the First Light house to incorporate 'tilt-and-turn' style windows. These windows are inward opening and are hinged at both the bottom and the side. This allows the window sash to either tilt in at the top for ventilation or open inwards from the side. Tilt \& turn windows were used in the bathroom, laundry and bedroom, and a bottom hung only window was used in the living room.

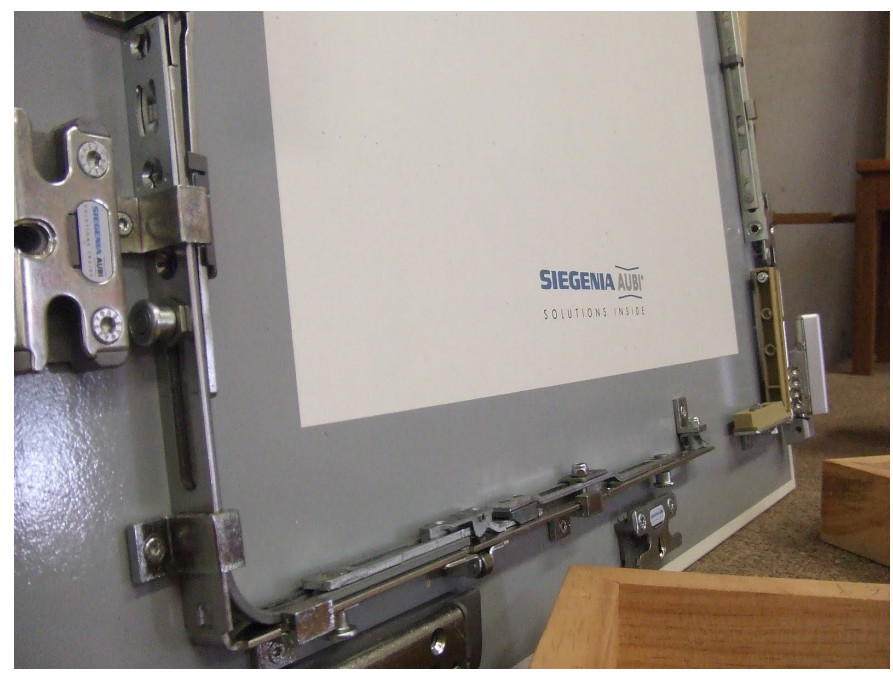

Figure 127: Window Hardware By Siegenia-Aubi

The large bifold doors are also timber framed with triple glazed IGU's. They incorporate high quality rubber seals to achieve air tightness and an aluminium floor track. The sheer weight of the IGU's in these doors put significant strain on the hinges. As a result the doors began to sag over the course of the Frank Kitts Park exhibit. To overcome this problem an additional hinge was installed to help better distribute the weight. The aluminium door track proved to be the biggest thermal weak point of the entire house. The timber framed windows themselves however demonstrated very uniform thermal performance, as was expected.

Custom formed flashings were designed and fabricated for each window and door [Figure 128]. A removable sill portion of the flashing was incorporated to expell any water to the outside of the cladding.

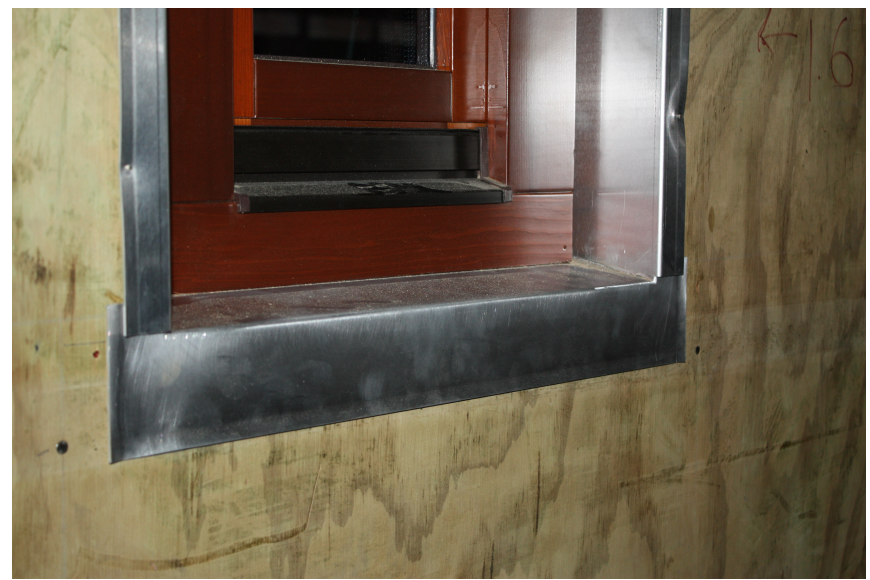

Figure 128: Construction Photo Showing Window Sill and Jamb Flashings 


\subsection{CLADDING}

The cladding was designed to be removed for transport and 'clipped-on' during assembly. This would enable continuous horizontal weatherboards to traverse the module joins, elongating the house visually while also providing an effective weatherproofing to the module join and protection for the cladding during transport.

A proprietary removable cladding system suited to the First Light house was not currently available on the market. The team needed to develop a new solution by either utilizing available components or by fabricating custom ones. It had already been decided that standard profile horizontal timber weatherboards would be used. To enable the many rain water downpipes (Section 9.0 Roofs) to be concealed behind the cladding, a minimum cavity of $70 \mathrm{~mm}$ was incorporated. For tolerance, this cavity was later increased to $82 \mathrm{~mm}$ during construction.

The weatherboards are arranged in panels of several weatherboards fixed together for ease of assembly. While the containerised panels were not susceptible to the same risks of damage as the modules, they did incur some surface damage through manual handling.

\subsubsection{Cladding Version 1.0 - Slip Battens}

The first system explored was a simple slip batten arrangement where a timber support interlocked with a corresponding slip batten on the back of the cladding panel. Each panel would then be fixed through the tongue of the top weatherboard with a bolt into a recessed nut in the cavity batten [Figure 131]. A neoprene layer or similar compressible material would be required to prevent the panels from rattling in the wind [Figure 129 \& Figure 130]. This system would be very quick to both assemble and disassemble. The support of the slip batten would allow 2 to 3 people to mount the panel easily and then fix it in place with hand drills. This method would also promote the desired finish with all fixings concealed behind the lap of the weatherboard panel above. Corner, window, and parapet details were yet to be developed.
Figure 129: Cladding Version 1.0 - Detail of Timber Support and Neoprene Dampener (BL)

Figure 130: Cladding Version 1.0 - Detail of Neoprene Dampener $(B L)$

Although drawings were prepared for the construction of a test prototype, this was never executed due to a shortfall in time and office resources. Many discussions were held alongside advice from senior architects within the First Light office. Concerns over this system were raised due to the potential inaccuracy in using timber as a locating medium. This system would rely on the precise alignment of the slip battens relative to both the weatherboards and the cavity batten. There was also a risk of compounding inaccuracies due to the panels being stacked one on top of the other, one slip batten out of line could throw the entire arrangement out. The inset nuts were employed to prevent this problem. This would work successfully however the system would then rely on the accurate compression of the neoprene buffer in order to prevent the panels from protruding at the bottom. There were also unknowns as to the extent to which the timber itself would deform over time and in varying climates. An alternative method was sought, based on the same principles but using more robust materials. 


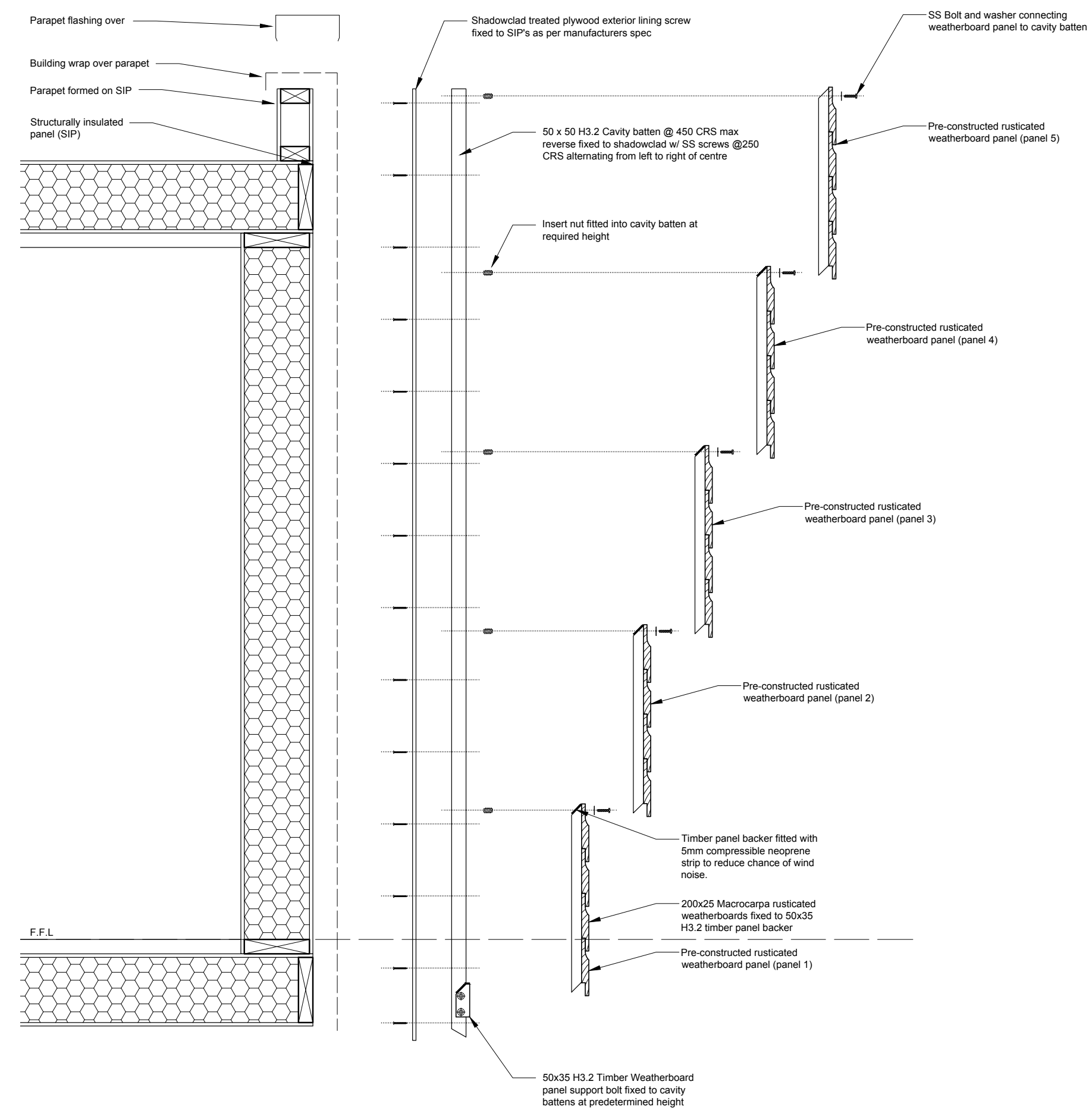

Figure 131: Cladding Version 1.0 (BL) 


\subsubsection{Cladding Version 2.0 - Aluminium Channels}

Concerns with the first cladding system were primarily centred on the issue of accuracy, both at production and during reassembly. A removable cladding system suited to the First Light house was neither tested nor available. Furthermore, there was little time in the programme for experimentation and almost no margin for error should the system fail during construction. For this reason a solution that achieved a maximum degree of accuracy was critical.

A second system was developed which relied on the use of aluminium channels for both the cavity battens and the cladding panel supports. A similar principle to the first version was employed whereby a series of weatherboards would be assembled into panels, which then rely on a gravity "slip" method to be mounted in place [Figure 133]. Rather than the angled timber batten this system incorporated an aluminium peg as part of the aluminium cavity batten and a corresponding slot in the aluminium cladding support channel [Figure 132].

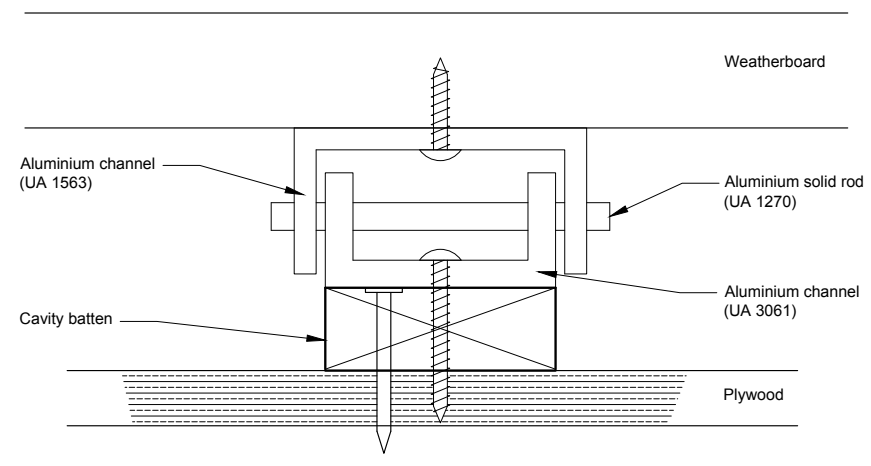

Figure 132: Cladding Version 2.0 - Plan Detail Showing Clipping Method (BL)

A combination of gravity and the proceeding cladding panel negated the requirement for any mechanical fixings. This system could be assembled extremely quickly and with minimal skill. Given the timeframe for assembly, and the level of experience of the student team, this easy and simple solution proved to be very attractive. The continuous aluminium cavity channel ensured that there would be no movement of the location pegs through use, transport, or multiple assemblies. The corresponding aluminium cladding channels provided the same advantage. This system would however rely on millimetre precision during the manufacturing process. Each cladding panel required consistent contact between the pegs and the slots along the length of the panel to ensure an even distribution of load and support. These channels would have to be machine cut using CNC (computer numerical control) or laser machinery.

The team was confident that this system would provide the level of accuracy, speed and ease of assembly needed for a successful finish to the house. 


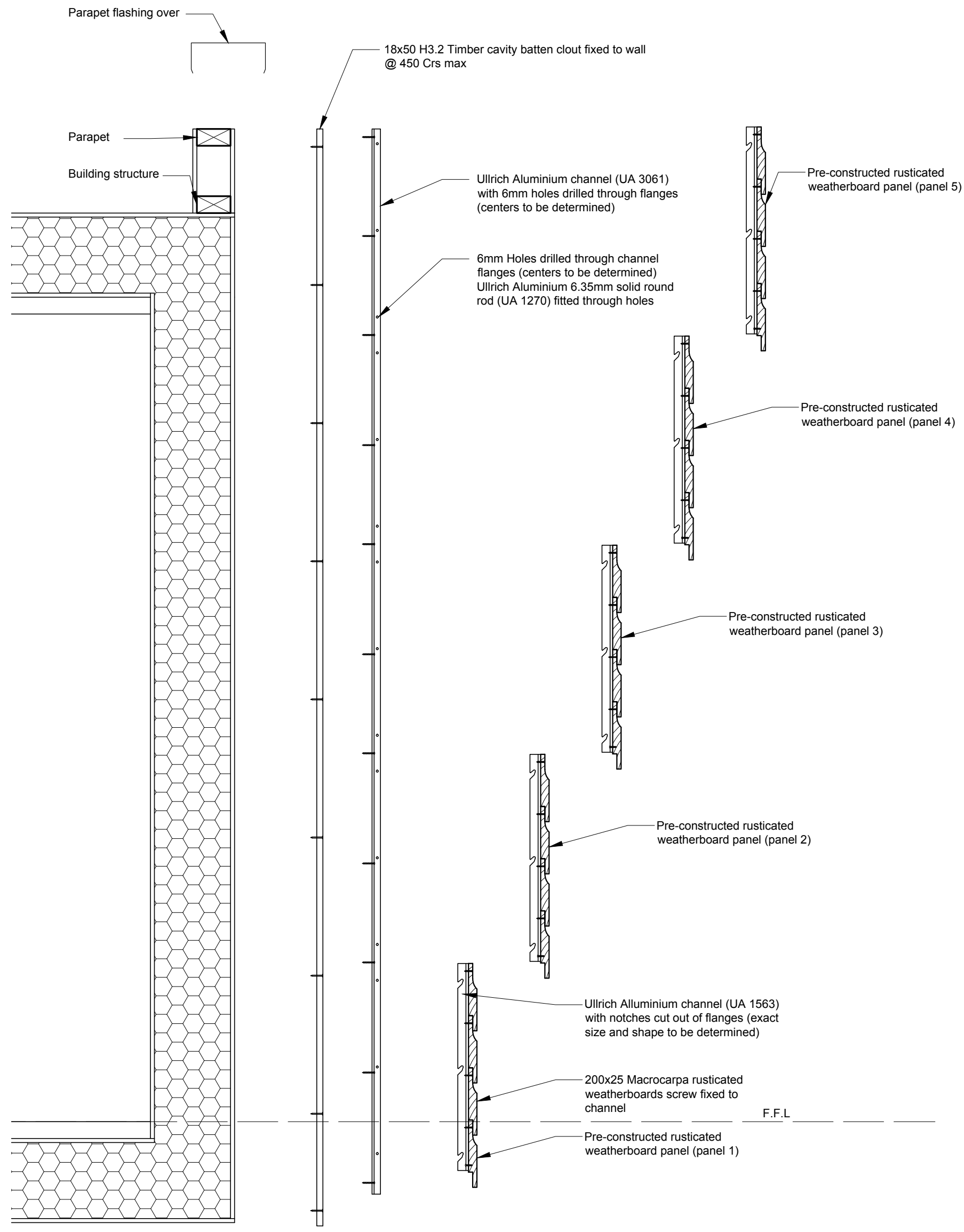

Figure 133: Cladding Version 2.0 - Section (BL) 


\subsubsection{Cladding Version 3.0 - Slots}

It was anticipated that some difficulty and additional cost would be incurred due to the use of custom machined aluminium channels. In an attempt to avoid the use of $\mathrm{CNC}$ or laser cutting two alternative systems were explored.

One option was to use a locating timber base block, similar to that used in Cladding Version 1.0, which the aluminium angle or timber cladding batten could "hook" onto. The top weatherboard of each panel would then slot into the gap created between the bottom weatherboard and the cladding channel of the above panel [Figure 135]. The top of the weatherboard would be direct fixed to a timber cavity batten. This fixing would then be concealed by the overlap of the weatherboard panel above. The cladding panels are held together with alternating timber and aluminium angle supports, and the system utilises timber cavity battens, quartering the use of aluminium compared to version 2.0 .

This system would rely on the interlocking of the top and bottom weatherboards of the panels to both locate and hold each one in place [Figure 134]. The aluminium provides accuracy and resistance to deformation for the panels. As with Version 1.0, fixings are required and great care is needed when mounting to avoid damaging the fragile top edge of the weatherboard.

This system would not be as accurate as version 2.0 however some flexibility and adjustability could be achieved with the direct fixing of the top of each cladding panel.

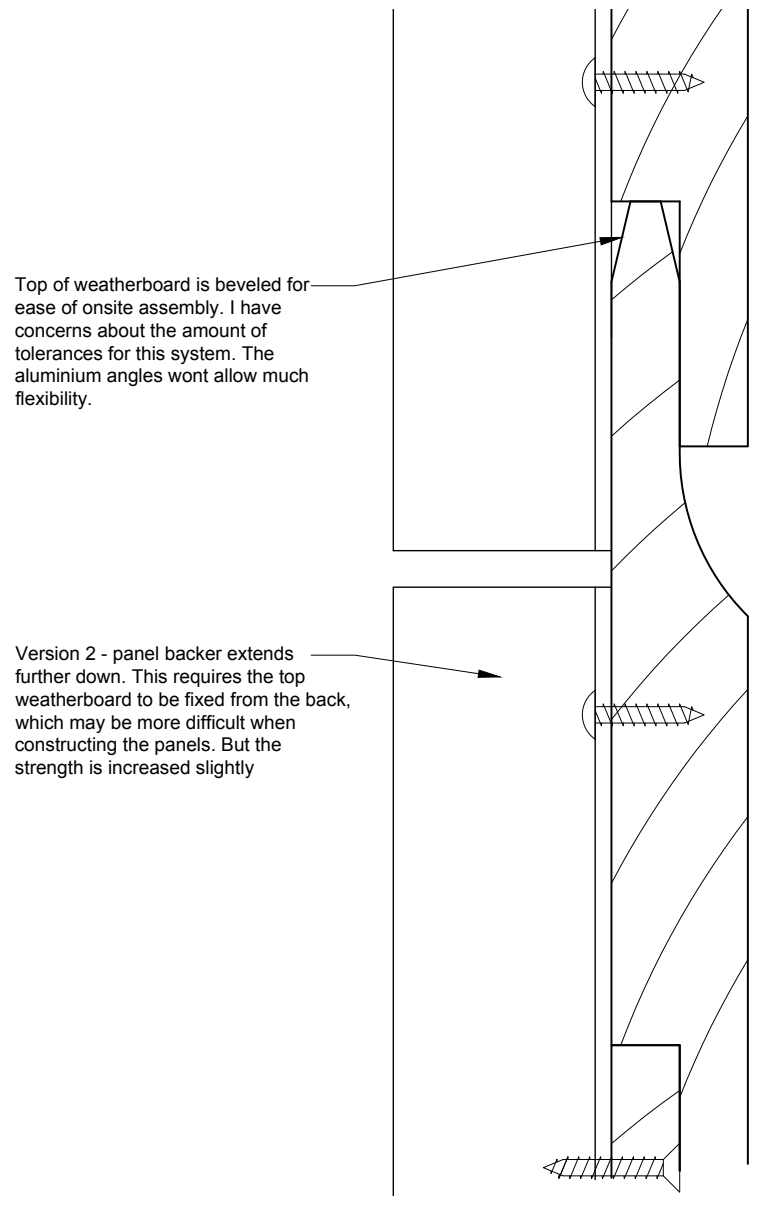

Figure 134: Cladding Version 3.0 - Section Detail Showing Lapping of Weatherboard Panels (BL) 


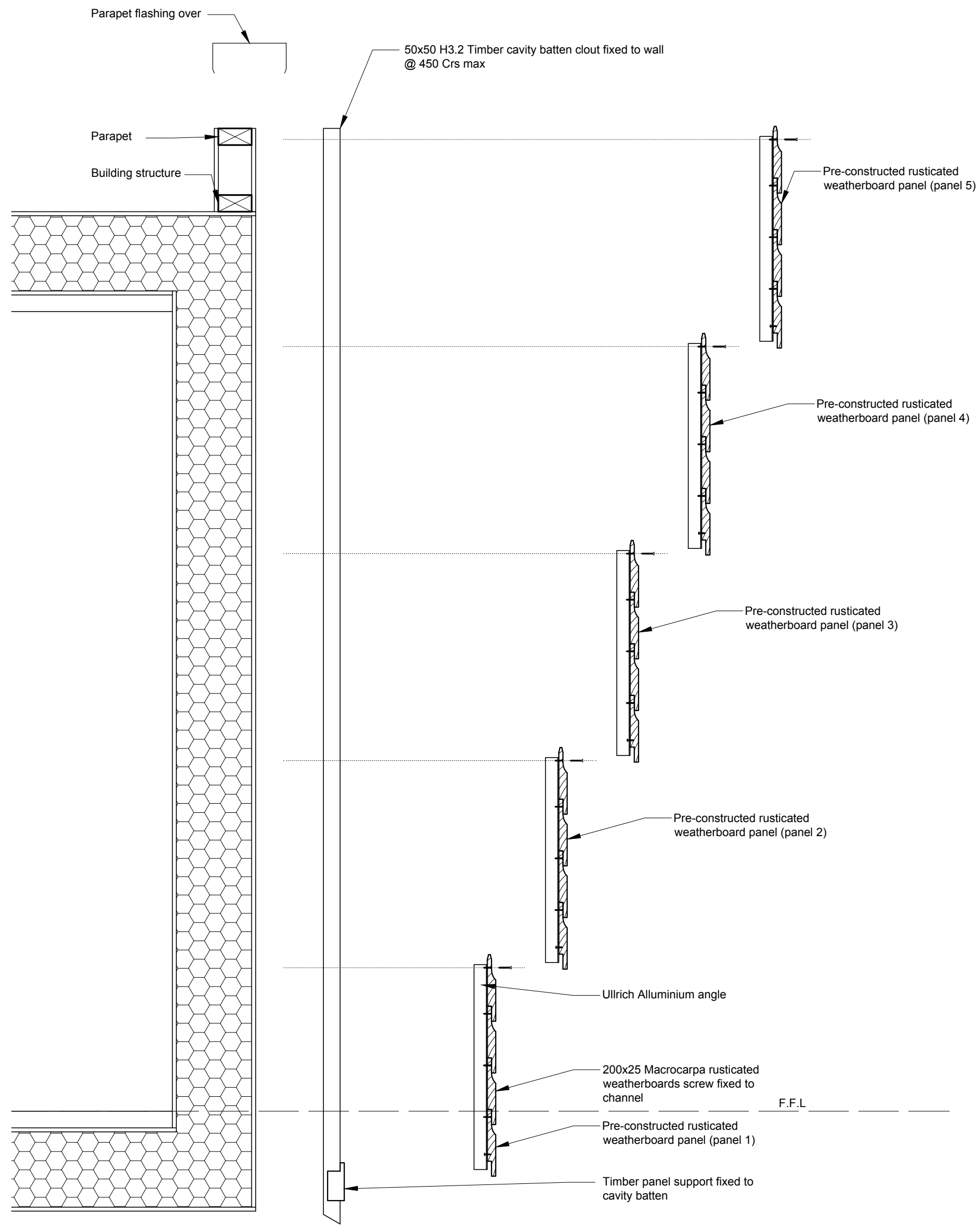

Figure 135: Cladding Version 3.0 - Section (BL) 


\subsubsection{Cladding Version 4.0 - Sherpa Connectors}

The "Sherpa System" was explored as a means of employing an already available fixing component [Figure 136]. Sherpa connectors are precision formed aluminium components which slide together to provide an easily demountable connection.

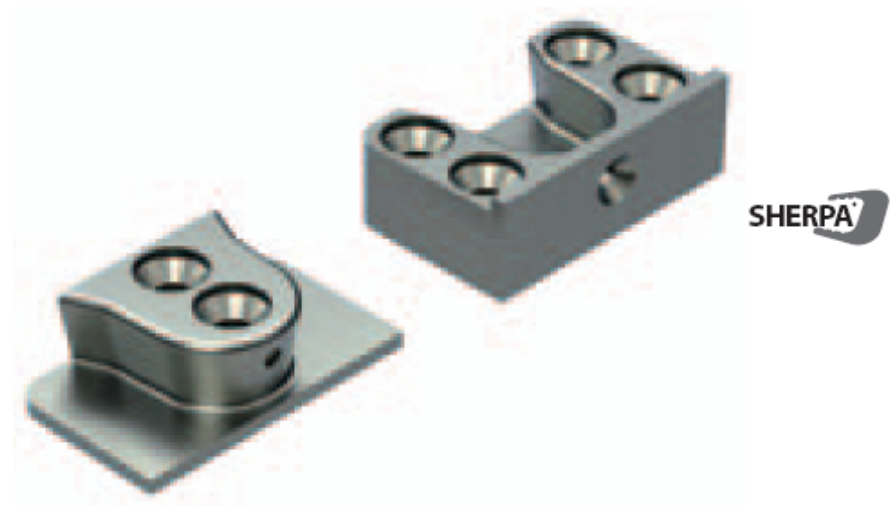

Figure 136: Cladding Version 4.0 - Sherpa WTS3 Spezial Connectors (Sherpa)

This cladding system would again incorporate alternating timber batten and aluminium angle cladding panel supports and timber cavity battens. The Sherpa connectors would be located at the top and bottom of each cladding panel corresponding with Sherpa connectors mounted to the cavity batten [Figure 137 \& Figure 138]. The panels would then simply slot onto the wall. A slight variation of this system could incorporate Sherpa connectors along the bottom edge of the panel only with direct fixings holding the top of the panel, halving the quanitity of potentially expensive Sherpa connectors.

This system would provide a very accurate and smooth mounting of the cladding panels provided they were fabricated accurately and there was no movement in the system over time. The accurate alignment during construction of Sherpa wall connectors relative to the corresponding connectors of the panels had yet to be resolved. 


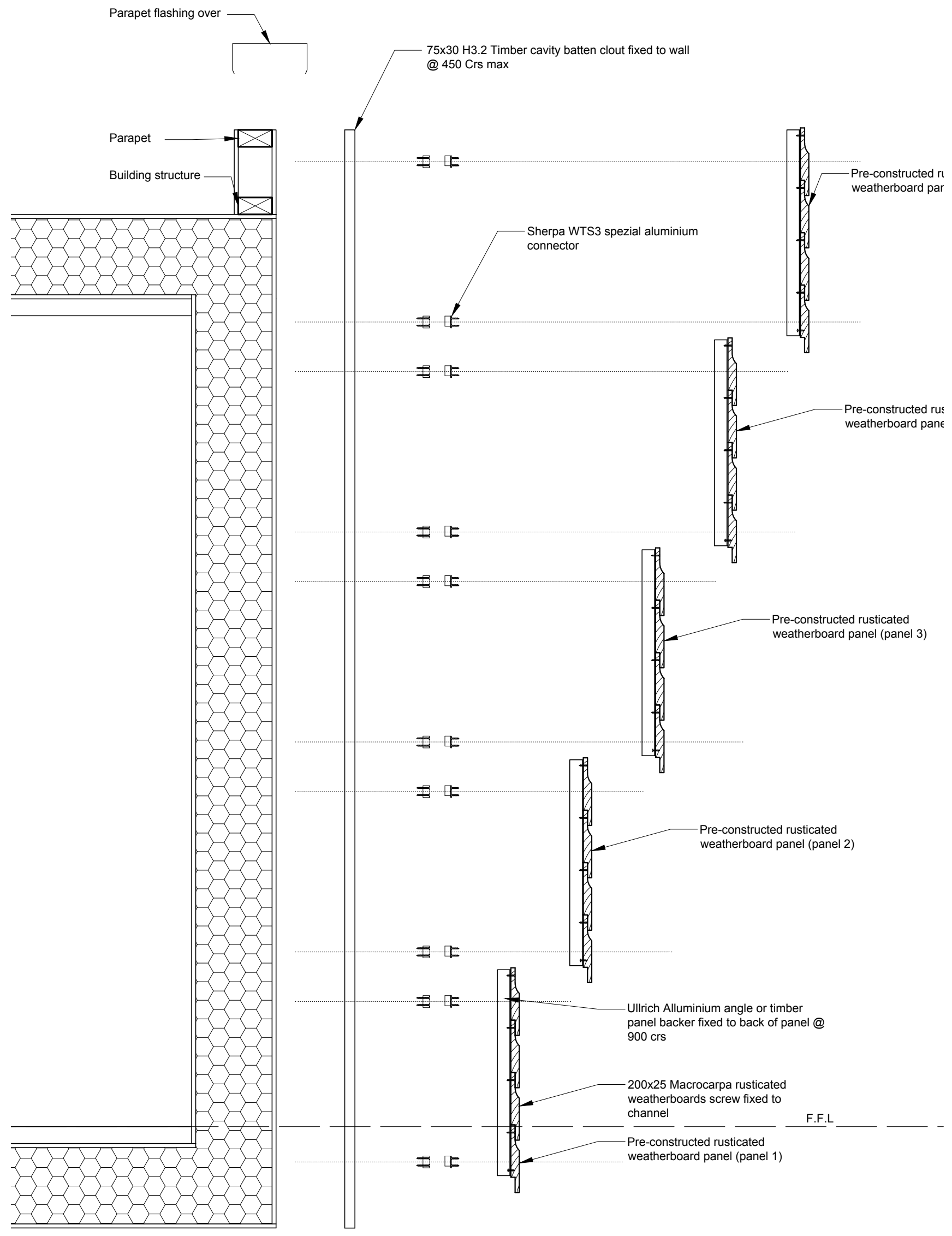

Figure 138: Cladding Version 4.0 - Section (BL) 


\subsubsection{Cladding Version 2.1 - Prototype}

It was determined that Cladding Version 2.0 had the most potential for achieving the desired level of accuracy and ease of assembly. A prototype for this method was investigated to test for any problems or difficulties that may arise during construction and reassembly [Figure 142 \& Figure 143]. An increase in the depth of the aluminium channels relative to the initial version was incorporated as a means to reduce the volume of aluminium and to simplify construction.

The prototype was made by hand using standard workshop tools and machines [Figure 139, Figure 140 \& Figure 141]. Great difficulty was found in constructing the system without the use of CNC or Laser cutting. An accurate solution was obtained but it took a lot of time and effort.

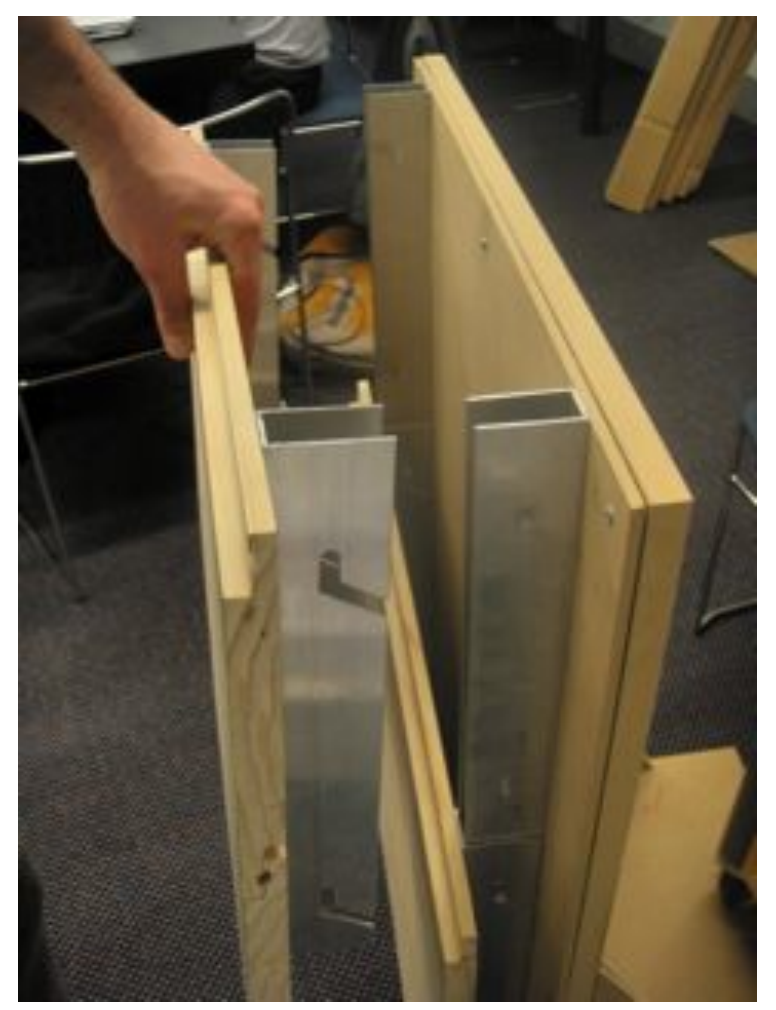

Figure 139: Cladding Version 2.1 - Photo 1 of Prototype (EH)

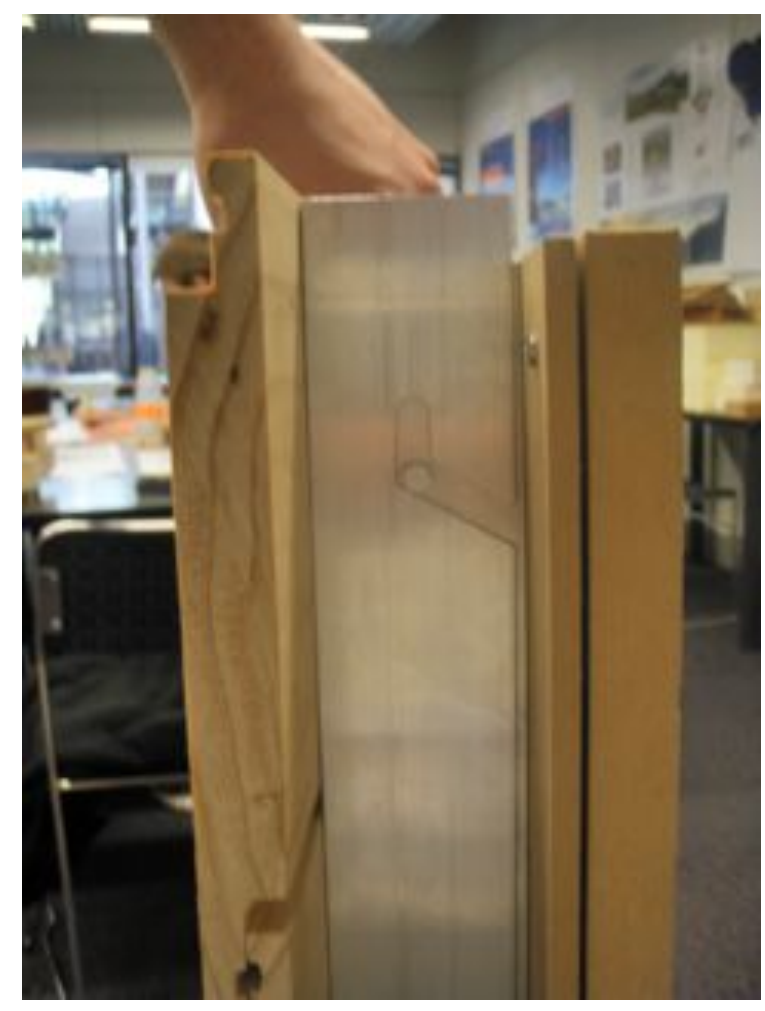

Figure 140: Cladding Version 2.1 - Photo 2 of Prototype (EH)

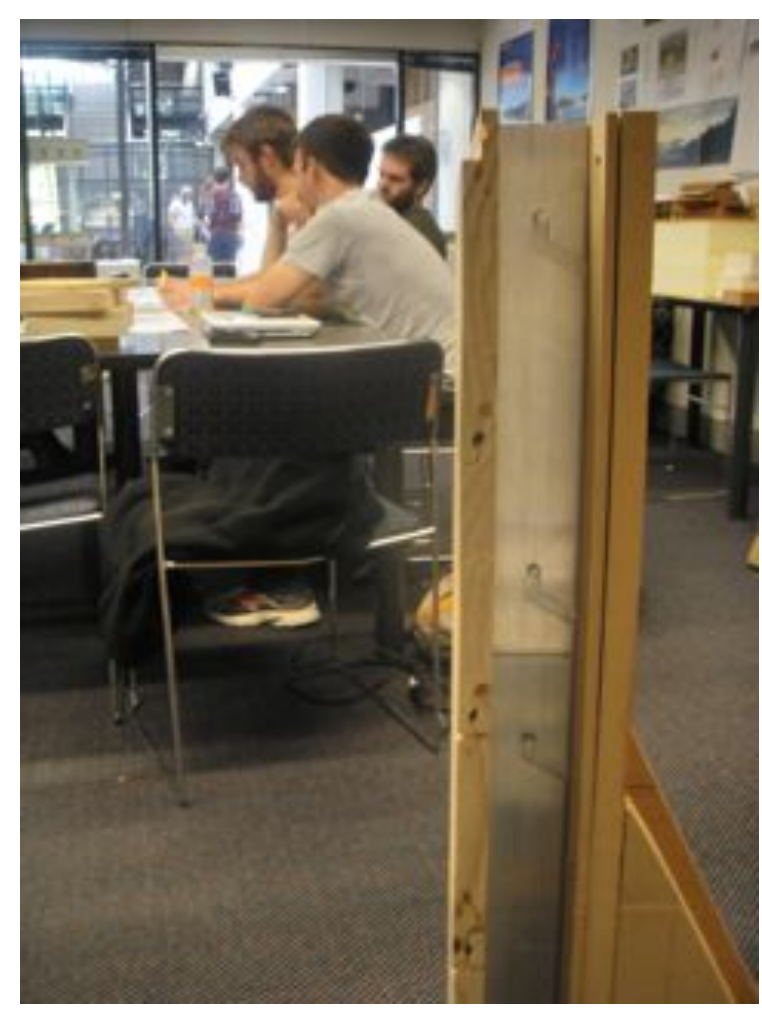

Figure 141: Cladding Version 2.1 - Photo 3 of Prototype (EH) 


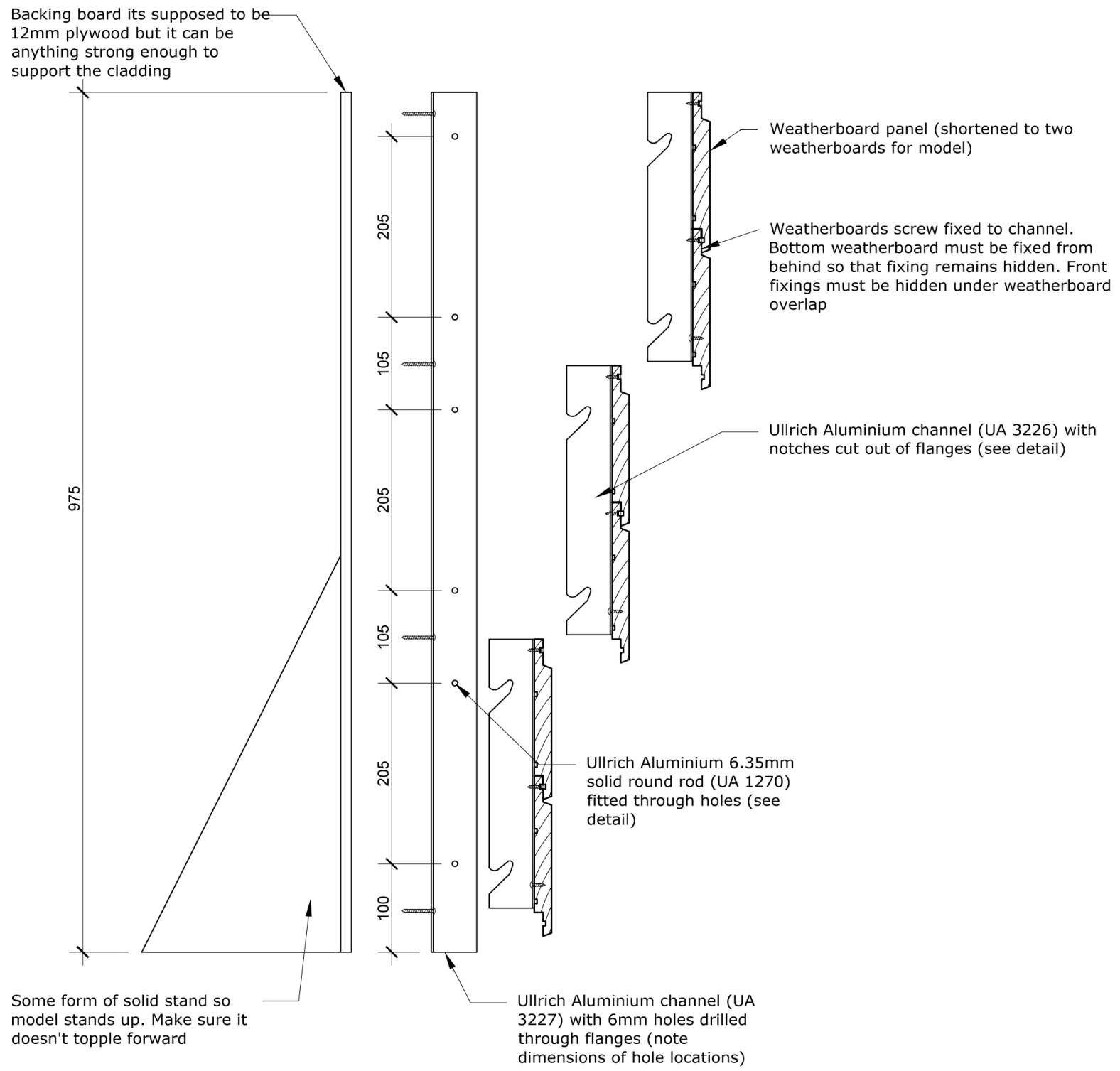

Figure 142: Cladding Version 2.1 - Section Detail for Prototype (BL)

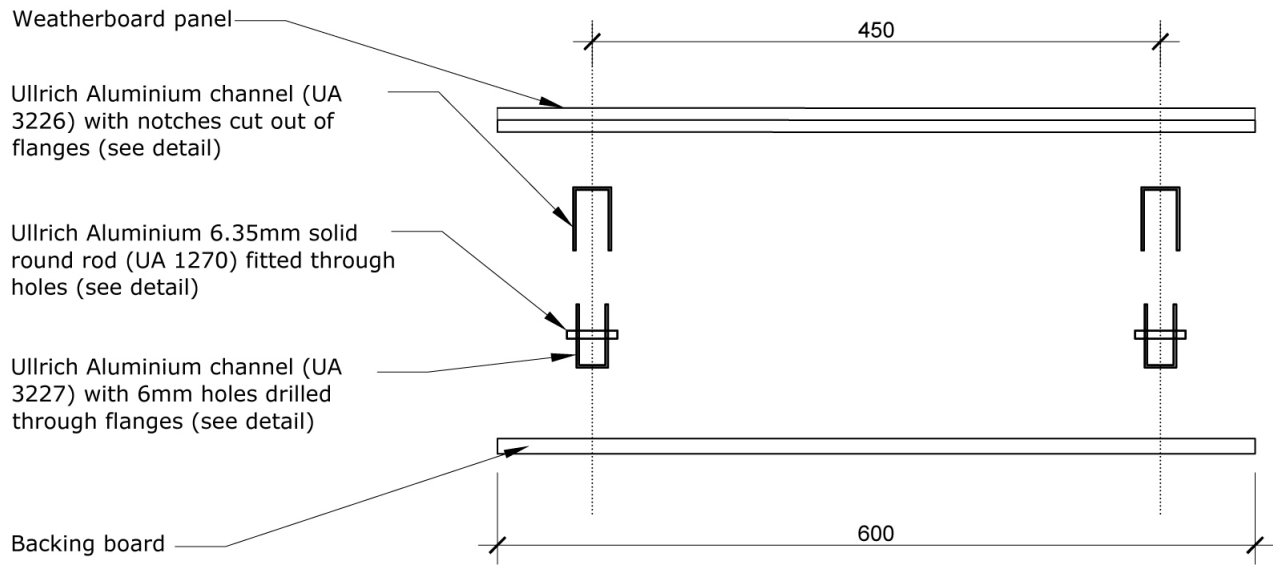

Figure 143: Cladding Version 2.1 - Plan Detail for Prototype (BL) 
It was found that the cladding panel would mount and hold its location firmly and accurately. Difficulty was however experienced in lining up the interlocking pegs and slots while at the same time fitting the cavity channel inside the cladding channel. It is important to note also that the prototype was of a small section of the system and that only two of the channels were required to be interlocked. All of the pegs needed to be lined up with the corresponding slots before the two could be fitted together. This was achievable with the scale prototype but would likely cause major problems with a full scale system.

The interlocking of the two channels provided millimetre perfect lateral accuracy. The lack of any tolerance in this direction however resulted in the panels getting stuck. This is the same problem that would have been encountered with the Sherpa system since it located both vertically and laterally. There was also very limited tolerance in the vertical direction of the system. Although the panel could move upwards it relied on the even support of the slots on the pegs. If one peg was too high it would carry the majority of the weight of the panel potentially deforming or splitting the individual weatherboards.

It was also found that the angle of the slot allowed a degree of movement at the bottom of the cladding panel. If the arrangement was not perfectly aligned there was the possibility that the panel would rotate about one of the pegs causing either the top or bottom of the weatherboard panel to rattle and protrude.

A further cladding iteration was explored with the intent of mitigating the problems experienced with this prototype.

\subsubsection{Cladding Version 2.2 - The As Built Solution}

To alleviate the problem of the aluminium channels clashing and/or becoming stuck due to the lateral intolerance, the cladding panel channel was replaced with an aluminium angle [Figure 144]. The aluminium angle was set to the centre of the cavity channel allowing a lateral tolerance of $+/-12 \mathrm{~mm}$ along the length of the panel. It was envisioned that "locking" channels would only be required at the two ends of the panel ensuring an accurate overall location for each panel. The locking channels incorporated a $2 \mathrm{~mm}$ thick plastic buffer as a means for locating the angle [Figure 145]

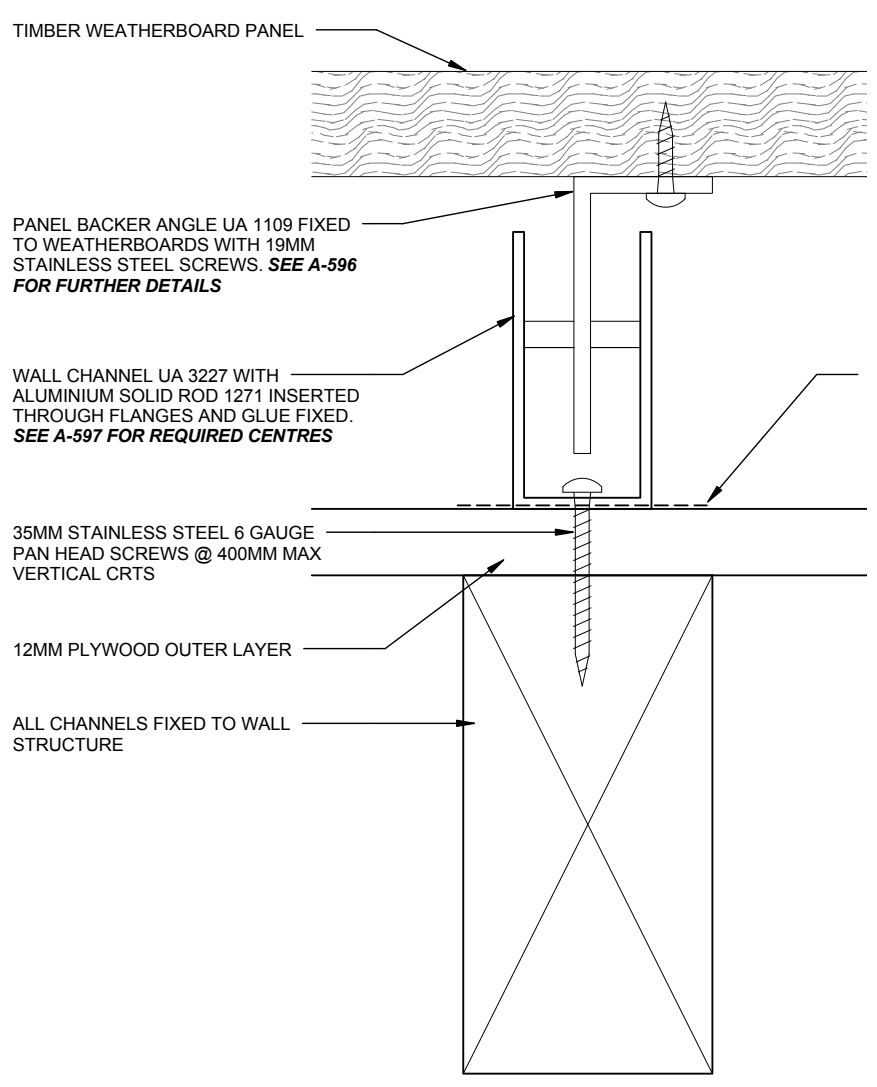

Figure 144: Cladding Version 2.2 - Plan Detail Showing Angle Used for Tolerance (BL)

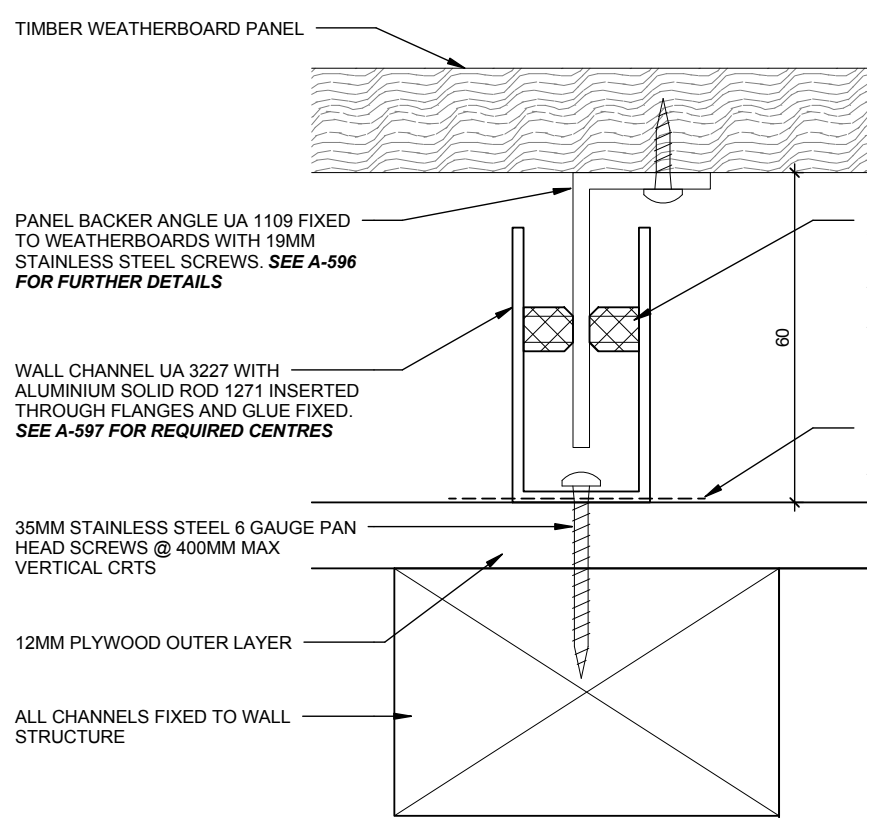

Figure 145: Cladding Version 2.2 - Plan Detail Showing Plastic Locking Buffer (BL)

Ultimately these locking channels were not required given that the positive window and corner reveal and trim details disguised the degree of tolerance created by the aluminium angles. This tolerance proved to be crucial during the final assembly of the house. Due to the 
accumulative effect of many small deformaties in the modules, the house had elongated overall. The tolerance that was built in to the cladding panels combined with the window and corner reveals resulted in a seamless cladding layer. Any one of the other cladding systems that did not allow for this degree of tolerance would have caused major problems during assembly.

To assist with locating the panels onto the aluminium pegs, the bottom slot is cut vertically with a slight chamfer on the leading edge [Figure 146]. The top slot is then cut with a wider mouth and inclined start to the notch which then leads into a vertical slot. This enables the panel to be located at the bottom and then tilted vertically until the top pegs enter the top notch. Once the panel is "hooked" by all slots it can then be dropped vertically down until firmly locked in place.
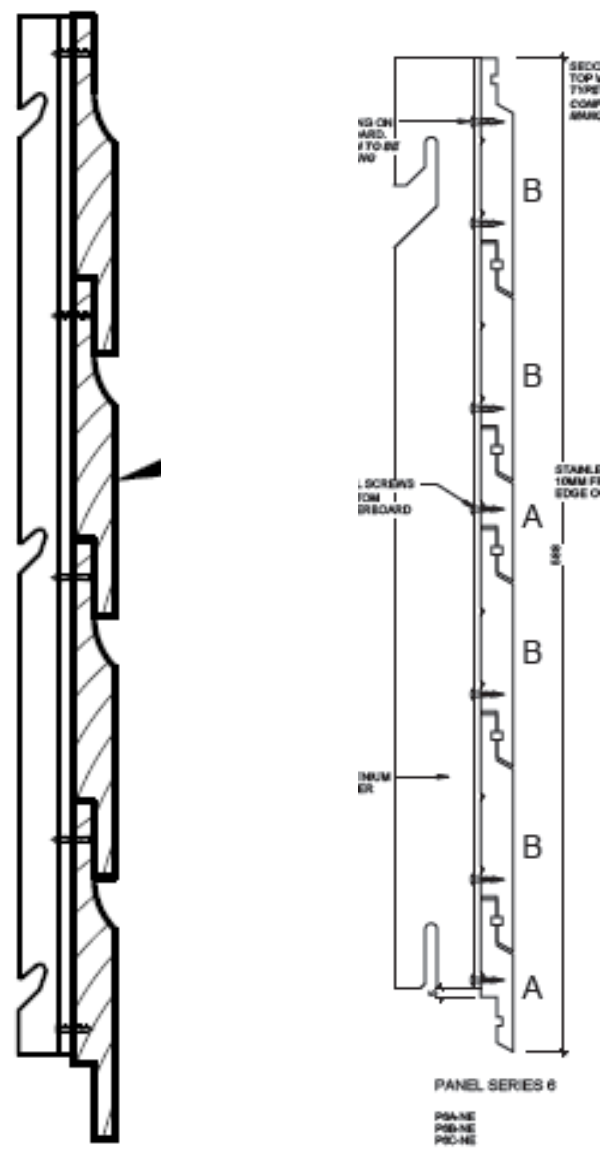

Figure 146: Cladding Version 2.2 - Optimised Aluminium Angle Slots for Ease of Assembly (Before and After) (BL)

Due to the location and size of windows and the random width of the weatherboard profile for aesthetics, twelve cavity channel types and seven cladding panel angle types were needed [Figure 149]. The overall system required a very high degree of precision in every phase of development, from the construction documents, to the aluminium fabrication, to the construction of the panels themselves. A fault in any one of these processes could have potentially led to the misalignment of panels and a visually dissatisfactory end result.

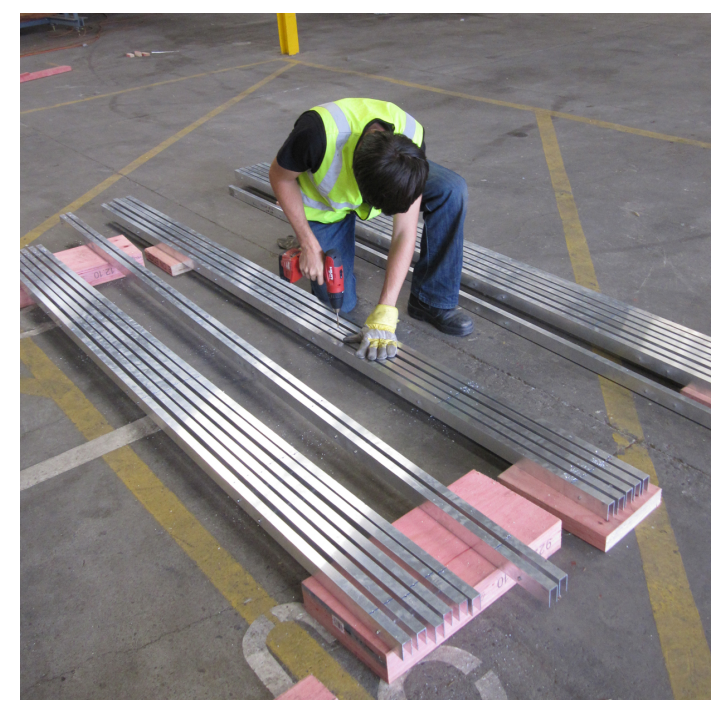

Figure 147: Construction Photo Showing Wall Cladding Channels

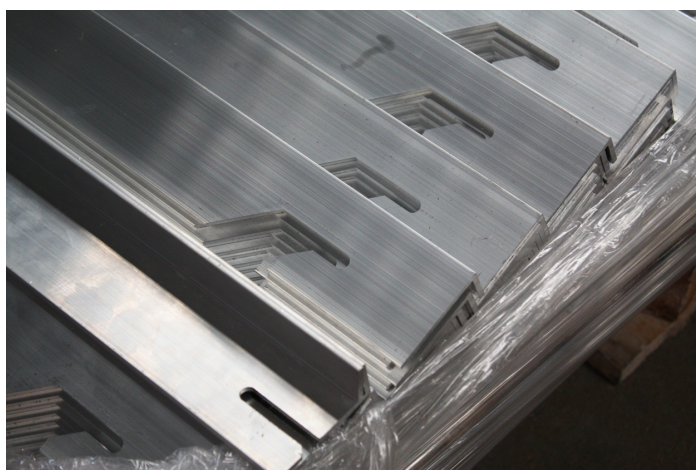

Figure 148: Construction Photo Showing Cladding Angles

The specified aluminium rod 'pegs' (UA1271) at a diameter $4.76 \mathrm{~mm}$ proved to be too pliable to support the cladding panels. Smaller $4.5 \mathrm{~mm}$ diameter stainless steel bolts with lock-nuts were used as an alternative. These were both stronger and more easily installed. It was later discovered that the small degree of tolerance between the bolt and the slot in the channel caused the cladding panels to rattle. A simple solution was found by wrapping a short length of electrical tape around the bolts, cushioning their contact with the channels. 


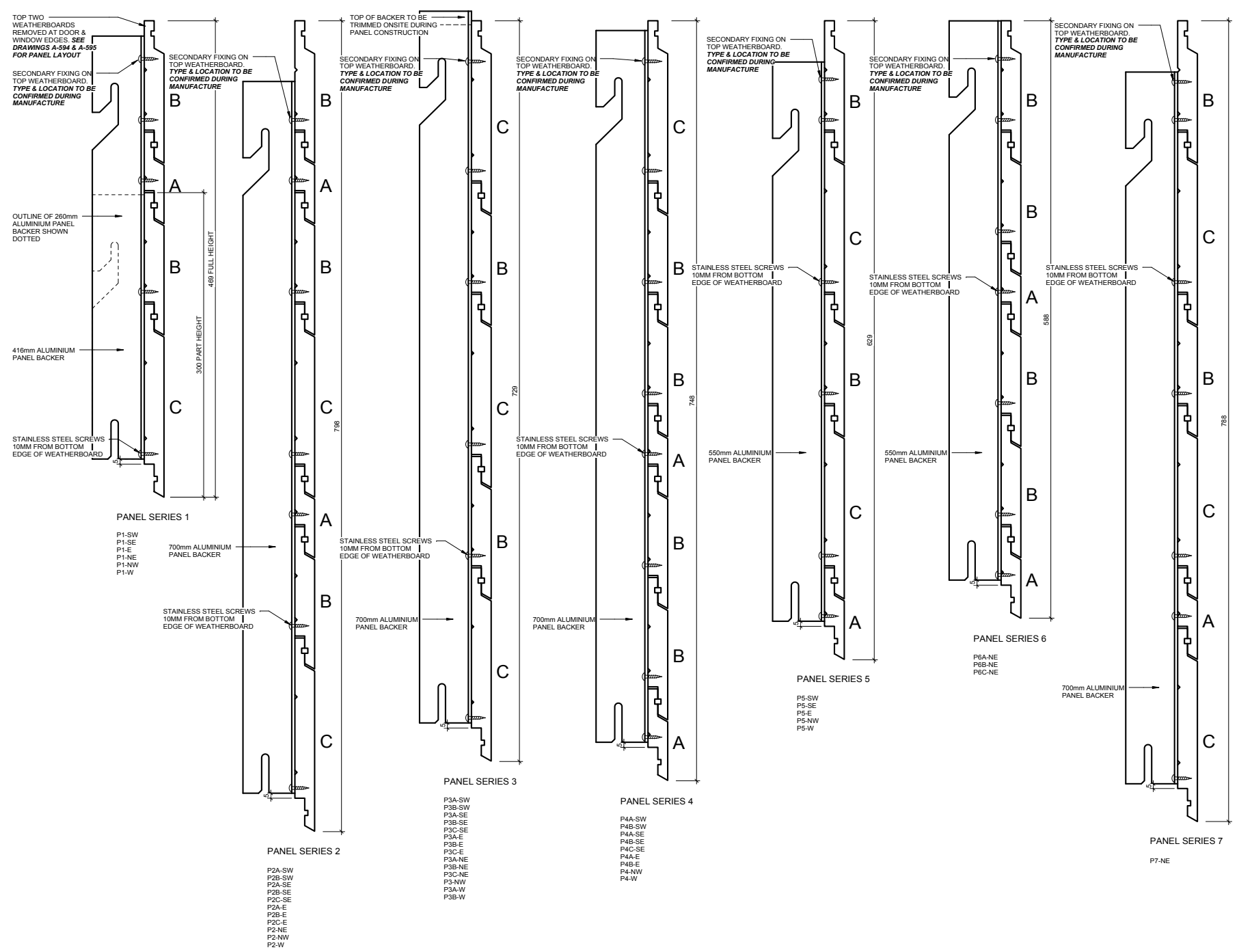

Figure 149: Cladding Version 2.2 - Cladding Panel Angle Types (BL)

\subsubsection{Weatherboards}

The initial concept proposal specified Macrocarpa weatherboards for use as the external cladding. It was found that although Macrocarpa would provide the desired natural, untreated timber finish, it also presented great uncertainty as to its performance over time and through multiple assemblies. While Macrocarpa is naturally resistant to rot it is known to warp relative to changes in it's moisture content. For the First Light house it was critical that the weatherboard panels maintain their stability during transport and/or reassembly.

Cedar overcame these concerns while still promoting the desired untreated timber finish. Cedar also had the added advantage of being extremely light weight and widely available in the USA. Although cedar is not typically grown and/or forested in New Zealand, it is a timber that is commonly imported and used in local construction. New Zealand importer and distributer Herman Pacific were approached for advice, supply, and sponsorship.
Herman Pacific import their cedar from Canada based company Interfor who forest and distribute timber throughout the world. Due to Interfor's presence in North America they saw great value in sponsoring the New Zealand entry at the Solar Decathlon. Herman Pacific equally saw value in the local exposure of the First Light house in New Zealand, the cedar in particular received a lot of visibility at both exhibitions.

Cedar may not be a local resource but it was clearly the right material for the job and given Interfor's FSC certification it still upheld the sustainability principles of First Light.

The team elected to use a random width shiplap profile primarily for aesthetic reasons. Given that the house adhered to a very strong sense of symmetry and rhythm, it was felt that a random variation in the horizontal lines of the weatherboards would give an appropriate visual contrast to this rigour. 


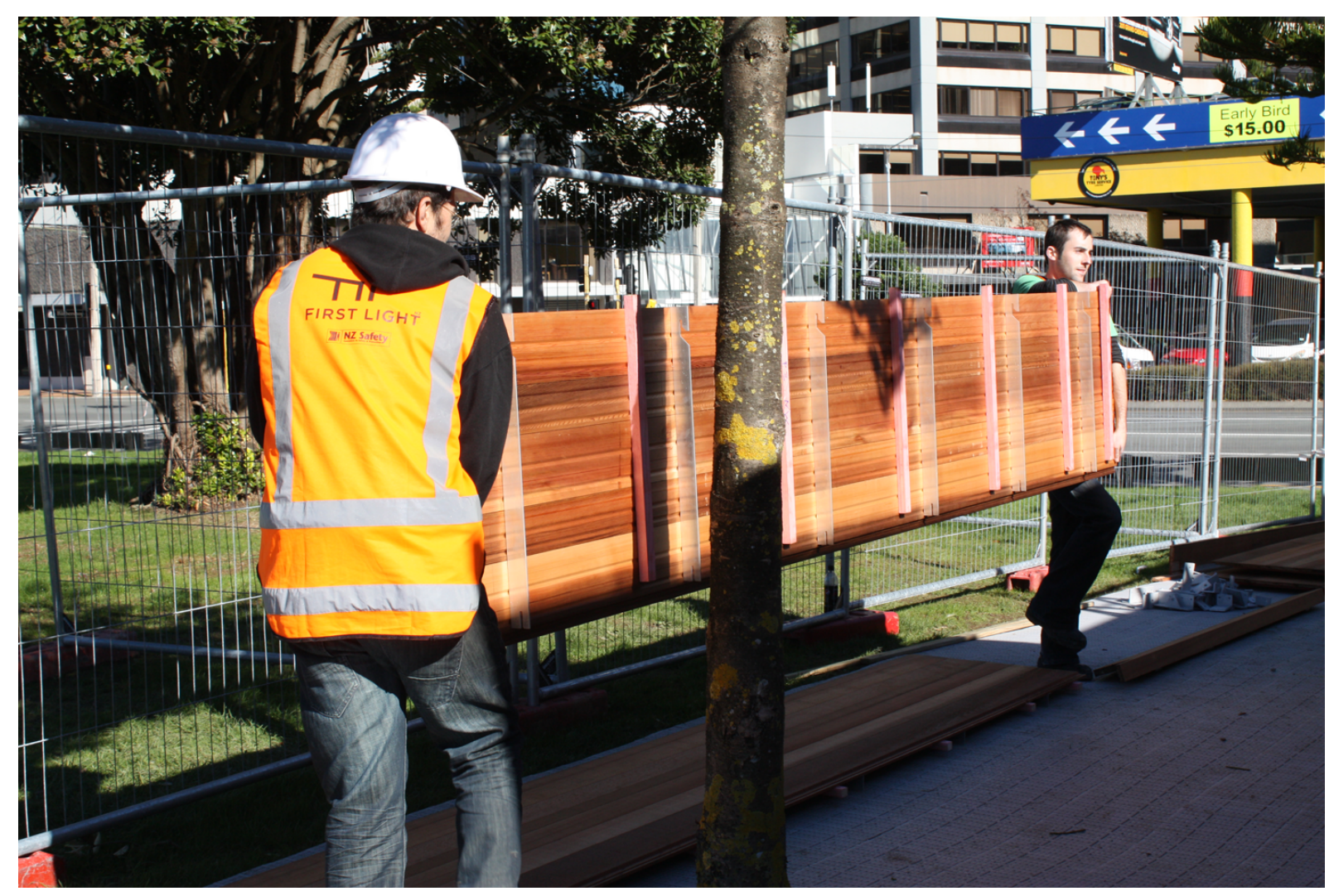

Figure 150:FKP Photo Showing the Ease of Carrying a Cladding Panel

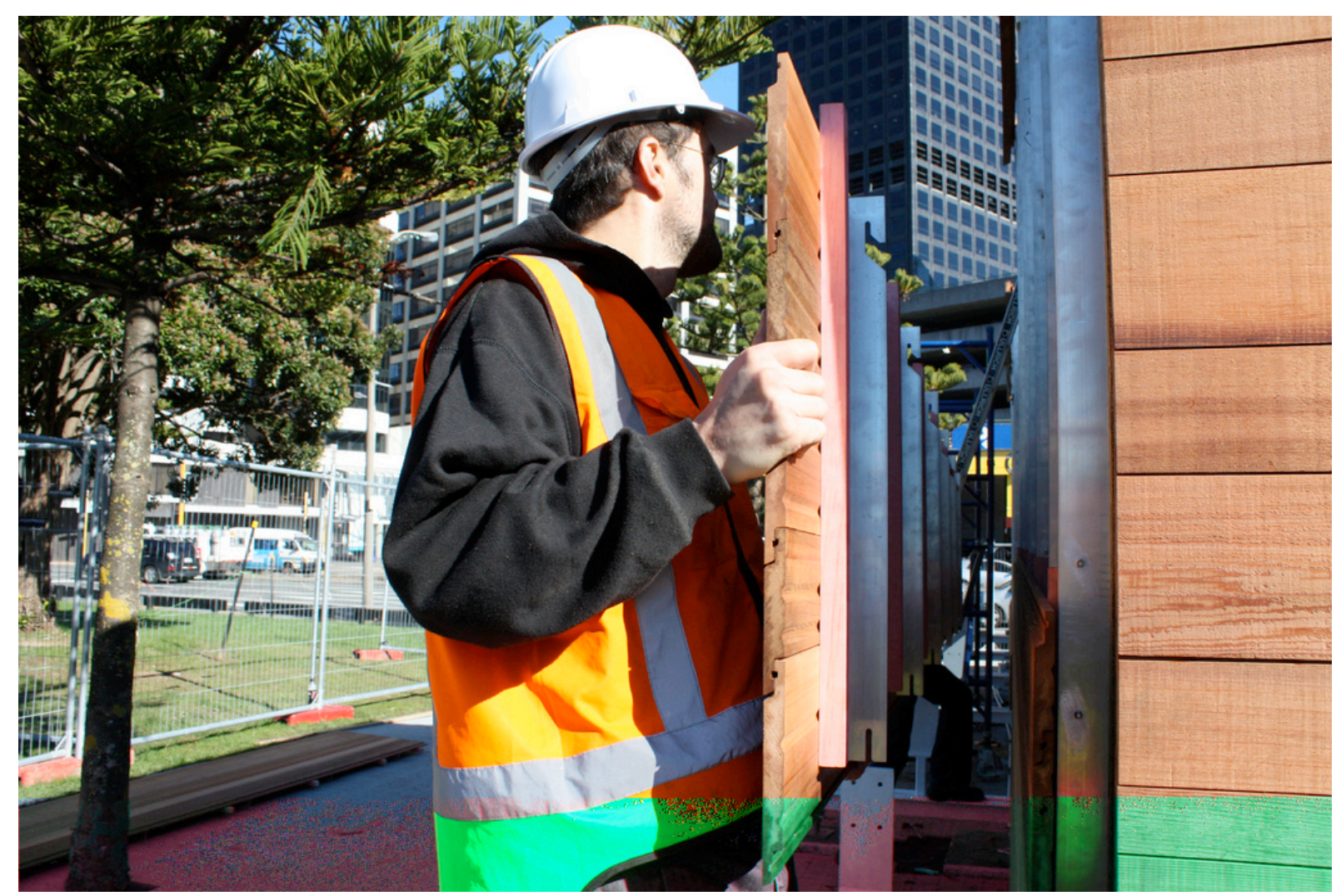

Figure 151: FKP Photo Showing the Installing of a Cladding Panel 


\subsection{SHED DOORS}

Although a late development in the design process, the detailing of the shed doors became a fundamental part of how the mechanical equipment would perform.

Two very different doors needed to be developed; a solid door to the electrical and HWC room, and a larger ventilated door to the mechanical side of the shed. For aesthetic purposes all of the services were to be contained within the visual envelope of the house. This presented many challenges particularly concerning the HVAC (heating ventilation and air-conditioning) equipment. The house utilised a reverse-cycle air-to-air heatpump, a airto-water heatpump, and an ERV (energy recovery ventilator). All of these systems demand unobstructed air flow both to and from the outside. The mechanical shed doors would need to enable the abundant flow of air while still maintaining a waterproof barrier and high aesthetic quality. They would also need to adequately separate the exhausted air from the incoming air. Furthermore they would need to provide full view of the equipment inside during public exhibit and be uninstalled for transport.

The obvious solution to these constraints was to incorporate louvres into the door sashes themselves. Proprietry aluminium and timber based systems were explored for their functional and aesthetic fit with the design. These systems however did not appropriately contrast with nor mimic the aesthetic of the random width cedar weatherboard cladding. A custom solution was sought. In consultation with the building performance team, a staggered cedar louvre arrangement was developed which would enable the necessary level of ventilation. Each louvre follows the width of the adjacent weatherboard. The result is a door which appeared as a subtle variation of the cladding itself. The solid vertical frames of the doors were designed to align with the framework around the heatpump units. This effectively divides the exhausted air from the fresh air intake.

In terms of code compliance the interior of the mechanical room was considered an outside space. The floor was constructed with free draining timber decking and there was no insulation in the walls, floor, or roof. A degree of waterproofing was however required for the purpose of keeping the mechanical equipment, tools and other outdoor gear dry. The depth of the door, or spacing of the louvres, coupled with an inclined cedar board, provides the necessary weatherproofing.

Several opening systems were explored as a means for achieving the required exposure during public exhibit. One system utilised garage door hardware and would enable the door to open vertically [Figure 152]. Although this would create a clear view to the interior, this system proved to be expensive and would potentially cause difficulties during reassembly.

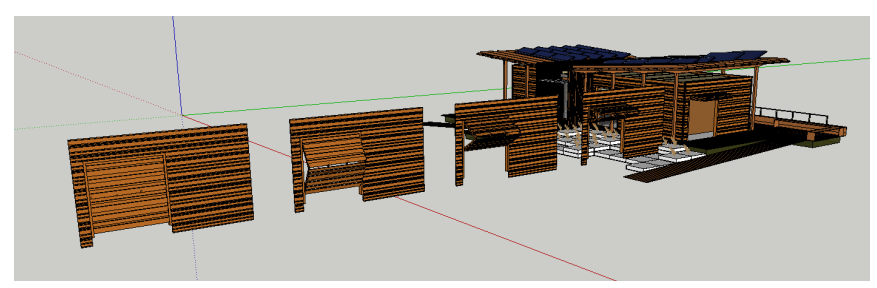

Figure 152: 3D Model Showing Vertical Bi-Fold Shed Door

A bi-fold system was also explored but gave rise to concerns over the significant weight bearing on the hinges given the overall width of the doors [Figure 153]. This would prove to be a challenge when it came to re-hanging the doors.

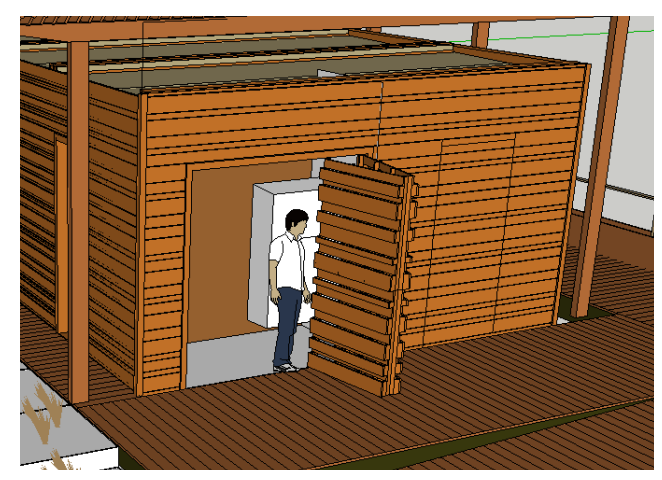

Figure 153: 3D Render Showing Bi-Fold Shed Door

The decision was made to proceed with the cheapest and simplest hardware available in the form of two French doors [Figure 154 \& Figure 155].

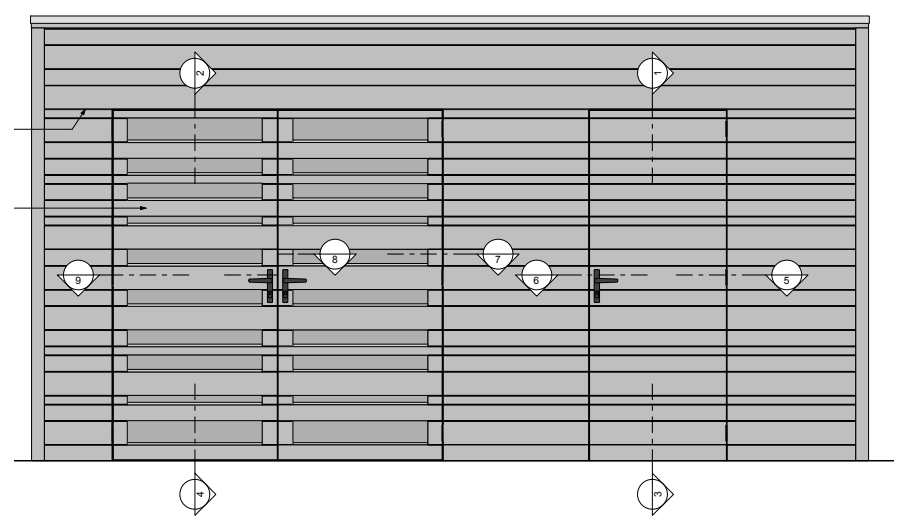

Figure 154: East Elevation Showing Shed Doors (JM) 
The detailing of the electrical room door followed a similar concept. However, instead of louvring the cedar panels, the door is simply made as a section of cladding. The size and positioning of the doors was adjusted so as to allow all three to open 180 degrees and sit flush against the cladding during presentations [Figure $156 \&$ Figure 157].

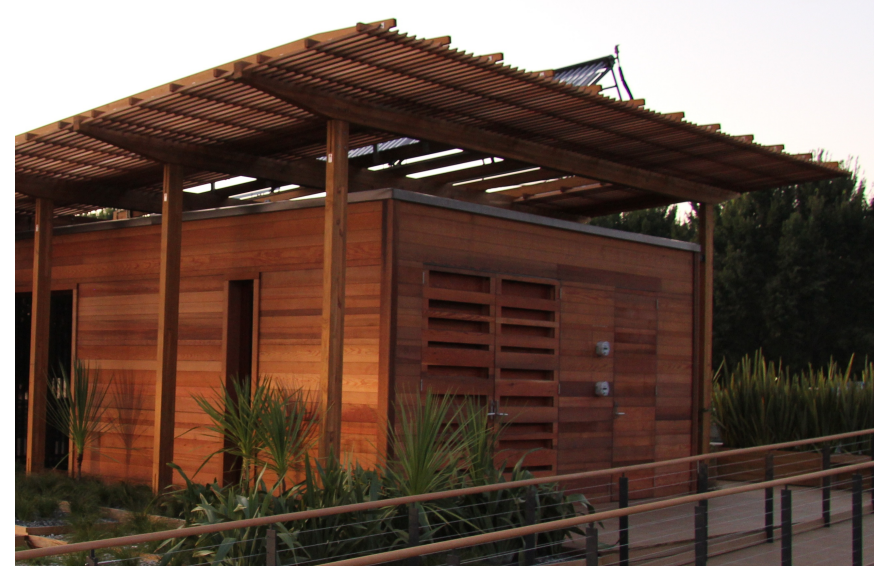

Figure 155: SD Photo Showing Closed Shed Doors

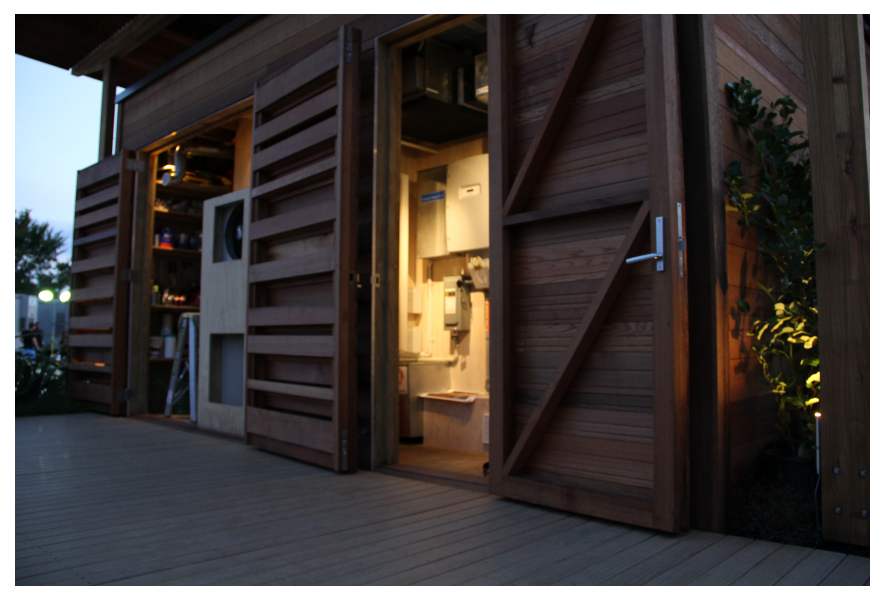

Figure 157: SD Photo Showing Shed Doors Open

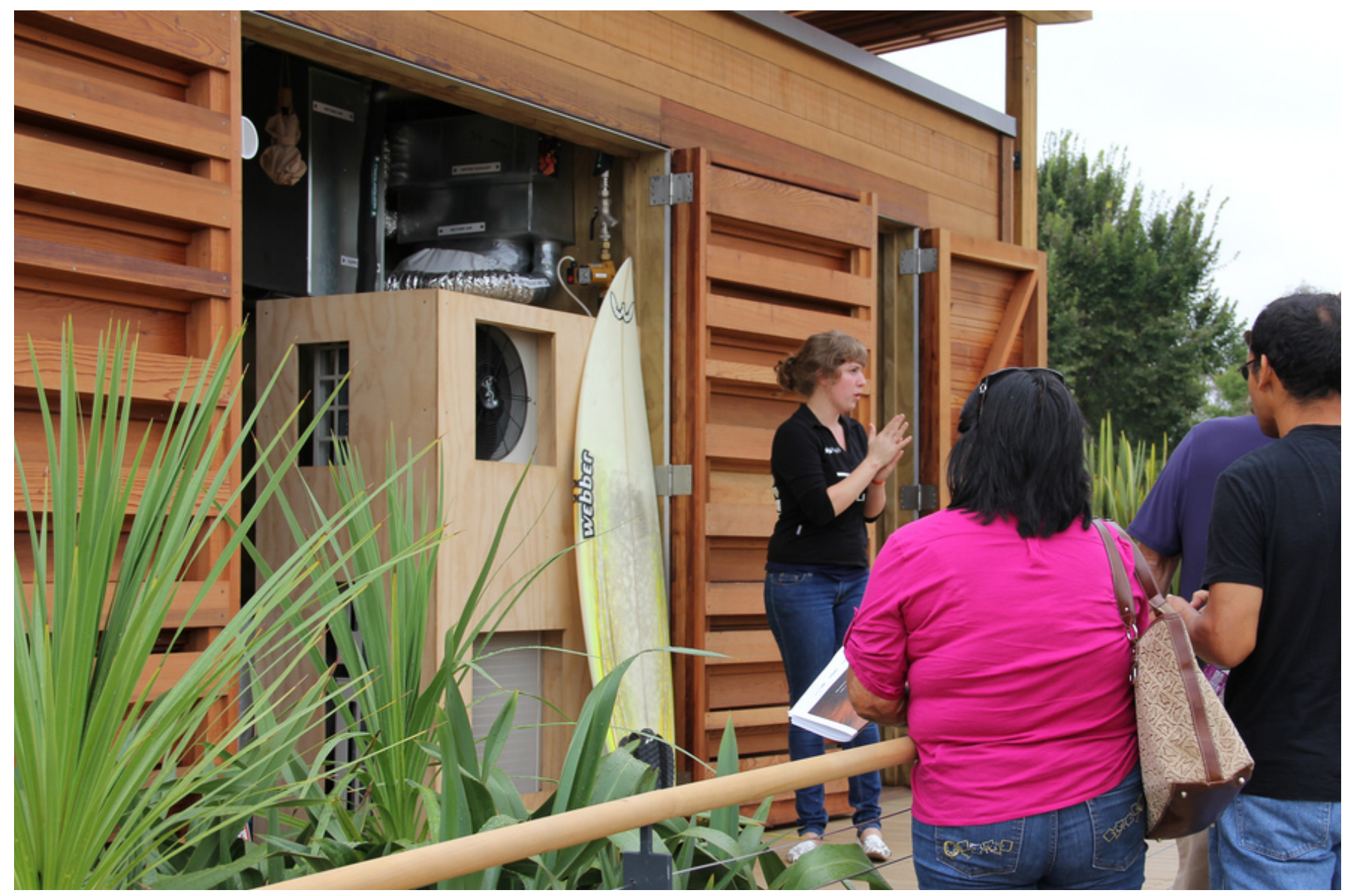

Figure 156: SD Photo Showing Shed Doors Open For Presentation 


\subsection{FLOOR}

As with the wall construction, close attention had to paid to the performance aspects of the floor panels [Figure $158]$.

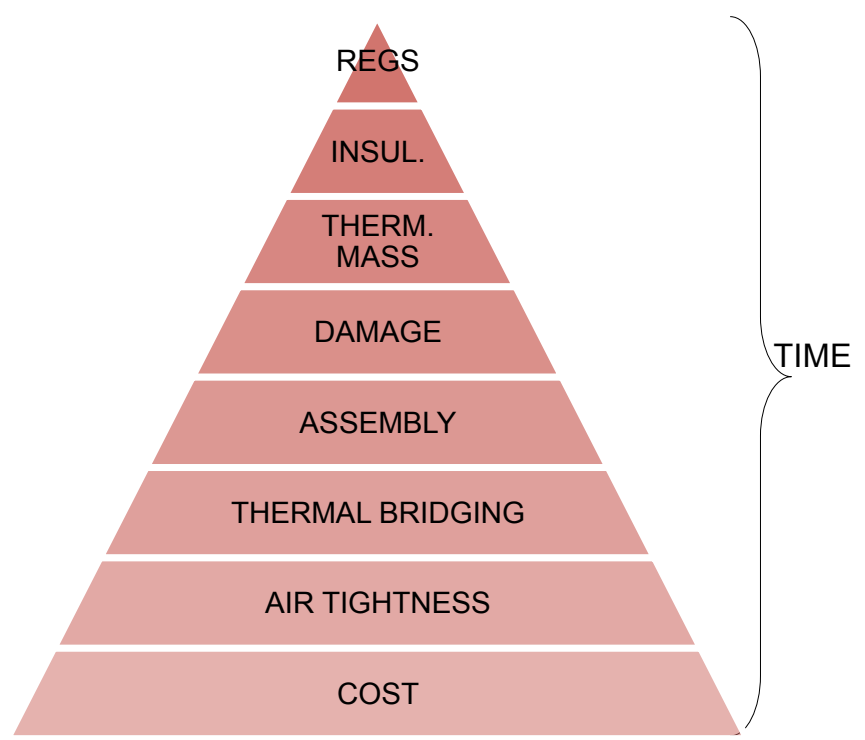

Figure 158: Decision Making Hierarchy - Floor Construction

\subsubsection{Regulations}

The floor construction would have to meet New Zealand code (particularly with respect to waterproofing), the IRC (refer relevant sections appended), the Solar Decathlon Building Code and the structural requirements for a typical Wellington site i.e. in a very high wind zone and with earthquake requirements.

\subsubsection{Insulation}

As previously discussed in section 8.1.2 Wall Insulation EcoInsulation's 'Ecofleece' product was selected for use in the entire building envelope. The $240 \mathrm{~mm}$ deep floor joists would accommodate sufficient insulation to achieve a composite floor R-Value of R5.5 (Jagersma, 2012).

\subsubsection{Thermal Mass}

Thermal mass became a higher priority for the purpose of better aligning the house with passive principles. With the potential for large solar heat gains in winter through the southern glazing, it made sense to collect this energy in the floor for dispersal later at night. This would promote the holistic and integrated performance story which would gain points in the Engineering contest (10\%). The additional thermal mass would also help stabilise daily peaks in air temperature likely to be experienced during the ten days in Washington DC (Jagersma, 2012).

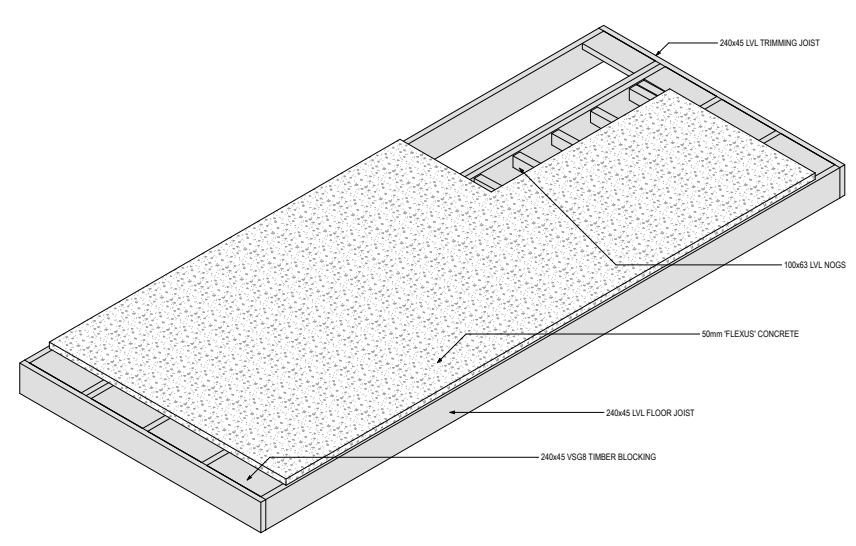

Figure 159: Fabrication Drawing - Thermal Mass

$50 \mathrm{~mm}$ of Flexus concrete was specified in order to realise the desired level of thermal mass [Figure 159]. Flexus concrete by Reids is an engineered cementitious compound based product (Reid Construction Systems). The fibres create an extremely strong slab and one that is resistant to cracking. The concrete slab rather bends and yields similarly to steel before failing. The structural strength of Flexus is utilised in conjunction with LVL floor joists to achieve a composite floor panel capable of spanning the $5.4 \mathrm{~m}$ between foundations. Each LVL joist is fitted with steel gang-nail shear connectors which are cast into the Flexus, bonding the two together.

\subsubsection{Damage}

The floors in particular were highly susceptible to both structural and surface damage. Tens of thousands of visitors were expected to walk through the house in New Zealand and at the Solar Decathlon. It was critical that the floors were durable and washable in order to cope with this level of foot traffic. The floors would also be subjected to significant forces during transport, forklifting, and cranelifting. Flexus concrete provided the perfect product to meet these requirements. The flexible nature of Flexus means that it is far more resistant to cracking during transport and assembly compared to standard concrete. As a finishing material the Flexus provides a very durable and easily cleaned floor surface. 
Unfortunately several problems were experienced in the manufacturing of the floor panels.

\section{Sagging of the floor slabs}

The composite system using LVL joists was not a typical solution of Reids and had not yet been tested. The sponsored LVL could not be pre-cambered to resist the sag across the large floor span and/or the tensile forces generated by the concrete. To counteract the anticipated sagging of the slab the floor panels were to be cured with their centres proped and counterweights at either end. However this did not sufficiently prevent the deforming of the floors resulting in a notable sag across the panel's length.

\section{Deformation of the formwork}

Faults with the formwork led to a bulging of the concrete slabs along their length and in places the concrete overhung the edge of the LVL joists [Figure 160 \& Figure 161]. These defects were later manually trimmed to achieve the correct floor panel dimensions [Figure $162 \&$ Figure 163].

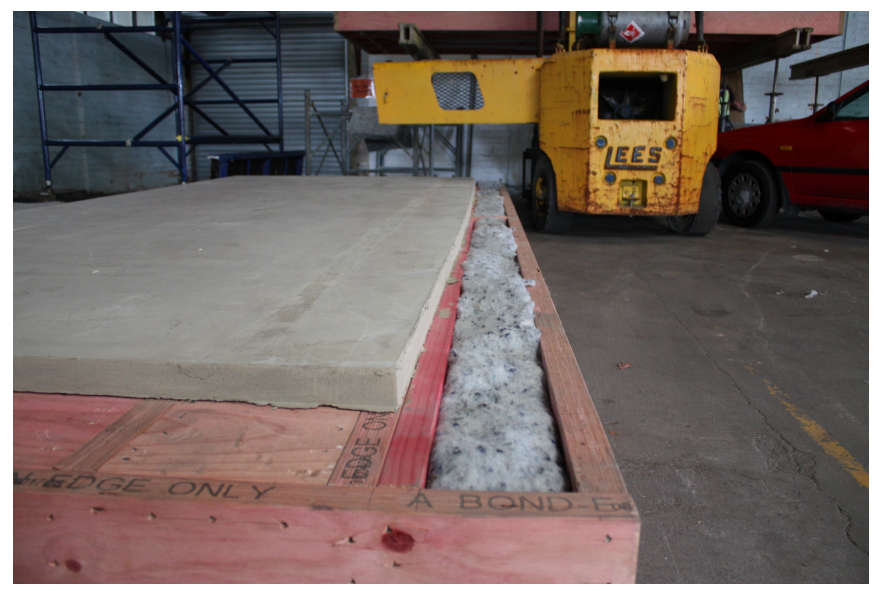

Figure 160: Bulging in Formwork

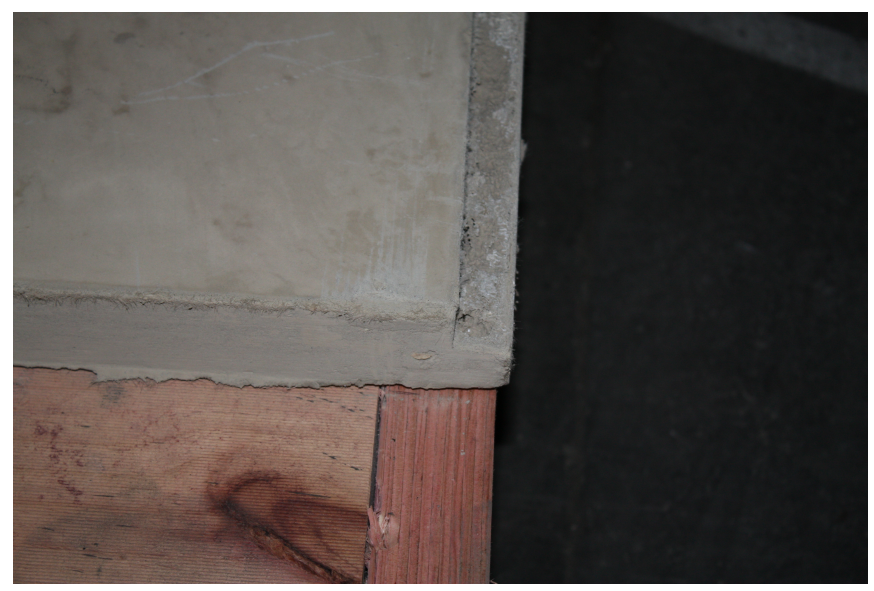

Figure 161: Slab Overhanging LVL Joist

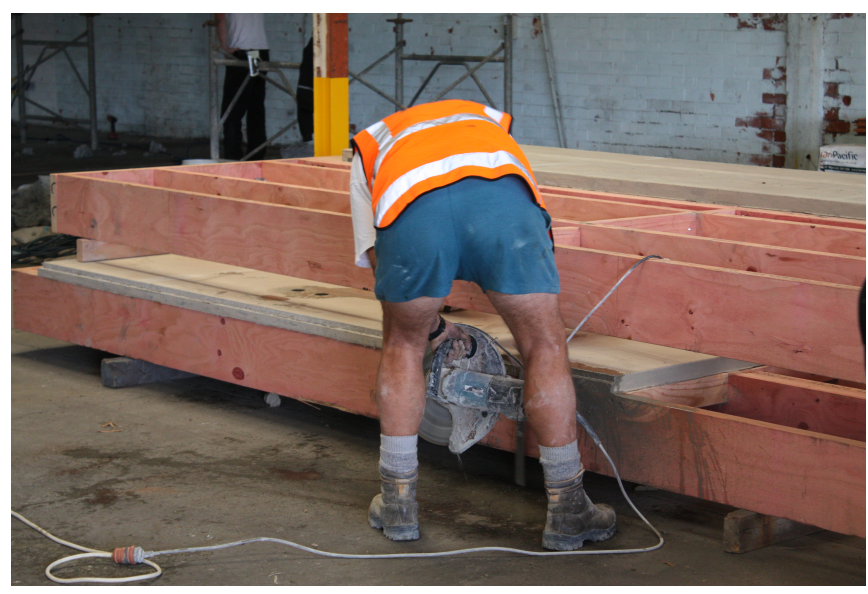

Figure 162: Flexus Overhang Trimmed

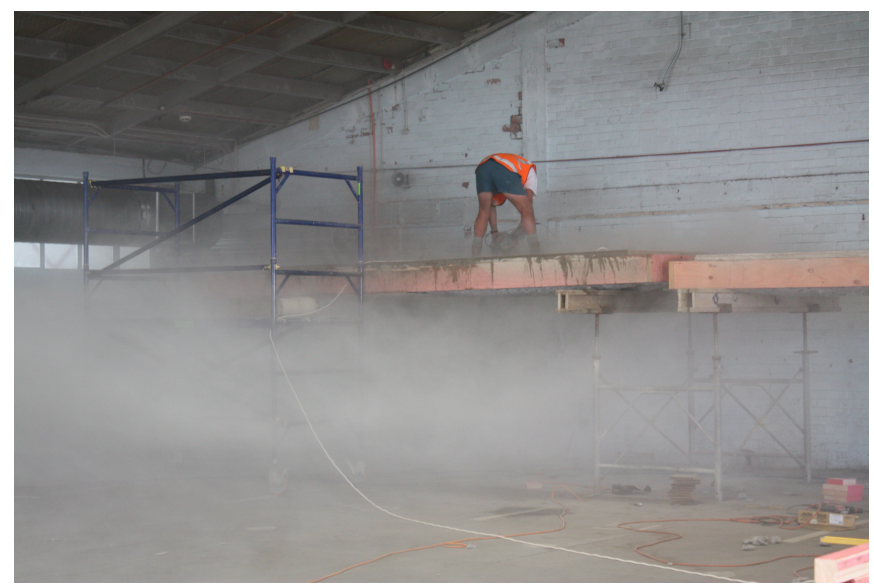

Figure 163: Flexus Overhang Trimmed 
The slabs were also poored to the incorrect LVL edge of one panel resulting in the shear connectors protruding from the slab [Figure 164]. This proved to be structurally insignifcant and it was possible to conceal the defect within the interior finishes.

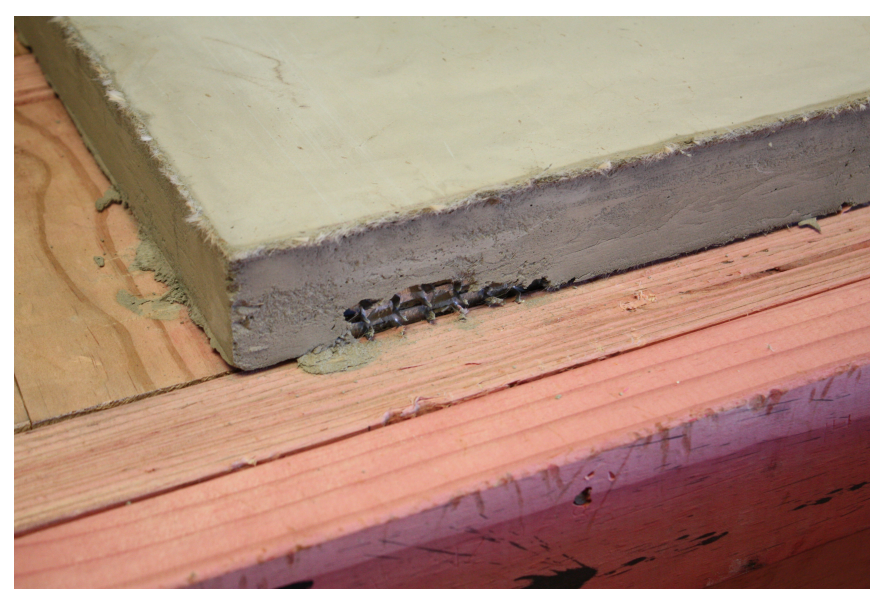

Figure 164: Shear Connector Protruding from Slab

\section{Aluminium edge clashings removed}

Aluminium angles were cast into the slabs as described below in Chapter 5.5.5 Assembly. These angles were intended to remain in the concrete slab permanently once curing was complete. Unfortunately these were removed leaving an exposed and chipped Flexus edge which had to be later remedied [fig Figure 165]. Defects and pockmarks were also visible in the slab surface [Figure $166 \&$ Figure 167].

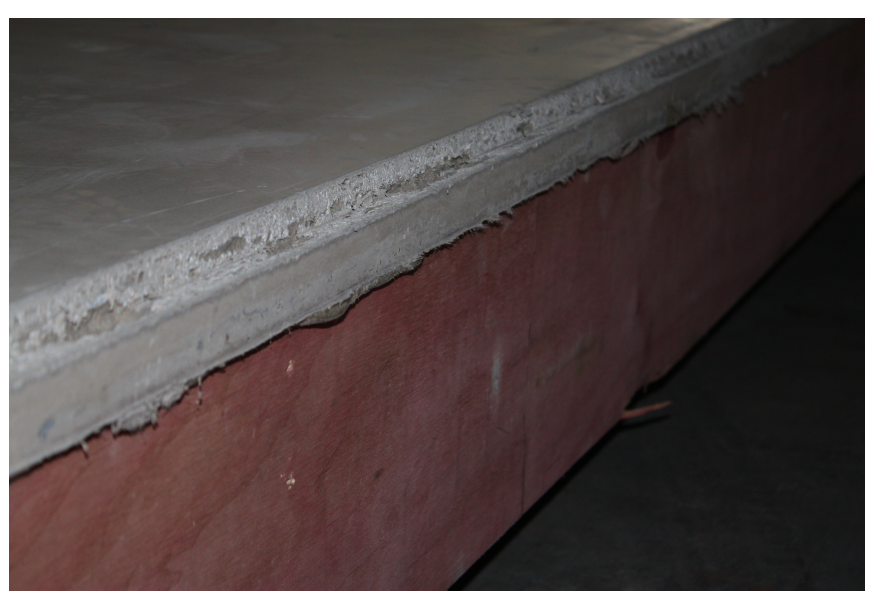

Figure 165: Aluminium Edge Clashing Removed

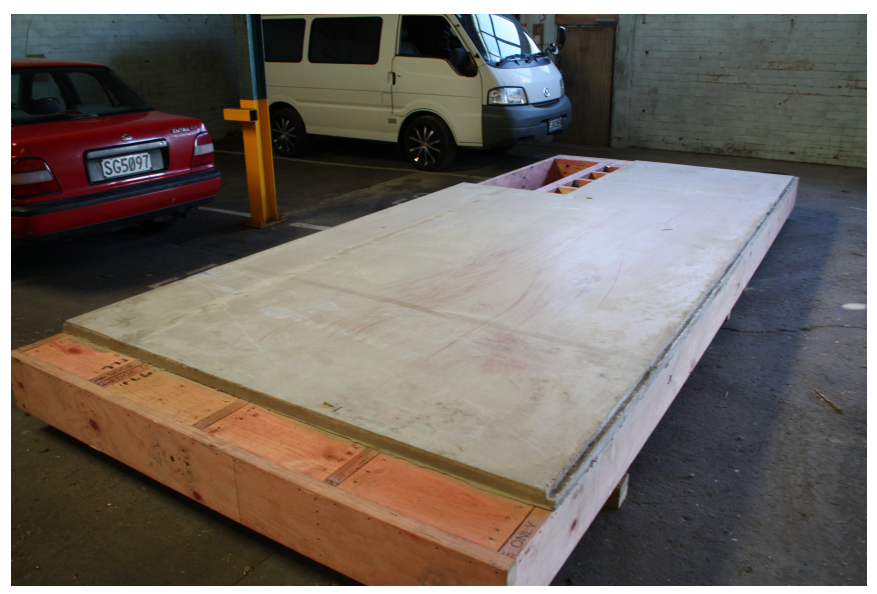

Figure 166: Surface Defects in Slab

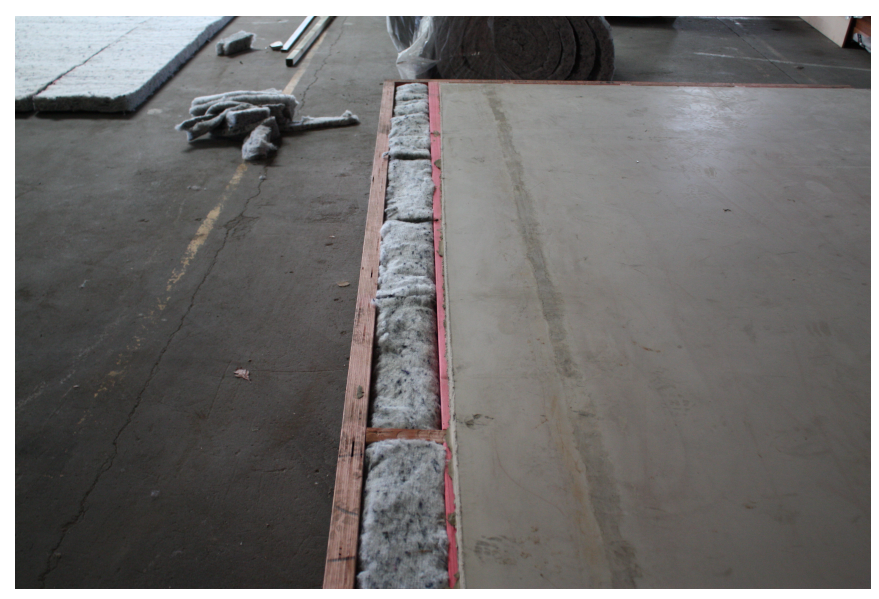

Figure 167: Surface Defects in Slab

Due to an extremely tight time schedule, coupled with the fact that the floors were fully sponsored, there was no possibility of having the floors re-cast.. The major defects would need to be remedied either by grinding the surface or by pouring an additional topping.

Spot tests were performed to assess the effects of grinding on the Flexus. The grinding process exposed the fine reinforcing fibres, these then had to be singed with a blow-torch to give a smooth finish. The surface would then require a protective coating. It was found that the small air pockets in the flexus were far more extensive than first conceived. As the top surface was ground down, large areas of pock-marks were exposed. Grinding would not give the desired finish, nor remedy the sag or edge damage.

The alternative was to build the floor slabs up and level with a topping compound. This would solve all of the major defects in one, although difficult, process; the floors would be made level, a desired finish could be achieved, and the aluminium edge clashings re-cast in 
place. Ardex Pandomo was selected as the appropriate product for the job. Pandomo is an easily pigmented floor levelling compound. Unfortunately the same colouring agent could not be used in the Pandomo as was used in the Flexus. A difficult matching process was undertaken to achieve a similar colour to that of the original Flexus. The Pandomo can be poured as thin as $8 \mathrm{~mm}$ while still maintaining its resistance to cracking. This was important given that the finish floor height relative to the main bifold doors relative to the deck height all needed to be within $10 \mathrm{~mm}$ to meet the accessibility standards of the competition. The floors could be taken up $8 \mathrm{~mm}$ at the highest points and the Pandomo would fill in the remaining $33 \mathrm{~mm}$ sag in the middle. The aluminium angles were re-aligned, packed, and screw-fixed into the floor slabs before the Pandomo was poured. This provided both a level formwork and a permanent edge protection for the slabs.

Problems were again experienced with the pouring of the Pandomo. Not enough product was mixed in the first pour which meant the floors could not be levelled to the correct height. Some flaws in the colouring were also evident with visible green swirls on the floor surface. The Pandomo would have to be re-poured. The second pour took place at Frank Kitts Park achieving the desired result and successfully resolving the prolonged issues with the floors.

Although the process of constructing and finishing the floors was a complicated one, the final result was acceptable and no damage was experienced through transport, reassembly, or wear.

\subsubsection{Assembly}

An integrated hardwood timber locating dowel was used to ensure the accurate reassembly of the house modules relative to one another [Figure 168]. Three dowels were specified in each floor panel to align within $1-2 \mathrm{~mm}$ of a corresponding hole in the adjacent floor. These dowels would be critical for the accurate reassembly of the house both at Frank Kitts Park and in Washington, DC. It was anticipated that the prefabricated floor, wall, and roof elements would each entail varying degrees of inaccuracy and hence some adjustment on site would be necessary when the three were brought together. By installing the dowels early in the process, the alignment of walls, roofs, finishes, and services would all be relative to the position of the dowels and therefore components would realign accurately during reassembly.
The locating dowels were however overlooked during construction and needed to be installed retrospectively as the house was prepared for transport to Frank Kitts Park. This meant that the completed modules had to be separated before the dowels could be installed negating their effectiveness as a locating device. In fact, the retrospective installation of the dowels caused some added difficulty in placing the modules on site. The modules were forced to align with the new dowel locations misaligning the modules and preventing their manual adjustment.

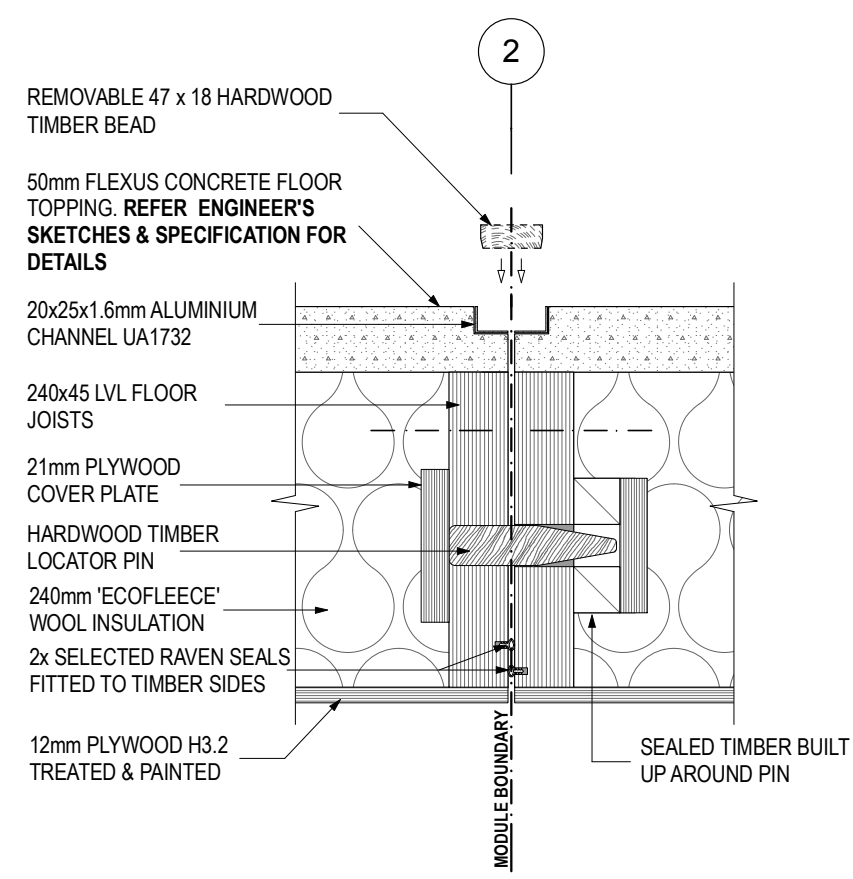

Figure 168: Construction Detail Showing Typical Inter-Module Floor Join

\subsubsection{Thermal Bridging}

Although important, the optimisation against thermal bridging in the floor panels gave way to more important structural requirements. Again, the use of timber construction would be of advantage in this respect with LVL utilised for the primary structure. Figure 169, Figure $170 \&$ Figure 171 below illustrate three of the possible framing options that were explored. 


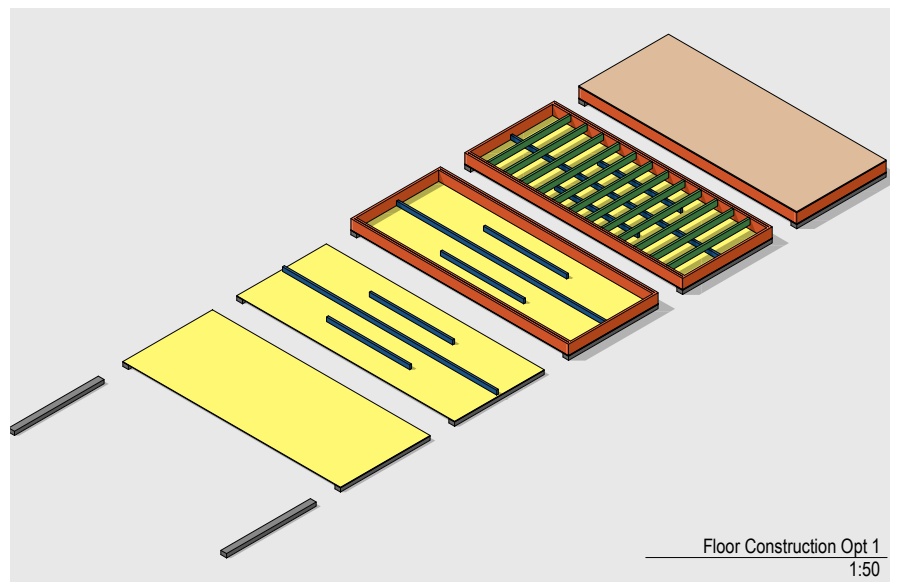

Figure 169: Floor Construction Option One - Transverse Joists Without Concrete (JM)

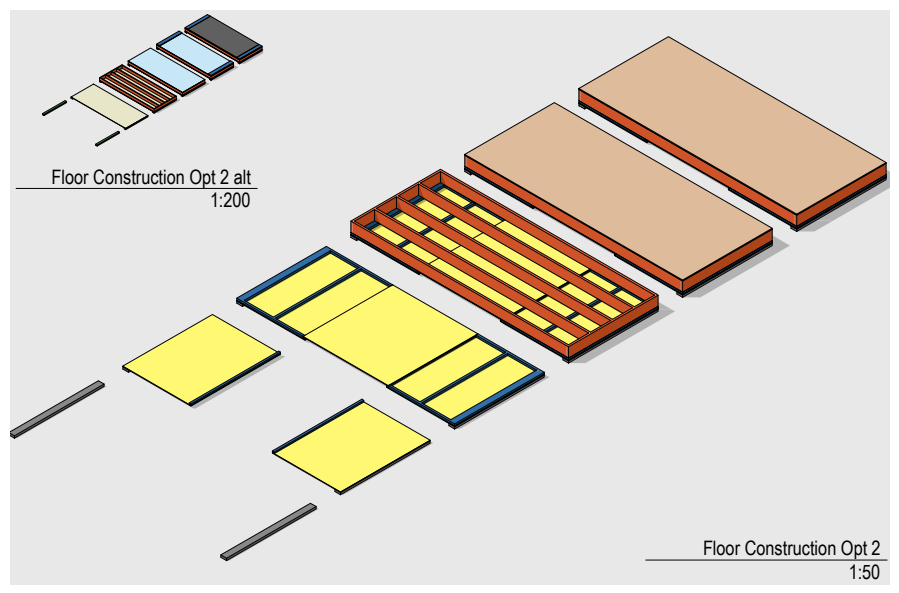

Figure 170: Floor Construction Option Two - Longitudinal Hyjoists Without Concrete (JM)

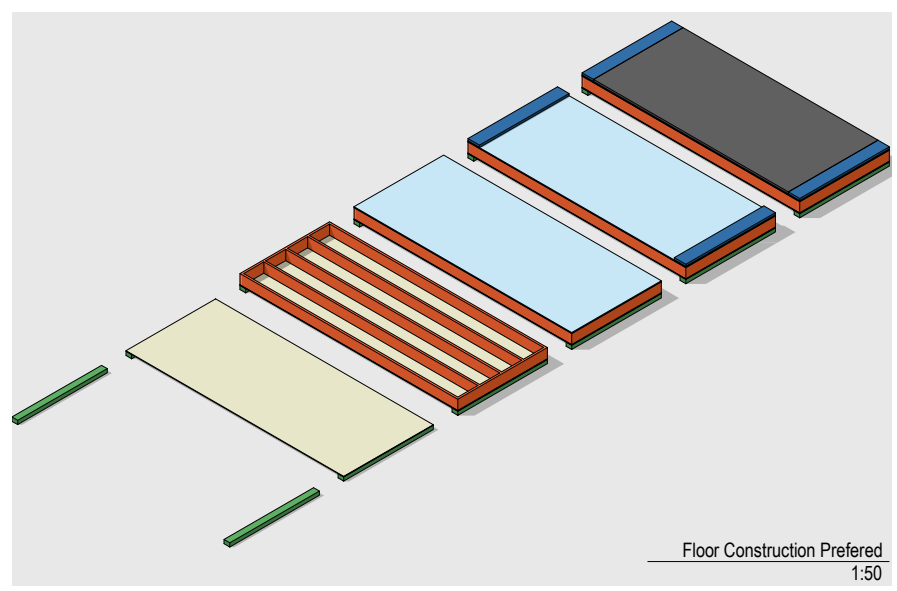

Figure 171: Floor Construction Option Three - Longitudinal LVL Joists With Flexus Slab (JM)

\subsubsection{Air Tightness}

The floor slabs are constructed as completely airtight sandwich panels. $12 \mathrm{~mm} \mathrm{H3.2} \mathrm{treated} \mathrm{plywood} \mathrm{is} \mathrm{used} \mathrm{on}$ the underside to both protect the floors during transport as well as provide a water and air tight protection to the insulation. The Flexus slab does the same on the top of the panel, sandwiching the insulation in between. In this instance, the potential for moisture build up within the panel was not fully understood. It was unclear as to the ability of the Flexus to both disperse moisture away from the insulation and/or prevent the ingress of moisture into the floor panels. This is one area where further research and analysis could be undertaken.

Air tightness of the module joins was particularly difficult to achieve in the floors. There would be no access to the underside of the house during assembly so joins could not be taped as was the case with the walls. To overcome this problem rubber Ravenseals were installed along the length of the LVL at the module edge. It was intended that these would provide an airtight seal once the modules were placed together. To further improve the airtightness of the join, a strip of Tescon-Vana tape was applied over the aluminium edge clashings. This tape was then concealed under a timber finishing bead. Additional timber blocks were fixed to the inside of the LVLs during construction to provide an airtight seal around the locating dowels.

Due to deformations in the floor slabs, the gap at the module join was far greater than had been anticipated. It became obvious that the Ravenseals alone would not provide the required thickness to form an airtight seal. Great difficulty was also experienced with the insetting of the Ravenseal and it was found that the rubber quickly deteriorated under the stresses of module placement. A more simple and cheaper solution was ultimately used in the form of PF rod. Lengths of PF (Polyethylene Foam) rod were taped to the LVL and disposed of after each assembly. The rod provided enough width to fill places of large gaps while also sufficiently compressing to fit within the smaller gaps.

\subsubsection{Cost}

Initial RLB US estimate $=$ US $\$ 18,550$

Final DOE QS US estimate = US $\$ 23,150$

Initial RLB NZ estimate $=\$ 25,700$

Final RLB NZ estimate $=\$ 38,500$ 


\subsection{ROOF}

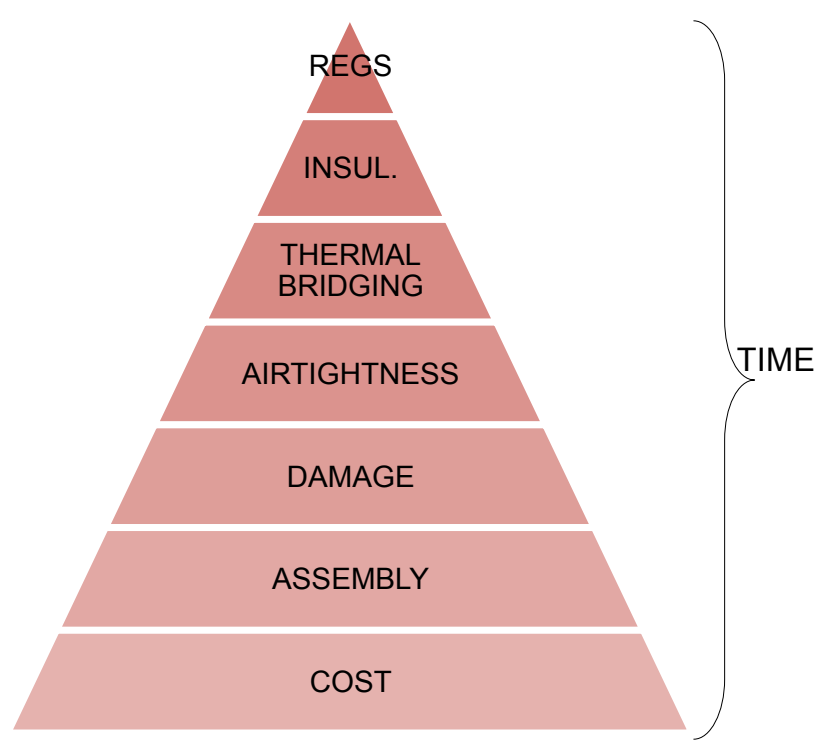

Figure 172: Decision Making Hierarchy - Roof Construction

\subsubsection{Regulations}

The roof construction would have to meet New Zealand code (particularly with respect to waterproofing), the IRC (refer relevant sections appended), the Solar Decathlon Building Code and the structural requirements for a typical Wellington site i.e. in a very high wind zone and earthquake prone.

Of particular importance for the roofs was achieving a slim overall panel depth, including structure, falls, weatherproofing, and ceiling finish. US Land transport regulations allow a maximum load height of 13' 6" or $4.11 \mathrm{~m}$ without a permit. Given that a double drop-deck lowboy trailer can achieve a bottom deck height of $0.61 \mathrm{~m}$, the maximum height remaining for the house modules would be $3.50 \mathrm{~m}$. This resulted in a module design height of $3.4 \mathrm{~m}$ with an allowance for packaging, strapping, and tolerance of $100 \mathrm{~mm}$. It was also important to maintain a minimum ceiling height of $2.5 \mathrm{~m}$ to create the desired sense of spaciousness inside the house. With a total floor panel depth of $\sim 400 \mathrm{~mm}$, these requirements left a total maximum depth for the roof panel, including finishes, of 500mm [Figure 173].

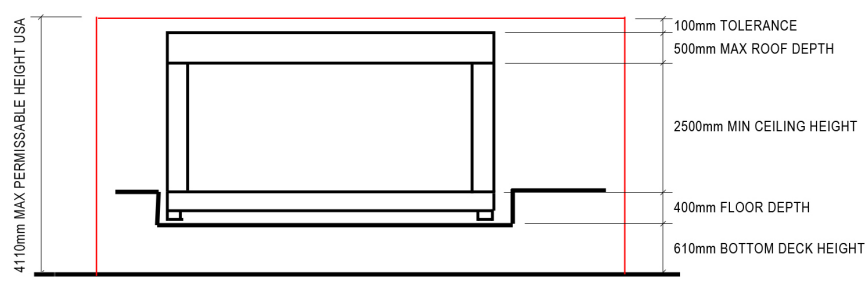

Figure 173: Maximum Permissible Roof Depth

The roof also needed to support a liveload of $1 \mathrm{kPa}$ to provide a suitable working platform for assembling the canopy and associated components.

\subsubsection{Insulation}

The strategy for achieving a high degree of thermal performance in the roof was to minimise the amount of fall necessary for drainage. The lower the falls, the greater the amount of insulation that could be fit within the allowable $500 \mathrm{~mm}$ panel depth. A near flat roof with a slope of $<3^{\circ}$ necessitated the use of a WPM (waterproof membrane) product to meet the building code. For aesthetic purposes it was important that the roof created a square finish to the top of the walls with no overhang or visible slope. This promoted a simplicity of form that would not conflict with the exposed structural detailing and angle of the canopy above. A flat roof would require parapets to maintain the square and level edge. Parapets to all four sides of each module would create the added advantage of rainwater drainage once the modules were separated for transport, i.e: The self contained roofs would be free to drain through the downpipes and away from the modules. Four solutions addressing these uncompromising requirements were developed, each utilising 240x45 LVL beams for the primary structure and achieving a sufficient thickness of insulation equal to approx. R6.

1. Central Gutter (panel depth $=505 \mathrm{~mm})$

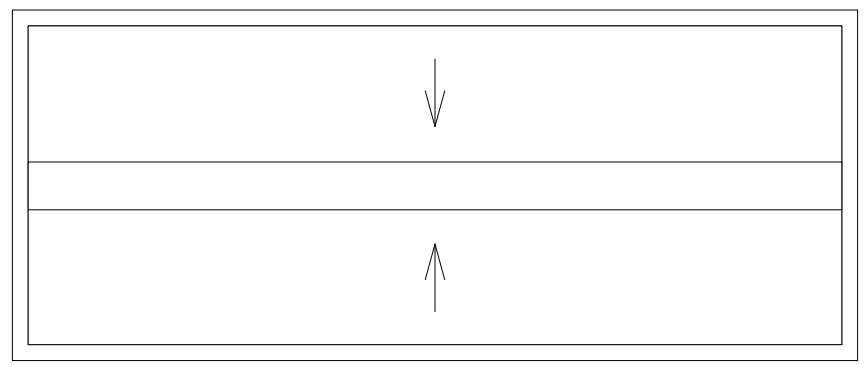

Figure 174: Option One, Central Gutter - Roof Plan (JM) 


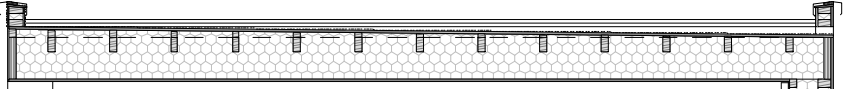

Figure 175: Option One, Central Gutter - Longitudinal Section (JM)

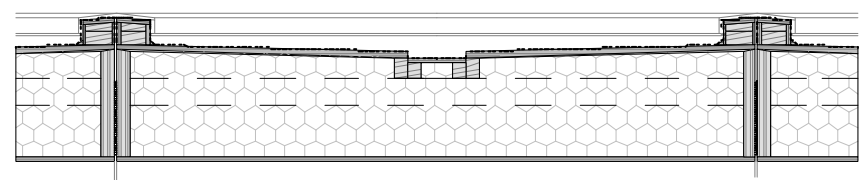

Figure 176: Option One, Central Gutter - Transverse Section $(J M)$

2. Transverse Gable Roof \& Large Gutters (panel depth $=480 \mathrm{~mm}$ )

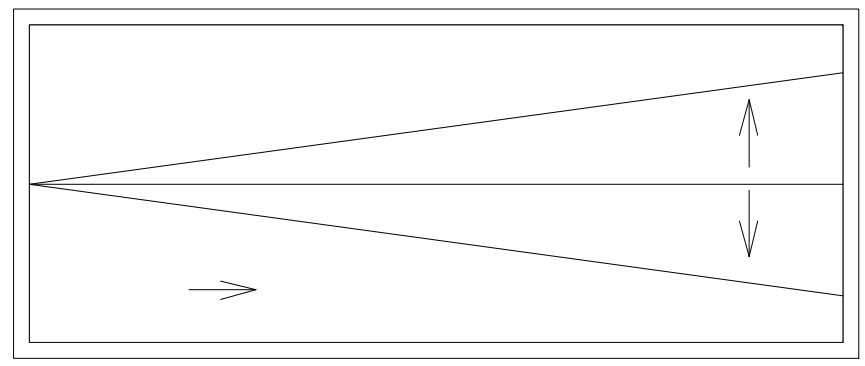

Figure 177: Option Two, Gable Roof \& Large Gutters - Roof Plan (JM)

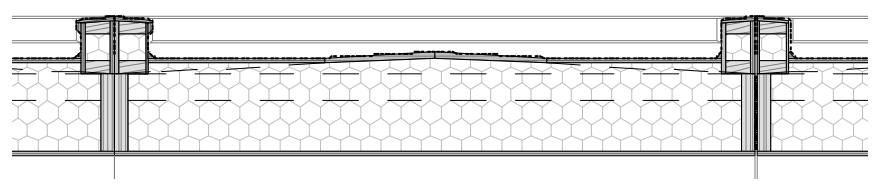

Figure 178: Option Two, Gable Roof \& Large Gutters Transverse Section (JM)

3. Transverse Gable $\&$ Edge Gutters (panel depth $=$ $475 \mathrm{~mm})$

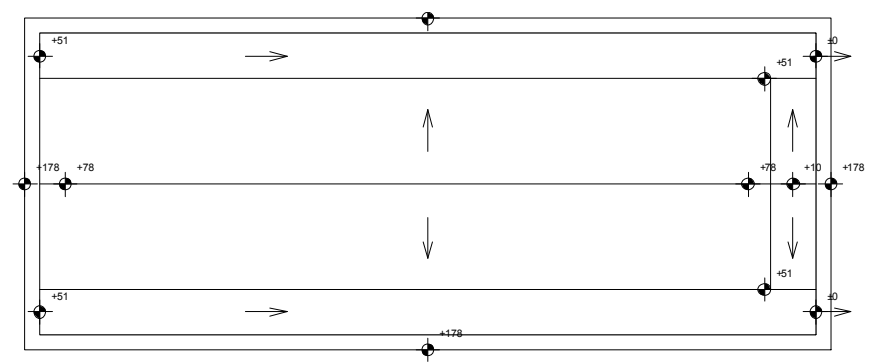

Figure 179: Option Three, Transverse Gable \& Edge Gutters Roof Plan (JM)

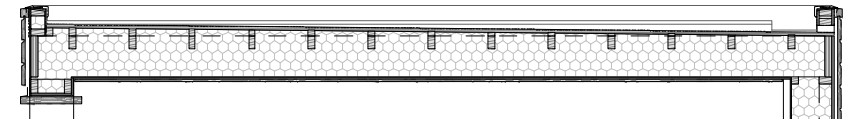

Figure 180: Option Three, Gable \& Edge Gutters Longitudinal Section (JM)

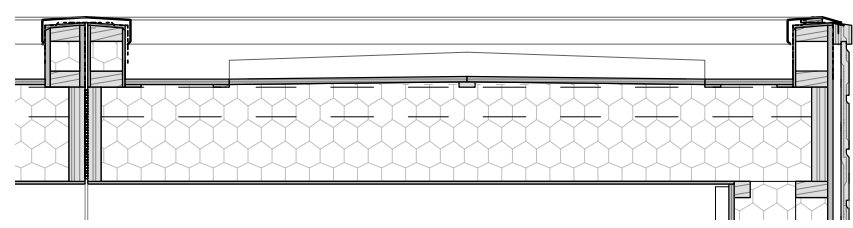

Figure 181: Option Three, Gable \& Edge Gutters - Transverse Section (JM)

4. Longitudinal Gable Roof (panel depth $=480 \mathrm{~mm})$

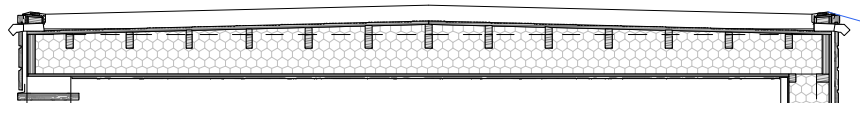

Figure 182: Option Four, Long. Gable Roof - Longitudinal Section (JM)

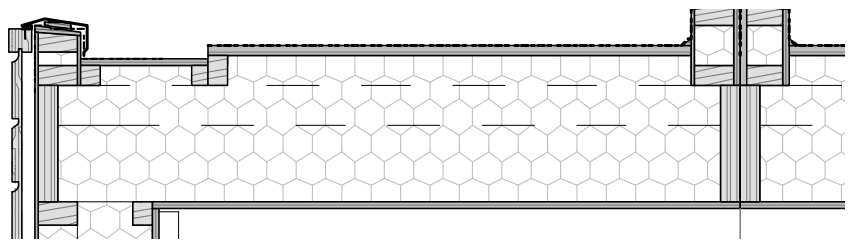

Figure 183: Option Four, Long. Gable Roof-Transverse Section (JM)

As with the floors, the roofs would require extensive framing in order to achieve the $5.4 \mathrm{~m}$ span. The greater the volume of framing the less space there would be for insulation. It would have proven difficult to accurately form the very shallow roof falls with standard timber framing. In consultation with the engineer, a CNC (computer numerical control) cut plywood "ribbed" arrangement was developed to address this issue [Figure 184]. Through detailed CAD modelling each plywood rib could be uniquely documented and cut [Figure 186]. When assembled, these ribs would create the gradiated framework necessary for achieving the shallow falls [Figure 185]. 


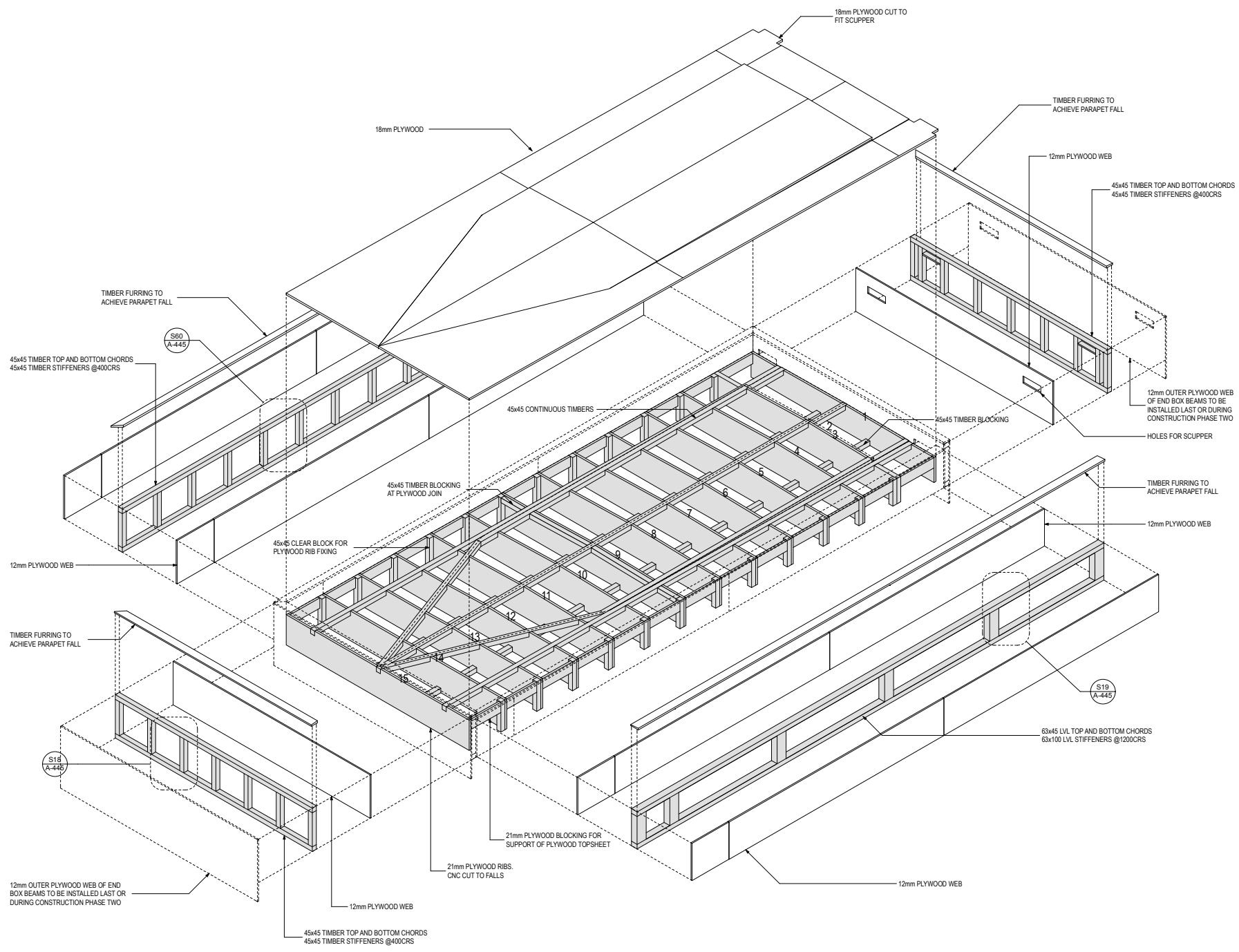

Figure 184: Fabrication Drawing - Exploded Roof Panel 


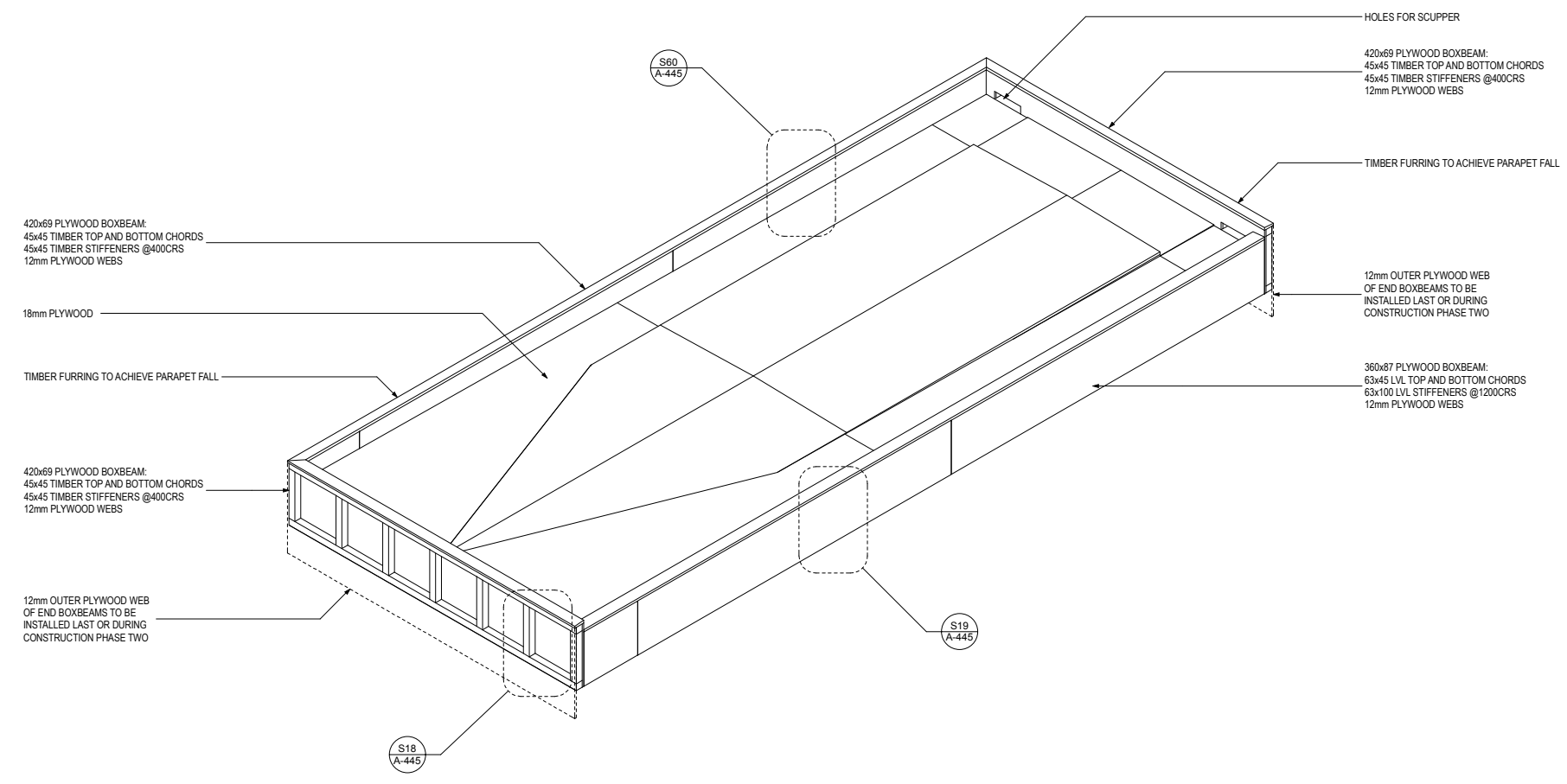

Figure 185: Fabrication Drawing - Complete Roof Panel 

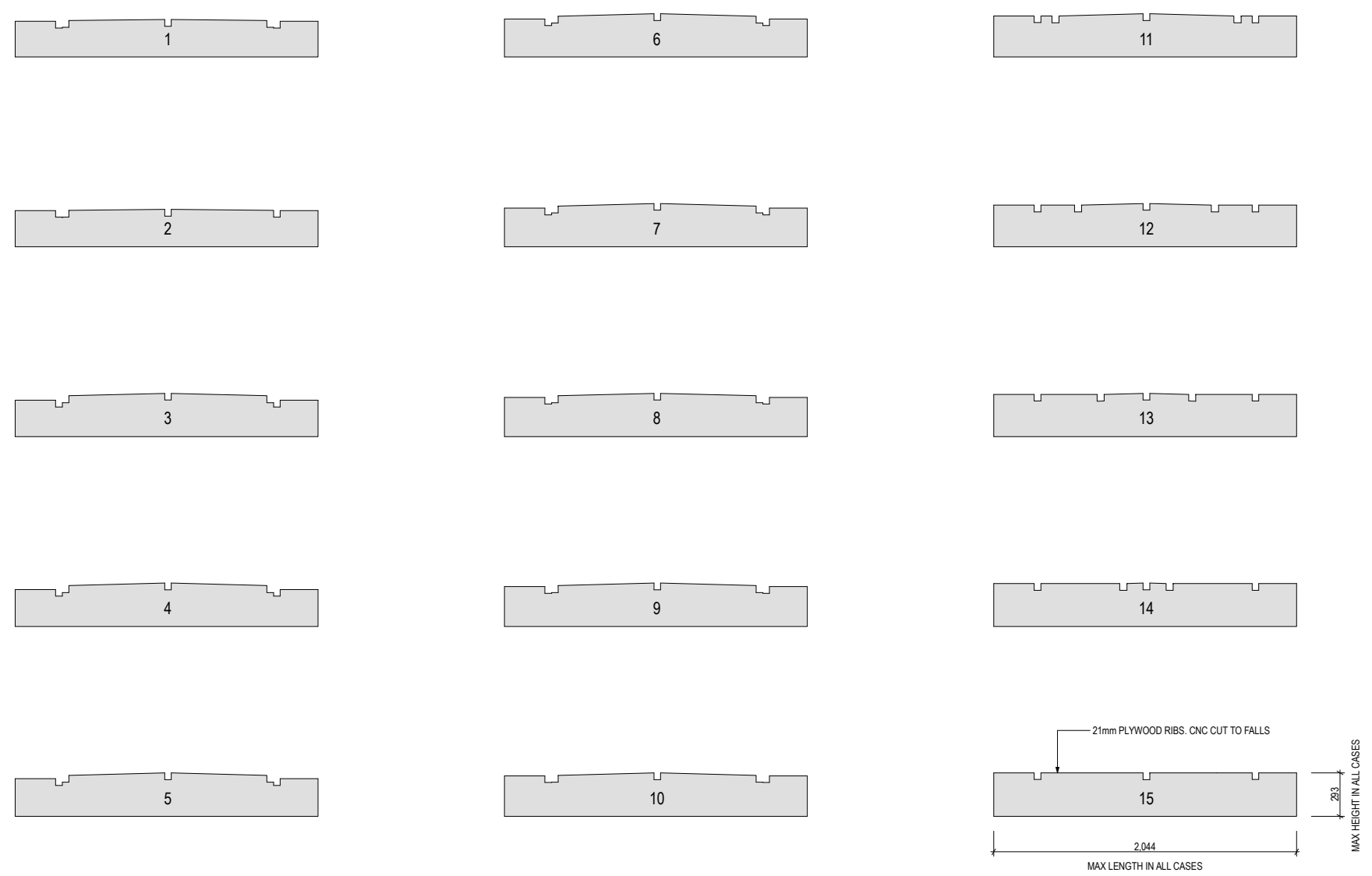

Figure 186: Fabrication Drawing Showing Individually CNC Cut Plywood Ribs

The high level of accuracy afforded by the CNC cutting process enabled the falls and construction of the roofs to be even further optimised. A combination of options two \& three above resulted in an extremely efficient roof panel depth while providing adequate rainwater drainage. It was a possibility to cut the plywood ribs using the VUW SOAD (Victoria University of Wellington School of Architecture and Design) Workshop CNC router. Some concerns were however raised with respect to; the availability of equipment and staff, the cutting limitations of the machine itself, and more importantly issues surrounding insurances and liability on behalf of the University. It was therefore decided that an independent joinery company would be engaged to carry out the CNC cutting. A joinery company would also bring the necessary skills, tools, and workspace required to accurately construct the complex roof panels. Furthermore, through a positive relationship with our sponsor and main contractor Mainzeal, local joinery company Ferndale Furniture Ltd agreed to fabricate the complete roof panels and at a discounted cost.

\subsubsection{Thermal Bridging}

The CNC cut frame consisted primarily of $21 \mathrm{~mm}$ thick plywood ribs [Figure 186]. This thin profile minimised the amount of thermal bridging occurring through the structure while at the same time accommodating a large volume of insulation. To further reduce the impacts of thermal bridging, the initially proposed LVL primary beams were replaced with hollow plywood boxbeams [Figure 187 \& Figure 191]. These beams could be filled with insulation and would also provide the parapeted edge to each roof panel. The structurally spanning boxbeams were constructed with $63 \times 45 \mathrm{~mm}$ LVL top and bottom chords. Boxbeams located above load bearing walls, and hence not required to span structurally, were constructed with lighter framing. The outer layer of plywood was left unattached during fabrication so that the beams could later be packed with "Ecofleece" insulation [Figure 189 \& Figure 190]. 


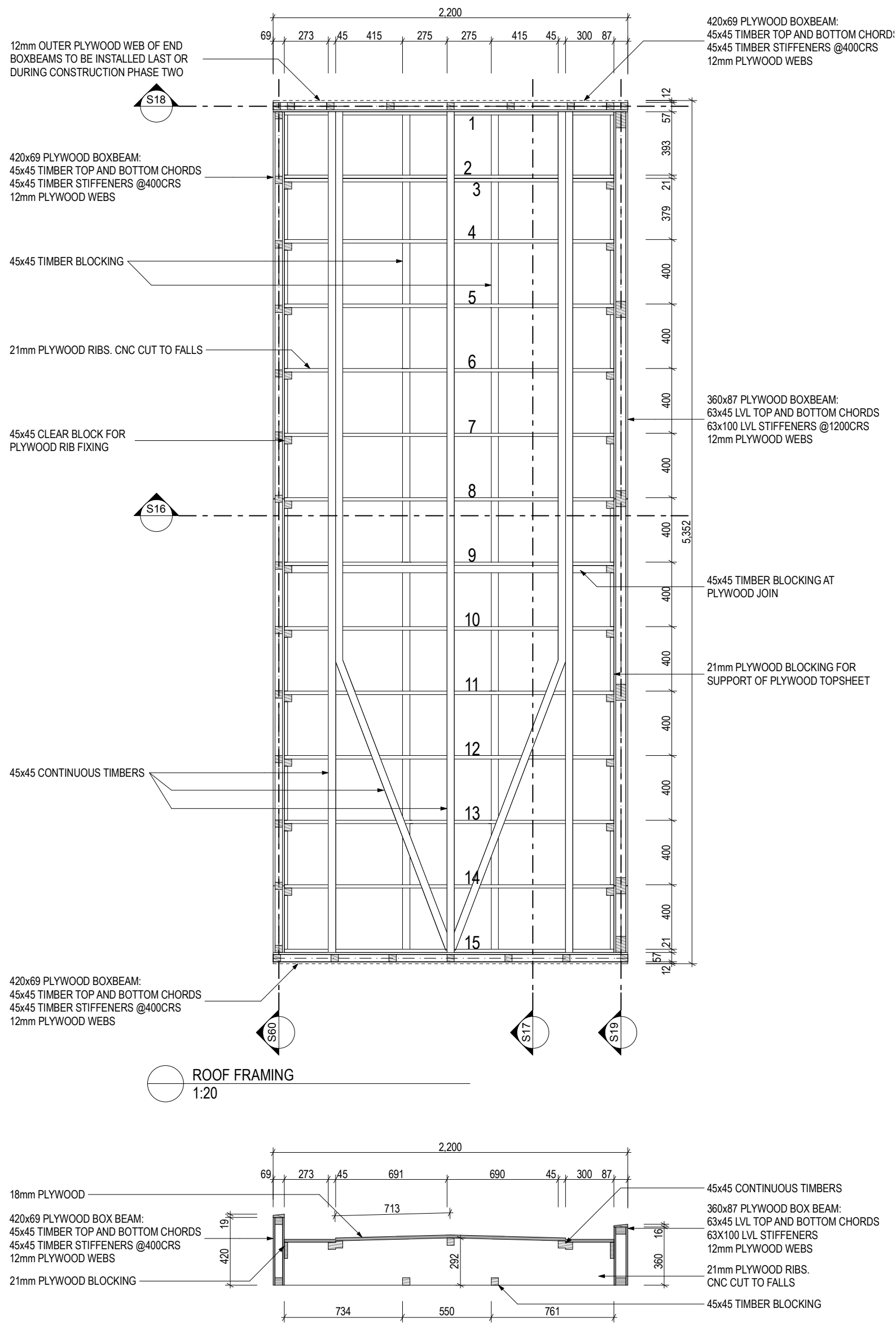

S16 TRANSVERSE SECTION

$1: 20$

Figure 187: Fabrication Drawing Showing Framing Elements of Roof Panel 


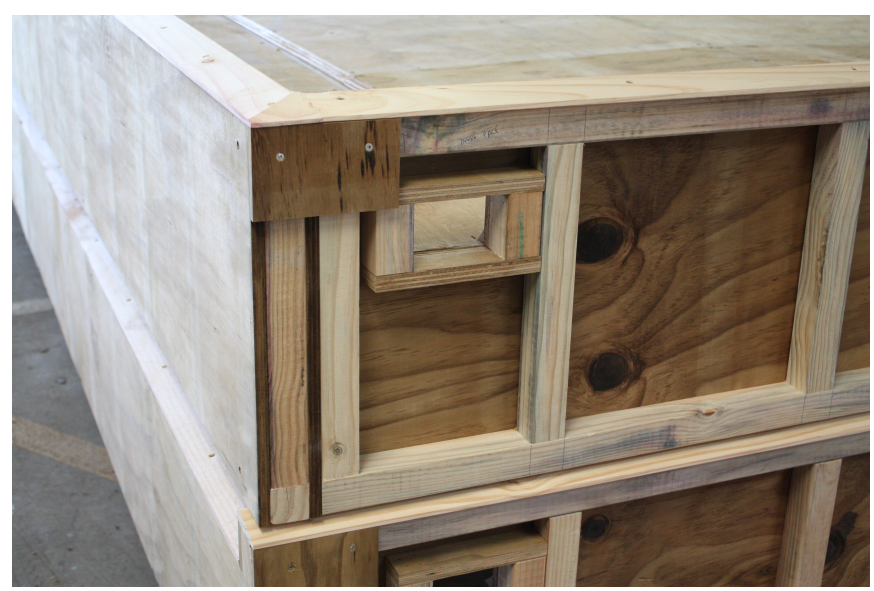

Figure 189: Construction Photo Showing Non-Load Bearing Box-Beam

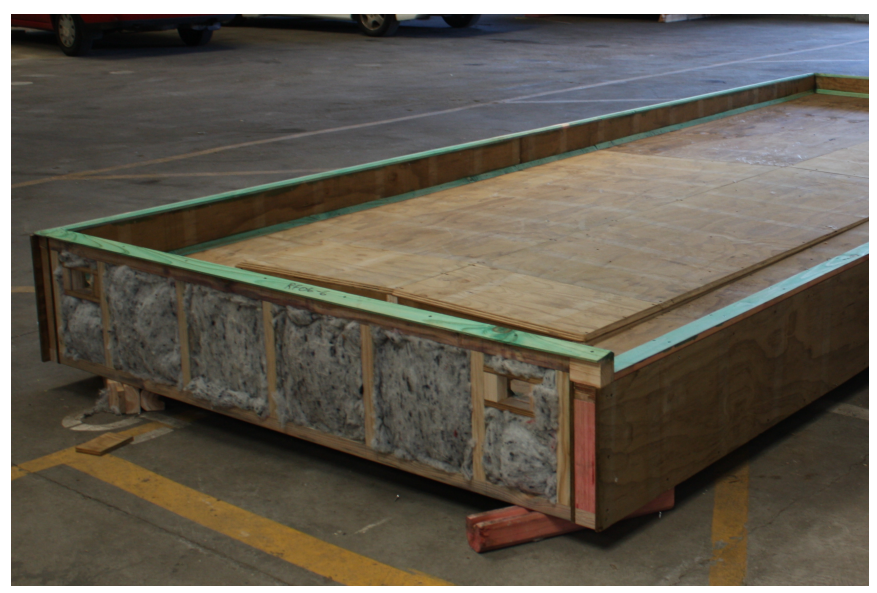

Figure 190: Construction Photo Showing Insulated Box-Beam

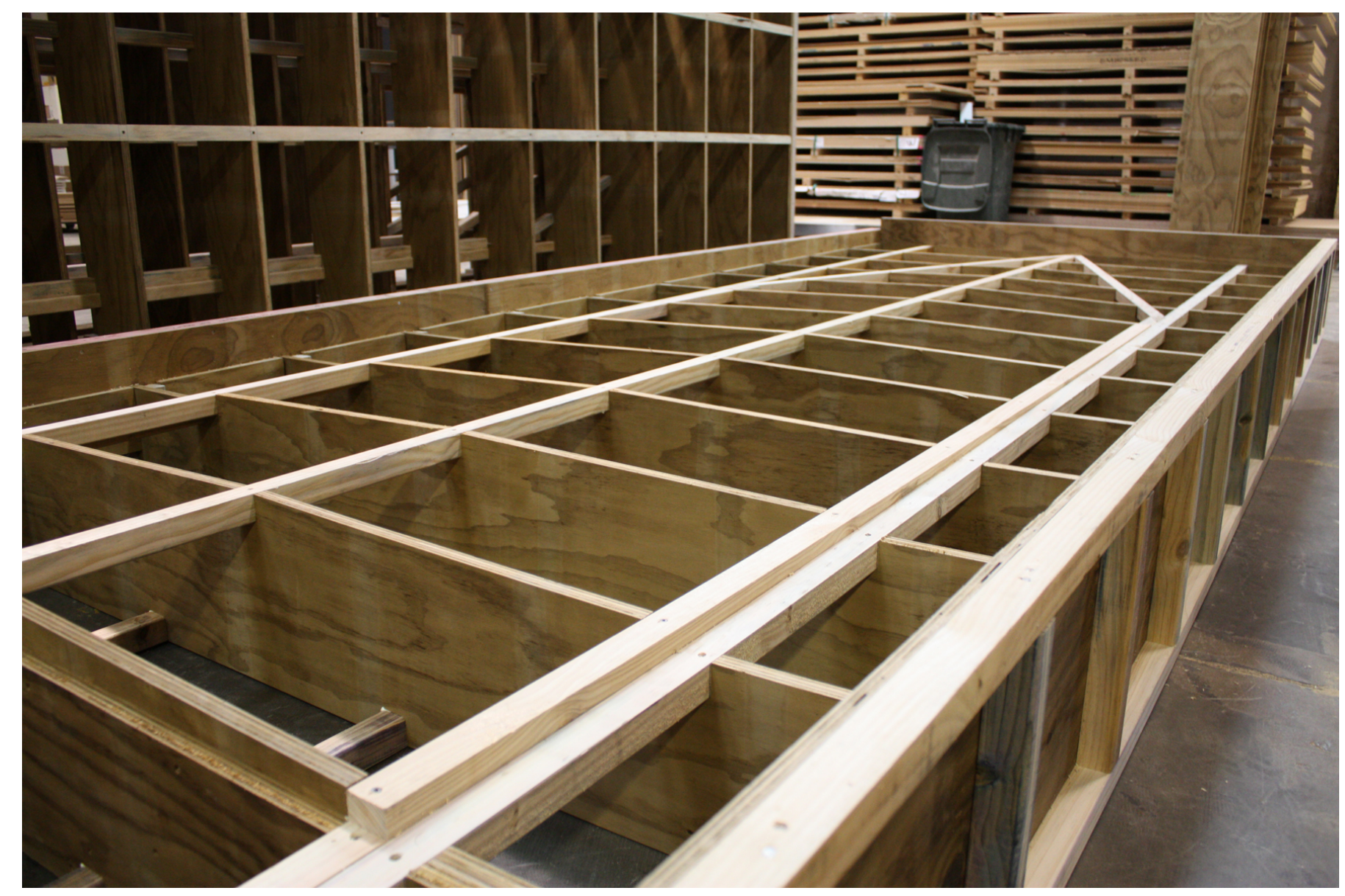

Figure 188: Construction Photo Showing Prefabricated Roof Frames at Ferndale Furniture Ltd 
The variation in boxbeam width, for spanning and nonspanning beams, meant that three different roof module types were needed to achieve the total five roof panels. The roof fall profile was essentially kept the same with the dimension of one of the longitudinal gutters adjusted to achieve the correct overall panel width [Figure 191]. This enabled the same CAD profiles to be used on the $\mathrm{CNC}$ machine with only minor adjustments.

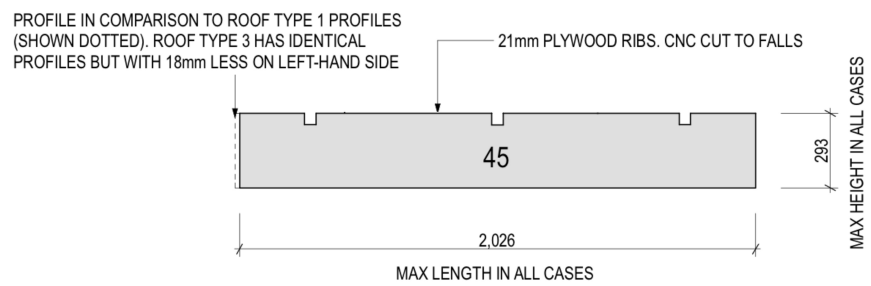

Figure 191: Fabrication Drawing Showing Change in Rib Width for Different Roof Types

Great care was taken during documentation to ensure that these small variations were noted and carried out correctly by the joiners and carpenters. Unique names were given to the roof types and three separate drawing sets were provided for each. A standard key and module count was included in the sheet title block to provide clarity during fabrication [Figure 192].

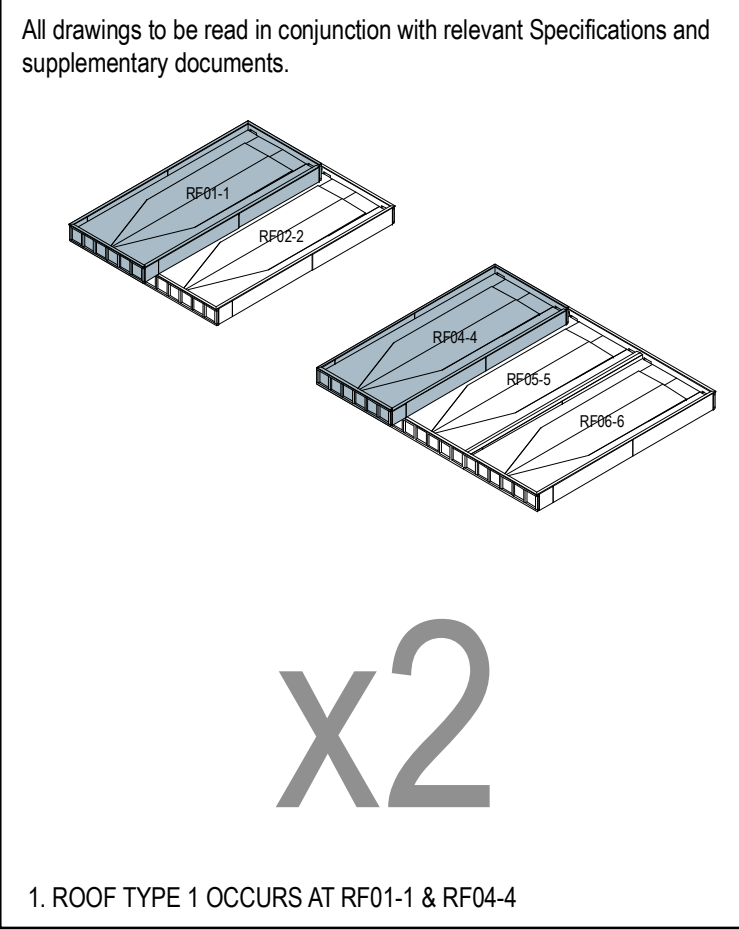

Figure 192: Fabrication Drawing - Example of Roof Type Key

\subsubsection{Air Tightness}

The roofs entailed the same set of circumstances, in terms of airtightness, as the wall construction. They consisted of an impermeable exterior RAB plywood layer, a large volume of insulation and a potentially permeable internal layer. The same method for achieving air and moisture control was adopted with the use of ProClima Intello vapour check membrane behind a white-washed $T \& G$ pine ceiling finish (chapter 8.1.4 Air Tightness for further explanation of methods for achieving air tightness).

\subsubsection{Damage}

Careful consideration was paid to the treatment of any corners on the roof so as to provide a sound substrate for the EPDM (ethylene propylene diene monomer) roofing membrane. Every ninety degree corner was either filleted or chamfered forming the correct substrate for the membrane [Figure 193]. Given the extent of foot traffic incident on the roof surface during assembly and disassembly, it would have proven greatly beneficial to have used a thicker gauge membrane. A $1.5 \mathrm{~mm}$ EPDM was used whereas a $2-3 \mathrm{~mm}$ would have been more appropriate.

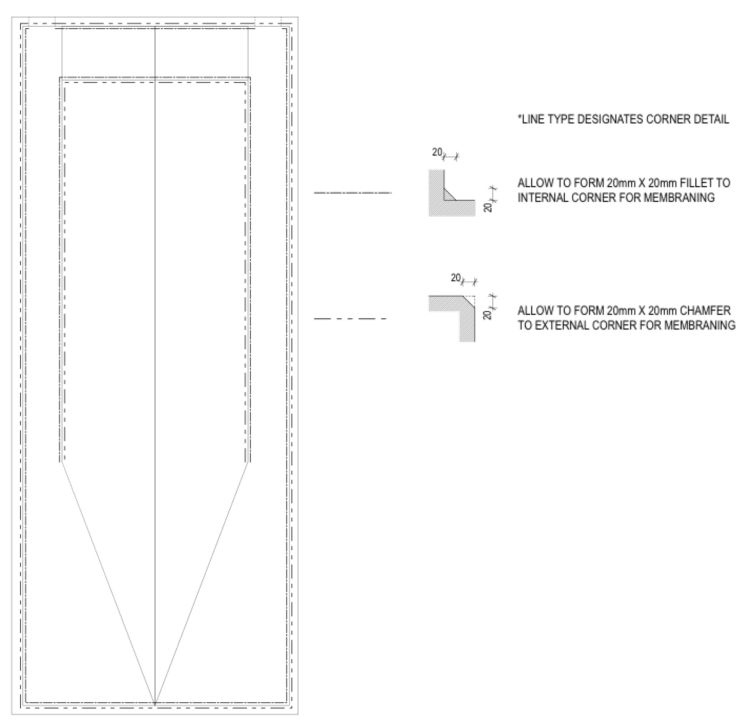

Figure 193: Fabrication Drawing Showing Fillets and Chamfers to Roof Surface (JM)

All chamfered or cut edges and untreated timber on the roofs surface were protected against rot with Metalex Concentrated Timber Preservative Green by Holdfast. This brush-applied preservative uses $\mathrm{CuAz}$ which is an accepted means of treatment in the USA AWPA. 
To ensure the longevity of the roof as a watertight system, two downpipes per module were specified along the north parapet [Figure 194]. One downpipe essentially provides a blockage overflow for the other. This is an important consideration given that both the scuppers and the downpipes are fully concealed within the exterior cavity. Proprietary 'All-Proof' scuppers were used with a plastic welded 90 degree downpipe adaptor to enable a tight junction within the confines of the cladding cavity [Figure 195]. It is recommended that regular maintainance be undertaken to keep the scuppers and downpipes clear from blockages.

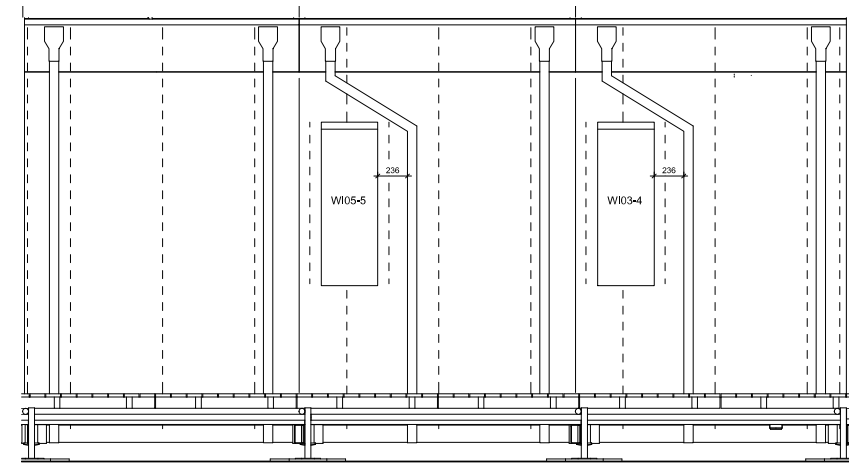

Figure 194: Construction Elevation Showing Downpipe Locations

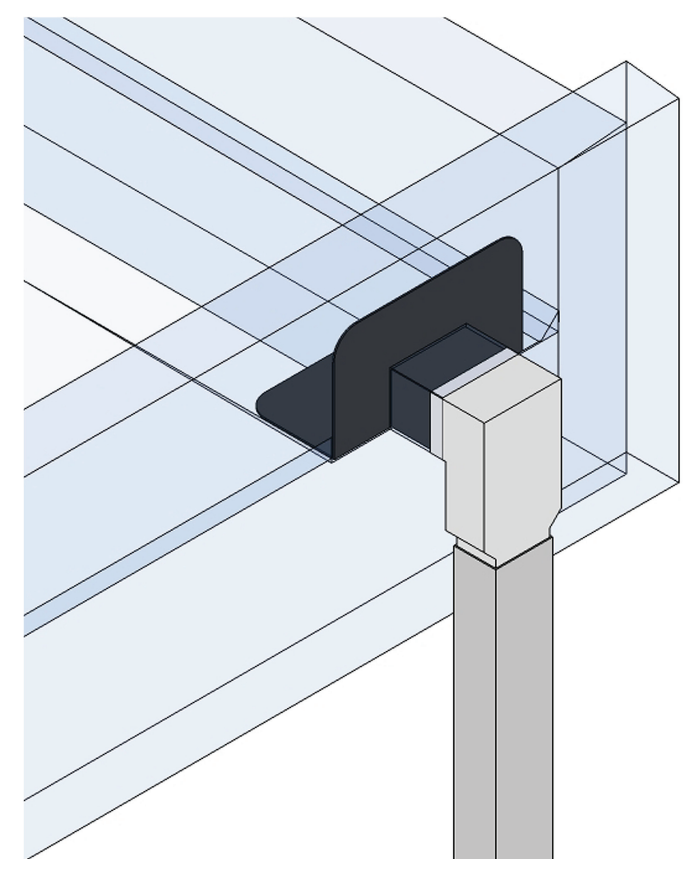

Figure 195: 3D Sketch Showing Scupper and Downpipe Components

\subsubsection{Assembly}

Hardwood locating dowels were again specfied as a means of accurately realigning the modules during assembly [Figure 196] These were designed on the same principle as the floors, with $3 x$ dowels per module roof. Again, the roof locating dowels were overlooked during construction and had to be installed retrospectively before reassembly. The dowels worked to join the modules on Frank Kitts Park with any minor misalignments (likely caused by retrospective installation of dowels) concealed by adjusting the internal finishes. During the assembly in Washington DC however, the dowels proved to be significantly out of line with their corresponding holes, preventing the modules from coming together. Consequently these dowels were cut so that assembly could resume. Some misalignment was apparent between the modules but not enough to account for the significant misalignment of the dowels. This could only be caused by independent deformation of the modules during transport either through structural racking or the expansion/contraction of the timber.

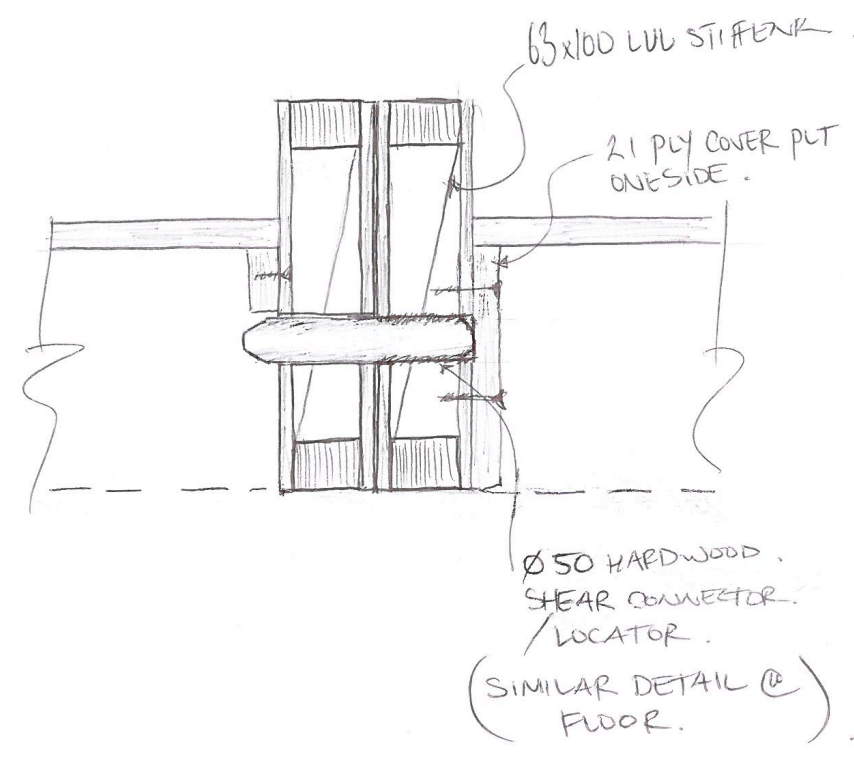

Figure 196: Engineers Detail of Roof Locating Dowel

\section{Membrane Strip}

An EPDM parapet strip is installed at the module join to create a continuous waterproof membrane [Figure 197]. At the time of disassembly this strip is simply cut along the module join. 


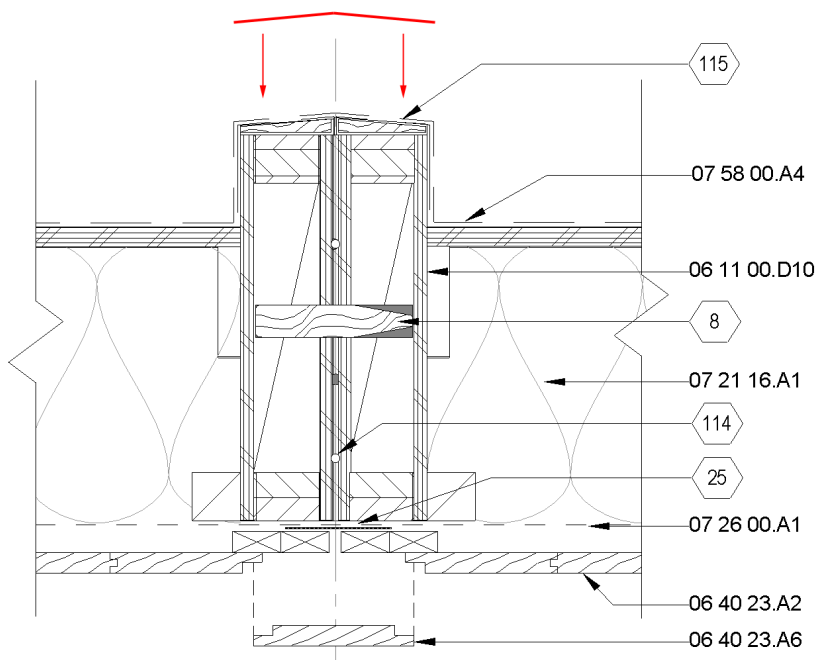

Figure 197: EPDM Parapet strip to Module Join Detail

\section{Flashings}

Clip-on parapet flashings were used to ensure a watertight envelope that was quick to install and could be removed for tranport. These consist of colorsteel tags that are fixed to the inside of the parapet which the colorsteel flashing "clips" onto [Figure 198]. The flashing face is extended down to clip under the edge of the top cedar cladding block [Figure 199]. All joins in the flashings are then glued with silicon and riveted. A dedicated flashing assembly drawing was prepared to ensure the correct placement of each flashing [Figure 200]. This system was effective for $2 \mathrm{x}$ assemblies only and new flashings will need to be fabricated for the final installation due to wear and tear.

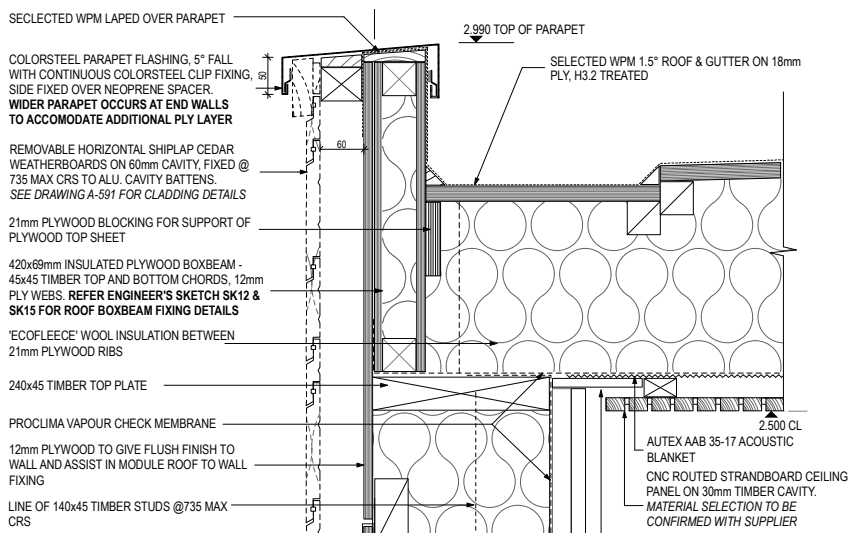

Figure 198: Clip-on Parapet Flashing Detail

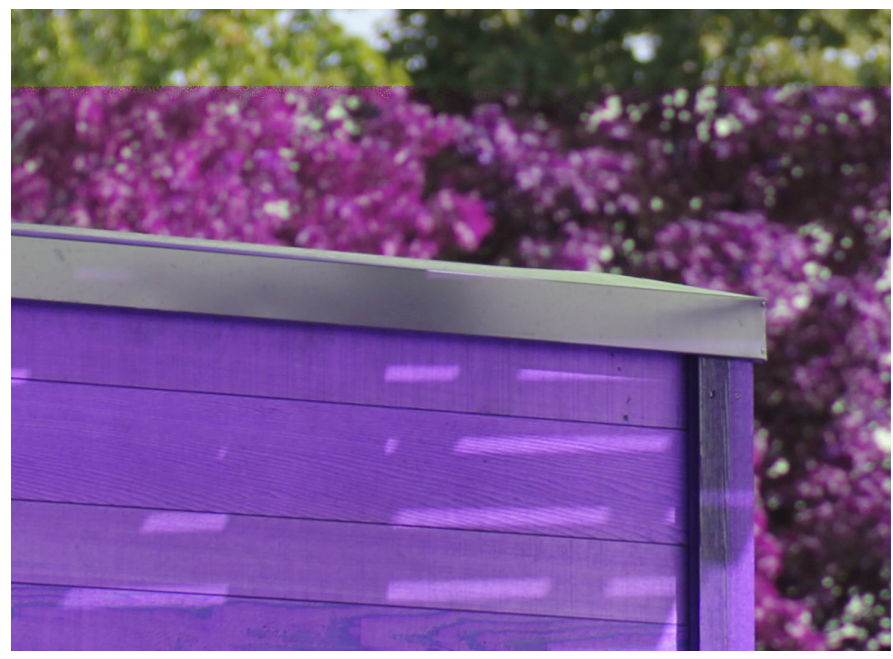

Figure 199: SD Photo Showing Clip-on Parapet Flashing Exterior Finish

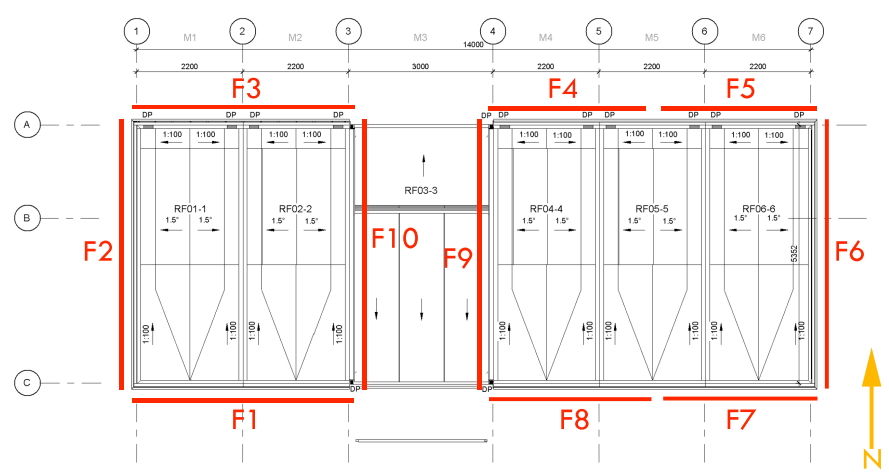

Figure 200: Clip-on Parapet Flashings - Assembly Drawing

\section{Fall Protection}

Access to the roof was required for three main purposes: To apply the parapet membrane strip at the module joins, to assist with the mounting of the top cladding panels and parapet flashings, and to assembly the canopy.

To comply with NZ OSH Laws; fall protection measures must be put in place for any work at a height of 3 metres or more. USA OSHA Laws are more onerous in this respect requiring fall protection from any height in excess of $1.8 \mathrm{~m}$. In either case the First Light house would require fall protection due to a roof height of $3.8 \mathrm{~m}$. This can be achieved through the use of guardrail systems, safety net systems, or personal fall arrest systems. For work on lowslope roofs of $15.25 \mathrm{~m}$ or less in width USA OSHA permits "the use of a safety monitoring system alone (i.e. without the warning line system)" (Occupational Health \& Safety Administration, 1982). This method entails a dedicated safety monitor who supervises the work being performed and advises the workers of any unsafe practice/situation and how to correct it. A safety 
monitoring system alone would not require any additional fall protection structures or equipment to be installed on the house. However, The SD Health \& Safety Template supersedes this option stating; "Monitoring systems are not allowed to be used to mitigate fall hazards from elevated heights".

To meet both NZ and USA standards, the house would need to employ fall protection measures. These measures would be governed by the more onerous regulations set out in the US OSHA Standard 1926.502 Fall protection systems criteria and practices. Given the low height and small scale of the First Light house it was not practical to incorporate a safety net or guardrail system. The team would have to provide the means for a Personal Fall Arrest or Restraint System.

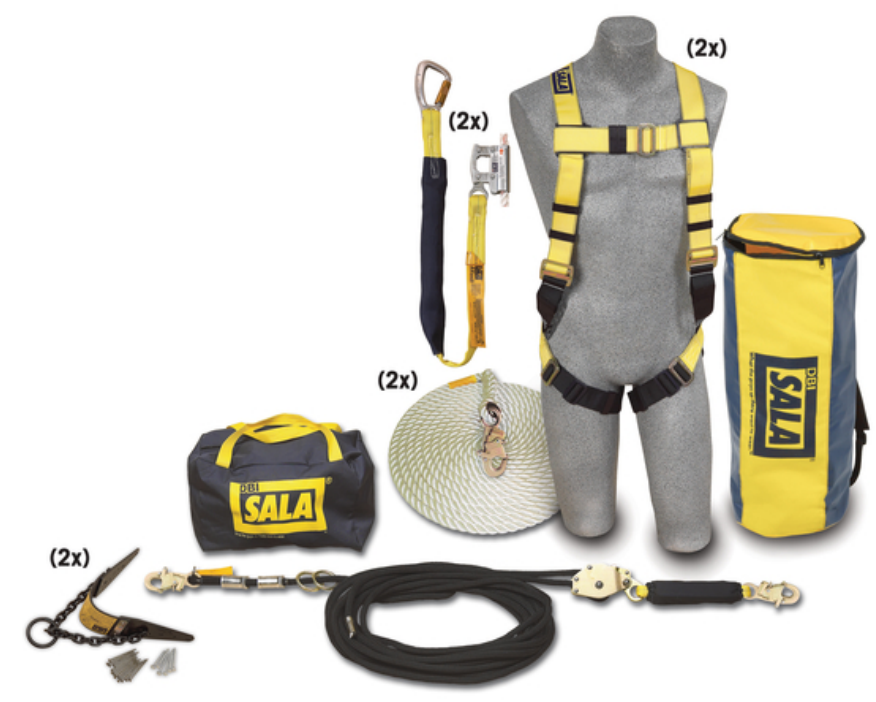

Figure 201: Fall Arrest/Restraint Equipment (Capital Safety, 2012)

A Personal Fall Arrest/Restraint system typically includes a harness, lanyards, and anchor points [Figure 201]. Due to the relatively low height of the First Light house (3.2m above foundation) the system would have to operate in restraint i.e. There was insufficient height to enable the necessary deceleration distance and safety factors for a fall arrest system [Figure 202]. Fall restraint systems are designed to prevent a worker from accessing the fall hazard altogether by restraining their range of movement [Figure 203].

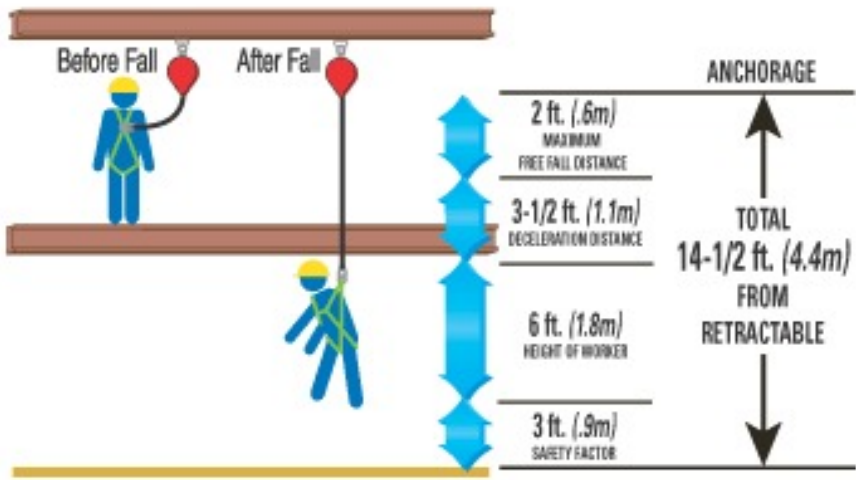

Figure 202: Calculating Fall Clearance Distance

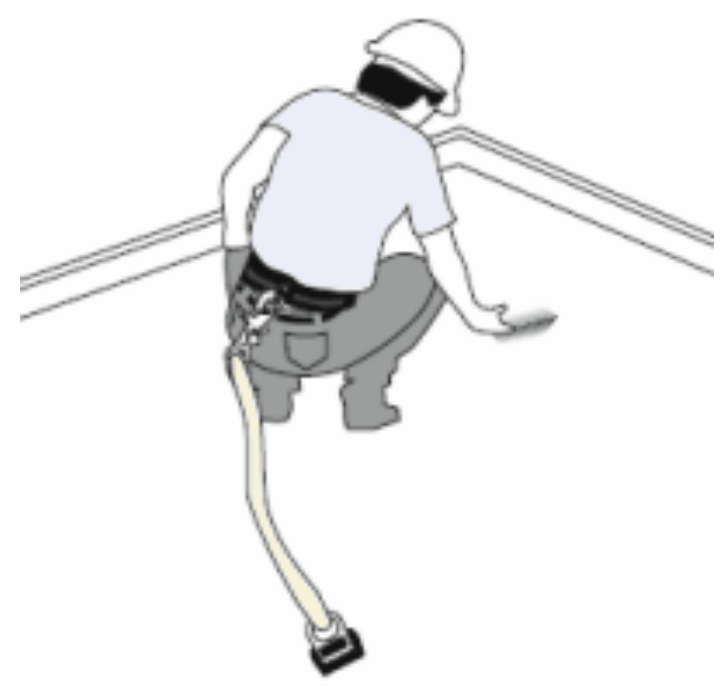

Figure 203: A Fall Restraint System (OSH Academy: Occupational Safety \& Health Training, 2010)

Five anchor points were specified for the Fall Restraint System [Figure 204]. These are positioned so as to provide workers with the range of movement needed to perform all necessary tasks on the roof. The anchors are DBI Sala L4544 Roof Anchors with a rating of $22 \mathrm{kN}$ [Figure $205 \&$ Figure 206] Access to the roof is from secured ladders on the North side of Module Three. 


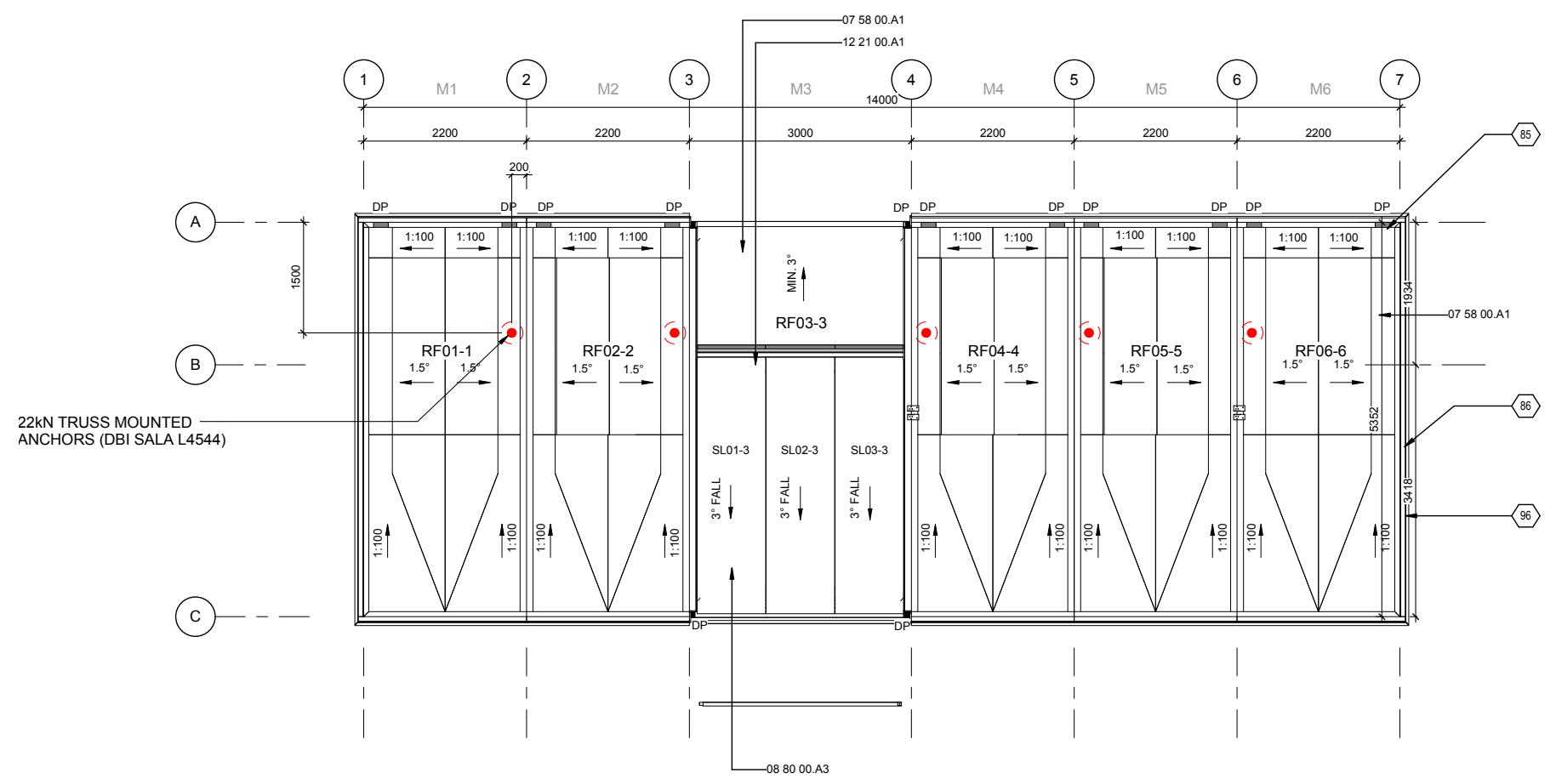

Figure 204: Roof Plan Showing Anchor Points

\section{Diagram 2}

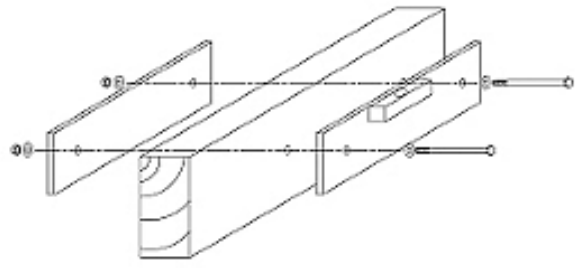

\section{Diagram 3}

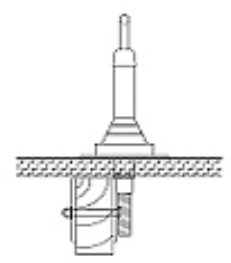

\section{Diagram 4}

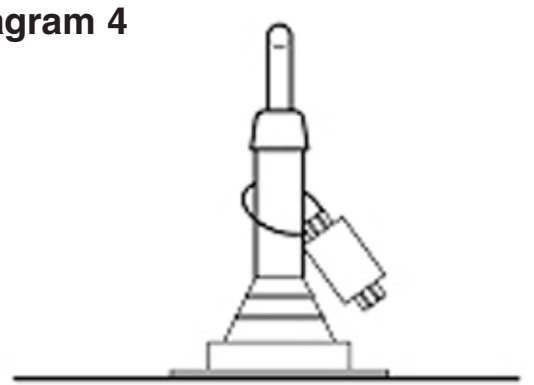

Figure 205: DBI Sala L4544 Roof Anchors - Installation

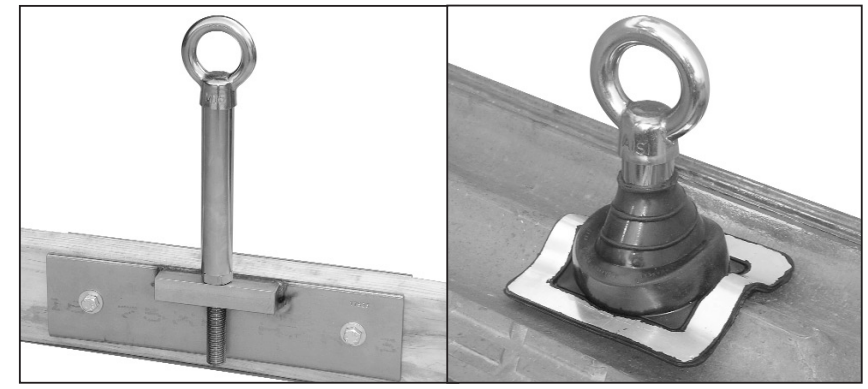

Figure 206: DBI Sala L4544 Roof Anchor

The requirement for a fall arrest system was identified very late in the design process, and the provision for it was not included until construction had already begun. This required a hasty design and fitting of the anchors before the internal linings were installed. Fortunately the roofs were structurally capable of resisting the specified $22 \mathrm{kN}$ load of the anchors. With only minor changes to construction, one anchor per roof module was installed [Figure 207]. The anchors had to be located near the box beam parapets for structural strength and thus within the longitudinal gutter. A gutter is not the ideal place for a penetration of this kind however, given the very flat nature of the roof, a penetration anywhere is not ideal. Close attention was paid to the waterproofing of these penetrations in both the detailing and the installation. 


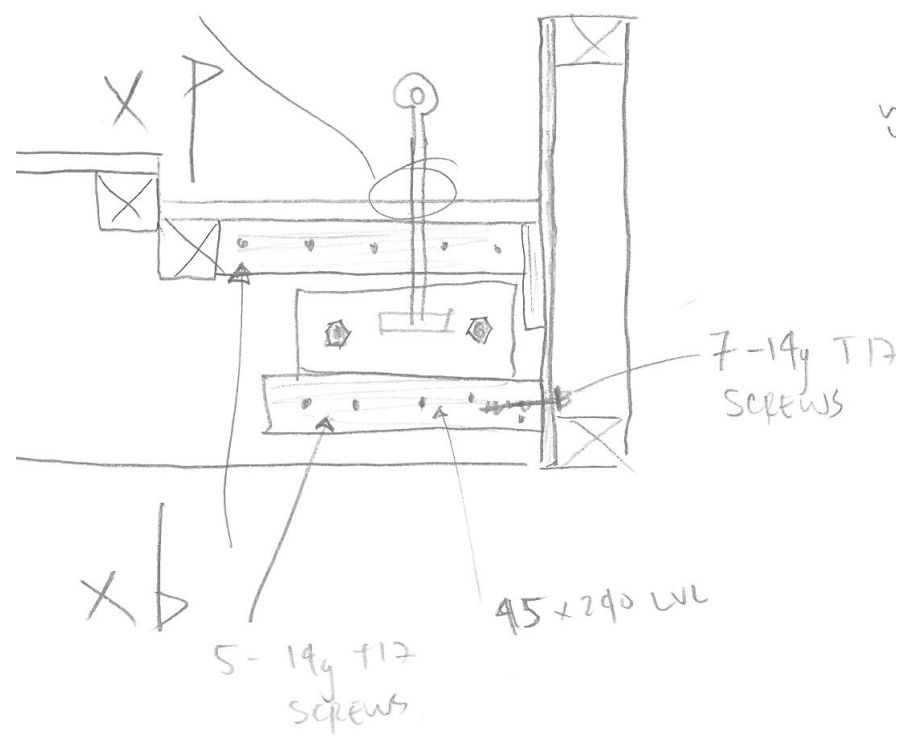

Figure 207: Fall Arrest Anchor - Structural Detail

A $15 \mathrm{~m}$ lifeline with a manual rope-grab adjuster is used to enable a large range of movement while maintaining the correct length of lanyard at all times [Figure 208]. A potential swing down hazard existed due to the length of the lanyard at certain locations on the roof [Figure $209 \&$ Figure 210]. This hazard was managed through the appropriate training and education of workers at height and mitigated with the provision of Fall Arrest.

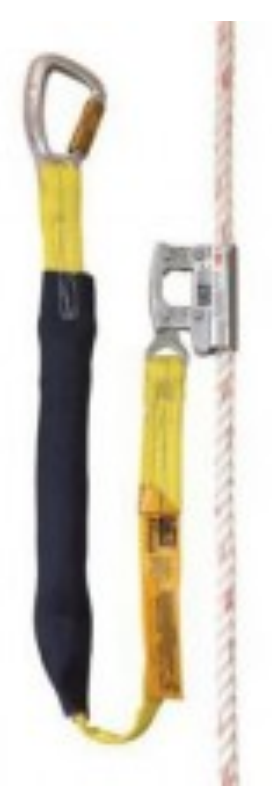

Figure 208: Manual Rope-Grab Adjuster and Lifeline (Capital Safety, 2012)

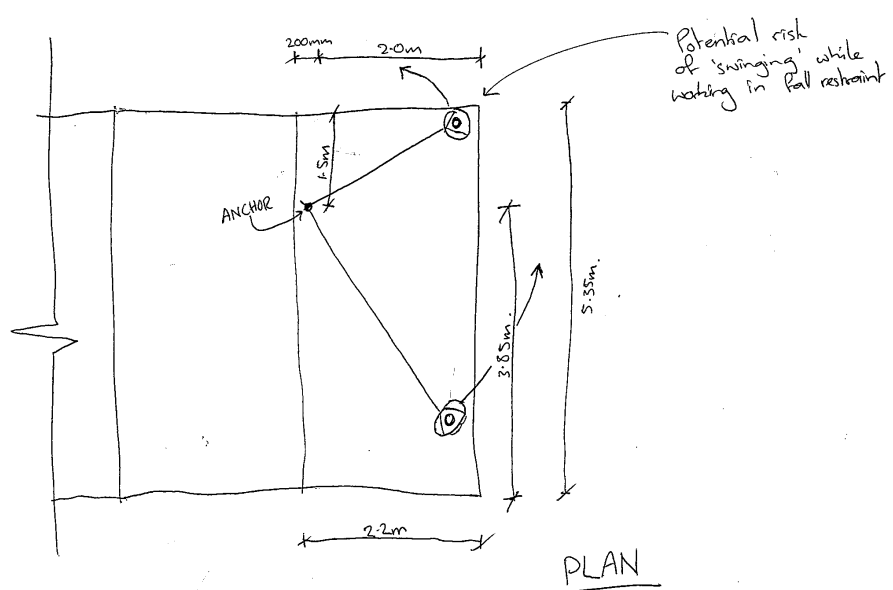

Figure 209: Swing Down Hazard - Roof Plan

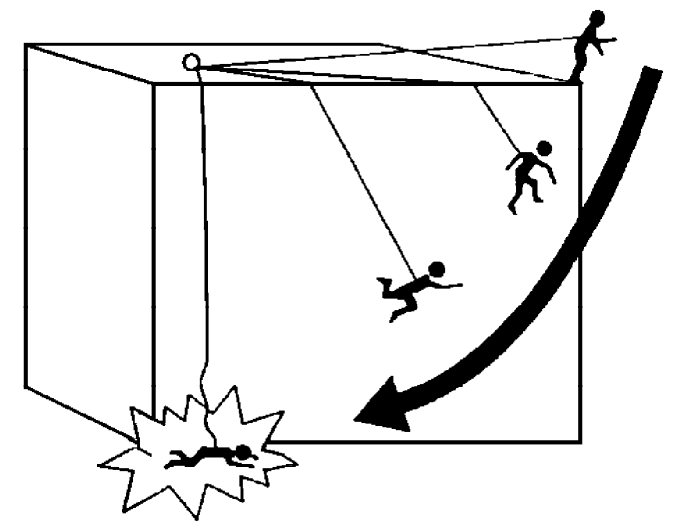

Figure 210: Swing Down Hazard

The system is designed to also function in fall arrest, as a last resort. Should a fall occur at any point on the roof, and provided the lanyard is being used correctly, the system will prevent the worker from coming into contact with the ground (thus anchors are rated to $22 \mathrm{kN}$ and lanyards include a shock absorber). This scenario however would facilitate a safety factor of only $0.5 \mathrm{~m}$ as opposed to the desired $0.9 \mathrm{~m}$ [Figure 211]. The roof top anchors provide sufficient fall protection while applying the membrane parapet strips, the mounting of the top cladding panels and the installation of the parapet flashings. 


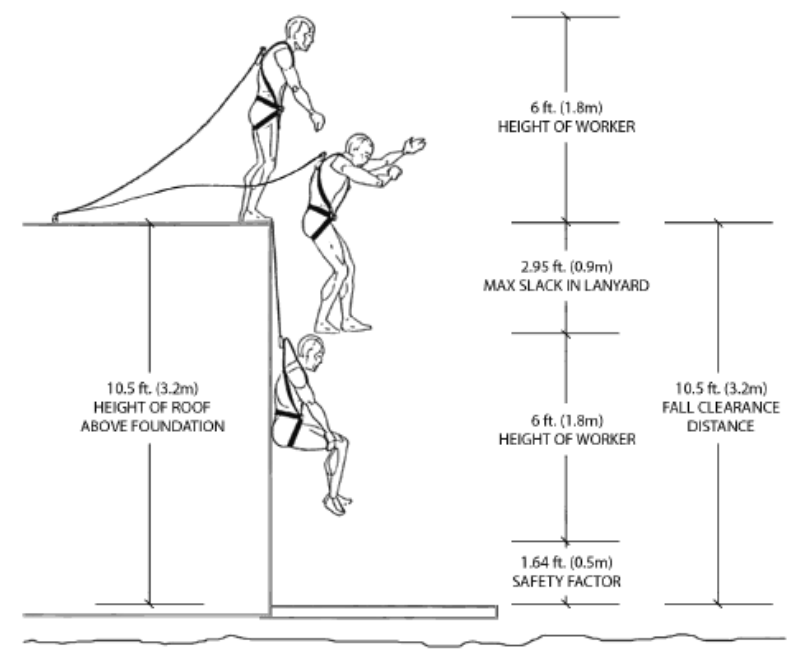

Figure 211: Fall Clearance Distance - First Light House

Once the glulam (glue laminated) canopy structure is erected and adequately braced, a secondary fall restraint system is utilized. This works on the same principles of restraint as previously described however in this case the Glulam structure is used as the anchor points [Figure 212]. Webstrap Anchor Webslings by Protecta are used to connect the lifelines to the canopy structure [Figure 213]. The Webslings are attached at specific locations to the primary $90 \times 315 \mathrm{~mm}$ Glulam beams and the lanyards can either pass over or under the rafters to the workers [Figure 214]. This system provides sufficient fall protection to workers installing the cedar slats, solar panels, and undertaking any roof top maintenance.

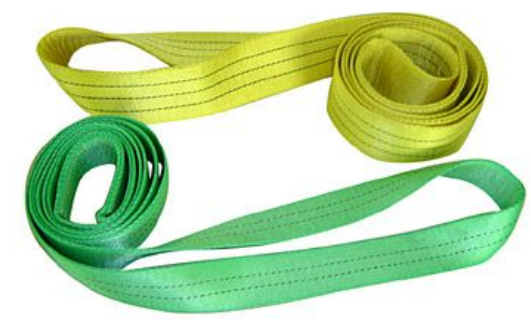

Figure 213: Webstrap Anchor Webslings

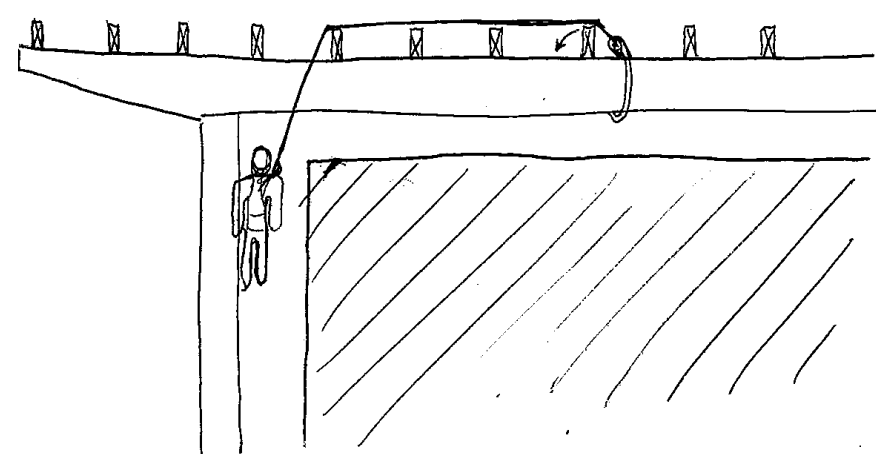

Figure 214: Websling Attached to Beam, Lanyard Over Rafters

The proposed Fall Restraint System with the ability to prevent serious injury if used in fall arrest, along with the correct training of workers was deemed by the US DOE Health \& Safety Inspector to be acceptable for construction at the Solar Decathlon 2011.

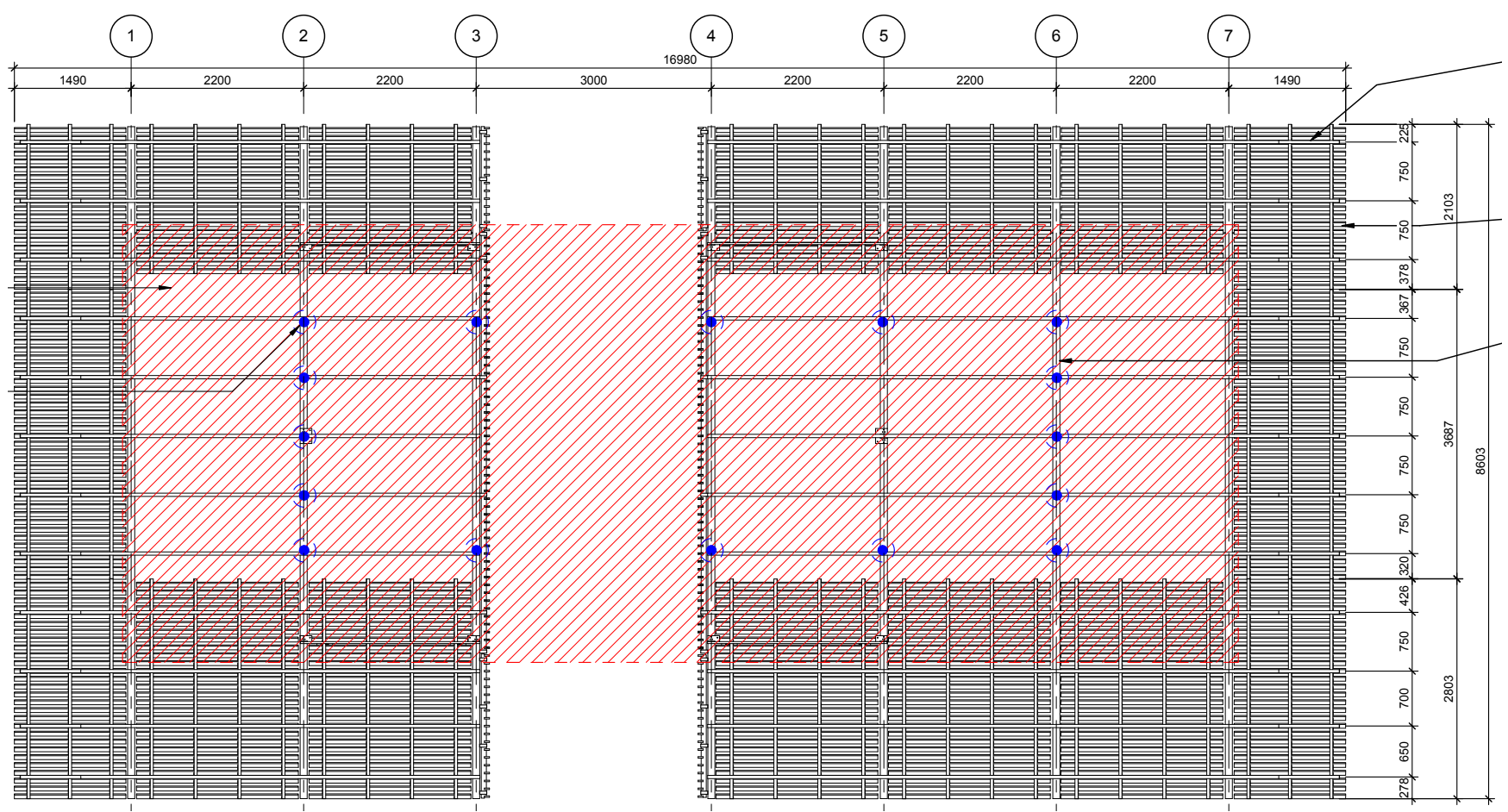

Figure 212: Roof Plan Showing Glulam Anchor Points 


\subsubsection{Cost}

Initial RLB US estimate $=$ US $\$ 15,590$

Final DOE QS US estimate $=$ US $\$ 25,900$

Final RLB NZ estimate $=\$ 62,700$

Actual NZ Cost $=$ Unknown

A direct cost comparison between timber framing and the proposed plywood rib system was undertaken by quantity surveyors, RLB. Ferndale Furniture had provided the following quote for the work both including and excluding the supply of materials;

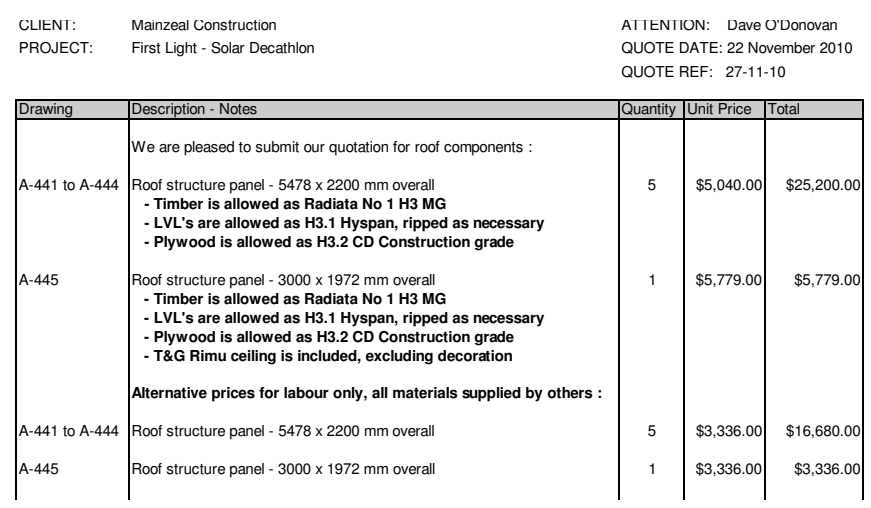

RLB compared this to their built up rates for the proposed timber framing option. It was anticipated that the complex plywood rib system would significantly increase costs. Upon RLB's assessment it was found that the Ferndale quote was very economic and in fact cheaper than the estimated cost of a timber framed option.

\section{Budget position for typical roof panel is:}

Roof panel

$\$ 2,844$

(\$3,710 less insulation, connection bolts \& cover plates not included in Ferndale's price)

Parapets

Form gutter outlets

Poly sheet to form falls

Total (panel installed)

X5 Roof Panels (installed)

$\$ 33,220$
Roof Panel (supply)

$\$ 5,040$

Allowance $\mathrm{p} / \mathrm{p}$ for installation

X5 Roof Panels (installed)

$\$ 27,700$

NB: With the central module still under development, costs for the $5 \mathrm{x}$ typical module roofs only were considered for comparison.

The plywood rib frame system proved to be a total of $\$ 5,520$ cheaper when compared with timber framed construction. Although surprising, these sorts of economies can be attributed to the efficiencies generated by the prefabrication process. The economic use of materials afforded by $\mathrm{CNC}$ cutting and the elimination of external influences such as the weather and other site specific delays markedly reduces material wastage, improves labour efficiency and reduces manufacturing time. Furthermore, by providing complete and accurate fabrication drawings a fixed quote can be obtained. It is important to note that a degree of complexity is added to this particular project due to the modular nature of the roofs and the shallow falls necessary for transportation. For this specific design it was cheaper to prefabricate the roofs in a joinery workshop, however further research would be needed to determine the most economic approach should the house be built on a permanent site.

Ferndale's corresponding price is: 


\section{MODULE THREE CONSTRUCTION}

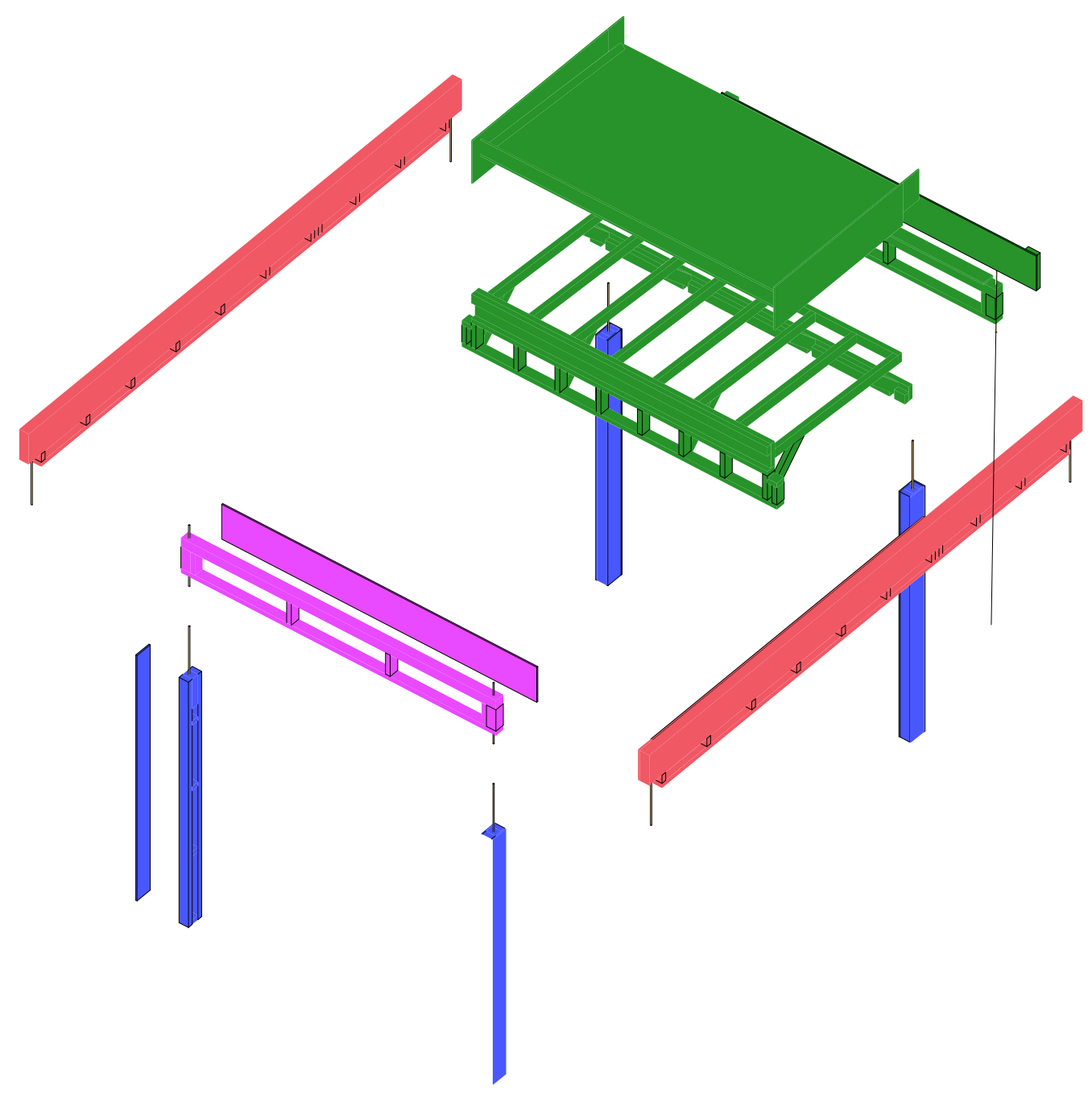

Figure 215: Exploded 3D Diagram Showing Module Three Components (Excl. Floor) 


\section{MODULE THREE CONSTRUCTION}

In terms of performance Module Three (M3) proved to be the most challenging of the house modules. The space that it creates is central to the design and it is through module three that the core concept of openness, social interaction, and connection with the outdoors would come to life. The decision making hierarchy below [Figure 216] presents the performance criteria surrounding module three. In this instance however, aesthetics, user experience and functionality were of far more importance than in the detailing of the building envelope [Chapter 5 ENVELOPE CONSTRUCTION].

Regulations

Design: Aesthetics, User Experience, Functionality

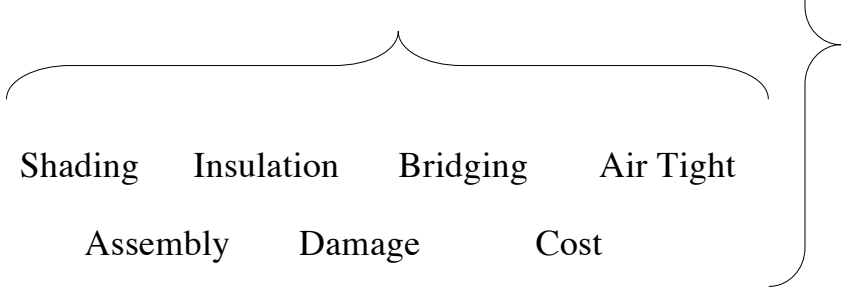

Figure 216: Decision Making Hierarchy - Module Three

Technical criteria were therefore challenged extensively by design and aesthetic motivations. It was agreed by the building performance team that this module might see a reduction in energy efficiency but only in so far as was necessary to achieve the desired architectural impact. A balance between performance and concept would again have to be reached.
M3 to the same dimensions as the other five house modules would greatly simplify the transportation and assembly process. This would however be a significant change when compared with the $2.8 \mathrm{~m}$ module width of the conceptual design submission.

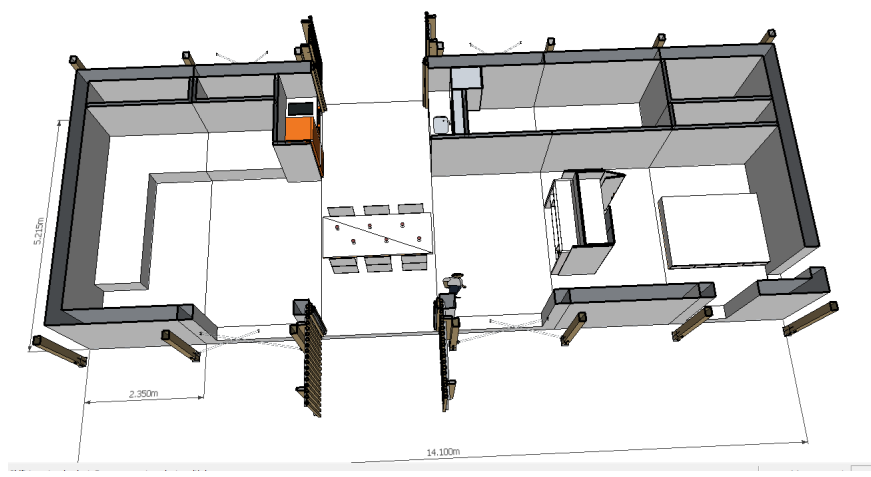

Figure 217: 2.2m Wide Module Three - Plan

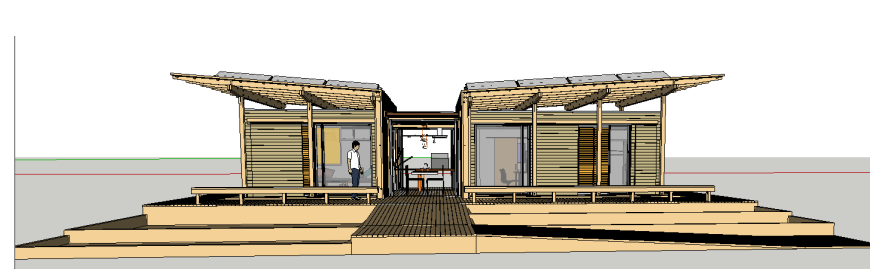

Figure 218: 2.2m Wide Module Three - Elevation

The shrinking of M3 was investigated at great length, pursuing many different dining and kitchen arrangements (Farrow, 2012). Through discussion with the Interior Design team it was agreed that it would not be possible to compress the central module to $2.2 \mathrm{~m}$ wide and still achieve the important sense of openness, connection with the outside, and degree of accessibility required by the competition. Consequently, M3 would be constructed oversize at a width of at least $2.8 \mathrm{~m}$ and any transportation issues would have to be overcome by breaking down the module into smaller components or otherwise. This decision had significant implications for detailing, construction and assembly, the development of which is outlined in Chapter 6.5 Assembly.

\subsection{REGULATIONS}

Regulatory requirements remained of high importance, particularly given the larger size of M3. A reduction in the width of Module Three was explored to meet the already established maximum module width for flat rack transportation of $2.2 \mathrm{~m}$ [Figure $217 \&$ Figure 218]. Fitting 


\subsection{SKYLIGHT}

Thermal Performance, Shading, Damage and Cost implications will be discussed here in combination since all are inseperably affected by the type of skylight used.

Through computer simulation modelling it quickly became obvious that overheating was the biggest problem facing Module Three (Jagersma, 2012). This was predominantly due to the large glazed area of the skylight allowing significant amounts of solar heat gains. The highly insulated envelope then traps this heat inside causing a "greenhouse effect" within the house. As the temperature rises above the comfort zone band, mechanical systems would need to be used to cool the house back down resulting in an increase in energy use. After thorough investigation it was found that the overall impact of the skylight on energy consumption during the competition would be nearly $30 \mathrm{kWh}$ more than if a solid roof was used (Jagersma, 2012). The contradiction of achieving lightness, openness, and views while at the same time preventing excessive energy use presented a significant challenge to the design team.

The impact that the skylight would have at the competition was rationalised through an understanding of the relationships between each of the contest criteria. The skylight would have a direct and significantly positive impact on the Architecture, Market Appeal, and Engineering contests. The negative effects that it would have on Comfort Zone, Affordability, and Energy Balance could all be deferred to indirectly impact on the
Affordability contest alone. I.e. The mechanical systems could be sized to appropriately mitigate the overheating effects of the skylight and additional shading elements could be installed to reduce heat gains, both at a cost. The increased energy demands of the mechanical system could then be offset with the inclusion of more solar panels.

The skylight itself already entailed a significant cost to the project and, with the additional deferred costs, it would prove to be even more expensive. The team had implemented the strategy of aiming for an overall construction cost of $<$ US $\$ 350,000$ [4.1.7 Cost]. The projected construction cost was sitting well within this limit at the detailed design phase. Hypothetically, if the direct and indirect costs of the skylight totalled say US $\$ 20,000$, only two points would be lost in the affordability contest. These would be two points out of a possible 1000 for the overall competition or $0.2 \%$. It was predicted that the architectural impact of the skylight would earn far more than an additional two points across the Architecture, Market Appeal, and Engineering contests. The inclusion of a skylight was well justified.

The first step towards improving the energy efficiency of the skylight was to reduce its size. The initial computer simulations modeled a double glazed skylight with an area of $16 \mathrm{~m} 2$. The simulations were then repeated for a glazed area that was $80 \%, 60 \%, 40 \%, 20 \%$ and $0 \%$ of the skylight's original size [Figure 219]. A significant change in internal air temperature can be seen here relative to the area of glazing.

A dramatic reduction in size of the skylight was proposed

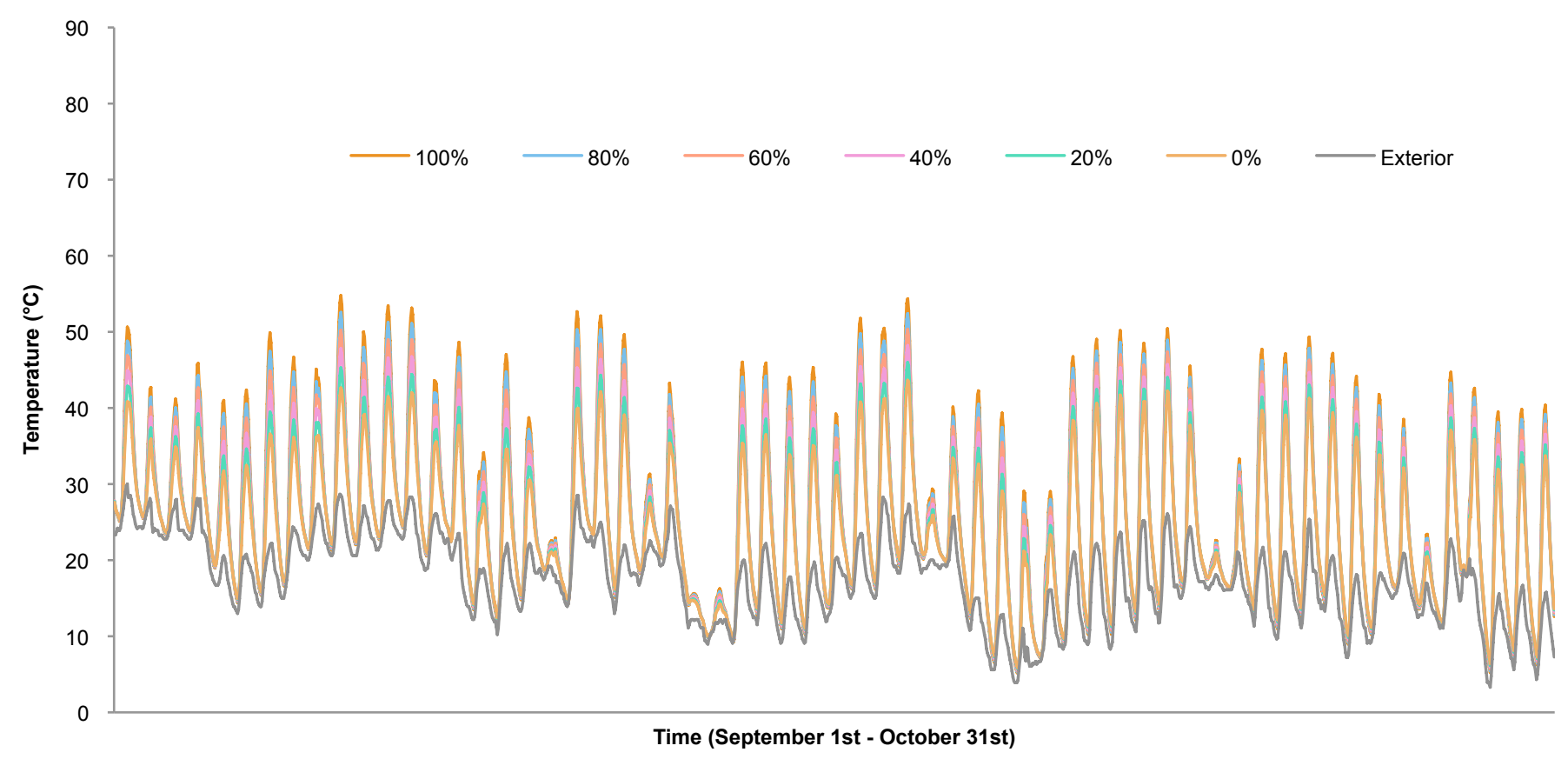

Figure 219: Variations in hourly internal air temperature with glazing area between $0 \%$ and 100\% of original skylight size for the period from Sept 15 - Oct 15 (Jagersma, 2012) 
by the building performance team so as to alleviate the extremes in internal air temperature. A smaller skylight would both improve thermal performance as well as provide some much needed roof space for services. With these two considerations in mind the design team agreed to the reduced skylight size and in fact saw some spatial strength in continuing the solid line of the interior core through the central space. The skylight was subsequently reduced to a maximum of $10 \mathrm{~m} 2$, roughly $62 \%$ of the original size, with the bulkhead extending across Module Three [Figure 220]. This decision occurred mid-way through the detailed design phase and was implicated by other factors such as the achievable falls of the skylight. Hence, the detailing of skylight options prior to this decision, including Danpalon, triple glazing, ETFE, and Nano-gel, were explored as if the skylight was at $100 \%$ of Module Three.
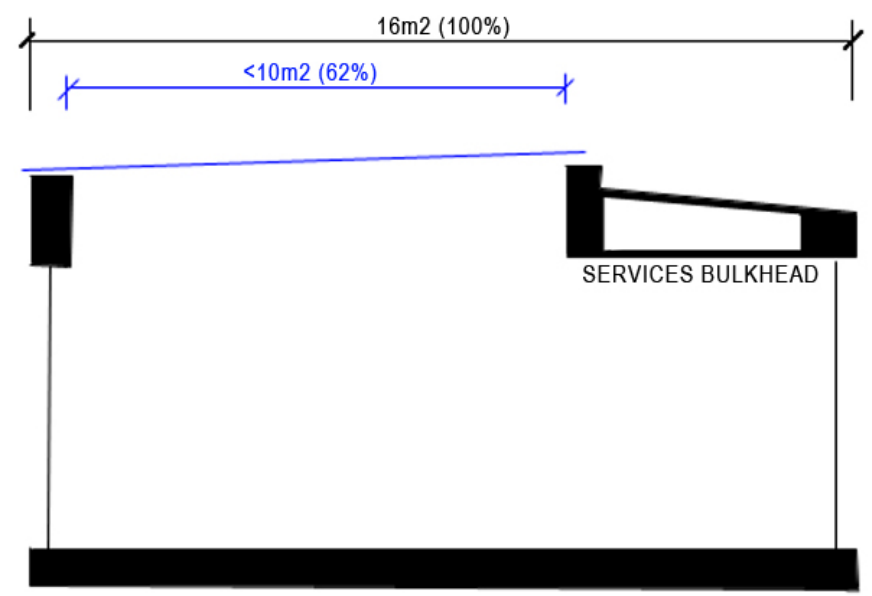

Figure 220: Section through Module Three showing reduced size of skylight and services bulkhead

Many skylight design iterations were explored in an attempt to reach the crucial medium between concept and performance. It was important that sufficient consideration was given to each option with respect to the technical criteria described above [Figure 216]. The most viable options were then reassessed through computer simulation modeling so as to determine their impact on thermal comfort and overall energy consumption. The results of the simulations are presented at the end of this chapter. These results and the systems described here are based on the following skylight options:

1. Triple Glazing

2. Double Glazing

3. 2x Double Glazing (Quad)

4. Polycarbonate

5. ETFE
6. Aerogel (Nano-Gel)

\subsubsection{Triple Glazing}

A series of triple glazed systems were explored with varying falls and supplementary blinds and shading devices. The desired performance characteristics of the triple glazed IGU's were as follows:

$\begin{array}{ccc}\text { LT \% } & \text { SHGC } & \text { R-value } \\ >40 \% & 0.3-0.4 & >1.1\end{array}$

LT $\%=\%$ of visible light transmission $(400-700 \mathrm{~nm})$

SHGC - Solar Heat Gain Coefficient, total solar energy transmitted through the panel

Option One: Central Ridge \& Internal Louvres [Figure 221]

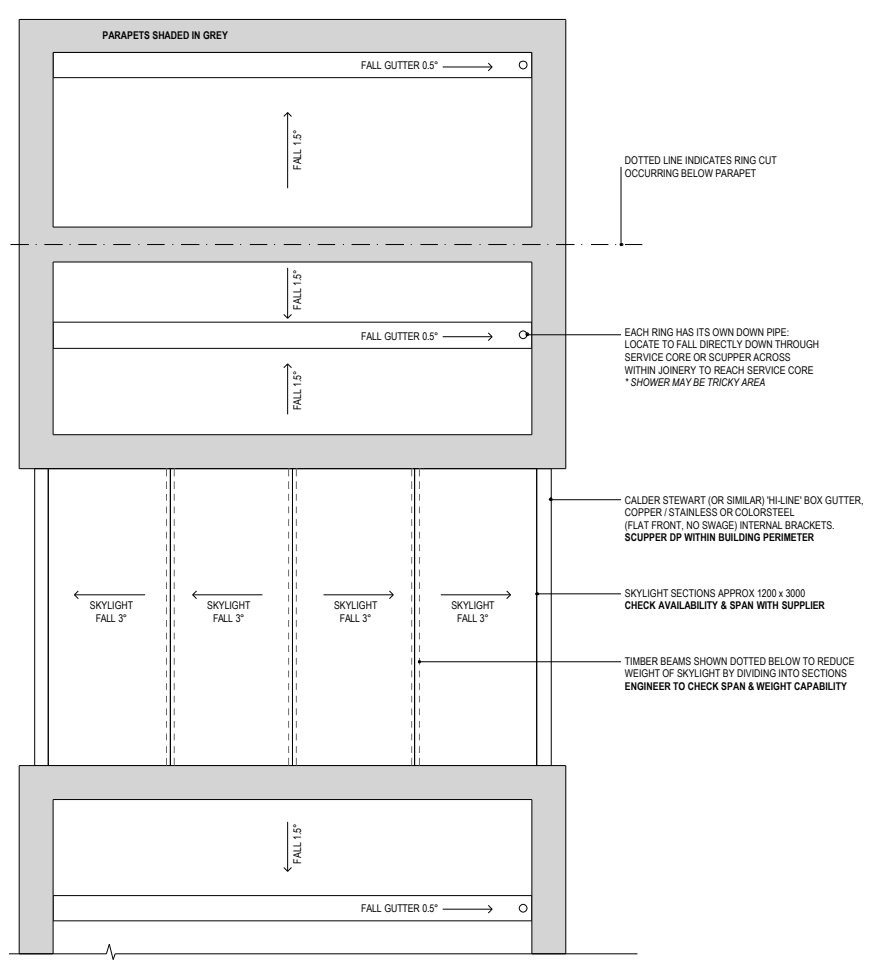

Figure 221: Roof Plan - Central Ridge Triple Glazed Skylight (RM) 


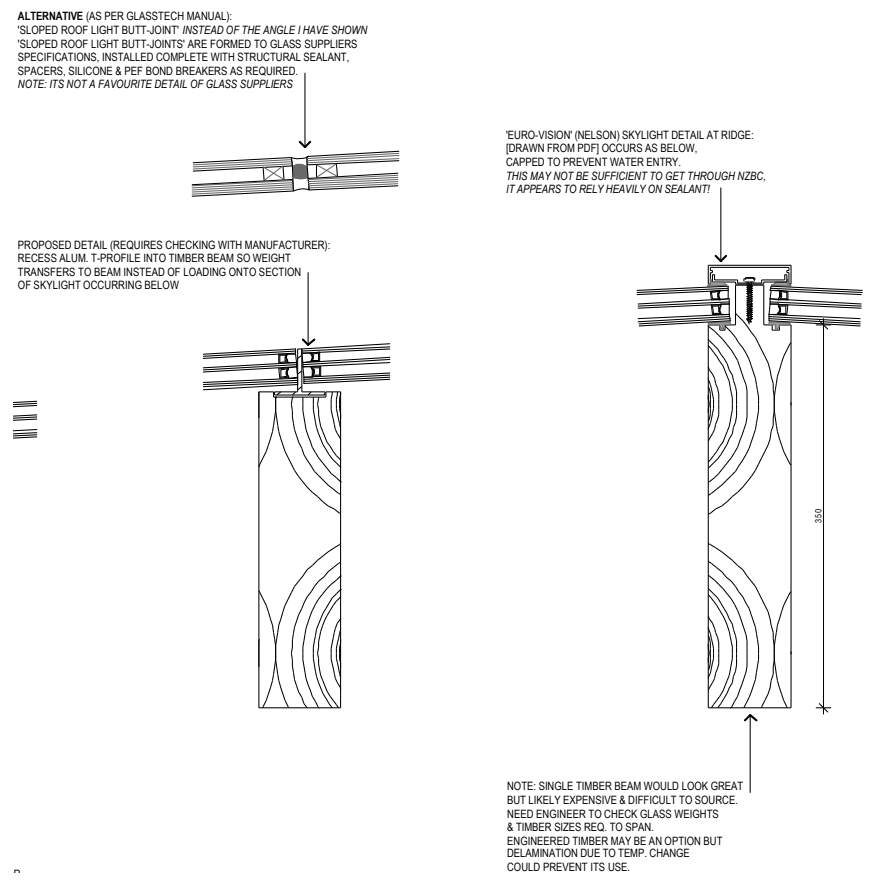

Figure 222: Central Ridge and IGU Connection Details - Triple Glazed Skylight (RM)

This system utilized German-made skylight profiles as provided by Nelson based distributer 'Eurovision'. These were available in New Zealand however there may have been some consent issues surrounding the weatherproofing details [Figure 222]. Tall timber beams are shown to finish flush with the bottom of the louvres $\left(180^{\circ}\right.$ cedar louvre profile shown). This resulted in a central timber beam of $350 \mathrm{~mm}$ which would potentially be expensive and difficult to source. Initial development of junction details and materials for the surrounds of the skylight were explored. These included bringing the exterior cladding through into the interior of Module Three [Figure 223 \& Figure 224] and the insetting of the doors relative to the rest of the house [Figure $225 \&$ Figure 226]. The location and treatment of the gutters was also investigated with a possibility of scuppering the downpipe through into the adjacent module wall [Figure 227]. This may have however proven difficult and could lead to reduced insulation and impaired weathertightness. The skylight jamb fixed directly into the tapered support beam [Figure 228]. The jamb frame was then flashed up and under the parapet cap flashing of the adjacent module. The vertical timber slats of the canopy were hoped to conceal this flashing. Further explanation as to the aesthetic intent and execution of the junction and finishing details is given in 6.6 Module Three - As Built,

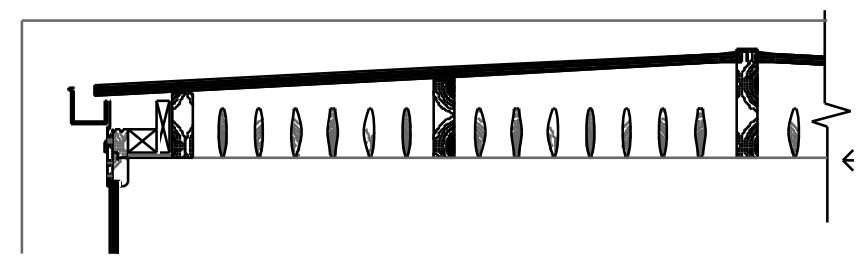

Figure 223: Ceiling Threshold Flush with Louvres, Protruding Gutter (RM)

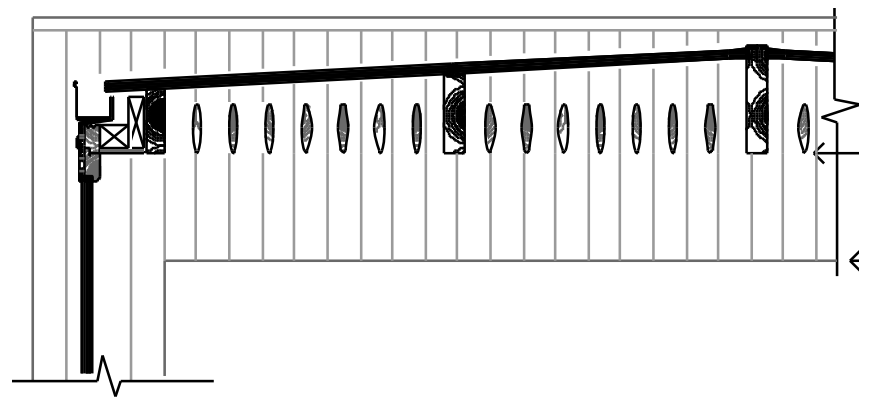

Figure 224: Ceiling Threshold Below Louvres, Flush Gutter and Vertical Weatherboard Linings (RM)

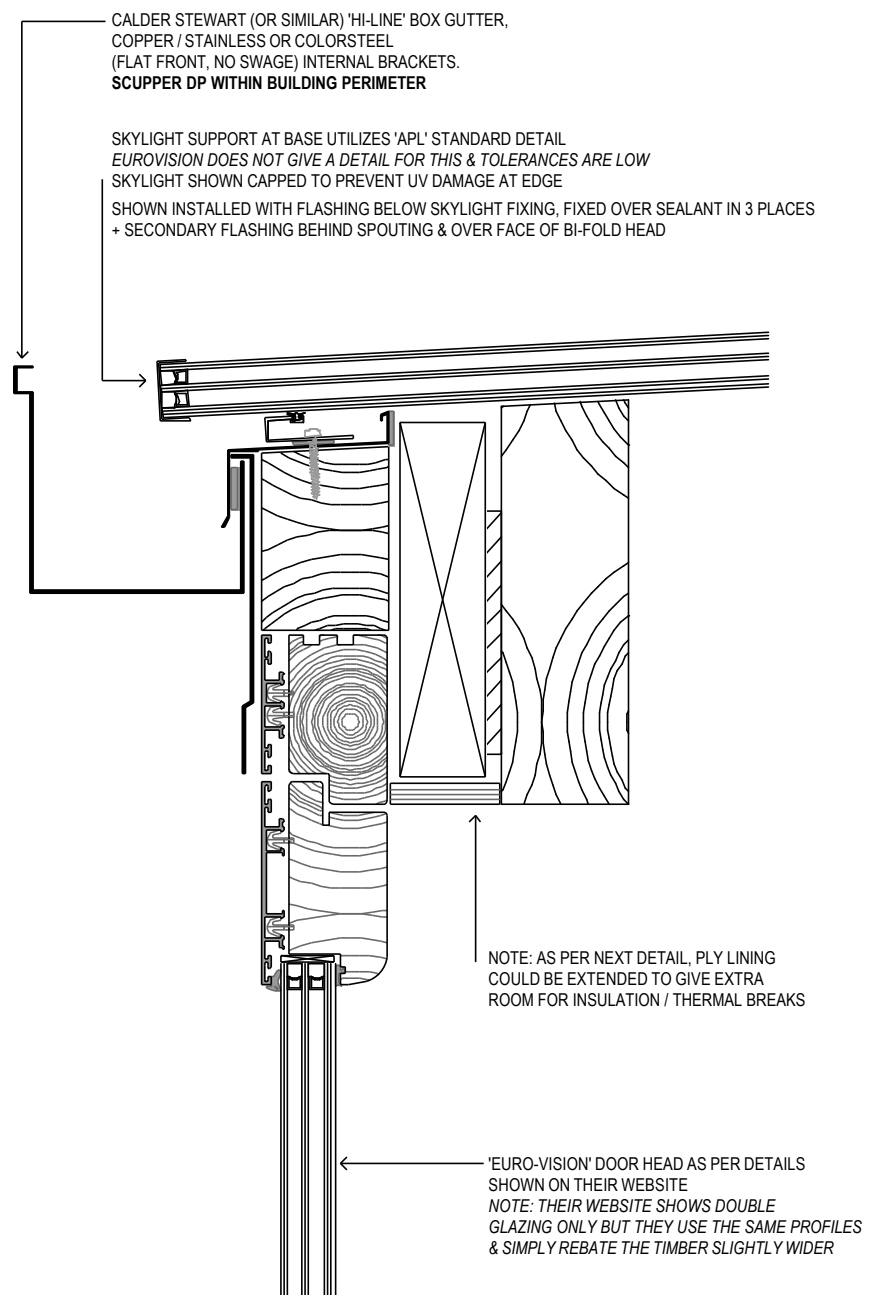

Figure 225: Door Head Detail - Protruding Gutter (RM) 


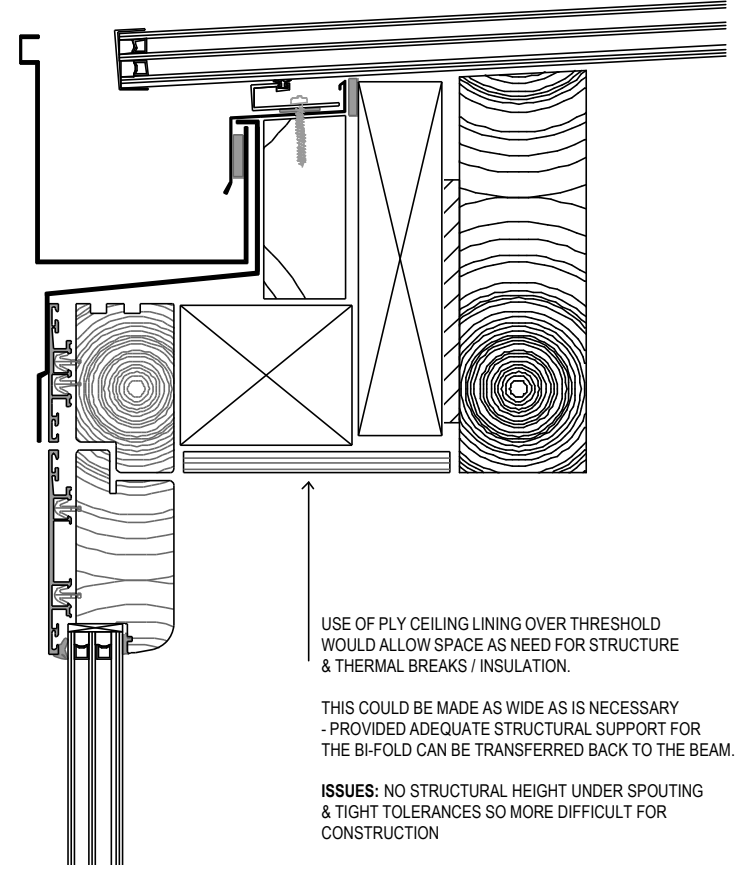

Figure 226: Door Head Detail - Flush Gutter (RM)

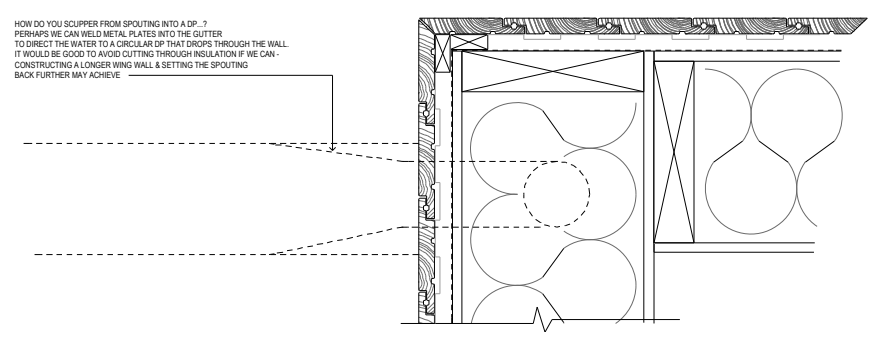

Figure 227: Scupper and Internal Spouting Plan Detail (RM)

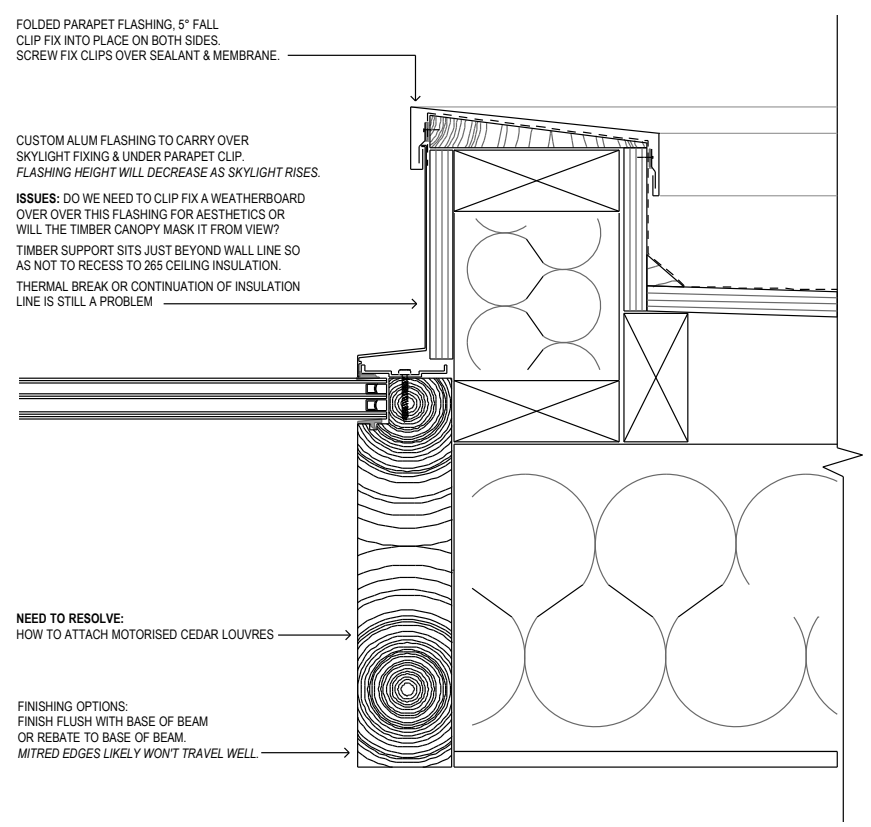

Figure 228: Jamb and Parapet Detail - Central Ridge Skylight (RM)
Internal cedar louvres were employed as a means for reducing solar heat gains as well as improving insulation [Figure 229]. These could be automated to open and close depending on the weather and internal air temperature [Figure 230 \& Figure 231]. Additional shading could also be provided to the glazed south bi-fold doors by extending the louvres out the front of the house. Although internal louvres would help reduce glare and direct radiant heat, they prove to have little effect on preventing the heating of the internal air temperature. If detailed correctly, the louvres could act as an additional layer of insulation thereby reducing heat losses through the skylight. This would be of significant advantage in New Zealand where heat losses in winter are equally as detrimental to annual energy consumption as the heat gains in summer. It was however predicted that, over the course of the competition in Washington DC, the biggest problem would be heat gains (Jagersma, 2012). Furthermore, the Comfort Zone contest takes into account the internal air temperature only and not the effects of radiant heat.

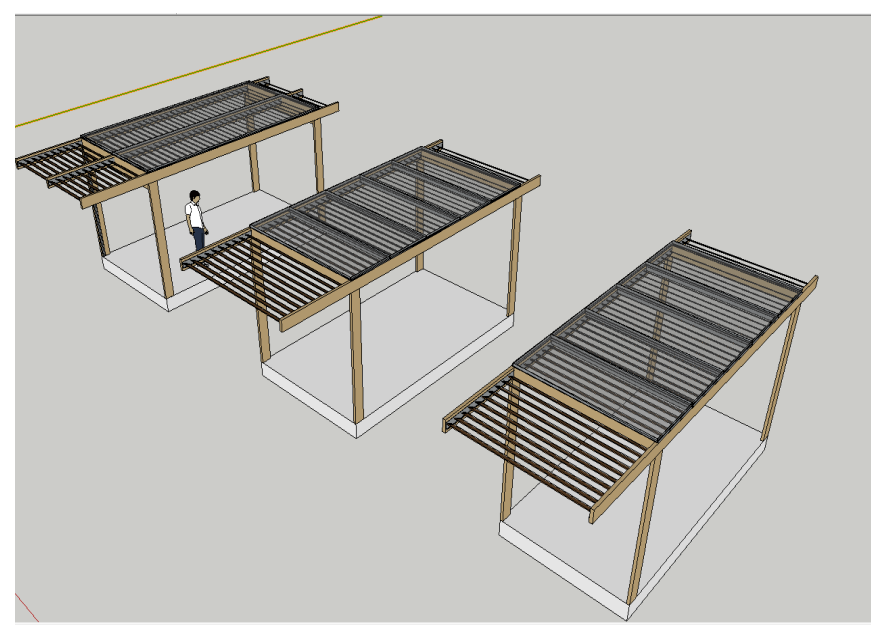

Figure 229: Triple Glazed Skylight - Internal Louvres 


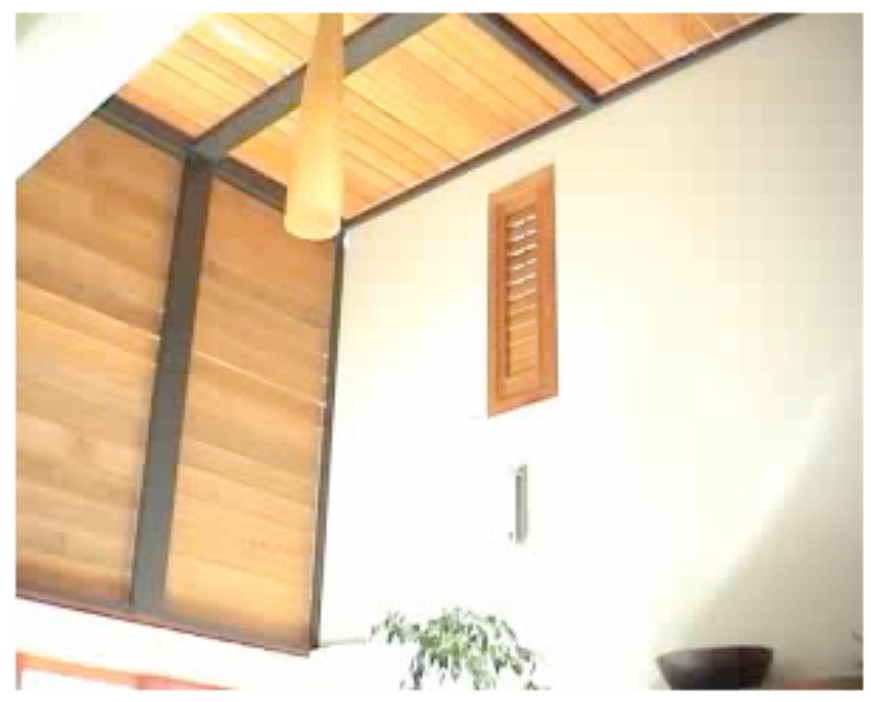

Figure 230: Example of Automated Internal Louvres - Closed (Atelier Workshop Aotearoa, 2005)

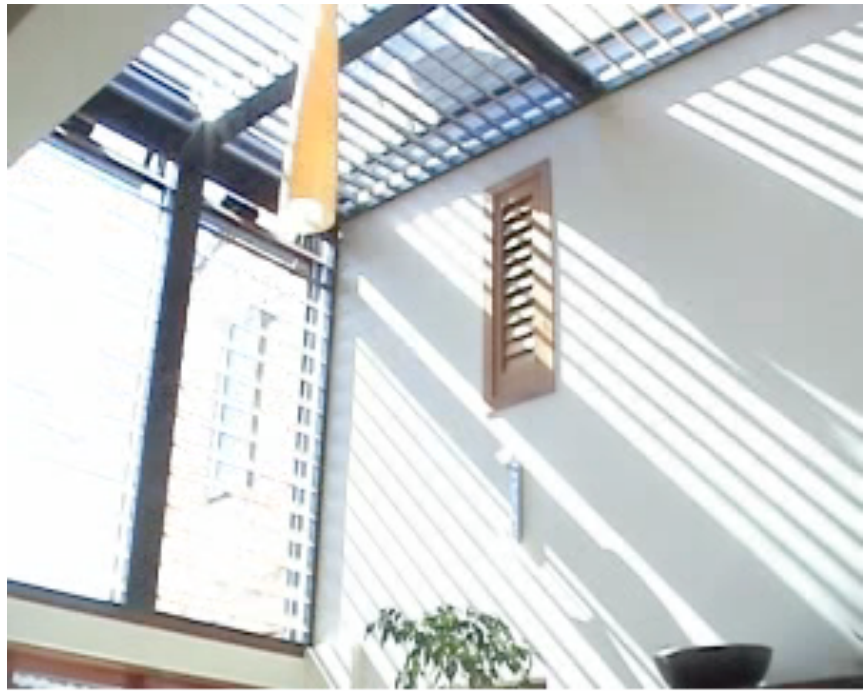

Figure 231: Example of Automated Internal Louvres - Closed (Atelier Workshop Aotearoa, 2005)

In terms of the aesthetics and user experience of the space, the louvres proved to be a disadvantage as they cannot be fully retracted to achieve uninterupted views out. The technical complexity of automation was again debated and a manual operating mechanism was investigated. This had the added advantage of providing occupants with the ability to manually control the performance of the house. This was very important to the concept in terms of creating a user connection with the surrounding environment [Figure 232].

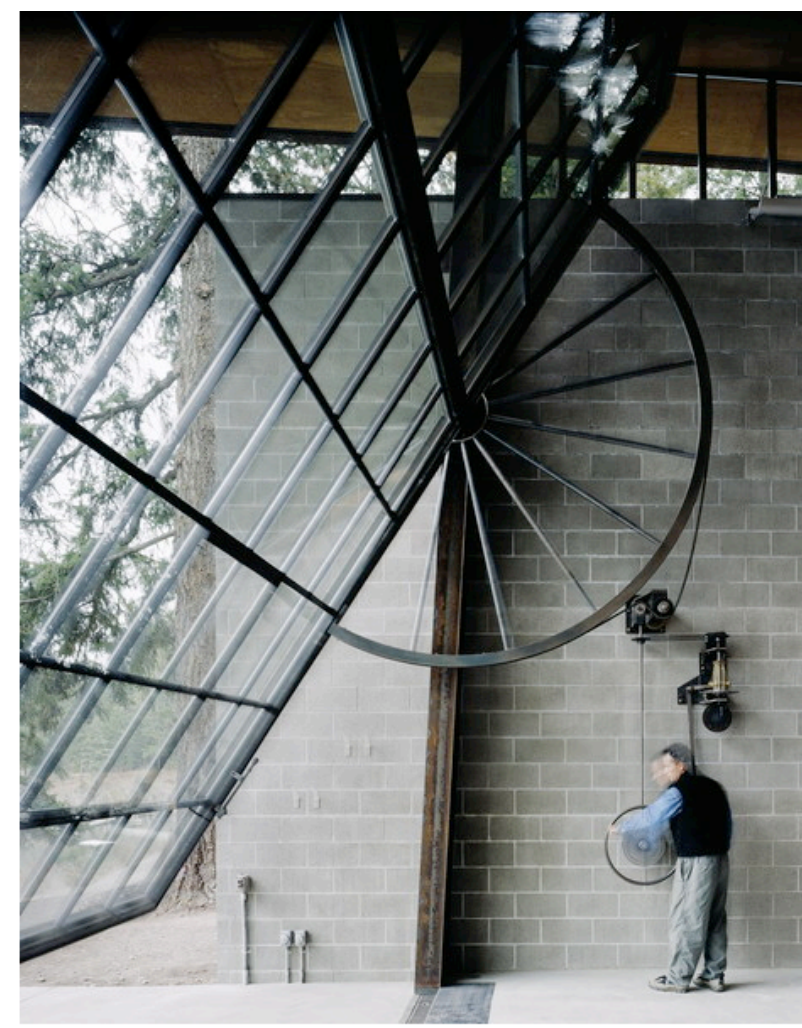

Figure 232: Example of Manual User Control - Chicken Point Cabin (Olson Kundig Architects, 2012)

Option Two: Central Ridge and Concealed Gutters [Figure 233]

This option was explored with the purpose of gaining better thermal performance at the skylight edge. The embeding of the skylight into some form of insulation was hoped to reduce the extent of thermal bridging [Figure 234]. This option would also promote a desireable symmetry to the central module with the ridge running North to South. Although internal concealed gutters could be achieved, the scupporing of them through to the adjacent module could prove risky in terms of weathertightness. 

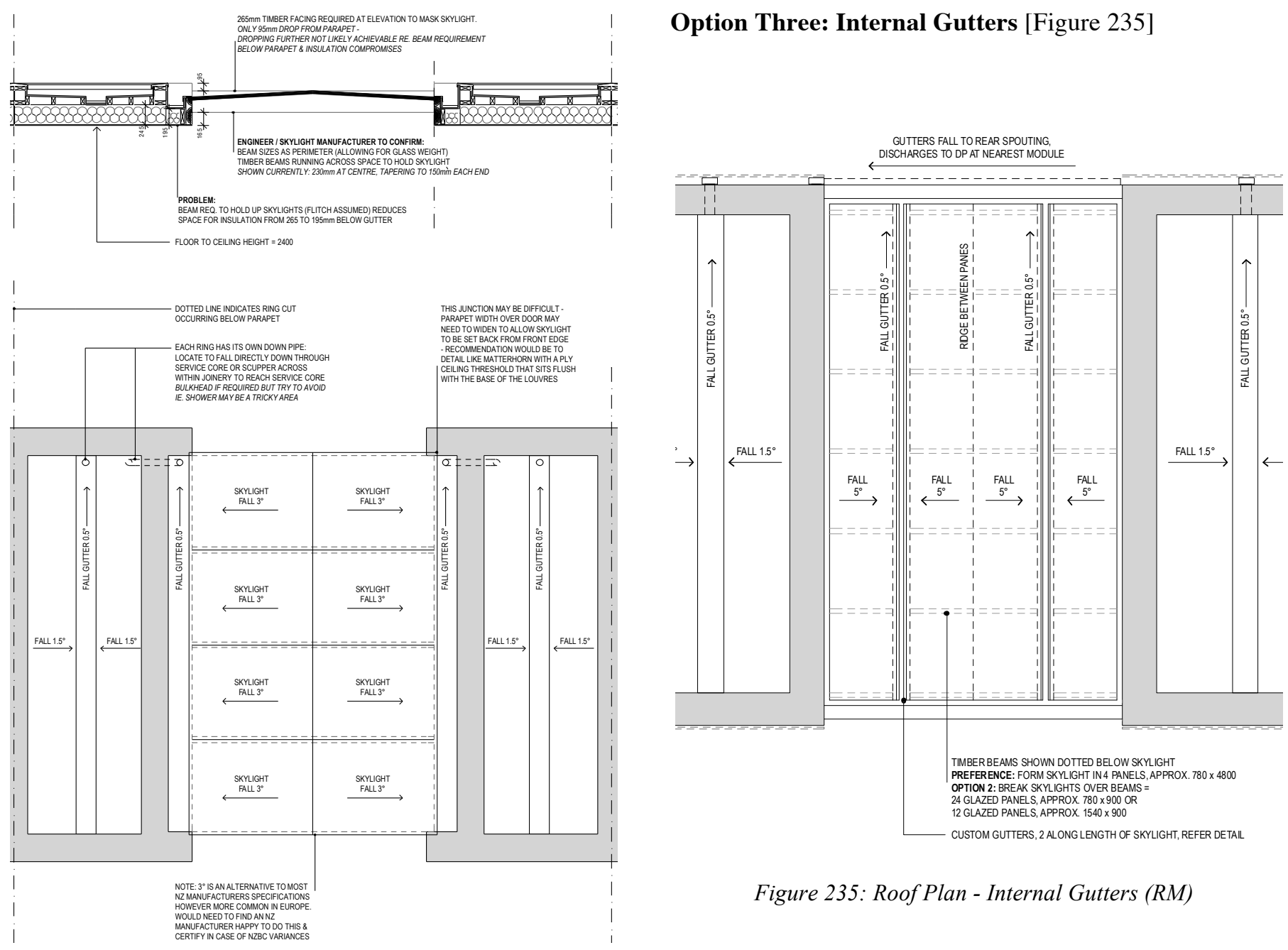

Figure 235: Roof Plan - Internal Gutters (RM)

Figure 233: Triple Glazed Skylight Option Two Roof Plan Central Ridge and Concealed Gutters (RM)

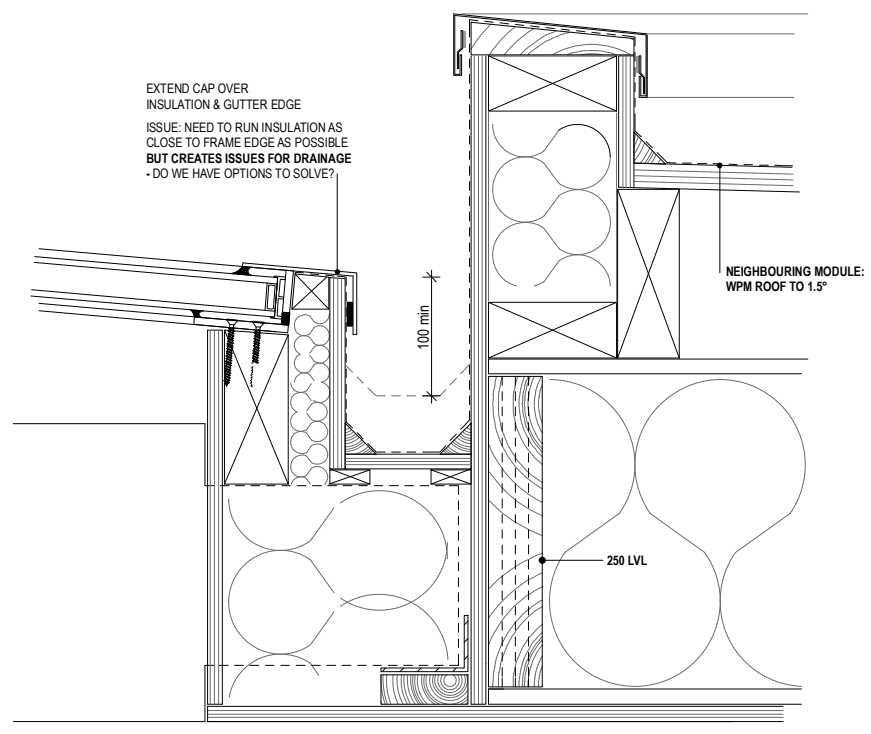

Figure 234: Triple Glazed Skylight Option Two - APL Profile Edge Detail (RM)

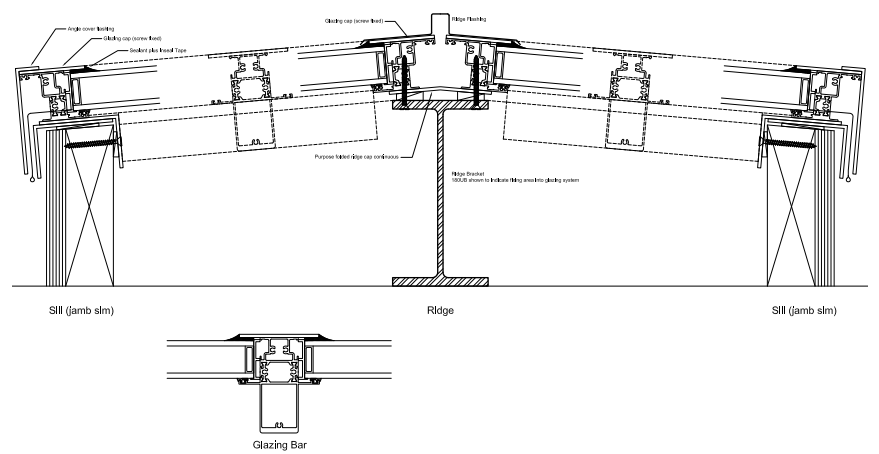

Figure 236: Metro Series Thermal Height Skylight Profiles by $A P L$ 

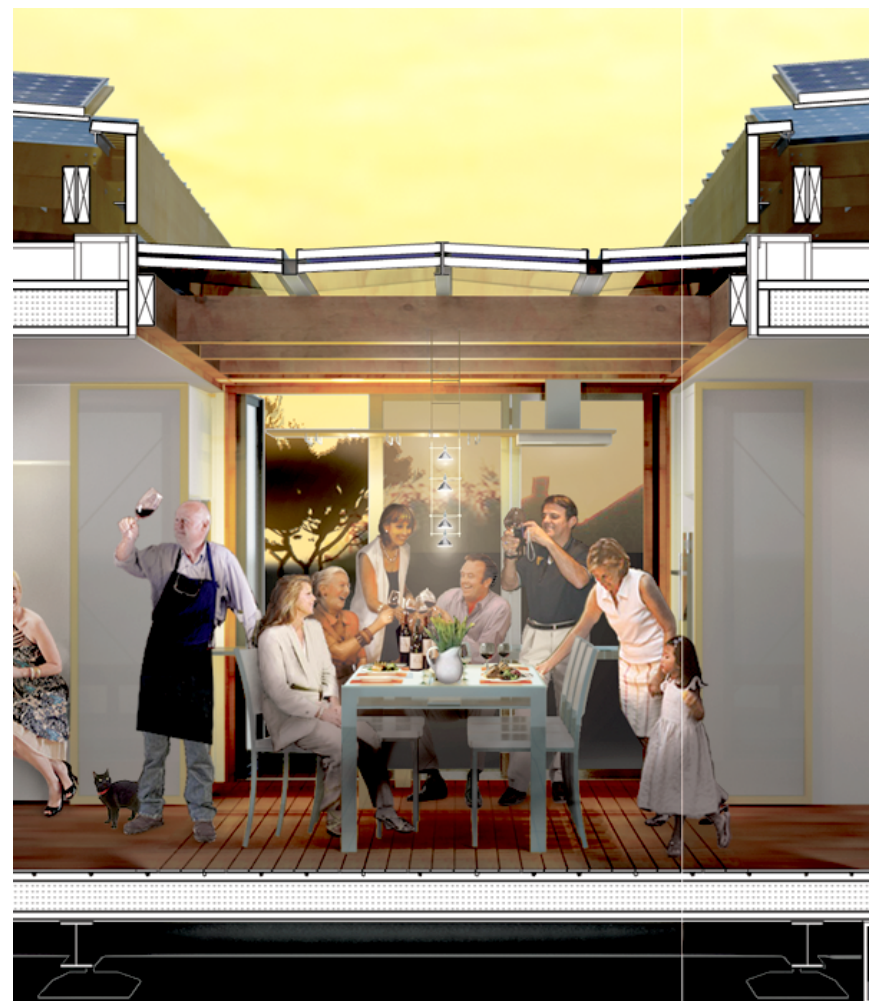

Figure 237: Conceptual Design Section of M3

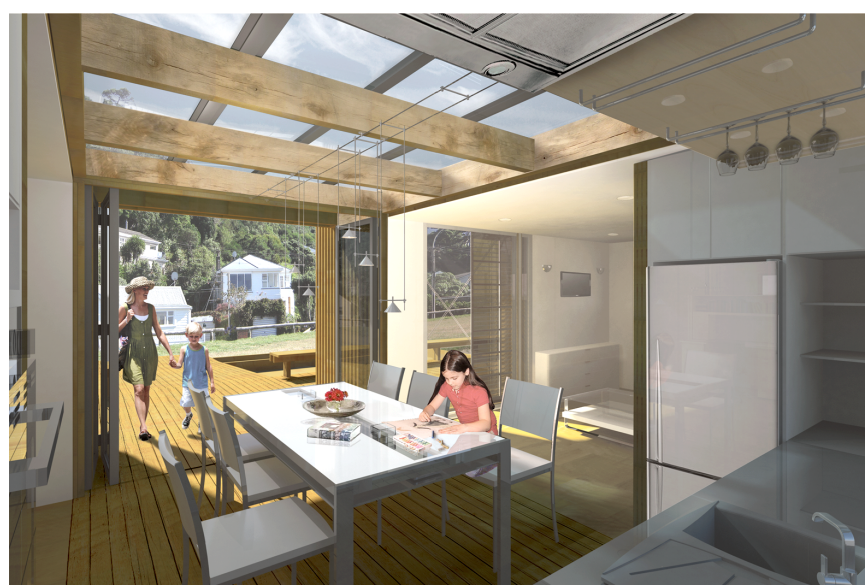

Figure 238: Conceptual Design Render of M3 - The Central Space

Custom formed gutters were required both for rainwater drainage and for structural support of the IGU's. Attention to thermal bridging was critical in this area given that the gutter would likely be formed from metal. Three possible gutter details were developed [Figure 239, Figure $240 \&$ Figure 241]. The skylight head detail would be very similar to the jamb detail proposed for the Central Ridge skylight, however the flashings would not need to be tapered with the fall [Figure 242]. The apex joint was yet to be resolved but would have likely incorporated the Metro Series Thermal Heart ridge detail [Figure 236].

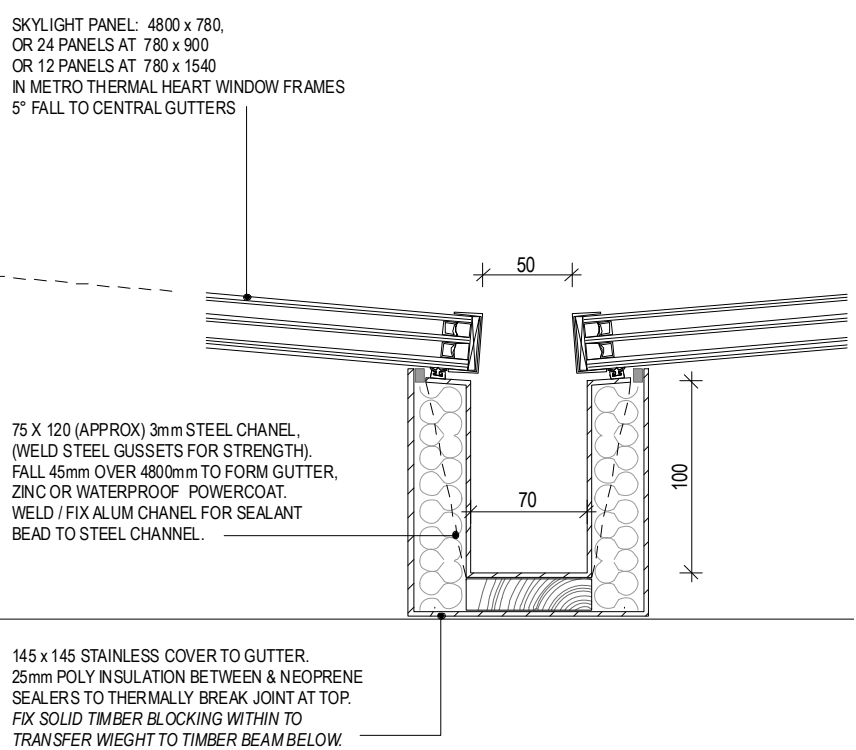

Figure 239: Custom Formed Internal Gutter - S/S Casing (RM)

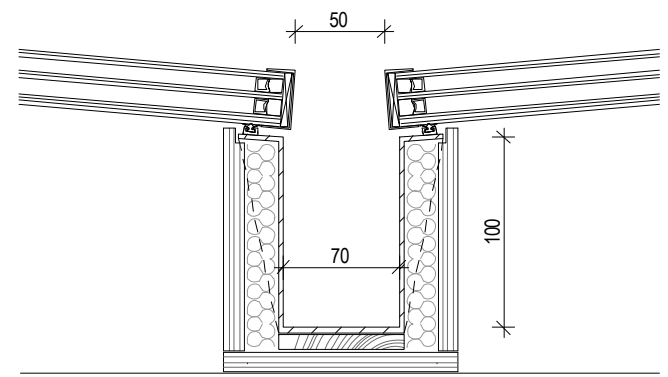

Figure 240: Custom Formed Internal Gutter - Plywood Casing (RM)

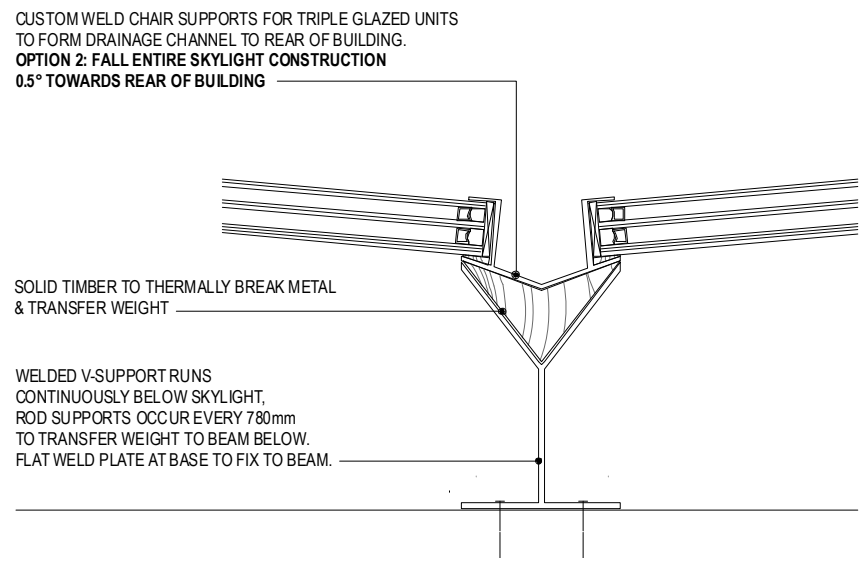

Figure 241: Custom Formed Internal Gutter - Welded Steel Support (RM) 


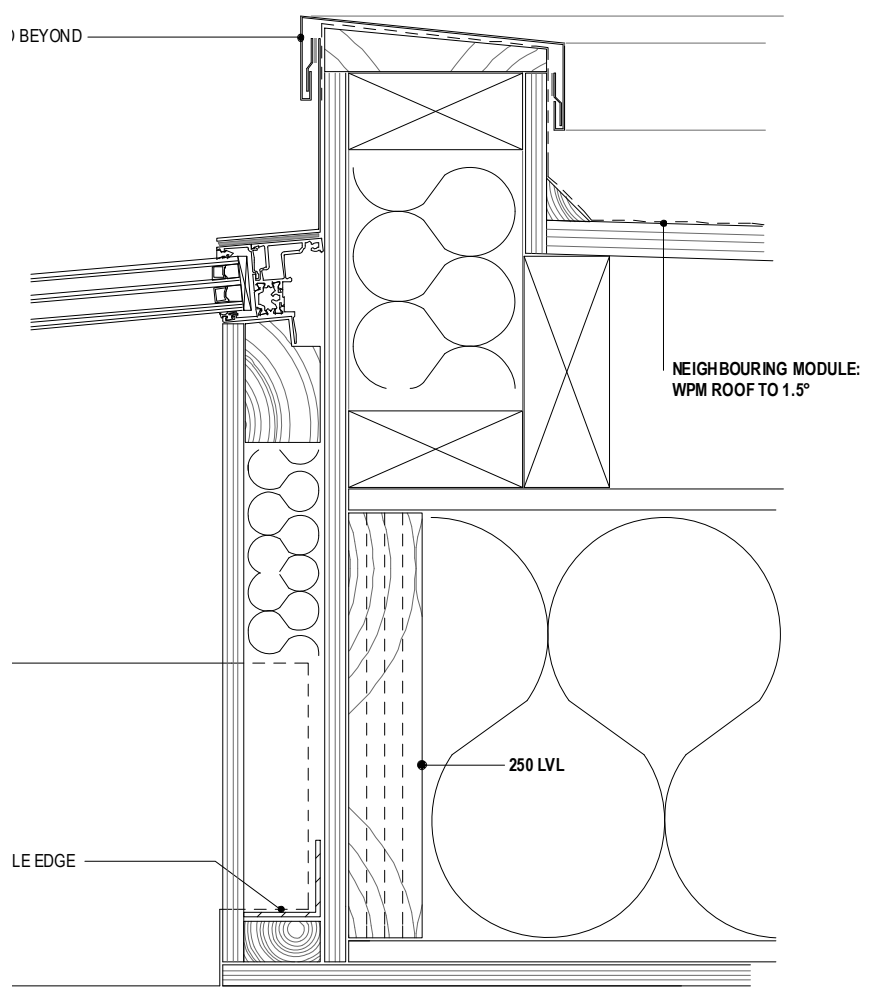

Figure 242: Skylight Head and Parapet Detail - Internal Gutter (RM)

Several options were explored for the treatment of the end gutter and downpipes. Option One was to scupper the internal gutters into the cladding cavity of the adjacent module [Figure 243]. Option Two scuppered the internal gutters into an exposed rectangular spouting, which was then taken through the cladding cavity and connected with the internal downpipe of the neighbouring module [Figure 244]. Option Three utilised the exposed spouting as a form of cladding in itself, with the downpipe again scuppered through to the neighbouring module [Figure 245]. Option Three would conceal any visible gutter and scupper details of the skylight and also distinguish Module Three from the rest of the house.

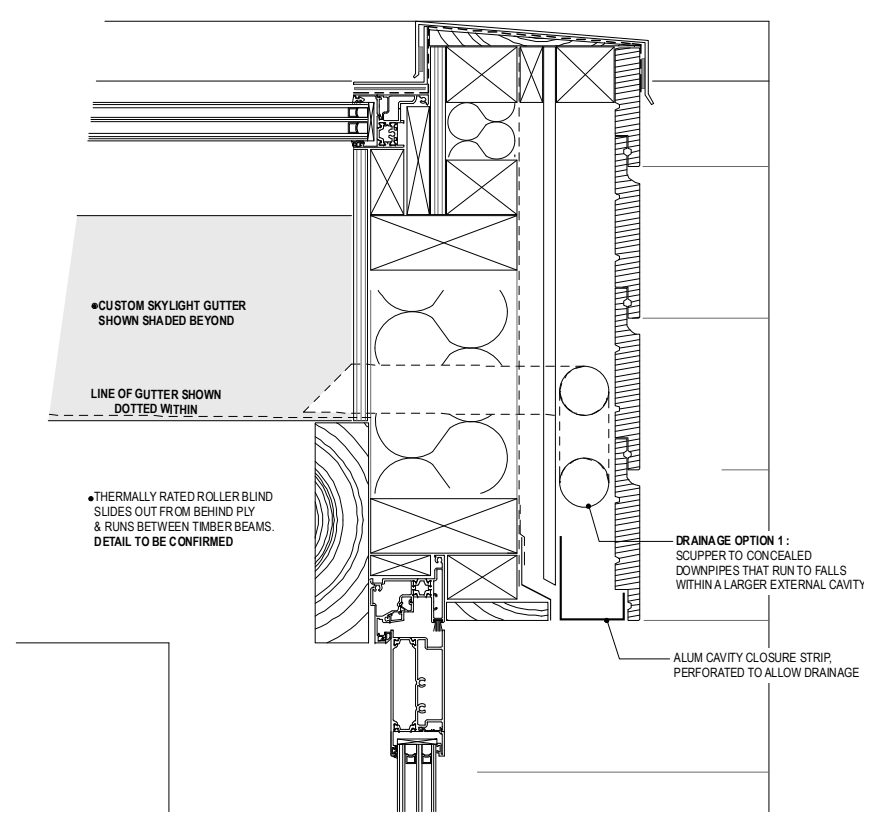

Figure 243: Option One Rear Section Detail - Concealed Downpipes (RM)

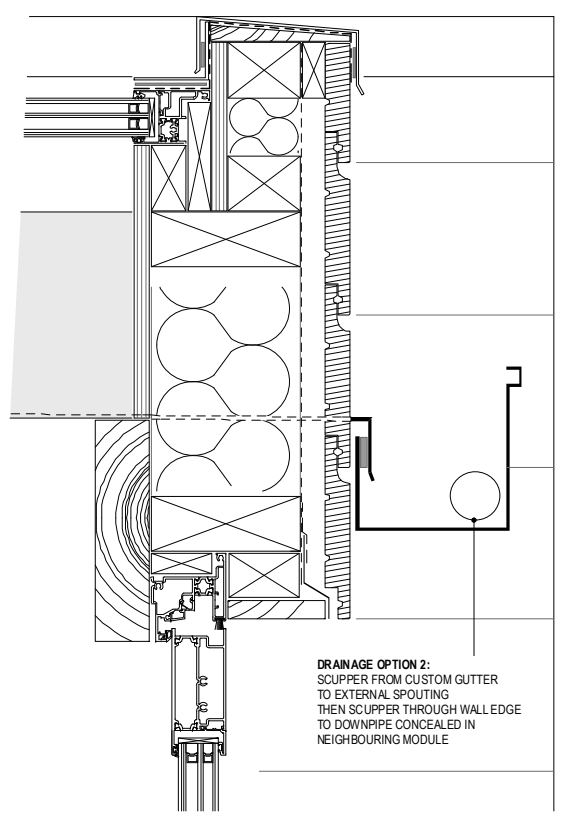

Figure 244: Option Two Rear Section Detail - Exposed Spouting (RM) 


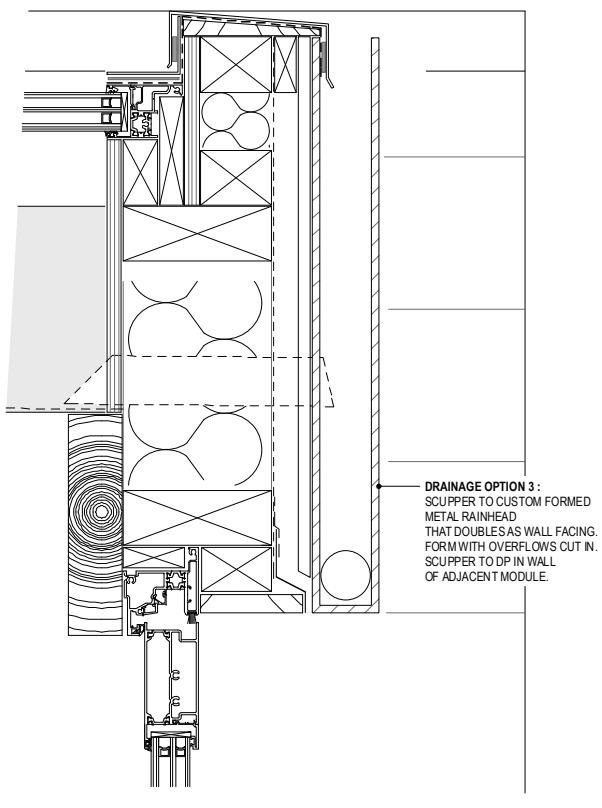

Figure 245: Option Three Rear Section Detail - Custom Formed Rain Head (RM)

Roller blinds could be incorporated beneath the skylight to improve thermal performance [Figure 246]. Provision was made for these to run in-between the supporting timber beams from a concealed roller blind at either side of the module [Figure 247]. Spaceloft insulation could also be incorporated in the form of a highly insulated upholstered blind (Cabot Corporation, 2010). Difficulty would be experienced in the rolling of a blind of this thickness so provision had to be made to allow it to draw back flat into a ceiling cavity of the adjacent module [Figure 248].
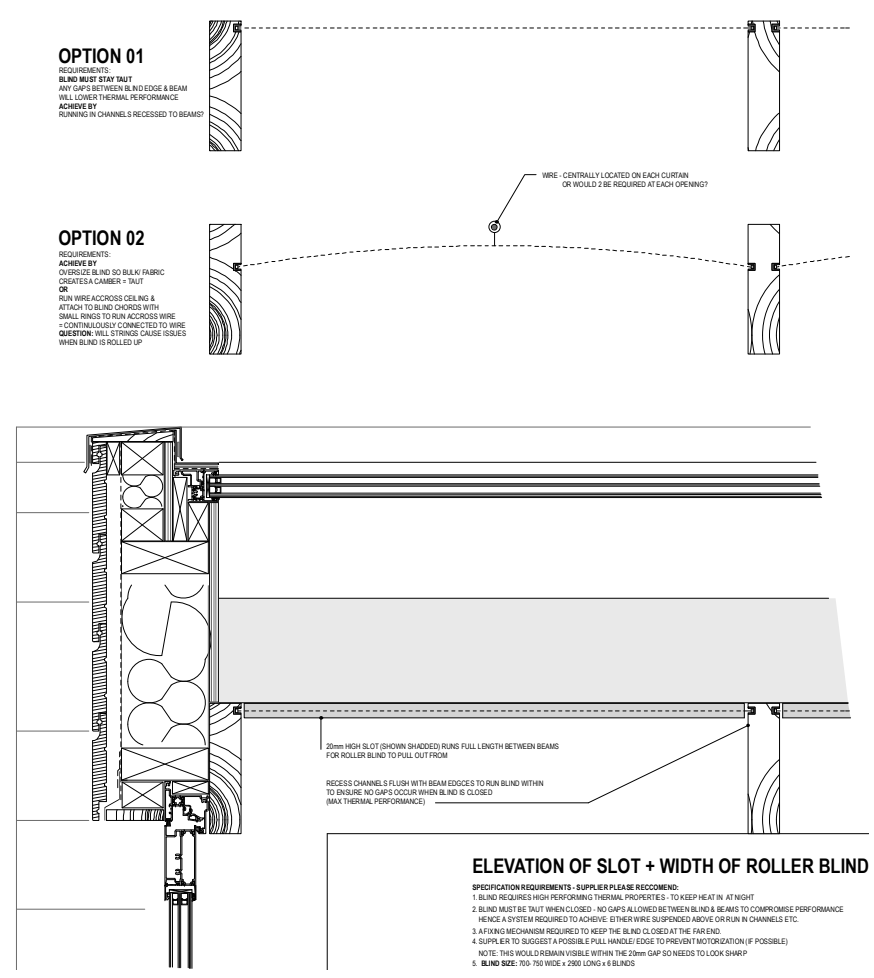

Figure 246: Triple Glazed Skylight Option Three Section Thermal Roller Blinds (RM)

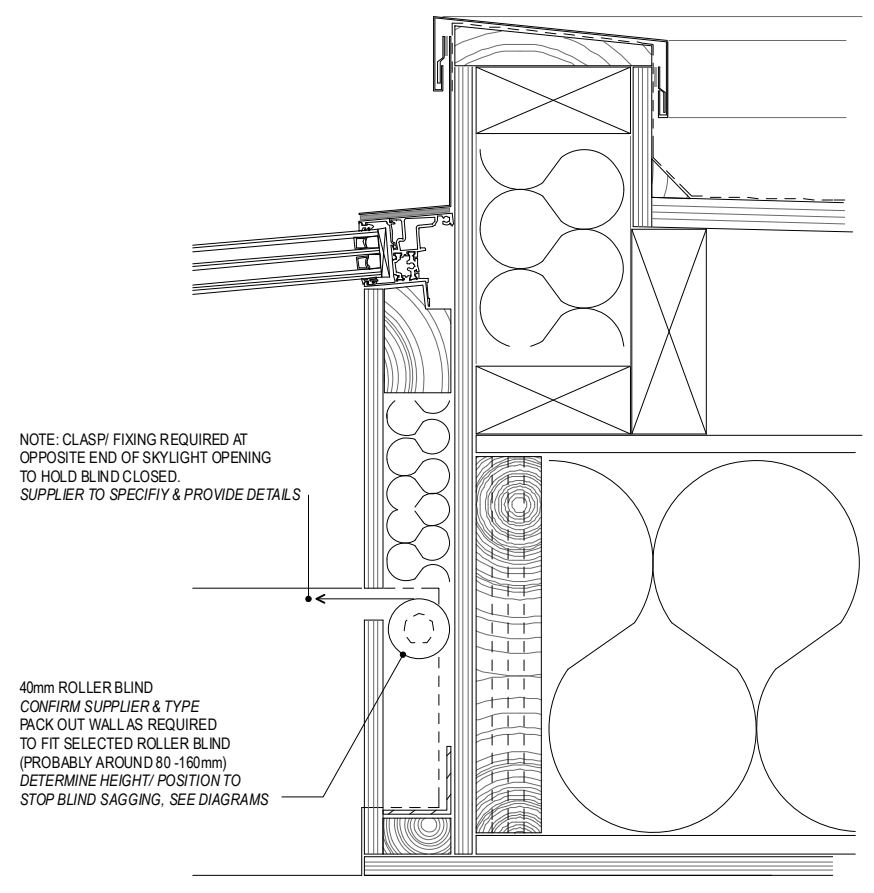

Figure 247: Triple Glazed Skylight Option Three Section Roller Blind Concealment (RM) 


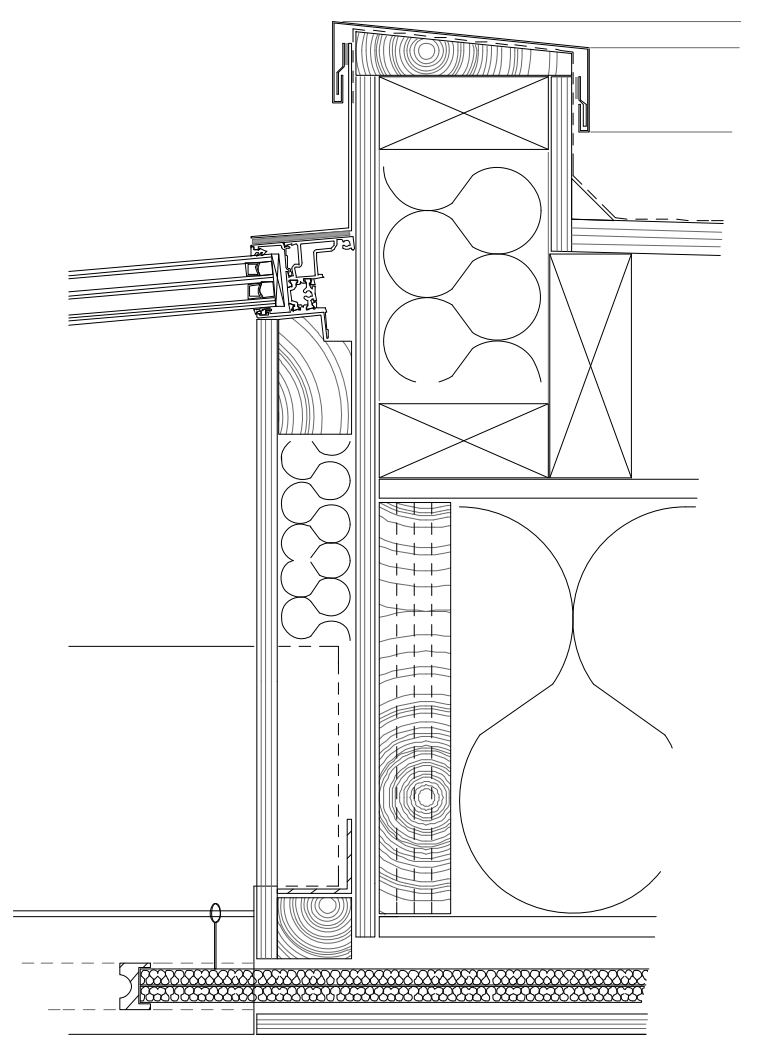

\section{SECTION: 'SPACELOFT' UPHOLSTERED BLIND}

$2 \times$ LAYERS OF $10 \mathrm{~mm}$ 'ULTRA THIN SPACELOFT' (NZ R-VALUE $=1.45$ AT $20 \mathrm{~mm}$ THICK)

[SUPPLIED BYASPEN AEROGELS, USA]

EQUIP. TO BE SPECIFIED:

RUN IN SUITABLE ROLLERS (THIN DIMS REQ, 45mm HEIGHT ALLOWED) BETWEEN CEILING BATTENS - BATTENS AT 780 CRS, IN LINE WITH BEAMS. EDGE FIXINGS REQUIRE SPECIFICATION, INCLUDING PULL HANDLE ATEDGE.

(IE. TOMAKE SURE NO GAPS TO CUTDOWNTHERMAL PEFORMANCE)

2 RUN WIRE ACCROSS WITH RING'S ATTACHED TO UPHOLSTERED CURTAIN

Figure 248: Triple Glazed Skylight Option Two Section Spaceloft Upholstered Blind Concealment (RM)

An external roller blind or a retractable louvre system was proposed as a means to control solar heat gains [Figure 249]. The parallel skylight jamb and parapet edge provided sufficient space and flexibility for the roller blind or louvre hardware [Figure 250]. It was determined that the retractable louvre/shutter system would be too bulky and complicated to install. Future shading options would consider the use of roller blinds only.

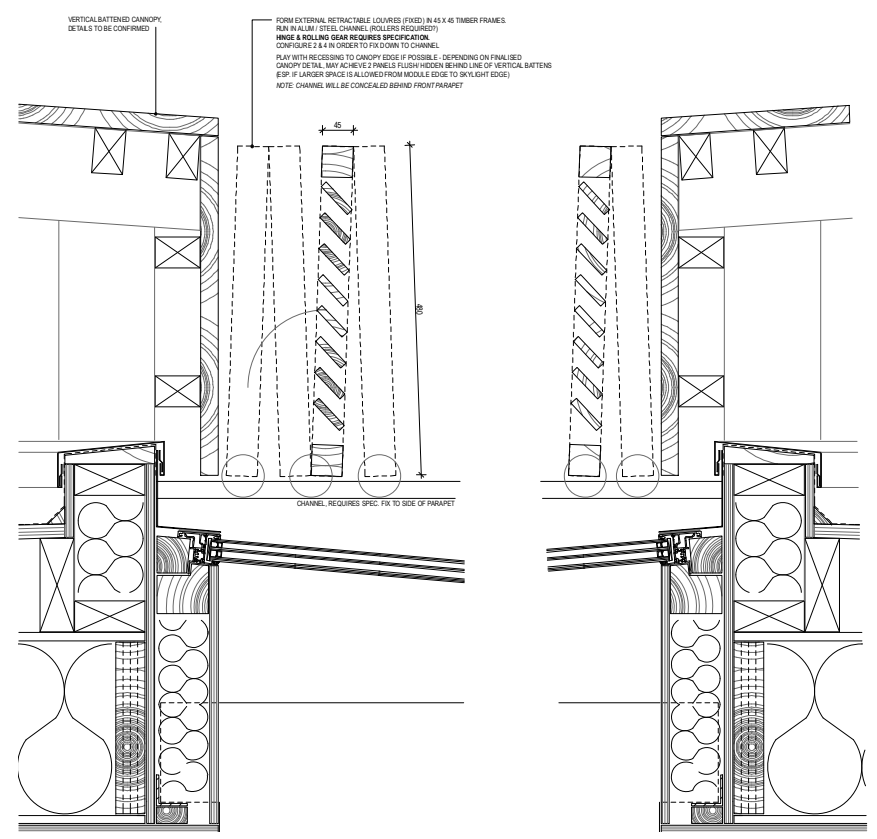

Figure 249: Triple Glazed Skylight Option Two Section Retractable Louvres (RM)

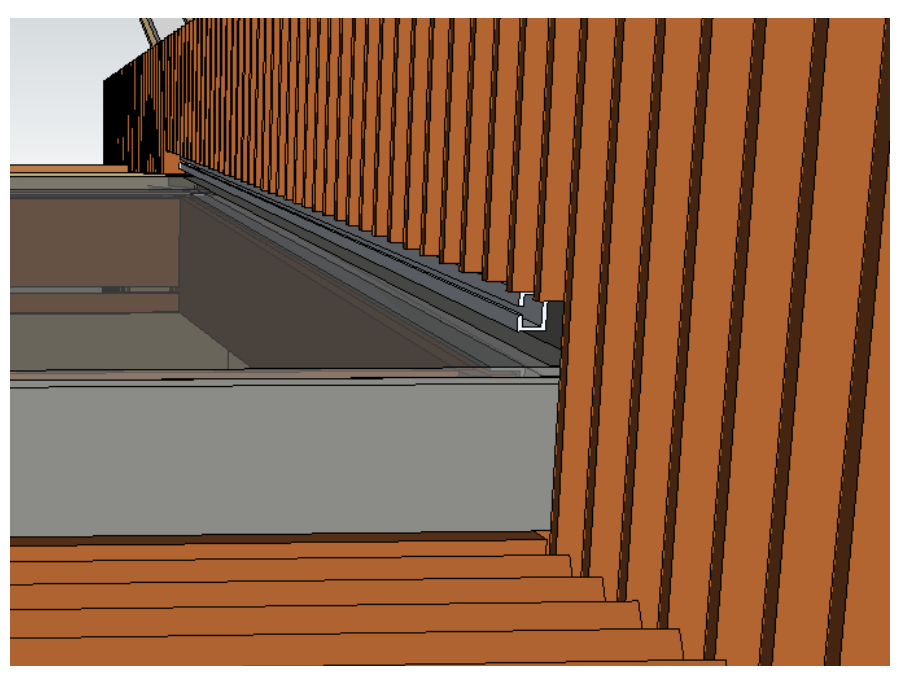

Figure 250: Triple Glazed Skylight Option Two - 3D Model Showing Concealed Louvre or Roller Blind Track 


\section{Option Four: Two Falls, Thermal Heart Skylight}

A new roof drainage arrangement was sought to accommodate the reduced size of the skylight and the solid bulkhead section. Option Four saw the skylight divided into three falls and utilised the APL Thermal Heart frame [Figure 251 \& Figure 252].

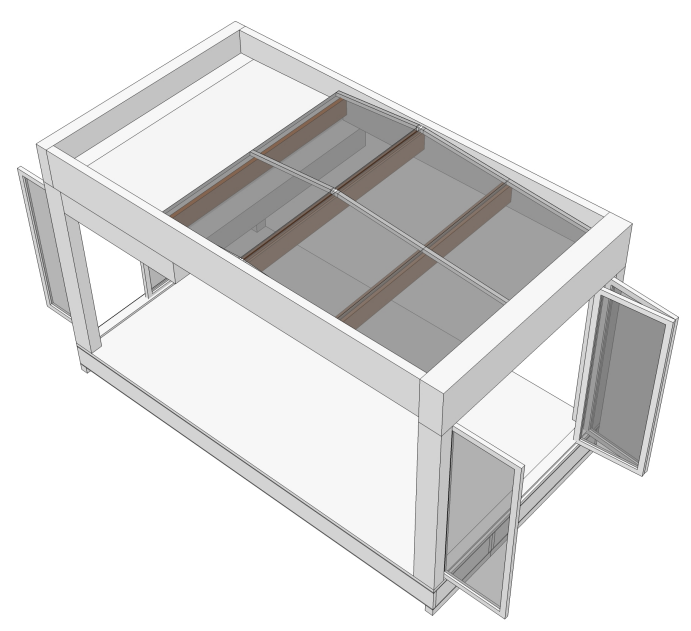

Figure 251: Two Falls, Thermal Heart Skylight

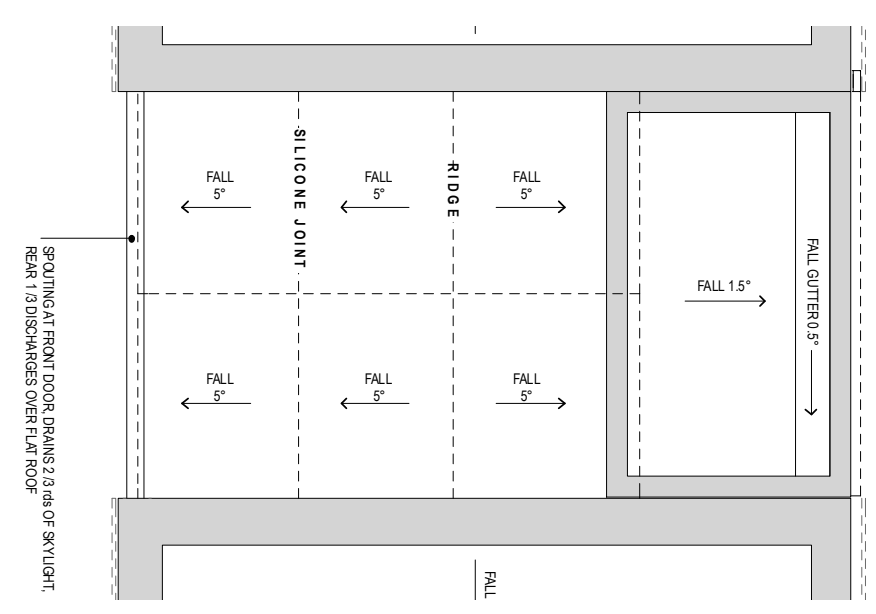

Figure 252: Two Falls, Thermal Heart Skylight - Roof Plan (RM)

The APL frame is typically used with double glazing however, through the inclusion of an aluminium angle for increased strength, APL were able to customize the frame to support triple glazed IGU's [Figure 253]. The thermal separation achieved by the plastic bridging component significantly improves the thermal performance of the Thermal Heart frame. It was proposed that the glazing bars get trimmed to fit with timber support beams [Figure 254]. Drainage to the north of the skylight could be easily detailed so as to fall onto the now solid section of roof [Figure 255]. An exposed gutter could be used along the front edge of the skylight to be scuppered through the cladding to connect with the neighbouring module downpipe [Figure 256].

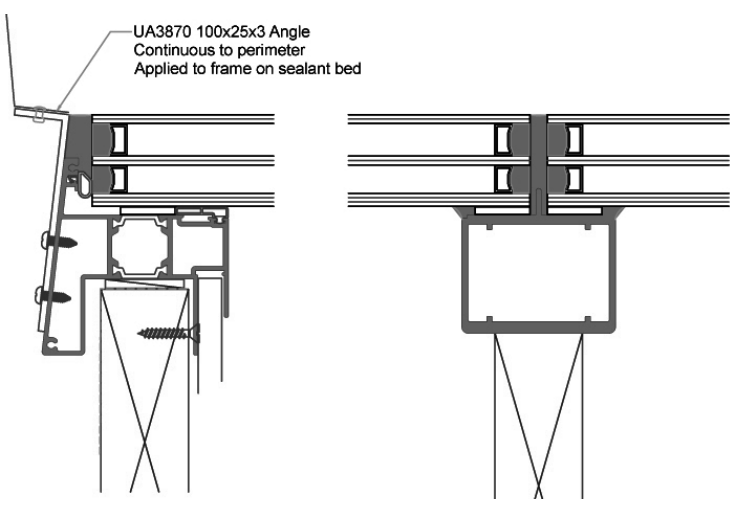

Figure 253: Thermal Heart Skylight Frame by APL Customized for $42 \mathrm{~mm} \mathrm{IGU}$

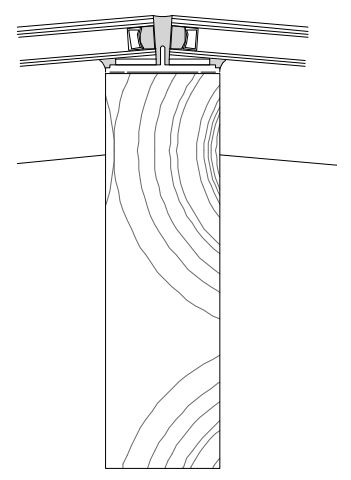

Figure 254: Thermal Heart Skylight - Glazing Bar Trimmed to Fit with Timber Beam (RM)

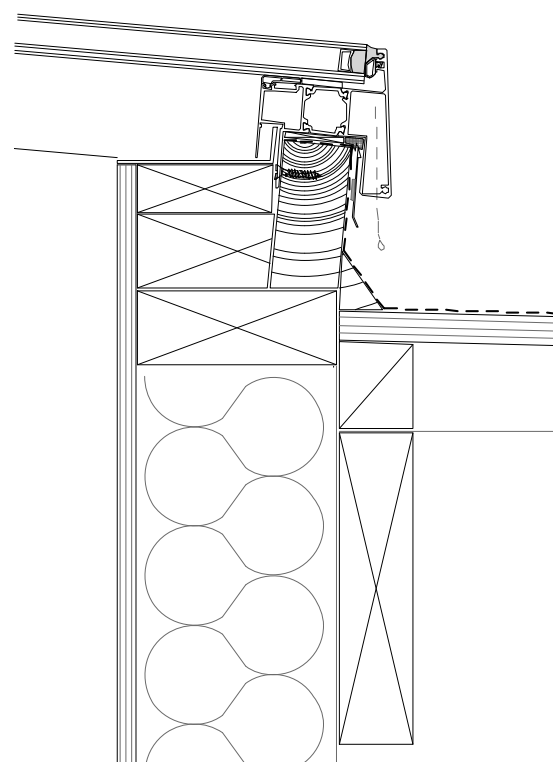

Figure 255: Thermal Heart Skylight - North Panel Draining Onto Solid Section of Roof (RM) 


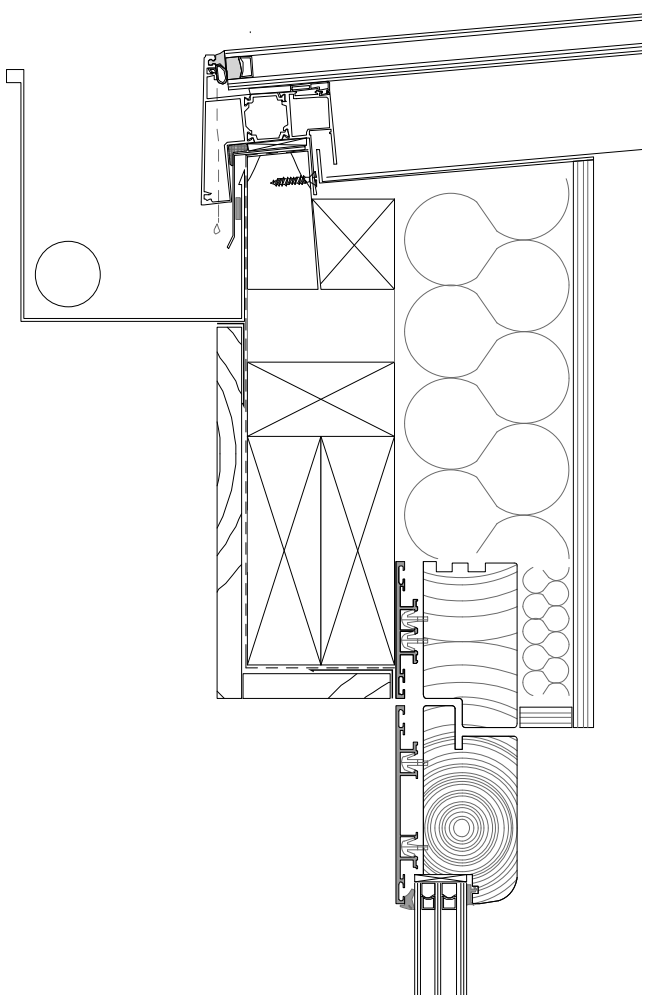

Figure 256: Thermal Heart Skylight - Exposed Front Gutter (RM)

The proposed falls and heights caused the skylight to begin lower than the neighbouring module, but then to rise above its parapet [Figure 257]. This would require the skylight jamb to have a custom formed tapered flashing to waterproof the join between the skylight and the adjacent module [Figure 258 \& Figure 259].

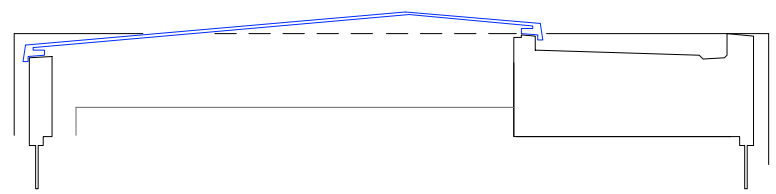

Figure 257: Thermal Heart Skylight - Partial Section Showing Falls Above and Below Neighbouring Module (RM)
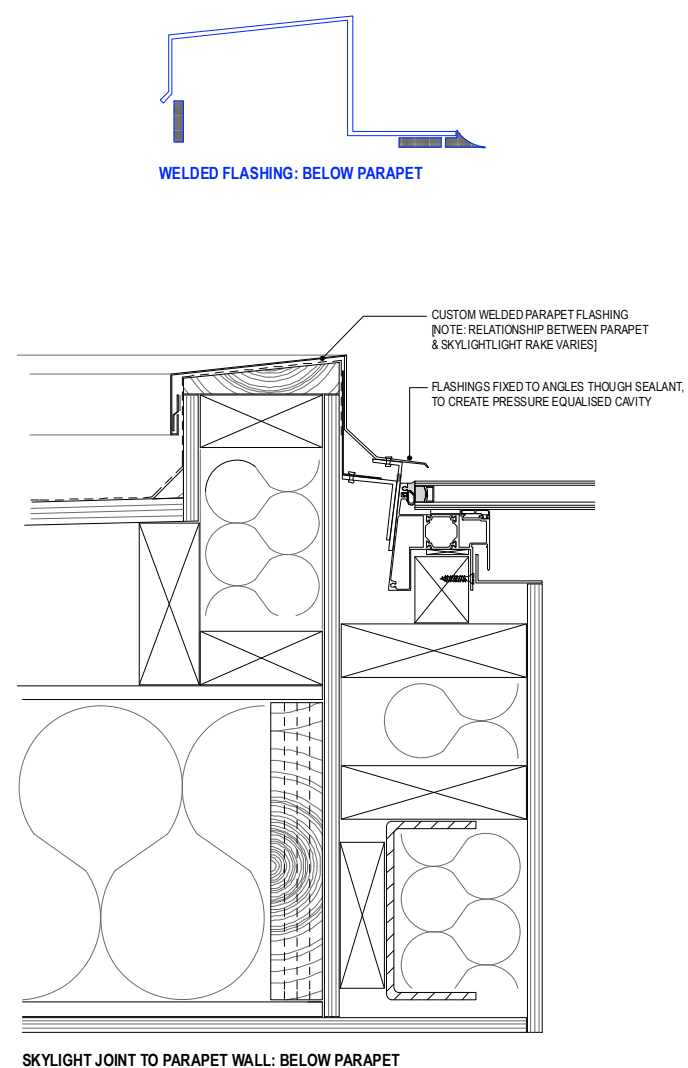

Figure 258: Thermal Heart Skylight Jamb Detail - Skylight Below Parapet (RM)

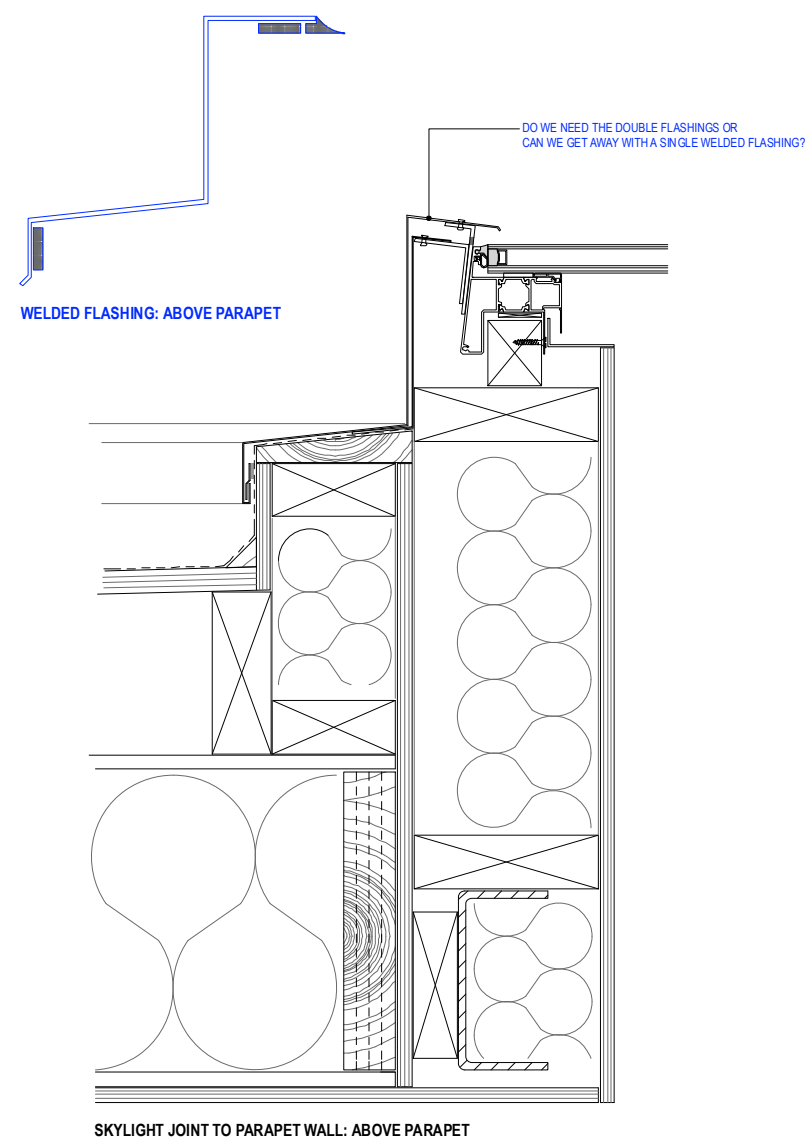

Figure 259: Thermal Heart Skylight Jamb Detail - Skylight Below Parapet (RM) 


\section{Option Five: One Fall, Thermal Heart Skylight}

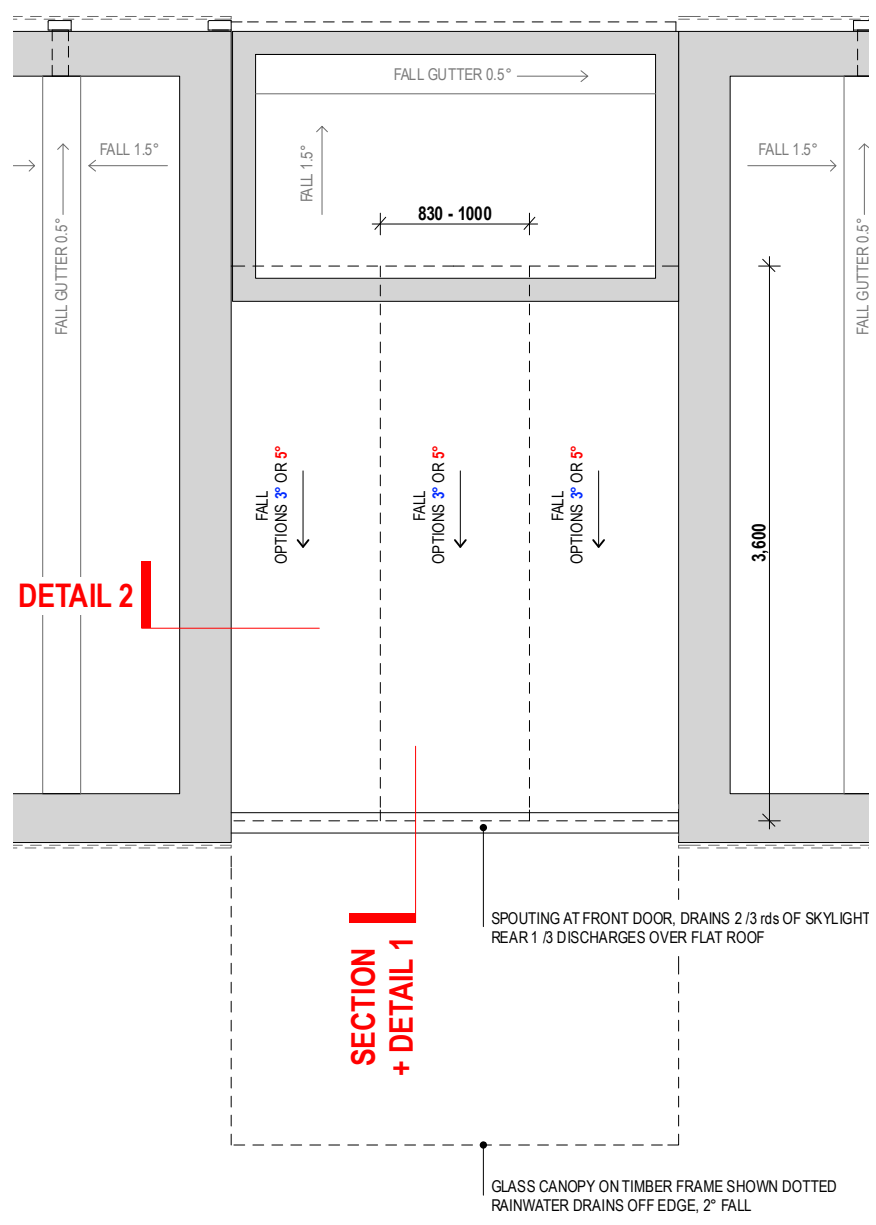

Figure 260: One Fall, Thermal Heart Skylight - Roof Plan (RM)

This skylight utilised the same APL Frames to Option Four, however only one fall towards the front of the house was specified [Figure 260]. This had the advantage of running the joins in the IGU's parallel to the fall and therefore achieving a better level of weathertightness and longevity at the silicon seal. Generally these frames will not accommodate a skylight with a pitch of less than $5^{\circ}$. There was however a possibility, through some minor adjustments, that APL could manufacture these frames fit for $3^{\circ}$. Both options were detailed to determine the effects of each [Figure 261]. Should the skylight have to fall at $5^{\circ}$ then the jamb frame would ascend higher than the neighbouring parapet [Figure 262]. At $3^{\circ}$ the frame would remain below the parapet. A $3^{\circ}$ skylight was the preferred option as it would achieve a cleaner, and more easily weatherproofed connection and remain within the land transport height restrictions [Figure 263].

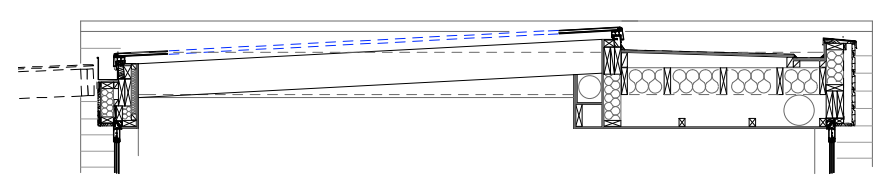

SECTION: SKYLIGHT AT $3^{\circ}$ FALL - REMAINS BELOW PARAPET

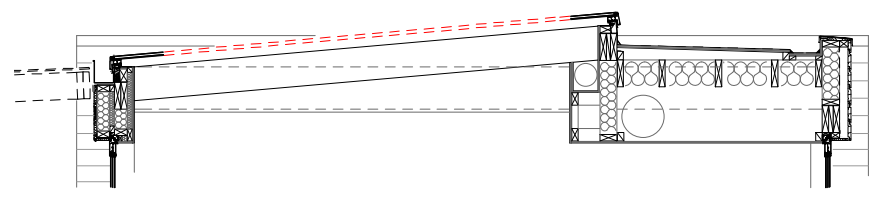

SECTION: SKYLIGHT AT $5^{\circ}$ FALL - TRAVERSES ABOVE PARAPET

Figure 261: One Fall at Both $3^{\circ}$ and $5^{\circ}$ (RM)

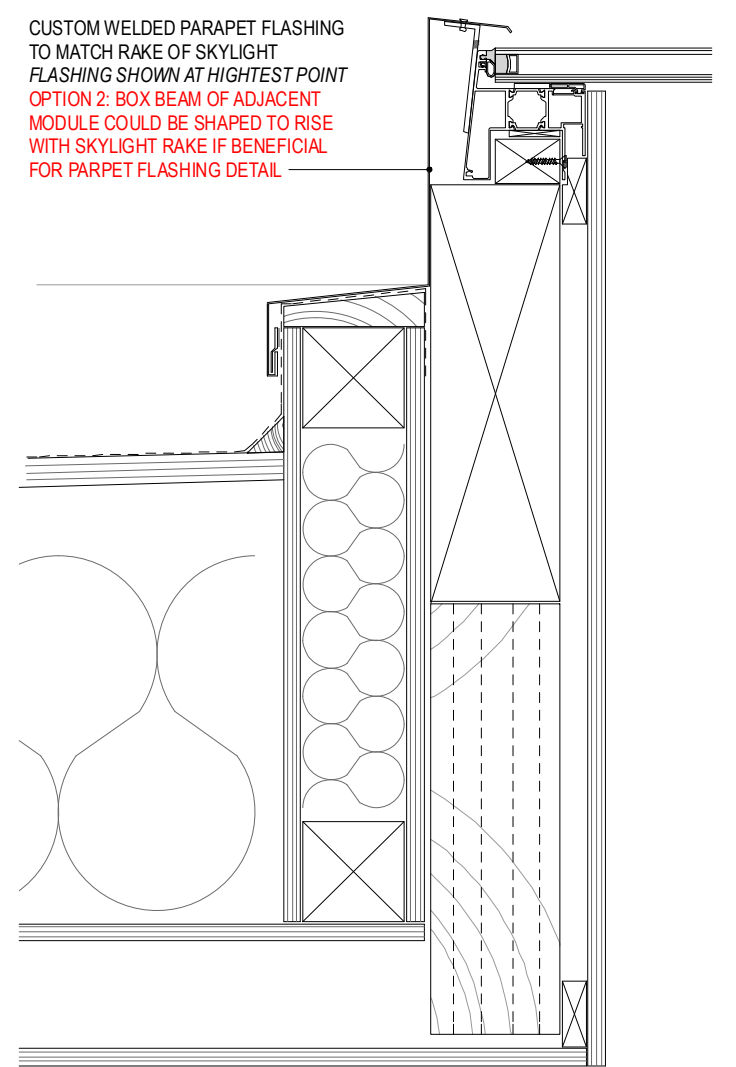

SECTION THROUGH PARAPET EDGE

'SKYLIGHT FALL, HIGHEST POINT OF SKYLIGHT

Figure 262: Skylight Jamb Detail Ascending Above Neighbouring Parapet at $5^{\circ}$ (RM) 


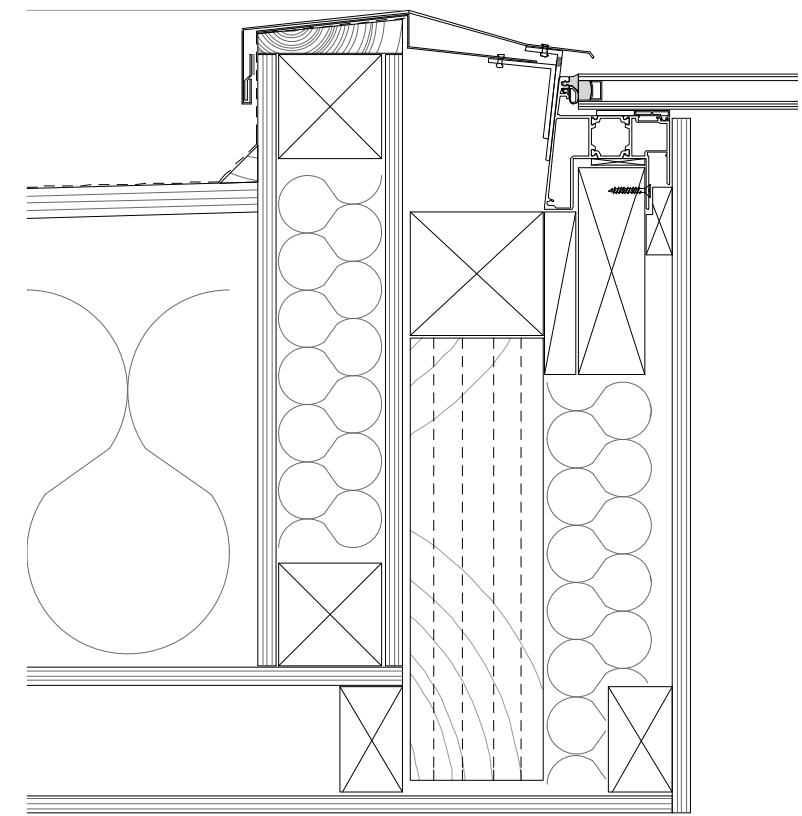

SECTION THROUGH PARAPET EDGE $3^{\circ}$ SKYLIGHT FALL, HIGHEST POINT OF SKYLIGHT

Figure 263: Skylight Jamb Detail Remaining Below Neighbouring Parapet at $3^{\circ}$ (RM)

The skylight head and gutter details would be very similar to those of Option Four [Figure 264 \& Figure 265]. A thermal roller blind could be incorporated within the solid bulkhead section of the roof [Figure 264]. The blind could then be drawn lengthwise with any tracks or hardware detailed along the jambs of the skylight frames. The new bulkhead roof also provided a space to install an external roller blind that could run parallel to the internal blind but on the outside of the skylight. A variation of this skylight arrangement was also developed using APL's Metro Thermal Heart Series frames [Figure 236].

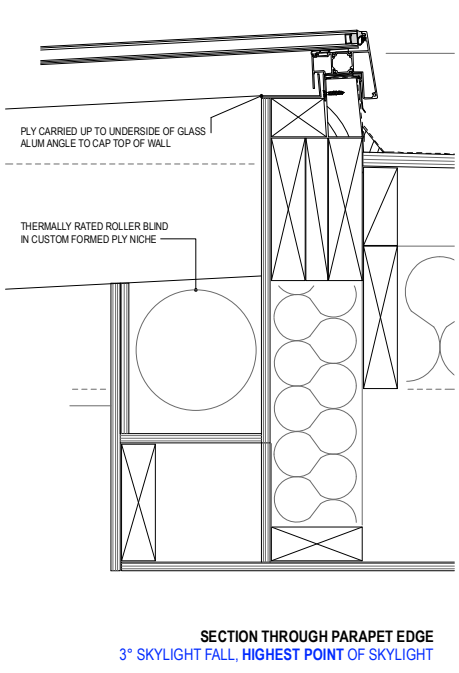

Figure 264: One Fall, Skylight Head Detail at $3^{\circ}$ (RM)

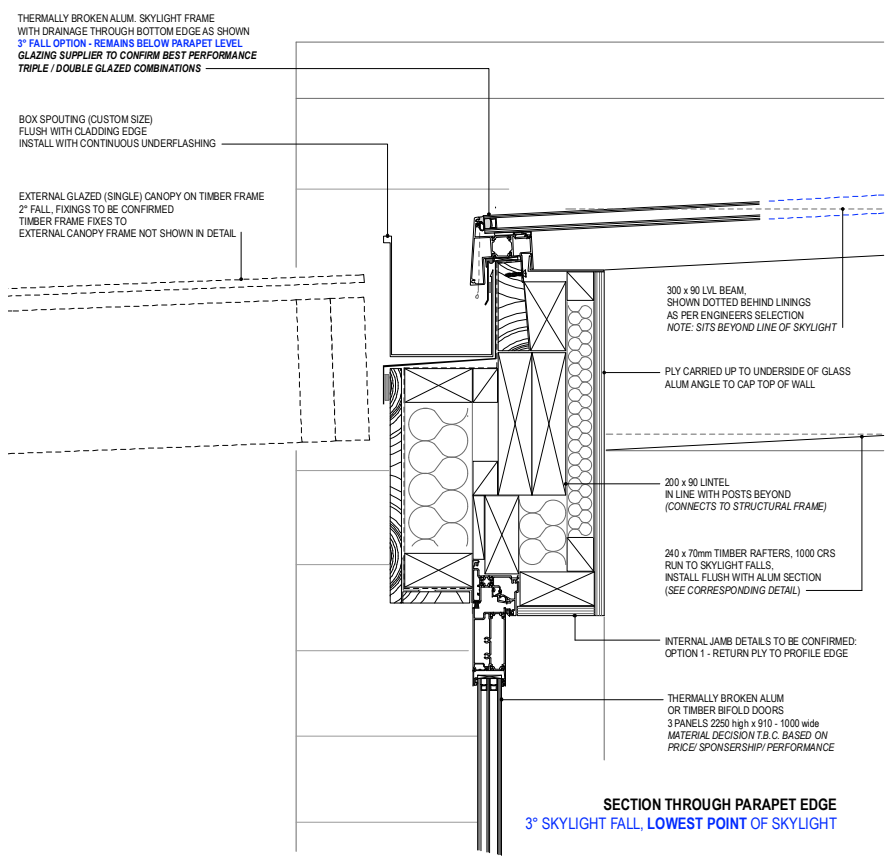

Figure 265: One Fall, Skylight Gutter Detail at $3^{\circ}(R M)$ 


\section{Option Six: One Fall, Thermosash}

Facing potential difficulty in achieving a fall of $\leq 3^{\circ}$, the design team approached commercial window manufacturer Thermosash for an alternative solution. Thermsash proposed the use of one of their typical extruded aluminium mullion frames to achieve the $3^{\circ}$ fall. The IGU's would each be structurally sealed to independent frames with the connection between skylight panels achieved by the 'clicking' together of the two frames [Figure 266]. This joint would then be weathersealed with silicon. This seal could be easily cut out and the frames disconnected to enable quick and easy disassembly. Although the integration of the Thermosash details were not fully explored, it was assumed that very similar waterproofing and flashing details to the APL Option Five would be used. Thermosash were quick to come back with an alternative frame arrangement which was very simple and proved to be the most well suited to the house. The detailing of this option is explained further in Chapter 6.2.8 Skylight Selection.

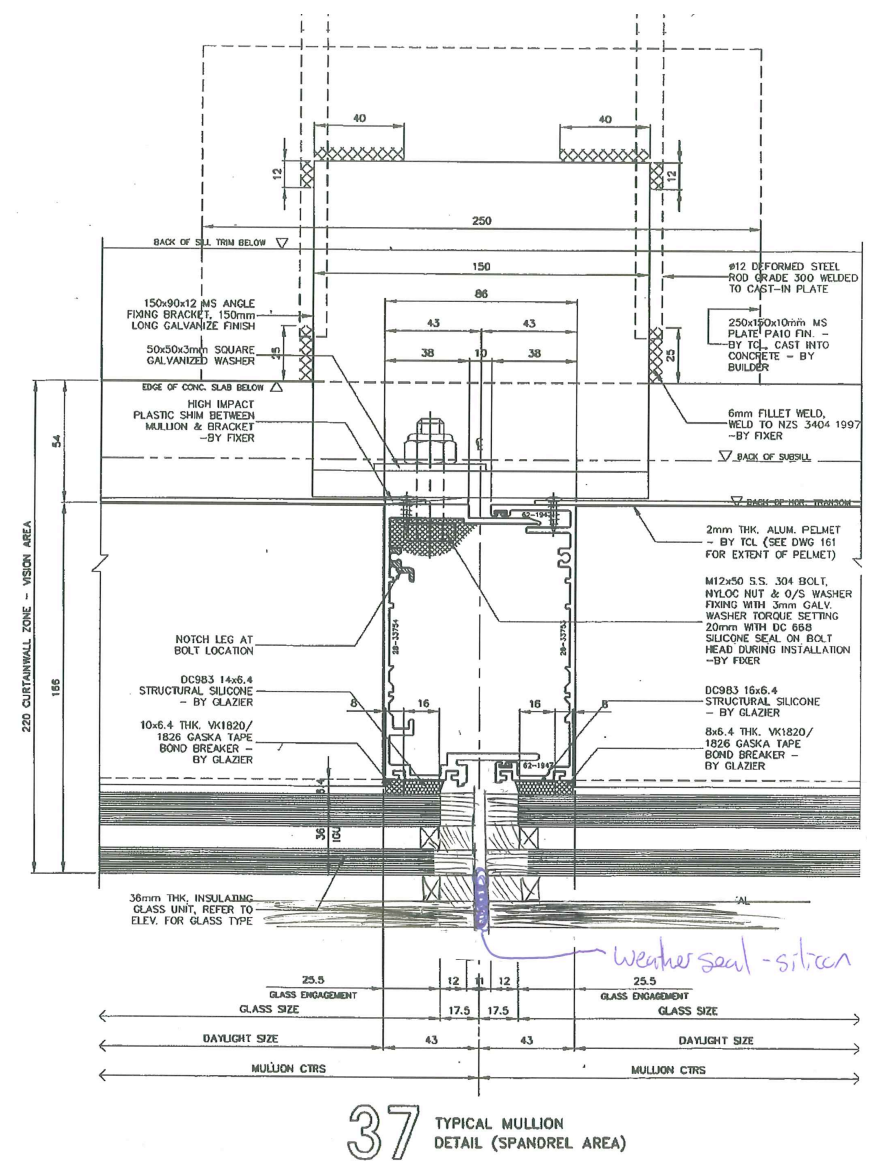

Figure 266: Thermosash Detail Proposal Using a Typical Mullion Frame

\subsubsection{Double Glazing}

Double glazing skylight options were explored only in so far as a change in the IGU specification from the triple glazed options described above. Most of the frames had been adapted from proprietry double-glazed frames and hence required little further investigation [Figure 267].

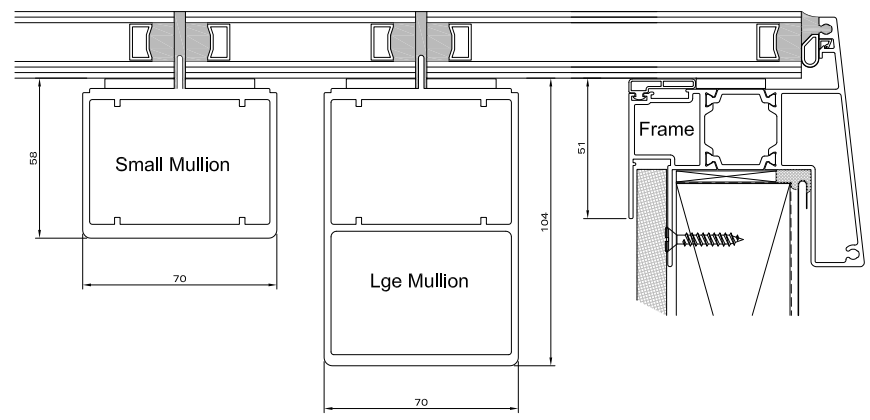

Figure 267: APL - Thermally Broken Double Glazed Skylight Details

The primary reason for exploring the use of double glazing was for comparative purposes only. Their analysis would give an understanding as to their impact on performance should other skylight options be infeasible, either due to expense or unavailability. The results of the comparative analysis are presented in Chapter 6.2.7 Performance Comparison.

\subsubsection{2x Double Glazing}

Quadruple Glazing was again only hypothetically explored for the purpose of aquiring a thermal performance assessment [Chapter 6.2.7 Performance Comparison]. 


\subsubsection{Polycarbonate}

A proposal for the use of a polycarbonate material such as Danpalon was made for its potential to achieve a high $\mathrm{R}$ value, a diffusing of direct solar gains while also keeping costs down.
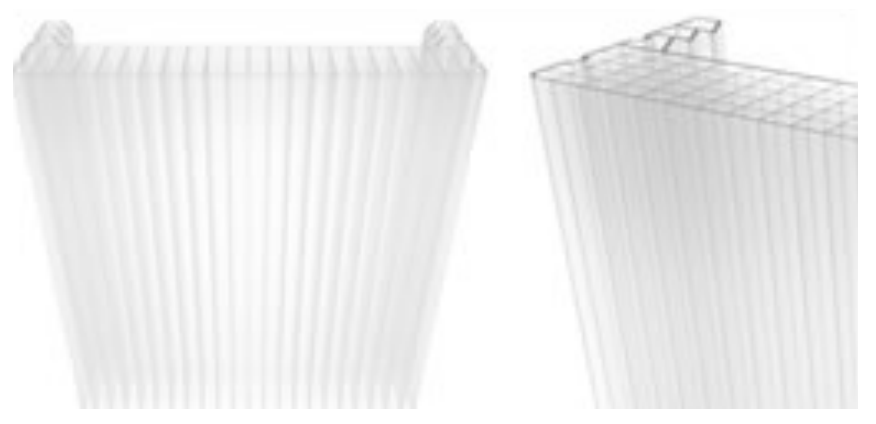

Figure 268: Danpalon Panels (Everlight NZ Ltd, 2009)

Performance characteristics of possible Danpalon options are summarised below. Double glazing is also presented here for comparative purposes.

\section{6mm Clear Multicell}

$\begin{array}{lllcc}\text { LT\% } & \text { ST\% } & \text { SR\% } & \text { SHGC } & \text { R-value } \\ 63.00 & 51.00 & 40.00 & 0.53 & 0.65\end{array}$

\section{6mm Double Glazed Clear Multicell $+16 \mathrm{~mm}$ Clear Multicell*}

$\begin{array}{lcccc}\text { LT\% } & \text { ST\% } & \text { SR\% } & \text { SHGC } & \text { R-value } \\ 25.01 & 13.27 & 78.40 & 0.15 & 1.60\end{array}$

\section{2x 10mm Clear Multicell + Wool*}

LT\% $\quad$ ST $\% \quad$ SR\% $\quad$ SHGC $\quad$ R-value

$\begin{array}{llll} & & & \\ - & - & - & 2.07\end{array}$
10mm Double Glazed Clear Multicell + 16mm Clear
Multicell*

$\begin{array}{lllcc}\text { LT\% } & \text { ST\% } & \text { SR\% } & \text { SHGC } & \text { R-value } \\ 40.32 & 22.22 & 68.90 & 0.24 & 1.36\end{array}$

\section{Double Glazed Argon Fill Low-E*}

$\begin{array}{ccccc}\text { LT\% } & \text { ST\% } & \text { SR\% } & \text { SHGC } & \text { R-value } \\ 64.00 & - & - & 0.27 & 0.83\end{array}$

$\mathrm{LT} \%=\%$ of visible light transmission $(400-700 \mathrm{~nm})$

$\mathrm{ST} \%=\%$ of total solar radiation transmission $(300-2800$ $\mathrm{nm})$

$\mathrm{SR} \%=\%$ of total solar reflection $(300-2800 \mathrm{~nm})$

SHGC - Solar Heat Gain Coefficient, total solar energy transmitted through the panel

It is important to note that many possible skylight options needed to be explored and in quick succession. Attention had to be paid to performance however time did not permit the development of each option to its full conclusion. Again, judgements had to be made based on the best evaluation of the information available. In this instance, the performance characteristics of the multilayered Danpalon systems were collated from a variety of sources with some estimations needed to fill in the gaps. I.e. thermal performance of some of the proposed combinations had not been verified, and data on the accumulative impact on light transmission and the SHGC was not available. The figures shown for the above options are not verified.

Although the R-value and SHGC is improved with multiple layers of Danpalon, the visible light transmission is significantly reduced. The preferred Danpalon option would be the three layers of $16 \mathrm{~mm}$ Clear Multicell achieving an R-value of R1.6, an SHGC of $\mathbf{0 . 1 5}$ and a visible light transmission of $25 \%$. This option achieves superior thermal performance when compared to double glazing which has an R-Value of 0.83 and a SGHC of 0.27 , however the visible light transmission is far less (Double glazing LT\% $=64 \%$ ). Danpalon panels are also 
extremely light weight (4kg per $\mathrm{m} 2$ ) and flexible, both important factors considering assembly and transportation requirements.

Draft details were prepared to help determine the appropriateness of a 3 layer Multicell option for use in the skylight [Figure 269, Figure 270, Figure 271, Figure 272 $\&$ Figure 273]. A layer of $6 \mathrm{~mm}$ PSP 'Satin Ice' Perspex was added to the underside of the skylight to help conceal the framing and flatten the striped appearance of the multicell. This would further reduce the visible light transmission down 23\% (Crystal Satin Ice LT\% = 92\%). The impact of the Perspex layer on the overall R-value and the SHGC is unknown but assumed to be minimal.

An initial cost estimate from supplier Everlight for single layer $16 \mathrm{~mm} \times 1040 \mathrm{~mm}$ panels with $\mathrm{AB}$ bar $=\$ 350-370$ per $\mathrm{m} 2$. If, for arguments sake, this cost was applied to the $3 \mathrm{x} 16 \mathrm{~mm}$ option the skylight would cost a total of approx. $\$ 350 \times 3 \times 9=\$ \mathbf{9 , 4 5 0}$.

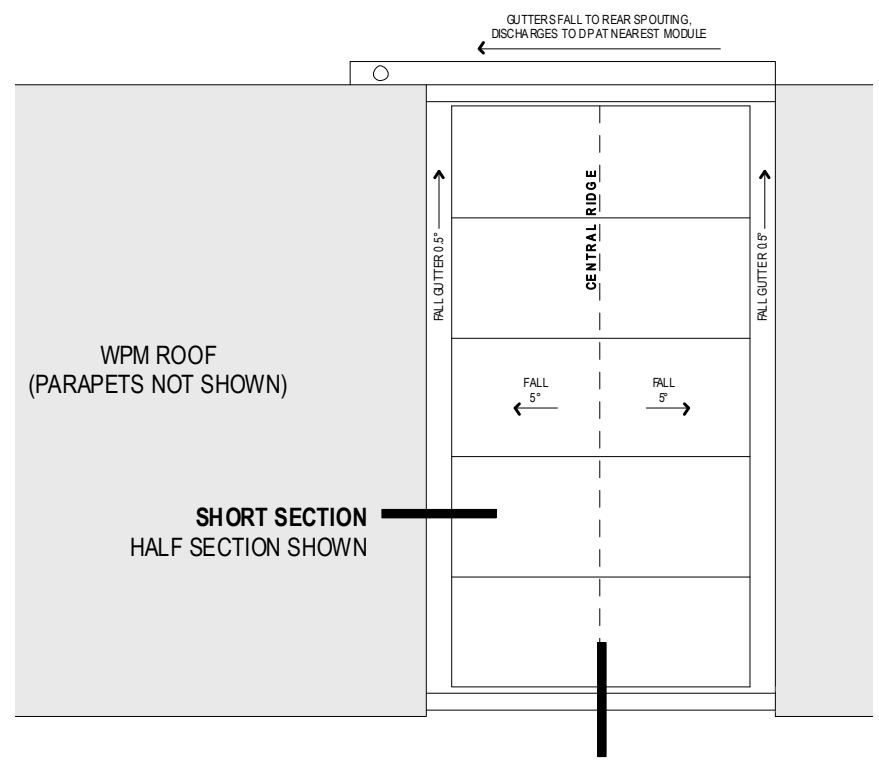

Figure 269: Danpalon Skylight - Drainage Plan (RM)

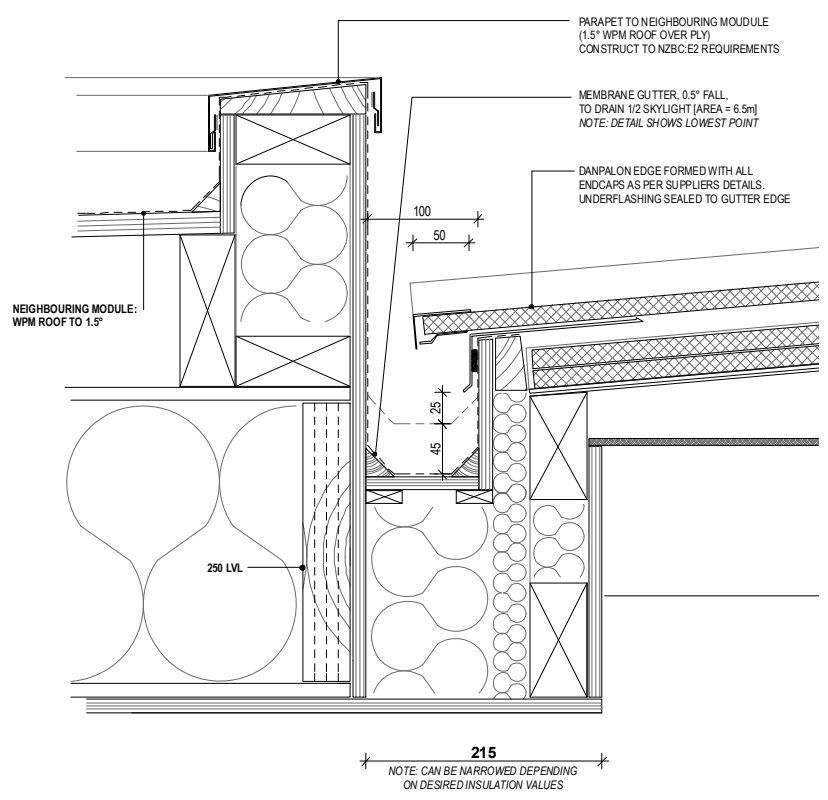

Figure 270: Danpalon Skylight - Gutter Detail (RM)

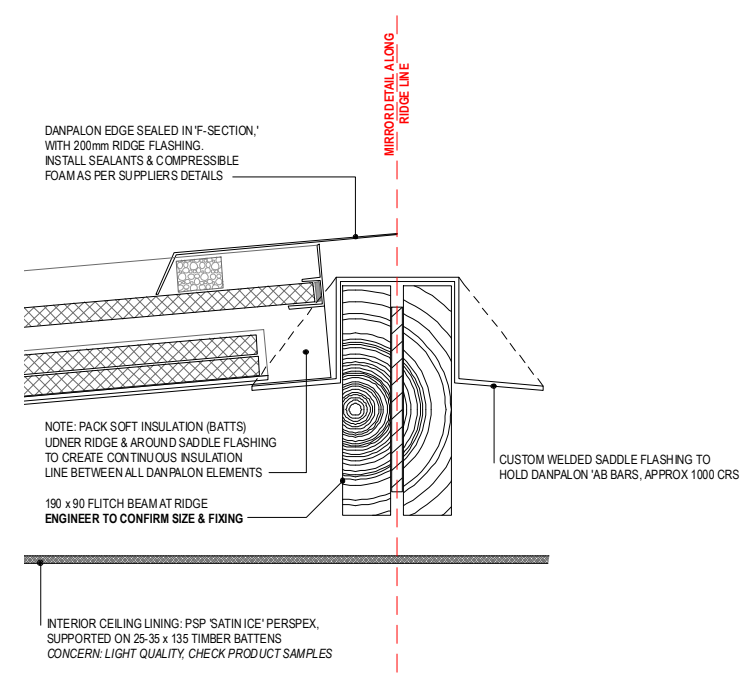

Figure 271: Danpalon Skylight - Apex Detail (RM)

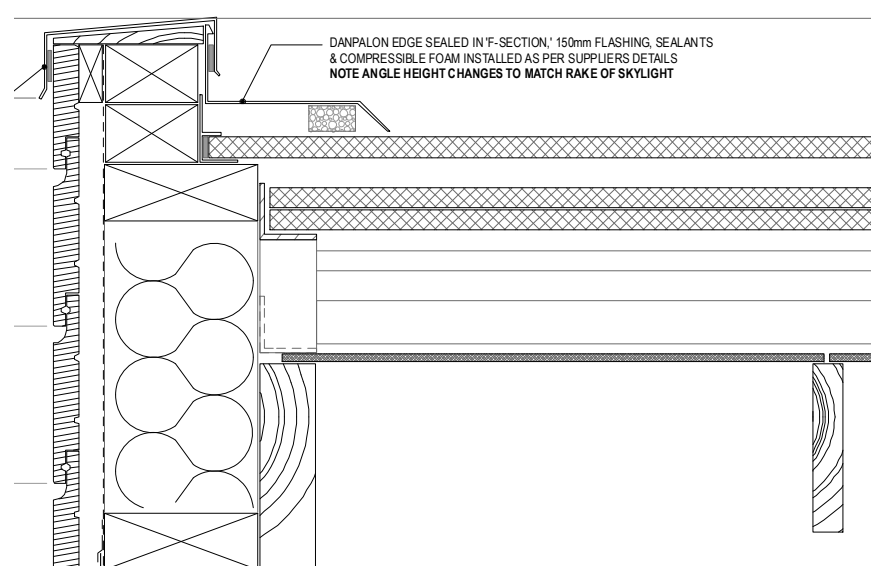

Figure 272: Danpalon Skylight - Jamb Detail (RM) 


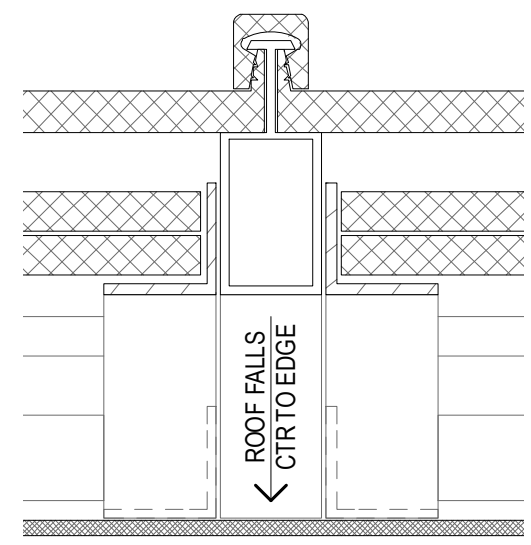

Figure 273: Danpalon Skylight-AB Bar Detail (Everlight NZ Ltd, 2009)

Danpalon would certainly diffuse direct sunlight and reduce solar heat gains, however there was some doubt as to just how visually effective it would be in situ. With the skylight directly between two large glazed bi-fold doors, it may in fact appear a lot duller than anticipated relative to the very light (particularly if open) doors. Figure 274 presents an example of Danpalon used within what appears to be an otherwise very dark space with few, if any, windows. Figure 275 \& Figure 276 demonstrate Danpalon's use in very light situations resulting in the panels appearing quite dull in comparison. Alternative skylight options continued to be explored in an attempt to achieve a better visual quality while still maintaining a high level of thermal performance.

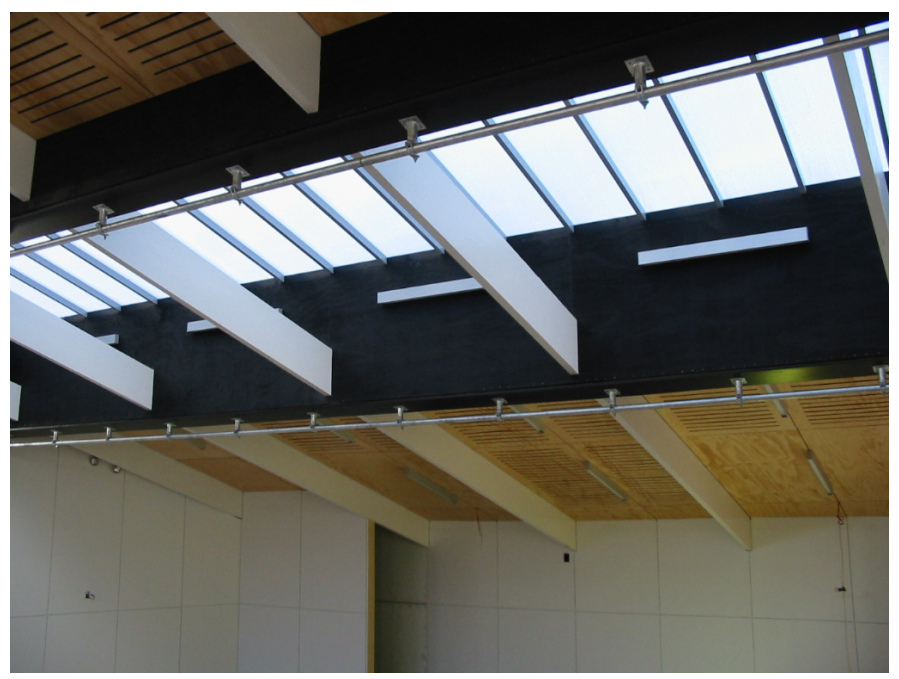

Figure 274: Example of Danpalon - Skylight

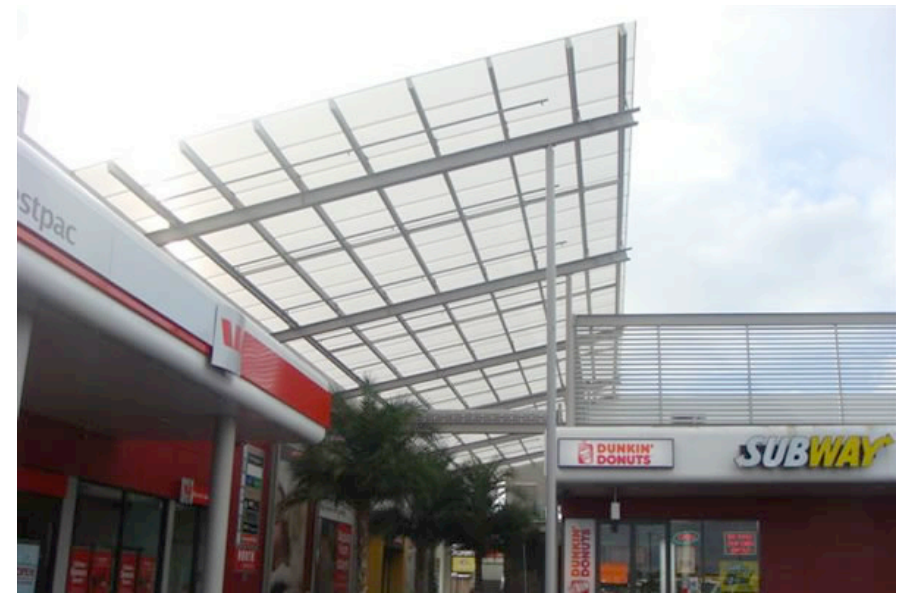

Figure 275: Example of Danpalon - Lincoln Rd, Auckland (Everlight NZ Ltd, 2009)

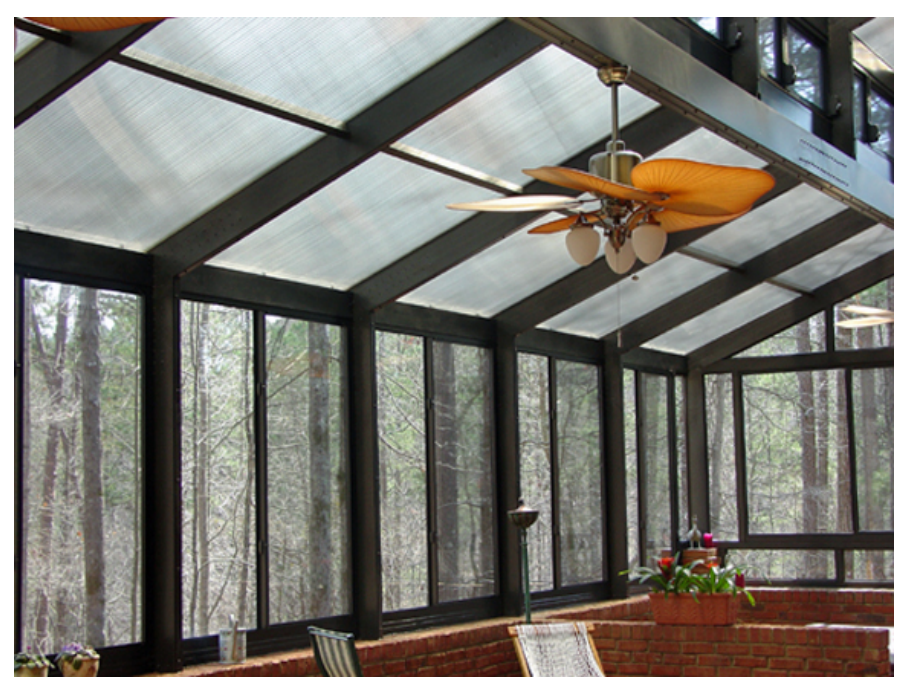

Figure 276: Example of Danpalon - Conservatory 


\subsubsection{ETFE}

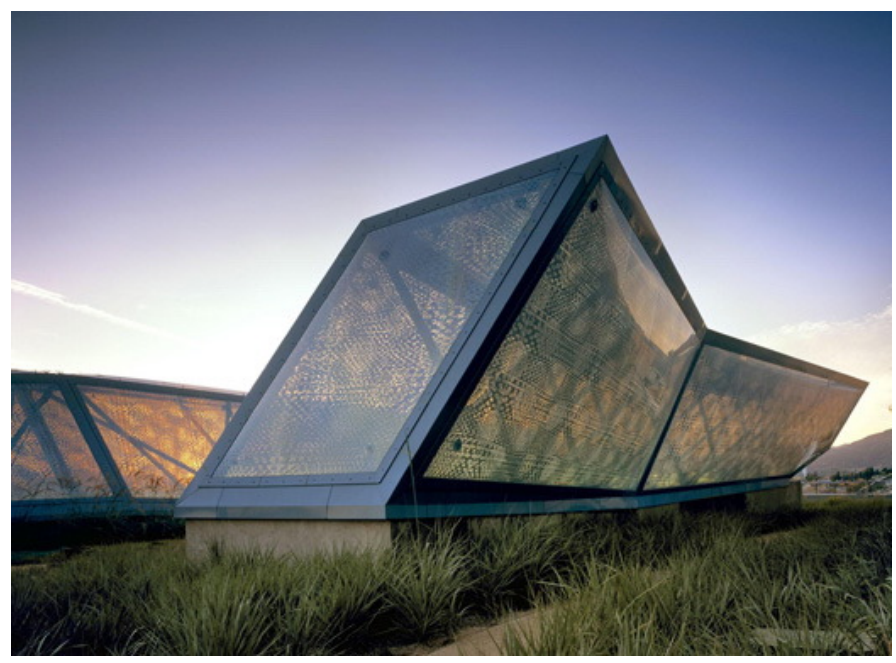

Figure 277: ETFE - Pasadena Art Centre by Daly Genik Architects (Woyke, 2007)

ETFE (ethylene tetrafluoroethylene) was explored for its ability to accommodate; high levels of light transmission, variable shading, insulation, large spans, self-cleaning, lightweight and high strength, all in one system. The insulation and visible light transmission properties of multiple-skin ETFE cushions are presented below (Robinson, 2004).

\section{ETFE}

$\begin{array}{cccc}\begin{array}{c}\text { No. of } \\ \text { Foils }\end{array} & \text { U-Value (Wm-2K) } & \text { R-Value } & \text { LT\%* } \\ 2 & 2.94 & 0.34 & 93 \\ 3 & 1.96 & 0.51 & 86 \\ 4 & 1.47 & 0.68 & 80 \\ 5 & 1.18 & 0.85 & 74\end{array}$

* Compound LT\% estimated based on 93\% LT of single layer of ETFE.

The Solar Heat Gain Coefficient (SHGC) for Etfe foils can range between $0.05-0.85$ depending on the types of additional coatings and colorings (Robinson, 2004). Furthermore, systems such as Vector Foiltech's Texlon multi-layered construction can change their insulation and solar transmission as required (Vector Foiltec, 2010). With overlapped graphics and patterns the Texlon foils can be pneumatically reconfigured to allow more or less direct solar gains [Figure 278, Figure 279 \& Figure 280]. By inflating and deflating the internal ETFE foils, the inverted patterns either align to provide shade or open to allow light to pass through. These ambitious properties were of great appeal to the design team considering the overheating issues that the house was facing. There would obviously be significant cost in incorporating a complex system of this nature. Some of these costs, however, would be offset by the fact that an additional shading system is not required.
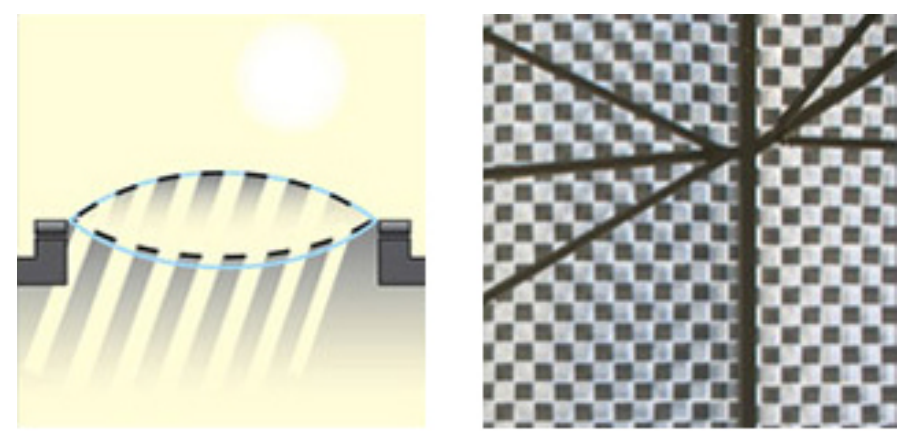

Figure 278: ETFE Variable Texlon - Open (Vector Foiltec, 2010)

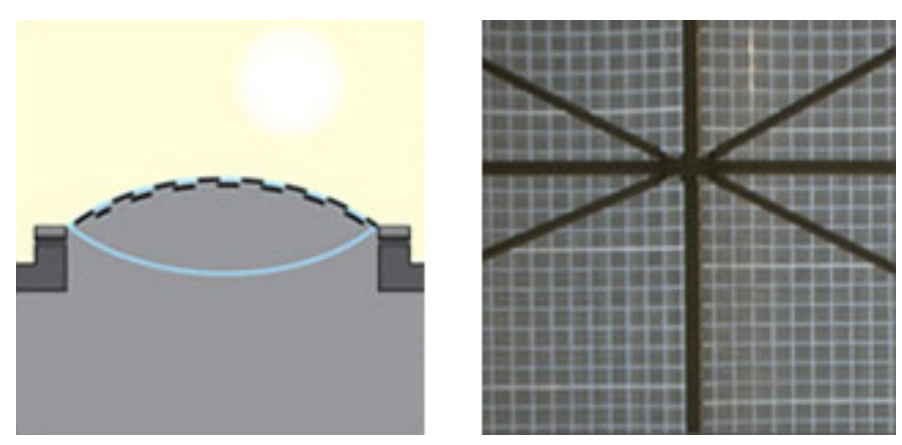

Figure 279: ETFE Variable Texlon - Closed (Vector Foiltec, 2010)

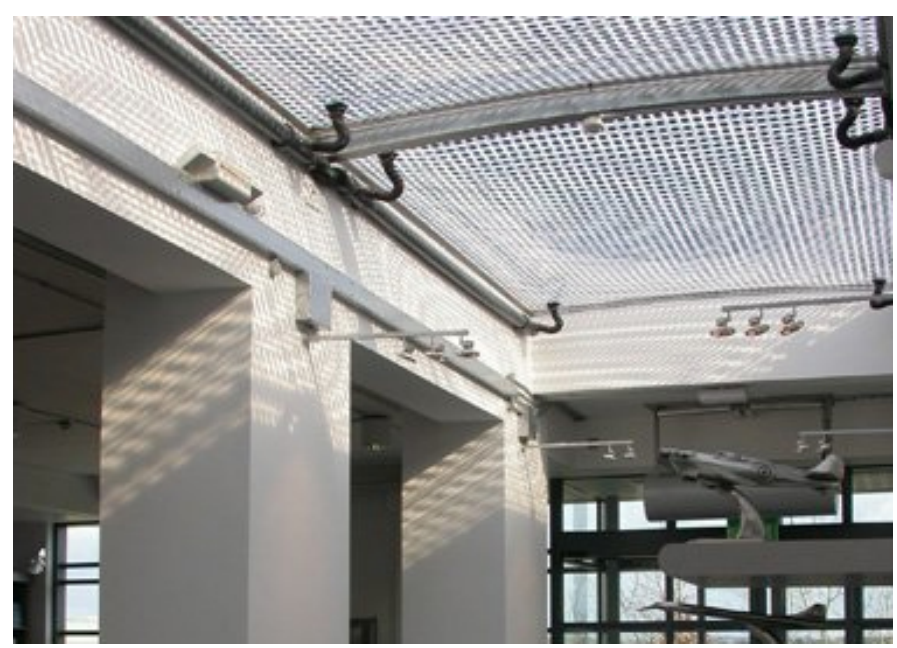

Figure 280: ETFE Variable Texlon - Duxford Visitors Centre (Vector Foiltec, 2010) 
Detailed drawings were again quickly established for review by engineers, suppliers and the rest of the design team [Figure 281, Figure $282 \&$ Figure 283]. An option of utilising ETFE for variable shading and rainwater drainage in combination with a triple-glazed skylight was also explored. This had the main advantage of increased insulation and management of thermal bridging while also providing an effective means of shading [Figure $284 \&$ Figure 285] The complexity and cost for this option were believed to be in far excess of the advantages that it offered.

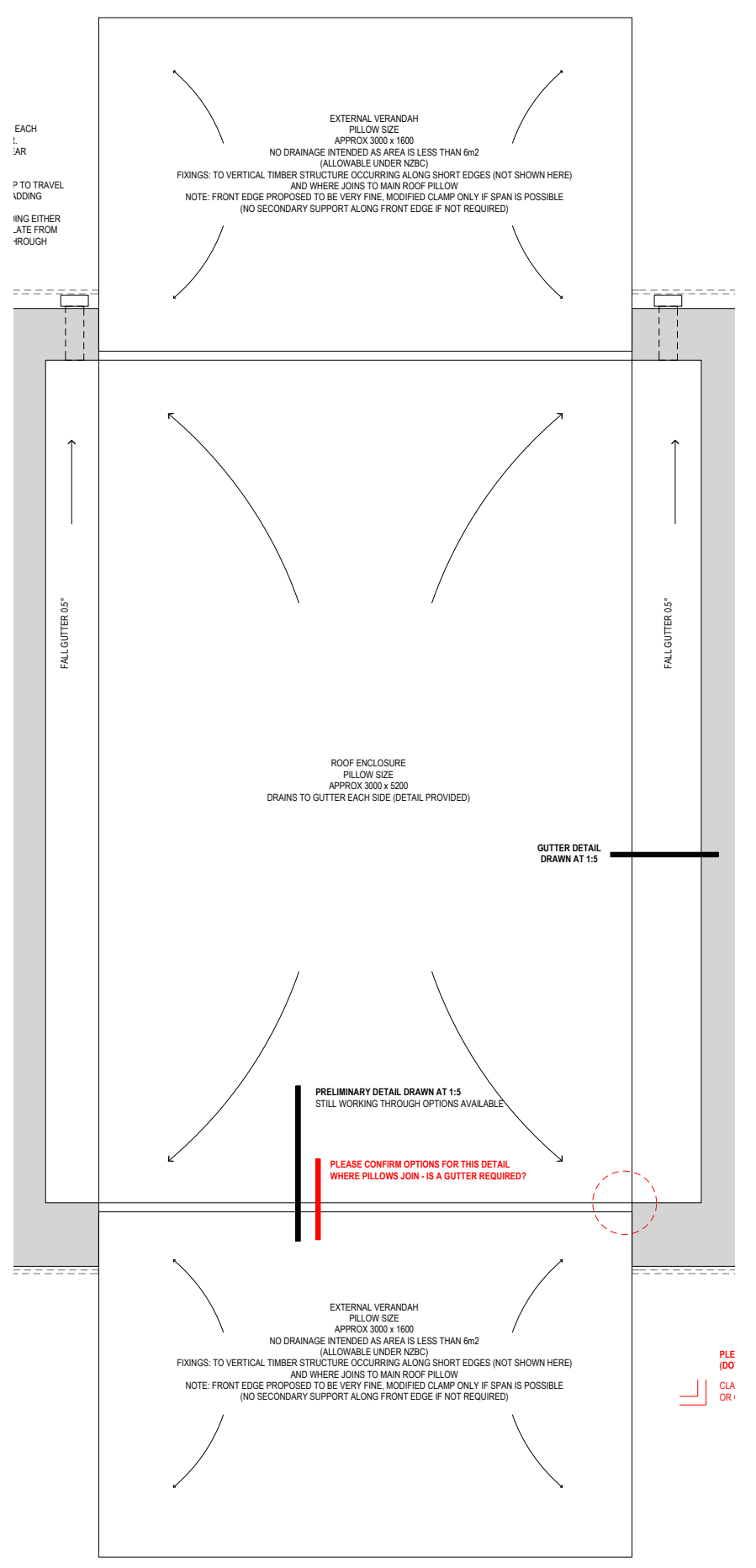

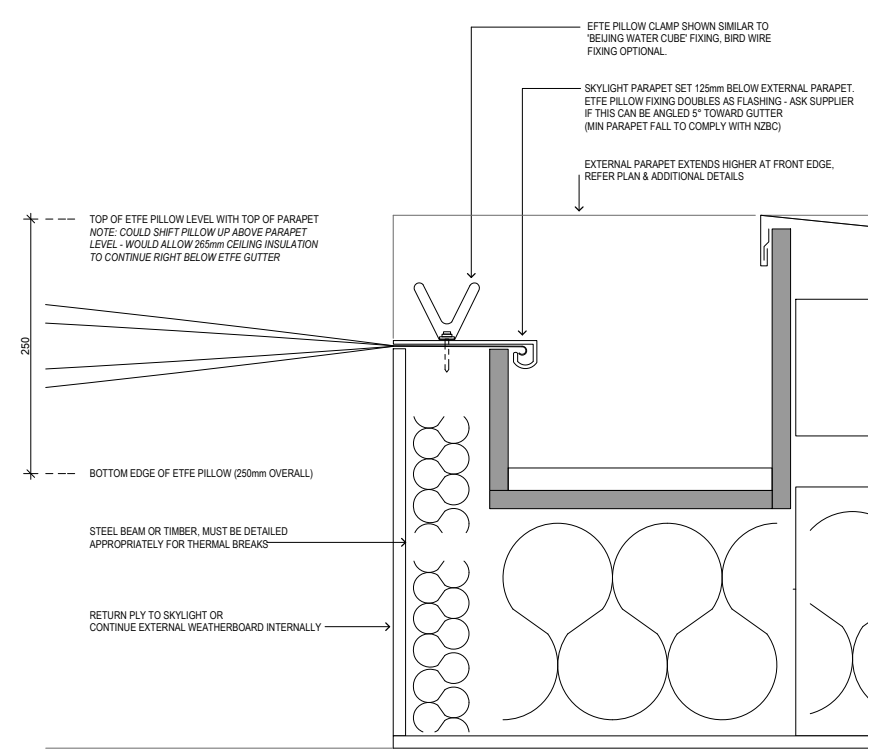

Figure 282: ETFE Skylight - Gutter Detail at Pillow Edge (RM)

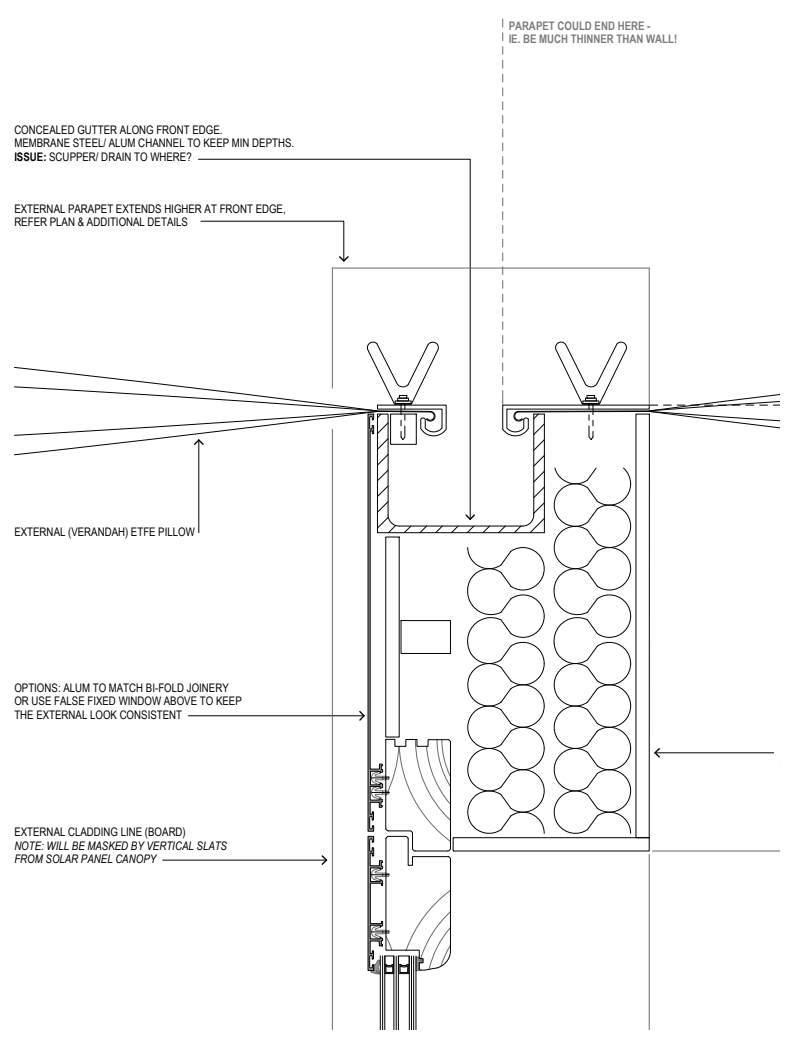

Figure 283: ETFE Skylight - Gutter Detail at Pillow Join (RM)

Figure 281: ETFE Skylight - Roof Plan (RM) 


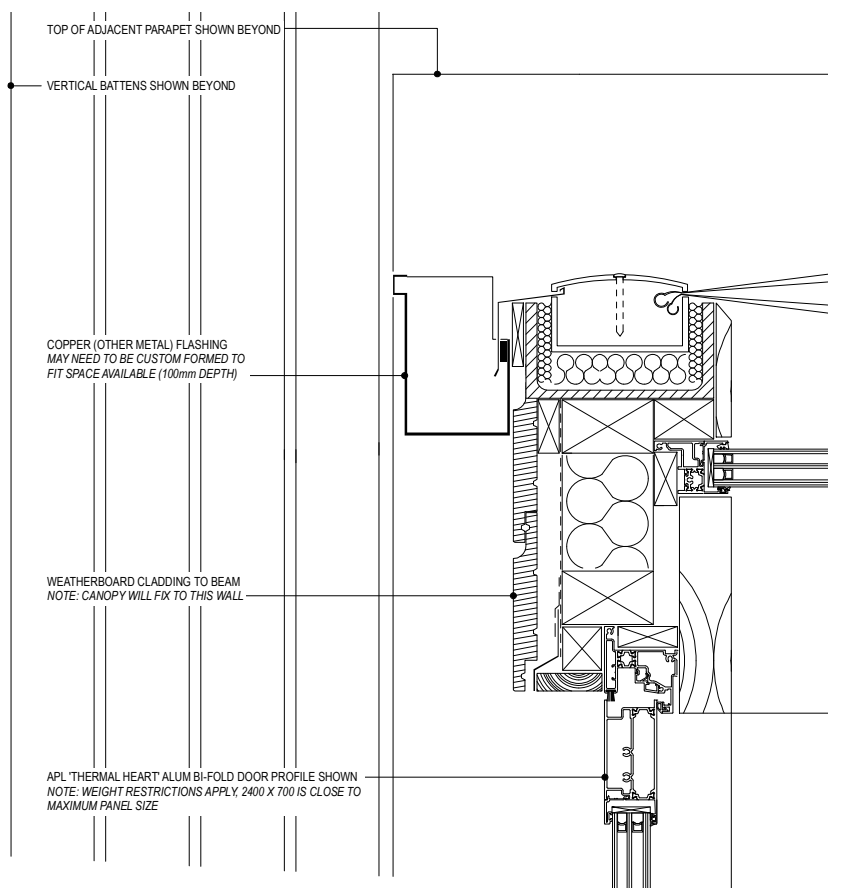

Figure 284: ETFE \& Triple-Glazing - Gutter Detail and BiFold Door Junction (RM)

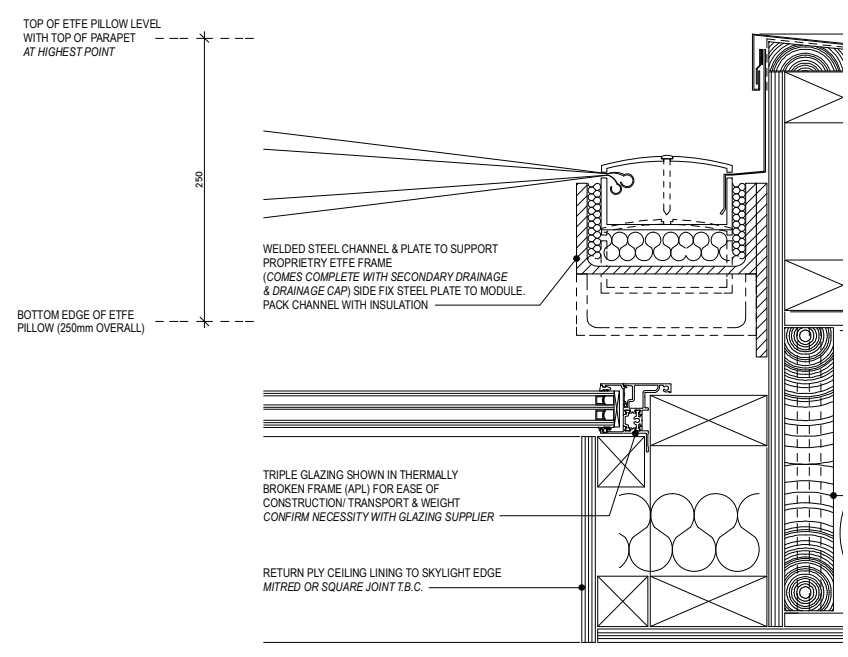

Figure 285: ETFE \& Triple-Glazing - Jamb Detail at Module Join (RM)

Although complex an ETFE system could be adapted for the First Light house, however there still existed many uncertainties as to its appropriateness. The insulating advantages that ETFE offered were minimal and the variable shading system might be susceptible to problems through multiple assemblies. It was also felt that this level of technical and mechanical complexity was moving away from the simplistic "bach" concept. An ETFE skylight would undoubtably open up the house to the sky but at the risk of poor thermal performance and confusing the core concept. The risks involved with an ETFE skylight option far outweighed its advantages, returning the design team to the drawing board to find a more suitable solution.

\subsubsection{Aerogel Profilit}

An Aerogel skylight option was explored in an attempt to achieve the best possible thermal performance while still maintaining a high level of visible light transmission. Pilkington Profilit channel glazing can be integrated with $25 \mathrm{~mm}$ of polycarbonate encased Lumira Aerogel to create a highly insulated and transluscent panalised system (Technical Glass Products, 2011) [Figure 286].

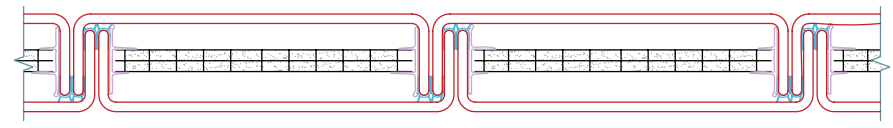

Figure 286: Pilkington Profilit Channel Glass with Luminaire Aerogel

The performance characteristics of Profilit channel glazing with Luminaire Aerogel are as follows (Technical Glass Products, 2011):

\section{Profilit Luminaire}

$\begin{array}{cccc}\text { LT\% } & \text { SHGC } & \text { U-Value } & \text { R-Value } \\ 38.0 \% & 0.31 & 0.19 & 5.26\end{array}$

This system achieves an extremely high R-value to Light Transmission ratio. Although it is reported to have an $\mathrm{R}$ value of R5.26 there is some concern as to the amount of thermal bridging that may be occurring at the joint between channels. In any case, this option presented the best possible thermal performance characteristics, on paper, out of any of the skylight options explored. Details for the integration of the Profilit channel glazing were developed to test for its appropriateness to the First Light house [Figure $287 \&$ Figure 288]. 


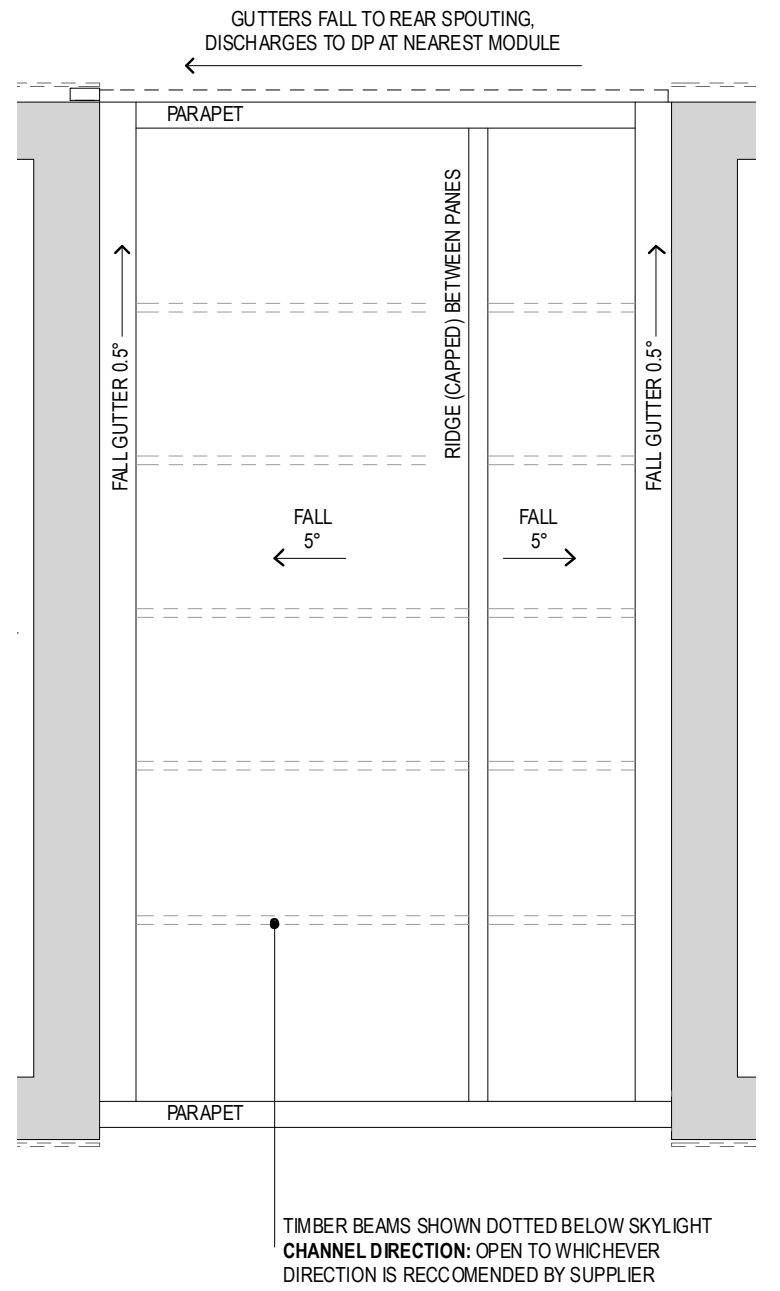

Figure 287: Profilit Aerogel Channel Glazing - Roof Plan (RM)

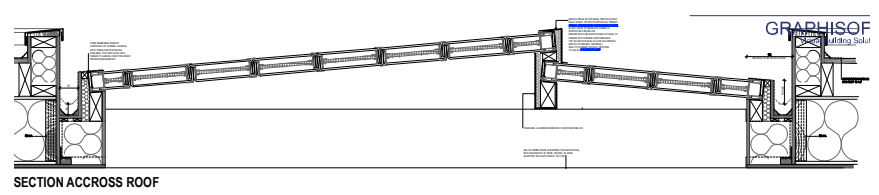

Figure 288: Profilit Aerogel Channel Glazing - Section (RM)

Great difficulty was found in the detailing of this system due to the team's inexperience with its use coupled with the unavailability of any examples of its application in New Zealand. Extensive correspondence with Pilkingtons would have been necessary to develop the skylight to a level fit for use in the First Light house, including the requirements of disassembly and transportation. The rudimentary details presented here were sufficient to predict the Profilits viability and to give the Building Performance team the data required to assess its thermal performance [Figure 289 \& Figure 290 \& Figure 291]. The results of this are presented in Chapter 6.2.7 Performance Comparison.

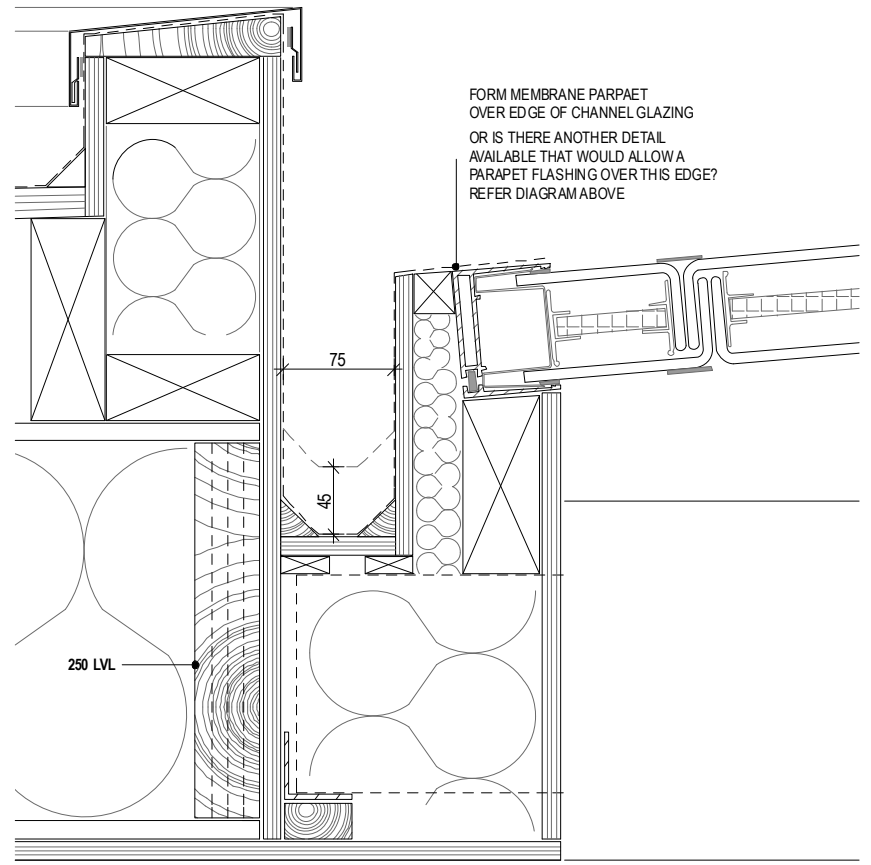

Figure 289: Profilit Channel Glazing - Gutter Detail (RM)

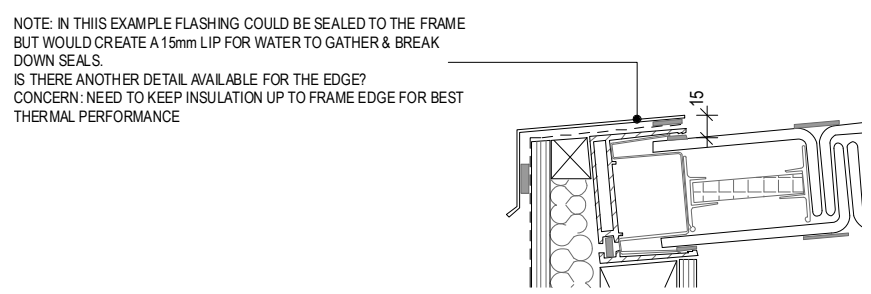

Figure 290: Profilit Channel Glazing - Gutter Detail 2 (RM)

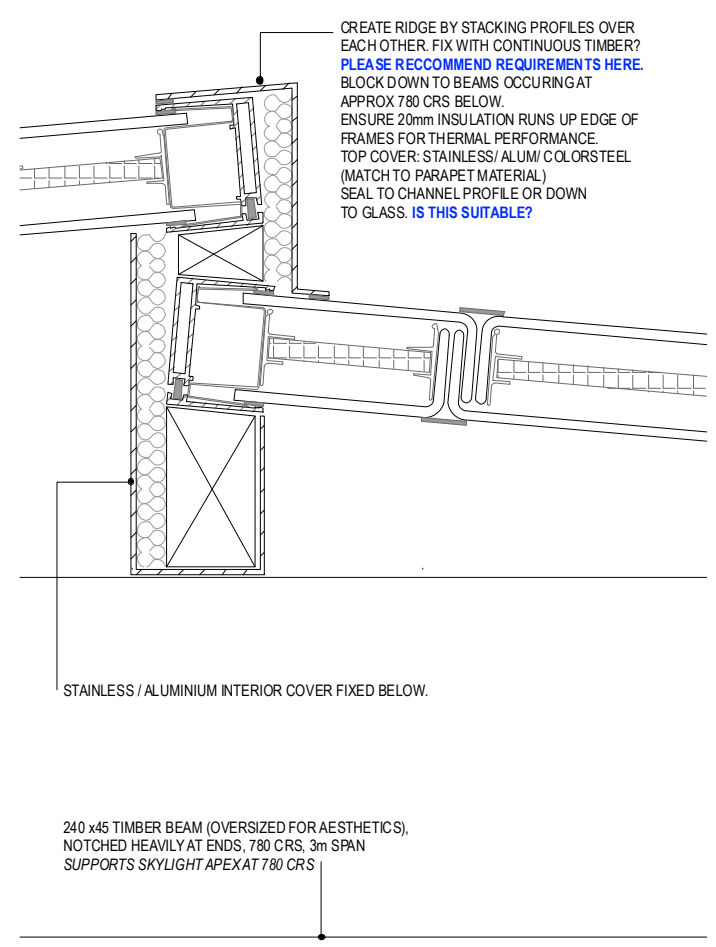

Figure 291: Profilit Channel Glazing - Ridge Detail (RM) 
Although this option initially presented superior thermal performance characteristics there were simply too many risks involved for it to be used. It would have to be imported (potentially significant lead times), it had not been used in New Zealand (code compliance issues), the team had no experience in its use, there was little known as to how it would disassemble and transport, and it would be significantly more expensive than any other skylight option. It also later proved to underperform greatly in the thermal analysis.

\subsubsection{Performance Comparison}

Figure 292 below illustrates the average daily HVAC energy use, both in heating and cooling, for each of the skylight options (Jagersma, 2012). The analysis was carried out for two months in Washington, DC. This provided a good approximation of the conditions likely to be experienced during the competion period. The results show that the Nanogel, ETFE and Danpalon options did not perform as well as was hoped. The triple-glazing options however proved to work quite well across the board with the reflective coating or tint greatly reducing cooling loads. These results lead to the recommendation to use triple glazed, argon filled, Low-e, and tinted IGUs for the skylight. The integration of an internal thermal blind was also recommended to help reduce average heating loads. More detailed explanation of the performance characteristics and analysis of each skylight option can be found in, The Ten Day Bach: A Net Zero Energy Home (Jagersma, 2012).

FirstLight Washington D.C. - Skylight Constructions: HVAC Energy Use (kWh) for September 1 - October 31

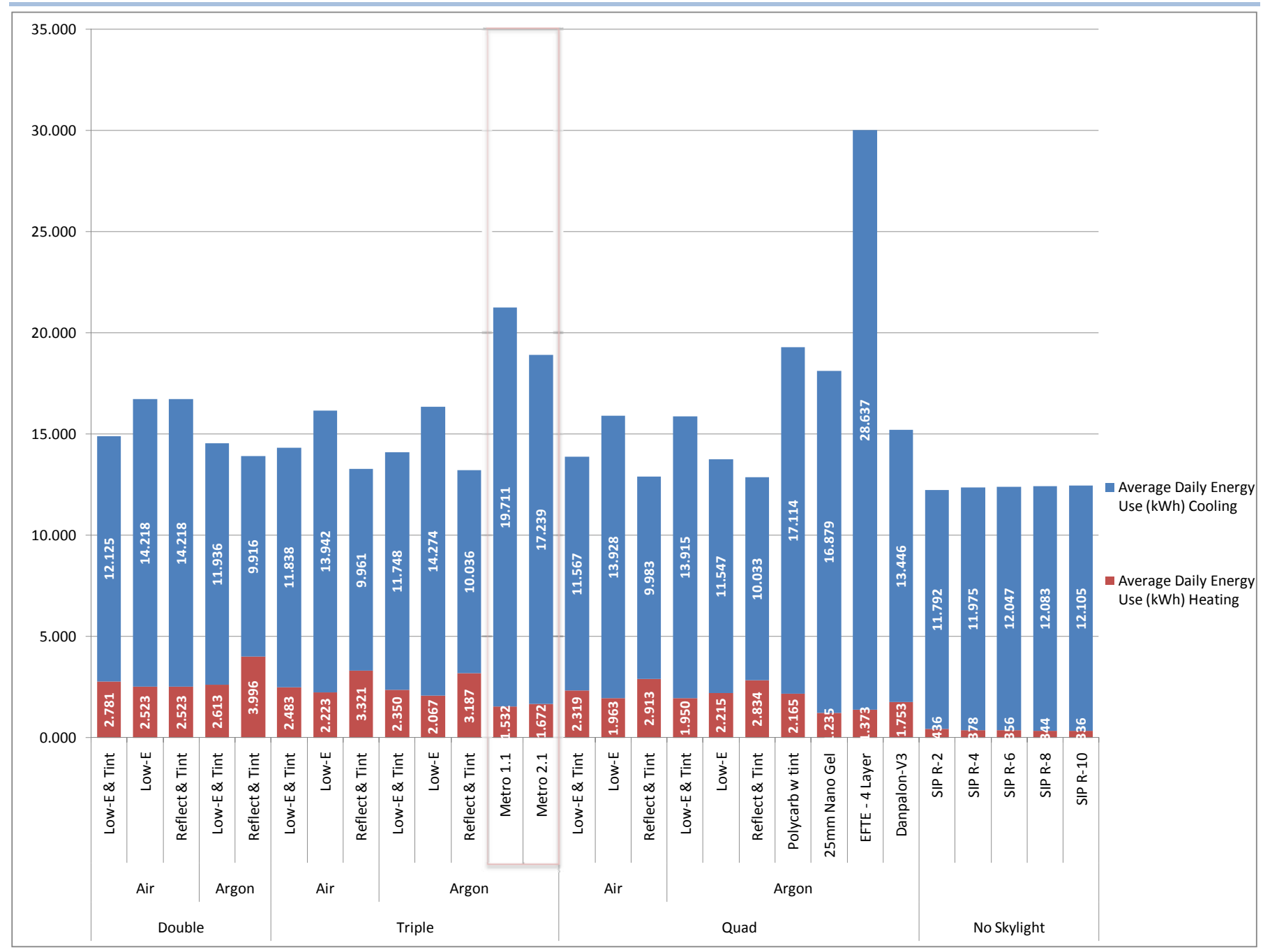

Figure 292: Graph Showing Average Heating and Cooling Loads for the Various Skylight Constructions for September 1 - October 31 in Washington, DC (Jagersma, 2012) 


\subsubsection{Skylight Selection}

With a sound understanding of construction and assembly details, weatherproofing issues, performance characteristics, and overall aesthetic qualities of each skylight option; a decision on the most appropriate method could be made. The comparatively good thermal performance of the triple glazed, argon filled, low-E, and tinted IGU, coupled with its local availability and relatively typical detailing, made it the most viable and visually suitable option.

Final performance characteristics of the IGUs:

$\begin{array}{llccc}\text { LT\% } & \text { ST\% } & \text { SR\% } & \text { SHGC } & \text { R-value } \\ 24.75 & 12.90 & 32.20 & 0.24 & 1.1\end{array}$

Thermosash proved to be the most appropriate supplier considering their business relationship with main contractor Mainzeal, their willingness to provide sponsorship, and ability to achieve a $3^{\circ}$ fall. The initially proposed extruded aluminium mullion details were superseded with a far more simplified aluminium angle [Figure 293]. This enables the skylights to be dropped in place side by side and bolted together. Any tolerance is then taken out either side of the skylight through the use of plastic packers.

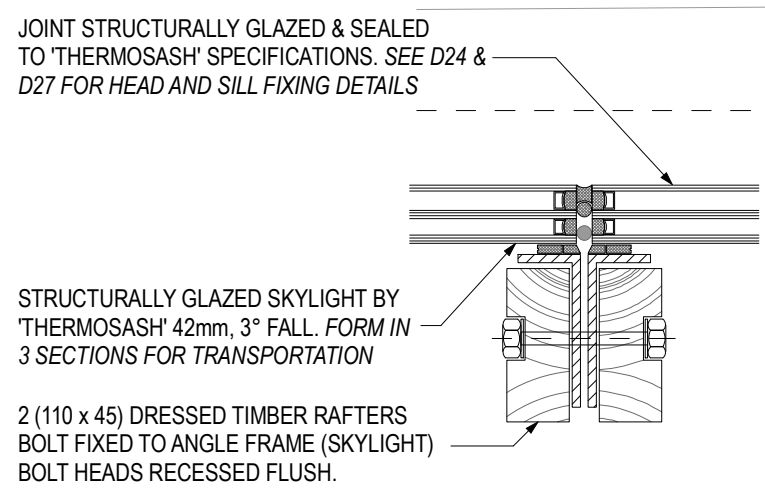

Figure 293: Construction Drawing Showing Skylight InterPanel Jamb Detail

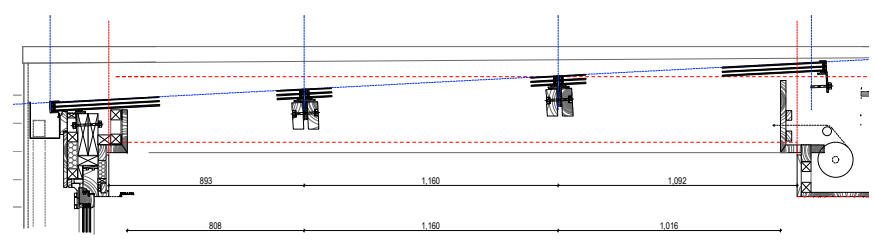

Figure 294: Thermosash Triple Glazed Skylight - Section Showing Transverse Orientation of Skylight Panels (RM)

With this new detail an alternative orientation of the skylight panels was explored for aesthetic purposes [Figure 294]. This however proved to have three main disadvantages; rainwater drainage was now perpendicular to the silicon weatherseal, the integration of an internal roller blind would be difficult, and the spacing of the internal beams would be uneven if each skylight panel was to be the same width (critical to enable a 'one-sizefits-all' spare skylight panel to be used). It was consequently decided that the original $3^{\circ}$ fall to the front of the house would be used with an exposed gutter. The scuppering of the gutter through into the cladding cavity of the neighbouring module was changed to an exposed zincalume downpipe to avoid complexity and weatherproofing issues. The final details and visual outcome of the skylight are presented at the end of this chapter in Section 6.6 Module Three - As Built.

\subsection{MODULE THREE ROOF}

The roof of module three is constructed using typical timber framing techniques. The main requirements were that it would achieve the following:

1. A self supporting unit that could be detached and packed into a container for transport

2. Sufficient clear space for the provision of services

3. Sufficient cavity for the installation of the internal roller blinds

4. Weatherproof

5. Airtight

6. Insulated

As discussed below in Chapter 6.5 Assembly, the roof is suspended between two primary LVL beams [Figure 295]. Timber framing is used to achieve the correct ceiling height and maintain a clear void for services [Figure 296] 
The roof is weatherproofed with an EPDM membrane over a plywood substrate. The unit is then packed with Ecoinsulation and an Intello membrane is installed to achieve airtightness. A clear void is preserved in the bulk head for the installation of services and the roller-blind.

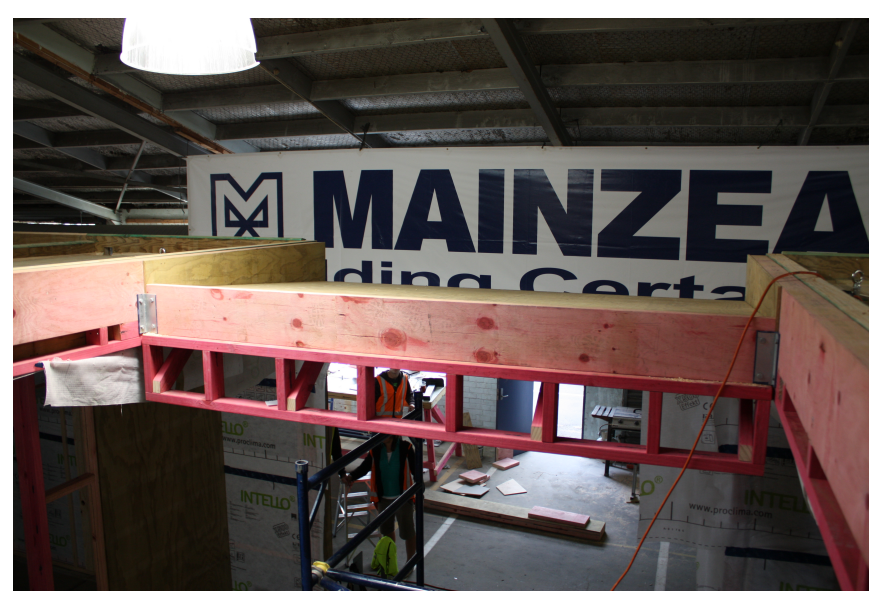

Figure 295: Construction Photo Showing Module Three Roof Suspended Between LVL Beams

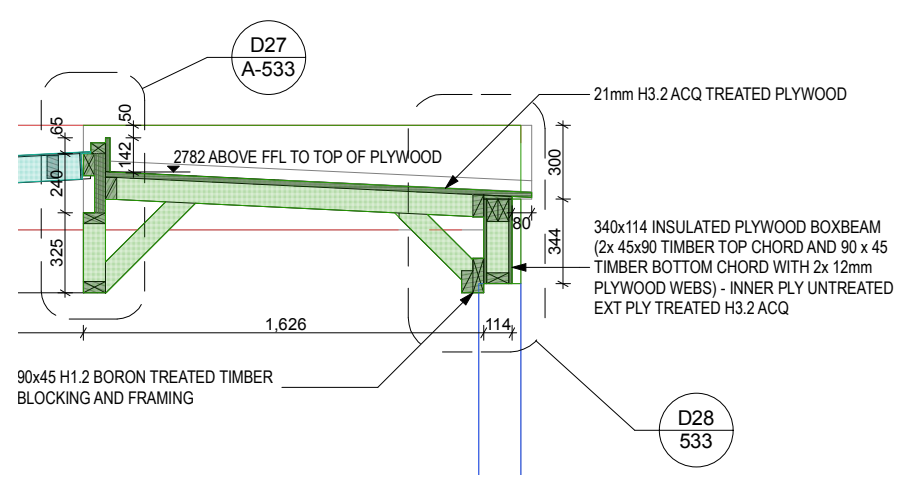

Figure 296: Module Three Roof - Section Showing Timber Framing (JM)

\subsection{MODULE THREE FLOOR}

At 3.0 metres wide the floor panel would not fit into a 40' Hi Cube container, even if it was placed on its side. The floor was consequently divided into two sections with the T\&G floor boards panelised and reinstalled during assembly. To alleviate any deflection caused by the weight of the concrete dining table, the floor was divided off centre and double LVL joists were incorporated beneath the table [Figure $297 \&$ Figure 299].

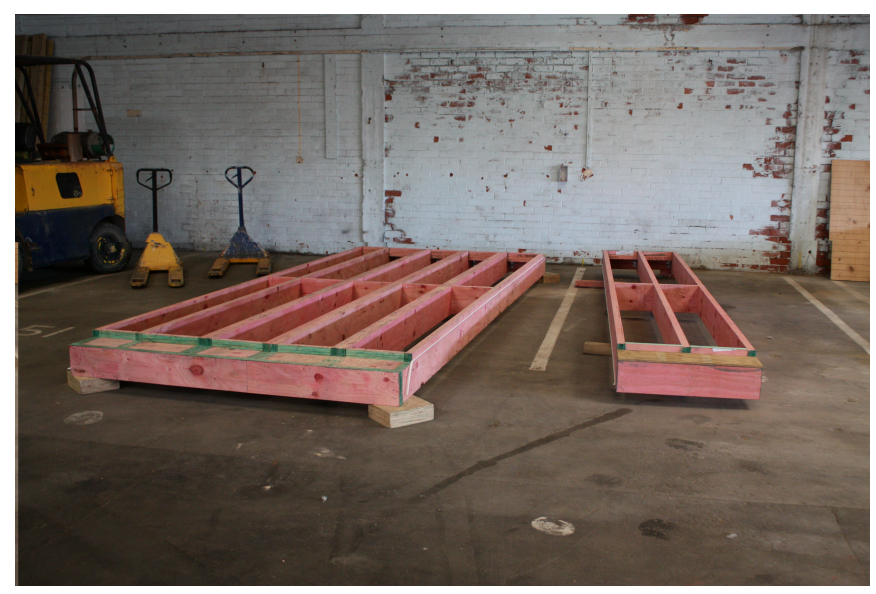

Figure 297: Module Three Floor Panels - Separated During Construction

The floor panels are packed with $240 \mathrm{~mm}$ of EcoInsulation and sealed on the bottom with $12 \mathrm{~mm}$ plywood. The LVL joists were notched to allow for the insetting of the aluminium bi-fold door tracks [Figure 298]. This enabled the door sill to sit flush with the finished floor level. This flush finish was critical for meeting the accessibility requirements of the competition. Detailed drawings of the door sill can be seen in Chapter 6.6 Module Three - As Built, Figure 306.

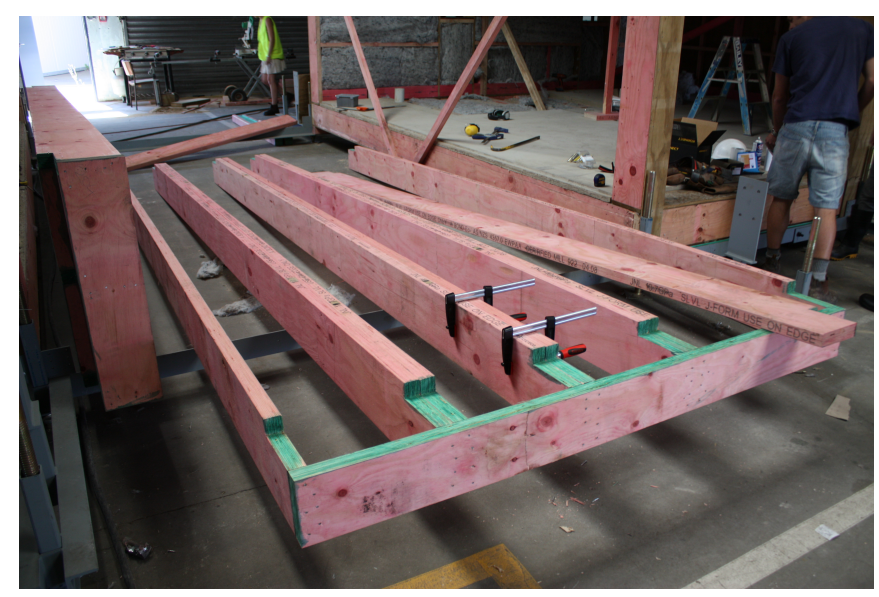

Figure 298: Module Three Floor Panels - LVL Joists Notched for Door Tracks 


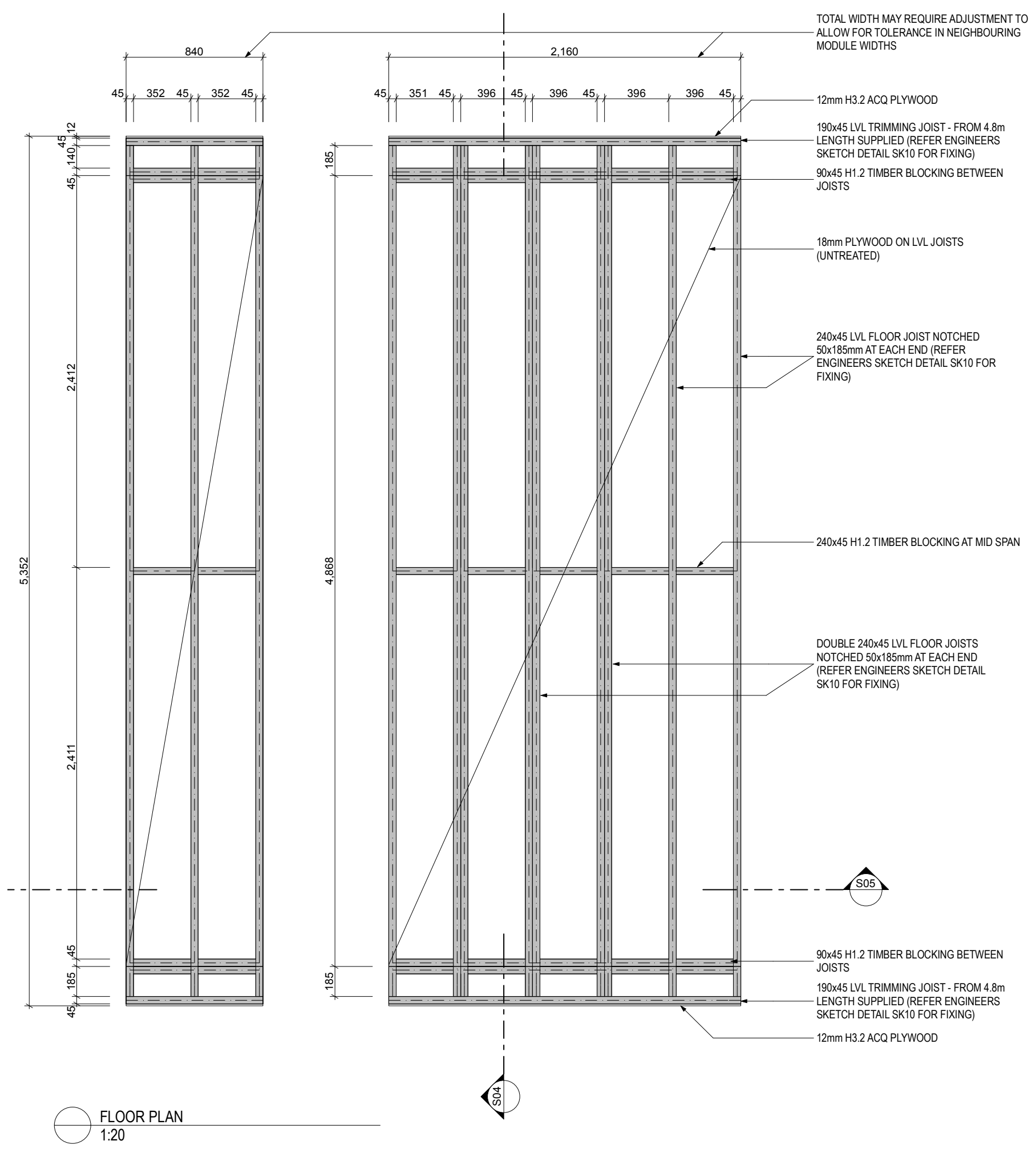

Figure 299: Module Three Floor Panels - Framing Plan 


\subsection{ASSEMBLY}

To enable the packaging of Module Three into a standard 40 ' Hi Cube shipping container, it had to be broken down into many independent components [Figure 303 \& Figure 304]:

1. Solid Roof Section

2. $2 x$ LVL Primary Beams

3. 2x Plywood Boxbeam Lintels

4. 2x Boxbeam Bi-Fold Door Frames

5. 2x Floor Panels

6. 3x Skylight Panels

7. $3 x$ Roller Blinds and Hardware

8. 6x Bi-Fold Door Sashes

9. T\&G Floor Panels \& Other Finishes

The detailing of the module join, the slats, the downpipe, and the bi-fold doors proved to be one of the most challenging of the project. Figure 300 illustrates a sketch from the 3D computer model that was used to help solve this detail. The plywood boxbeams used as framing to the Bi-Fold Doors are filled with EcoInsulation to improve the performance at what what otherwise be a thermal weakpoint [Figure 301].

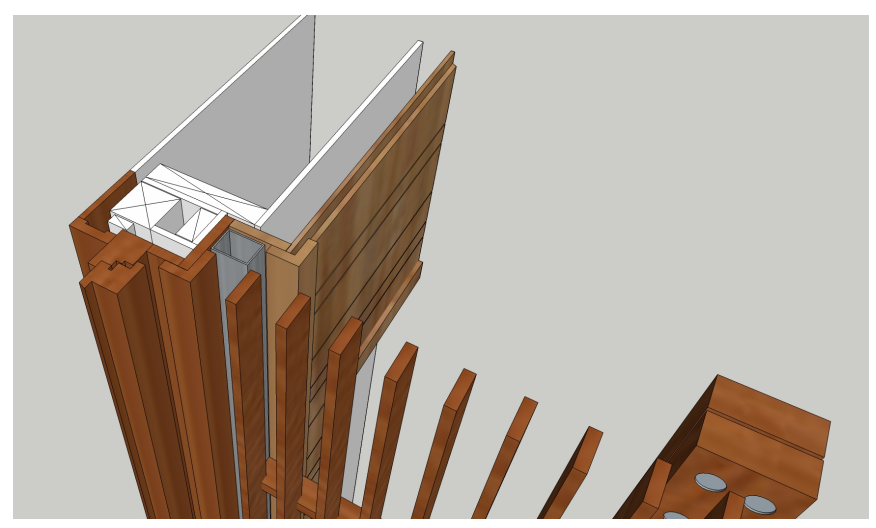

Figure 300: 3D Sketch Showing Inter-Module Junction

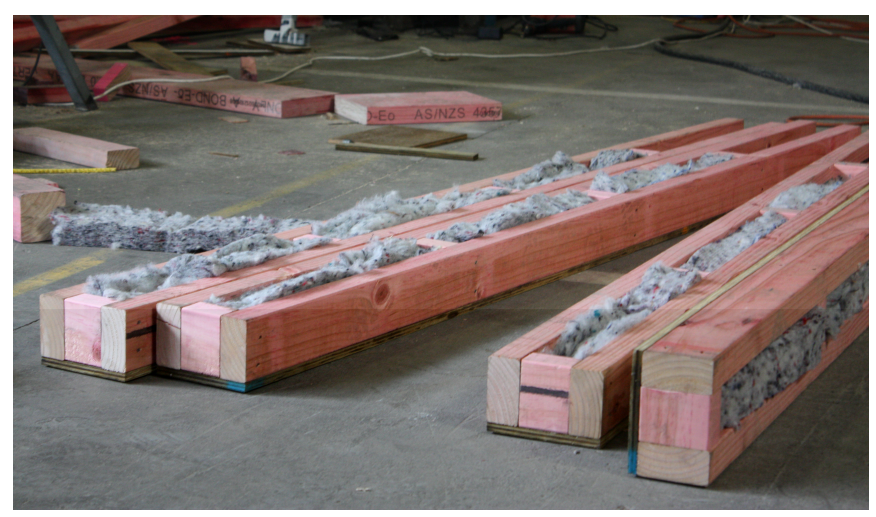

Figure 301: Module Three - Insulated Box-Beams
It was quickly realised that a period of 'preassembly' for Module Three would be required in order to complete assembly within the 7 days at the competition. This entailed the assembling of the major elements into a complete module that could be trucked to site and dropped in place, using the same method as with the other house modules [Figure 302].

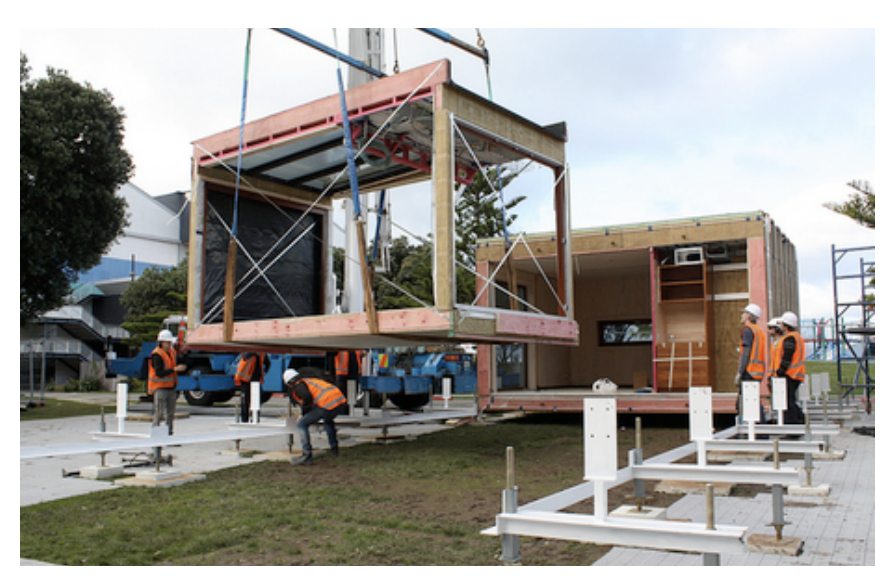

Figure 302: Module Three - Crane-Lifted Into Place

Once preassembly was complete module three is transported to site and assembled in exactly the same way as the other house modules. The locating dowels between module three and the adjacent modules were again left uninstalled both during construction and at the assembly on Frank Kitts Park. These dowels were essential for the structural support of module three against lateral loads. Without them module three had to rely on the weak corner connections and friction between modules to prevent it from collapsing - a significant risk given the weight of the triple glazed skylights. Although the dowels could not be utilised to realign the modules, other markings could be and the flexibility of the module enabled it to be 'racked' into place. Tek screws were then specified by the engineer to structurally hold the module in place against any lateral forces. 


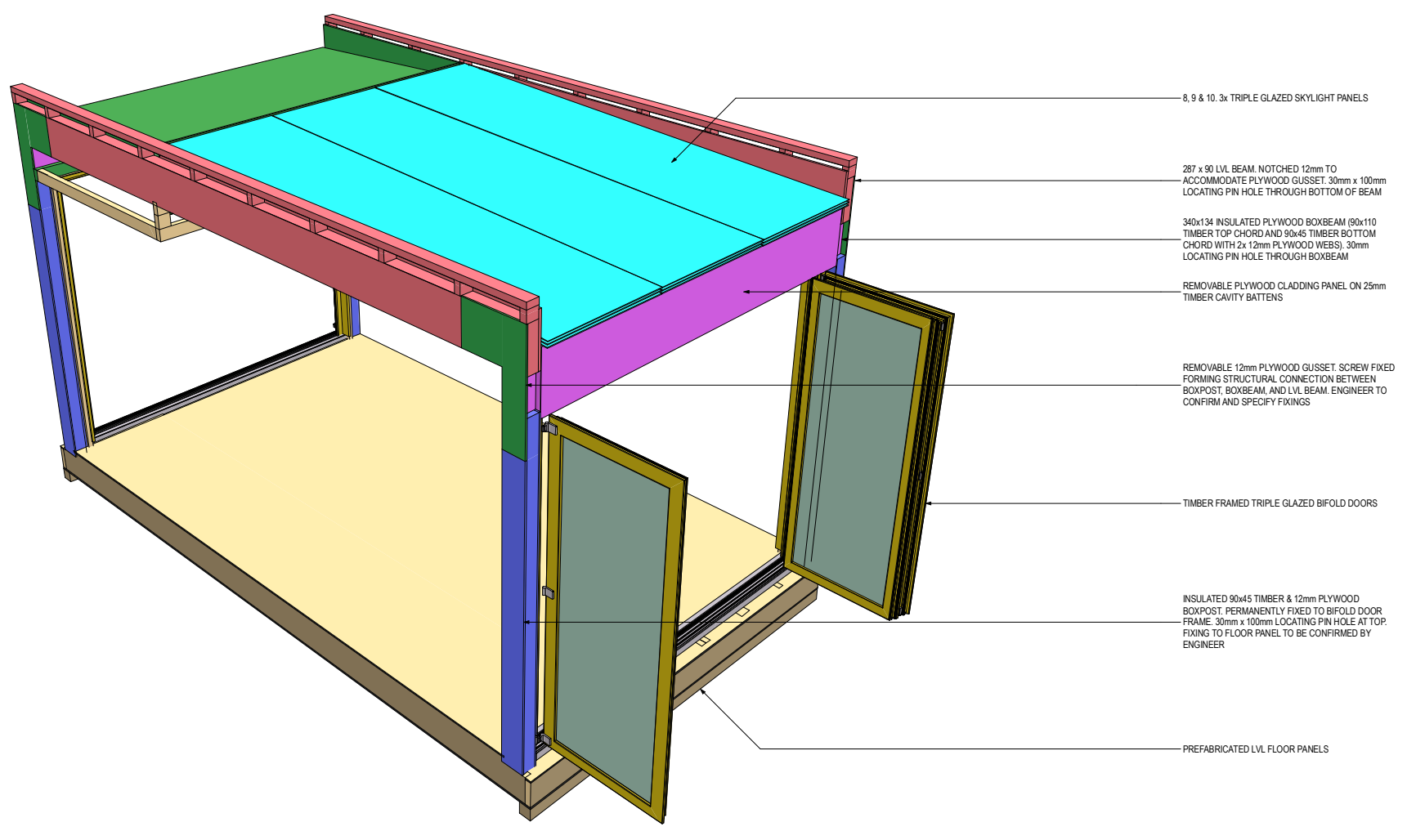

Figure 303: Module Three Main Elements - Assembled 


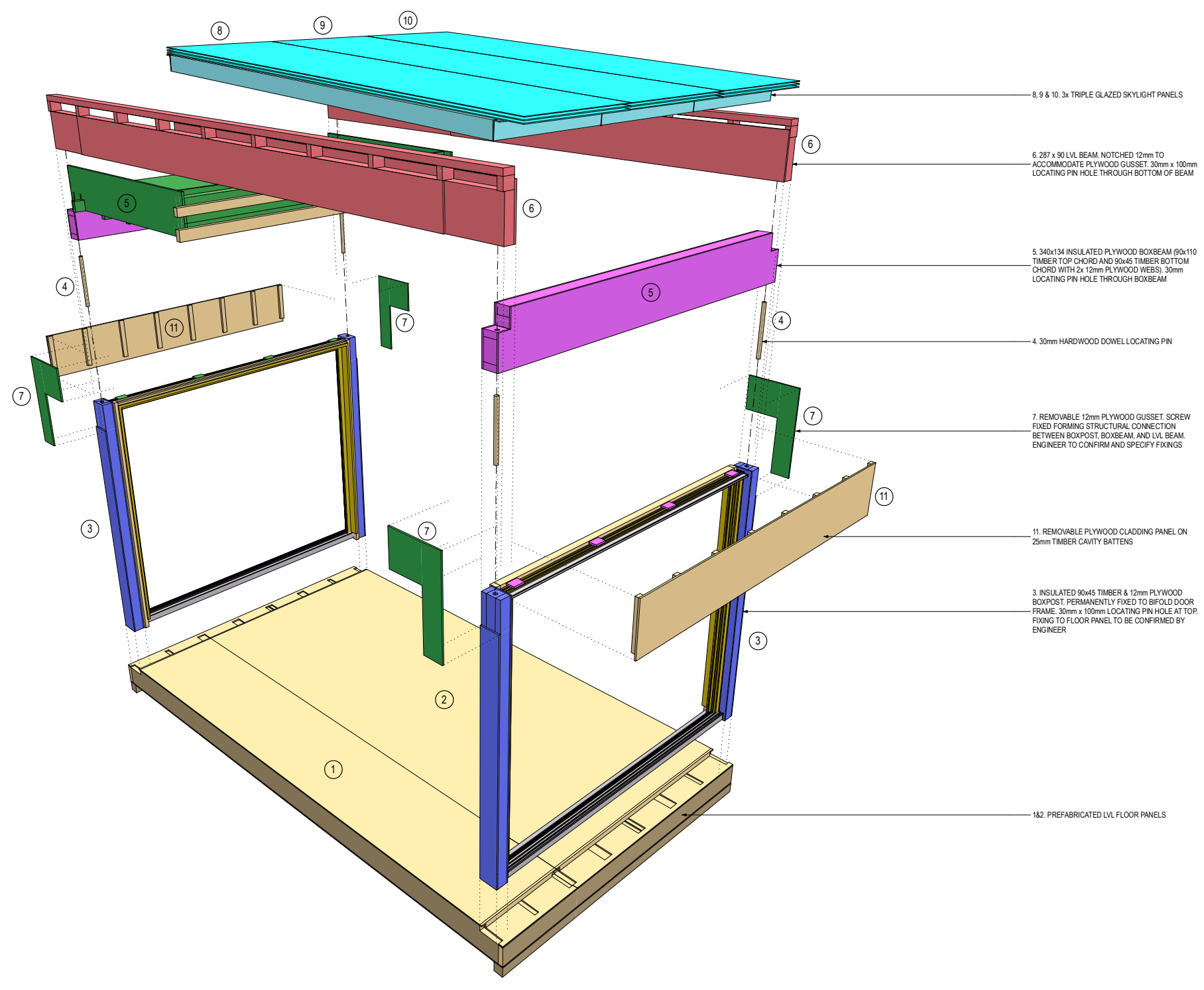

Figure 304: Module Three Main Elements - Exploded 3D 


\subsection{MODULE THREE - AS BUILT}

The drawings on the following pages have been included as a summary of the as-built details for the skylight and associated structures and finishes. 

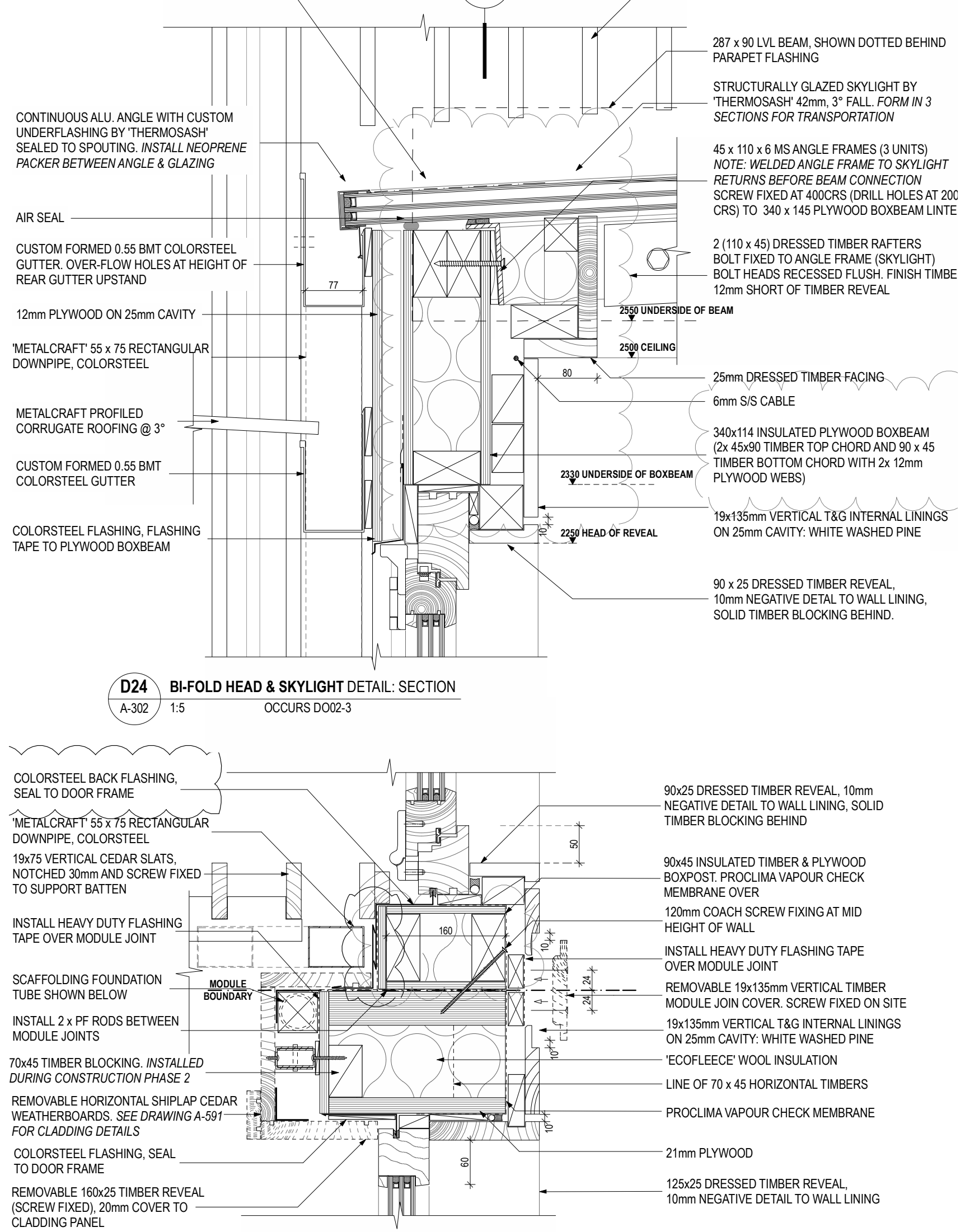

\begin{tabular}{|l|l}
\hline D25 BI-FOLD \& WINDOW JAMB DETAIL: PLAN \\
\hline A-111 & $1: 5 \quad$ OCCURS DO02-3
\end{tabular}

Figure 305: Construction Details Showing Bi-Fold Head \& Skylight Junction and Bi-Fold Jamb and Inter-Module Join 


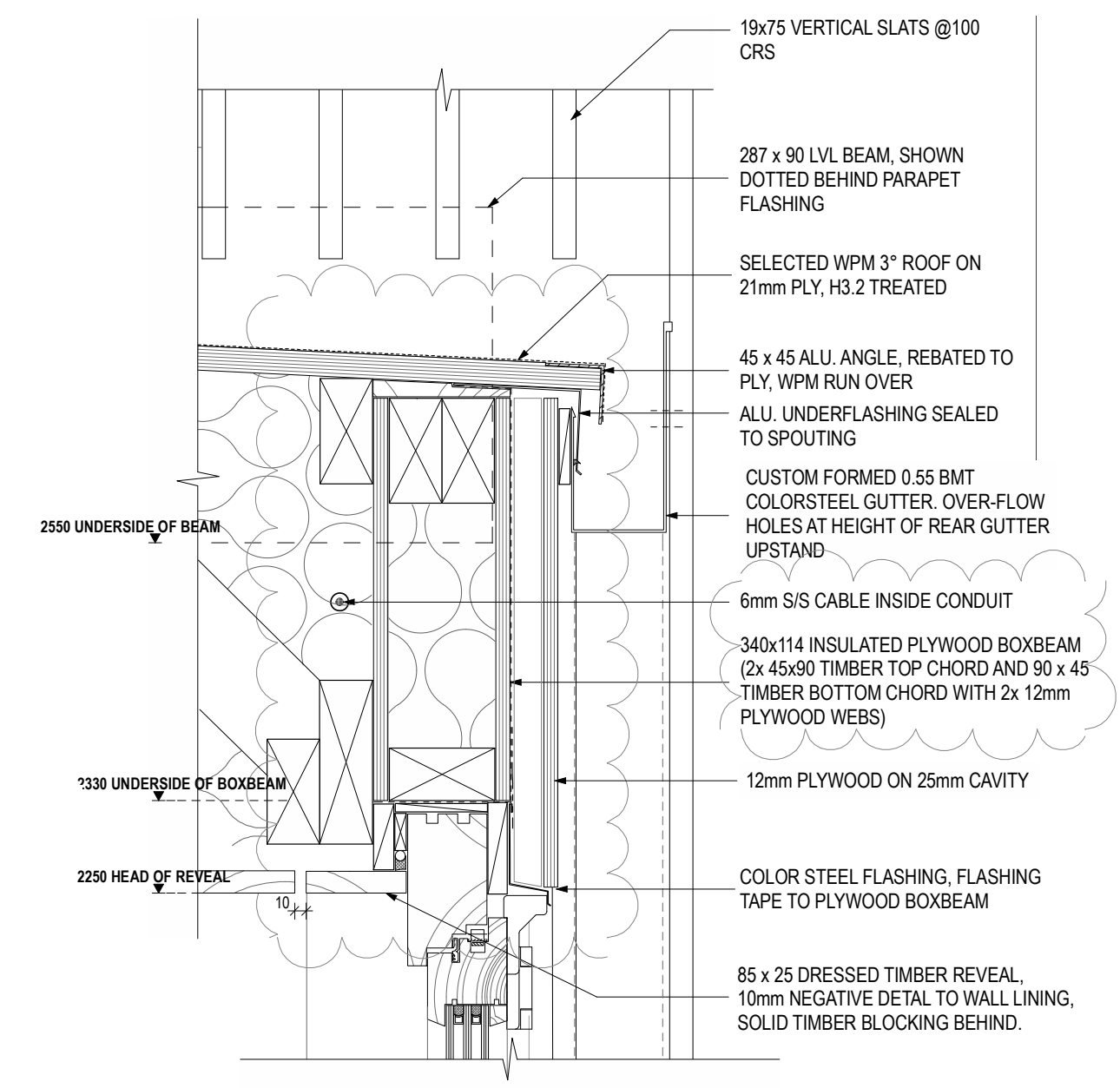

D29 BI-FOLD HEAD DETAIL: SECTION

A-302 $1: 5 \quad$ OCCURS DO01-3

$36 \mathrm{~mm}$ TRIPLE GLAZED BI-FOLDS, TIMBER FRAMES LOW PROFILE (ACCESSIBLE) ALU. BI-FOLD SILL ALL SUPPLIED BY 'ECO WINDOWS'

TRIM 25mm FLANGE OFF BI-FOLD SILL (SHOWN DOTTED) TO ACHIEVE FLUSH PROFILEAS SHOWN

$3 \mathrm{~m} \times 1.3 \mathrm{~m}$ PANELIZED $20 \times 140 \mathrm{~mm}$ TIMBER FLOORING ON PLYWOOD STRIP SPACERS (PLY $=200 \mathrm{~mm}$ WIDE @400 CRS) PLY THICKNESS TO BE DETERMINED BASED ON CONCRETE FINISHED LEVEL

PERMANENT 18mm PLYWOOD FIXED TO LVL FLOOR JOISTS (UNTREATED)

'METALCRAFT' $55 \times 75$ RECTANGULAR DOWNPIPE, COLORSTEEL. WELDED DOG-LEG SECTION TO STEP BETWEEN FLOOR JOISTS $\mathrm{N}_{240 \mathrm{~N}}$ $240 \mathrm{~mm}$ 'ECOFLEECE' WOOL INSULATION 240X45 LVL FLOOR JOISTS @500 MAX CRS NOTCHED 50x185mm AT DOOR SILL. NOTCHED SURFACE TO BE PAINTED WITH HOLDFAST METALEX CONCENTRATED PRESERVATIVE - GREEN $12 \mathrm{~mm}$ PLYWOOD H3.2 TREATED \& PAINTED PAST LINE OF FLOOR AND DECK STRUCTURE

PANELIZED $25 \times 140 \mathrm{~mm}$ DECKING TIMBERS. NB: DECK SITS $10 \mathrm{~mm}$ LOWER THAN INTERNAL FINISHED FLOOR LEVEL

140x45 TIMBER TRIMMER, FIXED THROUGH $20 \mathrm{~mm}$ PACKER OVER DOWNSTAND OF SILL FLASHING. SECONDARY PACKING AT TOP TO FIX DECKING

12mm H3.2 ACQ PLYWOOD

COLORSTEEL SILL FLASHING BELOW BI-FOLD FRAME, $5^{\circ}$. ENCASE TOP EDGE OF FLASHING WITH NEOPRENE SLEEVETO REDUCE THERMAL BRIDGING

190x45 LVL TRIMMING JOIST. RIPPED SURFACE TO BE

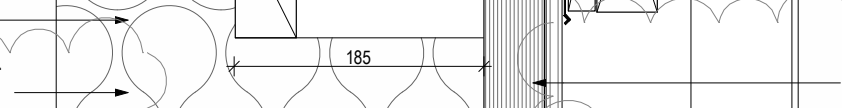
PAINTED WITH HOLDFAST METALEX CONCENTRATED PRESERVATIVE - GREEN A-302 1:5 OCCURS D001-3 (SAME CONSTRUCTION AS DOO02-3)

Figure 306: Construction Details Showing Bi-Fold Head \& Roof Junction and Bi-Fold Door Sill 


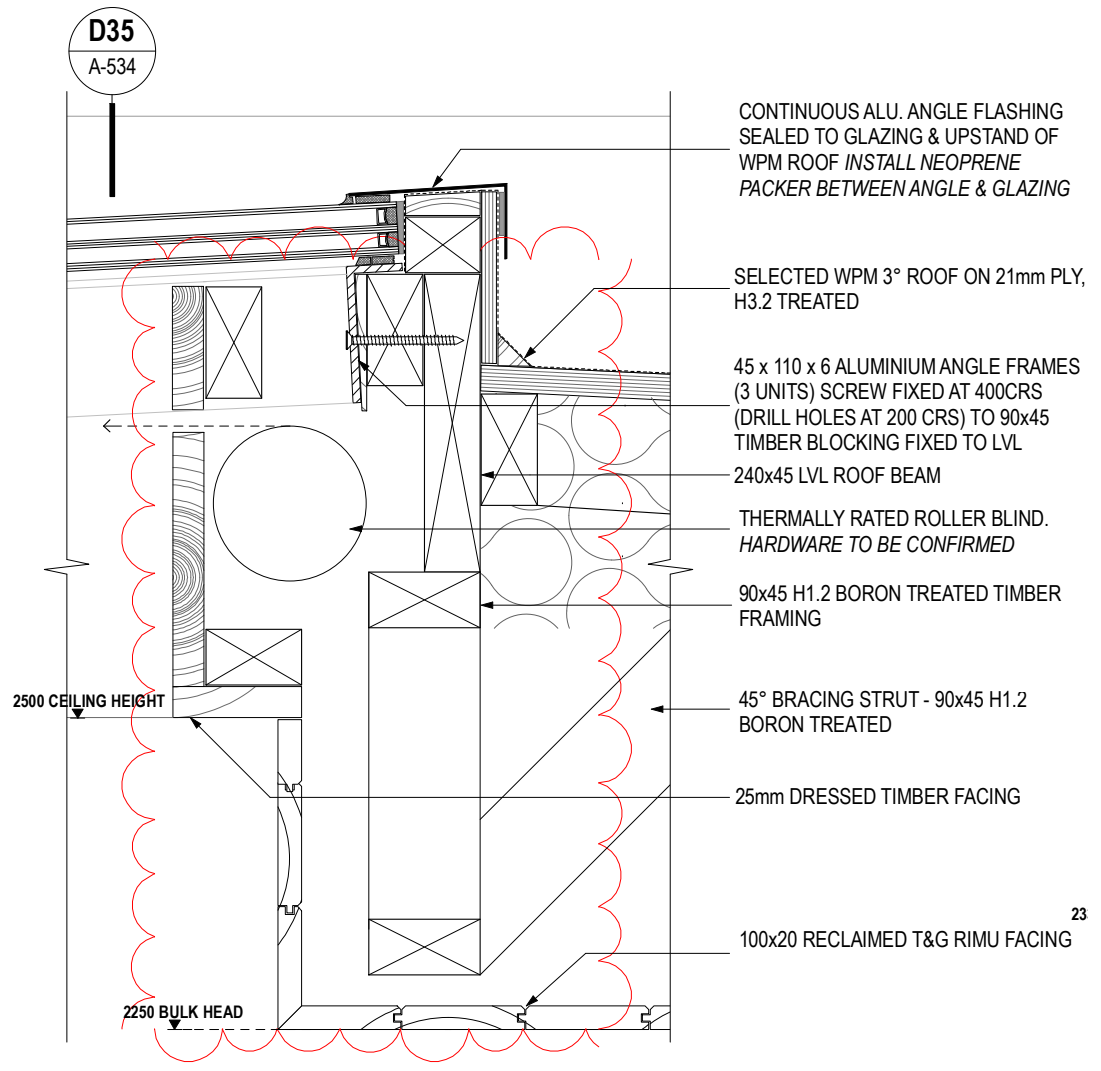

Figure 307: Construction Detail Showing Skylight Apex Detail and Roller Blind

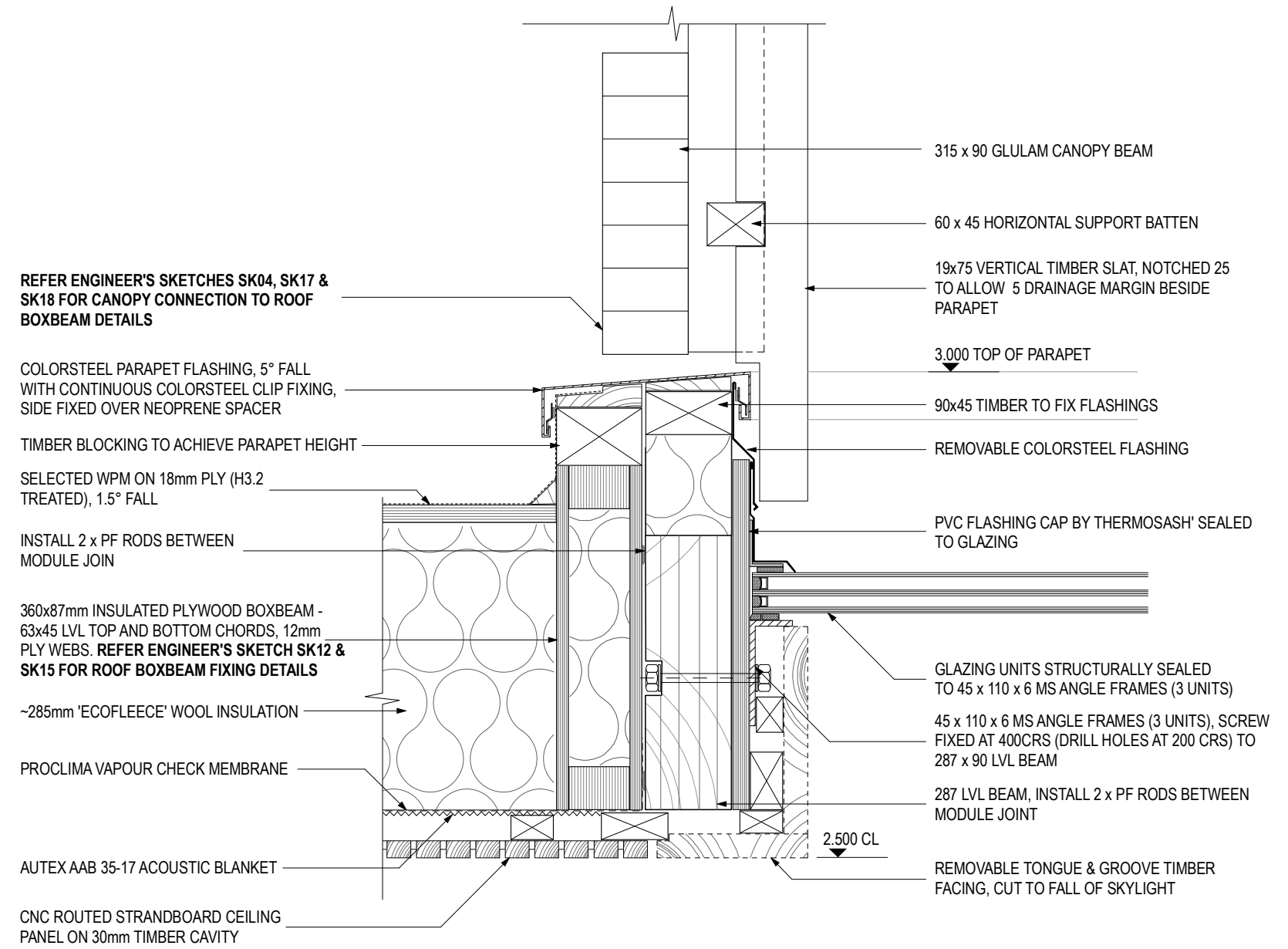

Figure 308: Construction Detail Showing Skylight Jamb and Inter-Module Join 
Considerable attention was given to all of the junction details and materials used in Module Three. The concept called for an architectural language that would separate M3 from the rest of the house and express it as an extension of the outdoors. These considerations, along with the technical requirements of the triple-glazed skylight, resulted in the as-built solution, presented here in a series of photographs.

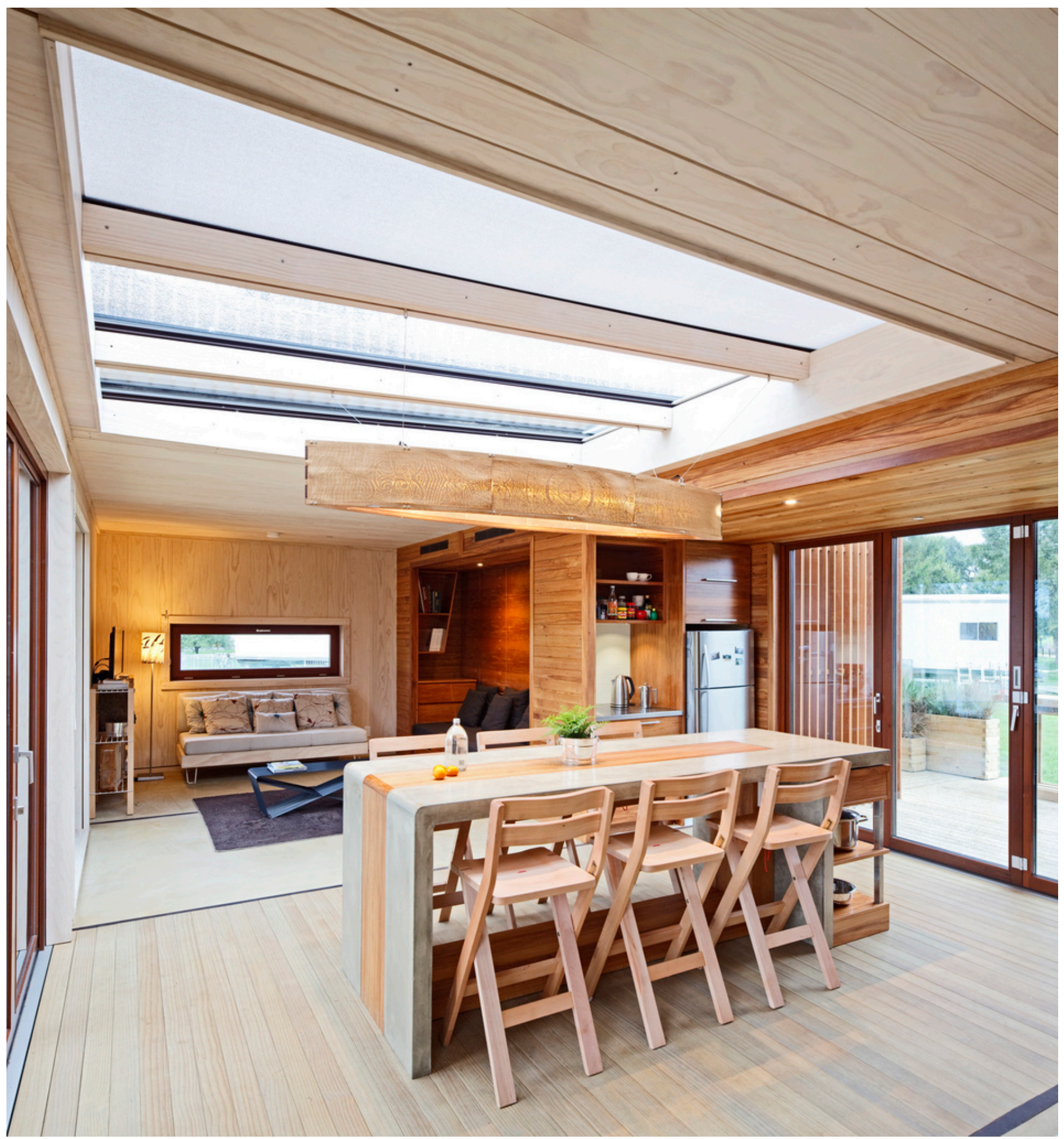

Figure 309: Interior Photo of Module Three From Study, One Roller-Blind Closed (Credit: Paul Hillier) 

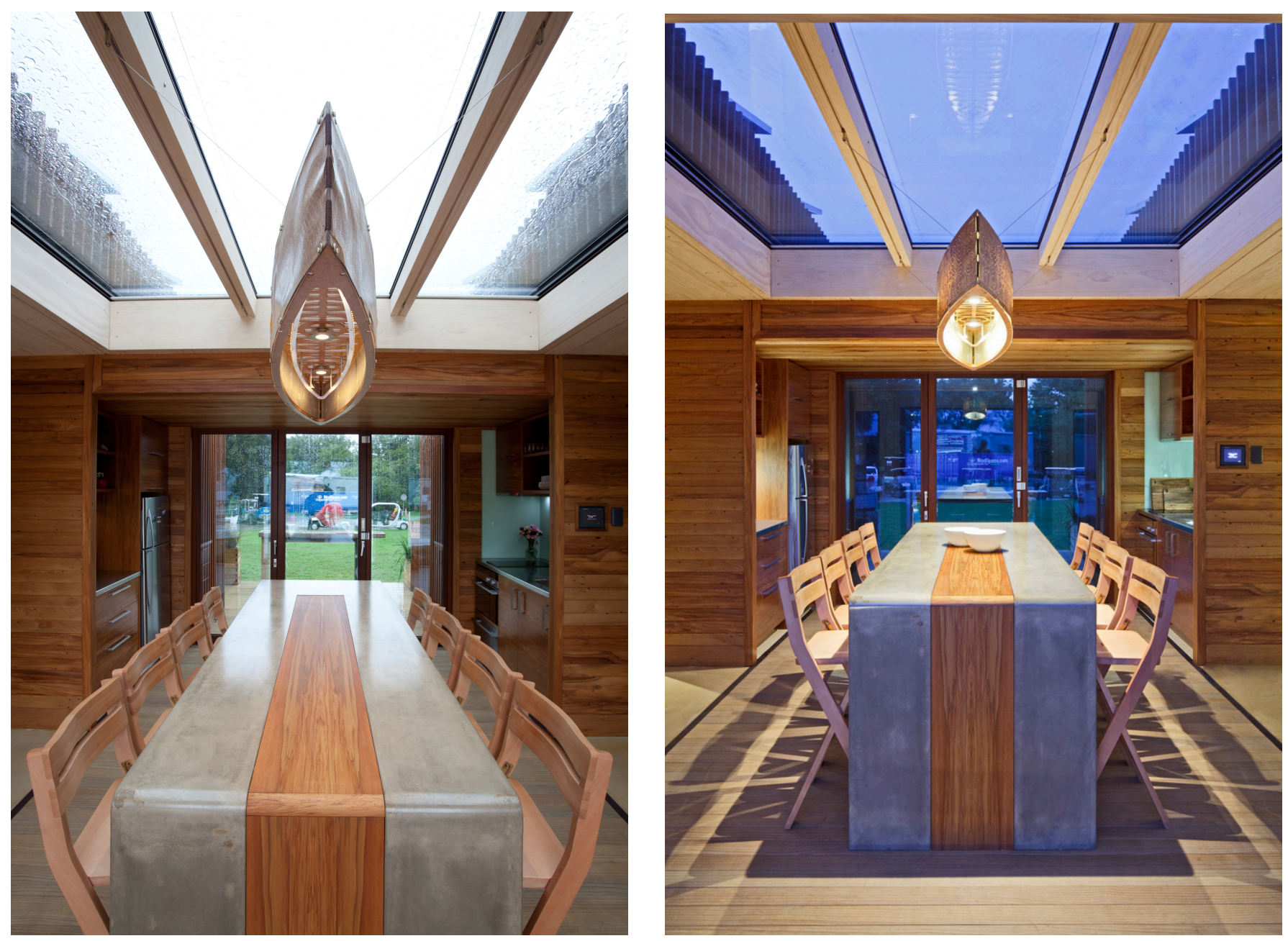

Figure 310: Interior Photos Showing Skylight During Wet Weather (left) and at Dusk (right) (Credit: Stefano Paltera/U.S. Department of Energy Solar Decathlon)

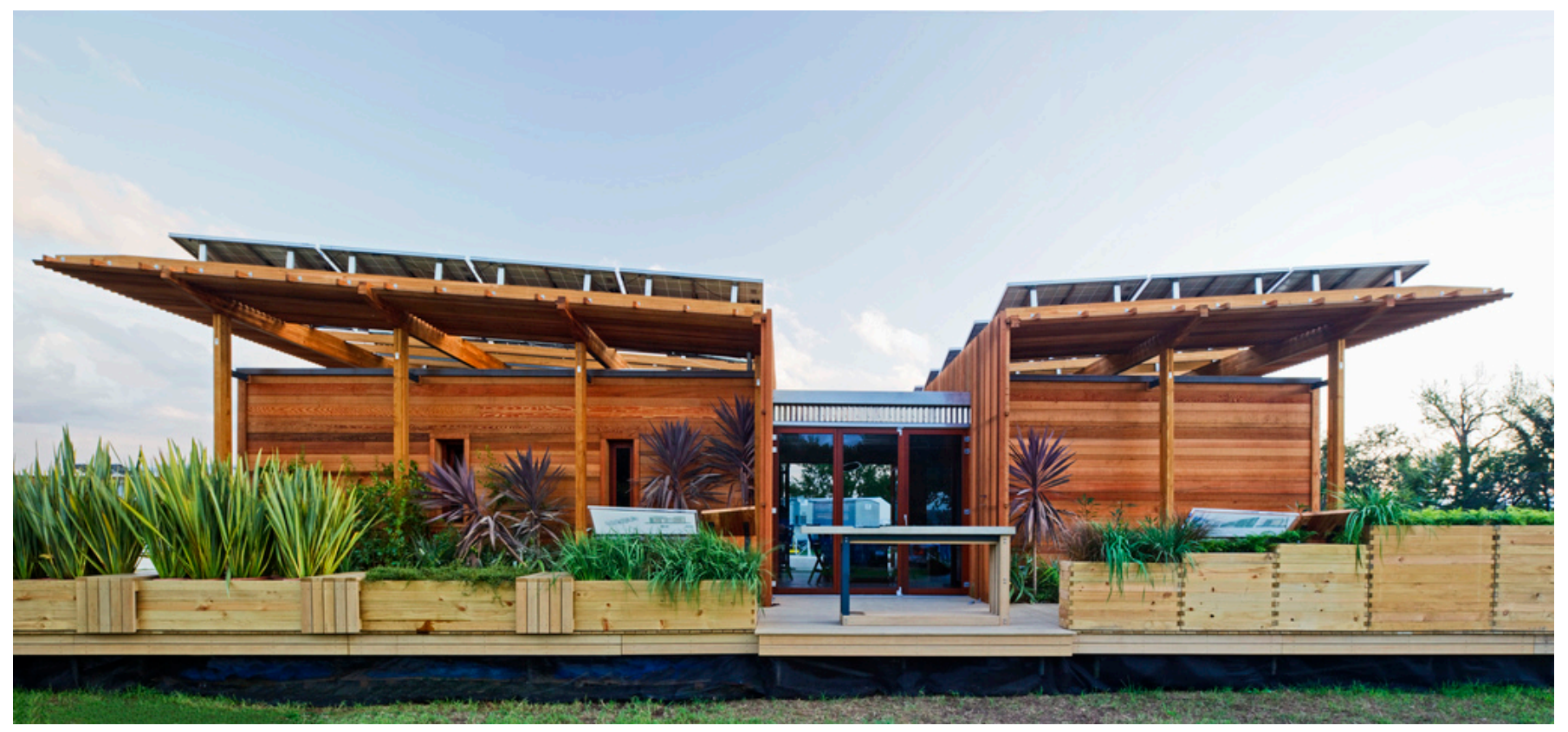

Figure 311: Exterior Photo Showing the Aluminium Corrugate Cladding Gutter of Module Three 


\section{CANOPY CONSTRUCTION}

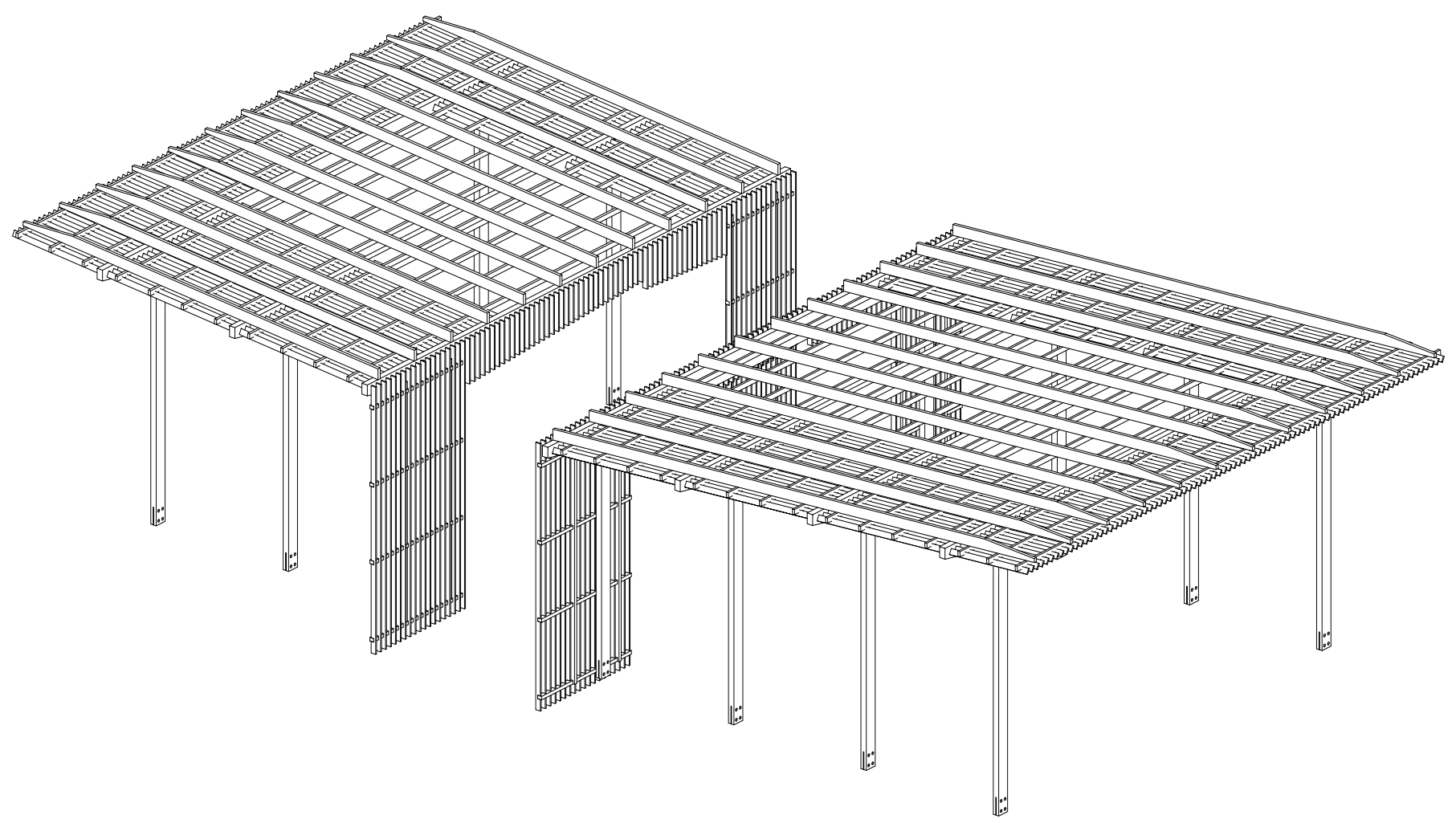

Figure 312: Construction Drawing Showing Assembled Canopy Timber Elements 
The design of the canopy was critical for achieving the expression of lightness and openness that was so central to the First Light concept. As the dominant exterior feature, it would make the first impression demanding the highest quality of materials, proportion and detailing. The canopy's primary functional purpose was for the support of the solar panels and to shade the large southern glazing in summer. The separation of the solar panels from the roof, or any other part of the envelope, greatly advantages the assembly process and the extent and complexity of weatherproofing. Conceptually the canopy was intended to focus the form of the house on the central space, distinguishing it as an expression of the outdoors.

The initial design as presented in the conceptual design submision proposed the following structure; $150 \times 120 \mathrm{~mm}$ timber columns, $250 \times 120 \mathrm{~mm}$ tapered timber primary flitch beams, $150 \times 50 \mathrm{~mm}$ tapered timber rafters, and $50 \times 22 \mathrm{~mm}$ timber slats fixed with steel purlins [Figure 313, Figure 314 \& Figure 315]. The solar panels were supported with steel brackets mounted to the timber rafters [Figure 316]. Visible steel tension cross-bracing was used in four of the column bays to provide lateral bracing. All fixings were to be bolted for ease of assembly/disassembly and for the packaging of individual components into standard 40' $\mathrm{Hi}$ Cube containers. Although little research had been undertaken into the use of materials, structural spans, shading efficiencies, and fixing details; this arrangement achieved the desired form and expression of elements that would be preserved throughout the detailed design phase.

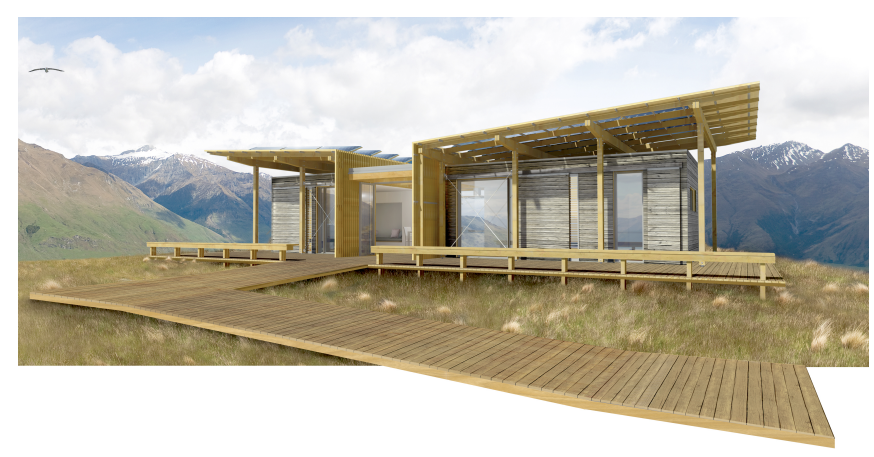

Figure 313: Conceptual Design Submission - Rendered Exterior Perspective

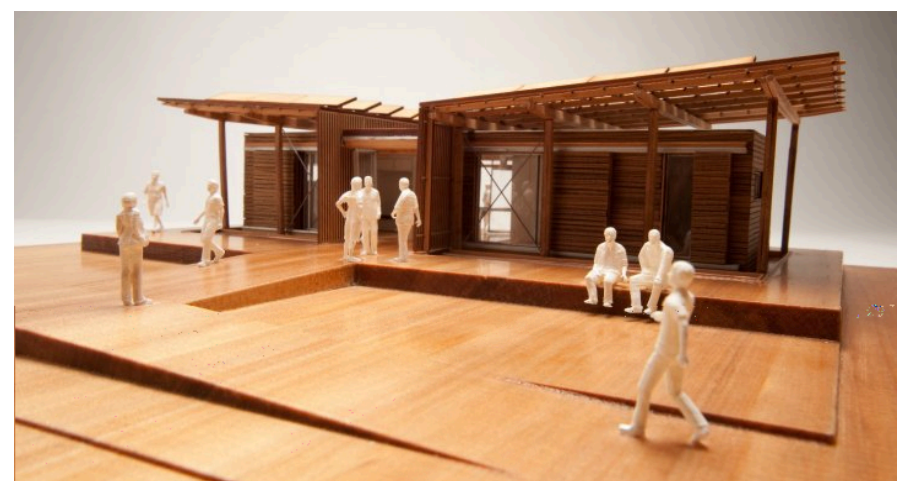

Figure 314: Conceptual Design Submission - 1:50 Scale Model

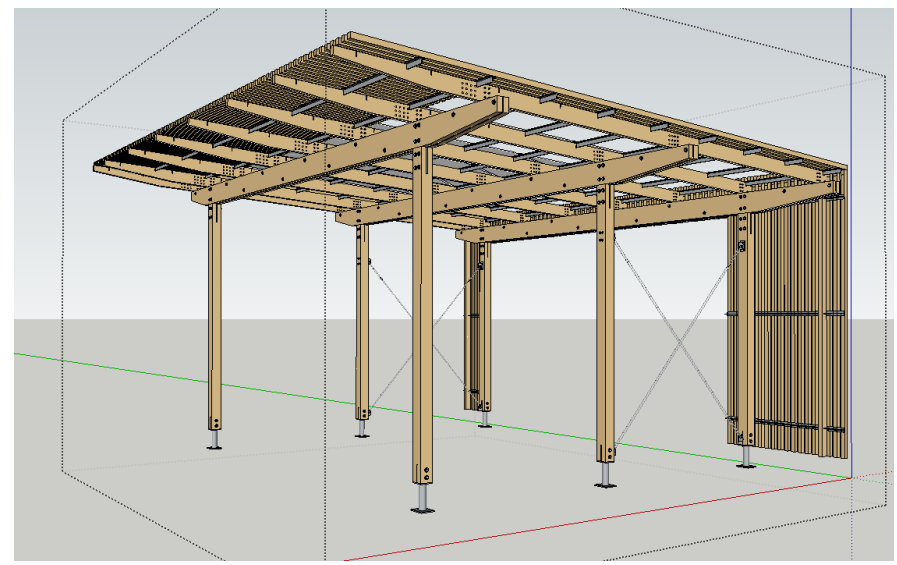

Figure 315: Conceptual Design - 3D Sketchup Model Showing Canopy

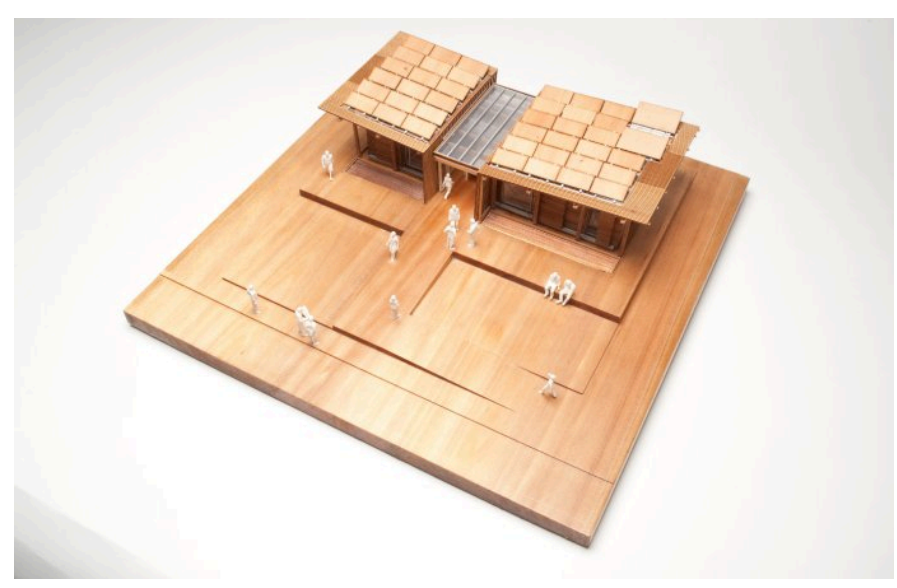

Figure 316: Conceptual Design Submission - 1:50 Scale Model Showing Solar Panel Arrangement

As developed design progressed, an understanding of the structural depth of the canopy framing elements, along with the overall size of the house, was gained. It was of upmost importance that the canopy appear to be lightweight and almost temporary so as not to bear down on the house or make it look top-heavy. Several design iterations were explored in an attempt to refine the 
structural composition of the canopy [Figure $317 \&$ Figure 318]. An option of reducing the angle of the canopy to horizontal was also explored [Figure 319]. Although this might simplify things during construction and assembly, it was felt that the angled gesture towards the central space was important for the concept. It was also determined that the flipping of the slats to the underside of the timber rafters would have a great impact on slimming the canopy profile.

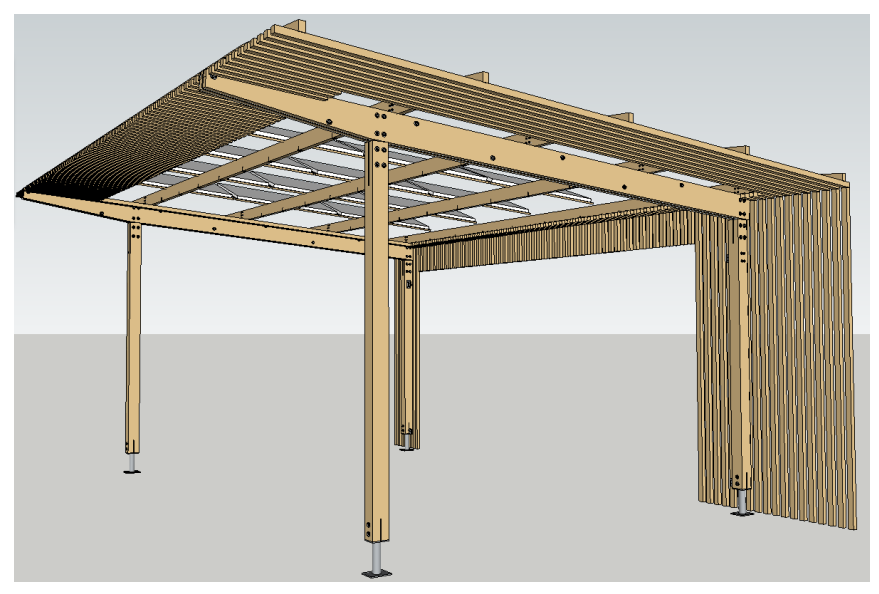

Figure 317: Canopy Structural Iteration - 3D Model Showing Longitudinal Primary Beams

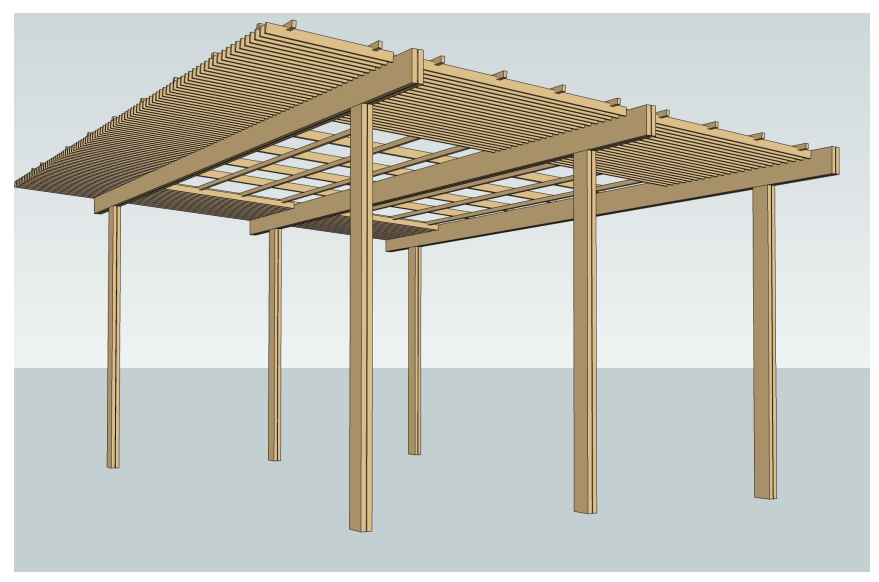

Figure 318: Canopy Structural Iteration - 3D Model Showing Slats on Underside of Rafters

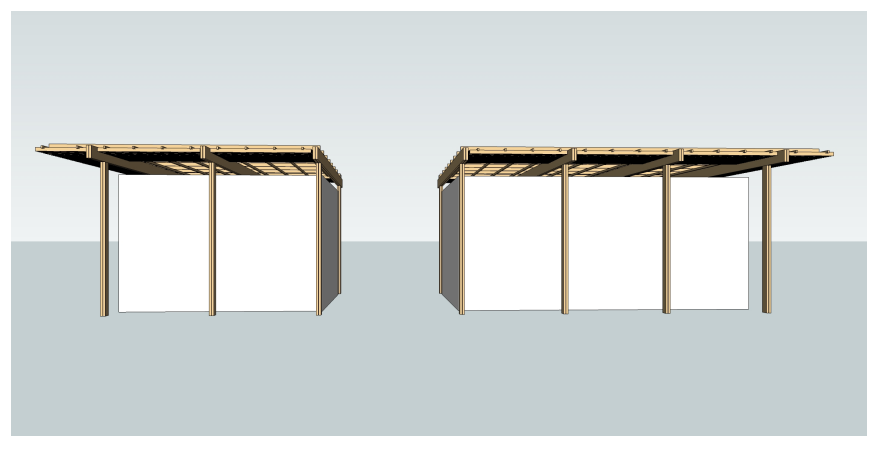

Figure 319: Canopy Structural Iteration - 3D Model Showing Flat Canopy

With a confirmed general structural arrangement, the canopy underwent a long and iterative process of development. For clarity, the final as-built design will be presented here with explanation given as to the main decisions that were made. It was well understood that a significant cost was being invested in the structural seperation of the canopy from the rest of the house. To make the most of this bold design move, the canopy would need to perform its main functions as efficiently and economically as possible. 


\subsection{SLAT PANELS}

The first step was to optimise the detailing of the slat panels in order to provide the degree of shading as specified by the building performance team. Again, due to the significant impact of overheating, the computer simulations suggested that a complete shading of the south windows would be required at the competition (Jagersma, 2012). This was an unrealistic objective and a compromise between aesthetics, functionality and performance would have to be reached. The overhang of the canopy to the south was increased to $1.8 \mathrm{~m}$ while the north overhang remained at $1.3 \mathrm{~m} .1 .8 \mathrm{~m}$ created an adequate overhang to provide full shading of the south windows in New Zealand during summer. During the competition period however it would only shade approx $70 \%$ of the windows.

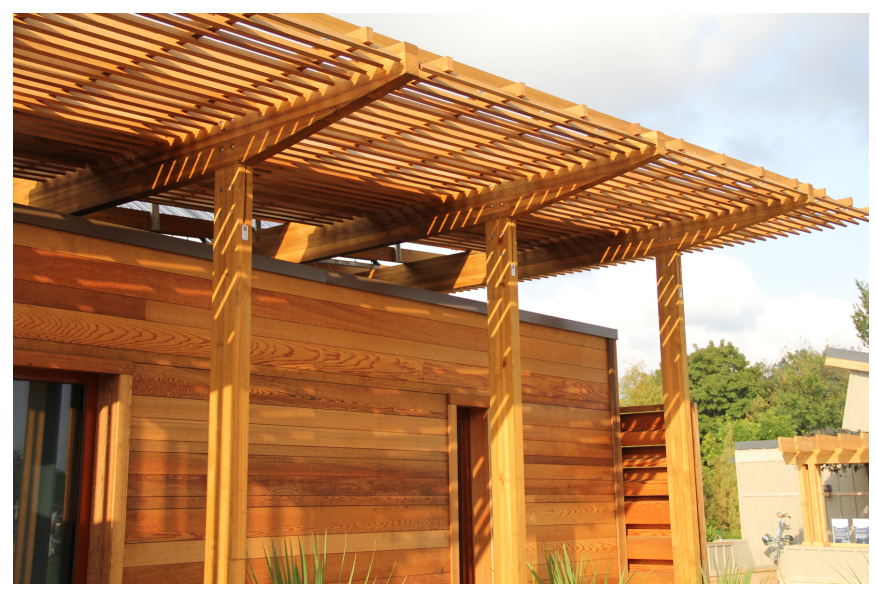

Figure 320: SD Photo Showing the Completed Canopy

The next step was to determine the angle at which the slats would need to be in order to provide the greatest amount of shade per timber quantity. At this stage Herman Pacific had confirmed their sponsorship for both the cladding and the cedar slats and support battens. Cedar was again elected for use in this situation due to its durability, light weight, and for the continuity that it would have with the cladding. Herman Pacific had recommended the use of $65 \times 19 \mathrm{~mm}$ timber for the slats. This dimension would be the most efficient and economic use of material considering the overall quantities that were required. A spacing between slat centres of no greater than $100 \mathrm{~mm}$ was felt to give the best visual aesthetic. The following results for slat angle vs \% shaded were obtained from a Sketchup model at the peak of summer in Wellington, New Zealand [Figure $321 \&$ Table 8].

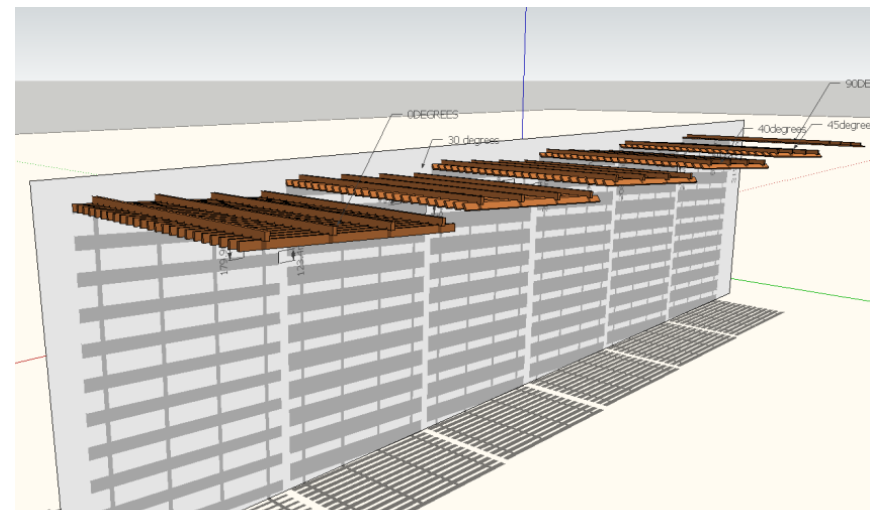

Figure 321: Canopy Slat Angle Tests at 100mm Centres Sketchup Model for Summer in Wellington, NZ

\begin{tabular}{|c|c|c|c|}
\hline ANGLE & SHADED & UNSHADED & \% SHADED \\
\hline $\mathbf{0}^{\circ}$ & 123 & 180 & 40.7 \\
$\mathbf{3 0}^{\circ}$ & 196 & 108 & 64.6 \\
$\mathbf{3 5}^{\circ}$ & 202 & 101 & 66.7 \\
$\mathbf{4 0}^{\circ}$ & 208 & 95 & 68.7 \\
$\mathbf{4 5}^{\circ}$ & 213 & 91 & 70.1 \\
$\mathbf{9 0}^{\circ}$ & 215 & 88 & 71.0 \\
\hline
\end{tabular}

Table 8: Canopy Slat Angle Tests at 100mm Centres - Summer in Wellington, $N Z$

It was initially felt that the $30^{\circ}$ slat angle was the most aesthetically desireable. However increasing the angle to $45^{\circ}$ gave $5.5 \%$ more shading and consequeuntly also provided the greatest degree of transparancy to the canopy when viewed from the main deck. An angle of $45^{\circ}$ would also make for a more simple fixing detail between the slat and the cedar batten [Figure 322]. Several fixing techniques were investigated through prototype models and in discussion with potential fabricators. A single fixing through the face of the cedar slat into a notched section of the batten proved to give a strong and visibly simple solution [Figure 323]. A minimum batten depth of $45 \mathrm{~mm}$ was specified by the engineer so as to span the distance between the timber rafters. The battens were also cantilevered by $280 \mathrm{~mm}$, further refining the visual edge of the canopy. An overall batten dimension of $65 \times 39 \mathrm{~mm}$ was required to enable a sufficient notch depth for fixing the slat into. 


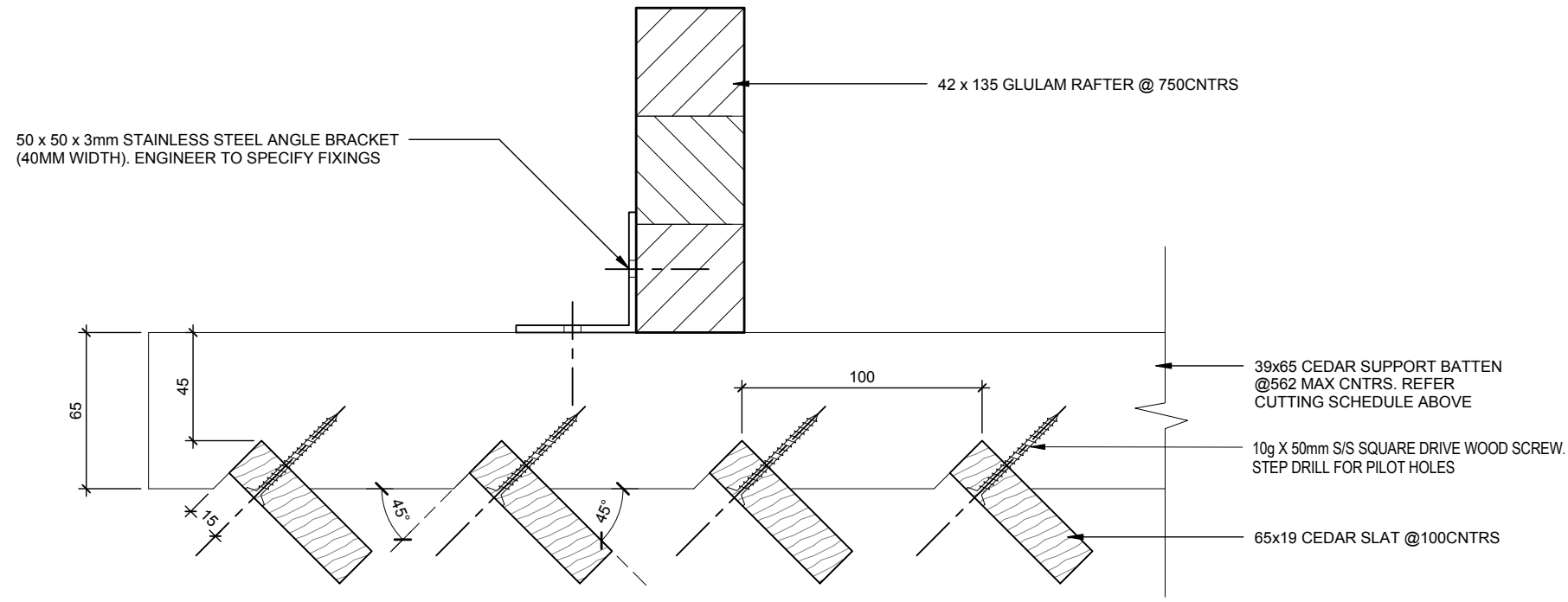

Figure 322: Cedar Slat Fixing Detail

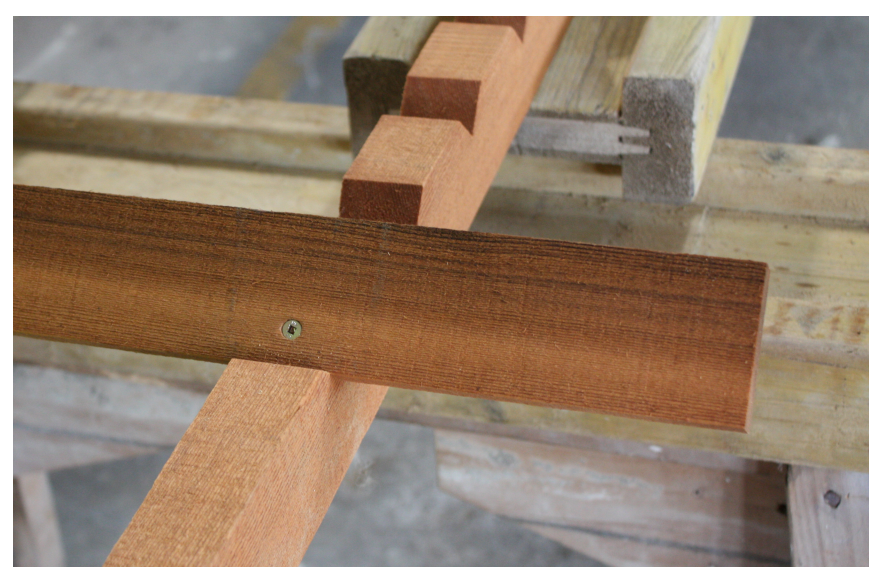

Figure 323: Construction Photo Showing Cedar Slat Fixing

It was critical that the cedar battens were accurately and consistantly notched in order to achieve the desired precision of the overal slat panel. To this end, the cedar battens were cut and notched off-site in a joinery workshop. A dedicated cutting schedule was prepared for the joiners illustrating batten types, and notes as to which lengths of supplied cedar were to be used [Figure 325]. This ensured the accurate notching of the battens while also achieving an economic use of material [Figure 324].

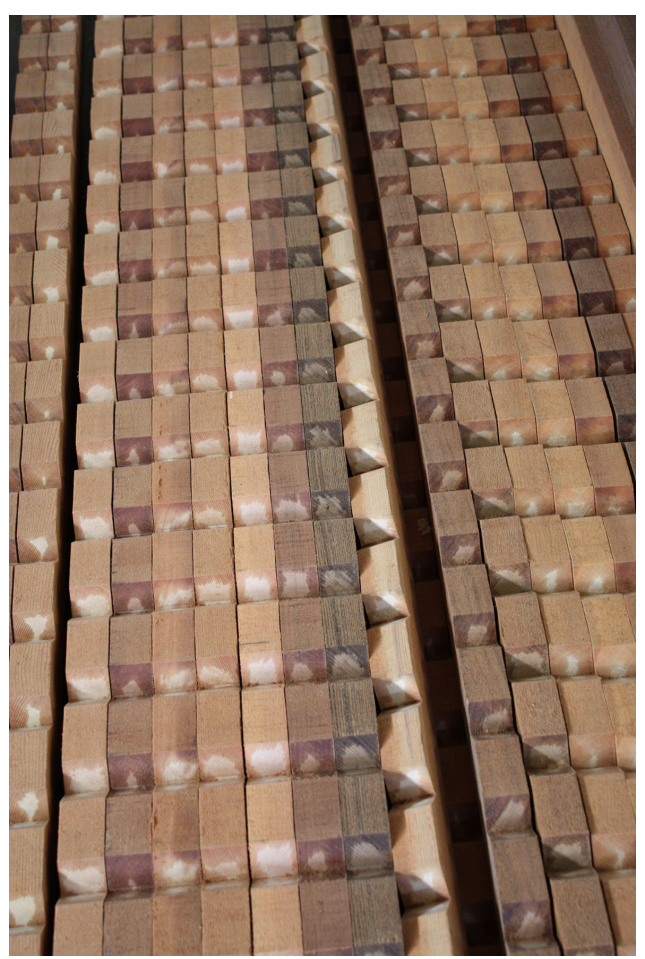

Figure 324: Construction Photo Showing Notched Cedar Battens 


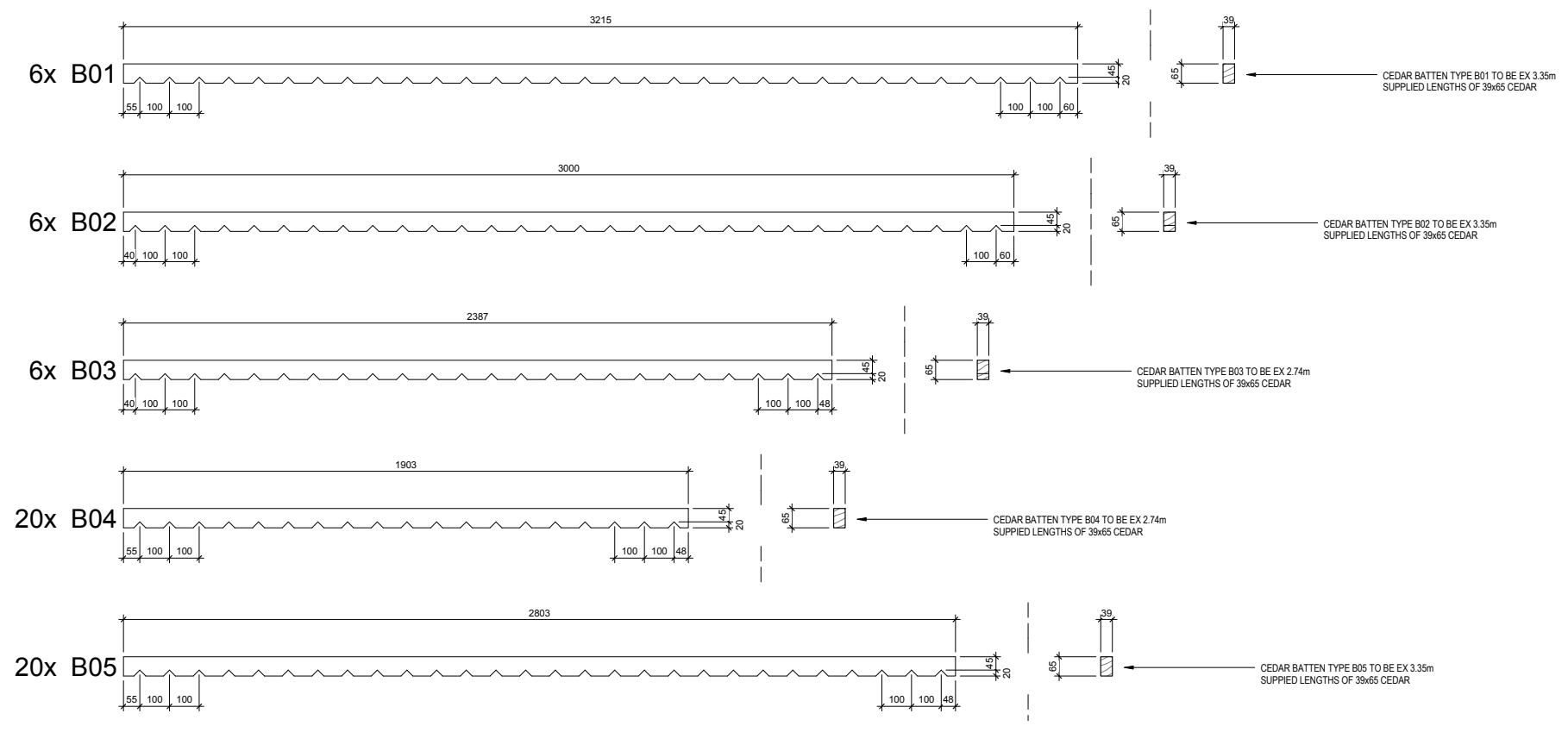

Figure 325: Cutting Schedule for Cedar Slat Battens
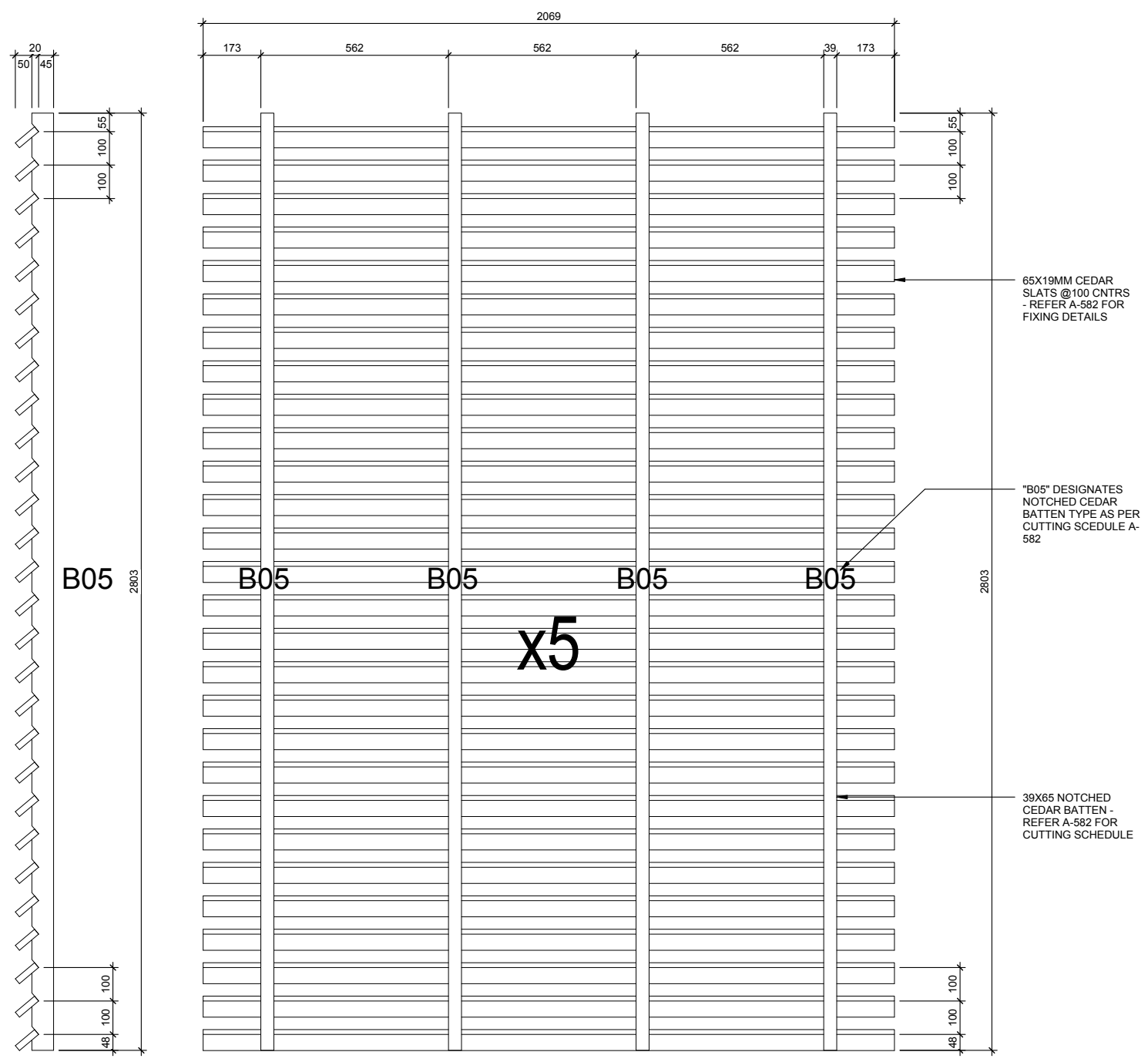

Figure 326: Fabrication Drawing Showing Cedar Slat Panel No. 5 
The slats were compartmentalised into managable panels for ease of assembly and packaging [Figure 326, Figure 327 \& Figure 328]. An assembly drawing outlining each slat panel type and location on the canopy was used to coordinate their assembly on site [Figure 329]. The slar panels are fixed to the underside of the glulam rafters with $50 \times 50 \times 3 \mathrm{~mm}$ stainless steel angle brackets and tek-screws [Figure 330]. After construction each panel was given a unique ID to ensure the accurate repeated assembly both at Frank Kitts Park and at the Solar Decathlon.

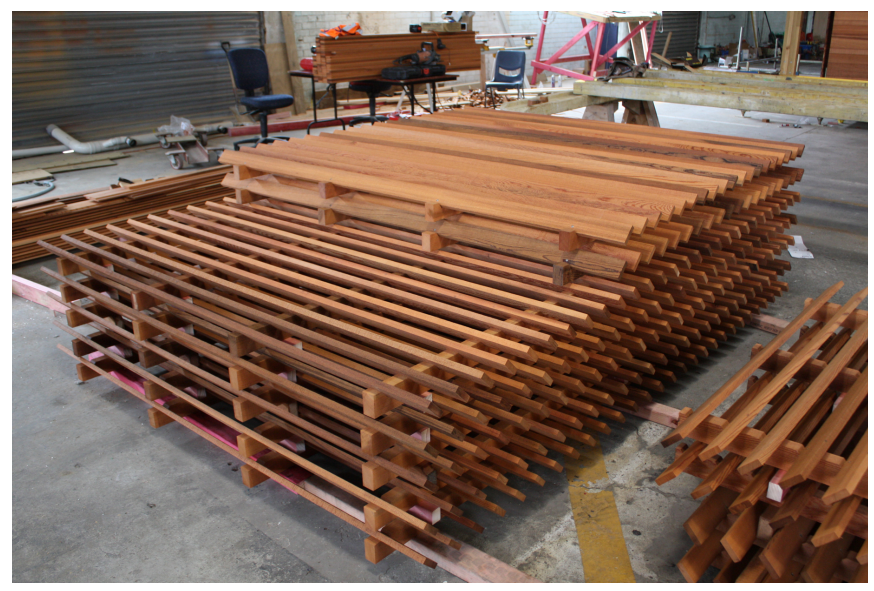

Figure 327: Construction Photo Showing Cedar Slat Panels

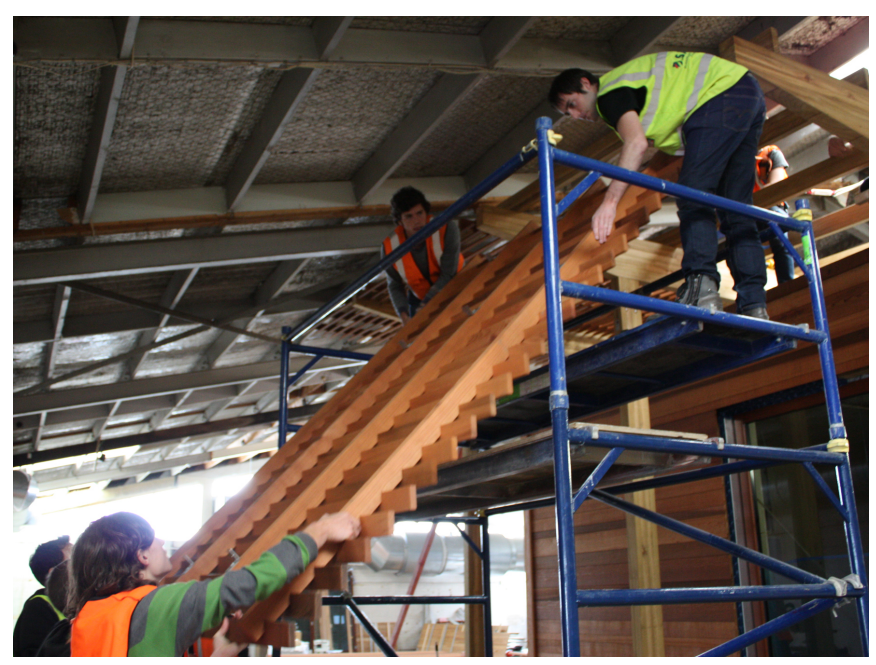

Figure 328: Construction Photo Showing the Installation of a Cedar Slat Panel
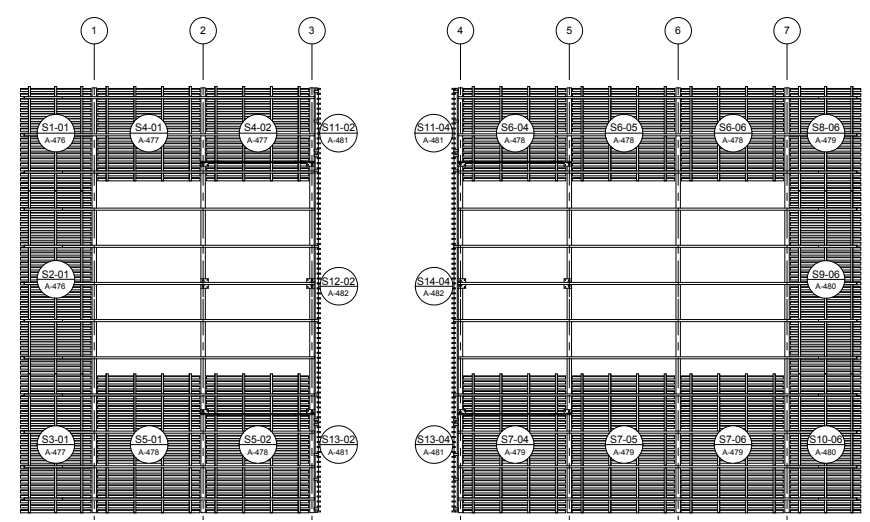

Figure 329: Assembly Drawing - Slat Panel Locations

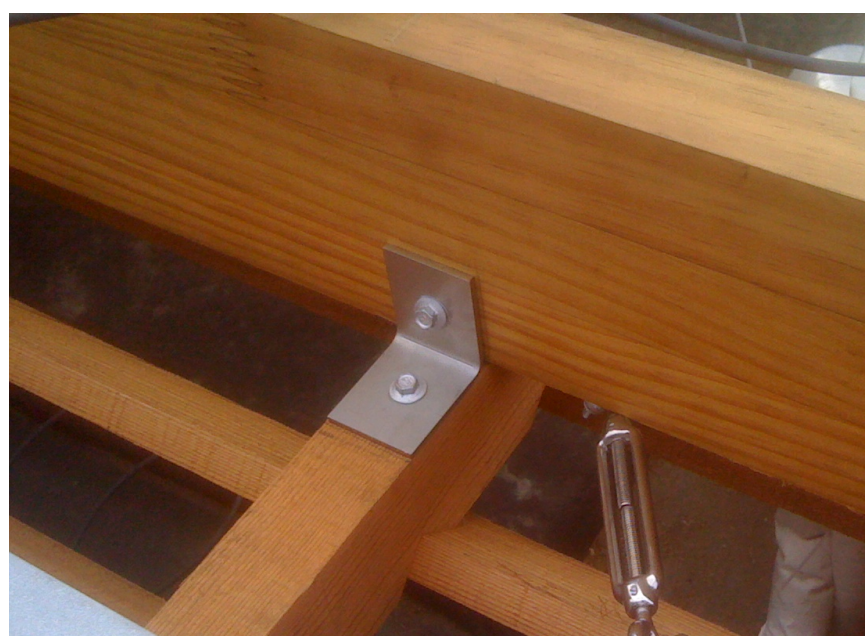

Figure 330: FKP Assembly Photo Showing Cedar Slat Panel Fixing Bracket

The vertical slats presented a slightly different challenge to detailing. These served little purpose in terms of shading however provided some much needed privacy to the dining room and again focused the occupant or visitor on the central space [ Figure $331 \&$ Figure 332]. Because these panels did not have to provide shade, the slats could be oriented perpendicular to the support battens. Several fixing methods were explored resulting in a notched, glued, and screwed arrangement [Figure 333 \& Figure 334]. A cutting schedule was again prepared for the offsite notching of the vertical slat panel battens [Figure 335]. 


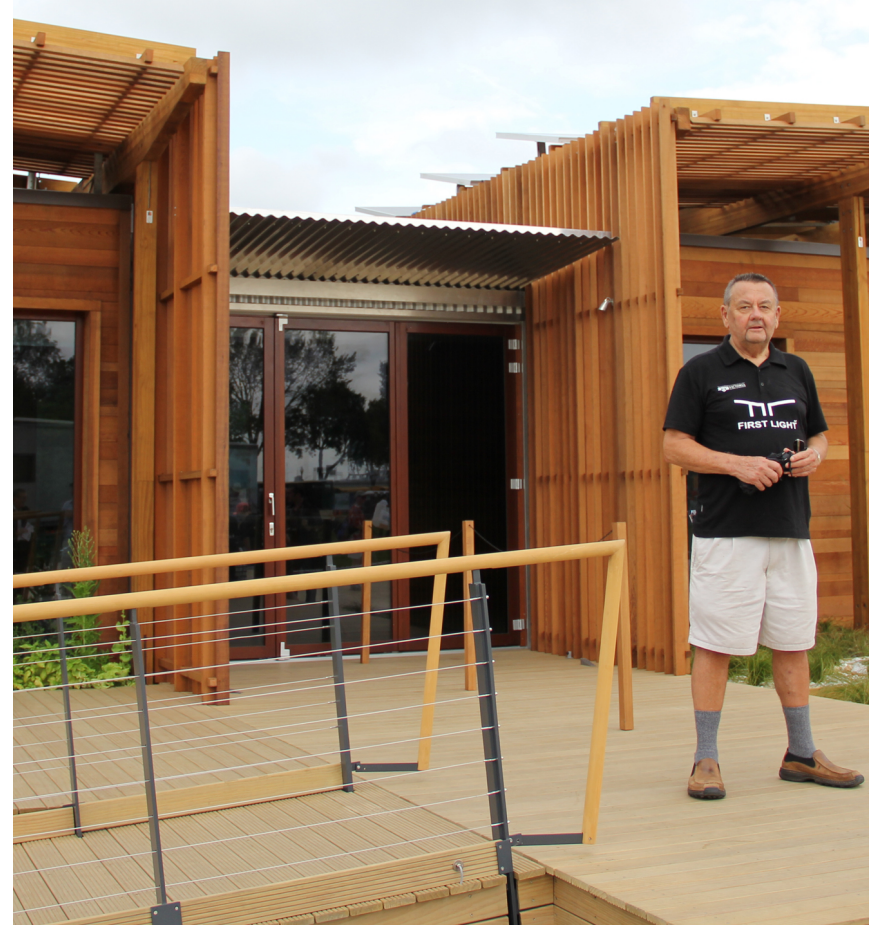

Figure 331: SD Photo Showing Vertical Cedar Slats

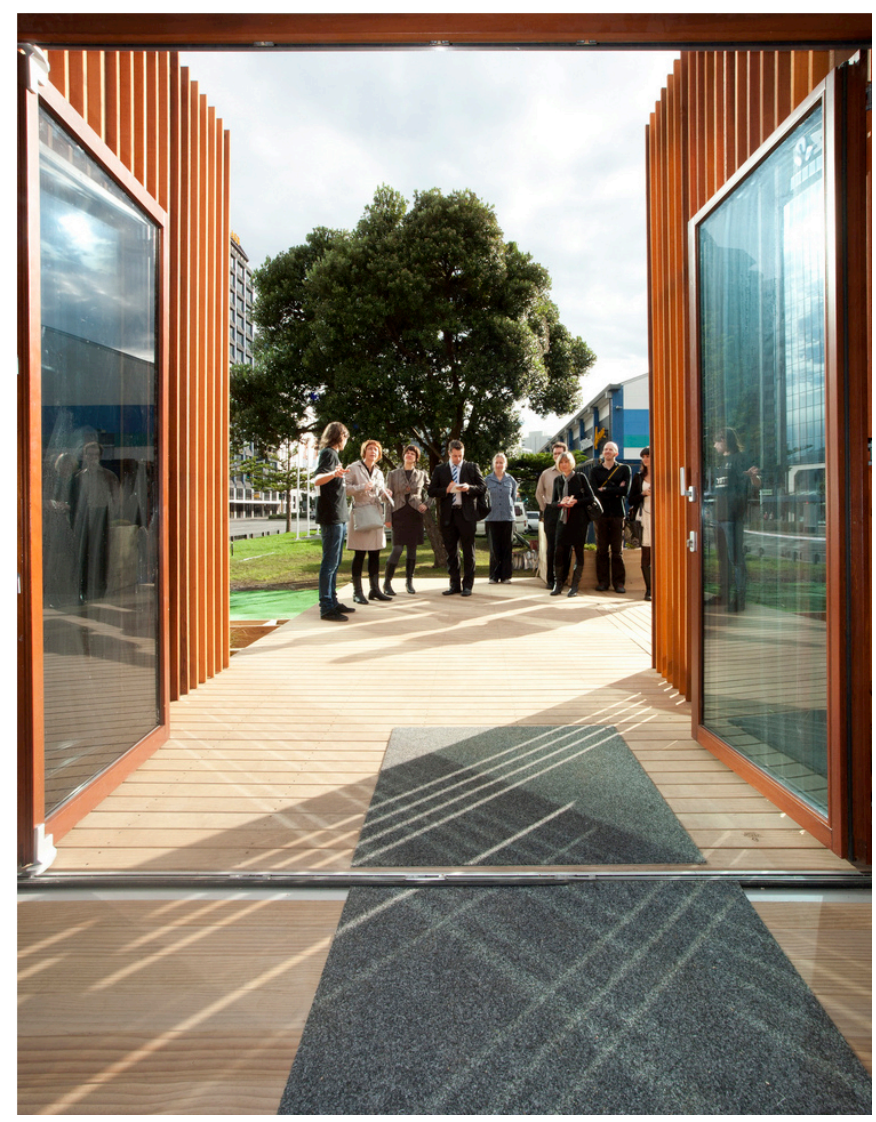

Figure 332: FKP Photo Showing Vertical Slats at Entrance to House (Credit: Paul Hillier)

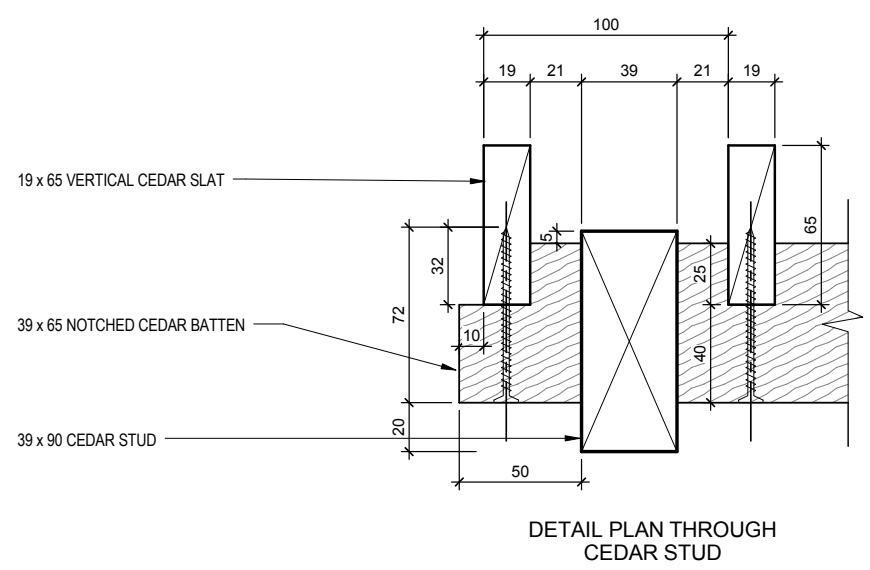

Figure 333: Fabrication Detail Showing Fixing of Vertical Cedar Slats

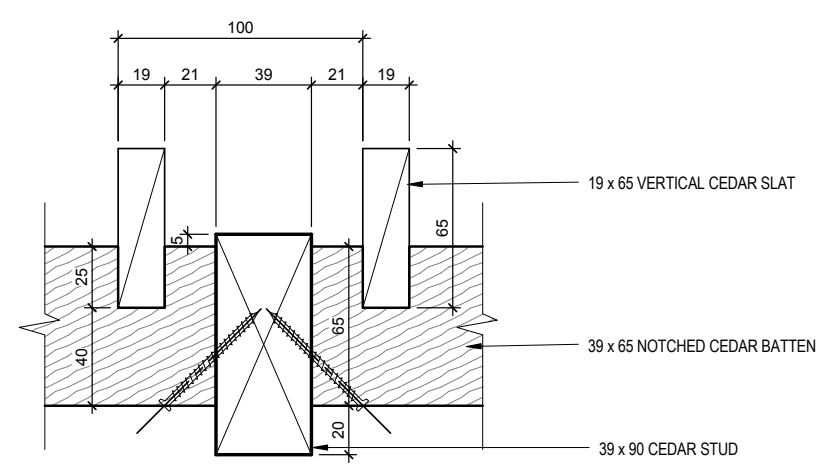

DETAIL PLAN THROUGH NOTCHED CEDAR BATTEN

Figure 334: Fabrication Detail Showing Fixing of Cedar Batten

\section{B06 $\times 32$}

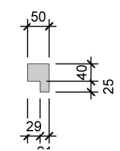

\section{B07 $\times 12 \quad$ B08 $\times 32$}

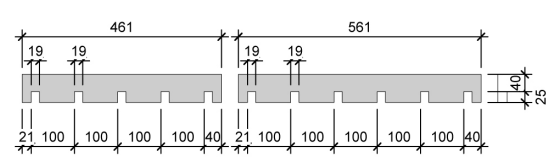

B09 $\times 8$

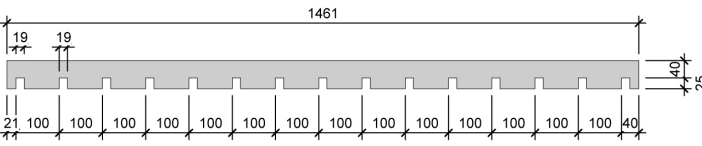

B10 $x 4$

$\mathrm{B} 11 \times 4$

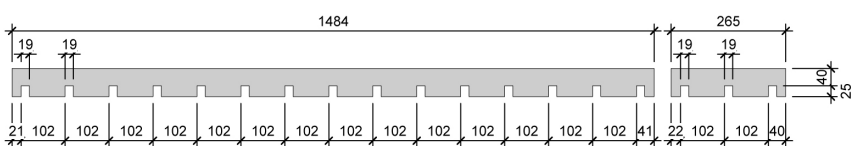

Figure 335: Cutting Schedule for Vertical Slat Battens 
During construction the contractor determined that the use of glue and bradding nails would be sufficient to hold the vertical slats in place. This was adequate in most cases however some slats, in particular the outer ones, eventually came loose after multiple assemblies. The fixing between the cedar batten and the cedar stud also proved to be weak causing the panels to break at this join several times during assembly. The fixing was sufficient to hold the panel together once installed however could not withstand the manual handling inflicted during assembly. Additional screws were skewd up through the underside of the batten into the stud to strengthen this join. In hindsight it may have been preferable to notch the batten into the stud, strengthening the join while also providing a more even line of battens.

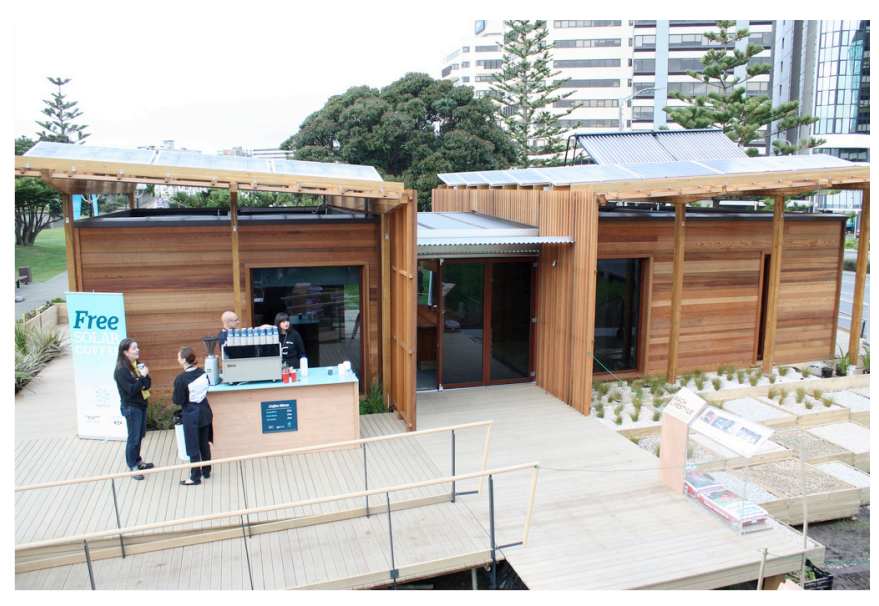

Figure 336: FKP Aerial Photo Showing Vertical Slats Above Skylight (Credit: Paul Hillier)

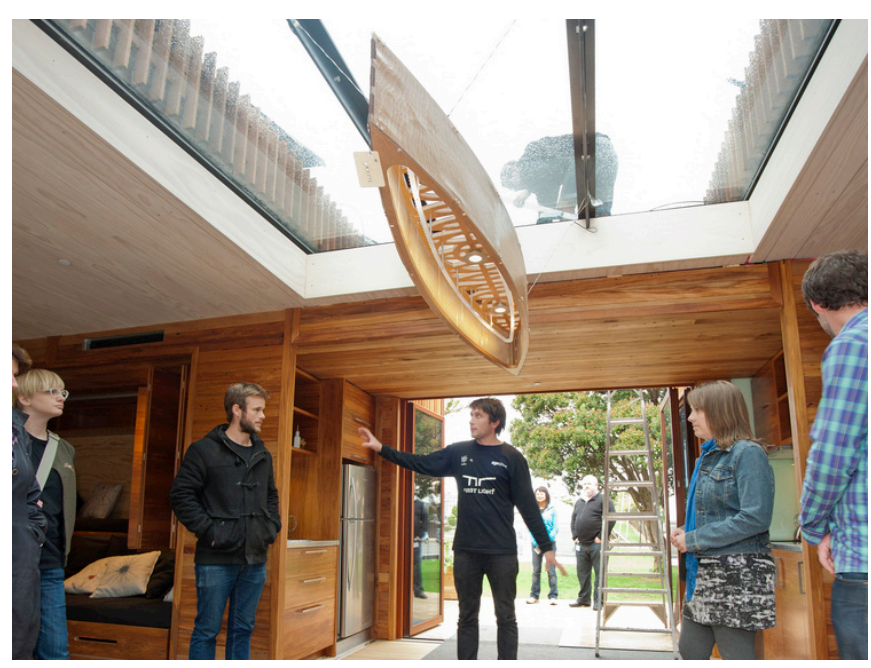

Figure 337: FKP Interior Photo Showing Vertical Slats Above Skylight (Credit: Paul Hillier)
A series of vertical slats also ran along the top of the central module completing the form of the canopy [Figure 336 \& Figure 337]. These slats were particularly difficult to construct given their overall length. Fabrication drawings also had to include a cutting schedule for every individual cedar slat since their height changed with the fall of the skylight and roof [Figure 339]. The vertical slat panels were screw fixed at the top directly to the primary glulam beams and at the base through the decking [Figure 338].

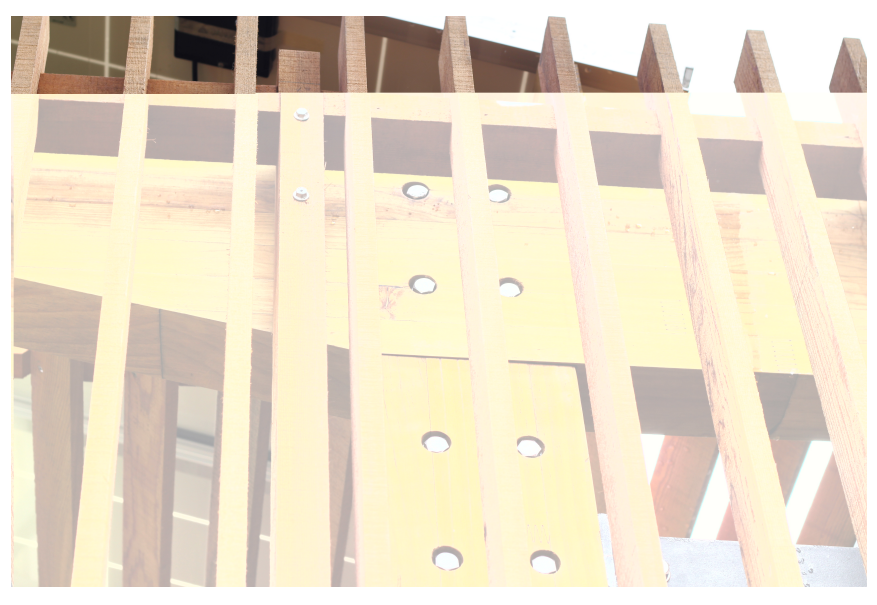

Figure 338: FKP Assembly Photo Showing Vertical Slat Panels Directly Fixed to Glulam Beam 

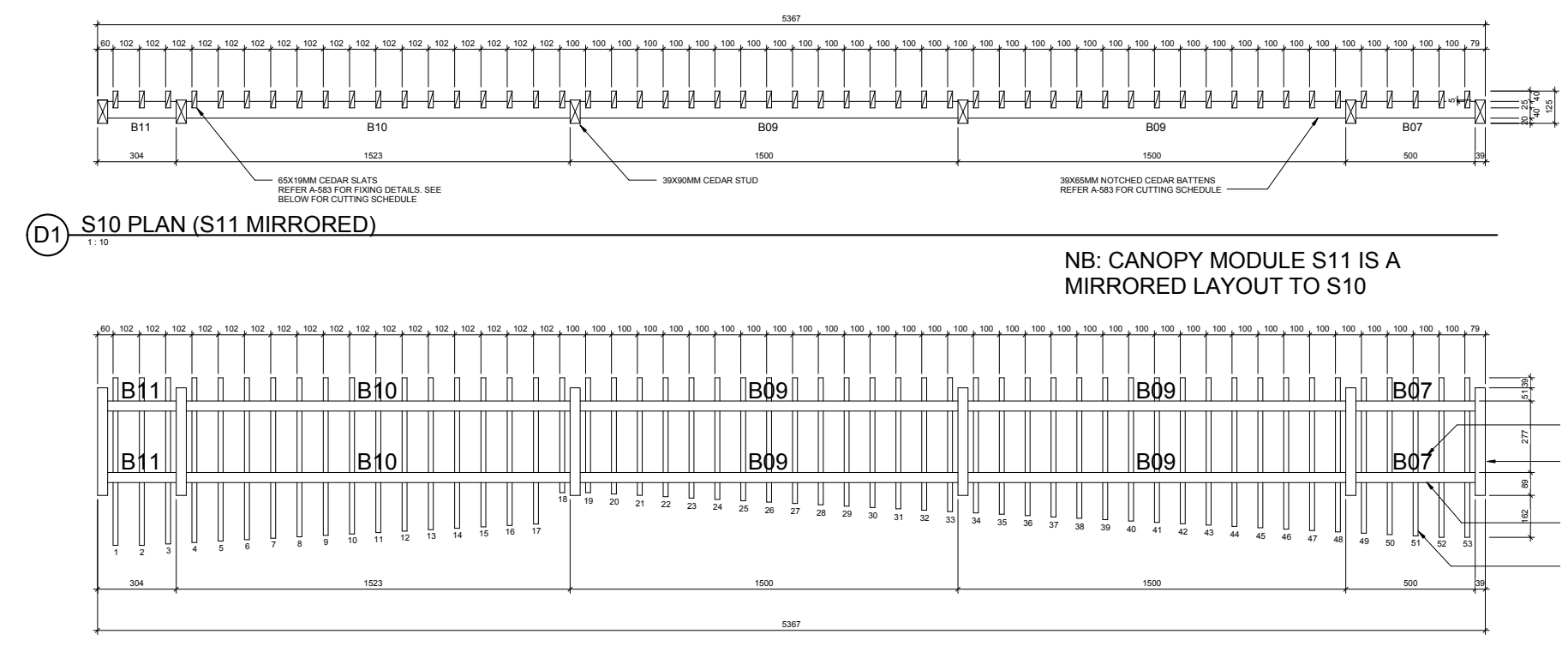

(C1) S10 ELEVATION (S11 MIRRORED)
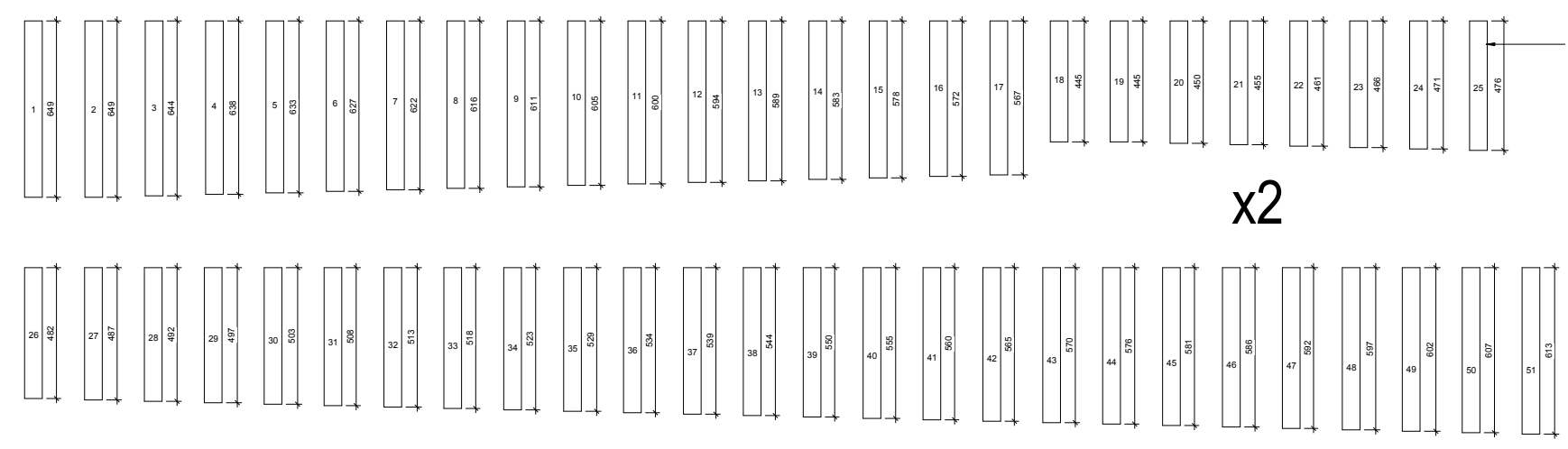

(A1) SLAT CUTTING SCHEDULE S10 \& S11

Figure 339: Fabrication Drawing Showing Slat Panels and Slat Cutting Schedule 


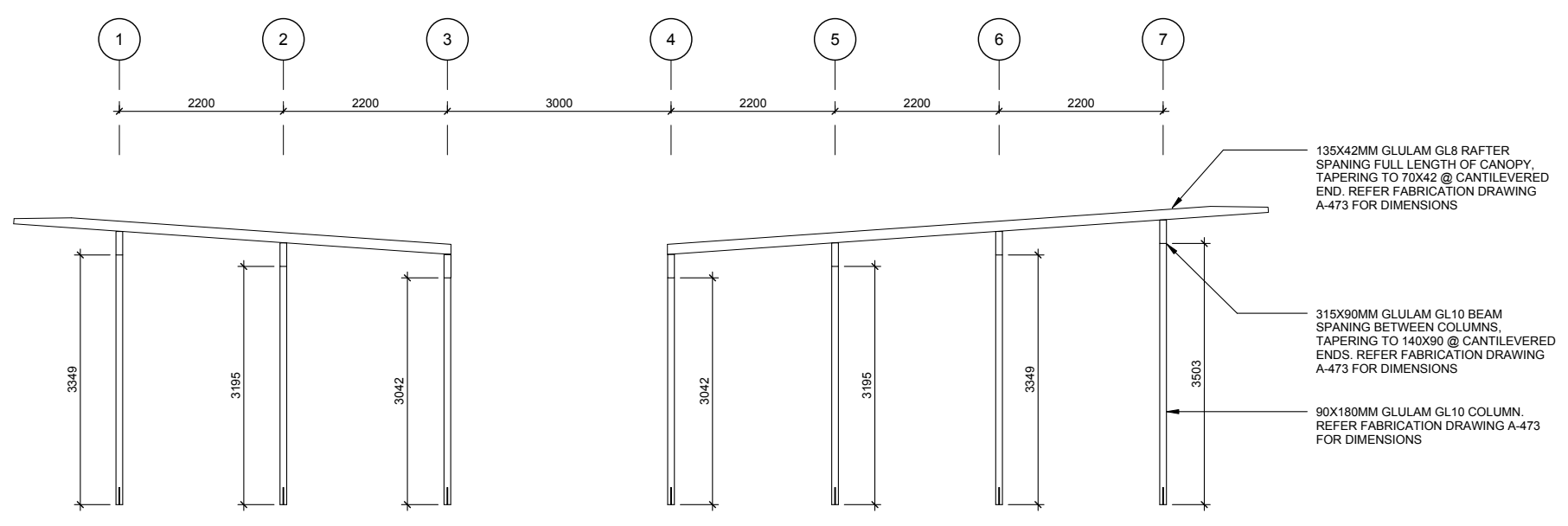

Figure 340: Fabrication Drawing - South Elevation Showing Structural Glulam Members

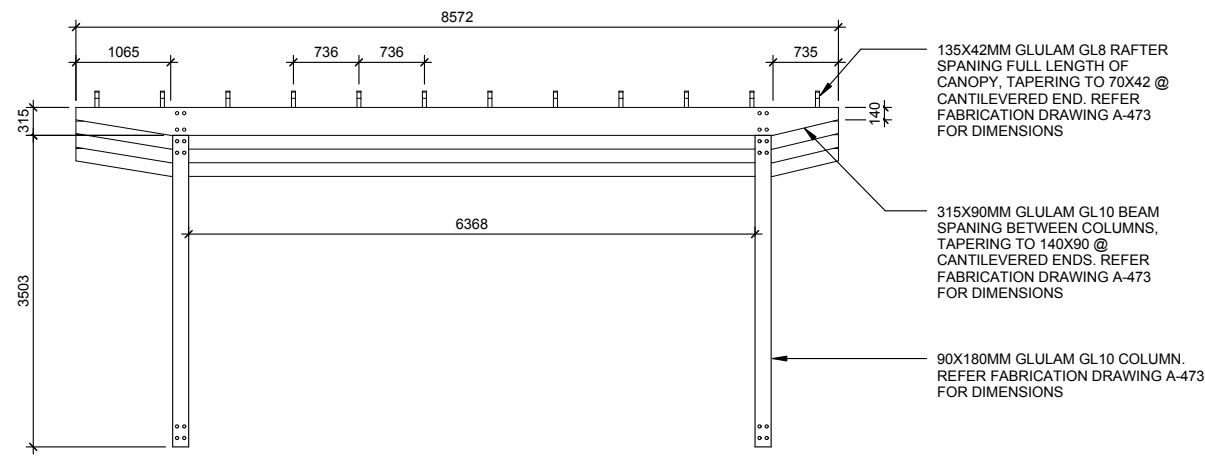

Figure 341: Fabrication Drawing - East Elevation Showing Structural Glulam Members 


\subsection{GLULAM STRUCTURE}

The as-built supporting structure is comprised of 90x180mm glulam columns, 90x315mm glulam beams, and $45 \times 135 \mathrm{~mm}$ glulam rafters; all made from locally sourced Pinus Radiata [Figure 340, Figure 341 \& Figure 342]. The increased strength of glulam meant that slimmer members could be used compared to standard framing. Timber/steel flitch beams or an alternative hardwood could also have been used. It was an objective of the team however to use local and/or sustainably grown timber where possible. In this case, glue laminated pinus radiata proved to be the ideal timber for the canopy structure. The ends of both the primary beams and the rafters were tapered to again further refine the canopy edge [Figure 343].

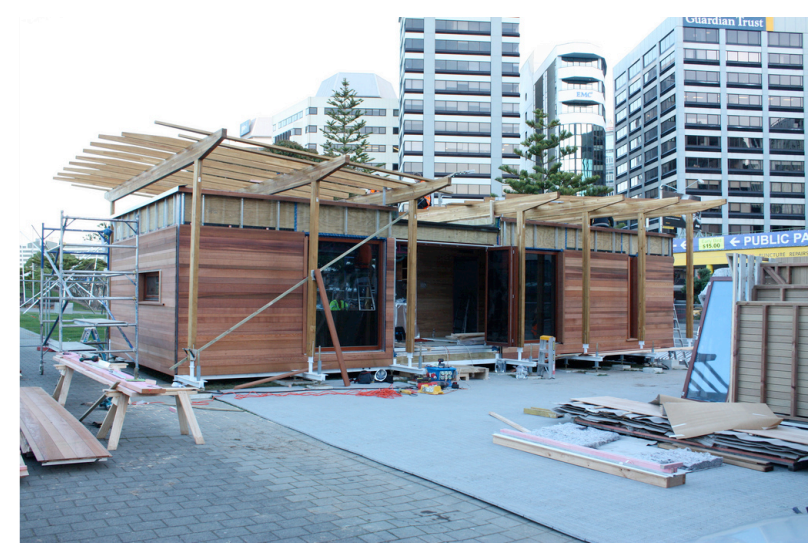

Figure 342: FKP Assembly Photo Showing Glulam Canopy Structure

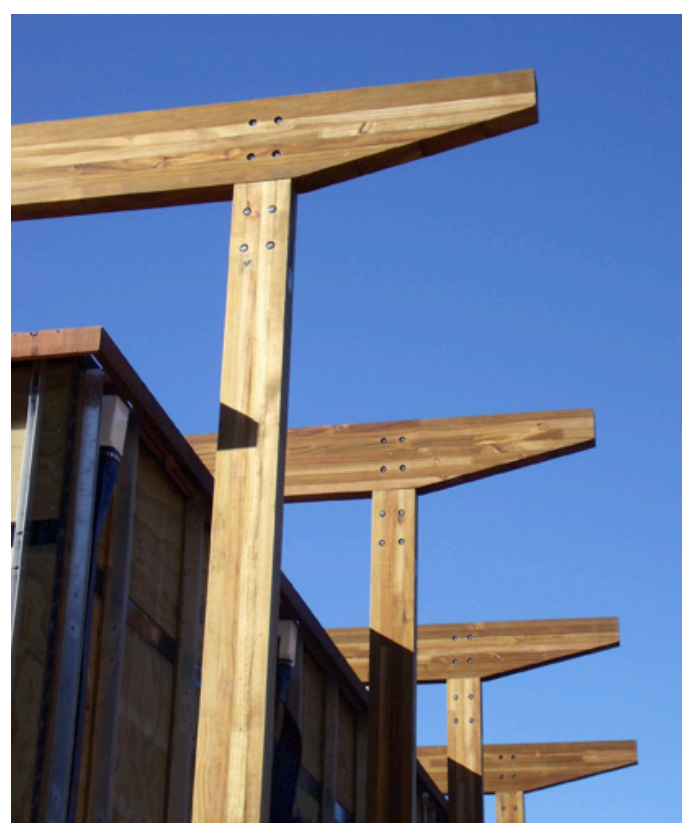

Figure 343: FKP Assembly Showing Tapered Primary Glulam Beams (Credit Ruth Armishaw - NZ Wood)
The glulam columns are bolted at their base to the steel foundation upright plates [Figure 344, Figure $345 \&$ Figure 346]. These plates are designed in a way so as to protrude through the landscaping planter boxes, concealing the bulk of the foundations and providing a very clean detail to the columns [Figure $347 \&$ Figure 348].

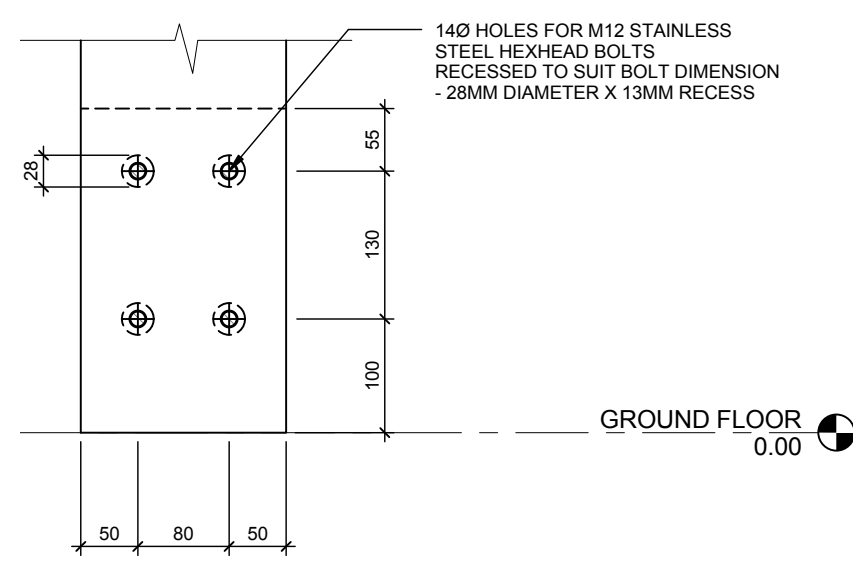

Figure 344: Fabrication Drawing - Column Base Fixing

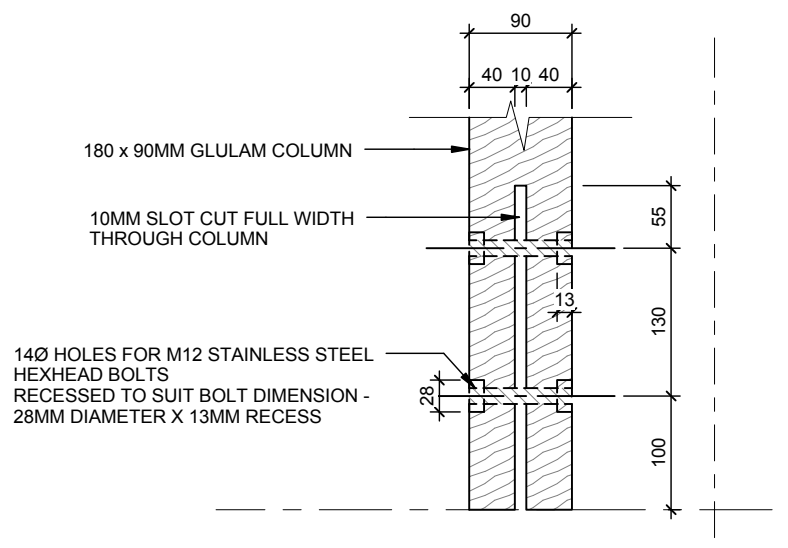

Figure 345: Fabrication Drawing - Column Base Fixing

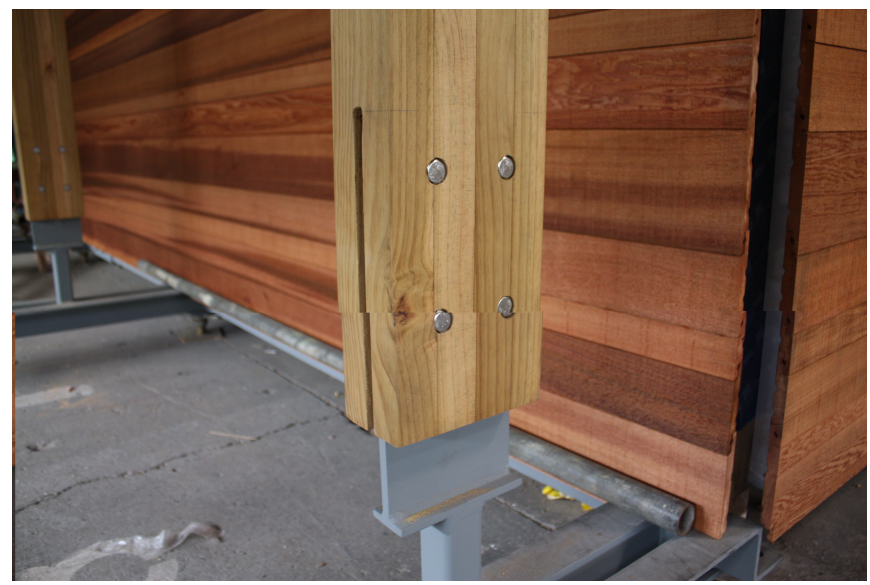

Figure 346: Construction Photo Showing Column Base Fixing 


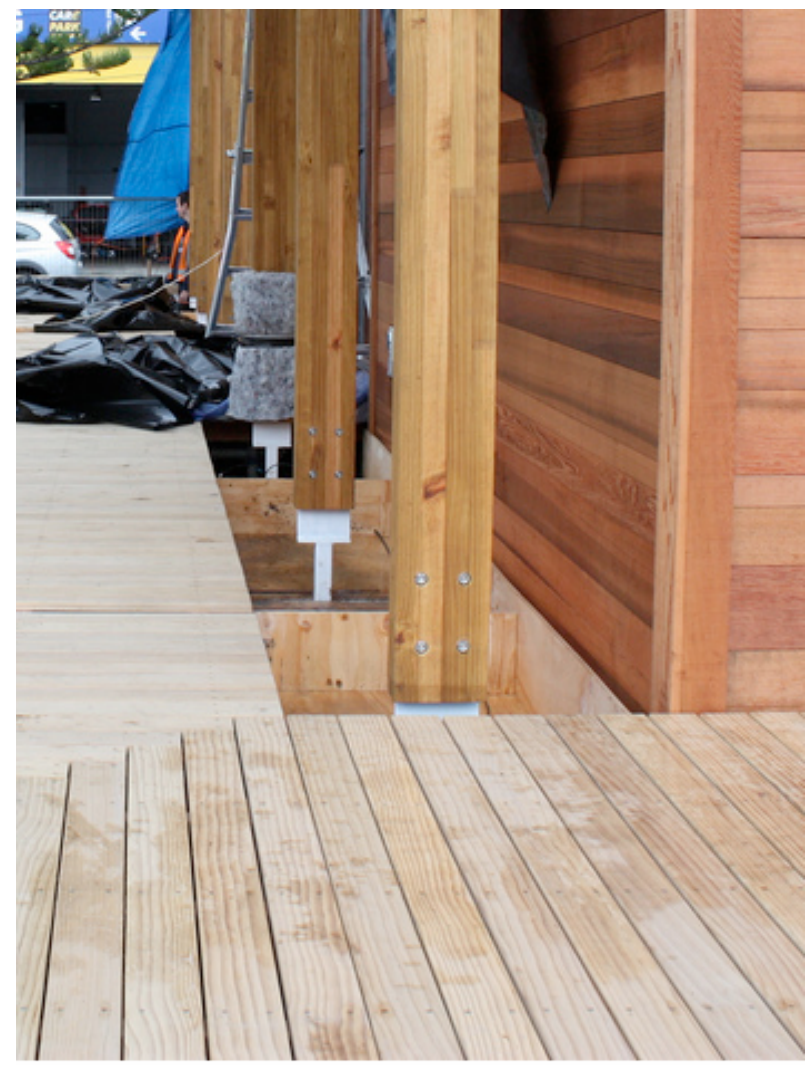

Figure 347: FKP Assembly Photo Showing Foundation Plate Protruding Through Planter Boxes

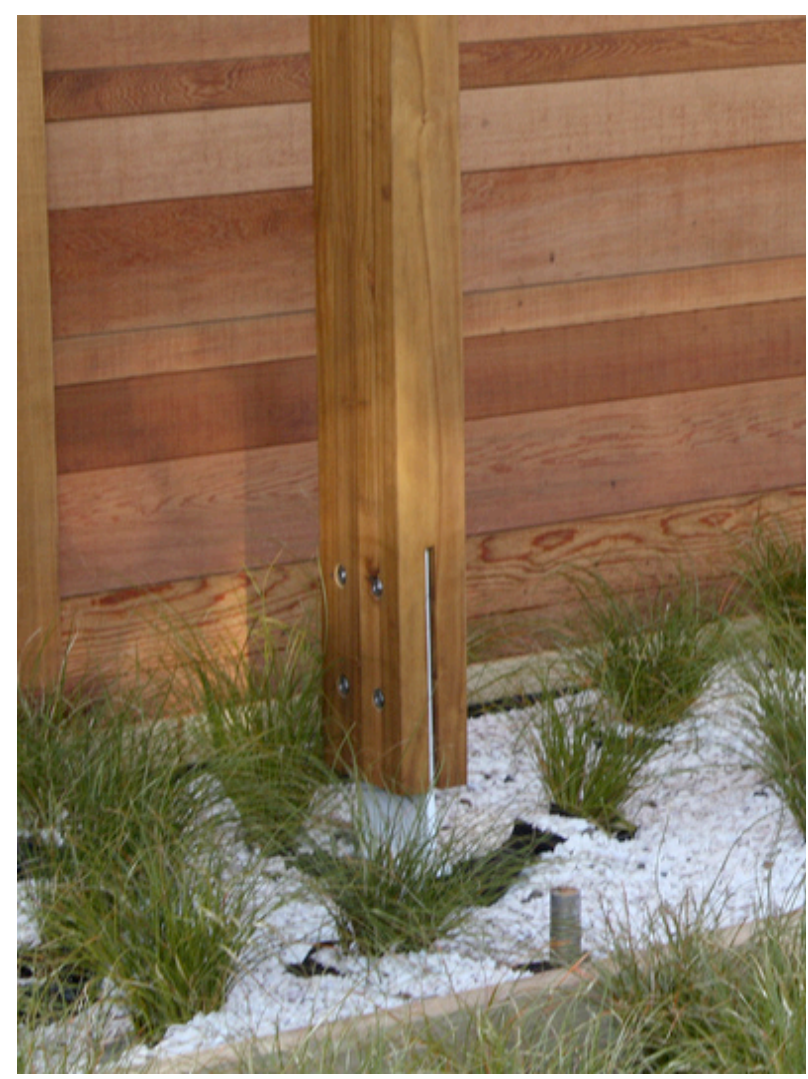

Figure 348: FKP Assembly Photo Showing Foundations Concealed by Landscaping
A similar $\mathrm{s} / \mathrm{s}$ plate is used at the top to fix the primary beams to the columns [Figure 349]. Some difficulty was experienced in the notching of the glulam columns. Although this was anticipated and accommodated for by having a joinery company perform the work, the desired accuracy of the cut was not achieved. Unfortunately some of the notches do not run completely parallel to the length of the column. The majority of the notches were also not cut to the specified depth requiring further manipulation on site, by chainsaw. These defects were not visible within the beams since the entire notch is concealed from view. Furthermore, the s/s plates were specified at $6 \mathrm{~mm}$ thickness however, due to the breaking of chains at the joinery workshop, the notch had to be increased to $10 \mathrm{~mm}$. This resulted in a degree of 'slop' between the plate and the glulam notch. To mitigate this problem visually, s/s washers were fixed to either side of the plate as required [Figure 350].

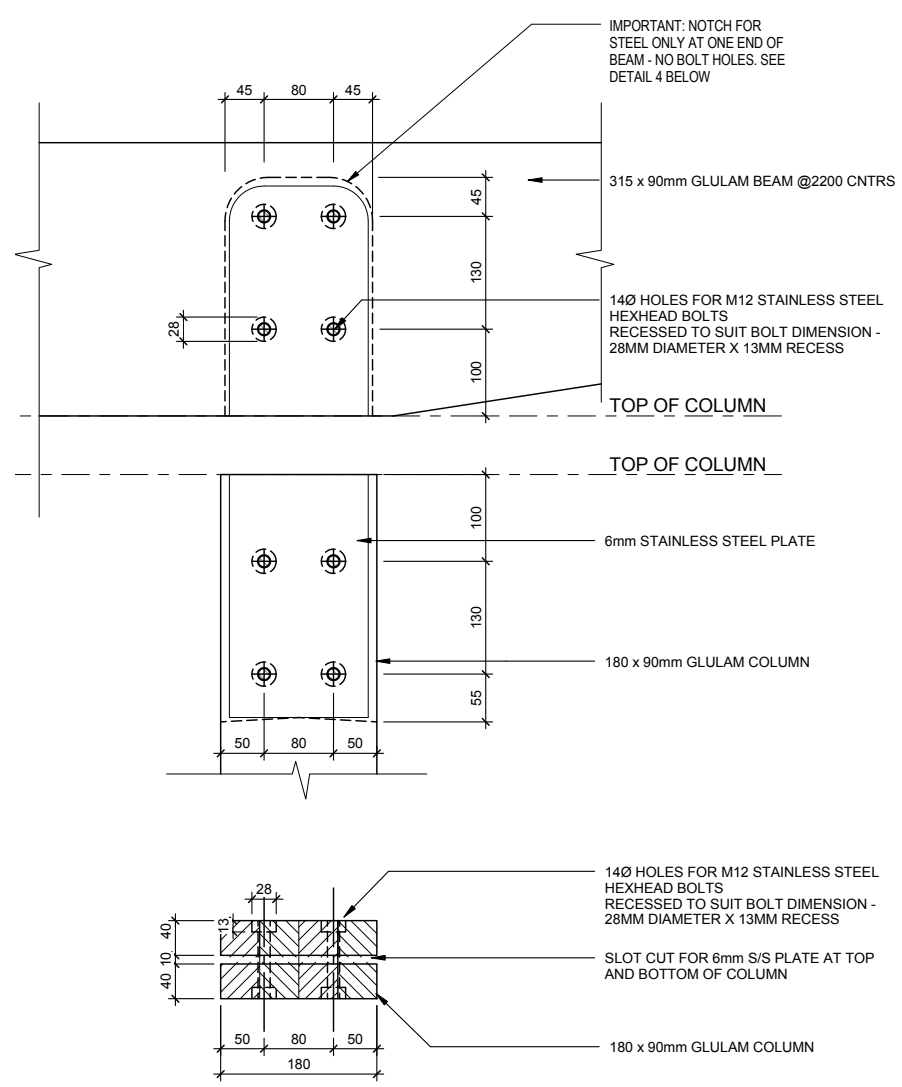

Figure 349: Fabrication Drawing Showing Primary Beam to Column Fixing 


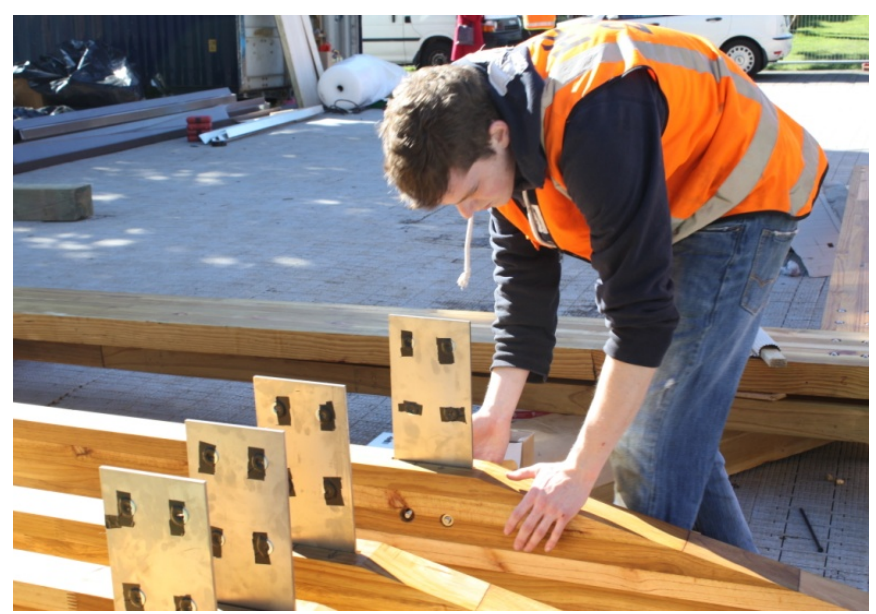

Figure 350: FKP Assembly Photo Showing S/S Glulam Plates

For assembly, the glulam beams are fixed to the columns while still on the ground [Figure 351]. A small crane or Hiab is then used to place the portal frames onto the foundation plates [Figure $352 \&$ Figure 353]. The portals are then temporarily braced while the glulam rafters and permanent bracing components are installed.

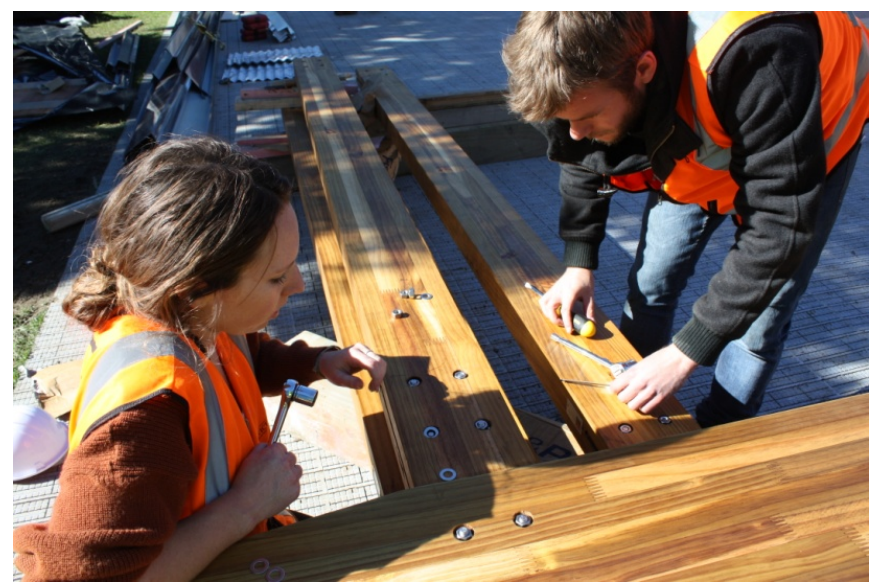

Figure 351: FKP Assembly Photo Showing Glulam Beams and Columns Fixed to Form Portal Frames

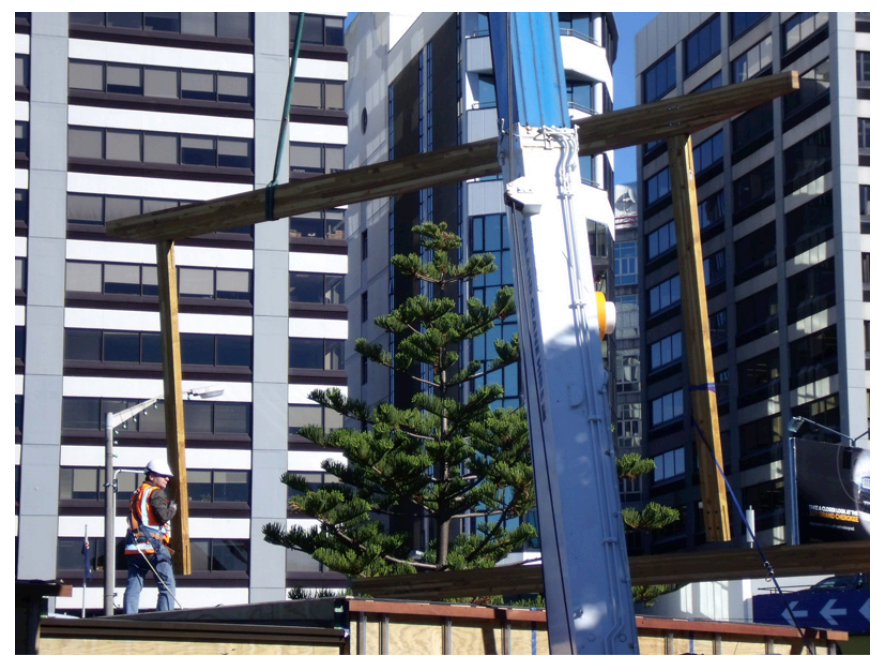

Figure 352: FKP Assembly Photo Showing Glulam Portals Lifted by Crane

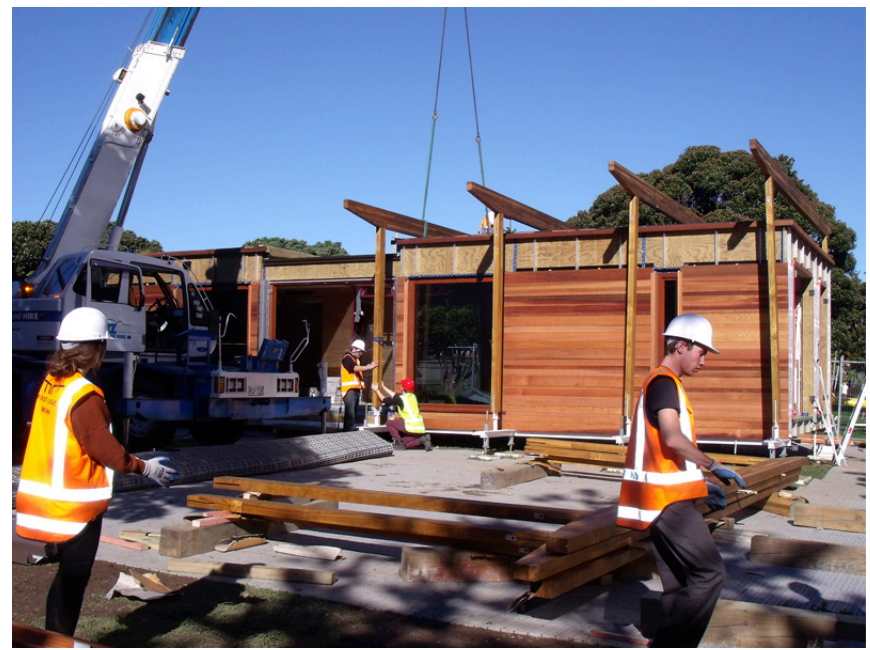

Figure 353: FKP Assembly Photo Showing Glulam Portals Place on Foundations (Credit: Ruth Armishaw - NZ

The $135 \times 45 \mathrm{~mm}$ glulam rafters are placed in bundles on top of the glulam portal frames using a crane. Each glulam column, beam and rafter is given a unique identity tag to ensure the accurate reassembly of the canopy. Unfortunately most of the members were not correctly tagged during construction and the layout had to be reestablished during assembly. This mistake highlighted the importance of maintaining an accurate and consistant labelling system. Although many elements were based on standardised components, each would become unique due to the tolerances of timber construction. 
The rafters are fixed to the primary beams using a single $10 \mathrm{~mm} \times 220 \mathrm{~mm}$ countersunk head Spax screw [Figure 354]. The spacing of the rafters was dictated by the spacing and fixing requirements of the solar panels. The direct fixing of the rafters caused the primary beams to tilt outwards towards alligning perpendicularly with the rafters [Figure 355]. The s/s plate prevented the tilt from being as radical as is shown in Figure 355, however the effect was still visibly noticable. This problem could have been avoided by 'birds-mouthing' the rafters at $4^{\circ}$ to enable them to sit flat on the beams.

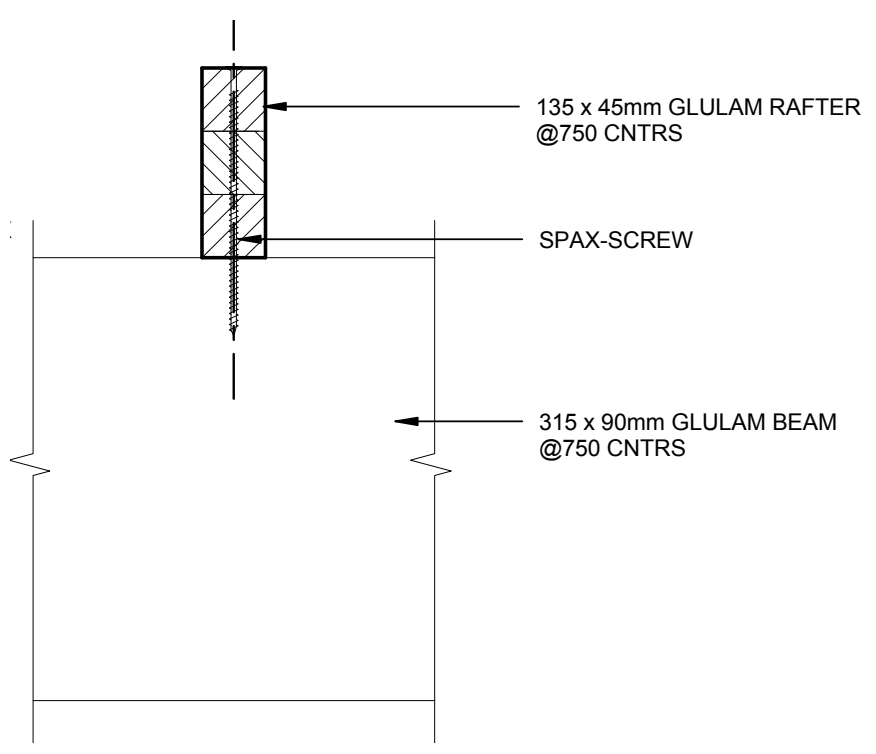

Figure 354: Fabrication Drawing Showing Spax Screw Fixing Between Glulam Rafter and Beam

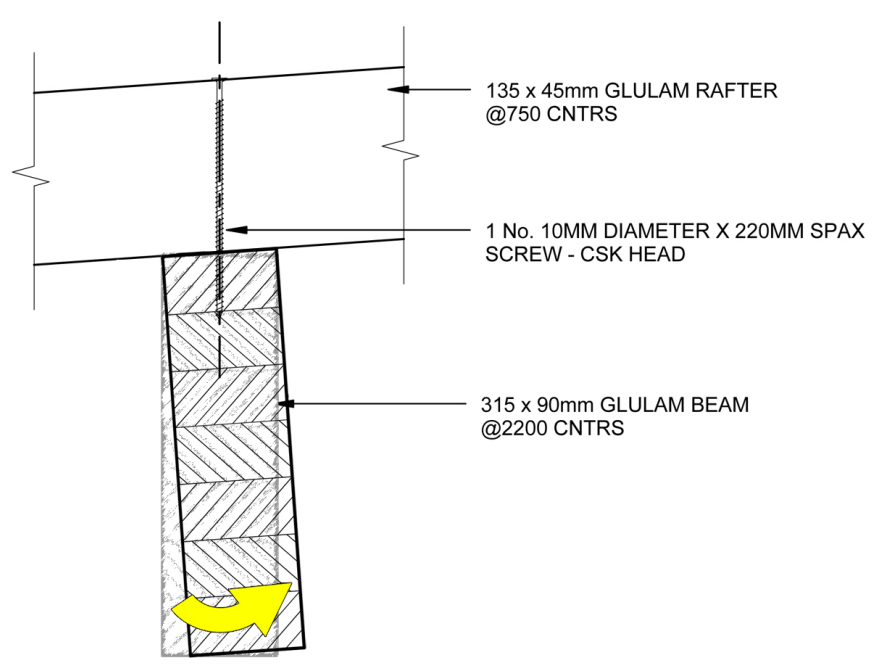

Figure 355: Sectional Drawing Showing Tilting Glulam Beam

\subsection{STRUCTURAL BRACING}

It was initially intended that the foundation outrigger and column plate would provide a fixed joint and hence lateral bracing. This was not however possible and supplementary bracing in both directions was required. The columns are braced transversely by steel struts that extend through the cladding to fix directly to the house modules [Figure $356 \&$ Figure 357]. These struts are only required on the north (back) side of the house leaving the front elevation unobstructed. The strut is designed so that the module bracket can be prefixed before the cladding is installed, with the remainder of the strut and column assembled later. The cladding penetration is then weathersealed and fnished with a cedar trim [Figure 358].

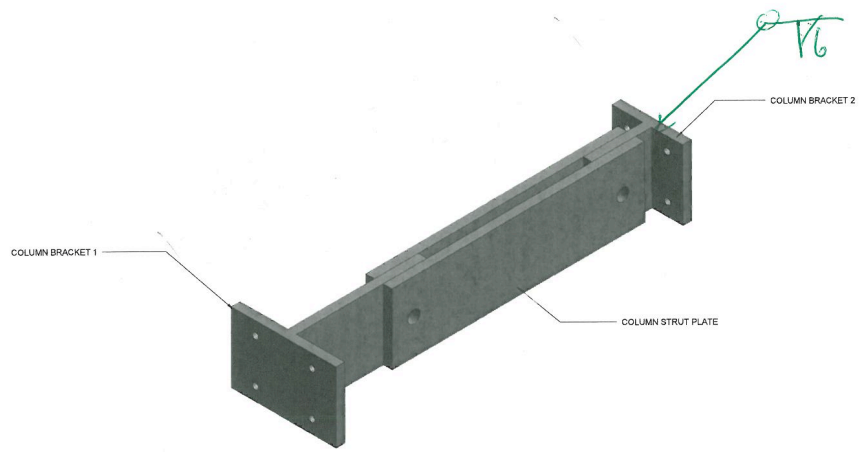

Figure 356: Fabrication Drawing Showing Column Bracing Strut

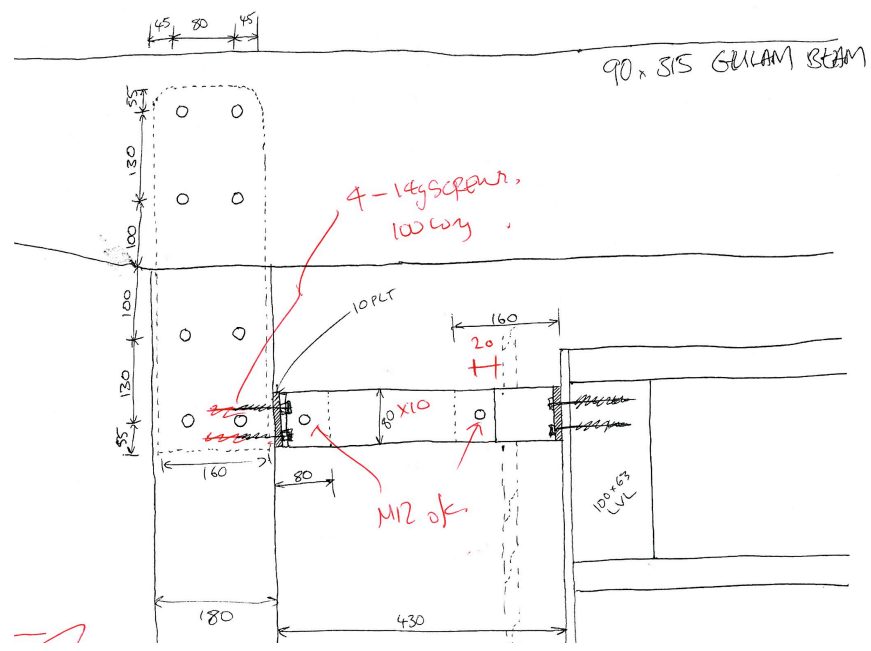

Figure 357: Construction Sketch Showing Installation of Column Bracing Strut 


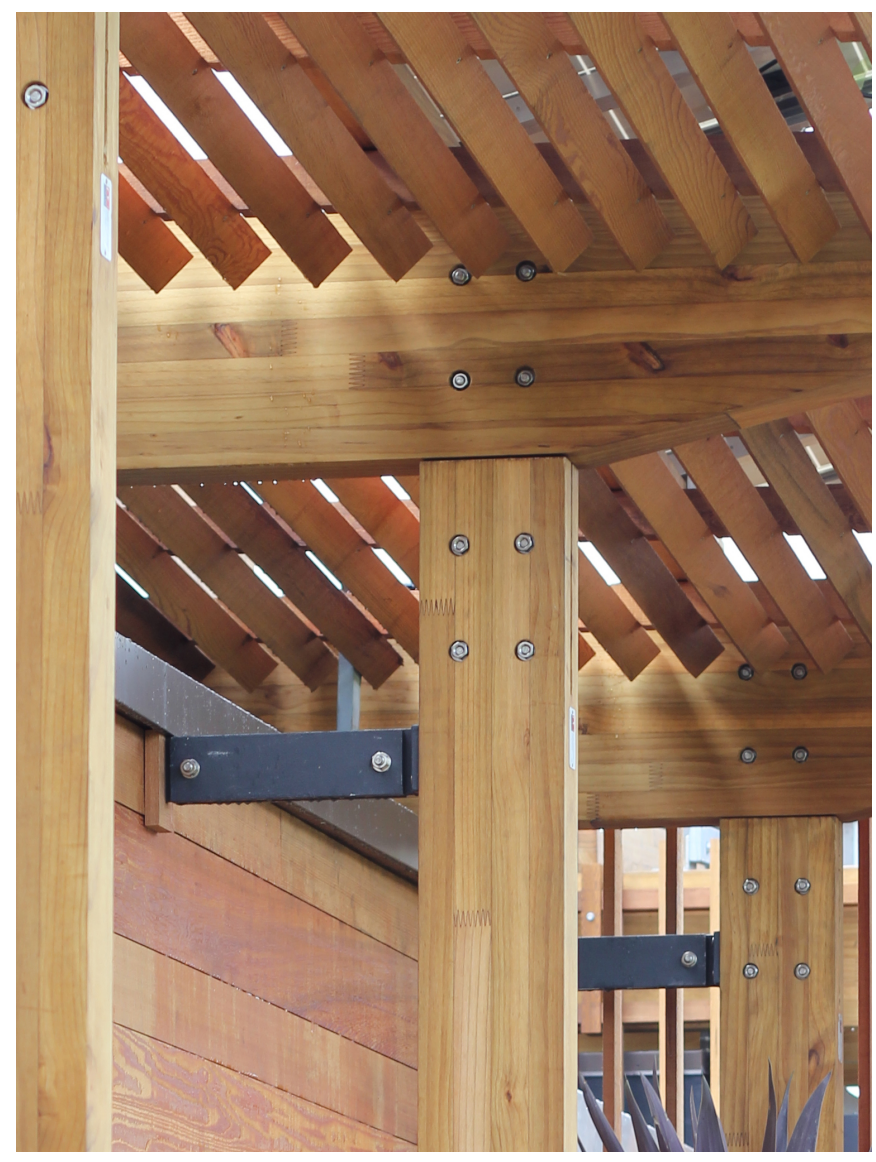

Figure 358: SD Photo Showing Column Bracing Strut and Cedar Trim

To resist lateral loads in the longitudinal direction a far more complex structural bracket arrangement is used. A large ' $C$ ' shaped steel section connects the first bay of the canopy to the longitudinal parapets of the house [Figure $359 \&$ Figure 360]. Any connection between the canopy and the roof could lead to potential weatherproofing issues. To ensure a watertight penetration and a connection that could be assembled and disassembled many times, permanent mounting brackets were fixed underneath the parapet cap flashing [Figure 361]. This enabled the screw-fixings to be concealed and waterproofed by the parapet flashing. The bracing bracket is then bolted to the mounting brackets at either end. The top flange spans between the two primary glulam beams and is bolted to another mounting bracket that is fixed to the top of the beams. The upright of the bracket is designed so as to fit between two slats of the slat panel [Figure 362]. Some difficulty is experienced in the assembling of the brackets with the slat panel needing to be installed at the same time.

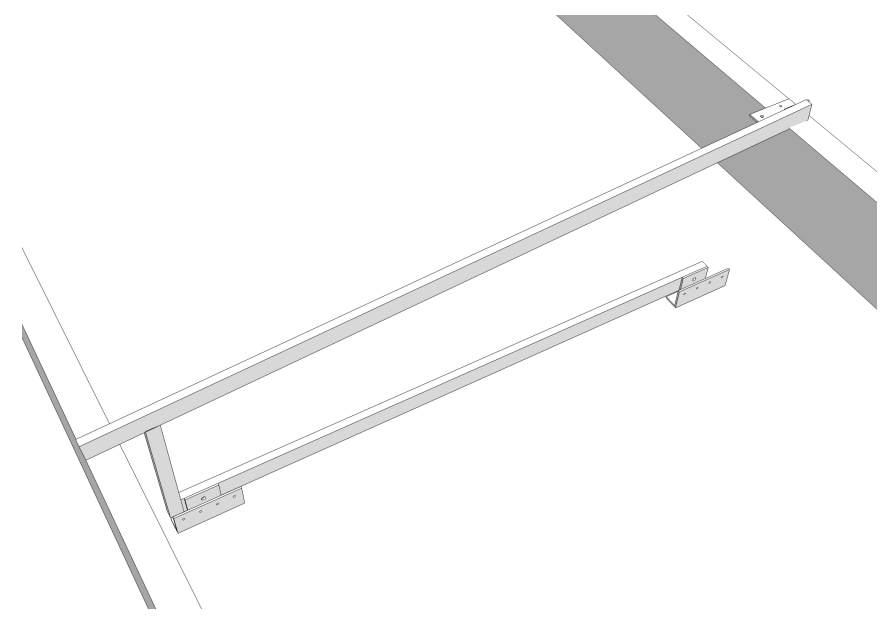

Figure 359: 3D Model Showing Canopy Bracing Bracket Between Primary Glulam Beams

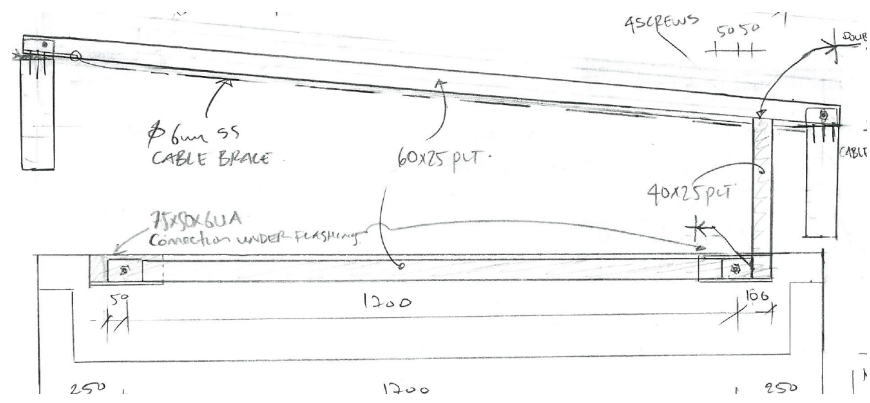

Figure 360: Engineers Sketch Showing Canopy Bracing Bracket

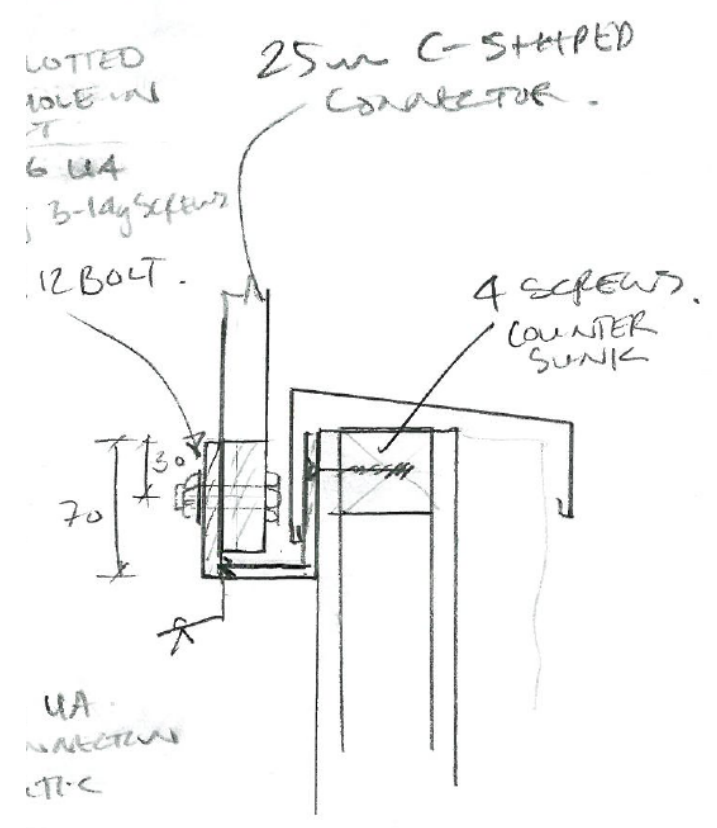

Figure 361: Engineers Sketch Showing Parapet Mounting Bracket 


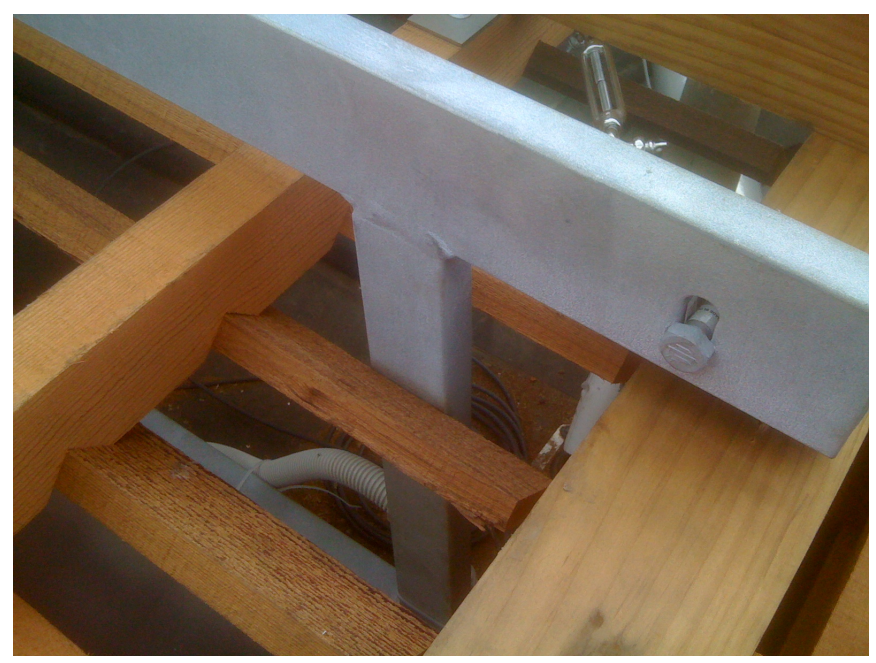

Figure 362: SD Assembly Photo Showing Canopy Bracing Bracket Protruding Through Slat Panel

Four canopy bracing brackets are located at the four internal corners of the canopy. These are then connected together to form a structural diaphragm with $\mathrm{s} / \mathrm{s}$ tension cross-bracing [Figure 363]. Most of the bracket and tension bracing is hidden from view, bar the vertical upright [Figure 358].

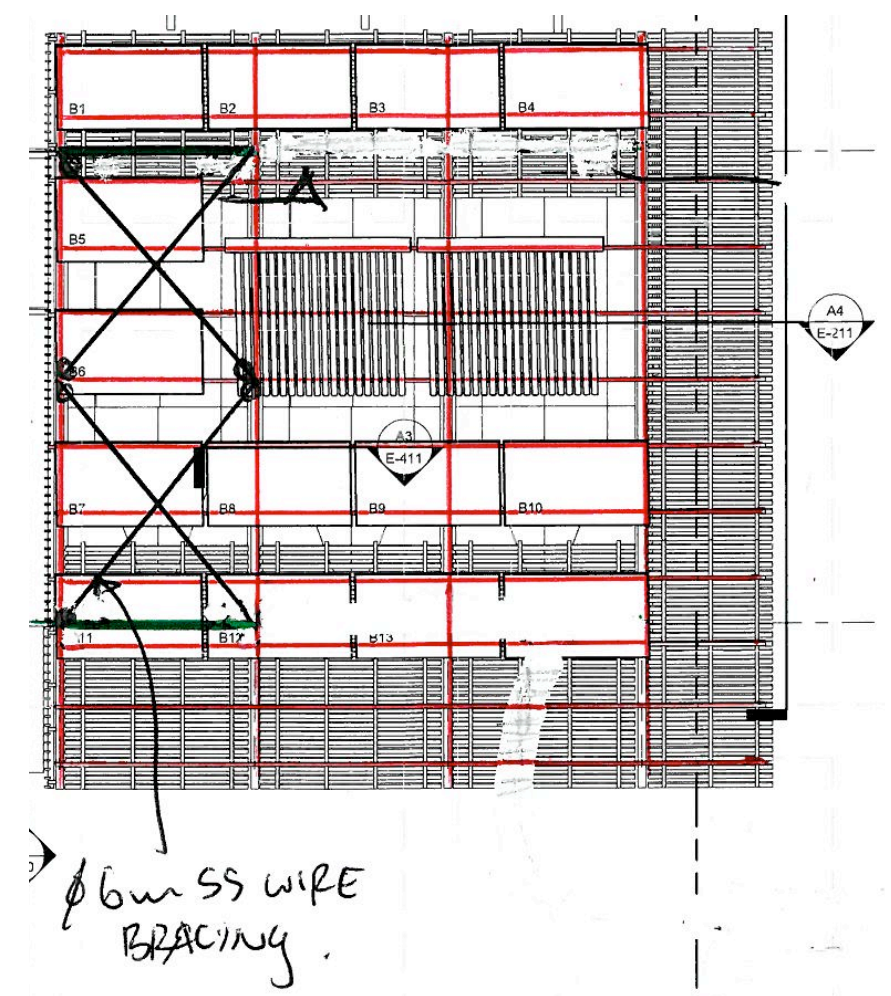

Figure 363: Engineers Sketch Showing Canopy Tension Bracing 


\section{CONCLUSION}

This thesis has provided an in depth analysis of the logistical and construction challenges that were involved in the making of the First Light house. As a case study, it is hoped that this will provide a valuable contribution towards an understanding of how these challenges might be overcome in other similar projects.

The design process has been presented, in detail, from concept to competition. The framework for this process has been outlined in each chapter relative to the main decision making criteria that were involved. Alternative outcomes have been presented and critiqued as to how they best meet these criteria. As a reflective document, the successes and/or failings of the chosen outcomes are then discussed based on the experiences gained at the 2011 competition.

Following a generally chronological process this thesis began with the exploration of international transportation requirements. These included land transport, sea freight, customs, and even air freight. The implications that these requirements had for modularisation and construction techniques were explored through a variety of different transport options. As the options were progressively explored a greater understanding of their impact to the project in terms of time, quality and cost was gained. The number of options was eventually narrowed to a preferred six transportation methods. With all factors considered the final method was selected, paving the way for the development of construction and assembly techniques.

The solution to the many interlinked foundation requirements was a simple perimeter 'track' design. This enabled the house modules to be dropped into place sequentially and then slid to their correct locations. This foundation system enabled the level adjustment that was needed to achieve a level and temporary substructure for the house. It also provided the means for supporting the large timber canopy.
Available construction methods for building the house modules were explored at great length. A detailed comparison between SIP (Structurally insulated Panel) and timber framed construction was carried out. This presented the many advantages and disadvantages of each option. Ultimately, the decision was made to proceed with the use of timber framed construction. This had advantages in terms of project timing, control over the design process, use of locally sourced materials, and environmental concerns.

Development of the timber construction details was driven by rigorous research and optimisation for performance, aesthetic quality, durability, and ease of assembly. Through a range of construction techniques specific details were developed to meet the unique requirements of the floor, wall, and roof. These included the use of Flexus concrete for thermal mass in the floors, double stud and LVL (laminated veneer lumber) framing in the walls, CNC (computer numerical sdds) cut plywood ribs for the roof, removable Cedar weatherboards, and an airtightness membrane combined with sheeps wool for insulation. The selected details and products proved to achieve the necessary qualities of a robustness, performance, and aesthetic quality.

One of the most difficult design challenges to the project was the detailing of the central module, Module Three. Due to the dimensional limitations of sea freight, Module Three had to be broken down into smaller components and 'flat packed' into standard shipping containers. This posed many challenges to the design team since this was to be the focal point of the entire house, not to mention that it contained two $3.0 \mathrm{~m}$ wide glazed bi-fold doors and a large skylight. This module also proved thermally to be the weakest part of the house. The large amount of glazing enabled too much heat gain in summer while also allowing significant heat losses in winter. 
Extensive design research was invested for the optimisation of the skylight to mitigate these negative affects. Significant development of the connection details for assembly, disassembly and weathertightness was also required. The triple glazed final solution, with integrated roller blinds and a portion of solid roof, met all of the performance and construction requirements as well as the design intent.

The timber canopy, which provided support to the solar panels and shading to the windows, also required a significant amount of refinement in terms of assembly and performance. It accounted for the first impression of the house and was critical for the expression of the concept and enhancement of the central space. The entire structure is compartmentalised for ease of assembly and containerisation. Naturally durable Cedar is used for the shading slats and treated glulaminated Pinus Radiata columns, beams and rafters make up the structure.

The unique requirements of the Solar Decathlon resulted in a house that could be transported to almost anywhere in the world, achieves the highest standards of performance and energy efficiency, and is completely powered by the sun. First Light excelled at the competition with a house that not only met these technical challenges but aslo achieved a functional and inspired piece of architecture.

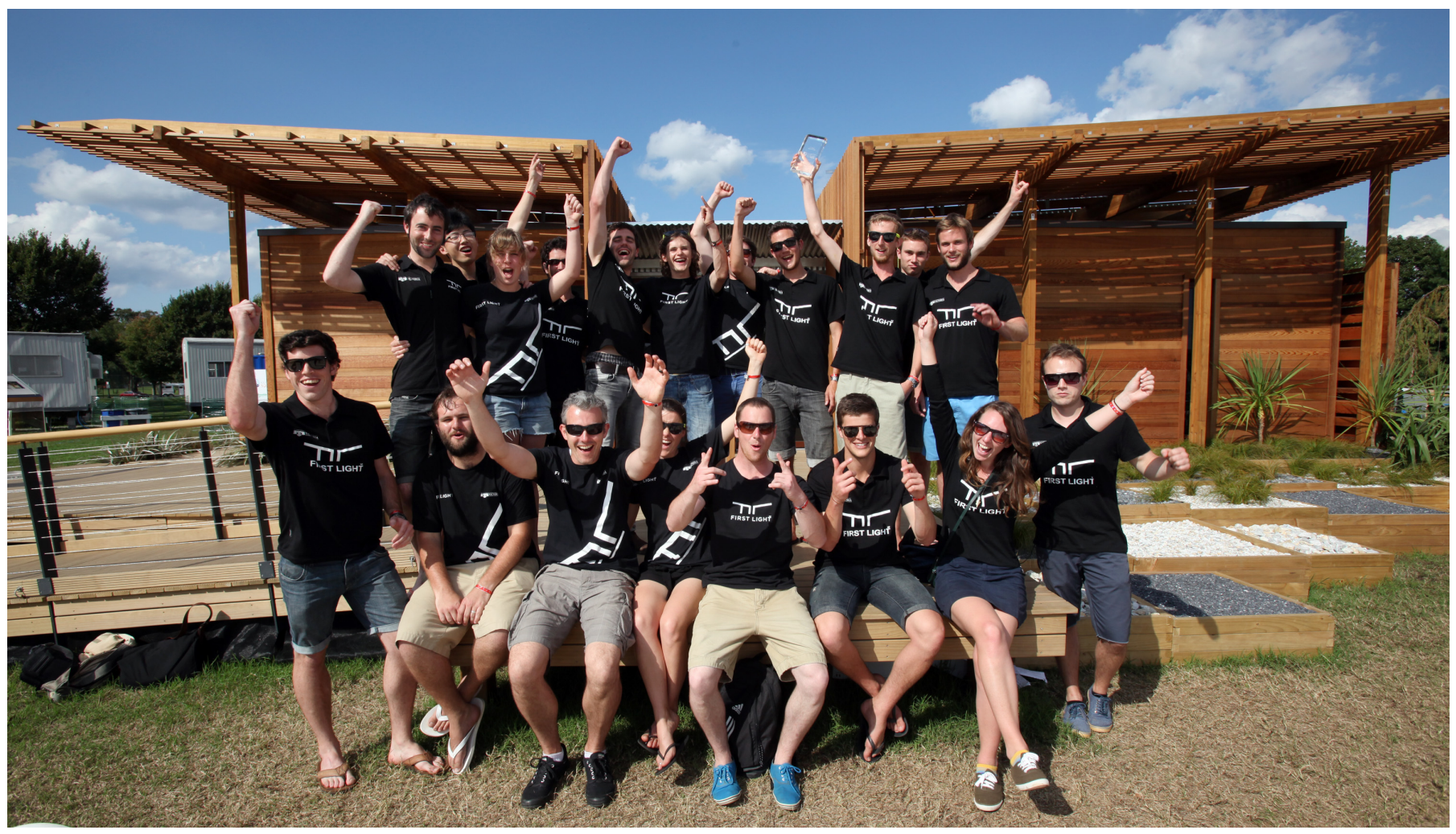

Credit: Stefano Paltera/U.S. Department of Energy Solar Decathlon 


\section{REFERENCES}

Atelier Workshop Aotearoa. (2005). atelierworkshop: products.louvre system. Retrieved February 16, 2012 from atelierworkshop:

http://www .atelierworkshop.com/louvre.htm

AWPA. (2009). AWPA Standards as Referenced in the 2009 IBC/IRC. American Wood Preservation Association.

Cabot Corporation. (2010). Nanogel Aerogel Thermal Wrap. Boston: Cabot Corporation.

Capital Safety. (2012). Sayfline Two Person Horizontal Lifeline Roof System. Retrieved February 16, 2012 from Capital Safety: http://en.capitalsafety.us

Commonwealth of Virginia Department of Motor Vehicles. (2009). Virginia Hauling Permit Manual. Virginia: Department of Motor Vehicles.

Department of Building and Housing. (2011). A Quick Guide to Timber Treatment for Enclosed Framing. Wellington: Department of Building and Housing.

Department of Building and Housing. (2010). Consultation on Proposals for a Single Hazard Class for Framing Timber Inside the Building Envelope. Department of Building and Housing.

Everlight NZ Ltd. (2009). Danpalon Polycarbonate Architectural Glazing Systems : Everlight NZ Ltd. Retrieved February 16, 2012 from Danpalon Polycarbonate Architectural Glazing Systems : Everlight NZ Ltd: http://www .everlight.co.nz/html/colour.htm

Farrow, A. L. (2012). Inside the First Light House. Wellington: Victoria University of Wellington.

Federation of American Scientists. (2010). Federation of American Scientists: C-130 Hercules. Retrieved February 14, 2012 from Federation of American Scientists: http://www.fas.org/programs/ssp/man/uswpns/air/cargo/c 130.html

Hamburg Sud. (n.d.). Hamburg Sud Liner Shipping: Cotainer Overview. Retrieved February 14, 2012 from Hamburg Sud Liner Shipping: http://www.hamburgsudline.com/hsdg/en/hsdg/servicesproducts/container_1/conta ineroverview.jsp
International Air Freight Shipping. (2012). Air Freight Shipping - Air Cargo Containers Categories. Retrieved February 14, 2012 from Air Freigh Shipping: http://www .shipbyair.net/solutions/containerscategories.htm

Jagersma, B. J. (2012). The Ten Day Bach: A Net Zero Energy Home. Wellington: Victoria University of Wellington.

Maersk Line. Container Equipment Guide. Maersk Line.

McInosh, J., \& Harrington, M. (2007). Bio-SIPs: A Deeper Shade of Green? New Zealand Sustainable Building Conference SB07. Wellington: Victoria University of Wellington.

Ministry of Transport. (2010). Land Transport Rule Vehicle Dimensions and Mass Amendment 2010. Wellington: Ministry of Transport.

Morley, M. (2000). Building with Structural Insulated Panels (SIPs). The Taunton Press.

North America's Transportation Service. (2009). Contract Flatbed Equipment Guide. NATS.

Occupational Health \& Safety Administration. (1982). Safety Monitoring Systems As It Applies to CFR $1926.500(G)(1)$. United States Department of Labour.

Officer, N. D. (2012). Everything But the Building: Project Organisation, the First Light House Solar Decathlon 2011. Wellington: Victoria University of Wellington.

Olson Kundig Architects. (2012). Olson Kundig Architects - Projects - Chicken Point Cabin. Retrieved February 16, 2012 from Olson Kundig Architects: http://www .olsonkundigarchitects.com/Projects/101/Chic ken-Point-Cabin\#

OSH Academy: Occupational Safety \& Health Training. (2010). OSHAcademy : Free Online Occupational Health and Safety Training. Retrieved February 16, 2012 from OSHAcademy : Free Online OSHA Health \& Safety Training: http://www .oshatrain.org/courses/

Proclima. (n.d.). Airtightness Membrane Moisture Control Energy Efficiency. Retrieved February 15, 2012 from Airtightness Energy Efficient Healthy Buildings Moisture Control: $\quad$ http://www.proclima.co.nz/airtightnessmembrane-moisture 
Race, G. L. (2006). Comfort, CIBSE Knowledge Series : KS6. London: The Chartered Institute of Building Services Engineers.

R-Control. (2008). Structural Insulated Panels : SIP Panels : R-Control SIPs. Retrieved February 15, 2012 from Structural Insulated Panels : SIP Panels : R-Control SIPs: http://www.r-control.com/default.asp

Reid Construction Systems. (n.d.). Reids : Flexus ECC. Retrieved February 16, 2012 from Reids: http://www.reids.co.nz/flexusecc/

Robinson, L. A. (2004). Structural Opportunities of ETFE (ethylene tetra fluoro ethylene). Ma: Massachusetts Institute of Technology.

SIPA. (2007). Structurally Insulated Panels : Product Guide. Structurally Insulated Panel Association.

Technical Glass Products. (2011). Pilkington Profilit Architectural Specification Manual. Technical Glass Products.

U.S. Department of Energy. (2012, January 26). DOE Solar Decathlon: About Solar Decathlon. Retrieved February 14, 2012 from U.S. Department of Energy Solar Decathlon: http://www.solardecathlon.gov/about.html

U.S. Department of Energy. (2012, January 26). U.S. Department of Energy Solar Decathlon. Retrieved February 14, 2012 from U.S. Department of Energy Solar Decathlon: http://www.solardecathlon.gov

Vector Foiltec. (2010). Vector Foiltec : Variable Skins. Retrieved February 16, 2012 from Vector Foiltec : Vector Foiltec - The Specialist ETFE Contractors: http://www.vector-foiltec.com/en/technical/variableskins.html

Ward, T. I. (2006). Assessing the Effects of Thermal Bridging at Junctions and Around Openings. BRE: Watford.

Werner, C. (2010, September 21). Conference Call with Past Cornell University Students. (E. N. al., Interviewer)

Woyke, E. (2007, April 24). Material for an Architectural Revolution. Retrieved February 16, 2012 from Businessweek - Business News, Stock market \& Financial Advice:

http://www.businessweek.com/innovate/content/apr2007/i d20070424_903199.htm 


\section{APPENDICES}

\section{SOLAR DECATHLON CONTEST CRITERIA}

\section{Architecture Contest}

(100 points)

For the Architecture contest of the U.S. Department of Energy Solar Decathlon 2011, teams were required to design and build attractive, high-performance houses that integrated solar and energy-efficiency technologies seamlessly into the design.

A jury of professional architects focused on:

1. - Architectural elementsArchitectural elements included the scale and proportion of room and facade features, indoor/outdoor connections, composition, and linking of various house elements.

2. - Holistic designHolistic design is an architectural design that is comfortable for occupants and compatible with the surrounding environment.

3. - LightingThe jury assessed the integration and energy efficiency of electrical and natural light.

4. - InspirationInspiration is reflected in a design that inspires and delights Solar Decathlon visitors.

DocumentationDocumentation included drawings, a project manual, and an audiovisual architecture presentation that accurately reflected the constructed project on the competition site.

\section{Market Appeal Contest}

\section{(100 points)}

Each U.S. Department of Energy Solar Decathlon 2011 team built its house for a target client of its choosing. The Market Appeal jury, composed of professionals from the homebuilding industry, evaluated the responsiveness of the house design to the characteristics and requirements of the target client.

The jury considered:

5. - LivabilityDid the design offer a safe, functional, convenient, comfortable, and enjoyable place to live? Did it feature intuitive house controls? Did it meet the unique needs and desires of the target client?

6. - MarketabilityDid the house have curb appeal, interior appeal, and quality craftsmanship? How well did its sustainability features and strategies contribute to its marketability? Did the house offer potential homebuyers within the target market a good value?

BuildabilityWould the construction documents enable a contractor to generate an accurate construction cost estimate and then construct the building as the design team intended it to be built? Could the house's materials and equipment be immediately adopted and built in the private sector?

\section{Engineering Contest}

(100 points)

The U.S. Department of Energy Solar Decathlon 2011 houses represent the best of modern engineering. For the Engineering Contest, a jury of professional engineers evaluated each house for:

7. - FunctionalityDid the house's energy and HVAC systems function as intended? 
8. - EfficiencyHow much energy would the house's systems save over the course of a year relative to conventional systems? Would the system controls facilitate a reduction in energy consumption during a year of operation?

9. - InnovationWere unique approaches used to solve design challenges? Did the innovations have true market potential?

10. - ReliabilityHow long are the systems expected to operate at a high level of performance? How much maintenance is required to keep them operating at a high level?

DocumentationDid the construction drawings, project manual, and audiovisual engineering presentation accurately reflect the constructed project as assembled on the competition site?

\section{Communications Contest}

\section{(100 points)}

From team websites to signage and public tours, the U.S. Department of Energy Solar Decathlon 2011 Communications Contest challenged teams to educate others about their houses, their experiences, and their projects.

A jury of communications professionals awarded points for delivering clear and consistent messages; images that represent the vision, process, and results of each project; and creativity in engaging audiences.

The Communications Jury evaluated:

11. - Web content quality, appropriateness, and originality

12. - Video walkthrough information, the accuracy of the representation of the as-built house on the competition site, accessible captioning, clarity of the audio narrative, and creativity

13. - The quality of onsite graphics, photos, displays, and signage

14. - The delivery of messages to target audiences and people of all abilities

The use of innovative methods to engage audiences, including website visitors and people waiting to tour a house.

\section{Affordability Contest}

\section{(100 points)}

New for the U.S. Department of Energy Solar Decathlon 2011, the Affordability Contest encouraged teams to design and build affordable houses that combined energy-efficient construction and appliances with renewable energy systems. In this way, the teams demonstrated how energy-saving features can help consumers save money today.

A professional estimator determined the construction cost of each house. Teams earned 100 points for achieving a target construction cost of $\$ 250,000$ or less. A sliding point scale was then applied to houses with estimated construction costs between $\$ 250,001$ and $\$ 600,000$. Houses with estimated costs more than $\$ 600,000$ would have received zero points.

\section{Comfort Zone Contest}

\section{(100 points)}

For the U.S. Department of Energy Solar Decathlon 2011 Comfort Zone Contest, teams designed their houses to keep temperature and humidity steady, uniform, and comfortable. Full points were awarded for maintaining narrow temperature and relative humidity ranges during specified periods of time.

For full points, the houses had to maintain:

15. - Temperatures between $71^{\circ} \mathrm{F}\left(22.2^{\circ} \mathrm{C}\right)$ and $76^{\circ} \mathrm{F}\left(24.4^{\circ} \mathrm{C}\right)$

Relative humidity less than $60 \%$. 
(100 points)

The U.S. Department of Energy Solar Decathlon 2011 Hot Water Contest assessed whether a house's water heating system could supply all the hot water needed for daily washing and bathing. Teams scored points by successfully completing several 15-gallon "hot water draws."

The goal of this task was to deliver 15 gallons $(56.81)$ of hot water $\left(110^{\circ} \mathrm{F} / 43.3^{\circ} \mathrm{C}\right)$ in 10 minutes or less.

\section{Appliances Contest}

(100 points)

The U.S. Department of Energy Solar Decathlon 2011 Appliances Contest was designed to mimic the appliance use of an average U.S. home. Teams earned points for refrigerating and freezing food, washing and drying laundry, and running the dishwasher. Points were awarded for:

16. - Maintaining the refrigerator temperature within $34^{\circ} \mathrm{F}\left(1.11^{\circ} \mathrm{C}\right)$ and $40^{\circ} \mathrm{F}\left(4.44^{\circ} \mathrm{C}\right)$

17. - Keeping the freezer temperature within $-20^{\circ} \mathrm{F}\left(-28.9^{\circ} \mathrm{C}\right)$ and $5^{\circ} \mathrm{F}\left(-1.5^{\circ} \mathrm{C}\right)$

18. - Washing a load of laundry within a specified period of time

19. - Returning a load of laundry to a total weight less than or equal to the load's total weight before washing using active or passive drying methods

Running the dishwasher through a complete, uninterrupted cycle, at some point during which a temperature sensor placed in the dishwasher had to reach $120^{\circ} \mathrm{F}\left(48.9^{\circ} \mathrm{C}\right)$.

\section{Home Entertaimment Contest}

\section{(100 points)}

The Home Entertainment Contest in the U.S. Department of Energy Solar Decathlon 2011 gauged whether a house had what it takes to be a home. How well did it accommodate the pleasures of living, such as sharing meals with friends and family, watching movies in a home theater, and surfing the Web? How well did it accommodate a small home office for a telecommuter?

The contest included:

20. - Holding two dinner parties for neighbors, who awarded the host team points based on the quality of the meal, ambiance, and overall experience

21. - Keeping all interior and exterior house lights on during specified periods of time

22. - Operating a television and computer during specified time periods

23. - Hosting a movie night for neighbors, who rated their hosts based on the quality and design of the home theater system as well as ambiance and overall experience

Simulating cooking by using a kitchen appliance to vaporize 5 pounds ( $80 \mathrm{oz}$ or $2.268 \mathrm{~kg}$ ) of water within a specified period of time.

\section{Energy Balance Contest}

(100 points)

For the U.S. Department of Energy Solar Decathlon 2011, each team house was equipped with a bidirectional utility meter that enabled competition organizers to measure the net energy a house produced or consumed over the course of the competition. 
In the Energy Balance Contest, a team received full points for producing at least as much energy as its house needed, thus achieving a net energy consumption of zero during contest week. This was accomplished by balancing production and consumption.

http://www.solardecathlon.gov/contest_energy_balance.html 
